Roland Klopfleisch

Fiskalische

Konsequenzen

der Europäischen

Währungsunion

Die Veränderung des Seigniorage und dessen Bedeutung für die nationalen EWU-11 Haushalte 
Roland Klopfleisch

\section{Fiskalische Konsequenzen der Europäischen Währungsunion}

Spätestens nachdem 1997 in Deutschland eine Diskussion über die geplante Verteilung der Gewinne der Europäischen Zentralbank an die nationalen Zentralbanken entbrannte, ist der Seigniorage neuer Mittelpunkt in der Streitfrage um Kosten und Nutzen der Europäischen Währungsunion. Ziel dieser Arbeit ist es, die Veränderung des Seigniorage seit Inkrafttreten des Maastrichter Vertrags im Jahre $1992 \mathrm{zu}$ analysieren, festzustellen, welche Bedeutung das Bemühen hatte, die Konvergenzkriterien einzuhalten und zu bestimmen, welche Auswirkungen die Übertragung des Banknotenmonopols von den nationalen Zentralbanken auf die Europäische Zentralbank haben wird. Im Anschluß an diese Analyse werden die allerdings geringen - Auswirkungen des Verteilungsschlüssels untersucht.

Roland Klopfleisch, geboren 1966 in Frankfurt am Main, studierte Wirtschaftsingenieurwesen an der TU Darmstadt. Von 1994 bis 1999 war er wissenschaftlicher Mitarbeiter am Fachgebiet Finanzwissenschaft der TU Darmstadt. 
Fiskalische Konsequenzen

der Europäischen Währungsunion 


\section{Sozialökonomische Schriften}

Herausgegeben von Bert Rürup

\section{Band 19}

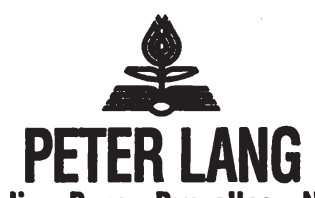

Frankfurt am Main - Berlin - Bern - Bruxelles - New York - Oxford - Wien 


\title{
Roland Klopfleisch
}

\section{Fiskalische Konsequenzen der Europäischen Währungsunion}

\author{
Die Veränderung des Seigniorage \\ und dessen Bedeutung für die nationalen
}

EWU-11 Haushalte

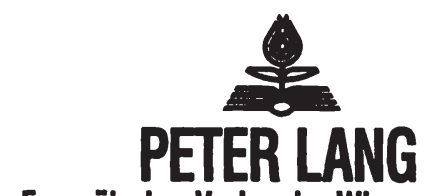

Europäischer Verlag der Wissenschaften 
Die Deutsche Bibliothek - CIP-Einheitsaufnahme Klopfleisch, Roland:

Fiskalische Konsequenzen der Europäischen Währungsunion : die Veränderung des Seigniorage und dessen Bedeutung für die nationalen EWU-11 Haushalte / Roland Klopfleisch. -

Frankfurt am Main ; Berlin ; Bern ; Bruxelles ; New York ;

Oxford ; Wien : Lang, 2000

(Sozialökonomische Schriften ; Bd. 19)

Zugl.: Darmstadt, Techn. Univ., Diss., 1999

ISBN 3-631-35946-2

Open Access: The online version of this publication is published on www.peterlang.com and www.econstor.eu under the international Creative Commons License CC-BY 4.0. Learn more on how you can use and share this work: http://creativecommons. org/licenses/by/4.0.

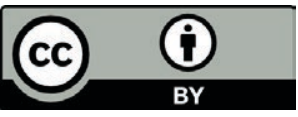

This book is available Open Access thanks to the kind support of ZBW - Leibniz-Informationszentrum Wirtschaft.

Gedruckt auf alterungsbeständigem, säurefreiem Papier.

\author{
D 17 \\ ISSN 0172-1747 \\ ISBN 3-631-35946-2 \\ ISBN 978-3-631-75045-2 (eBook) \\ (C) Peter Lang GmbH \\ Europäischer Verlag der Wissenschaften \\ Frankfurt am Main 2000 \\ Alle Rechte vorbehalten.
}

Das Werk einschließlich aller seiner Teile ist urheberrechtlich geschützt. Jede Verwertung außerhalb der engen Grenzen des Urheberrechtsgesetzes ist ohne Zustimmung des Verlages unzulässig und strafbar. Das gilt insbesondere für Vervielfältigungen, Übersetzungen, Mikroverfilmungen und die Einspeicherung und Verarbeitung in elektronischen Systemen.

Printed in Germany 134567 


\section{Danksagung}

Ich möchte all jenen danken, die zum Gelingen dieser Arbeit beigetragen haben.

Zunächst gilt mein Dank meinem Chef und Doktorvater Herrn Prof. Dr. Dr. h.c. Bert Rürup, der die Arbeit am Lehrstuhl für Finanzwissenschaft angeregt und betreut hat.

Für die vielen unterstützenden Worte während einiger Durststrecken und für die gelegentlich nötigen Strukturierungen meiner Gedanken möchte ich meinen Kollegen und Freunden PD Dr. Werner Sesselmeier und Dr. Martin Setzer danken.

Ein ganz herzliches Dankeschön richtet sich an Herrn Dr. Henning Stumpp für die sehr gründliche Durchsicht des Manuskripts. Eventuell verbliebene Fehler gehen natürlich zu meinen Lasten.

Für die vielleicht wichtigste nämlich persönliche aber auch inhaltliche Unterstützung danke ich meiner zukünftigen Frau Simone Schmiedl, die mich immer wieder motiviert hat, mit konstruktiver Kritik und konzeptionellen Anregungen eine große Hilfe war und bei der Erstellung von Tabellen, Abbildungen und Grafiken einen großen Anteil hatte.

Und zum Schluß möchte ich meinen Eltern für ihre stetige Unterstützung schon zu Schul- und Studienzeiten und damit ihrem Beitrag zum Gelingen dieser Arbeit danken.

Darmstadt, im Januar 2000

Roland Klopfleisch 
Roland Klopfleisch - 978-3-631-75045-2

Downloaded from PubFactory at 01/11/2019 08:55:36AM

via free access 


\section{Inhalt}

$1 \quad$ Einleitung

1.1 Aufgabenstellung

1.2 Methodisches Vorgehen und Aufbau der Arbeit

\section{Teil I:}

Ergebnisse und theoretische Grundlagen bisheriger Studien

2 Die fiskalischen Umverteilungswirkungen als Folge der Europäischen Währungsunion: Der Stand der Diskussion

2.1 Empirische Befunde von Gros

2.2 Empirische Befunde von Lange/Nolte

2.3 Empirische Befunde von Sinn/Feist

2.4 Empirische Befunde von Läufer

2.5 Empirische Befunde von Maennig/Hunger

2.6 Synoptische Zusammenfassung der empirischen Befunde

$3 \quad$ Konzepte zur Messung des Seigniorage

Exkurs: Zentralbankgeld

3.1 Monetärer Seigniorage

3.2 Opportunitätskosten-Seigniorage $\quad 26$

3.3 Fiskalischer Seigniorage 27

3.4 Theoretischer Vergleich der Konzepte 28

3.4.1 Vergleich Opportunitätskosten-Seigniorage Monetärer Seigniorage $\quad 28$

3.4.2 Vergleich fiskalischer und monetärer Seigniorage 29

3.4.3 Vergleich fiskalischer und Opportunitätskosten-Seigniorage 30

3.5 Empirischer Vergleich der Konzepte für Deutschland 30

$4 \quad$ Kritik an der bisherigen Diskussion 33

4.1 Beurteilungskriterien 33

4.1.1 Seignioragekonzept 33

4.1.2 Trennung der Währungsunionseffekte für den Seigniorage 33

4.1.3 Berücksichtigung der Zinsstruktur 34

4.1.4 Berücksichtigung der Geldnachfrage 36

4.2 Defizitanalyse der vorliegenden empirischen Befunde 36

4.2.1 Defizitanalyse von Gros 1989 und Gros $1996 \quad 36$

4.2.2 Defizitanalyse von Lange/Nolte $1997 \quad 38$

4.2.3 Defizitanalyse Sinn/Feist $1997 \quad 40$

4.2.4 Defizitanalyse von Läufer 1997

4.2.5 Defizitanalyse von Maennig/Hunger $1996 \quad 41$ 
4.3 Erkenntnisse aus der Defizitanalyse 42

4.3.1 Wahl des Konzepts des monetären Seigniorage 42

4.3.2 Zinsannahme 42

4.3.3 Vermischung verschiedener Effekte mit Einfluß auf den Seigniorage 43

4.3.4 Aggregation der Geldnachfrage $\quad 44$

5 Anforderungen an ein Modell zur Berechnung des Seigniorage als staatliche Einnahmequelle

Teil II:

Einnahmeverluste und -gewinne aus der Geldschöpfung als Folge der Konvergenz innerhalb der EWU-11 Staaten

6 Einfluß der Konvergenz auf den fiskalischen Seigniorage der Nationalbanken im Vorfeld der Europäischen Währungsunion

6.1 Konzeption des fiskalischen Seigniorage für die Staaten der EWU

6.1.1 Die Bilanz der Deutschen Bundesbank

6.1.2 Geldpolitisches Instrumentarium

6.1.3 Das geldpolitische Instrumentarium der Europäischen Notenbanken

6.1.4 Modifizierter fiskalischer Seigniorage

6.1.4.1 Zinsertrag aus Forderungen an das Ausland

6.1.4.2 Kredite an die öffentlichen Haushalte

6.1.4.3 Zinsertrag aus Forderungen an inländische Geschäftsbanken

6.1.4.4 Einlagefazilitäten und sonstige Instrumente zur Abschöpfung von Liquidität

6.1.4.5 Kosten

54

6.1.4.6 Thesaurierte Gewinne

55

6.2 Bestimmung der durch die Konvergenz veränderten

Einflußfaktoren auf den fiskalischen Seigniorage

6.2.1 Zins und Bestände aus Refinanzierungsgeschäften 57

6.2.2 Zins und Bestände zur Liquiditätsabschöpfung 58

6.2.3 Einlagezins 58

6.2.4 Nachfrage nach Zentralbankgeld 58

$\begin{array}{lll}6.2 .5 & \text { Kosten } & 62\end{array}$

6.2.6 Konvergenzeffekt 62 
7.1 Quantifizierung für Deutschland 63

7.1.1 Quantifizierung des Konvergenzeffekts 63

7.1.1.1 Zinsertrag aus Forderungen gegen inländische Geschäftsbanken

7.1.1.2 Zinsaufwand für Verbindlichkeiten aus abgegebenen Mobilisierungs- und Liquiditätspapieren 63

7.1.1.3 Zinsgewinne aus Währungsreserven 65

7.1.1.4 Kosten 66

7.1.1.5 Gesamteffekt 66

$\begin{array}{lll}7.1 .2 & \text { Ursachenanalyse } & 67\end{array}$

7.1.2.1 Zins aus Diskont-, Lombard- und Offenmarktgeschäften 67

7.1.2.2 Zins zur Liquiditätsabschöpfung 70

7.1.2.3 Nachfrage nach Zentralbankgeld 71

$\begin{array}{ll}7.1 .2 .4 \text { Kosten } & 73\end{array}$

$\begin{array}{ll}\text { 7.1.2.5 Währungsreserven } & 73\end{array}$

7.1.2.6 Gesamteffekt $\quad 74$

$\begin{array}{ll}7.2 \text { Quantifizierung für Belgien } & 75\end{array}$

7.2.1 Quantifizierung des Konvergenzeffekts 75

7.2.1.1 Zinsertrag, Zinsaufwand im inländischen Kreditgeschäft und anteilige Kosten $\quad 75$

7.2.1.2 Zinseinnahmen aus Währungsreserven $\quad 75$

7.2.1.3 Gesamteffekt $\quad 76$

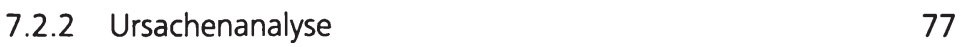

7.2.2.1 Bestände aus Diskont-, Lombard- und Offenmarktgeschäften sowie Zinssätze $\quad 77$

7.2.2.2 Zins für liquiditätsabschöpfende Maßnahmen $\quad 78$

7.2.2.3 Nachfrage nach Zentralbankgeld $\quad 79$

$\begin{array}{ll}7.2 .2 .4 \text { Kosten } & 80\end{array}$

7.2.2.5 Währungsreserven 80

7.2.2.6 Gesamteffekt 80

$\begin{array}{ll}7.3 \text { Quantifizierung für Finnland } & 81\end{array}$

7.3.1 Quantifizierung des Konvergenzeffekts 81

7.3.1.1 Zinsertrag aus Forderungen gegen inländische Geschäftsbanken 81

7.3.1.2 Zinsaufwand aus liquiditätsabschöpfenden Maßnahmen und der verzinsten Mindestreserve 82

7.3.1.3 Zinsertrag aus Währungsreserven 83

7.3.1.4 Kosten 83

7.3.1.4 Gesamteffekt $\quad 84$ 
7.3.2 Ursachenanalyse 84

7.3.2.1 Zins aus Lombard- und Offenmarktgeschäften $\quad 84$

7.3.2.2 Zins zur Liquiditätsabschöpfung und Verzinsung der Mindestreserve $\quad 85$

7.3.2.3 Nachfrage nach Zentralbankgeld 86

$\begin{array}{ll}\text { 7.3.2.4 Kosten } & 87\end{array}$

7.3.2.5 Währungsreserven $\quad 87$

7.3.2.6 Gesamteffekt 88

$\begin{array}{ll}7.4 \text { Quantifizierung für Frankreich } & 89\end{array}$

7.4.1 Quantifizierung des Konvergenzeffekts 89

7.4.1.1 Zinsertrag, Zinsaufwand im inländischen Kreditgeschäft und anteilige Kosten $\quad 89$

7.4.1.2 Zinsgewinne aus den Währungsreserven $\quad 89$

7.4.1.3 Gesamteffekt 90

$\begin{array}{ll}\text { 7.4.2 Ursachenanalyse } & 90\end{array}$

7.4.2.1 Bestände aus Diskont-, Lombard- und
Offenmarktgeschäften

7.4.2.2 Zins für liquiditätsabschöpfende Maßnahmen 92

7.4.2.3 Nachfrage nach Zentralbankgeld 93

$\begin{array}{ll}7.4 .2 .4 \text { Kosten } & 94\end{array}$

7.4.2.5 Währungsreserven 94

7.4.2.5 Gesamteffekt 95

7.5 Quantifizierung für Irland 96

7.5.1 Quantifizierung des Konvergenzeffekts 96

7.5.1.1 Einnahmen, Ausgaben und Kosten aus dem inländischen Geschäft 96

7.5.1.2 Zinseinnahmen aus den Währungsreserven $\quad 97$

7.5.1.3 Gesamteffekt 97

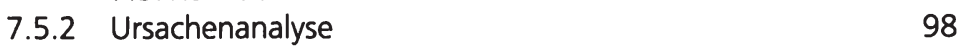

7.5.2.1 Bestände und Zinssätze

7.5.2.2 Bestände und Zinssätze der liquiditätsabschöpfenden Maßnahmen 99

7.5.2.3 Kosten 99

7.5.2.4 Nachfrage nach Zentralbankgeld 99

7.5.2.5 Währungsreserven 101

7.5.2.6 Gesamter Konvergenzeffekt 101 
7.6 Quantifizierung für Italien

7.6.1 Quantifizierung des Konvergenzeffekts

7.6.1.1 Zinsertrag aus Forderungen gegen inländische Geschäftsbanken

7.6.1.2 Zinsaufwand

7.6.1.3 Zinseinnahmen aus Währungsreserven

7.6.1.4 Kosten

104

7.6.1.5 Gesamteffekt

7.6.2 Ursachenanalyse

7.6.2.1 Zins aus Diskont-, Lombard- und Offenmarktgeschäften

7.6.2.2 Zins für Liquiditätsabschöpfung und Verzinsung der Mindestreserve

106

7.6.2.3 Währungsreserven

7.6.2.4 Nachfrage nach Zentralbankgeld 107

7.6.2.5 Kosten

109

7.6.2.6 Gesamteffekt

109

7.7 Quantifizierung für die Niederlande

7.7.1 Quantifizierung des Konvergenzeffekts

7.7.1.1 Einnahmen, Ausgaben und Kosten aus dem inländischen Geschäft

7.7.1.2 Zinserträge aus Währungsreserven

7.7.1.3 Gesamteffekt

7.7.2 Ursachenanalyse

7.7.2.1 Bestände und Zinssätze der Refinanzierungsgeschäfte

7.7.2.2 Bestände und Zinssätze der liquiditätsabschöpfenden Maßnahmen

7.7.2.3 Kosten

7.7.2.4 Nachfrage nach Zentralbankgeld

7.7.2.5 Währungsreserven

7.7.2.5 Gesamter Konvergenzeffekt

7.8 Quantifizierung für Österreich

7.8.1 Quantifizierung des Konvergenzeffekts

7.8.1.1 Zinsertrag aus Forderungen gegen inländische Geschäftsbanken

7.8.1.2 Zinsaufwand

7.8.1.3 Zinseinnahmen aus Währungsreserven

7.8.1.4 Kosten

7.8.1.5 Gesamteffekt 
7.8.2 Ursachenanalyse

7.8.2.1 Zins aus Eskont-, Darlehens- und Offenmarktgeschäften

7.8.2.2 Zins für Einlagefazilität

7.8.2.3 Nachfrage nach Zentralbankgeld

7.8.2.4 Kosten

7.8.2.5 Währungsreserven

7.8.2.5 Gesamteffekt

7.9 Quantifizierung für Portugal

7.9.1 Quantifizierung des Konvergenzeffekts

7.9.1.1 Zinsertrag

7.9.1.2 Zinsaufwand

125

7.9.1.3 Kosten

7.9.1.4 Gesamteffekt 126

7.9.2 Ursachenanalyse

7.9.2.1 Bestände aus Diskont-, Lombard- und Offenmarktgeschäften

7.9.2.2 Liquiditätsabschöpfende Maßnahmen und Verzinsung der Mindestreserve

7.9.2.3 Nachfrage nach Zentralbankgeld

7.9.2.4 Kosten

7.9.2.5 Währungsreserven

7.9.2.6 Gesamteffekt

7.10 Quantifizierung für Spanien

7.10.1 Quantifizierung des Konvergenzeffekts

7.10.1.1 Zinsertrag, Zinsaufwendungen und Kosten

7.10.1.2 Zinserträge aus Währungsreserven

7.10.1.3 Gesamteffekt

7.10.2 Ursachenanalyse

7.10.2.1 Zins aus Offenmarktgeschäften

7.10.2.2 Zins zur Liquiditätsabschöpfung

7.10.2.3 Nachfrage nach Zentralbankgeld

7.10.2.4 Kosten

7.10.2.5 Währungsreserven

7.10.2.6 Gesamteffekt

7.11 Vergleich der Konvergenzeffekte 
Teil III:

Einnahmeverluste und -gewinne aus der Geldschöpfung als Folge des Übergangs zum Euro

8 Ein Prognosemodell zur Berechnung des zukünftigen

Geldschöpfungsgewinns des ESZB

8.1 Empirischer Vergleich der Konzepte des fiskalischen Seigniorage und des Opportunitätskosten-Seigniorage für die EWU-Staaten für die Jahre 1992 bis 1997

8.1.1 Opportunitätskosten-Seigniorage - Variante 1

8.1.2 Opportunitätskosten-Seigniorage - Variante 2

8.1.3 Opportunitätskosten-Seigniorage - Variante 3

8.2 Ergebnisse des empirischen Vergleichs der OpportunitätskostenSeigniorage-Konzepte und des fiskalischen Seigniorage

9 Prognose des Opportunitätskosten-Seigniorage für die EWU-11

9.1 Prognose des Opportunitätskosten-Seigniorage - Variante 1

9.2 Prognose des Opportunitätskosten-Seigniorage - Variante 2

9.3 Prognose des Opportunitätskosten-Seigniorage - Variante 3

9.4 Prognose des fiskalischen Seigniorage des ESZB nach dem Übergang zum Euro

10 Quantifizierung des Übergangseffekts

Teil IV:

Einnahmeverluste und -gewinne aus der Geldschöpfung als Folge des Verteilungsschlüssels der EZB

11 Wirkung des Verteilungsschlüssels auf die Einnahmen der EWU-

Mitgliedsstaaten aus der Geldschöpfung

11.1 Die föderale Struktur des ESZB und der Begriff der monetären

Einkünfte

11.2 Verteilungsmodus zur Bestimmung des nationalen Seigniorage $\quad 159$

11.3 Quantifizierung des Verteilungseffekts

Teil V:

Zusammenfassung, Wirtschaftspolitische Optionen und Ausblick 163

12 Zusammenfassung von Konvergenz-, Übergangs- und Verteilungseffekt

13 Wirtschaftspolitische Optionen 
XIV

Literatur

Abbildungen

Tabellen

187

Abkürzungen

189

Anhang

193 


\section{$1 \quad$ Einleitung}

Seit 1980 weist der Jahresabschluß der Deutschen Bundesbank einen durchgängig positiven Jahresüberschuß aus und der Bilanzgewinn betrug zwischen 0,2 Mrd. (1987) und 24,2 Mrd. DM (1997), wovon durchschnittlich rund $10 \mathrm{Mrd}$. DM ausgeschüttet wurden. Auch 1998 betrug der ausgeschüttete Bundesbankgewinn wieder mehr als $16 \mathrm{Mrd}$. DM. Von dem ausgeschütteten Gewinn werden seit 19957 Mrd. DM dem Bundeshaushalt und der Rest dem Erblastentilgungsfonds zur Zahlung seiner Zins- und Tilgungsverpflichtungen zugeführt. Im wesentlichen entstehen diese Gewinne durch die Geldschöpfung, aber auch durch währungspolitische Maßnahmen (Stabilisierung von Wechselkursparitäten) und Aufwertungen von Devisen und Goldbeständen'.

Gegenstand dieser Arbeit soll der Teil der Notenbankgewinne sein, der als Folge der Geldschöpfung betrachtet werden kann, der sogenannte Seigniorage ${ }^{2}$, da gerade dieser Teil im Zusammenhang mit der Vollendung der Europäische Währungsunion jüngst in den Mittelpunkt des Interesses rückte3. Es wurde die Frage aufgeworfen, ob der bundesdeutsche Haushalt auch nach Einführung der gemeinsamen Währung und der Übertragung des Notenbankmonopols von der Deutschen Bundesbank an die Europäische Zentralbank (EZB) mit ähnlich hohen Überweisungen wie in der Vergangenheit rechnen kann. Von vielen Autoren wird dies verneint und gleichzeitig darauf hingewiesen, daß die Ursache der vermuteten Mindereinnahmen in der Abgabe des Notenbankmonopols an die EZB und der ihrer Meinung nach "falschen" Verteilung der dort entstehenden Geldschöpfungsgewinne an die Staaten der Europäischen Währungsunion zu suchen ist.

Es existieren zu dieser Fragestellung bislang verschiedene quantitative Arbeiten, die allesamt für den bundesdeutschen Haushalt mehr oder weniger hohe Mindereinnahmen aus der Geldschöpfung im Zuge der Währungsunion prognostizieren, wobei diese allerdings recht unterschiedliche Ursachen haben, die in den erwähnten Arbeiten bislang nicht getrennt behandelt werden. Zudem werden dort

1 Zwar gilt für die Bewertung der Devisen- und Goldreserven der Deutschen Bundesbank das strenge Niederstwertprinzip, allerdings ergeben sich Gewinne durch den Verkauf solcher Bestände zu einem höheren Marktpreis als dem historischen Tiefststand. Zudem resultierte ein großer Teil des Bundesbankgewinns von 1997 aus der marktnäheren Bewertung (1,5396 DM/Dollar statt 1,3620 DM/Dollar) der Dollarreserven. Dies ist als Zwischenschritt zur marktnahen Bewertung der Währungsreserven nach den Rechnungslegungsvorschriften des ESZB zu sehen (vgl. Geschäftsbericht der Deutschen Bundesbank 1997, 65).

2 Unter dem Begriff Seigniorage versteht man den realen Vermögens- oder Einkommenstransfer vom privaten Sektor an den Staat aufgrund der Tatsache, daß Private zinslos Zentralbankgeld halten (vgl. Klein/Neumann 1990, 206). Zu den verschiedenen Seignioragekonzepten siehe Kapitel 3.

3 Erstmalig innerhalb einer umfassenden Kosten-Nutzen-Analyse der Europäischen Währungsunion wurde der Seigniorage bei Emerson (1992, 205f) behandelt, wobei hier allerdings nur positive Aspekte der Verdrängung des US-Dollar durch den Euro Berücksichtigung fanden (vgl. Kapitel 13). 
zwar einfach zu handhabende aber für eine fiskalische Betrachtung womöglich ungeeignete analytische Konzepte zur Berechnung verwendet, so daß valide fiskalpolitische Schlußfolgerungen nicht möglich sind.

\subsection{Aufgabenstellung}

Folgende Fragen sollen im Rahmen dieser Arbeit beantwortet werden:

1. Welche Veränderungen der Einnahmen aus der Geldschöpfung haben sich seit dem Inkrafttreten des Maastrichter Vertrags 1992 für die einzelnen Staaten ex post ergeben?

2. Worauf lassen sich die Veränderungen der Einnahmen aus der Geldschöpfung zurückführen, bzw. welcher Anteil an den Einnahmeveränderungen ist auf die Bestrebungen der Mitgliedsstaaten zurückzuführen, die Maastrichter Konvergenzkriterien zu erfüllen?

3. Mit welchen Einnahmeveränderungen aus der Geldschöpfung muß die Gesamtheit der teilnehmenden europäischen Staaten (EWU-11-Staaten) durch den Einstieg in die dritte Stufe der Europäischen Währungsunion, d.h. durch den Übergang der nationalen Währungen auf die gemeinsame europäische Währung und der Übertragung des Notenbankmonopols auf die EZB ab 1999, rechnen?

4. Mit welchen Einnahmeveränderungen aus der Geldschöpfung der EZB müssen die nationalen Haushalte innerhalb der Währungsunion rechnen, d.h. wie wirkt sich die Verteilung des Gewinns nach dem Gewinnverteilungsschlüssel nach BIP- und Bevölkerungsanteil aus?

5. Welche wirtschaftspolitischen Schlußfolgerungen lassen sich aus den Einnahmeveränderungen auf europäischer und nationaler Ebene ziehen? Gibt es einen „gerechten" Verteilungsschlüssel? Sollte der derzeit gültige Verteilungsschlüssel überarbeitet werden?

Bezüglich der ersten Frage existieren in der Literatur zwei Prognoserechnungen, deren verwendetes Berechnungskonzept allerdings hinsichtlich der Anforderungen an eine fiskalische Betrachtung der Geldschöpfungsgewinne zu überprüfen wäre. Zudem lassen sich, da die Untersuchungen bereits 10 bzw. 4 Jahre alt sind, inzwischen aktuellere (ex-post) Berechnungen anstellen.

Die Frage 2 wurde für Deutschland bislang nur in einer Untersuchung von Lübbersmann (1995) für die Bilanzgewinne zwischen 1948 und 1991 versucht zu beantworten. Eine derartige Untersuchung für den Geldschöpfungsgewinn auf europäischer Ebene und/oder für den Zeitraum der Konvergenz zur Erfüllung der Maastricht-Kriterien existiert bislang nicht.

Die Frage 3 nach den Einnahmeveränderungen aus der Geldschöpfung für die Europäische Währungsunion wurde auf theoretischer Ebene bislang in verschiedenen Beiträgen angeschnitten, allerdings auf der quantitativen Ebene meist mit 
den Effekten der Einhaltung der Konvergenzkriterien, d.h. mit der Beantwortung der Frage 1, vermischt.

Die Frage nach der fiskalischen Wirkung der Verlagerung der Entstehung des Geldschöpfungsgewinns von der nationalen Ebene auf die europäische Ebene (Frage 4) wurde bislang auf die Wirkung des Verteilungsschlüssels eingeschränkt. Inwieweit sich aber die nationalen Haushalte durch die Veränderungen des gesamten europäischen Geldschöpfungsgewinns inklusive der Anwendung des Verteilungsschlüssels besser oder schlechter stellen, läßt sich nur bei einer Betrachtung der Veränderungsursachen analysieren.

Frage 5 wird sowohl in der Tagespresse als auch in der wissenschaftlichen Literatur oftmals mit dem Ruf nach einem neuen Verteilungsschlüssel beantwortet, da die Lasten Deutschlands als Folge der Reduzierung des Geldschöpfungsgewinns im Zuge der Europäischen Währungsunion zu groß seien. Der Verteilungsschlüssel werde den ökonomischen Ursachen der Gewinnerzielung nicht gerecht, da Deutschland den größten Beitrag zum europäischen Geldschöpfungsgewinn leiste, aber nur einen weitaus geringeren Anteil daran über den Verteilungsschlüssel an den bundesdeutschen Haushalt "zurücküberwiesen" bekomme. Die Antwort auf diese Frage läßt sich nur nach einer differenzierten Betrachtung der Effekte auf den Geldschöpfungsgewinn, die in dieser Arbeit vorgenommen wird, finden.

\subsection{Methodisches Vorgehen und Aufbau der Arbeit}

Die Arbeit gliedert sich in fünf Teile.

Im ersten Teil werden die oben erwähnten bislang zu diesem Thema vorliegenden empirischen Untersuchungen vor dem Hintergrund der fiskalischen Bedeutung des Geldschöpfungsgewinns kritisch analysiert. Zur Beurteilung der Untersuchungen werden die dort verwendeten theoretischen Konzepte des "Seigniorage" dargestellt und hinsichtlich ihrer fiskalpolitischen Aussagefähigkeit überprüft.

Die drei folgenden Teile definieren sich anhand der Struktur der oben aufgezeigten Fragestellungen: Teil II befaßt sich auf der Grundlage der Theorie des Seigniorage und der Kritik an den bisherigen Arbeiten mit den Einnahmeveränderungen aus der Geldschöpfung im Zuge der Konvergenzbestrebungen im Vorfeld der Europäischen Währungsunion (Konvergenzeffekt). Teil III betrachtet den fiskalischen Effekt des Übergangs der nationalen Währungen auf den Euro auf die Haushalte der Mitgliedsstaaten und Teil IV den fiskalischen Effekt der Gewinnverteilung auf die nationalen Zentralbanken durch die EZB.

Teil $\vee$ schließt die Arbeit mit einem quantitativen Vergleich aller drei Effekte sowie wirtschaftspolitischen Schlußfolgerungen und einem Ausblick ab.

Die einzelnen Arbeitsschritte gliedern sich wie folgt:

In Kapitel 2 des ersten Teils werden die Ergebnisse der vorliegenden quantitativen Studien miteinander verglichen. Um die Ursachen der höchst unterschiedlich ausfallenden Ergebnisse erklären zu können, werden anschließend die den Untersu- 
chungen zugrundeliegenden theoretischen Konzepte zur Berechnung der Geldschöpfungsgewinne dargestellt, analysiert und für Deutschland empirisch betrachtet (Kapitel 3). Mit Hilfe dieses Instrumentariums lassen sich dann die Ursachen für die Abweichungen der Ergebnisse analysieren und gleichzeitig ist es möglich, eine Kritik an der vorliegenden Literatur vornehmen (Kapitel 4).

Auf Grundlage dieser Kritik werden zu Beginn des Teils II Anforderungen an ein Konzept zur Messung des Geldschöpfungsgewinns aus fiskalischer Sicht formuliert (Kapitel 5). Kapitel 6 beschäftigt sich mit der Modellbildung zur Berechnung des Konvergenzeffekts auf den Seigniorage der beteiligten Staaten. Zunächst wird dort ein theoretisches Konzept des Seigniorage ausgewählt und für die fiskalische Betrachtungsweise modifiziert, anschließend die Einflußfaktoren der Konvergenzbestrebungen im Zuge des Maastrichter Vertrags auf diesen Seigniorage bestimmt und abschließend ein Modell zur Berechnung der Seigniorageveränderungen auf nationaler Ebene als Folge der Konvergenz gebildet. In Kapitel 7 wird mit Hilfe des in Kapitel 6 erarbeiteten Modells der Rückgang des Seigniorage und der Konvergenzeffekt für alle EWU-11 Staaten quantifiziert.

Zu Beginn des dritten Teils (Kapitel 8) wird zunächst ein Modell zur Prognose des Geldschöpfungsgewinns erarbeitet. Dazu werden verschiedene für Prognosen geeignete Seignioragekonzepte mit den in Teil II berechneten Seigniorageverläufen der Mitgliedsstaaten verglichen, um eine Näherung an die tatsächlich fiskalisch relevanten Geldschöpfungsgewinne zu erhalten. Mit Hilfe des so gefundenen Modells werden anschließend die Geldschöpfungseinnahmen der EWU-11 Staatengemeinschaft nach dem Übergang zum Euro (Kapitel 9) und der für die einzelnen Mitgliedsstaaten damit verbundene Übergangseffekt (Kapitel 10) quantifiziert.

Kapitel 11 (Teil III) befaßt sich schließlich mit den fiskalischen Wirkungen des Verteilungsschlüssel, der die Zuteilung der auf der Ebene des Europäischen Systems der Zentralbanken (ESZB) erzielten Geldschöpfungsgewinne an die nationalen Zentralbanken regelt.

In Kapitel 12 werden die in Teil II bis IV erarbeiteten empirischen Ergebnisse vergleichend zusammengefaßt, um insbesondere die Relevanz der verschiedenen untersuchten Einflüsse auf den Seigniorage zu erfassen und in Kapitel 13 wirtschaftspolitische Implikationen auf europäischer und nationaler Ebene zu beleuchten, wobei die Frage nach der Sinnhaftigkeit des Verteilungsschlüssel im Mittelpunkt steht. Ein Ausblick auf mittel- und langfristige Veränderungen der Einnahmen aus der Geldschöpfung (Kapitel 14) beendet die Analyse. 
Teil I: Ergebnisse und theoretische Grundlagen bisheriger Studien

\section{Die fiskalischen Umverteilungswirkungen als Folge der Europäischen Währungsunion: Der Stand der Diskussion}

Der angebliche Einnahmeverlust der Deutschen Bundesbank durch die Europäische Währungsunion zwischen 3,5 Mrd. und $150 \mathrm{Mrd}$. genannt. Dabei fällt nicht nur die große Diskrepanz zwischen den Ergebnissen der verschiedenen Studien auf, sondern auch unterschiedliche Begrifflichkeiten bei der Beschreibung des Einnahmeverlusts, unterschiedliche Ursachenfindungen und unterschiedliche zeitliche Horizonte. Aufsehen zu diesem Thema erregte eine Studie von Sinn/Feist 1997. Darin wurden der Europäischen Währungsunion Mindereinnahmen in Höhe von 90 Mrd. DM zugerechnet, die sich aus der Verteilung der Geldschöpfungsgewinne der EZB auf die Nationalbanken für Deutschland ergeben sollen. Wenger kommt in einem Leserbrief an die FAZ (vgl. Wenger/Kaserer 1997) zu dem Schluß, daß diese Mindereinnahmen noch viel zu gering geschätzt wurden. Seine These lautet, daß sich die Kosten für Deutschland auf mindestens $150 \mathrm{Mrd}$. DM belaufen. Die Zeitschrift Central Banking (vgl. o. V. 1997b) kommt zu dem Ergebnis, daß die Verteilung der Geldschöpfungsgewinne zwischen den Mitgliedern einer Europäischen Währungsunion (12 Mitgliedsstaaten) Deutschland rd. $70 \mathrm{Mrd}$. US\$, d.h. bei einem Wechselkurs von 1,80 DM/Dollar $126 \mathrm{Mrd}$. DM, Verlust an Geldschöpfungsvermögen bescheren wird. Um einen jährlichen Verlust zu berechnen, unterstellen die Autoren einen Zinssatz von 3,1 \% (Offenmarktsatz der Bundesbank vom Februar 1997), so daß sie zu dem Ergebnis gelangen, daß Deutschland jährlich etwa 3,5 Mrd. DM „draufzahlen” werde. Die gleiche Zeitschrift veröffentlichte 2 Ausgaben vorher eine Gewinn- und Verlustrechnung für die Teilnehmerstaaten an der EWU, wonach Deutschland 1995 einen jährlichen Verlust von 2,6 Mrd. US\$ (knapp 4,7 Mrd. DM) erlitten hätte, wäre die Währungsunion zu diesem Zeitpunkt in Kraft getreten (vgl. o. V. 1997a, 7). Die Dresdner Bank dagegen errechnete im Sommer 1997, daß der Euro Deutschland bis zu 25 Mrd. DM koste (vgl. o. V. 1997c, 9), und eine Studie der WestLB. (vgl. Radl 1997, A5) gelangt zu dem Ergebnis, daß Deutschland pro Jahr 4 Mrd. DM verliere. Die anschließend einsetzende Kritik an der Höhe und Berechnungsweise der verschiedenen Prognosen erhellte die Problematik der höchst unterschiedlichen Ergebnisse recht wenig (vgl. o. V. 1997d; Kurm-Engels 1997; Hasse 1997).

Zur Zeit liegen fünf Beiträge zur Problematik der Geldschöpfungsgewinne innerhalb der Europäischen Währungsunion vor, auf die sich die beschriebenen Pressemeldungen teilweise beziehen. Im folgenden sollen diese Veröffentlichungen zunächst im Rahmen einer Bestandsaufnahme dargestellt werden.

\subsection{Empirische Befunde von Gros}

Gros (1989 und 1996) betrachtete, welchen Einfluß die Europäische Währungsunion bzw. die Konvergenzbemühungen im Vorfeld der Europäischen Wäh- 
rungsunion auf die Einnahmen aus der Geldschöpfung hat. Er bemißt dabei insbesondere den Effekt der Integration der Finanzmärkte und der sinkenden Inflationsraten im EWS auf die Einnahmen aus der Geldschöpfung für die EU-Staaten, insbesondere für die Hochinflationsländer. Gros nimmt in seiner ersten Studie (vgl. Gros 1989) an, daß in seinem Prognosejahr 1992 alle EU-Mitglieder am EWS teilnehmen werden und daß die Mindestreservesätze der Mitgliedsstaaten durch die Integration der Finanzmärkte einheitlich auf deren Durchschnittswert bzw. die Inflationsraten auf 1 bis $2 \%$ konvergiert seien.

Abbildung 2-1: Entwicklung der Geldschöpfungsgewinne nach Gros 1989, Methode 1

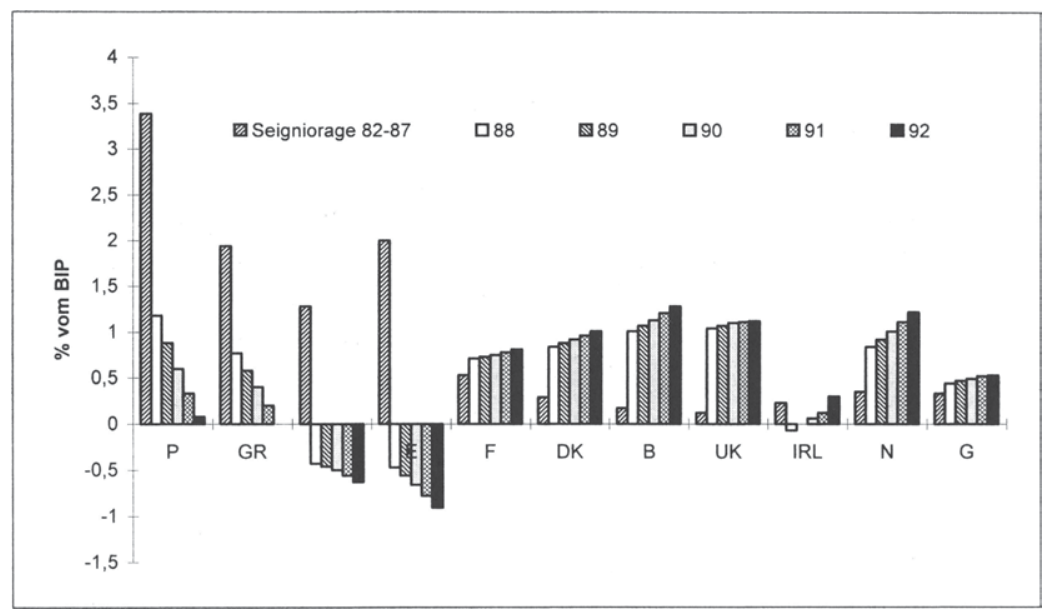

Quelle:

vgl. Gros 1989, 6

Gros kommt zu dem Ergebnis, daß der Seigniorage für all diejenigen Staaten stark fallen wird, die aufgrund einer Kombination aus hohen Inflationsraten und höheren Mindestreservesätzen als die übrigen EG-Staaten im Vergleich mit diesen bislang höhere Einnahmen aus der Geldschöpfung hatten. So ergeben sich nach seinen Berechnungen für Italien und Spanien für die Jahre 1988 bis 1992 sogar negative Einnahmen aus der Geldschöpfung - bis zu 0,63\% des BIP für Italien und bis zu 0,91\% des BIP für Spanien -, nachdem diese zwischen 1979 und 1987 bei positiven 1,28 \% des BIP (Italien) bzw. 2 \% (Spanien) lagen. Die höchsten einmaligen Geldschöpfungsgewinne erzielte Spanien im Jahre 1984 mit $7,51 \%$ des BIP. Portugal, das innerhalb der EU während der 80er Jahre die höchsten nachhaltigen Geldschöpfungsgewinne zu verzeichnen hatte, muß laut Gros mit einem Rückgang dieser Einnahmen von 3,39 \% des BIP (1979-1987) auf 0,08 $\%$ des BIP (1992) rechnen und Griechenland mit einem Rückgang von 1,94 \% des BIP auf 0,00 \% (vgl. Gros 1989, 6).

In einer zweiten Berechnung innerhalb der gleichen Studie prognostiziert Gros ebenfalls starke Einnahmeausfälle aus der Geldschöpfung für diese Staaten, aller- 
dings fallen diese nicht ganz so hoch aus und vor allem entstehen keine negativen Einnahmen für Italien und Spanien (vgl. Gros1989, 7).

Abbildung 2-2: Entwicklung der Geldschöpfungsgewinne nach Gros 1989, Methode 2

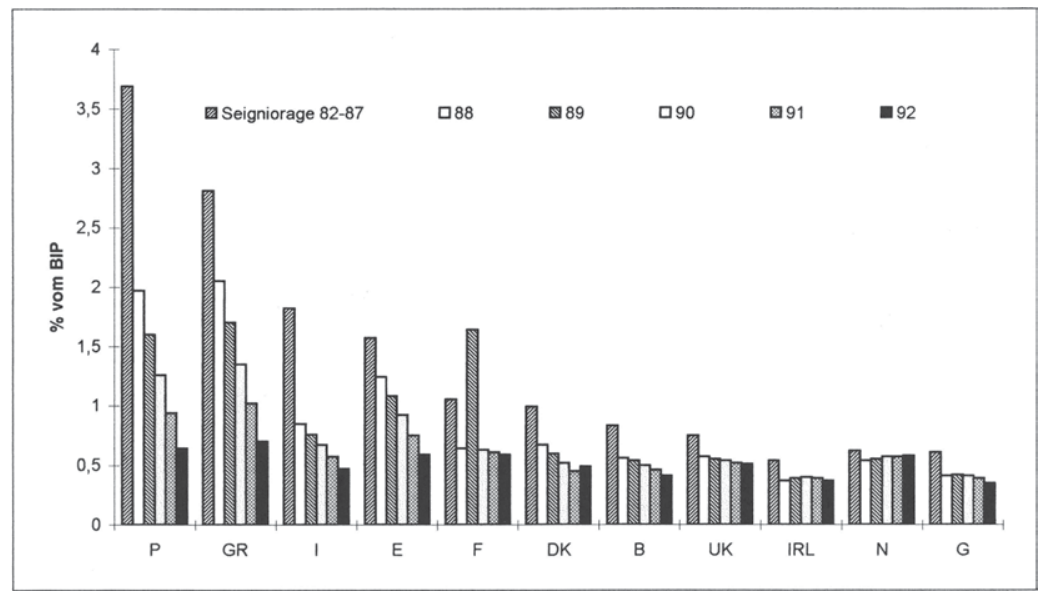

Quelle:

vgl. Gros 1989, 7

Deutschland kann dagegen nach der ersten Berechnung von Gros mit einem Zuwachs von 0,33\% des BIP (Durchschnitt der Jahre 1982 bis 1987) auf 0,53\% des BIP (1992) aufwarten, bzw. muß nach einer zweiten Berechnung einen geringen Verlust von $0,75 \%$ auf $0,51 \%$ des BIP erleiden. Ähnlich wie in Deutschland verhält es sich mit den übrigen EU-Mitgliedsstaaten.

Als Erklärung für seine Ergebnisse sieht Gros vor allem zwei Veränderungen der Finanzmärkte, die sich aufgrund deren zunehmender Integration ergeben. Zum einen nimmt Gros an, daß die Bemühungen zur Einhaltung der Maastrichter Konvergenzkriterien eine Reduktion der Inflationsraten auf 1-2 \% erwirken. Für Portugal und Griechenland, die bis zum Prognosezeitpunkt noch zweistellige Inflationsraten hatten, wird der Rückgang des Geldschöpfungsgewinns deshalb mit etwa $2 \%$ vom BIP höher sein als bei Staaten deren absolute Inflationsreduktion zur Erreichung der Maastrichter Kriterien geringer bemessen ist.

Für Italien und Spanien, deren Inflationsraten nur 3-4 \%-Punkte über denen der stabilsten EWS-Staaten liegen, erklären sich dagegen die hohen Einbußen aus der Reduktion der Mindestreservesätze.

Somit kommt Gros zu dem Ergebnis, daß das EWS und die Integration der Finanzmärkte zu einer Reduktion der Einnahmen aus der Geldschöpfung für einige Staaten führt. Aus ökonomischer Perspektive schätzt er die Verluste für Italien und Spanien allerdings als gering ein, während er für Portugal und Griechenland hohe Verluste konstatiert (vgl. Gros 1989, 12). 
1996 veröffentlichte Gros eine weitere Studie zu diesem Thema (vgl. Gros 1996) und kommt mit veränderten Annahmen und Szenarien zu ähnlichen Ergebnissen wie in seiner ersten Studie. Allerdings sinken nun in den Prognosen bis 1998 die Geldschöpfungsgewinne noch deutlicher und werden unter der Annahme vollständiger Konvergenz (Geldnachfrage, Wachstumsraten, Inflationsraten, Zinssätze für Staatsanleihen und Mindestreservesätze) der EU-Mitgliedsstaaten selbst für Deutschland in einem Szenario negativ. Portugals "Einnahmen" werden mit $3,61 \%$ des BIP am niedrigsten prognostiziert, Spaniens, Griechenlands und Italiens "Einnahmen" liegen zwischen $-0,75 \%$ (Italien) und $-1,34 \%$ (Spanien und Griechenland) des BIP (vgl. Abbildung 2-3).

Abbildung 2-3: Entwicklung der Geldschöpfungsgewinne nach Gros 1996, volle Konvergenz, Methode 1

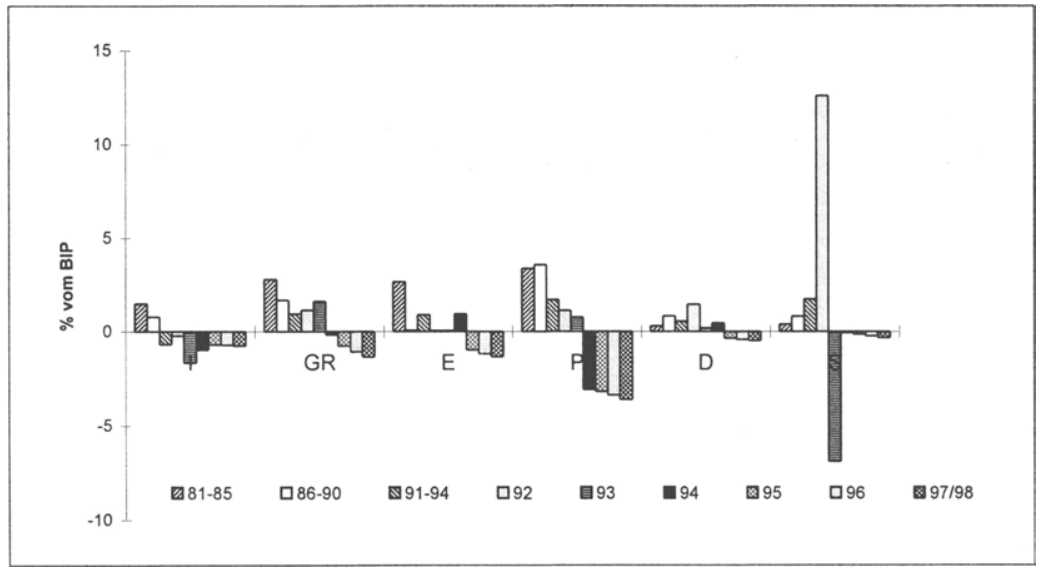

Quelle:

vgl. Gros 1996, 439

Sollte es nur zu einer Konvergenz der Inflationsraten und Zinssätze sowie der Geldnachfrage bzw. der Inflationsraten und Zinssätze sowie der Mindestreservesätze kommen, so ergeben sich für 1998 positive Einnahmen, die sich - außer für Portugal - von denen Anfang der 90er Jahre kaum unterscheiden (zwischen 0,4 und $0,94 \%$ des BIP) (vgl. Abbildung 2-4).

Die schon in seiner ersten Studie verwandte zweite Berechnungsmethode läßt die Geldschöpfungsgewinne für alle Staaten der Währungsunion bei vollständiger Konvergenz auf einen Anteil von 0,56 \% des BIP sinken (vgl. Abbildung 2-5). 
Abbildung 2-4: Entwicklung der Geldschöpfungsgewinne nach Gros 1996, unvollständige Konvergenz, Methode 1

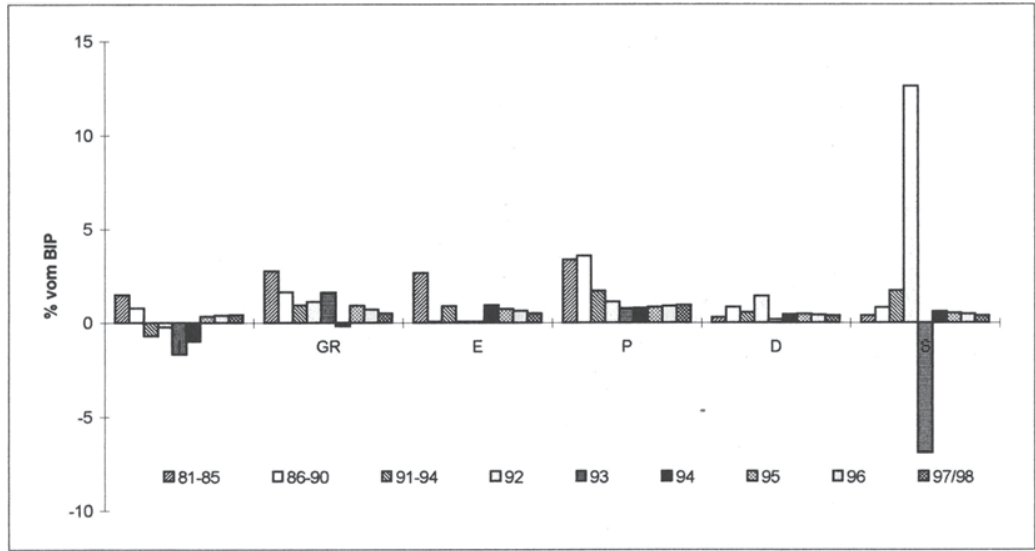

Quelle: $\quad$ vgl. Gros 1996,439

Abbildung 2-5: Entwicklung der Geldschöpfungsgewinne nach Gros 1996, volle Konvergenz, Methode 2

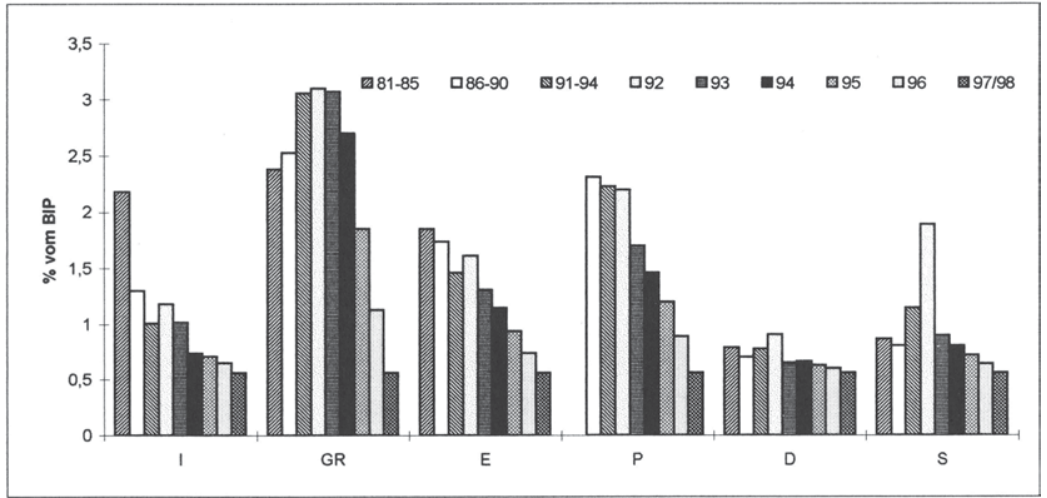

Quelle: $\quad$ vgl. Gros 1996,443

Weiterhin untersucht Gros den Effekt, der sich ergibt, wenn die Geldschöpfungsgewinne der EZB nach den EZB-Statuten verteilt werden. Unter der Annahme der vollständigen Konvergenz beträgt der Umverteilungseffekt der EZB-Statuten für die „Gewinnerstaaten" Griechenland und Portugal etwa 0,4 \% für Spanien ca. $0,15 \%$ des BIP. Die Gewinne und Verluste der übrigen Staaten belaufen sich auf Werte zwischen 0 und $0,1 \%$. Deutschlands Verlust beläuft sich auf etwa ein halbes Prozent des BIP. 
Abbildung 2-6: Gewinne und Verluste durch die Verteilung des Geldschöpfungsgewinns

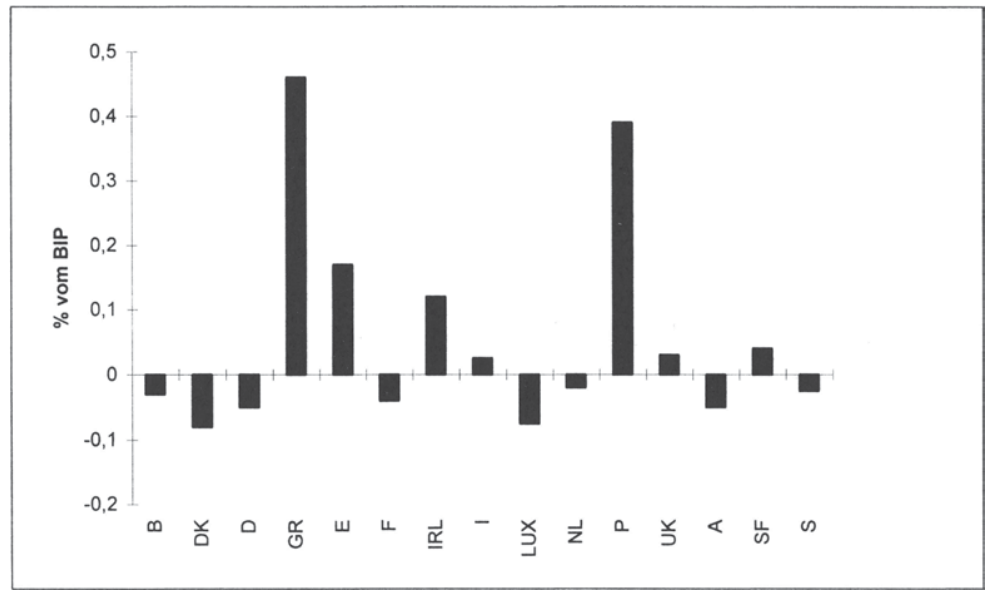

Quelle:

vgl. Gros 1996, 449

\subsection{Empirische Befunde von Lange/Nolte}

Lange/Nolte (1997) betrachten zunächst die Geldschöpfungseinnahmen der Europäischen Staaten in einem Zeitraum zwischen 1980 und 1995. Dabei verwenden auch sie zwei unterschiedliche Berechnungsmethoden, die hier allerdings gemittelt über den genannten Zeitraum zu sehr ähnlichen Ergebnissen führen. Eine Clusteranalyse der Ergebnisse führt zu drei Gruppen von EU-Mitgliedsstaaten, die jeweils ähnlich hohe Geldschöpfungseinnahmen verzeichnen konnten. Für die EU-Staaten Nordeuropas ergeben sich im Untersuchungszeitraum durchschnittliche jährliche Einnahmen von 0,66\% bzw. 0,42\% des BIP (je nach Berechnungsmethode), die Staaten Spanien und Italien erzielen im Mittel Einnahmen von 2,14 bzw. $1,43 \%$ des BIP, während Griechenland und Portugal 3,43 bzw. 3,04\% des BIP erzielen. Deutschlands Einnahmen belaufen sich in diesem Zeitraum auf 0,73 bzw. 0,43 \% vom BIP.

Auch in dieser Studie wird der Rückgang der Einnahmen in der ersten Hälfte der neunziger Jahre im Vergleich zum gesamten Untersuchungsraum analysiert. Die Einnahmerückgänge unterscheiden sich hier je nach Berechnungsmethode allerdings erheblich. So liegen die Einnahmen Griechenlands bspw. zwischen 1991 und 1995 bei der einen Berechnungsmethode um 0,87 Prozentpunkte unter dem gesamten Durchschnitt von 1980-95, während die zweite Berechnungsmethode im Gegensatz dazu sogar einen leichten Anstieg der Einnahmen konstatiert. Ähnliche Unterschiede aufgrund der Berechnungsmethoden lassen sich für Portugal ($1,39 \%$-Punkte versus - $0,27 \%$-Punkte) und Italien $(-1,02$ versus $0,35 \%$-Punkte) feststellen. Dies sind neben Spanien (-0,76 und -0,8\%-Punkte) die Staaten mit den höchsten Einnahmeverlusten bis in die Mitte der 90er Jahre. Den übrigen EU- 
Mitgliedsstaaten werden nur leichte Verluste bzw. Schweden $(+0,4$ versus $+0,08)$ und Finnland $(+0,25$ und $+0,1)$ leichte Gewinne attestiert.

Abbildung 2-7: Veränderung der Geldschöpfungsgewinne vor Einführung der EWU nach Lange/Nolte 1996, Methode 1

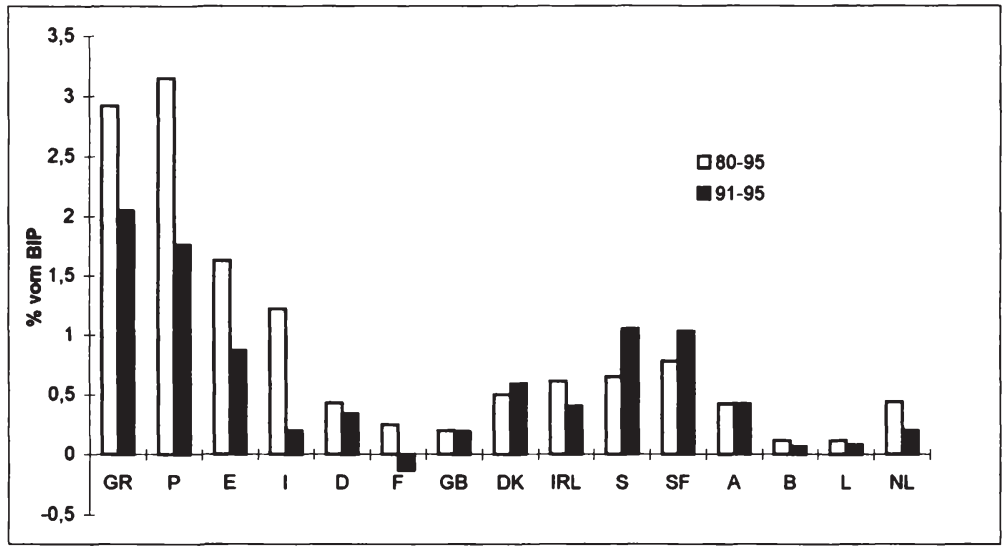

Quelle:

vgl. Lange/Nolte 1996, 7

Abbildung 2-8: Veränderung der Geldschöpfungsgewinne vor Einführung der EWU nach Lange/Nolte 1996, Methode 2

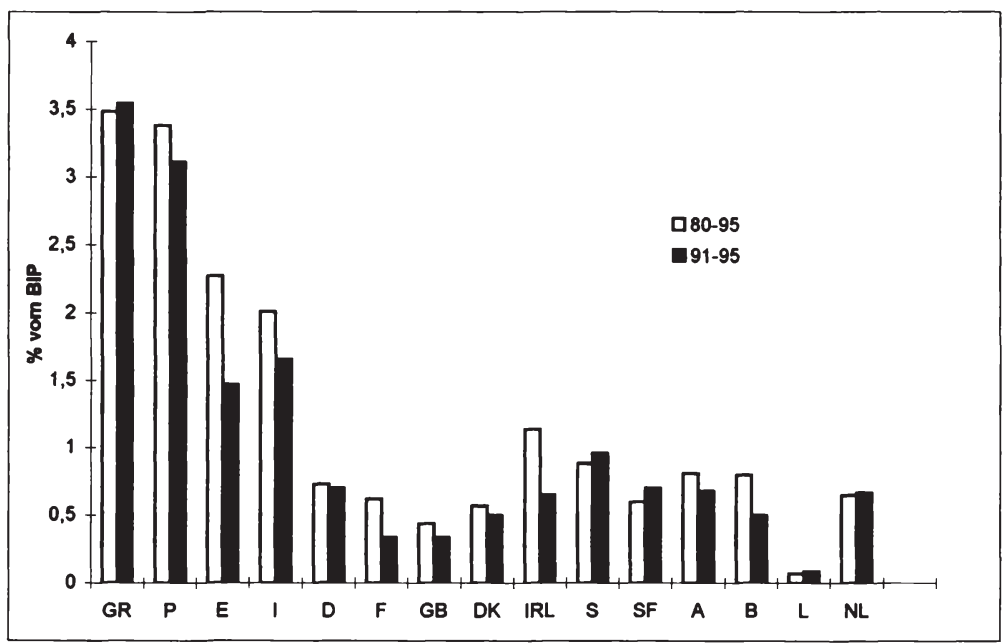

Quelle:

vgl. Lange/Nolte 1996, 7

Die Prognose der zukünftigen Einnahmen der Europäischen Zentralbank basiert bei Lange/Nolte auf verschiedenen Annahmen über Geldnachfrage, Reservesatz, 
Realzinssatz, Inflationsrate und Wirtschaftswachstum. Sie gehen dabei - außer bei der Geldnachfrage für die einzelnen Mitgliedsstaaten - von einem vollkommenen Konvergieren der Größen aus. Der Geldschöpfungsgewinn der EZB beläuft sich dann je nach Szenario (12 verschiedene) zwischen 0,22 \% und 0,71\% vom BIP der Währungsgemeinschaft.

Dementsprechend vielfältig fallen die Prognosen für die Gewinne und Verluste der einzelnen Staaten an Geldschöpfungseinnahmen im Vergleich zu der Zeitspanne 1990-95 aus. Den größten Verlust erleiden demnach Portugal und Griechenland mit über die Szenarien gemittelten $-2,70$ bzw. $-1,37 \%$-Punkten des BIP (Griechenland) und -2,22 bzw. -1,04 \%-Punkten (Portugal) je nach Berechnungsmethode der Geldschöpfungseinnahmen. Es folgen Spanien $(-0,80$ bzw. $0,33 \%$-Punkte), Italien (-1,11 bzw. +0,25 \%-Punkte), Schweden (-0,48 bzw. $0,65 \%$-Punkte) und Finnland (-0,61 bzw. -0,17 \%-Punkte). Die Gewinne und Verluste der übrigen Staaten bewegen sich zwischen -0,22 (Dänemark) und $+0,54 \%$-Punkten (Frankreich). Dabei ist zu beachten, daß die Ergebnisse der Szenarien stark streuen. So ergeben sich für Deutschland bspw. Veränderungen je nach Szenario zwischen -0,35 und +0,27 \%-Punkten.

Abbildung 2-9: Ånderung des Geldschöpfungsgewinns nach Einführung der EWU gegenüber 1991-95, Durchschnitt von 12 Szenarien

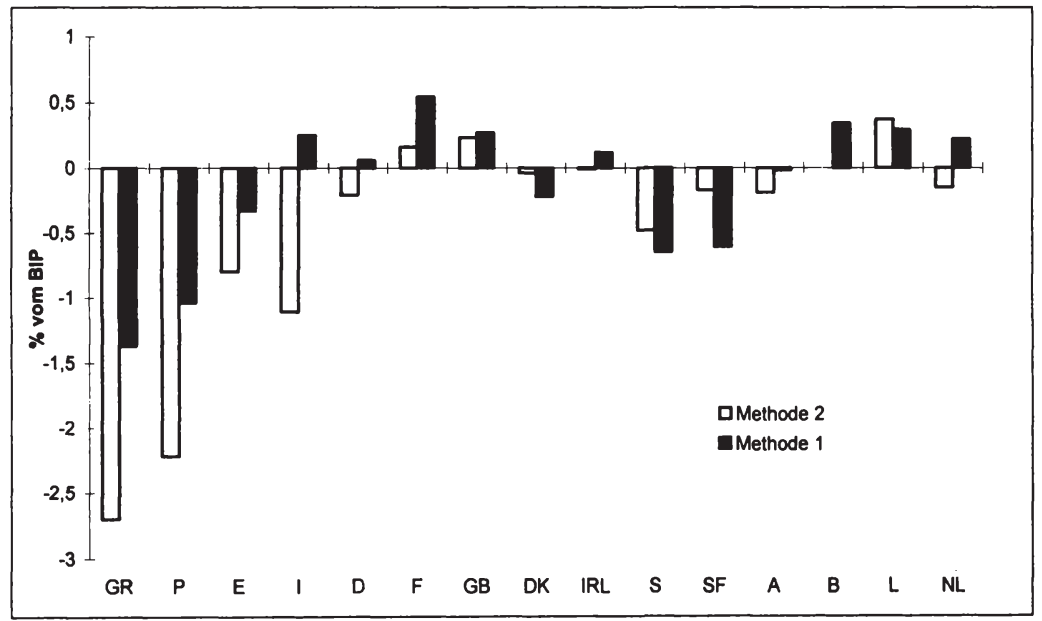

Quelle:

vgl. Lange/Nolte 1997, 35

Wirtschaftspolitische Implikationen sehen Lange/Nolte vor allem darin, daß eine Lösung für die vermutlich schweren Anpassungsprobleme der Länder Griechenland und Portugal gefunden werden muß, da beide Staaten jährliche Einbußen in Höhe von 2,5 (P) und 3 \%-Punkten (GR) zu erleiden haben, welche somit immerhin in der Größenordnung der Defizitgrenze des Maastrichter Vertrags liegen. 


\subsection{Empirische Befunde von Sinn/Feist}

Sinn/Feist (1997) betrachten den Verlust an sogenanntem "Geldschöpfungsvermögen", der sich beim Übertragen desselben an die EZB ergibt. Die Grundüberlegung bei Sinn/Feist besteht darin, daß die nationalen Zentralbanken in der Vergangenheit angesammelte Vermögen, die aus der Geldschöpfung resultieren, beim Übergang in die EWU auf die EZB übertragen müssen. Die Gewinne, die durch die Anlage dieses Vermögens gemacht werden, fließen den Mitgliedshaushalten zwar wieder zu, aber die Verteilung dieser Gewinne ist eine andere als die der Vermögensübertragung. D.h. auch langfristig kommt es zu einer Umverteilung innerhalb der EWU-Mitgliedsstaaten.

Eine umfassende Währungsunion hätte somit folgende Gewinner und Verlierer aufzuweisen (vgl. Abbildung 2-10): Frankreich und Großbritannien sind die beiden größten Gewinner dieser Umverteilung mit 31 Mrd. bzw. 29 Mrd. ECU, gefolgt von Italien (14 Mrd.). Ebenfalls Gewinner, allerdings mit kleineren Umverteilungsgewinnen, sind Belgien $(1,7)$, Griechenland $(1,4)$, Irland $(0,2)$, Luxemburg $(0,6)$ und Portugal $(2,6)$. Die großen Verlierer sind Deutschland $(-41,1 \mathrm{Mrd}$. ECU), Spanien $(-14,1)$ und Schweden $(-7,3)$. Ebenso werden die Staaten Niederlande ($2,4)$, Finnland $(-3,9)$, Dänemark $(-1,8)$ und Österreich $(-4,4)$ an Seignioragevermögen verlieren. In verschiedenen Szenarien variieren Sinn/Feist die Mindestreservesätze der nationalen Zentralbanken, so daß sich die absoluten Größen zwar verringern, die großen Gewinner- und Verliererstaaten allerdings die gleichen bleiben.

Abbildung 2-10: Gewinne und Verluste an Geldschöpfungsvermögen bei Einführung der EWU

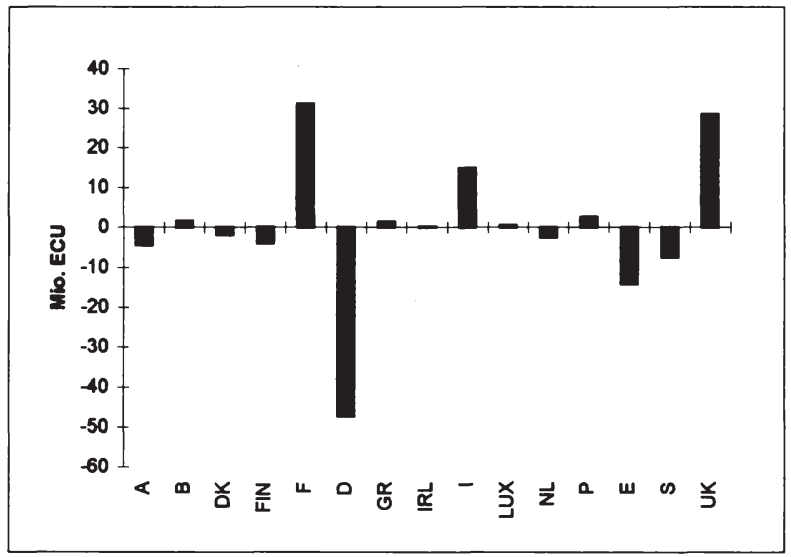

Quelle:

vgl. Sinn/Feist 1997, 12

Sinn/Feist entwickeln darauf aufbauend eine Grenzverlust-Grenzgewinn-Matrix, mit deren Hilfe sie versuchen, die Beitrittsentscheidungen auf Grundlage der Um- 
verteilung der Seignioragevermögen zu simulieren. Das "teuerste Mitglied der Union" (vgl. Sinn/Feist 1997, 18) wäre demnach Frankreich. Wäre dieser Staat der letzte, der der Gemeinschaft beitritt, würde dieser Beitritt alle anderen Staaten $20 \mathrm{Mrd}$. ECU kosten. Deutschland dagegen würde bei einem Beitritt 33,1 Mrd. ECU Gewinn für die übrigen Mitglieder erbringen.

Als politische Konsequenz schlagen Sinn/Feist einen anderen Umverteilungsschlüssel vor, der sich nicht am BIP bzw. der Bevölkerung orientiert, sondern am Anteil an der gesamteuropäischen monetären Basis ${ }^{4}$.

\subsection{Empirische Befunde von Läufer}

Läufer (1997) kommt zu quantitativ ähnlichen Ergebnissen wie Sinn/Feist, allerdings ist seine Herangehensweise eine andere. Seine These lautet, selbst ohne Umverteilung von Geldschöpfungsgewinnen könne es zu einem Verlust für Deutschland kommen, da die Bundesbank ihre Monopolstellung in Europa verliert. Geldnachfrager aus dem Ausland, insbesondere Osteuropa, die aus Stabilitätsgründen bislang DM nachgefragt haben und so zum Geldschöpfungsgewinn der Bundesbank beigetragen haben, werden ihre Nachfrage, falls der Euro ähnliche Qualitäten aufweist wie die DM, nun auf Euro umstellen. Diese Nachfrage müssen sie aber nicht mehr in Deutschland artikulieren, sondern können auf jedem beliebigen Geldmarkt innerhalb der EWU auftreten, und so anderen nationalen Zentralbanken zu Geldschöpfungsgewinnen verhelfen.

Die Umverteilung von Geldschöpfungsgewinnen durch die EZB kann zu weiteren Verlusten oder Gewinnen für die Mitgliedsstaaten führen, ist aber völlig unabhängig von der ersten Fragestellung.

Ganz andere Ergebnisse erhielte man - so Läufer -, wenn man unterstellte, der Euro hätte nicht die gleiche Qualität wie die DM, da dann sogar die gesamte Geldnachfrage beeinflußt würde.

Eine Harmonisierung der Mindestreservevorschriften, d.h. für Deutschland eine Reduktion der Mindestreservesätze, erhöht nach Läufer $(1997,6)$ entgegen der Behauptung von Sinn/Feist (1997) die Einnahmeverluste für Deutschland.

Im quantitativen Ergebnis, d.h. bei einem Verlust an Geldschöpfungseinnahmen von 90 Mrd. DM für Deutschland, gibt Läufer Sinn/Feist allerdings wieder recht, wobei sich seiner Meinung nach die Fehler bei Sinn/Feist „zufällig kompensieren” (Läufer 1997, 6) würden.

\subsection{Empirische Befunde von Maennig/Hunger}

Maennig/Hunger (1996) berechnen die Gewinne und Verluste an Geldschöpfungseinnahmen für eine Währungsunion mit allen EU-Mitgliedsstaaten. Sie unterstellen eine konstante reale Geldmenge, d.h. die Geldnachfrage sei entweder

4 Zur Erläuterung des Begriffs „monetäre Basis” vgl. Exkurs „Zentralbankgeld” in Kapitel 3. 
vom Wachstum unabhängig oder es gebe kein Wachstum, und die Geldmenge der EWU sei die Summe der vierzehn nationalen Geldmengen im Durchschnitt der Jahre 1988-92. Durch die Verteilung der Geldschöpfungsgewinne nach dem Schlüssel der EZB - so Maennig/Hunger - wäre ein Rückgang der durchschnittlichen Einnahmen von rd. $1 \%$ des BIP auf $0,3 \%$ zu beobachten, allerdings ungleichmäßig verteilt. Die größten Verlierer seien Portugal, Griechenland, Spanien und Italien mit Verlusten zwischen 1,44 (Italien) und 4,81\%-Punkten des BIP (Portugal). Die übrigen Staaten verlieren weniger Einnahmen, leichte Gewinne können nur Großbritannien $(+0,18)$ und Belgien $(+0,17 \%$-Punkte des BIP) verzeichnen.

Würde man die Anzahl der Mitgliedsstaaten einer Europäischen Währungsunion um die Staaten Portugal, Italien, Griechenland und Spanien reduzieren (10erUnion), ergäbe sich unter sonst gleichen Annahmen eine noch deutlichere durchschnittliche Verringerung der Geldschöpfungsgewinne als bei der 14er-Union, nämlich auf $0,23 \%$ des BIP.

Abbildung 2-11: Veränderung der Geldschöpfungsgewinne bei Einführung der EWU

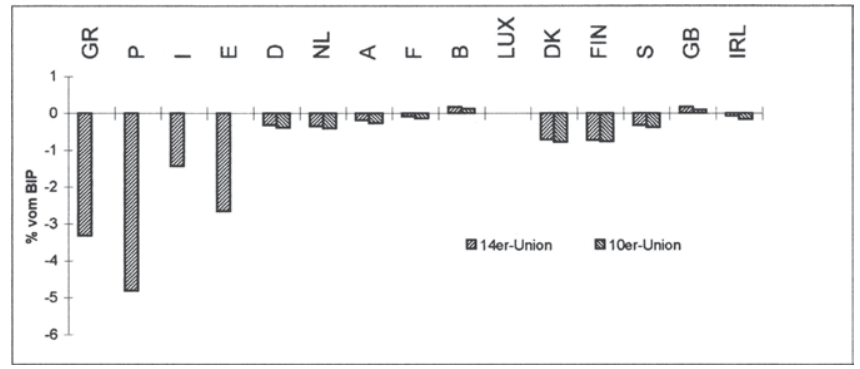

Quelle:

vgl. Maennig/Hunger 1996, 230

Maennig/Hunger begründen diesen Unterschied mit der deutlich höheren Geldumlaufgeschwindigkeit in den Staaten der 10er-Union, die die Geldschöpfungsgewinne weiter reduzierten. Die größten Verlierer in diesem Szenario sind Dänemark $(-0,77 \%$-Punkte des BIP) und Finnland $(-0,76)$, während Großbritannien und Belgien mit einem geringen Plus von 0,09 (Großbritannien) bzw. 0,12\%Punkten des BIP (Belgien) rechnen können. Die übrigen Staaten machen geringe Verluste.

Die fiskalischen Konsequenzen für den Haushalt überschlagen Maennig/Hunger $(1996,231)$ indem sie eine durchschnittliche Ausschüttung in Höhe von ca. 35 \% der Geldschöpfungsgewinne durch die Zentralbanken annehmen. Der Anteil der ausgeschütteten Notenbankgewinne an den gesamten Staatseinnahmen verringert sich infolgedessen bei einer $14 \mathrm{er}$-Union von durchschnittlich $0,55 \%$ auf rd. $0,31 \%$ bzw. bei einer $10 \mathrm{er}-$ Union auf $0,16 \%$. 
Abbildung 2-12: Bisherige und zu erwartende Finanzierungsbeiträge der ausgeschütteten Notenbankbeiträge

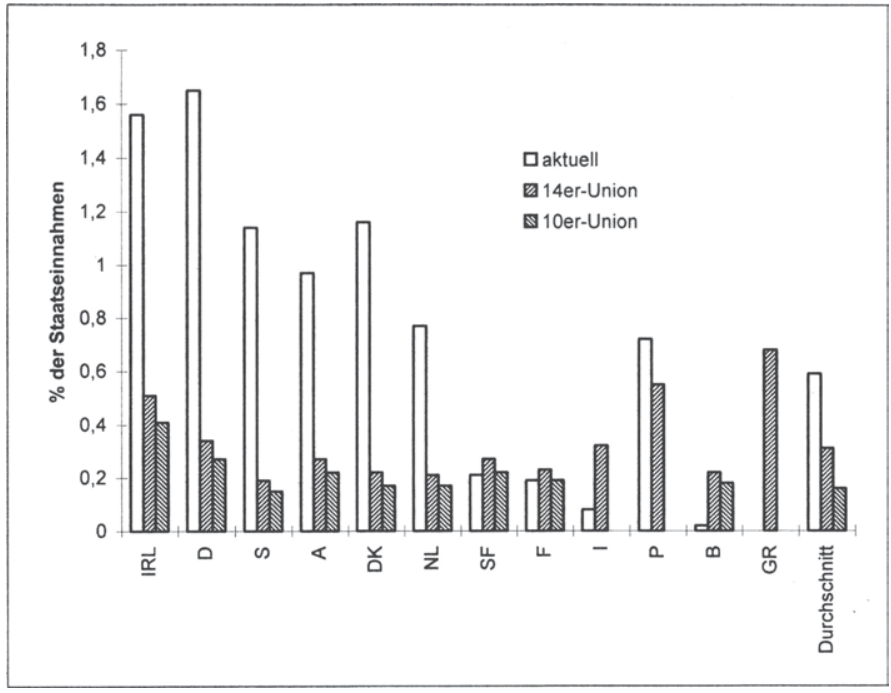

Quelle:

vgl. Maennig/Hunger 1996, 231

„Die am härtesten betroffenen Staatsetats sind der deutsche, der irische und der schwedische. Hier dürften sich zusätzliche Finanzierungslücken in Höhe von ca. $1 \%$ der Etats ergeben. Angesichts dessen, daß diese Länder nur bedingt erfolgreich mit der im Maastrichter Vertrag festgelegten maximalen Staatsdefizitquote von $3 \%$ des BIP kämpfen, dürfte dies erhebliche Probleme auslösen" (Maennig/Hunger 1996, 231f).

\subsection{Synoptische Zusammenfassung der empirischen Befunde}

Ein Vergleich der Ergebnisse ist aufgrund der in den Studien teilweise höchst unterschiedlich getroffenen Annahmen nur bedingt aussagekräftig und selbst Studien mit ähnlichen Annahmen weisen recht unterschiedliche Ergebnisse auf. Die Tabellen 2.1 und 2.2 sowie die Abbildungen 2.13 bis 2.15 fassen die Ergebnisse und die getroffenen Annahmen noch einmal synoptisch bzw. graphisch zusammen. Die Ergebnisse von Läufer sind nicht explizit aufgeführt, da sie sich nur in ihrer Herleitung nicht aber quantitativ von Sinn/Feist unterscheiden. Um eine Vergleichbarkeit der Ergebnisse herzustellen ${ }^{5}$, sind die Ergebnisse von Sinn/Feist mit einem Zinssatz von $4 \%$ verzinst und auf das dort angegebene BIP bezogen (vgl. Sinn/Feist 1997, 9).

5 Die Ergebnisse von Sinn/Feist beziehen sich auf das Geldschöpfungsvermögen statt auf die Geldschöpfung. 
Sowohl Tabelle 2.1 als auch Abbildung 2.1 lassen für die Änderungen der Geldschöpfungsgewinne allerdings kein eindeutiges Ergebnis erkennen. Die Autoren sind sich offenbar darin einig, daß die größten Veränderungen wohl die Staaten Griechenland, Portugal, Italien und Spanien treffen werden, aber schon beim Vorzeichen der Änderungen gehen die Prognosen auseinander. Während Maennig/Hunger und Lange/Nolte für diese Staaten im wesentlichen starke Verluste errechnen, kommen Sinn/Feist und Gros zu Zuwächsen bei den Geldschöpfungsgewinnen. Auch für Deutschland ergeben sich je nach Autor höchst unterschiedliche Veränderungen. Während Maennig/Hunger und Lange/Nolte (Methode 1) Verluste zwischen 0,3 und $0,4 \%$ des BIP berechnen, liegen die Verluste bei Sinn/Feist, Gros und Lange/Nolte (Methode 2) nur bei ca. 0,1\% des BIP.

Tabelle 2.1: $\quad$ Synoptische Zusammenfassung der Ergebnisse bisheriger Studien zur Verteilung der Geldschöpfungsgewinne innerhalb einer Europäischen Währungsunion - Änderung der Geldschöpfungsgewinne

\begin{tabular}{|c|c|c|c|c|c|c|}
\hline \multirow{2}{*}{\begin{tabular}{|l|} 
\\
Annahmen
\end{tabular}} & \multicolumn{2}{|c|}{ Maennig/Hunger 1996} & \multicolumn{2}{|c|}{ Lange/Nolte 1997} & Sinn/Feist 1997 & Gros 1996 \\
\hline & & & & & & \\
\hline & $\begin{array}{r}\text { Geldmenge } \\
\text { Summe aller } \\
\text { Geldmenger } \\
\text { cons }\end{array}$ & $\begin{array}{l}\text { in } E W U= \\
\text { nationalen } \\
\text { n, } \cdot M / P= \\
\text { st. }\end{array}$ & $\begin{array}{r}M=f(M, \cdot k= \\
=2 \%, \cdot k \text { bleib } \\
\text { EWU konstan } \\
p=\underline{2 \%}, 7 \%, \\
\underline{2,5 \%}, 1,5\end{array}$ & $\begin{array}{l}\text { const., mrs } \\
\text { iben auch in } \\
\text { int, ir }=4 \% \text {, } \\
6,4 \% \cdot w r= \\
5 \%, 3,5 \%\end{array}$ & $\begin{array}{l}\text { Ubertragung der } \\
\text { monetăren Basis } \\
\text { der nationalen } \\
\text { ZB auf die EZB } \\
\text { abzgl. Gewinn- } \\
\text { zuteilung der } \\
\text { EZB = Verlust }\end{array}$ & $\begin{array}{l}\text { vollständige } \\
\text { Konvergenz der } \\
\text { EWU Mitglieds- } \\
\text { staaten, } k=6 \% \text {, } \\
p=1-2 \%, w r= \\
2-3 \%, i r=4-5 \% \text {, } \\
\text { mrs }=2 \%\end{array}$ \\
\hline \multirow{2}{*}{$\begin{array}{l}\text { Anzahl der } \\
\text { Berechnungsmethoden }\end{array}$} & & & & & & \\
\hline & 14er-Union ${ }^{1}$ & 10er-Union & Methode 1 & ${ }^{2}$ Methode 2 & 1 & \\
\hline \multirow[t]{2}{*}{ Bezugsjahr } & Durchschnitt & t 1980-92 & Durchschnit & litt 1991-95 & 1998 & 1998 \\
\hline & \multicolumn{6}{|c|}{ Ánderung der Geldschöpfungsgewinne in \% des BIP } \\
\hline GR & $-3,32$ & - & $-2,94$ & $-1,6$ & 0,07 & 0,46 \\
\hline $\mathbf{P}$ & $-4,81$ & - & $-2,48$ & $-1,29$ & 0,15 & 0,39 \\
\hline 1 & $-1,44$ & - & $-1,26$ & 0,09 & 0,07 & 0,03 \\
\hline E & $-2,66$ & - & $-0,99$ & $-0,51$ & $-0,13$ & 0,17 \\
\hline D & $-0,33$ & $-0,39$ & $-0,35$ & $-0,08$ & $-0,11$ & $-0,05$ \\
\hline $\mathrm{NL}$ & $-0,36$ & $-0,41$ & $-0,3$ & 0,07 & $-0,03$ & 0,02 \\
\hline A & $-0,19$ & $-0,27$ & $-0,33$ & $-0,15$ & $-0,11$ & $-0,05$ \\
\hline$F$ & $-0,09$ & $-0,15$ & 0,02 & 0,4 & 0,11 & $-0,04$ \\
\hline B & 0,17 & 0,12 & $-0,14$ & 0,2 & 0,04 & $-0,03$ \\
\hline LUX & & & 0,24 & 0,16 & 0,22 & $-0,08$ \\
\hline DK & $-0,72$ & $-0,77$ & $-0,17$ & $-0,35$ & $-0,06$ & $-0,08$ \\
\hline FIN & $-0,73$ & $-0,76$ & $-0,32$ & $-0,75$ & $-0,19$ & 0,04 \\
\hline s & $-0,33$ & $-0,38$ & $-0,62$ & $-0,79$ & $-0,17$ & $-0,03$ \\
\hline GB & 0,18 & 0,09 & 0,07 & 0,11 & 0,14 & 0,03 \\
\hline IRL & $-0,08$ & $-0,17$ & $-0,19$ & $-0,06$ & 0,02 & $-0,04$ \\
\hline
\end{tabular}

Quelle: $\quad$ Maennig/Hunger 1996, 230; Lange/Nolte 1997, 35; Sinn/Feist 1997, 12; Gros 1996, 449 
Abbildung 2-13: Ergebnisse bisheriger Studien über die Veränderung der Geldschöpfungsgewinne

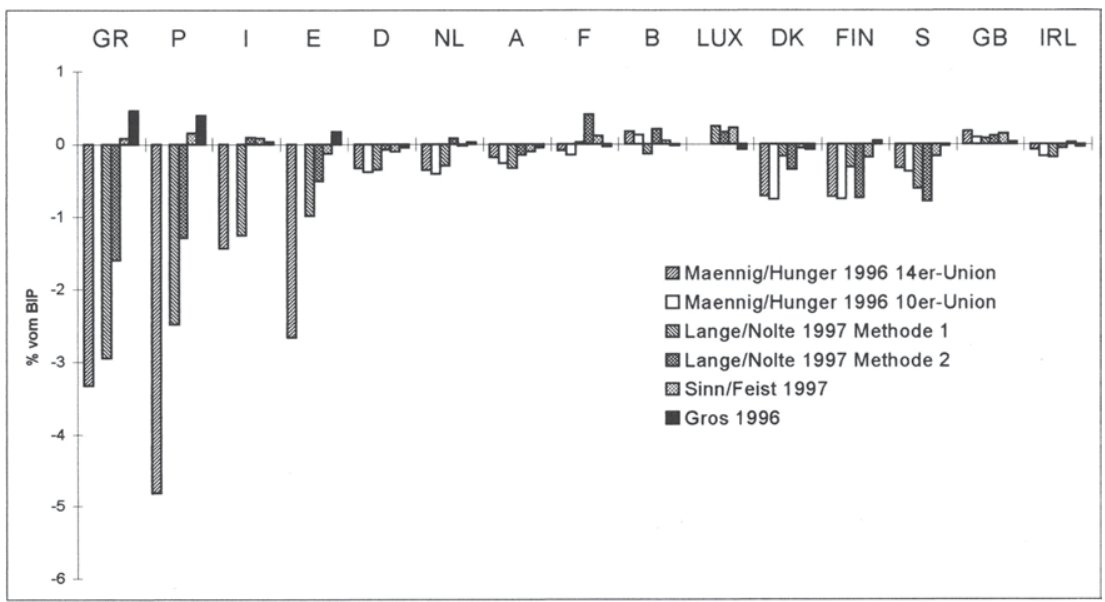

Quelle: angegebene und eigene Berechnungen

Abbildung 2-14: Ergebnisse bisheriger Studien zur Änderung der Geldschöpfungsgewinne für Deutschland

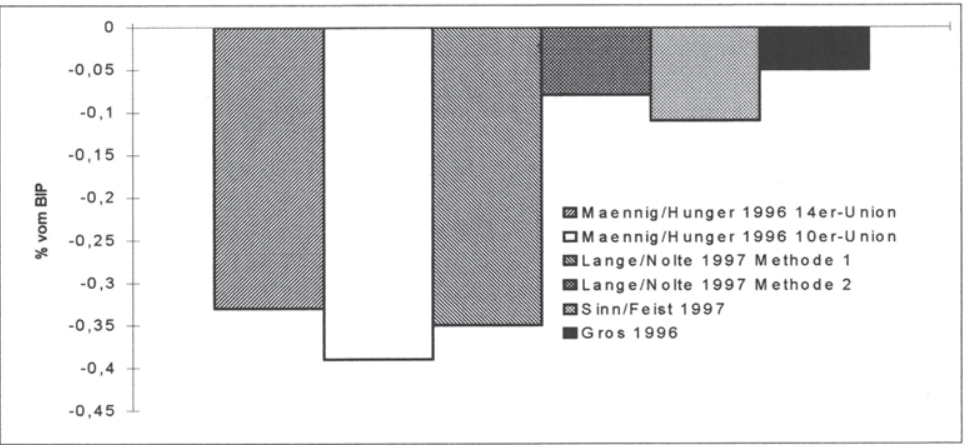

Quelle:

angegebene und eigene Berechnungen

Bei diesen Vergleichen muß allerdings berücksichtigt werden, daß die Bezugsjahre der Berechnungen unterschiedlich sind. Um trotzdem einen Vergleich zu ermöglichen, werden in Tabelle 2.2 und Abbildung 2.15 die prognostizierten Geldschöpfungsgewinne in Prozent des BIP dargestellt. 
Tabelle 2-2: $\quad$ Synoptische Zusammenfassung der Ergebnisse bisheriger Studien zur Verteilung der Geldschöpfungsgewinne innerhalb einer Europäischen Währungsunion - Höhe der Geldschöpfungsgewinne

\begin{tabular}{|c|c|c|c|c|c|c|}
\hline & $\begin{array}{l}\text { Maennig/ } \\
\text { Hunger } \\
1996 \text { 14er- } \\
\text { Union }\end{array}$ & $\begin{array}{l}\text { Maeninig/ } \\
\text { Hunger } \\
1996 \text { 10er- } \\
\text { Union }\end{array}$ & $\begin{array}{l}\text { Lange/Nolte } \\
1997 \\
\text { Methode } 1\end{array}$ & $\begin{array}{l}\text { Lange/Nolte } \\
1997 \\
\text { Methode } 2\end{array}$ & Sinn/Feist 1997 & Gros 1996 \\
\hline & \multicolumn{6}{|c|}{ Geldschopfungsgewinne in \% des BIP } \\
\hline GR & 0,53 & - & $\overline{0,6}$ & 0,45 & 0,4 & 1,02 \\
\hline $\mathbf{P}$ & 0,53 & - & 0,63 & 0,47 & 0,36 & 0,95 \\
\hline I & 0,28 & - & 0,39 & 0,29 & 0,25 & 0,59 \\
\hline $\mathbf{E}$ & 0,34 & - & 0,48 & 0,36 & 0,52 & 0,73 \\
\hline D & 0,28 & 0,22 & 0,35 & 0,26 & 0,39 & 0,51 \\
\hline NL & 0,28 & 0,23 & 0,37 & 0,28 & 0,33 & 0,54 \\
\hline A & 0,27 & 0,21 & 0,35 & 0,26 & 0,39 & 0,51 \\
\hline $\mathbf{F}$ & 0,27 & 0,21 & 0,36 & 0,27 & 0,17 & 0,52 \\
\hline B & 0,27 & 0,22 & 0,36 & 0,27 & 0,25 & 0,53 \\
\hline LUX & - & - & 0,33 & 0,24 & 0,04 & 0,49 \\
\hline DK & 0,25 & 0,2 & 0,33 & 0,25 & 0,33 & 0,48 \\
\hline FIN & 0,26 & 0,21 & 0,38 & 0,28 & 0,49 & 0,61 \\
\hline $\mathbf{s}$ & 0,25 & 0,2 & 0,34 & 0,26 & 0,45 & 0,54 \\
\hline GB & 0,42 & 0,33 & 0,41 & 0,31 & 0,19 & 0,59 \\
\hline IRL & 0,48 & 0,39 & 0,46 & 0,34 & 0,36 & 0,52 \\
\hline
\end{tabular}

Quelle: $\quad$ vgl. Maennig/Hunger 1996, 230; Lange/Nolte 1997, 34;

Sinn/Feist 1997, 12; Gros 1996, 443

Abbildung 2-15: Ergebnisse bisheriger Studien über die Höhe der Geldschöpfungsgewinne innerhalb einer Europäischen Währungsunion

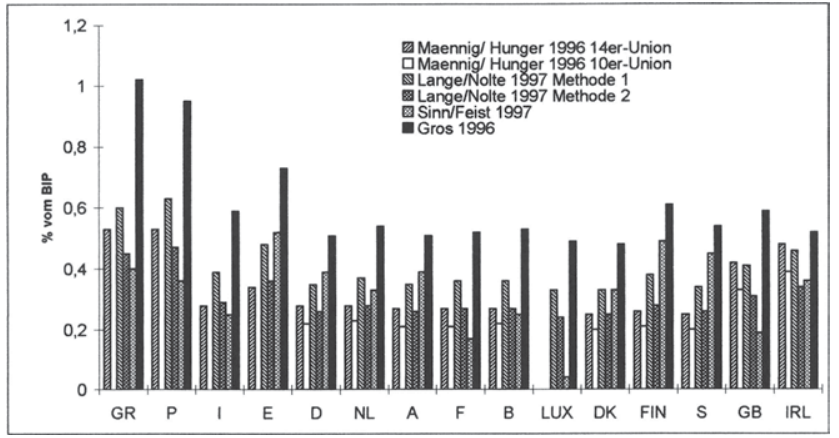

Quelle:

angegebene und eigene Berechnungen

Auch hier läßt sich erkennen, daß sich die Autoren uneinig darin sind, wie hoch die Geldschöpfungsgewinne im Verhältnis zum jeweiligen BIP ausfallen werden. Insbesondere Gros prognostiziert für die vier Staaten Griechenland, Portugal, Italien und Spanien fast doppelt so hohe Beträge wie die übrigen Autoren. Sehr unterschiedliche Ergebnisse im Vergleich zu den übrigen Studien erhalten Sinn/Feist: Während die Prognosen der Geldschöpfungsgewinne dort für die Staaten Griechenland, Portugal, Italien, Spanien, Deutschland, Niederlande, Österreich, Frankreich, Dänemark, Irland und Belgien etwa die gleiche Größenordnung wie bei Maennig/Hunger und Lange/Nolte erreichen, liegen sie für Luxemburg und Groß- 
britannien deutlich unter, für Schweden und Finnland deutlich über deren Werten. Relativ einig sind sich nur die Autoren Maennig/Hunger (Szenario 14erUnion) und Lange/Nolte (Methode 1).

Die Unterschiedlichkeit der Ergebnisse der Studien zeigen den Forschungsbedarf hinsichtlich der Frage nach den Geldschöpfungsgewinnen in einer Europäischen Währungsunion auf. Im folgenden sollen deshalb zunächst die Grundlagen zur Berechnung der Geldschöpfungsgewinne dargestellt werden, um anschließend die Ergebnisse der unterschiedlichen Studien vor einem analytisch strukturierten Hintergrund noch einmal beleuchten zu können. 


\section{$3 \quad$ Konzepte zur Messung des Seigniorage}

Seigniorage ist der in der wissenschaftlichen Literatur gebräuchliche Begriff für den Vermögens- oder Einkommenstransfer vom privaten Sektor an den Staat aufgrund dessen Fähigkeit, Zentralbankgeld zu schöpfen. Der Begriff des Seigniorage leitet sich aus dem "seigneur" ab, dem englischen Münzherren, der zu Zeiten des Goldstandards den Schlagsatz erheben konnte, wenn ein Bürger Goldbarren in Goldmünzen ausprägen ließ (vgl. Bofinger/Reischle/Schächter 1996, 47f). Aufgrund verschiedener Sichtweisen dieses Transfers zwischen Privaten und dem Staat existieren derzeit drei verschiedene Seignioragekonzepte.

Stellt man auf den Vermögenstransfer zwischen Privaten und dem Staat ab, so gelangt man zum Konzept des monetären Seigniorage und versteht darunter die Differenz zwischen dem Nennwert von staatlich emittiertem Geld - dem Zentralbankgeld - und seinen Produktionskosten, wobei die geringen Produktionskosten meist vernachlässigt werden.

Steht dagegen der Einkommenstransfer im Vordergrund, so versteht man unter Seigniorage den Ertrag des Staates aus der Geldproduktion bzw. die Kosten der Privaten, Geld zu halten (Opportunitätskosten-Seigniorage).

Ein drittes Konzept unterteilt den Staatssektor in Haushalt und Zentralbank und versteht unter Seigniorage die Mittel, die dem Haushalt von seiner Zentralbank zufließen, d.h. die an den Haushalt ausgeschütteten Zentralbankgewinne und die Kredite der Zentralbank an den Staat (fiskalischer Seigniorage).

Bevor jedoch die drei Konzepte genauer vorgestellt werden soll zunächst im Rahmen eines Exkurses der Begriff des Zentralbankgelds erläutert werden.

\section{Exkurs: Zentralbankgeld}

Unter Zentralbankgeld (ZBG) versteht man das von der Zentralbank geschaffene Geld, welches in Form von Sichtguthaben bei der Notenbank oder in Form von Banknoten und Münzen existiert ${ }^{6}$. Bargeld wird vorwiegend von den Nichtbanken, aber in geringem Umfang auch von den Geschäftsbanken gehalten, Sichtguthaben bei der Zentralbank halten im westlichen die Geschäftsbanken entweder aus Gründen der Liquiditätsvorhaltung in Form der Überschußreserven oder wegen gesetzlicher Bestimmungen in Form der Mindestreserve. Sichtguthaben in geringem Umfang halten auch öffentliche und private Nichtbanken (vgl. Abb. 31). Unterschieden wird vom Begriff des Zentralbankgelds die monetäre Basis, die eine Ausgangsgröße zur Bestimmung des Geldangebots darstellt. Quantitativ ist

6 In der Bundesrepublik steht abweichend von dieser Darstellung dem Bund das Recht zur Ausgabe von Münzen zu. Der Anteil der Münzen am gesamten Bargeldumlauf und -bestand ist allerdings vernachlässigbar gering, so daß im folgenden beides, Banknoten und -münzen, als Bargeld bezeichnet wird. Weiterhin muß unterschieden werden zwischen dem Bargeldumlauf, d.h. dem Bargeld der öffentlichen und privaten Nichtbanken, sowie dem Bargeldbestand der Geschäftsbanken, der z.B. nicht in der Geldmenge M1 enthalten ist. 
der Unterschied allerdings gering, da sich die monetäre Basis vom Zentralbankgeld nur durch das Fehlen der vernachlässigbaren Guthaben der öffentlichen und privaten Nichtbanken bei der Zentralbank unterscheidet (vgl. Issing 1993, 5).

Abbildung 3-1: Zentralbankgeld und monetäre Basis

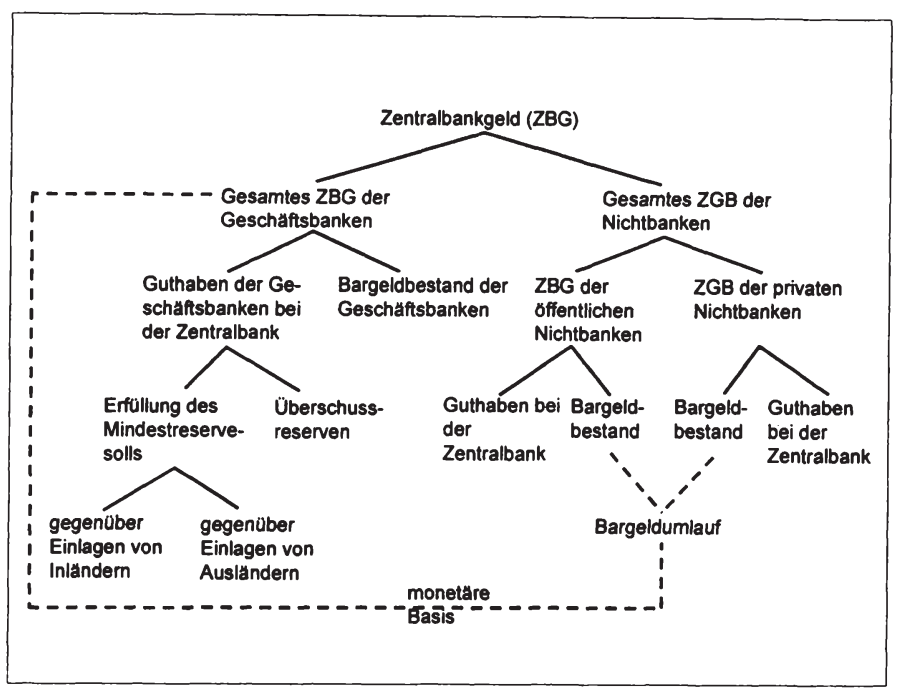

Quelle:

Issing 1993, 5

Die vereinfachte Notenbankbilanz gibt Aufschluß über die Größenordnung der einzelnen Posten (vgl. Tab. 3-1).

Tabelle 3-1: Vereinfachte Notenbankbilanz am Beispiel der Deutschen Bundesbank 1997

\begin{tabular}{|lr|lr|}
\hline Aktiva (Mrd. DM) & & Passiva (Mrd. DM) & \\
\hline Währungsreserven & 116,8 & Guthaben ausländischer Anleger & 12,4 \\
Kredite an Inländische & & Guthaben inländischer Geschäftsbanken & 48,7 \\
Geschäftsbanken & 235,2 & Guthaben inländischer öffentlicher & \\
Kredite an inländische & & Haushalte & 0,3 \\
öffentliche Haushalte & -- & Guthaben der privaten Nichtbanken & 1,0 \\
sonstige Aktiva & & Banknotenumlauf & 260,7 \\
(Gebäude, Grundstücke) & 17,5 & sonstige Passiva & 46,2 \\
\hline Summe & 369,5 & & 369,5 \\
\hline
\end{tabular}

Quelle:

Geschäftsbericht 1997 Deutsche Bundesbank

Faßt man die Währungsreserven und die Guthaben ausländischer Einleger zu Forderungen an das Ausland zusammen, sowie die Kredite an inländische öffent- 
liche Haushalte und deren Guthaben zu Forderungen an den Staat, ergibt sich folgende saldierte Notenbankbilanz.

Tabelle 3-2: Vereinfachte saldierte Notenbankbilanz

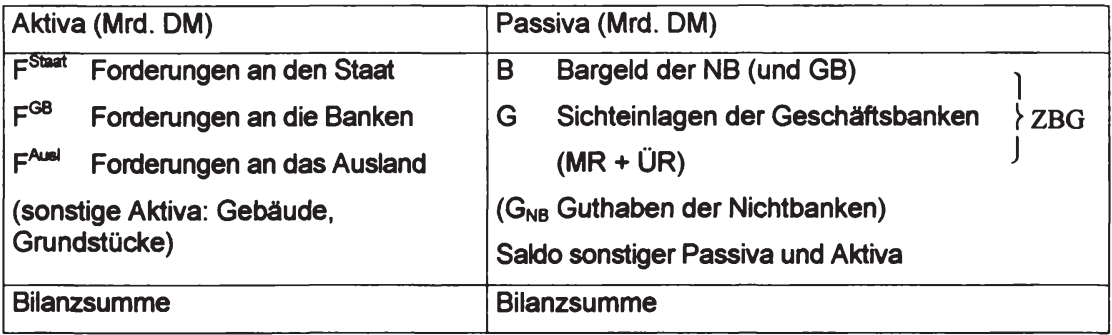

Quelle:

Bofinger/Reischle/Schächter 1996, 511

Ein Geldschöpfungsgewinn der Notenbank entsteht dadurch, daß die Sichteinlagen und das Bargeld zinslos gehalten werden, während sich die dafür bei der Notenbank hinterlegten Sicherheiten (Forderungen an den Staat, die Banken und das Ausland) in der Regel aus verzinslichen Wertpapieren zusammensetzen.

Somit läßt sich die Höhe des Geldschöpfungsgewinns, im folgenden Seigniorage genannt, aus der Höhe des Zentralbankgelds bzw. der - wie oben gezeigt quantitativ nahezu identischen monetären Basis $M$ mit Hilfe verschiedener Seignioragekonzepte ermitteln. Diese sollen im folgenden dargestellt werden und im Hinblick auf inre Unterschiede, Gemeinsamkeiten und Tauglichkeit analysiert werden.

\subsection{Monetärer Seigniorage}

Der monetäre Seigniorage Smon setzt direkt bei der Geldschöpfung an und stellt die Nichtrückzahlbarkeit von Zentralbankgeld in den Vordergrund. Ein MaB für den real entstandenen Geldschöpfungsgewinn ist somit die Veränderung der Zentralbankgeldmenge bezogen auf das Preisniveau P.

$S_{t}^{m o n}=\frac{\Delta M_{t}}{P_{t}}=\frac{\Delta M_{t}}{M_{t}} \frac{M_{t}}{P_{t}}=m_{t} \frac{M_{t}}{P_{t}}$

Die o.a. Formel zeigt, daß der monetäre Seigniorage auch als das Produkt aus Wachstumsrate der nominalen Basisgeldmenge $m$ und realer Geldmenge dargestellt werden kann. Angenommen die reale Geldmenge bliebe bei wachsender nominaler Geldmenge konstant (z.B. bei Nullwachstum des BIP und einer geringen Inflation, die zwar die nominale Geldmenge wachsen aber gleichzeitig die reale Geldmenge unverändert läßt), dann kann $S$ auch als Steueraufkommen interpretiert werden, wobei die reale Geldbasis die Bemessungsgrundlage und $\mathrm{m}$ der Steuersatz ist (vgl. Lange/Nolte 1997, 4). 
Wird die Basisgeldmenge ausgedehnt, so fließen der geldschaffenden Instanz noch in derselben Periode reale Mittel in Form von Wertpapieren, internationalen Währungsreserven oder Gold zu (Issing 1993, 53f).

Auf der Aktivseite der Notenbankbilanz schlägt sich der monetäre Seigniorage durch eine Bilanzverlängerung bei der Zentralbank nieder, er entspricht also der Summe der Zunahme an Zentralbankforderungen abzüglich der thesaurierten sprich der den Rücklagen zugeführten - Gewinne.

$S_{t}^{\text {mon }}=\frac{\Delta M_{t}}{P_{t}}=\frac{\Delta F_{t}^{\text {Staat }}}{P_{t}}+\frac{\Delta F_{t}^{G B}}{P_{t}}+\frac{\Delta F_{t}^{\text {Ausl }}}{P_{t}}-\frac{G_{t}^{\text {thes }}}{P_{t}}$

Die Zunahme der Zentralbankgeldmenge als Gewinn zu sehen, vernachlässigt die Passivseite der Zentralbankbilanz, nämlich die Verbindlichkeiten, die sich im Tausch durch den Erhalt der Finanz- und Sachaktiva ergeben. Diese Vernachlässigung läßt sich mit der Nichtrückzahlbarkeit und der Unverzinslichkeit von Zentralbankgeld erklären (vgl. Lange 1995, 32ff). Die Hypothese über die Nichtrückzahlbarkeit setzt an dem langfristigen Trend der wachsenden Geldnachfrage an. Mit Rückzahlungsansprüchen sei deshalb in einer Wirtschaft mit wachsendem nominalen Sozialprodukt nicht zu rechnen, weil sich aufgrund des positiven Zusammenhangs zwischen Geldnachfrage und Sozialprodukt die Geldmenge ebenfalls kontinuierlich ausweite. Zwar werde das einzelne Wertpapier nach Ablauf der Fälligkeit von der Zentralbank wieder zurückgegeben, aber gleichzeitig würden zur Aufrechterhaltung des Geldangebots neue Wertpapiere in gleicher Höhe, bzw. bei wachsender Geldmenge in steigender Höhe aufgenommen. Der Wertpapierstock einer Zentralbank wachse demnach in einer Volkswirtschaft mit wachsendem Sozialprodukt ebenfalls an.

Aber selbst für den Fall, daß die Geldnachfrage z.B. aufgrund eines sinkenden Sozialprodukts zurückgeht - so die Verfechter dieses Konzepts -, gäbe es keine Zwangsmittel, die bei Ansprüchen gegen Hoheitsträger anwendbar wären. Dies hieße, daß es keinen Anspruch auf Herausgabe der Wertpapiere gegenüber der Zentralbank gäbe. Allerdings ist dieser Fall nur schwer vorstellbar, wenn man bedenkt, daß die meisten Wertpapiere mit Rückkaufvereinbarung an die Zentralbank vergeben werden, bzw. spätestens nach Fälligkeit ihre Ertragsfähigkeit verlieren. Allenfalls durch eine Kreditvergabe an den Staat ließe sich die Geldmenge dann noch steigern, die Ausweitung der Geldmenge würde dann genau dem Mittelzufluß des Haushalts entsprechen.

Allerdings reicht auch die Nichtrückzahlbarkeit alleine noch nicht aus, bei dem monetären Seigniorage von einem Gewinn zu sprechen, da z.B. auch ewige Renten nicht getilgt werden, die Zinszahlungen aber dennoch zu einem positiven Barwert für den Gläubiger führen. Sind Verbindlichkeiten aber weder rückzahlbar noch verzinslich, ist zu fragen, ob überhaupt noch eine Verbindlichkeit vorliegt (vgl. Lange 1995, 33f). 
Makroökonomisch läßt sich die Entstehung des monetären Seigniorage durch seine Aufteilung in eine wachstumsinduzierte und eine inflationsinduzierte Komponente erklären (vgl. Lange 1995, 31):

Ausgehend von der Quantitätsgleichung

$$
M=\frac{1}{v_{M}} P Y
$$

mit

$M=$ Zentralbankgeldmenge

$V_{M}=$ konstante Umlaufgeschwindigkeit der Zentralbankgeldmenge

$P \quad=$ Preisniveau

$Y=$ reales Sozialprodukt

und deren totalem Differential

$$
d M=\underbrace{d \frac{1}{v} P Y}_{=0}+d P \frac{1}{v} Y+d Y \frac{1}{v} P
$$

ergibt sich für den monetäre Seigniorage

$$
\begin{aligned}
& S_{t}^{\text {mon }}=\frac{d M_{t}}{P_{t}}=\frac{d P_{t}}{P_{t}} \frac{1}{v_{t}} Y_{t}+d Y_{t} \frac{1}{v_{t}} \\
& \Leftrightarrow \\
& S_{t}^{\text {mon }}=\frac{d P_{t}}{P_{t}} \frac{M_{t}}{P_{t}}+\frac{M_{t}}{P_{t}} \frac{d Y_{t}}{Y_{t}}
\end{aligned}
$$

Somit wird deutlich, daß der monetäre Seigniorage vom Wachstum und der Inflationsrate abhängig ist.

Zieht man von diesem originären monetären Seigniorage die Kosten der Geldschöpfung $a b$, dann erhält man den monetären Nettoseigniorage (vgl. Lange 1995, 36f).

Eine Variante dieses Konzepts stellt der erweiterte monetäre Seigniorage dar (vgl. Lange 1995, 37). Hier werden die Zinseinnahmen und Gewinne, die aus Kursänderungen entstehen, noch hinzugezählt. Der erweiterte Seigniorage wird dann zu $S_{t}^{\text {mon,erw }}=\frac{\Delta M_{t}}{P_{t}}+i \frac{M_{t}}{P_{t}}+U m_{t}$

mit $U m=$ Umbewertungen .

Man erhält so alle realen Werte, die dem Staat in einer Periode zugeflossen sind, und damit auch konsumtiv oder investiv verwendet werden können. Hier genau 
liegt allerdings das Problem dieses erweiterten Konzepts, denn wenn der Staat mehr als den Zinsgewinn aus der monetären Basis verausgabt, z.B. durch eine Kreditvergabe der Zentralbank an den Staat zulasten der Kreditvergabe an die Geschäftsbanken, so ist in der Periode $t+1$ der Bestand der ertragbringenden Aktiva (Forderungen gegenüber den Geschäftsbanken oder dem Ausland) gegenüber dem Bestand an nicht-zinsbringenden Aktiva (Forderungen an den Staat) zurückgegangen. Der Bestand an zinsbringenden Aktiva würde also immer weiter aufgezehrt, bis dem Staat nur noch der originäre monetäre Seigniorage übrig bliebe (vgl. Drazen 1985, 329). Dies zeigt, daß der erweiterte monetäre Seigniorage den originären nur übertreffen kann, wenn in der Vergangenheit monetärer Seigniorage durch Kreditvergabe an die Geschäftsbanken oder das Ausland also ertragsbringend - erzielt wurde. "Damit ist das Konzept des erweiterten monetären Seigniorage nur sehr bedingt geeignet, den Geldschöpfungsgewinn einer Periode wiederzugeben" (Lange 1995, 40).

\subsection{Opportunitätskosten-Seigniorage}

„Beim Opportunitätskosten-Seigniorage steht die Unverzinslichkeit des Basisgelds im Vordergrund. Der Geldschöpfungsgewinn wird nicht zum Zeitpunkt der Geldschöpfung erfaßt, sondern erst dann, wenn der Zentralbank aus der Geldschöpfung der Vergangenheit Zinserträge entstehen bzw. entstehen könnten" (Lange/Nolte 1997, 2). Von der Kostenseite her betrachtet ist der Opportunitätskosten-Seigniorage die Summe der Kosten, die dem Staat entstanden wären, wenn er sich die zinslos erhaltenen Mittel auf dem Kapitalmarkt zum Marktzins i hätte beschaffen müssen (vgl. Lange 1995, 40).

$S_{t}^{o p p}=\frac{i M_{t}}{P_{t}}$

Von der Ertragsseite läßt er sich als der Gewinn erklären, der durch die Verzinsung der bei der Notenbank hinterlegten Aktiva entsteht. Zu beachten ist allerdings, daß der Opportunitätskosten-Seigniorage dabei nur auf den potentiell erzielbaren Zinsertrag abstellt (Lange/Nolte 1997, 3). Inwieweit die Zentralbank die Geldbasis tatsächlich zum Marktzins anlegt oder ob sie statt dessen subventionierte Kredite, z.B. Diskontkredite, an die Geschäftsbanken vergibt oder konsumtiv verausgabt, ist für die Höhe des Opportunitätskosten-Seigniorage nicht relevant.

Aus der Perspektive der Aktivseite der Notenbank erhält man folgende Gleichung für den Opportunitätskosten-Seigniorage:

$S_{t}{ }^{o p p}=\frac{i_{t}\left(F_{t}^{S t a a t}+F_{t}^{G B}+F_{t}^{A u s l}-R V_{t}\right)}{P_{t}}$ 


\subsection{Fiskalischer Seigniorage}

Der fiskalische Seigniorage soll die Mittel abbilden, die dem Staatshaushalt aufgrund der Geldschöpfung der Zentralbank tatsächlich real zufließen. Zentralbank und Staatshaushalt werden dabei im Gegensatz zu den anderen beiden Konzepten als voneinander getrennte Institutionen betrachtet.

Die eingehenden Komponenten des fiskalischen Seigniorage bestehen aus dem ausgeschütteten Gewinn der Zentralbank und der Nettokreditgewährung der Zentralbank an den Staat (Bruttokreditgewährung abzüglich evtl. Tilgungen). Abzuziehen davon sind dementsprechend die vom Staat an die Zentralbank zu zahlenden Kreditzinsen. Deflationiert mit dem Preisniveau ergibt sich für den fiskalischen Seigniorage:

$S_{t}{ }^{\text {fisk }}=\frac{G_{t}^{\text {ausg }}}{P_{t}}+\frac{\Delta F_{t}^{\text {Staat }}}{P_{t}}-\frac{i_{t} F_{t}^{\text {Staat }}}{P_{t}}$

Betrachtet man die Entstehungsseite des ausgeschütteten Gewinns der Zentralbank genauer, so besteht dieser aus den Erlösen abzüglich der Kosten, wobei die Erlöse vereinfacht aus den erwirtschafteten Zinsen aus Forderungen an den Staat, die Geschäftsbanken und das Ausland bestehen. Vernachlässigt werden die nicht direkt der Geldschöpfung zurechenbaren Gewinne und Verluste aus Umbewertungen oder aus An- und Verkäufen von Währungspositionen sowie Gebühren.

Nach Abzug der thesaurierten Gewinne erhält man:

$S_{t}{ }^{\text {fisk }}=\underbrace{\frac{i_{t} \cdot\left(F_{t}^{\text {Staat }}+F_{t}^{G B}+F_{t}^{\text {Ausl }}\right)-K_{t}-G_{t}^{\text {thes }}}{P_{t}}}_{G_{t}^{\text {ausg }}}+\frac{\Delta F_{t}^{\text {Staat }}}{P_{t}}-\frac{i_{t} F_{t} \text { Staat }}{P_{t}}$

$\Leftrightarrow$

$S_{t}^{\text {fisk }}=\frac{\Delta F_{t}^{\text {Staat }}}{P_{t}}+\frac{i_{t} \cdot F_{t}^{G B}}{P_{t}}+\frac{i_{t} \cdot F_{t}{ }^{\text {Ausl }}}{P_{t}}-\frac{K_{t}}{P_{t}}-\frac{G_{t}{ }^{\text {thes }}}{P_{t}}$

Hierbei wird erkennbar, daß die Zinsen auf Kredite an den Staat bei der Betrachtung der Entstehungsseite unberücksichtigt bleiben, da sie einerseits vom Staatshaushalt an die Zentralbank fließen, andererseits aber gleichzeitig den Gewinn der Zentralbank erhöhen.

Das Konzept des fiskalischen Seigniorage ist ein Nettokonzept, d.h. die Kosten der Geldschöpfung werden vom Ertrag abgezogen. Hierunter fallen z.B. Materialkosten für Noten und Münzen, Personalkosten für das Prägen und Drucken, Buchungs- und Verwaltungskosten, Kontroll- und Wartungskosten, Kosten der volkswirtschaftlichen Abteilung, Repräsentationskosten etc. (vgl. Lange 1995, 27f.). 
Eine Abgrenzung gegenüber solchen Aufwendungen, die keine Kosten aus der Geldschöpfung darstellen, ist allerdings schwierig. So interpretiert Rühmann $(1991,625)$ zwar einige Kosten, „soweit sie für die Durchführung ihrer [der Zentralbank] Geschäfte nicht unbedingt erforderlich sind, als eine Form der Verwendung eines Geldschöpfungsgewinns". Allerdings ist eine solche Abgrenzung nicht praktikabel. Druckkosten lassen sich zwar noch eindeutig der Geldschöpfung als Geldproduktionskosten zuordnen, problematisch ist aber die Bestimmung des auf die Geldschöpfung entfallenden Anteils der sonstigen Verwaltungskosten. Die Deutsche Bundesbank veröffentlicht dazu keine Angaben, nicht zuletzt vermutlich deshalb, weil ihr aufgrund einer fehlenden GuV-Rechnung auch intern keine Daten vorliegen dürften (vgl. Lange 1995, 28). „Tatsächlich wäre aber auch jede [...], auf der Grundlage unvollständiger Informationen getroffene Annahme über die Aufteilung der Verwaltungskosten letztlich willkürlich" (Lübbersmann 1995, 88).

Zudem lassen sich die Kosten der Geldschöpfung noch weiter fassen, wenn „auBer den Produktionskosten auch die Ausgaben einbezogen werden, die nötig sind, um das Vertrauen in die Währung zu gewährleisten" (Lange 1995, 29). Diese Vorgehensweise ist nicht ungerechtfertigt, ist die Nachfrage nach Geld und damit die Generierung von Geldschöpfungsgewinnen doch auch von der Reputation einer Währung bzw. deren Notenbank abhängig (vgl. Läufer 1997, 2).

Der fiskalische Seigniorage versucht nicht, den Akt der Geldschöpfung abzubilden, sondern den durch die Geldschöpfung ermöglichten Mittelzufluß an den Staatshaushalt. „Die Abgrenzung des fiskalischen Seigniorage erscheint deshalb eher für eine Staatshaushaltsbetrachtung als für eine theoretische Fundierung der durch die Geldschöpfung entstehenden Gewinne geeignet" (Lange 1995, 29).

\subsection{Theoretischer Vergleich der Konzepte}

Bei näherer Betrachtung der zunächst recht unterschiedlich anmutenden Konzepte zur Bestimmung des Geldschöpfungsgewinns werden Ähnlichkeiten offenbar, die im folgenden herausgearbeitet werden sollen.

\subsubsection{Vergleich zwischen Opportunitätskosten-Seigniorage und Monetärem Seigniorage}

Der Zusammenhang zwischen beiden Konzepten wird deutlich, wenn man die unendlich viele Perioden anhaltende Auswirkung einer einmaligen Basisgeldmengenvergrößerung auf den Opportunitätskosten-Seigniorage mit den Auswirkungen auf den monetären Seigniorage vergleicht. Der monetäre Seigniorage fällt direkt in der Periode 0 der Vergrößerung an, während der OpportunitätskostenSeigniorage erst in den Folgeperioden anfällt. Läßt man Zins- und Preisniveauvariationen außer acht, so zeigt sich, daß der abgezinste OpportunitätskostenSeigniorage der Periode 0 gleich dem monetären Seigniorage der Periode 0 ist. 
$\sum_{t=1}^{\infty} \frac{i \Delta M_{0}}{P} \frac{1}{(1+i)^{t}}=\frac{\Delta M_{0}}{P}$

Während sich also die Auswirkungen einer Veränderung der Geldbasis z.B. infolge wirtschaftspolitischer Maßnahmen auf den Opportunitätskosten-Seigniorage wegen der resultierenden Zinserträge auf die folgenden Perioden verteilt, tritt die Wirkung für den monetären Seigniorage sofort in der gleichen Periode ein, da der Barwert der induzierten Zinserträge in derselben Periode ausgewiesen wird.

„Damit ist der monetäre Seigniorage gut geeignet, sämtliche aus einer geldpolitischen Maßnahme zukünftig resultierenden Folgen für den Geldschöpfungsgewinn in der aktuellen Periode abzubilden, weist aber gerade wegen dieser Eigenschaft in der Regel höhere Schwankungen auf als der OpportunitätskostenSeigniorage" (Lange/Nolte 1997, 4).

\subsubsection{Vergleich zwischen fiskalischem und monetärem Seigniorage}

Für den Vergleich der beiden Konzepte des fiskalischen und des monetären Seigniorage werden zweckmäßigerweise die Entstehungsgleichungen herangezogen:

$S_{t}{ }^{\text {fisk }}=\underbrace{\frac{i_{t} \cdot\left(F_{t}^{\text {Staat }}+F_{t}{ }^{G B}+F_{t}{ }^{\text {Ausl }}\right)-K_{t}-G_{t}^{\text {thes }}}{P_{t}}}_{G_{t}^{\text {ausg }}}+\frac{\Delta F_{t} \text { Staat }}{P_{t}}-\frac{i_{t} F_{t} \text { Staat }}{P_{t}}$

$S_{t}^{\text {mon }}=\frac{\Delta M_{t}}{P_{t}}=\frac{\Delta F_{t}^{\text {Staat }}}{P_{t}}+\frac{\Delta F_{t}^{G B}}{P_{t}}+\frac{\Delta F_{t}^{\text {Ausl }}}{P_{t}}-\frac{G_{t}^{\text {thes }}}{P_{t}}$

Die Unterschiede zwischen den beiden Konzepten liegen zum einen in der Unterscheidung zwischen Brutto- (monetärer Seigniorage) und Nettokonzept (fiskalischer Seigniorage), da beim monetären Seigniorage die Kosten der Geldschöpfung nicht berücksichtigt werden, sowie in der Behandlung der Geschäftsbankenkredite und der Kredite an das Ausland. Diese beiden werden beim monetären Seigniorage in voller Höhe ihrer Veränderung berücksichtigt, während zum fiskalischen Seigniorage lediglich die eingehenden Zinsen aus den Krediten zählen.

Fand und findet eine Geldmengenausweitung nur über Kreditvergabe an den Staat statt (wie z.B. in vielen südamerikanischen Staaten), so sind beide Konzepte gleich, bis auf den Unterschied der Netto- bzw. Bruttokonzeption. Denn Geschäftsbankenkredite und Kredite an das Ausland gibt es in diesem Fall nicht und eine Erhöhung der Zentralbankgeldmenge fließt sofort dem Staat zu, bzw. Zinszahlungen des Staates an die Zentralbank werden als Zentralbankgewinn sofort wieder an den Staat ausgeschüttet. 


\subsubsection{Vergleich zwischen dem fiskalischen und dem Opportunitätskosten- Seigniorage}

Für den Vergleich dieser beiden Konzepte ist es zweckmäßig, zunächst die Entstehungsgleichung der Opportunitätskosten-Seigniorage herzuleiten:

$S_{t}^{o p p}=\frac{i M_{t}}{P_{t}}$

Da die gesamte Zentralbankgeldmenge durch Forderungen an die Geschäftsbanken, das Ausland und den Staat, reduziert um die Summe der thesaurierten Gewinne (Reinvermögen RV), entsteht, kann Gleichung 8 auch folgendermaßen geschrieben werden:

$S_{t}^{o p p}=\frac{i_{t} \cdot\left(F_{t}{ }^{\text {Staat }}+F_{t}^{G B}+F_{t}^{A u s l}-R V_{t}\right)}{P_{t}}$

Der Vergleich mit der Entstehungsgleichung der fiskalischen Seigniorage

$S_{t}$ fisk $^{\text {in }}=\frac{\Delta F_{t}^{\text {Staat }}}{P_{t}}+\frac{i_{t} \cdot F^{G B}}{P_{t}}+\frac{i_{t} \cdot F_{t}{ }^{\text {Ausl }}}{P_{t}}-\frac{K_{t}}{P_{t}}-\frac{G_{t}{ }^{\text {thes }}}{P_{t}}$

ergibt folgende Unterschiede:

Folgt man dem Bruttoprinzip ( $K=0$ ) und vernachlässigt die Gewinnthesaurierung ( $G^{\text {thes }}$ und $R V=0$ ), unterscheiden sich beide Konzepte in der Betrachtung der Staatskredite. Beim Opportunitätskosten-Seigniorage werden die Zinsen betrachtet, die der Staat für die an ihn gewährten Kredite am Markt hätte zahlen müssen, während beim fiskalischen Seigniorage die komplette Neukreditgewährung an den Staat gezählt wird. Wird die Geldmengenerweiterung ausschließlich über eine Kreditgewährung an die Geschäftsbanken oder das Ausland vorgenommen, so sind beide Konzepte annahmegemäß gleich.

\subsection{Empirischer Vergleich der Konzepte für Deutschland}

Im folgenden soll eine quantitative Betrachtung der verschiedenen Konzepte erfolgen, um zum einen die o.a. theoretischen Zusammenhänge zu verdeutlichen und zum anderen eine Vorstellung über die Höhe und Bedeutung des Seigniorage zu erhalten.

Zur Berechnung der verschiedenen Konzepte wurden der Daten des IMF (vgl. International Monetary Fund 1997) verwendet. Dabei berechnet sich der Opportunitätskosten-Seigniorage als Produkt aus der monetären Basis (Reserve Money, Linie 14) und dem Zinssatz für Staatsanleihen (Government Bond Yield, Linie 61). Der monetäre Seigniorage berechnet sich als Differenz der monetären Basis (Reserve Money, Linie 14) zwischen den Zeitpunkten $t$ und $t-1$. Der fiskalische Seigniorage setzt sich zusammen aus dem ausgeschütteten Bundesbankgewinn (vgl. Geschäftsbericht der Deutschen Bundesbank, verschiedene Jahrgänge) plus 
der Veränderung der Forderungen an die öffentlichen Haushalte (Claims on Central Government, Linie 12a), abzüglich der mit dem Zinssatz für Staatsanleihen verzinsten Forderungen an die öffentlichen Haushalte. Alle drei Konzepte werden real berechnet, d.h. durch den Deflator des BIP (Basis 1990, GDP Deflator, Linie 99 bi r) dividiert. Folgende Abbildung zeigt die Ergebnisse der Berechnungen:

Abbildung 3-2: Empirische Gegenüberstellung der verschiedenen Seignioragekonzepte für Deutschland 1979 - 1996

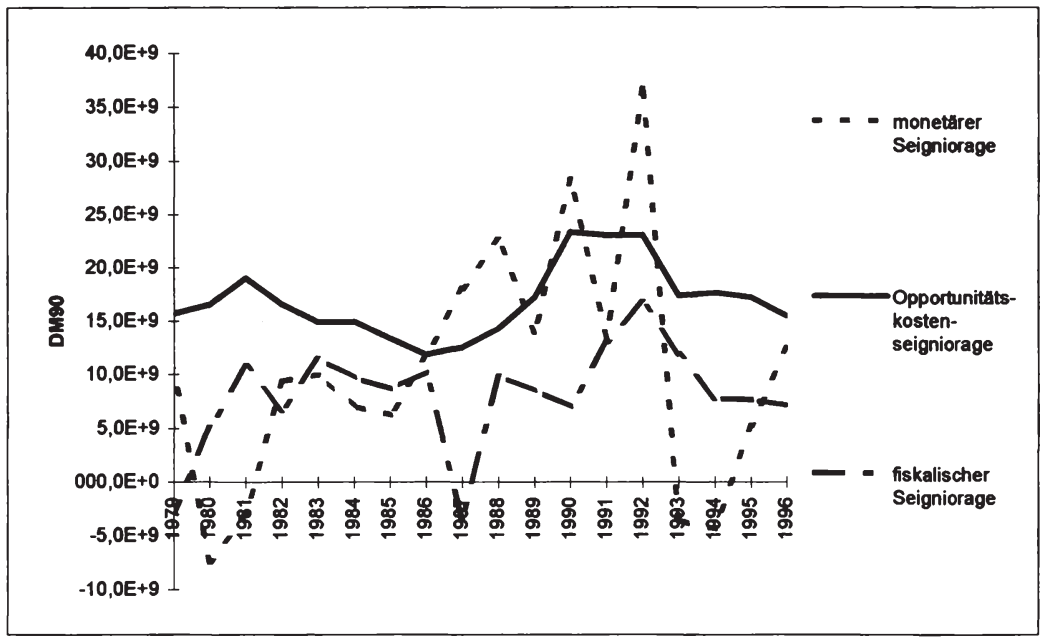

Quelle:

International Monetary Fund (1997), Geschäftsbericht der Deutschen Bundesbank, verschiedene Jahrgänge, eigene Berechnungen

Zunächst zeigt sich sehr deutlich der Unterschied der Konzepte. Sowohl die Höhe aber auch der zeitliche Verlauf des Seigniorage differieren zwischen den drei Konzepten erheblich. Bei einem Vergleich zwischen Opportunitätskosten-Seigniorage und monetärem Seigniorage fällt auf, daß sich der monetäre Seigniorage wesentlich volatiler als der Opportunitätskosten-Seigniorage verhält. Die Erklärung dafür ergibt sich aus dem theoretischen Konzept der beiden SeigniorageDefinitionen. Während der monetäre Seigniorage jegliche Veränderung der Zentralbankgeldmenge sofort abbildet, d.h. auch eine Abnahme der Geldmenge als negativer monetärer Seigniorage dargestellt wird, zeigen diese Veränderungen der Geldmenge beim Opportunitätskosten-Seigniorage erst in den Folgeperioden Wirkung, und dies über einen längeren Zeitraum verteilt, da der Opportunitätskosten-Seigniorage nur die verzinste Zentralbankgeldmenge betrachtet.

Ein Vergleich von Opportunitätskosten-Seigniorage und fiskalischem Seigniorage hingegen läßt - zunächst vom theoretischen Gesichtspunkt her betrachtet - einen ähnlichen Verlauf beider Größen vermuten, da sich beide Größen nur in der Kreditvergabe an den Staat unterscheiden (vgl. 3.4.3), die in Deutschland gemäß $\S 20$ Abs. (1) BBankG beschränkt ist. Dennoch ist der Unterschied bei einer empi- 
rischen Betrachtung erheblich, wobei insbesondere das niedrigere Niveau des fiskalischen Seigniorage auffällt.

Die Unterschiede liegen in den Annahmen begründet, die dem Opportunitätskosten-Seigniorage zugrunde liegen (vgl. Lange 1995). Zunächst ist die Kreditvergabe an den Staat zwar beschränkt, aber nicht zu vernachlässigen, da sie sowohl in ihrer Höhe Schwankungen unterliegt als auch das Zinsniveau einen nicht unerheblichen Einfluß auf die Höhe der Zinszahlungen des Staates haben dürfte. Allerdings wird diese Abweichungsursache seit 1992 mit dem Verbot der Kreditvergabe der europäischen Zentralbanken an die öffentlichen Haushalte deutlich an Gewicht verloren haben (vgl. Art. 104 Vertrag zur Gründung der Europäischen Gemeinschaft, Fassung vom 1. Januar 1995).

Weitere Gründe für die Abweichungen zwischen beiden Konzepten liegen in der Vernachlässigung der Kosten beim Konzept des Opportunitätskosten-Seigniorage und darin, daß die Gewinnthesaurierung durch offene aber auch stille Reservenbildung durchaus relevante Größenordnungen erreichen können. Der allerdings wichtigste Grund liegt vermutlich in der Reduzierung des OpportunitätskostenZinssatzes auf einen einzigen Zinssatz, ohne zu berücksichtigen, daß sich das Portefeuille der Zentralbank aus höchst unterschiedlichen Werten zusammensetzt, die auch höchst unterschiedlich verzinst werden. Insbesondere die Zinssubventionierung durch den Diskont dürfte zu einem niedrigeren Niveau des fiskalischen Seigniorage gegenüber dem Opportunitätskosten-Seigniorage geführt haben. 


\section{$4 \quad$ Kritik an der bisherigen Diskussion}

\subsection{Beurteilungskriterien}

\subsubsection{Seignioragekonzept}

Die theoretische Diskussion der drei unterschiedlichen Seignioragekonzepte hat gezeigt, daß nur der fiskalische Seigniorage ein Abbild von den tatsächlichen fiskalischen Be- und Entlastungen des Haushalts durch die Geldschöpfung leisten kann (vgl. Baltensperger/Jordan 1997, 149). Allenfalls der Opportunitätskosten-Seigniorage kann eine Annäherung erzielen, wenn er als Nettokonzept verwendet wird, d.h. wenn die Kosten der Geldschöpfung vom Bruttoseigniorage abgezogen werden. Ungeeignet ist die Betrachtung des monetären Seigniorage, da hier keine Erträge, sondern nur die absoluten Veränderungen der Zentralbankgeldmenge betrachtet werden. Insofern läßt sich mit Hilfe des monetären Seigniorage zwar darstellen, welche Wirkungen eine geldpolitische Maßnahme - diskontiert auf den heutigen Zeitpunkt - erzielt, über den tatsächlichen Mittelzufluß an die Haushalte kann - wenn wie innerhalb der Industriestaaten üblich keine direkte Kreditvergabe der Notenbank an den Haushalt möglich ist - daraus aber nichts abgeleitet werden.

\subsubsection{Trennung der Währungsunionseffekte für den Seigniorage}

Um die fiskalischen Wirkungen der Seigniorageveränderungen als Folge der Europäischen Währungsunion zu erfassen, müssen drei Effekte unterschieden werden:

Zunächst ergeben sich schon im Vorfeld des Übergangs zum Euro Konvergenzen zwischen den potentiellen Teilnahmestaaten bezüglich Zinsniveau, Inflation, etc., die entweder aus den Anstrengungen zur Erfüllung der Maastrichter Verträge oder aus einer Integration der Finanzmärkte resultieren. Dieser Konvergenzeffekt ist zunächst unabhängig von den Seigniorageveränderungen nach dem Übergang zum Euro zu betrachten, da sich die Geldnachfrage nicht auf die neue Europäische Währung, sondern noch auf die alten nationalen Währungen bezieht. Da sich der Konvergenzeffekt im Zuge der Konvergenzbestrebungen der Teilnehmerstaaten an der Währungsunion einstellt, ist zur Quantifizierung dieses Effekts ein Zeitrahmen zu bestimmen, innerhalb dessen sich die Veränderungen abgespielt haben, d.h. es muß eine Ausgangsbasis definiert werden, mit welcher der Seigniorage nach der Konvergenzphase verglichen wird.

Der zweite Effekt, der Übergangseffekt, tritt im Zuge des Übergangs zum Euro auf, insbesondere aufgrund des für viele nationalen Zentralbanken neuen Instrumentariums der EZB und dessen Ausgestaltung.

Der dritte fiskalische Effekt für die Mitgliedsstaaten ergibt sich als Folge der Verteilung der EZB-Gewinne an die nationalen Haushalte, da die monetäre Basis, nach der die "fiktiven" Seigniorageeinnahmen ermittelt werden, von den Kapitalanteilen, die die tatsächlichen Seignioragezuteilungen bestimmen, ver- 
schieden sein können. Analysen, die diese drei Effekte nicht separieren, lassen keine validen Rückschlüsse auf die Ursachen der Seigniorageveränderungen zu und damit auch keine seriösen Forderungen bezüglich der Art des Verteilungsschlüssels der EZB.

Langfristig werden zudem vermutlich weitere fiskalische Effekte auftreten, da sich die Geldnachfrage nach Euro in den Mitgliedsstaaten eventuell anders verhalten wird als die nach den nationalen Währungen, da insbesondere die Monopolstellung der deutschen Währung nicht mehr gegeben ist und zudem der Euro den US-Dollar als Währungsreserve und Handelswährung partiell substituieren könnte, die Nachfrage nach Euro insgesamt also höher sein könnte als die aggregierte Nachfrage nach den nationalen Währungen. Die fiskalischen Veränderungen als Folge dieses Effekts werden sich allerdings nicht unmittelbar einstellen, sondern eventuell nur über mehrere Jahre nach dem Übergang zum Euro beobachtbar sein.

\subsubsection{Berücksichtigung der Zinsstruktur}

Bei der Berechnung des Opportunitätskosten-Seigniorage und des fiskalischen Seigniorage spielt der gewählte Zinssatz eine entscheidende Rolle für die Höhe des Geldschöpfungsgewinns, denn bei der Berechnung des Opportunitätskosten-Seigniorage bestimmt der Opportunitätskosten-Zins direkt die Höhe der aus dem Zentralbankgeld erzielbaren Erträge und beim fiskalischen Seigniorage beeinflußt er die Höhe der staatlichen Zinszahlungen an die Zentralbank. Betrachtet man die Entstehungsgleichung des fiskalischen Seigniorage, so wird deutlich, daß ein Grund für die empirischen Abweichungen beider Konzepte darin liegen könnte, daß hier unterschiedliche Zinssätze zum Zuge kommen. Denn während beim fiskalischen Seigniorage die tatsächliche Verzinsung der Aktiva den ausgeschütteten Zentralbankgewinn bestimmt, wird beim Opportunitätskosten-Seigniorage ein Zinssatz verwendet, der unter Umständen den tatsächlichen Zinssätzen gar nicht entspricht, zumal dem fiskalischen Seigniorage höchst unterschiedliche Aktiva, die einer höchst unterschiedlichen Zinsstruktur entsprechen, zugrunde liegen (vgl. Barro 1982, 329).

Wie die empirische Analyse für Deutschland zeigte, verlaufen Opportunitätskosten-Seigniorage und fiskalischer Seigniorage zwar weitgehend parallel, das Niveau des fiskalischen Seigniorage liegt dabei aber meist unter dem des Opportunitätskosten-Seigniorage. Für dieses Abweichen des OpportunitätskostenSeigniorage vom tatsächlichen Ertrag der Aktiva lassen sich neben der Vernachlässigung der Kosten beim Bruttokonzept des OpportunitätskostenSeigniorage (vgl. Kap. 3.3) verschiedene Ursachen ermitteln, die insbesondere mit der Annahme eines einzigen Zinssatzes in Höhe des Marktzinses bzw. des Zinses der langfristigen Staatspapiere und damit der Vernachlässigung verschiedener Einflüsse auf die tatsächliche Rendite bei der Berechnung des Opportunitätskosten-Seigniorage zusammenhängen. 
Erstens erfordert eine Zentralbankpolitik einen erheblichen Anteil an Währungsreserven, um einerseits - vor allem bei kleinen Staaten - die Glaubwürdigkeit in die eigene Währung herzustellen und andererseits Interventionen am Devisenmarkt vornehmen zu können, um die eigene Währung zu stabilisieren. Diese Reserven unterliegen zum einen Wechselkursschwankungen, die den Notenbankgewinn beeinflussen, und zum anderen einem Zinssatz, der dem des heimischen Marktes nicht unbedingt entspricht.

Zweitens erfordern Devisenkäufe eine "Sterilisation", d.h. eine Rückführung von Krediten an Kreditinstitute, um eine Ausweitung der Geldbasis zu verhindern (vgl. Bofinger/Reischle/Schächter 1996, 514), die mit Kosten verbunden ist. Üblicherweise werden zur Abschöpfung überschüssiger Zentralbankguthaben sogenannte Absorptionsfazilitäten eingesetzt, die mit dem Refinanzierungssatz oder einem um einen halben oder ganzen Prozentpunkt niedrigeren Satz verzinst werden (vgl. Bofinger/Reischle/Schächter 1996, 397 und Kapitel 6.1.2) und damit Kosten verursachen, die im Konzept des Opportunitätskosten-Seigniorage nicht enthalten sind.

Eine dritte Abweichungsursache liegt in einer konservativen Anlagestrategie jeder Notenbank, um die Sicherheit und Stabilität der Währung zu gewährleisten. Dies hat einen im Vergleich zum Marktzinssatz niedrigeren Zinssatz zur Folge, da hier nicht die Rediteerzielung, sondern das Vertrauen in die Währung und in das Finanzsystem im Vordergrund steht ( $v g l$. Baltensperger/Jordan 1998, 83f).

Betrachtet man die einzelnen Posten der Aktivseite der Notenbankbilanz, so zeigen sich noch weitere Abweichungsursachen. Insbesondere die Kredite an inländische Kreditinstitute weisen eine sehr heterogene Zinsstruktur auf. Dort finden sich Wertpapiere, die in Offenmarktgeschäften erworben wurden, in Diskontgeschäften erworbene Inlandswechsel sowie Lombardforderungen. Die Zinserträge dieser Positionen sind höchst unterschiedlich und müssen bei der Berechnung des tatsächlichen Ertrags Berücksichtigung finden (Lübbersmann 1995, 113ff). Bis 1992 spielten in Deutschland auch kurzfristige Buchkredite der Bundesbank an öffentliche Stellen, wie Bund, Bundesbahn, Bundespost, den Ausgleichsfonds, das ERP-Sondervermögen und die Länder eine Rolle bei der Erklärung der beobachteten Abweichungen, da diese in der Regel eine niedrigere Verzinsung als marktüblich erfuhren. Inwieweit eine solche Kreditvergabe in der Europäischen Währungsunion allerdings noch möglich ist bzw. welche Konsequenzen ein Verbot dieser Praxis auf die öffentlichen Haushalte hat, muß ebenfalls bei der Betrachtung der fiskalischen Konsequenzen der EWU Berücksichtigung finden. Völlig unbeachtet blieben bislang ebenfalls die Verzinsung und Umbewertung der Auslandspositionen und Goldbestände. Auch hier läßt sich ein erheblicher Erklärungsbeitrag für die Abweichungen finden (vgl. Lübbersmann 1995, 118ff).

Faßt man diese Überlegungen zusammen, sollte eine Schätzung des Seigniorage nach dem Opportunitätskostenansatz den zu wählenden 9pportunitäts- 
kosten-Zinssatz mit Hilfe eines Durchschnittszinssatzes des Portefeuilles der Zentralbank bestimmen. Mit anderen Worten sollte eine Schätzung mit Hilfe des fiskalischen Seigniorage die unterschiedlichen Zinssätze der verschiedenen Aktivapositionen berücksichtigen.

\subsubsection{Berücksichtigung der Geldnachfrage}

Die Zentralbankgeldmenge hängt über den Geldschöpfungsmultiplikator des Geschäftsbankensystems mit der Geldnachfrage nach M1 zusammen. D.h., daß die Schöpfung von Zentralbankgeld und damit die Einnahmen aus Seigniorage auch von der Nachfrage nach Geld abhängen. Eine Prognose der Geldschöpfungsgewinne muß demnach auch die Veränderungen bei der Geldnachfrage berücksichtigen. $D a ß$ es zu solchen Veränderungen im Rahmen des Übergangs auf die europäische Währung kommen kann, ist nicht auszuschlieBen, weshalb sie Berücksichtigung in den Prognosen finden müssen.

\subsection{Defizitanalyse der vorliegenden empirischen Befunde}

Vor dem Hintergrund der verschiedenen Seignioragekonzepte lassen sich nun die Ergebnisse der bisherigen Diskussion in der Literatur über die Seignioragegewinne der Europäischen Zentralbank einordnen. Dabei sollen die Studien auf ihre theoretische Basis hin überprüft werden und der Einfluß der unterschiedlichen Annahmen aufgezeigt werden.

\subsubsection{Defizitanalyse von Gros 1989 und Gros 1996}

Gros unterscheidet in seinen Studien zwei Effekte. Zunächst betrachtet er nur die Einnahmeveränderungen aus Seigniorage, die sich aus der Konvergenz der potentiellen EWU-Staaten ergeben. Erst in seiner zweiten Studie untersucht er die Einnahmeveränderungen, die nach Erreichen der Konvergenz aufgrund der Verteilung des Seigniorage an die Mitgliedsstaaten entstehen.

Zur Berechnung des Einflusses der Konvergenz verwendet Gros zwei Methoden, die der Methode des Opportunitätskosten-Seigniorage und des monetären Seigniorage ähneln. Die erste Methode besteht darin, die Einnahmen des Staates zu berechnen, die sich durch eine Vergrößerung des Geldumlaufs und der Mindestreserven der Geschäftsbanken bei der Zentralbank abzüglich der darauf gezahlten Zinsen ergeben, wobei diese Größen auf das nominale BIP bezogen werden (vgl. Gros 1989, 2). Sind die Zinszahlungen auf Mindestreserven höher als das Wachstum an Mindestreserven und Geldumlauf, so kann, wie oben dargestellt, der Seigniorage einen negativen Wert annehmen.

Zur Berechnung des fiskalischen Effekts auf den Seigniorage ist dieses Konzept allerdings kaum geeignet, da es zum einen die Trennung zwischen Haushalt und Zentralbank nicht vornimmt und zum anderen den Vermögenstransfer anstatt des Einkommenstransfers zwischen privatem Sektor und Staat bestimmt. 
Die zweite von Gros verwendete Methode ist an das Prinzip des Opportunitätskosten-Seigniorage angelehnt und berücksichtigt die Kosten des privaten Sektors des Geldumlaufs und der Mindestreserven bzw. die Einsparungen des Staates (vermiedene Zinszahlungen bei Kreditaufnahme) durch die Zinsgewinne der hinterlegten Aktiva abzüglich der Zinszahlungen auf die Mindestreserve. Als Zinssatz für die fiktiven Zinseinsparungen des Staates bzw. für die Zinsverluste der Privaten wurde bei Gros der Zinssatz für die Staatsverschuldung verwendet. Zwar wird dieser Zinssatz auch von den meisten anderen Autoren bei der Bestimmung des Opportunitätskosten-Seigniorage präferiert (vgl. Klein/Neumann 1990, 209; Lange 1995, 82; Jordan 1994, 31), allerdings ist dieser in der Literatur nicht unumstritten, da bei der Anlagestrategie der Zentralbank nicht das Renditeziel im Mittelpunkt steht, was einen ganz anderen Zinssatz zur Folge haben kann, als den, den der Staat für seine langfristigen Kredite zahlen muß (siehe 4.1.4).

Bei beiden Berechnungsmethoden ist zudem zu bemängeln, daß die Größen nicht auf das Preisniveau bezogen werden. Denn erhöht sich dieses in den untersuchten Staaten unterschiedlich, sind die Veränderungen des nominalen Seigniorage kaum miteinander zu vergleichen.

Die Berechnung der Verteilungseffekte bei der Bemessung der Seigniorageanteile der EWU-Mitgliedsstaaten erfolgt bei Gros nach der Methode des Opportunitätskosten-Seigniorage. Zunächst trifft er die Annahme, daß alle relevanten Einflußfaktoren auf den Seigniorage in den Mitgliedsstaaten konvergieren werden, so daß ein Opportunitätskosten-Seigniorage von 0,56 \% des BIP entstehen würde. Damit ergibt sich für Gros ein EZB-Seigniorage, der sich aus der Summe der Geldschöpfungsgewine der nationalen Notenbanken zusammensetzt. Der Seigniorage der einzelnen Notenbanken nach der vollständigen Konvergenz hat gerade den gleichen Anteil an dem EZB-Seigniorage wie das Bruttoinlandsprodukt des jeweiligen Staates am gesamten Bruttoinlandsprodukt der Mitgliedsstaaten.

Der nach dem Kapitalschlüssel ausbezahlte Gewinnanteil an dem Seigniorage der EZB wird anschließend mit dem Seigniorage bei vollständiger Konvergenz verglichen, um einen Verlust pro BIP des jeweiligen Landes festzustellen.

Die Kritik an dieser Vorgehensweise ist vielfältig. Zwar wird die Zuteilung des EZB-Gewinns tatsächlich nach einem ähnlichen Schlüssel vorgenommen ${ }^{7}$, ob aber der tatsächliche Gewinn aus der Geldschöpfung diesem entspricht, ist zu bezweifeln. Die Gründe für diese Zweifel sind die gleichen, wie bei der oben betrachteten Berechnung des Opportunitätskosten-Seigniorage, da die maß-

7 Die Verteilung der EZB-Gewinne wird nach folgendem Schlüssel vollzogen: Zunächst werden fiktive Gewinne der nationalen Zentralbanken anhand der monetären Basis der Nationalstaaten ermittelt. Diese „monetären Einkünfte” werden ähnlich dem Opportunitätskosten-Seigniorage anhand des Bargeldumlaufs und der Mindestreserve, multipliziert mit ei-

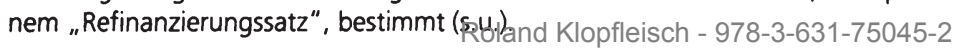


geblichen Beiträge an die Notenbank, so sie denn überhaupt den hier berechneten entsprechen, von den tatsächlichen Notenbankgewinnen abweichen können (vgl. Gros 1989, 15). Der Gewinn und Verlust durch die Verteilung der EZB-Gewinne kann also nicht aus der Differenz zwischen den fiktiv berechneten "monetären Einkünften" und deren Zuteilung nach dem Kapitalschlüssel erfolgen, sondern muß bemüht sein, den tatsächlichen Gewinn aus der Geldschöpfung zu berücksichtigen.

Gros unterstellt in seiner ersten Untersuchung eine konstante Geldnachfrage im Verhältnis zum nominalen BIP (Kassenhaltungskoeffizient) für alle Staaten auf dem Niveau von 1987 und begründet dies mit der zu beobachtenden Unabhängigkeit dieses Verhältnisses von der Inflation oder den Zinssätzen, da in der Vergangenheit ein Absinken der Inflationsraten und der Zinssätze zeitgleich mit einer Verringerung des Kassenhaltungskoeffizienten zu beobachten war. Diese Annahme ist für die Betrachtung der nationalen Geldnachfrage sicherlich richtig, allerdings ist fraglich, ob der Kassenhaltungskoeffizient eines einzelnen Jahres für eine Prognose repräsentativ sein kann. In seiner zweiten Untersuchung unterstellt er eine Konvergenz der Geldnachfrage in allen Staaten auf einen einheitlichen Kassenhaltungskoeffizienten von 6\% (Durchschnittlicher Kassenhaltungskoeffizient in Europa 1996). Diese Annahme ist allerdings aufgrund der höchst unterschiedlichen Zahlungsgewohnheiten innerhalb Europas kaum haltbar. Alternativ dazu verwendet er staatenspezifische Kassenhaltungskoeffizienten von 1994, wobei zu der bereits oben angebrachten Kritik der Einwand hinzuzufügen ist, daß sich beim Übergang auf den Euro die Kassenhaltungskoeffizienten aller teilnehmenden Staaten ändern könnten.

\subsubsection{Defizitanalyse von Lange/Nolte 1997}

Lange/Nolte berechnen die Geldschöpfungseinnahmen der europäischen Staaten sowohl nach dem monetären als auch nach dem OpportunitätskostenSeigniorage. Für die Berechnung des Opportunitätskosten-Seigniorage wird die monetäre Basis und der Zinssatz für langfristige Staatspapiere verwendet. Hier schließt sich die gleiche Kritik an, die auch für Gros gilt: Der Opportunitätskosten-Seigniorage zielt nur auf den mit einer bestimmten Zentralbankgeldmenge potentiell erzielbaren Zinsertrag ab, nicht auf den tatsächlich erzielten. Ebenfalls muß der monetäre Seigniorage bei Lange/Nolte kritisch betrachtet werden, da dieser für den Mittelzufluß an die Haushalte keine empirische Relevanz aufweist (s. Kap. 3.5).

Eine weitere Schwäche weist das Modell bei der Abschätzung der Geldbasis sowohl bei der Berechnung des monetären als auch des OpportunitätskostenSeigniorage auf. Unabhängig von Geldnachfragemodellen unterstellt das Modell der Quantitätstheorie folgend unkritisch einen proportionalen und sich national nicht signifikant ändernden Zusammenhang zwischen Geldbasis und nominalem Bruttoinlandsprodukt in Form des Kassenhaltungskoeffizienten (vgl. Lange/Nolte 1997, 14), d.h. 
$M=k * P * Y$

mit $\mathrm{k}=$ Kassenhaltungskoeffizient.

Positiv gegenüber Gros ist zu bemerken, daß der Kassenhaltungskoeffizient als Durchschnitt einer längeren Periode ermittelt wird und so einmalige kurzfristige Einflüsse vermindert werden. Die Konstanz der Kassenhaltungskoeffizienten kann allerdings gerade bei einem Strukturbruch, wie bei der Einführung des Euros, nicht garantiert werden.

Genauso kritisch muß die bei Lange/Nolte mit Hilfe der jeweiligen Anteile am Bruttoinlandsprodukt der Europäischen Union vorgenommene Aggregation der nationalen Geldnachfragen zu einer Geldnachfrage der Europäischen Währungsunion betrachtet werden (vgl. Lange/Nolte 1997, 16), da z.B. auf Währungen der EWU-11-Mitgliedstaaten lautende Währungsreserven bei Zentralbanken als auch im privaten Sektor wegfallen könnten ( $\mathrm{vgl}$. Monticelli/Papi 1996, 155).

Zur Berechnung des Opportunitätskosten-Seigniorage der EZB wird - im Gegensatz zur Berechnung des Opportunitätskosten-Seigniorage der nationalen Zentralbanken - als Opportunitätszins ein langfristiger Nominalzins von $4 \%$ angenommen, der sich aus der Summe eines Realzinses von $2 \%$ und einer Inflationsrate von ebenfalls $2 \%$ zusammensetzt. Der anschließende Vergleich der zwei so unterschiedlich berechneten Seignioragegrößen ist methodisch unsauber, da hier zwei unterschiedliche Kostengrößen betrachtet werden. Bei der Berechnung des Opportunitätskosten-Seigniorage gehen Lange/Nolte offensichtlich von der Perspektive des Staates aus, der seine Reserven ohne die Einnahmen aus der Geldschöpfung mit dem langfristigen Zins für Staatspapiere hätte versteuern müssen. Der Seigniorage der EZB dagegen wird aus der Perspektive der Privaten betrachtet, die einen Zinsverlust als Folge der Geldhaltung erleiden. Dies zeigt sich durch die Verwendung des Marktzinses bei der Berechnung der so entstehenden Opportunitätskosten. Dann ist allerdings zu fragen, ob die so errechneten Verluste der Privaten den Gewinnen des Staates entsprechen, da sich der Marktzins von dem der öffentlichen Anleihen in der Regel unterscheidet. Schon die Verwendung des Zinssatzes aller öffentlichen Anleihen oder des Zinssatzes der öffentlichen Anleihen mit einer Restlaufzeit von 10 Jahren bewirkt einen Unterschied von bis zu 9 \% (vgl. Lange 1995, 83).

Ein weiterer Einwand gegen die Berechnungen von Lange/Nolte ist nicht unerheblich: Der Vergleich der wie auch immer berechneten derzeitigen Seigniorage mit dem verteilten Seigniorage der Europäischen Zentralbank vermischt die beiden Effekte der Konvergenz der EWU-Mitgliedsstaaten (einschließlich Übergangseffekt) mit dem des Verteilungsschlüssels. Zwar lassen sich so die absoluten Einbußen oder Gewinne während des Prozesses zur Europäischen Währungsunion bezüglich des Seigniorage ermitteln. allerdings ist zu fragen, welche Einflüsse direkt der Währungsunion zugerechnet werden können. Eine Konvergenz bestimmter Einflußfaktoren auf den Seigniorage, z.B. die abneh- 
mende Bedeutung der Diskontgeschäfte, wäre vermutlich auch ohne die Bestrebungen zu einer Währungsunion allein aus der Finanzmarktintegration im Zuge der Globalisierung erwachsen. Selbst wenn die politisch gewollte und ökonomisch sinnvolle Konvergenz allein der Europäischen Währungsunion zuzuschreiben wäre, ist dieser Effekt nochmals von dem der Verteilung der EZBGewinne zu unterscheiden, will man eine wie auch immer definierte "gerechte" Verteilung anstreben.

\subsubsection{Defizitanalyse Sinn/Feist 1997}

Sinn/Feist 1997 betrachten die Gewinne und Verluste, die sich aus dem Verteilungsschlüssel des Seigniorage an die nationalen Notenbanken ergeben. Sie gehen davon aus, daß die gesamten Aktiva der nationalen Zentralbanken, die sich aus der Geldschöpfung der Vergangenheit angesammelt haben, an die Europäische Zentralbank übertragen werden und die Gewinne daraus gemäß der Kapitalanteile wieder verteilt werden. Dieser Ausgangsüberlegung folgend wird der Seigniorage nicht nach einem der drei herkömmlichen Konzepte berechnet, sondern die komplette Geldbasis wird als Seigniorage betrachtet, da sich in der Zukunft aus dieser Geldbasis Gewinne erwirtschaften ließen.

Zwar wird die diesem Ansatz zugrundeliegende Hypothese später durch die Aussage relativiert, daß diese Übertragung nicht den tatsächlichen rechtlichen Gegebenheiten entsprechen würde (vgl. Sinn/Feist 1997, 4), aber aus ökonomischer Perspektive sei die Verteilung des Seigniorage dieser Sichtweise gleichzusetzen. Richtig ist zwar, daß zur Verteilung des Seigniorage ein fiktiver Gewinn der nationalen Zentralbanken aus der monetären Basis errechnet wird, der dann nach dem Kapitalschlüssel verteilt wird. Diese monetäre Basis kann sich aber von den bislang angesammelten Aktiva durchaus unterscheiden, wenn sich beispielsweise die Geldnachfrage ändert. Der Einfluß auf die Geldnachfrage kann bis zur Einführung der Europäischen Währungsunion aus der Konvergenz der Mitgliedsstaaten erfolgen oder direkt beim Übergang der Währung von den nationalen Einheiten auf den Euro. Diese beiden Effekte werden in der Betrachtung von Sinn/Feist miteinander vermischt und als Resultat der Gewinnverteilung bzw. des "Poolings" der Gewinne dargestellt.

Sinn/Feist gehen davon aus, daß die monetären Basen der Nationalstaaten nach Einführung der Währungsunion die gleichen sind wie z. Zt. und sich daher die europäische Geldnachfrage durch einfache Aggregation der nationalen Geldnachfragen ermitteln läßt. Diese Vorgehensweise ist allerdings nicht korrekt bzw. bedarf einer genaueren Analyse (vgl. 4.2.2). Insbesondere geht sie davon aus, daß der Euro "so gut" wird wie das alte Geld, d.h. die Nachfrage genauso hoch bleibt, und daß die Verteilung der Geldbasis des Euro die gleiche sein wird, wie es bei der Geldbasis heute der Fall ist (vgl. Läufer 1997, 2). Die Richtigkeit beider Annahmen kann bezweifelt werden, denn ob der Euro die gleiche Nachfrage wie die bisherigen nationalen Währungen erfährt, hängt stark von der Geldpolitik der EZB ab, und selbst wenn der Euro "so gut" wie 
die DM wird, d.h. die bisherige Nachfrage nach DM sich vollkommen und in gleicher Höhe auf den Euro verlagern wird, wird die Geldbasis der Bundesbank nicht die gleiche sein wie derzeit. Dies hängt vor allem mit der hohen Nachfrage nach DM im Ausland ab. Daß sich diese Nachfrage dann in der Nachfrage nach Euro artikuliert, könnte man noch für möglich halten, aber ob diese Nachfrage nach Euro in Deutschland stattfindet und somit zur Geldmengenproduktion in Deutschland beiträgt, ist zumindest zweifelhaft (vgl. Läufer 1997, 3). Es könnte sogar der Fall eintreten, daß sich die Nachfrage nach Geld hinreichend aus Deutschland heraus in andere EWU-Mitgliedsstaaten hinein verlagert, so daß der fiktive Geldschöpfungsgewinn Deutschlands einen geringeren Anteil am gesamten Seigniorage haben könnte als der Kapitalanteil Deutschlands an der EZB, so daß Deutschland eine Nettozahlung erhalten würde.

Aber sollten selbst diese Fälle nicht eintreten, d.h. aus genau der bei Sinn/Feist errechneten aggregierten monetären Basis ließen sich in der Zukunft Gewinne erzielen, so hängen diese dennoch von der Geldpolitik der EZB ab, insbesondere der Refinanzierungs- und Währungspolitik. Die Annahme, die monetäre Basis stelle den diskontierten zukünftigen Gewinn der EZB dar, negiert diese Tatsache, wie Sinn/Feist selbst feststellen (vgl. Sinn/Feist 1997, 5).

\subsubsection{Defizitanalyse von Läufer 1997}

Läufer 1997 bringt den oben bereits erwähnten Aspekt in die Diskussion, nämlich daß die Geldnachfrage nach Einführung der Europäischen Währungsunion aufgrund von Reputationsverlusten niedriger sein könnte als die aggregierte Geldnachfrage der EU-Staaten heute. Das würde auch einen Verlust an Geldschöpfungsgewinnen für die deutschen Geschäftsbanken zur Folge haben (vgl. Läufer, 3). Läufer trennt den Verlust für Deutschland in einen Teil, der sich aus der Verlagerung der Geldmengenproduktion in andere Staaten ergibt, und einen Verlust, der sich nach der Umverteilung ergibt. Diese Vorgehensweise ist prinzipiell richtig, allerdings fehlt bei ihm eine quantitative Bestimmung der beiden Effekte, da er auf eigene Berechnungen völlig verzichtet, sondern nur zeigen will, daß die Berechnungen bei Sinn/Feist falsch sein müssen. Im Ergebnis gibt er den beiden allerdings inkonsequenterweise wieder recht.

\subsubsection{Defizitanalyse von Maennig/Hunger 1996}

Maennig/Hunger verwenden das Konzept des monetären Seigniorage zur Prognose des zukünftigen Notenbankgewinns, schränken dabei aber auch gleich selbst die Aussagekraft einer solchen Berechnung ein, da die ausgeschütteten Gewinne der Europäischen Notenbanken in keinem Zusammenhang zu dem empirisch feststellbaren monetären Seigniorage stehen (vgl. Maennig/Hunger 1996, 229). Auch konzeptionell stellt der monetäre Seigniorage zumindest in Europa das ungeeignetste Konzept dar, da er mit dem fiskalischen Seigniorage nur bei einer vollständigen Geldschöpfung über die Kreditvergabe an den Staat 
übereinstimmt. Insbesondere in der Europäischen Währungsunion ist diese Kreditvergabepraxis gerade nicht erlaubt.

Ungeachtet der Auswahl des Seignioragekonzepts sind weitere Annahmen von Maennig/Hunger bedenklich. So schätzen auch sie, wie Sinn/Feist, die Geldmenge der Europäischen Währungsunion als Summe der vierzehn nationalen realen Geldmengen. Diese Aggregation ist aber wie oben bereits dargelegt vermutlich nicht korrekt. Ferner wird eine konstante reale Geldmenge unterstellt, was allerdings nur bei Nullwachstum oder einer hinreichend steigenden Umlaufgeschwindigkeit realistisch ist. Zudem wird offensichtlich die Veränderung der Mindestreservevorschriften nicht in Erwägung gezogen, was jedoch im Zuge der Harmonisierung zu erwarten ist.

\subsection{Erkenntnisse aus der Defizitanalyse}

In den untersuchten Diskussionsbeiträgen existieren verschiedene Ansätze, die der Aufgabenstellung dieser Arbeit gerecht werden. Allerdings kann kein Modell befriedigend die Verluste an Seigniorage den verschiedenen Ursachen quantitativ zuordnen. Im folgenden soll zunächst die Kritik an den Modellen zusammengefaßt werden, um anschließend die Anforderungen an ein eigenes Modell zu formulieren.

\subsubsection{Wahl des Konzepts des monetären Seigniorage}

Maennig/Hunger, Sinn/Feist und auch Läufer bedienen sich des Konzepts des monetären Seigniorage zur Abschätzung der Gewinne und Verluste an Geldschöpfungseinnahmen der EWU-Mitgliedsstaaten. Der monetäre Seigniorage beschreibt aber nur den Zuwachs an Aktiva bei den Notenbanken, eine direkte Verbindung zwischen Gewinn und monetärem Seigniorage besteht aber nicht. Gewinn erzielt eine Notenbank erst, "wenn die Geldschöpfung zur Finanzierung von ertragbringenden Aktiva verwendet wird und diese die ersten Erträge abwerfen" (Lange 1995, 35). Dieser Sachverhalt zeigt sich auch in den empirischen Untersuchungen, denn dort ließ sich kein Zusammenhang zwischen Gewinn und monetärem Seigniorage feststellen (vgl. Kap. 3.5). Allenfalls bei einer Geldmengenerweiterung allein über die Vergabe von Krediten an den Staat sind die Bruttokonzepte des fiskalischen und des monetären Seigniorage gleich. Da aber weder in Deutschland noch innerhalb der Europäischen Währungsunion diese Kreditart erlaubt ist, ist das Konzept des monetären Seigniorage zwar ein einfach zu handhabendes aber genauso schlecht zu verwendendes, wenn die dem Haushalt zufließenden Mittel aus dem Geldschöpfungsgewinn vor und nach Einführung der Währungsunion verglichen werden sollen.

\subsubsection{Zinsannahme}

Gros und Lange/Nolte verwenden neben dem Konzept des monetären Seigniorage auch das des Opportunitätskosten-Seigniorage für ihre Berechnungen. Hierfür müssen Annahmen über einen Zinssatz getroffen werden, die einen 
erheblichen Einfluß auf die Höhe des Opportunitätskosten-Seigniorage haben. Aus fiskalischer Sicht ist es erforderlich, einen Zinssatz zu wählen, der dem durchschnittlichen Zinssatz des Zentralbankportefeuilles entspricht. Diese Vorgehensweise findet sich allerdings in keiner der betrachteten Studien. Vielmehr wird meist der langfristige Zinssatz für Staatsanleihen herangezogen, um die Kosten anzunähern, die dem Staat entstehen würden, würde er die Mittel, die inm durch die Geldschöpfung zufließen, am Geldmarkt aufnehmen müssen. Diese Sichtweise hat aber mit der fiskalischen Realität wenig gemein, da nicht die gesamte Geldbasis dem Haushalt zufließt, sondern nur die durch die Notenbank erzielten Zinseinnahmen. Zur Bestimmung der fiskalischen Effekte durch die Geldschöpfung ist es also nötig, den durchschnittlich erzielten Zinssatz der Notenbanken zu ermitteln.

\subsubsection{Vermischung verschiedener Effekte mit Einfluß auf den Seigniorage}

Bei der Analyse der bislang vorliegenden Studien zur Veränderung der Seigniorage als Folge der Europäischen Währungsunion lassen sich drei Effekte unterscheiden, die in den betrachteten Studien teilweise miteinander vermischt werden und so zu den sehr unterschiedlichen Ergebnissen beitragen.

Der erste Effekt wurde bereits von Gros (1989) vorgetragen und auch von ihm als einzigem Autor isoliert von anderen Effekten betrachtet. Er beschäftigt sich allein mit dem Einfluß der Konvergenz der potentiellen Mitgliedsstaaten im Vorfeld der Währungsunion, d.h. mit dem Einfluß, den sich verändernde Zinssätze, Inflationsraten, Mindestreservesätze etc. auf den Seigniorage der beteiligten Staaten besitzen. Die Konvergenz kann ihre Ursache in einem politischen Willensprozeß haben, z.B. zur Erfüllung der Maastrichter Kriterien, oder aber aus der Integration der Finanzmärkte resultieren.

Kein Autor berücksichtigt die mögliche und wahrscheinliche Veränderung des Seigniorage beim Übergang der nationalen Währungen auf den Euro bzw. beim Übergang des Notenbankmonopols von den nationalen Zentralbanken auf die Europäische Zentralbank; im Gegenteil: Die Autoren, die den Einfluß des Verteilungsschlüssels der EZB-Gewinne untersuchen (vgl. Sinn/Feist 1997, Maennig/Hunger 1996, Lange/Nolte 1997), nehmen an, daß sich die monetäre Basis der Mitgliedsstaaten beim Übergang zum Euro nicht verändert, und verwenden für die Prognose des Seigniorage nach dem Übergang auf den Euro auch weiterhin den gleichen Opportunitätskosten-Zinssatz. Läufer (1997) spricht einen Teilaspekt einer möglichen Änderung an, nämlich die mögliche Verlagerung der Nachfrage nach Geld von insbesondere der Deutschen Bundesbank auf andere nationale Notenbanken als Folge des Wegfalls des deutschen Wettbewerbsvorsprungs auf dem internationalen Geldbasismarkt. Weitere Einflußgrößen sind Veränderungen der Devisenreserven, insbesondere von Drittländern, die US-Dollar gegen Euro tauschen könnten, oder Strukturbrüche, die möglicherweise zu Verhaltensänderungen bei der Geldnachfrage in Europa führen. 
Der Effekt der Konvergenz im Vorfeld der Europäischen Währungsunion wird bei Lange/Nolte (1997) mit dem dritten Effekt, der Wirkung des Verteilungsschlüssels auf den Seigniorage vermischt. Andere Autoren versuchen inn zwar isoliert zu betrachten (Gros 1996, Maennig/Hunger 1996 und Sinn/Feist 1997), allerdings gehen sie von einer falschen monetären Basis zum Zeitpunkt der Verteilung aus. Maennig/Hunger (1996) und Sinn/Feist (1997) vernachlässigen den Konvergenzeffekt im Vorfeld der Währungsunion ganz, während Gros (1996) die Veränderungen der Nachfragefunktionen nicht berücksichtigt.

Alle drei Effekte müssen aber, um die Frage nach einer "gerechten" Verteilung der EZB-Gewinne beantworten zu können, quantifiziert und getrennt voneinander behandelt werden.

\subsubsection{Aggregation der Geldnachfrage}

Auch wenn das Konzept des Opportunitätskosten-Seigniorage eventuell für eine erste Annäherung an die Größenordnung der Gewinne und Verluste an Seigniorage beim Übergang zur Europäischen Währungsunion genügt, besteht eine wichtige Aufgabe zur Bestimmung der Höhe darin, die Zentralbankgeldmenge oder die monetäre Basis der Europäischen Zentralbank zu schätzen. Dieses Geldangebot ist allerdings schwer zu quantifizieren, da es im Rahmen des Geldschöpfungsprozesses eine politische Größe ist, die diskretionären Entscheidungen entspringt, nicht aber statistisch erfaßbaren Größen. Um diese Schwierigkeiten bei der Quantifizierung des Geldangebots zu umgehen, ist auf den engen Zusammenhang zwischen Geldangebot und Geldmenge hinzuweisen. Diese läßt sich als Funktion exogener volkswirtschaftlicher Variablen zumindest auf nationaler Ebene schätzen. Sollte sich eine stabile aggregierte europäische Geldnachfrage schätzen lassen, so könnten unter Berücksichtigung der Europäischen Geldpolitik Rückschlüsse auf die angebotene monetäre Basis gezogen werden.

Die untersuchten Analysen gehen dagegen diesen Weg bei der Bestimmung der europäischen monetären Basis nicht, statt dessen wird die monetäre Basis der europäischen Währung - teilweise für nur ein Jahr erhoben - durch einfache Addition der nationalen Basen ermittelt. Dieses Vorgehen scheint aber vor dem Hintergrund der recht unterschiedlichen Geldnachfragefunktionen in Europa und der unterschiedlichen Geldpolitik zumindest diskussionswürdig. Insbesondere wird bei der Aggregation der europäischen Geldnachfrage von allen Autoren offenbar unterschätzt, "daß die methodischen und konzeptionellen Schwierigkeiten eines solchen Unterfangens nicht trivial sind" (Hayo 1998, 172). Grundsätzlich wichtig bei der Schätzung der europäischen Geldnachfrage ist die Annahme, daß die EWU keine strukturellen Brüche in den aggregierten Verhaltensfunktionen verursacht. In der Vergangenheit gibt es keinen vergleichbaren Fall, der einen Hinweis auf Strukturbrüche geben könnte. Selbst "die Auflösung des Bretton-Woods-Systems oder die Gründung des EWS sind keine Ereignisse, welche mit den potentiellen Auswirkungen der EWU auf die 
Geldsysteme in den betreffenden Ländern auf eine Stufe gestellt werden können" (Hayo 1998, 173). Mit großer Wahrscheinlichkeit treten solche Strukturbrüche auf, wobei die konkreten Auswirkungen auf die Geldnachfrage unklar sind.

Das gilt sowohl für die absolute Höhe der Geldnachfrage und damit für die Höhe der monetären Basis beim Übergang zur Europäischen Währungsunion als auch für die Parameter der Geldnachfragefunktion. Die absolute Höhe könnte sich aufgrund von Auflösungen von Devisenbeständen in europäischen Währungen sowohl bei den Nichtbanken als auch bei den Geschäftsbanken verändern. Bei der Bestimmung der Parameter einer Europäischen Geldnachfrage ergeben sich noch vielfältigere methodische und technische Probleme. Insbesondere stellt sich die Frage, welche ökonomische Bedeutung die Variablen am Ende eines Aggregationsprozesses besitzen. Ist beispielsweise der berechnete aggregierte Zinssatz dann ein repräsentativer europäischer Zinssatz? „Dahinter steckt die Frage, wie begründet werden kann, daß die aggregierten Werte auch Bedeutung für ökonomische Zusammenhänge haben" (Hayo 1998, 175).

Die bislang vorliegenden Studien ignorieren diese Einwände bei der Aggregation der Geldnachfrage offenbar. Allerdings reichen die bislang gefundenen Zusammenhänge nicht aus, um die Veränderung der nationalen Geldnachfragen im Zuge der Europäischen Währungsunion zu quantifizieren bzw. eine Europäische Geldnachfragefunktion als Grundlage der Prognose des Seigniorage nach Vollendung der dritten Stufe der EWWU heranzuziehen. Für die Prognose des Seigniorage (Teil III und IV) wird daher, um eine Quantifizierung zu ermöglichen, hinsichtlich der Geldnachfrage eine Vergangenheits-Zukunfts-Symmetrie unterstellt. Diese Überlegungen sollen und werden in eine langfristige Betrachtung des Seigniorage qualitativ einfließen (Teil V). 


\section{Anforderungen an ein Modell zur Berechnung des Seigniorage als staatliche Einnahmequelle}

Die Anforderungen an ein Modell zur Berechnung des zukünftigen Seigniorage müssen sich an den unter 4.1 beschriebenen Beurteilungskriterien ausrichten. Dazu gehören in erster Linie

- die Verwendung des Konzepts des fiskalischen Seigniorage,

- die Trennung der unter 4.1.2 beschriebenen unterschiedlichen durch die Europäische Währungsunion induzierten Effekte auf den Geldschöpfungsgewinn,

- die Berücksichtigung der Zinsstruktur der Aktiva einer Notenbankbilanz und

- die qualitative Berücksichtigung der Geldnachfrage bei der Prognose langfristig zu erzielender Geldschöpfungsgewinne.

Zudem beinhaltet das Konzept des fiskalischen Seigniorage in einer offenen Volkswirtschaft auch Einnahmen, die nicht unmittelbar der Geldschöpfung zuzuordnen sind. Dazu gehören in erster Linie die Zinseinnahmen auf Forderungen gegenüber dem Ausland, aber auch Buchgewinne oder -verluste, die aus der Bewertung von Devisen resultieren, welche im Zuge einer Währungspolitik gehalten werden. Das Konzept des fiskalischen Seigniorage muß demnach derart modifiziert werden, daß das Modell nur Gewinne und Verluste beinhaltet, die aus der Geld- und nicht aus der Währungspolitik resultieren.

Bei der Systematik der nachfolgenden Modellentwicklung steht aber zunächst die getrennte Behandlung der drei unterschiedlichen Effekte der Europäischen Währungsunion auf den Seigniorage im Vordergrund, während die übrigen Anforderungen innerhalb dieser Systematik behandelt und erfüllt werden.

Zu Beginn von Teil II wird in Kapitel 6 das unter 3.3 dargestellte Konzept des fiskalischen Seigniorage so weit verfeinert, daß die Wirkungen der Konvergenz auf die Geldschöpfungsgewinne quantifiziert werden können (Kapitel 7). AnschlieBend wird in Teil III ein Modell zur Berechnung des Einflusses des Währungsübergangs erstellt, um diesen zu quantifizieren und in Teil IV werden die Wirkungen der Verteilung des Seigniorage auf die nationalen Haushalte nach dem geltenden Schlüssel analysiert. 
Teil II:

\section{Einnahmeverluste und -gewinne aus der Geldschöpfung als Folge der Konvergenz innerhalb der EWU-11 Staaten}

\section{Einfluß der Konvergenz auf den fiskalischen Seigniorage der Nationalbanken im Vorfeld der Europäischen Währungsunion}

\subsection{Konzeption des fiskalischen Seigniorage für die Staaten der EWU}

Das Konzept des fiskalischen Seigniorage ist, wie oben gezeigt, die geeignete Methode, die fiskalischen Auswirkungen der Veränderungen des Geldschöpfungsgewinns auf die nationalen Haushalte zu analysieren. Ausgangspunkt der Modellbildung ist deshalb die in 3.3 dargestellte Berechnungsformel für den fiskalischen Seigniorage:

$S^{\text {fisk }}=\frac{\Delta F^{\text {Staat }}}{P}+\frac{i F^{G B}}{P}+\frac{i F^{\text {Ausl }}}{P}-\frac{K}{P}-\frac{G^{\text {thes }}}{P}$

um die erste Anforderung (siehe 5) an das Modell zu erfüllen.

Der Einfluß der Geldnachfrage kann für den in diesem Kapitel zu untersuchenden vergangenheitsorientierten Konvergenzeffekt ausgeklammert bleiben, da die zur Berechnung des Seigniorage benötigten Aktivposten der Notenbanken bereits vorliegen.

Allerdings stellt die Formel (15.) des fiskalischen Seigniorage ein zu stark vereinfachtes Modell der tatsächlichen Einnahmen dar. Insbesondere die einfache Struktur der Forderungen - Forderungen an das Ausland und Forderungen an die Geschäftsbanken - läßt sich, wie zu zeigen ist, bei näherer Betrachtung der Zentralbankbilanz nicht aufrechterhalten, wobei es sich zudem bei den „Forderungen an das Ausland" um eine durch die Währungspolitik der Zentralbanken beeinflußte Größe handelt, die nicht aus Gründen der Geldschöpfung entsteht.

Im folgenden soll daher exemplarisch die Bilanz der Deutschen Bundesbank herangezogen werden, um zu einem detaillierteren Modell des fiskalischen Seigniorage zu gelangen.

\subsubsection{Die Bilanz der Deutschen Bundesbank}

Die Aktivseite der Bundesbankbilanz setzt sich zusammen aus den Währungsreserven und sonstigen Auslandsaktiva, den Krediten an inländische Kreditinstitute und den Krediten und Forderungen an inländische öffentliche Haushalte (vgl. Tab. 6.1). Bis 1995 hielt die Bundesbank zudem noch in geringen Mengen Wertpapiere des Bundes, der Länder sowie der Post und der Telekom.

Die Währungsreserven setzen sich wiederum aus Gold, Reservepositionen im IWF und Sonderziehungsrechten, Forderungen an das EWI sowie Devisen und Sorten zusammen. Kredite an inländische Kreditinstitute setzen sich aus im Offenmarkt- 
geschäft angekauften Wertpapieren, Wechseln und Lombardforderungen zusammen.

Tabelle 6-1: Notenbankbilanz am Beispiel der Deutschen Bundesbank (Stand am Jahresende 1997)

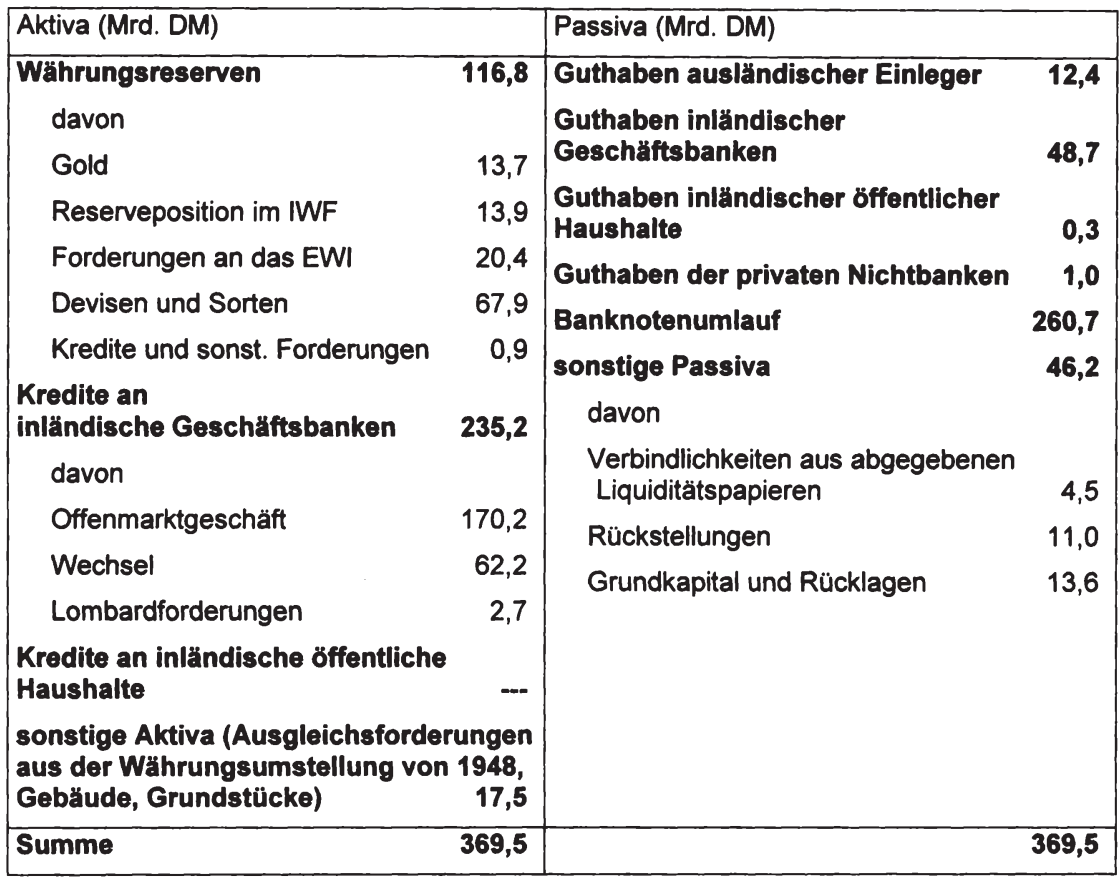

Quelle: $\quad$ Deutsche Bundesbank

Welche Positionen der Bilanz allgemein durch eine Geldmengenpolitik und im speziellen durch die Geldpolitik der Deutschen Bundesbank berührt werden, soll im folgenden untersucht werden.

\subsubsection{Geldpolitisches Instrumentarium}

Die geldpolitische Steuerung auf dem Markt für Zentralbankgeld läßt sich - zunächst unabhängig von der geldpolitischen Konzeption - entweder über eine Zins- oder über eine Geldbasissteuerung realisieren. Bei der Zinssteuerung versucht eine Notenbank ihre Instrumente so einzusetzen, daß sie in der Lage ist, den Geldmarktzinssatz zu kontrollieren. Dazu genügen als "Minimalkonzeption" (Bofinger/Reischle/Schächter 1996, 394) zwei Instrumente: eines zur Bestimmung der Zinsobergrenze und eines zur Bestimmung der Zinsuntergrenze. Liegen beide Zinssätze auseinander, so ergibt sich ein Zinsband, während von einer Punktsteuerung gesprochen wird, wenn beide Zinssätze zusammenfallen. 
Die Obergrenze des Zinsbandes läßt sich durch das Instrument der Refinanzierungsfazilität bestimmen, mit deren Hilfe eine Notenbank den Geschäftsbanken Zentralbankgeld bereitstellt, indem sie von innen verzinsliche Aktiva (Auslandsforderungen, Forderungen gegenüber inländischen öffentlichen Haushalten, Forderungen gegenüber inländischen Kreditinstituten) erwirbt. Der Refinanzierungszinssatz bestimmt dann den Zinssatz, zu dem sich die Banken jederzeit mit Zentralbankgeld versorgen können. In der Bilanz schlagen sich die Refinazierungstransaktionen folgendermaßen wieder: Auf der Passivseite erhöhen sich die Positionen Bargeldumlauf und/oder Guthaben inländischer Kreditinstitute und auf der Aktivseite erhöht sich die Position Kredite an inländische Geschäftsbanken. Darin enthalten sind zwar auch Aktiva, die aus Forderungen gegen öffentliche Haushalte und das Ausland bestehen, da sie allerdings nur eine Sicherheit im Rahmen einer Kreditvergabe an die Geschäftsbanken darstellen, werden sie wie auch in praxi der Deutschen Bundesbank als Kredite an inländische Geschäftsbanken verbucht.

Als Untergrenze des Zinsbandes dient ein Zins, zu dem die Geschäftsbanken überschüssiges Zentralbankgeld anlegen können. Diese „Absorptionsfazilität” dient in erster Linie dazu, überschüssige, z.B. aus Interventionsverpflichtungen resultierende Liquidität vom Markt abzuschöpfen. Ist eine Notenbank verpflichtet, eine fremde Währung anzukaufen, so muß sie über ein Instrument verfügen, das es ihr ermöglicht, die mit den Devisenzuflüssen einhergehende Ausweitung der Geldbasis zu kompensieren. Denn mit zunehmendem Zentralbankguthaben reduziert sich die Refinanzierung der Geschäftsbanken - im Extremfall bis auf null. Eine zusätzliche Geldbasisausweitung kann dann den Geldmarktzinssatz unter die Refinanzierungszinssätze drücken. Die Absorptionsfazilität bewirkt in diesem Fall, daß die Geschäftsbanken Zentralbankgeld nicht unter diesem Zinssatz verleihen, da sie jederzeit das überschüssige Zentralbankgeld bei der Notenbank anlegen können. Dieses Vorgehen wird als "Sterilisation" bezeichnet.

In der Zentralbankbilanz wirkt sich die "Sterilisation" wie folgt aus: In der vereinfachten saldierten Notenbankbilanz ( $\mathrm{vgl}$. Tabelle 3-2) reduzieren sich die Sichteinlagen der Geschäftsbanken und / oder das Bargeld der Geschäftsbanken und es erhöht sich der Saldo der sonstigen Passiva und Aktiva. In der vereinfachten unsaldierten Notenbankbilanz (vgl. Tabelle 3-1) reduzieren sich auf der Passivseite die Guthaben inländischer Geschäftsbanken und / oder der Banknotenumlauf und es erhöhen sich die sonstigen Passiva.

\subsubsection{Das geldpolitische Instrumentarium der Europäischen Notenbanken}

Das im vorherigen Kapitel beschriebene Zinsband findet sich in der Politik der Europäischen Notenbanken durch verschiedene geldpolitische Instrumente repräsentiert. Zudem lassen sich weitere Instrumente identifizieren, für deren Zinssatz gilt, daß dieser innerhalb des oben beschriebenen Zinsbandes liegt. Im folgenden sollen die wesentlichen Instrumente der Notenbanken dargestellt werden. 
Dauerhafte Fazilitäten

Alle EU-Zentralbanken nutzen derzeit dauerhafte Fazilitäten bei der praktischen Umsetzung der Geldpolitik (vgl. Europäisches Währungsinstitut 1995, 123). Dazu gehören im wesentlichen drei Formen:

1. Spitzenrefinanzierungslinien als Zinsobergrenze, auch Strafzins genannt, praktiziert in Dänemark, Deutschland, Griechenland, Frankreich, Irland, Italien, Portugal, Finnland, Schweden und Großbritannien.

2. Einlagefazilitäten als Zinsuntergrenze, praktiziert in Belgien, Dänemark, Irland, Portugal, Finnland und Schweden.

3. Kreditlinien mit einem unter dem Marktzins liegendem Zins, praktiziert in Belgien, Deutschland, Griechenland, Italien, Niederlande und Österreich.

\section{Offenmarktgeschäfte}

Neben diesen in vielen Staaten nur noch Signalwirkung besitzenden "klassischen" Instrumenten haben in den meisten Ländern Offenmarktgeschäfte an Bedeutung gewonnen: Die Notenbank kauft oder verkauft Wertpapiere am offenen Markt, d.h. zu "Marktsätzen". Dabei darf die Notenbank "keine willkürlichen, abseits vom Marktgeschehen liegenden Kurse für ihre Transaktionen wählen" (Deutsche Bundesbank 1995, 111).

Innerhalb der Offenmarktgeschäfte gibt es ebenfalls unterschiedliche Arten von Instrumenten (vgl. Escrivá/Fagan 1996, 11). Am verbreitetsten sind hierbei die Offenmarktgeschäfte mit Rückkaufvereinbarung, bei welchen den Banken nur für einen von im voraus befristeten Zeitraum Zentralbankguthaben zur Verfügung gestellt wird. In einigen Staaten finden auch "echte" Transaktionen, d.h. ein Kauf oder Verkauf von Wertpapieren ohne Rückkaufvereinbarung Anwendung, die sogenannten Outright-Offenmarktgeschäfte. Ähnliche Wirkungen wie die Offenmarktgeschäfte mit Rückkaufvereinbarung entfalten die Devisenswap- und Devisenpensionsgeschäfte. Hierbei kauft die Notenbank im Rahmen eines SwapGeschäfts Devisen bzw. Auslandsaktiva an und stellt so den Geschäftsbanken für eine bestimmte Zeit Zentralbankguthaben zur Verfügung.

Alle Offenmarktgeschäfte lassen sich auch zur Kontraktion einsetzen, indem die Aktiva auf Zeit bzw. endgültig an die Geschäftsbanken verkauft werden. Insbesondere die zu den Offenmarktgeschäften zählende Emission von kurzfristigen Schuldtiteln wird zur Abschöpfung von überschüssiger Liquidität benutzt.

\subsubsection{Modifizierter fiskalischer Seigniorage}

Die obigen Ausführungen machen deutlich, daß zur Bestimmung des fiskalischen Seigniorage die Formel

$$
S_{t}{ }^{\text {fisk }}=\frac{\Delta F_{t} \text { Staat }}{P_{t}}+\frac{i_{t} \cdot F_{t}^{G B}}{P_{t}}+\frac{i_{t} \cdot F_{t}^{\text {Ausl }}}{P_{t}}-\frac{K_{t}}{P_{t}}-\frac{G_{t}{ }^{\text {thes }}}{P_{t}}
$$


nicht genau genug ist, um damit einen Zentralbankgewinn zu schätzen, d.h. die verbleibenden Summanden müssen zunächst genauer analysiert werden.

\subsubsection{Zinsertrag aus Forderungen an das Ausland}

Zinsen auf Forderungen an das Ausland sind zwar nicht direkt der Geldschöpfung zuzuschreiben, sondern resultieren aus zinsbringend angelegten Währungsreserven, die in Folge von Interventionen am Devisenmarkt - größtenteils schon in den $60 e r$ und 70er Jahren - aufgebaut wurden. Die Währungsreserven der Deutschen Bundesbank resultieren beispielsweise im wesentlichen aus den Interventionsverpflichtungen innerhalb des Systems fester Wechselkurse von Bretton Woods, da die Bundesbank insbesondere in der letzten Phase bis zum Herbst 1973 US-Dollar kaufen mußte, um der Aufwertung der DM entgegenzuwirken. Auch nach dem Zusammenbruch des Systems von Bretton Woods griff die Bundesbank in den Devisenmarkt ein und in den Jahren 1977/78 und 1986/87 kam es "im Zusammenhang mit den internationalen Bemühungen zur Stabilisierung der in diesen Perioden zur Schwäche neigenden US-Währung" (Geschäftsbericht der Deutschen Bundesbank 1997, 62) zu umfangreichen Dollarzuflüssen. Seit 1990 stiegen die Dollarreserven dann weniger aufgrund von Interventionen am Devisenmarkt als vielmehr durch die Zinserträge auf die Dollaranlagen.

Der zweite Einfluß auf die Devisenbestände resultierte aus den Interventionsverpflichtungen innerhalb des EWS seit seiner Einführung am 13. März 1979. Zwar galt es nun nicht mehr, einen fixen Wechselkurs zu halten, aber die Marktkurse innerhalb des EWS durften nur innerhalb einer bestimmten Bandbreite um bilaterale Leitkurse schwanken. Entsprechend der Schwankungsbreite wurden Interventionspunkte festgelegt, an denen die Zentralbanken durch Kauf- oder Verkauf intervenieren mußten. D.h. überschritt ein Wechselkurs den festgelegten Interventionspunkt, so waren die beiden beteiligten Zentralbanken gezwungen, die schwach tendierende Währung gegen die stark tendierende Währung zu kaufen. Drohte also z.B. der Franc gegenüber der DM unter den bilateralen Leitkurs zu sinken, mußten sowohl die Banque de France als auch die Bundesbank Franc gegen DM kaufen ${ }^{8}$. Bei der Bundesbank führte dies zu einem Anstieg der Währungsreserven bei gleichzeitiger Geldmengensteigerung, die Banque de France hingegen reduzierte das Geldmengenangebot. Kurzfristig hatte die Bundesbank auf diese Weise beträchtliche Zuflüssen an Reservebeständen zu verzeichnen, langfristig allerdings hatten diese Interventionen keinen nachhaltigen Einfluß auf die Reserveposition der Deutschen Bundesbank, da die "Devisenbestände nach Realignments regelmäßig wieder abgeflossen sind oder - soweit es sich dabei um die Inanspruchnahme von Finanzierungen der Partnerländer über den EFWZ [Europäischer Fonds für währungspolitische Zusammenarbeit, Anm. d. Verf.] be-

8 Innerhalb der Bandbreiten konnten die Zentralbanken des EWS ebenfalls Partnerwährungen kaufen oder verkaufen, um zu verhindern, daß die Wechselkurse an die Interventionspunkte stoßen. 
ziehungsweise EWI handelte - von den anderen Notenbanken ausgeglichen wurden" (Geschäftsbericht der Deutschen Bundesbank 1997, 63f).

Somit lauten die Devisenreserven - neben den Goldbeständen - fast ausschließlich auf US-Dollar und sind zinsbringend angelegt ${ }^{9}$.

Da Devisenkäufe der Zentralbanken zwangsläufig mit einer Geldschöpfung verbunden waren, z.B. durch die Einräumung eines Zentralbankguthabens für die Geschäftsbanken in Höhe des Wertes der gekauften Devisen, müssen die daraus resultierenden Zinsen bei der Berechnung des fiskalischen Seigniorage mitberücksichtigt werden. Denn eine dem Geldmengenziel verpflichtete Zentralbank muß sogar ihre Kreditvergabe an die inländischen Geschäftsbanken in dem Maße reduzieren, wie sie durch den Kauf der Währungsreserven Geld geschöpft hat, d.h. der Zinsertrag aus der Position „Forderungen gegenüber inländischen Geschäftsbanken" reduziert sich ebenfalls. Für die Betrachtung des tatsächlichen Geldschöpfungsgewinns ist es demnach unausweichlich, die Zinsgewinne aus den Währungsreserven mitzuberücksichtigen, da andernfalls - z.B. bei unterschiedlichem Zwang der nationalen Zentralbanken Europas zur Intervention am Devisenmarkt die Geldschöpfungsgewinne verzerrt dargestellt wären ${ }^{10}$.

Zwar wird es innerhalb der Europäischen Währungsunion keine Interventionsverpflichtungen mehr geben, so daß die Höhe der Forderungen selbst - bis auf Zinszuwächse aufgrund von Zinsen auf die bestehenden Forderungen - keine Veränderungen mehr erfahren, allerdings hat es während des Beobachtungszeitraums, der dem empirischen Teil dieser Arbeit zugrunde liegt, solche Interventionen insbesondere während der EWS-Krise 1992/93 gegeben und wird es zumindest gegenüber den "Pre-Ins" innerhalb des EWS-II Wechselkursmechanismus weiterhin geben (vgl. Frenkel/Nickel 1999), so daß dieser Teil des Seigniorage sowohl bei der ex-post Analyse als auch bei der Prognose der zukünftigen Geldschöpfungsgewinne innerhalb des ESZB unbedingt zu berücksichtigen ist.

Zudem ist nicht auszuschließen, daß die EZB währungspolitisch gegenüber dem US-Dollar agieren wird, d.h. US-Dollar kaufen oder verkaufen wird, um den Wechselkurs dieser beiden Währungen zu stabilisieren. D.h. auch in der Zukunft

9 Die Position der Bilanz der Deutschen Bundesbank „Kredite und Forderungen an das Ausland" erreichte am 31.12.1997 fast 78 Mrd. DM, während die in Sorten vorhandenen Währungsreserven nur 32 Mio. DM ausmachten. Die übrigen Währungsreserven resultieren aus der Mitgliedschaft der Bundesrepublik Deutschland im Internationalen Währungsfonds (IWF) (14 Mrd. DM) und der Beteiligung der Deutschen Bundesbank am Europäischen Währungsinstitut bzw. der Europäischen Zentralbank (23 Mrd. DM).

10 Z.B. würde die Nichtberücksichtigung der Zinseinkünfte aus den Währungsreserven Portugals dazu führen, daß der Seigniorage dieser Zentralbank negativ ausfallen würde. Tatsächlich besitzt der Banco de Portugal aber in großen Mengen Devisen, die vorwiegend in ausländischen zinsbringenden Wertpapieren angelegt sind. Ein Großteil der Aktiva der Zentralbank Portugals sind demnach ausländische Wertpapiere, deren Zinserträge ebenso zum Geldschöpfungsgewinn zu zählen sind. 
sind Geldschöpfungsprozesse oder Kontraktionen - bedingt durch Deviseninterventionen - möglich, die bei einer Prognose des Seigniorage zu berücksichtigen sind.

Für die Erträge der Zentralbanken aus den Währungsreserven sind im wesentlichen die Guthaben bei Banken im Ausland von Bedeutung, da Sorten- und Goldbestände als Währungsreserve im wesentlichen nur hohe Lagerkosten verursachen und nur wenig Zinseinnahmen erbringen (vgl. Feldsieper 1998, 312). Deshalb sollen letztere aus den weiteren Betrachtungen ausgeklammert werden und nur die Bestände bei den ausländischen Banken und die damit verbundenen Zinserträge berücksichtigt werden. Aus dem gleichen Grund können auch die Reserveposition im IWF und die Forderungen an den Europäischen Fonds für währungspolitische Zusammenarbeit im Rahmen des EWS vernachlässigt werden (vgl. Schenk 1997, 26).

\subsubsection{Kredite an die öffentlichen Haushalte}

Kredite an die öffentlichen Haushalte spielen innerhalb des EWS seit 1994 keine Rolle mehr, da sie gemäß Art. 104 des Maastricht-Vertrags (vgl. Deutsche Bundesbank Geschäftsbericht 1993, 144) untersagt sind. Innerhalb des Teils des Betrachtungszeitraumes, der vor 1994 liegt, wurden sie allerdings auch nur in sehr geringem Umfang vergeben, so daß sie für die Analyse nicht berücksichtigt werden sollen.

\subsubsection{Zinsertrag aus Forderungen an inländische Geschäftsbanken}

Die Zinseinnahmen der Notenbanken auf Forderungen gegenüber den Geschäftsbanken sollen entsprechend der in den EWU-Mitgliedsstaaten angewendeten geldpolitischen Instrumenten differenziert betrachtet werden. Dazu sollen die Zinserträge anhand der verschiedenen Aktivpositionen dieser Forderungen und den Zinssätzen der entsprechenden geldpolitischen Instrumente berechnet werden.

Die Zinserträge aus Krediten an die inländischen Geschäftsbanken lassen sich direkt den Gewinn- und Verlustrechnungen (GuV) der Notenbanken entnehmen bzw. mit Hilfe der entsprechenden Aktivpositionen und den korrespondierenden Zinssätzen schätzen. Folgende Differenzierung der Position Kredite an inländische Kreditinstitute läßt sich zur Bestimmung der Zinserträge in Anlehnung an die in den meisten EWU-Staaten praktizierten geldpolitischen Instrumente vornehmen: im Offenmarktgeschäft erhaltene Wertpapiere (mit oder ohne Rücknahmevereinbarung) incl. Devisenswapgeschäften verzinst zum Offenmarktzinssatz, im Zuge von Spitzenrefinanzierungsgeschäften erworbene Forderungen verzinst zum Spitzenrefinanzierungszinssatz und Kreditfazilitäten unter bzw. nahe an Marktkonditionen. 
6.1.4.4 Einlagefazilitäten und sonstige Instrumente zur Abschöpfung von Liquidität

Werden Einlagefazilitäten zur Liquiditätsabschöpfung angeboten, so müssen die dafür erbrachten Zinsaufwendungen vom Geldschöpfungsgewinn abgezogen werden. Ebenso verhält es sich mit ausgegebenen Schuldtiteln. Lassen sich die Zinsaufwendungen nicht direkt aus der GuV entnehmen, so ist eine Schätzung mit Hilfe der entsprechenden Passivposition und einem in den jeweiligen Geschäftsberichten angegebenen Zinssatz unterhalb von Marktkonditionen vorzunehmen.

\subsubsection{Kosten}

Die Kosten der Notenbanken sollen analog zu den Zinserträgen auch nur den Anteil der Kosten enthalten, der durch die Geldschöpfung verursacht wird. Wie oben bereits erläutert (vgl. 3.3) ist eine Abgrenzung hier allerdings willkürlich, da eine Kostenrechnung der Zentralbanken - falls sie überhaupt durchgeführt wird - nicht zugänglich ist ${ }^{11}$. Dennoch soll an dieser Stelle zumindest eine Obergrenze der Kosten der Geldschöpfung gefunden werden, indem die nicht direkt zuordenbaren Kosten der GuV als Gemeinkosten betrachtet werden und einer Kostenschlüsselung zugeführt werden (vgl. Lübbersmann 1993, 87f).

Als Grundlage zur Schlüsselung der Kosten soll die GuV der jeweiligen Notenbanken dienen.

Der Geldschöpfung voll zugeordnet werden die Druckkosten, in der GuV ausgewiesen als Notendruck. Problematischer ist die Bestimmung der auf die Geldschöpfung entfallenden sonstigen Verwaltungskosten, nämlich der Personalaufwand, Sachaufwand und sonstige Aufwendungen sowie Abschreibungen auf Grundstücke und Gebäude, Betriebs- und Geschäftsausstattungen und sonstige Vermögensgegenstände. In Anlehnung an Lübbersmann 1993 sollen diese Kosten anhand der Bilanzbestände geschlüsselt werden. D.h. es wird unterstellt, daß sowohl die Aktiv- als auch die Passivposten jeweils $50 \%$ der sonstigen Verwaltungskosten verursachen und daß innerhalb der Bilanzseiten sich diese Kosten nach Maßgabe der wertmäßigen Bilanzbestände verteilen ${ }^{12}$. In diesen Schlüssel sollen folgende Posten eingehen: auf der Passivseite der Banknotenumlauf, die Einlagen von Kreditinstituten, die Verbindlichkeiten aus abgegebenen Liquiditätspapieren bzw. Einlagefazilitäten und auf der Aktivseite die Kredite an inländische Kreditinstitute.

11 Auch bei der Deutschen Bundesbank ist eine Kostenrechnung - wie der deutsche Rechnungshof moniert - nur teilweise vorhanden (vgl. Bundesrechnungshof 1989, 121).

12 Allerdings ist zu erwarten, daß der überwiegende Teil der Verwaltungskosten auf das Aktivgeschäft entfällt. Da der Banknotenumlauf auf der Passivseite z.B. der Deutschen Bundesbank 1997 fast $70 \%$ erreicht, werden die sonstigen Verwaltungskosten in dieser Art der Kalkulation tendenziell überschätzt, dienen deshalb also als Obergrenze. 


\subsubsection{Thesaurierte Gewinne}

Die Höhe der thesaurierten Gewinne läßt sich aus den Bilanzen der Notenbanken direkt ablesen. Allerdings ist es kaum möglich eine Zuordnung vorzunehmen, welcher Anteil der Rücklagen auf den Ertrag aus der Geldschöpfung zurückzuführen ist. Nur in wenigen Fällen gibt es für geringe Anteile der Rücklagen einen gesetzlich bestimmten Zusammenhang ${ }^{13}$, weshalb die thesaurierte Gewinne nicht vom fiskalischen Seigniorage abgezogen werden sollen. Zudem ist zu erwarten, daß sich thesaurierte Gewinne nicht beliebig akkumulieren lassen, sondern zu einem späteren Zeitpunkt ausgeschüttet werden.

Aus diesen Überlegungen heraus ergibt sich folgende Berechnungsformel des fiskalischen Seigniorage, wobei der Übersichtlichkeit halber in allen folgenden Formeln der Zeitindex $t$ weggelassen wird. Der Seigniorage bezieht sich natürlich weiterhin immer auf eine Periode:

$$
\begin{gathered}
S_{I}^{f i s k}=i_{\text {subv }} \frac{F^{\text {subv }}}{P}+i_{\text {spitze }} \frac{F^{\text {spitze }}}{P}+i_{\text {offen }} \frac{F^{\text {offen }}}{P}+i \frac{F^{\text {Ausl }}}{P}-i_{\text {liq }} \frac{V^{\text {liq }}}{P}-\frac{K}{P} \\
=\frac{E_{G P}}{P}-\frac{A_{G P}}{P}-\frac{K}{P}
\end{gathered}
$$

mit

$S_{I}^{f i s k}=$ fiskalischer Seigniorage der Konvergenzphase

$i_{\text {subv }} \frac{F^{\text {subv }}}{P}=$ Zinseinnahmen aus Kreditfazilitäten unterhalb des Marktzinssatzes

$i_{\text {spitze }} \frac{F^{\text {spitze }}}{P}=$ Zinseinnahmen aus der Spitzenrefinanzierung

$i_{\text {offen }} \frac{F^{\text {offen }}}{P}=$ Zinseinnahmen aus dem Offenmarktgeschäft

$i \frac{F^{\text {Ausl }}}{P}=$ Zinseinnahmen aus den Währungsreserven

13 Zumindest im Falle der Deutschen Bundesbank besteht ein direkter Zusammenhang zwischen dem den gesetzlichen Rücklagen zugeführten Anteil des Jahresüberschusses und der Geldschöpfung, da die gesamte gesetzliche Rücklage maximal 5\% des Banknotenumlaufs betragen darf. Da diese zumindest in den letzen Jahren voll ausgeschöpft wurde, können also zusätzliche Rücklagen nur noch bei einer entsprechenden Ausweitung des Banknotenumlaufs erfolgen. 
$i_{\text {liq }} \frac{V^{\text {liq }}}{P}=$ Zinsaufwendungen aus Einlagefazilitäten oder Ausgabe von Schuldtite In

$\frac{K}{P}=$ Kosten der Geldschöpfung

$\frac{E_{G P}}{P}=$ Zinseinnahmen für die Geldpolitik

$\frac{A_{G P}}{P}=$ Zinsausgaben der Geldpolitik

Die Größen sollen in ECU zum jeweiligen Umrechnungskurs und deflationiert mit Hilfe des BIP-Deflators auf Preise von 1990 berechnet werden. Um einen Anhaltspunkt über die Bedeutung dieser Einnahmen für die Volkswirtschaft zu bekommen, wird diese Größe zusätzlich in Prozent vom Bruttoinlandsprodukt berechnet.

\subsection{Bestimmung der durch die Konvergenz veränderten Einflußfaktoren auf den fiskalischen Seigniorage}

1991 wurden im Vertrag von Maastricht die sogenannten Konvergenzkriterien zum Beitritt zur Europäischen Währungsunion festgehalten. Danach mußten die Beitrittsstaaten folgende Kriterien erfüllen (vgl. Vertrag zur Gründung der Europäischen Gemeinschaft in der Fassung vom 1.Januar 1995, Art. 109j):

1. einen hohen Grad an Preisstabilität,

2. eine auf Dauer tragbare Finanzlage der öffentlichen Hand,

3. die Einhaltung der normalen Bandbreiten des Wechselkursmechanismus des Europäischen Währungssystems seit mindestens zwei Jahren ohne Abwertung gegenüber der Währung eines anderen Mitgliedstaats und

4. die Dauerhaftigkeit der von dem Mitgliedstaat erreichten Konvergenz und seiner Teilnahme am Wechselkursmechanismus des Europäischen Währungssystems, die im Niveau der langfristigen Zinsen zum Ausdruck kommt.

In einem separaten Protokoll werden diese Ziele operationalisiert, indem ein Mitgliedstaat eine anhaltende Preisstabilität und eine während einer Periode von einem Jahr vor der Prüfung gemessene durchschnittliche Inflationsrate aufweisen muß, die nicht mehr als 1,5 Prozentpunkte über der Inflationsrate jener - höchstens drei - Mitgliedstaaten liegt, die auf dem Gebiet der Preisstabilität das beste Ergebnis erzielt haben. Gleiches gilt zur Erfüllung des vierten Kriteriums, gemessen anhand der langfristigen Zinsen mit einer Abweichung von 2 Prozentpunkten. 
Das zweite Kriterium - fiskalischer Natur - soll hier nicht weiter betrachtet werden, da seine Einhaltung kaum Einfluß auf den Geldschöpfungsgewinn gehabt haben dürfte.

Demgegenüber haben aber gerade die sich durch die Konvergenz ergebenden Veränderungen des fiskalischen Seigniorage ihre Ursachen in den Veränderungen der durch Kriterium eins, drei und vier tangierten Größen Zins, Inflationsrate und Mindestreserve.

Der Einfluß der Konvergenz auf den Seigniorage sollen in diesem Abschnitt anhand der Formel des für die Konvergenzphase modifizierten fiskalischen Seigniorage identifiziert werden und ihr geldpolitischer Hintergrund beleuchtet werden. Im empirischen Teil (Kapitel 7) wird der Einfluß dieser aus der Erfüllung der Konvergenzkriterien resultierenden Ursachen quantifiziert und für jedes Land vor dem Hintergrund der jeweiligen Geldpolitik analysiert.

\subsubsection{Zins und Bestände aus Refinanzierungsgeschäften}

Die Einnahmen aus den Refinanzierungsgeschäften bestimmen sich aus den durch diese Geschäfte entstehenden Beständen an Forderungen an inländische Geschäftsbanken und dem von den Geschäftsbanken darauf zu zahlenden Zinssatz, der entweder - bei den ständigen Fazilitäten - administrativ oder - bei den Offenmarktgeschäften - im Verhandlungsprozeß mit den Geschäftsbanken gefunden wird. Im Zuge der Konvergenz dürften beide Werte im Zeitablauf gesunken sein, da einerseits das Zinskriterium dazu geführt hat, daß die Notenbankzinsen gesenkt werden mußten, und andererseits das Inflationskriterium die Notenbanken zwang, die Kreditvergabe an die Geschäftsbanken restriktiv zu handhaben, um die Geldmenge zu kontrollieren. Zur Berechnung dieses Effekts werden die Bestände der Notenbanken von 1997 mit den 1992 geltenden Zinssätzen verknüpft, um so den potentiellen Zinsertrag jeder einzelnen Notenbank ohne eine Zinskonvergenz zu erhalten. Die Differenz zwischen dem potentiellen Zinsertrag und dem tatsächlich 1997 erreichten wird als Zinseffekt definiert. Um einen realen Wert zu erhalten, wird ein Deflator mit der Basis 1990 verwendet, der sich allerdings von dem tatsächlichen Deflator darin unterscheidet, daß die Preissteigerungsrate von 1992 über den gesamten Beobachtungszeitraum konstant angenommen wird (siehe 6.2.4). Dieses Verfahren kann allerdings nur dann zum Einsatz kommen, wenn man die Zinseinnahmen durch die Bestände und die entsprechenden Zinssätze hinreichend genau schätzen kann. Ist dies nicht der Fall, wird der Zinseffekt mit Hilfe der Zinseinnahmen und dem Verhältnis der Offenmarktzinsen von 1992 und 1997 gemessen. Somit werden zur Berechnung des Zinseffekts folgende zwei Verfahren angewendet.

Methode 1 multipliziert die Aktiva aus dem Refinanzierungsgeschäft (Forderungen an die Geschäftsbanken) von 1997 mit den jeweiligen Zinsdifferenzen zwischen 1997 und 1992, wenn eine Schätzung der Zinserträge mit Hilfe der Aktiva und den Zinssätzen für den gesamten Beobachtungszeitraum zufriedenstellend 
möglich ist. Methode 2 verwendet im anderen Fall die tatsächlich erzielten Zinseinnahmen und gewichtet diese mit dem Verhältnis der Offenmarktzinssätze von 1992 und 1997.

Methodel:

Zinseffekt $=\sum_{j} F_{j}^{G B} \cdot\left(i_{j}^{1997}-i_{j}^{1992}\right)$

wenn Schätzungder Zinserträgemit Hilfevon $F^{G B}$ undimöglich.

sonst :

Methode2:

Zinseffekt $=$ Zinseinnahmen $^{1997} \cdot\left(\frac{i_{\text {Offenmarkt }}^{1992}-1}{i_{\text {Offenmarkt }}^{1997}}\right)$

\subsubsection{Zins und Bestände zur Liquiditätsabschöpfung}

Die Kosten der Geldpolitik bestimmen sich im wesentlichen aus den Zinsausgaben für liquiditätsabschöpfende Maßnahmen. Beeinflußt werden diese Kosten zum einen durch den von den Notenbanken dafür zu zahlenden Zins, der im Zuge der Erfüllung des Zinskriteriums gesunken sein dürfte, und zum anderen durch das Volumen der Maßnahmen. Reichte eine restriktive Kreditvergabe der Notenbanken nicht aus, die Geldmenge im gewünschten Maße zu reduzieren, bzw. waren parallel dazu sogar noch Devisenkäufe als Folge von Interventionsverpflichtungen im EWS zu tätigen, so mußte sich zwangsläufig das Volumen der liquiditätsabschöpfenden Maßnahmen erhöhen. Der Effekt der Zinsveränderung auf die Zinsausgaben aufgrund der Konvergenzbemühungen der Notenbanken soll in gleicher Weise erfolgen, wie bei den Zinseinnahmen (vgl. 6.2.1).

\subsubsection{Einlagezins}

Die Kosten für die Einlagefazilität bestimmen sich ebenfalls aus durchschnittlichem Bestand und dafür zu zahlenden Zinsen, wobei für beide Faktoren die gleichen Ausführungen wie unter 6.2.2 gelten, mit dem Unterschied, daß bei den Einlagefazilitäten die Geschäftsbanken selbst überschüssiges Zentralbankgeld bei der Notenbank einlegen, während bei den Liquiditätspapieren die Initiative zur Liquiditätsabschöpfung von der Notenbank ausgeht.

\subsubsection{Nachfrage nach Zentralbankgeld}

Nach der Betrachtung der Geldmarktoperationen und den zugehörigen Zinssätzen als Ursache der Seigniorage-Veränderungen, läßt sich in einem weiteren Schritt fragen, wie sich das Kreditnachfrageverhalten der Geschäftsbanken be- 
stimmt. Hierbei soll auf eine detaillierte Analyse des Geldangebots- und Geldnachfragemechanismus auf dem Markt für Zentralbankgeld verzichtet werden (vgl. dazu Gebauer 1996, 254ff) und statt dessen innerhalb einer komparativ-statischen Analyse der Mindestreservesatz als Determinante der Kreditnachfrage betrachtet werden und das Wachstum sowie die Inflation als Determinante der Geldnachfrage.

\section{Mindestreserve}

Bei einer statischen Betrachtung des Zusammenhangs zwischen Reservesatz und Kreditnachfrage, kommt man zu dem Ergebnis, daß eine Ausweitung (Verringerung) der Reservepflicht in gleichem Maße zu einer Erhöhung (Verringerung) der Kreditnachfrage führen wird. Dies gilt allerdings nur unter der Bedingung, da $\beta$ die Kosten der Refinanzierung, d.h. die Refinanzierungssätze, konstant gehalten werden und keine Bedeutung für die Kreditnachfrage der Geschäftsbanken spielen. Für die Vergangenheit wird man zumindest die Konstanz der Refinanzierungssätze verneinen müssen, da die Mindestreserve in den europäischen Staaten, in denen sie eingesetzt wurde, gerade als Instrument der Liquiditätssteuerung im Zusammenhang mit einer Veränderung der Refinanzierungssätze verwendet wurde. D.h. eine Erhöhung der Mindestreservesätze ging meist auch mit einer Erhöhung der Diskont- und Lombardsätze einher bzw. mit einer nachfragebedingten Erhöhung des Offenmarktzinssatzes. In der jüngsten Vergangenheit spielten die Mindestreservesätze allerdings nicht mehr die liquiditätspolitische Rolle wie zuvor. Seit 1993 wurden z.B. die Reservesätze der Deutschen Bundesbank von teilweise über $12 \%$ auf 1,5 - $2 \%$ zurückgeführt. Ohne die dadurch eventuell induzierten Zinsänderungen zu betrachten, wird man bei einer komparativ-statischen Analyse die Annahme treffen können, daß die Verminderung der Mindestreservesätze zu einer Verringerung der Reservehaltung und damit zu einer Verringerung der Nachfrage nach Krediten bei der Zentralbank geführt hat. D.h.

$\Delta F_{G B}=\Delta Z B G$,

$Z B G=C+M R+\ddot{U R}$ und

$M R=m r s * D_{M R}$

mit

$F_{G B}=$ Forderungen der Zentralbank gegenüber den Geschäftsbanken

$Z B G=$ Zentralbankgeld bestehend aus

$C=$ Bargeldumlauf,

$M R=$ Mindestreserve und

$\ddot{U} R=\ddot{U b e r s c h u ß r e s e r v e ~ s o w i e ~}$

$m r s=$ Mindestreservesatz

$D_{M R}=$ mindestreservepflichtige Depositen bei den Geschäftsbanken . 


\section{Inflation und Wachstum}

Ein weiterer Grund für eine zurückhaltende Entwicklung der Kreditnachfrage der Geschäftsbanken könnte in einem Nachfragerückgang nach Geld begründet sein. Ausgehend von der Quantitätsgleichung für die Zentralbankgeldmenge (siehe 3.1 Formel 4) läßt sich die Veränderung der Zentralbankgeldmenge auf eine Wachstums- und eine inflationsbedingte Komponente zurückführen:

$$
d M=\underbrace{d \frac{1}{v} P Y}_{=0}+d P \frac{1}{v} Y+d Y \frac{1}{v} P
$$

Ein Rückgang der Inflation wäre bei gleichbleibender Umlaufgeschwindigkeit des Zentralbankgelds gleichbedeutend mit einem Rückgang der Nachfrage nach Zentralbankgeld in gleicher Höhe, da die Geldnachfrager eine Konstanz der realen Kassenhaltung anstreben. Dieser lineare Zusammenhang kann zumindest für den Bereich der empirisch relevanten Inflationsraten der EWU-11 Staaten zugrunde gelegt werden, auch wenn der Zusammenhang zwischen Inflation und Geldnachfrage theoretisch exponentieller Art ist bzw. der Zusammenhang zwischen Inflation und Seignioragegenerierung sogar der Form einer Laffer-Kurve entspricht, d.h. der Seigniorage geht ab einer maximierenden Inflationsrate wieder zurück ${ }^{14}$. Für Deutschland kann der Lafferkurvenverlauf allerdings nicht nachgewiesen werden (vgl. Lange 1995, 107ff), so daß im folgenden vereinfachend ein linearer Zusammenhang auch für die übrigen EWU-11-Staaten unterstellt wird.

Eine Stagnation des Wachstums hat ähnliche Folgen für die Nachfrage nach Zentralbankgeld und somit für den Seigniorage. Allerdings ist der Zusammenhang zwischen den Konvergenzbemühungen und dem Wachstum der europäischen Staaten weniger eindeutig als der zwischen den Konvergenzkriterien und der Inflation. Auf der einen Seite können die Sparmaßnahmen der Staaten zur Rückführung des Schuldenstands und zur Einhaltung des Defizitkriteriums einen negativen Einfluß auf die Wachstumsrate gehabt haben. Auf der anderen Seite sprechen die niedrigen Zinsen und das Zustandekommen der Währungsunion für einen positiven Einfluß auf das Wachstum. Zudem existiert ein positiver empirischer Zusammenhang zwischen Preisstabilität und Wachstum (vgl. Barro 1995), so daß

14 Die Laffer-Kurven-Eigenschaft des Seigniorage gilt bei Vorliegen einer exponentiellen Geldnachfragefunktion (Cagan-Nachfragefunktion), wenn die Inflationselastizität der Geldnachfrage mit der Inflationsrate zunimmt, d.h. für die Wirtschaftssubjekte die Kosten der Geldhaltung zunehmen und sie deshalb mit zunehmender Inflation weniger Geld oder Devisen nachfragen (sogenannte "Dollarisierung"), vgl. Wagner 1992, 343ff. Die den Seigniorage maximierende Inflationsrate kann sogar noch weiter unten liegen, wenn der reale Wert der Steuereinnahmen des Staates aufgrund hoher Inflationsraten bei gleichzeitigem time-lag zwischen Steuererhebung und Einnahme der Steuer sinkt. Dieser Effekt wurde vor allem für die Hochinflationsländer Südamerikas zunächst theoretisch analysiert (vgl. Olivera 1967) und später empirisch bestätigt ( $\mathrm{vgl}$. Tanzi 1977, 162ff). Zudem ist die maximierende Inflationsrate vom Wachstum abhängig (vgl. Friedman 1985, 846). 
die Wirkung zwischen der Konvergenzkriterien und dem Wachstum innerhalb der EWU-11 Staaten kaum festgestellt werden kann.

Deshalb soll im folgenden das Wachstum als exogene Größe betrachtet werden, die nicht von den Bemühungen um die Einhaltung der Konvergenzkriterien beeinflußt wurde, und deshalb in den weiteren Überlegungen nicht weiter berücksichtigt wird.

Die Preisstabilität wird dagegen gerade von der Geldpolitik beeinflußt und wurde in den Jahren nach der Unterzeichnung des Vertrags von Maastricht in vielen Staaten zur Erfüllung des Inflationskriteriums auf ein historisches Tief zurückgeführt. Die Auswirkungen des Rückgangs der Inflationsrate sollen ebenso wie die der Verminderung der Mindestreserve im empirischen Teil quantifiziert werden. Dazu wird die vereinfachende Annahme getroffen, daß die Verhältnisse von mindestreservepflichtigen Depositen sowie dem Bargeldumlauf zu nominalem Bruttoinlandsprodukt konstant sind (vgl. Gros 1989, 9), d.h.

$$
\begin{aligned}
& \frac{D_{M R}}{B I P_{\text {nom }}}=\text { const. }=k_{3} \\
& \frac{C}{B I P_{\text {nom }}}=\text { const } .=c
\end{aligned}
$$

mit $D_{M R}=$ mindestreservepflichtige Depositen .

Dies bedeutet, daß sich die Nachfrage nach Zentralbankgeld für 1997 unter der Annahme einer konstanten Inflationsrate über den gesamten Betrachtungszeitraum und konstanten Mindestreservesätzen (ZBG97) folgendermaßen errechnen läßt:

$$
\begin{aligned}
& Z B G^{97}=C^{97}+M R^{97} \\
& C^{97}=c^{*} B I P_{n}^{97} \\
& M R^{97}=m r s^{92}{ }^{*} D M R^{97} \\
& D M R^{97}=k_{3} B I P_{n}{ }^{97} \\
& B I P_{n}{ }^{97}=B I P_{r} 90(97)^{*} \times\left(1+\pi^{92}\right)^{7}
\end{aligned}
$$

mit

$X^{97}=$ Größen, die bei gleichbleibender Inflationsrate bzw. Mindestreservesatz von $1992\left(\pi^{92}\right.$ und $\mathrm{mrs}^{92}$ ) 1997 erreicht worden wären.

$B P_{r} 90(97)=$ reales BIP von 1997 bezogen auf 1990 . 
Ermittelt man nun die Differenz zwischen der tatsächlichen Zentralbankgeldmenge (Banknotenumlauf + Mindestreserve der Geschäftsbanken) und der soeben errechneten Zentralbankgeldmenge c. p. und nimmt an, daß diese Differenz durch eine Refinanzierung über Offenmarktgeschäfte (zum Offenmarktzinssatz von 1992) durch die Geschäftsbanken hätte finanziert werden müssen, so läßt sich der Seigniorageverlust durch die Veränderung der Preissteigerungsraten und der Mindestreservesätze quantifizieren. Um die absolute Seigniorageveränderung in eine reale Größe zu überführen, wird diese wiederum durch den Deflator Basisjahr 1990 - dividiert. Dabei muß ein modifizierter Deflator verwendet werden, da der Konvergenzeffekt von einer Konstanz der Inflationsraten ab dem Jahr 1992 ausgeht. Der modifizierte Deflator - Deflator von 1997 unter der Annahme, daß die Preissteigerungsrate von 1992 bis 1997 auf dem Niveau von 1992 verharren würde -, berechnet sich wie folgt:

Deflator $97=\left((1+\pi)^{\wedge} 5\right) *$ Deflator 92

\subsubsection{Kosten}

Die anteiligen Kosten der Verwaltung verändern sich zum einen mit den gesamten Verwaltungskosten der Notenbanken und zum anderen mit dem Anteil der geldpolitischen intendierten Bilanzposten, mit Hilfe derer dieser Anteil berechnet wird. Einen Einfluß der Konvergenz auf diese Kosten läßt sich hierbei allerdings kaum feststellen.

\subsubsection{Konvergenzeffekt}

Der Konvergenzeffekt soll den Einfluß der Konvergenzbemühungen der Notenbanken zur Erfüllung der Maastrichter Kriterien abbilden und muß daher die oben beschriebenen Einflüsse berücksichtigen. Somit ergeben sich zwei Komponenten des Konvergenzeffekts. Zum einen der Zinseffekt, der eine Konstanz der Zinsen von 1992 über den gesamten Beobachtungszeitraum annimmt und zum anderen der Preisstabilitäts- und Mindestreserveeffekt, der eine Konstanz der Inflation von 1992 und die Konstanz der Mindestreservesätze annimmt. Beide Effekte werden mit Hilfe eines Deflators (Deflator97) auf das Basisjahr 1990 bezogen, unter der Annahme der Konstanz der Preissteigerung von 1992. Der Konvergenzeffekt beschreibt also, um wieviel höher der fiskalische Seigniorage der einzelnen Staaten hätte ausfallen können, hätte es keinen Zwang zur Erfüllung der Konvergenzkriterien gegeben. 


\section{Quantifizierung des Konvergenzeffekts}

In diesem Kapitel soll der Konvergenzeffekt für die Staaten, die an der Europäischen Währungsunion teilnehmen, mit Hilfe der in Kapitel 6 erarbeiteten Formel für den fiskalischen Seigniorage

$$
\begin{aligned}
S_{I}^{f i s k} & =i_{\text {subv }} \frac{F^{\text {subv }}}{P}+i_{\text {spitze }} \frac{F^{\text {spitze }}}{P}+i_{\text {offen }} \frac{F^{\text {offen }}}{P}+i \frac{F^{\text {Ausl }}}{P}-i_{\text {liq }} \frac{V^{\text {liq }}}{P}-\frac{K}{P} \\
& =\frac{E_{G P}}{P}-\frac{A_{G P}}{P}-\frac{K}{P}
\end{aligned}
$$

quantifiziert werden und anschließend mit den Ergebnissen aus der Berechnung mit Hilfe des Opportunitätskosten-Seigniorage verglichen werden. Der Beobachtungszeitraum ist 1992 (Unterzeichnung des Maastrichter Vertrags) bis 199713. Datengrundlage sind die Geschäftsberichte der nationalen Notenbanken. Die Beträge werden zunächst in den jeweiligen Währungen preisbereinigt mit Basisjahr 1990 dargestellt. Zur Vereinfachung werden preisbereinigte Größen mit einer dem Währungskürzel angestellten "90" gekennzeichnet, z.B. DM90. Zur besseren Vergleichbarkeit des Seigniorage der verschiedenen Staaten wird dieser anschließend auch in ECU, und zwar preisbereinigt auf das Jahr 1990 und zum Wechselkurs von 1990, dargestellt. Die Bedeutung für den jeweiligen Staat wird deutlich beim Bezug auf das BIP.

\subsection{Quantifizierung für Deutschland}

\subsubsection{Quantifizierung des Konvergenzeffekts}

\subsubsection{Zinsertrag aus Forderungen gegen inländische Geschäftsbanken}

Die Zinserträge aus den Forderungen gegenüber den inländischen Geschäftsbanken lassen sich iterativ aus den Kommentaren zur GuV der Bundesbank ablesen; der letztmalige explizite Ausweis dieser Größe findet sich im Geschäftsbericht für 1990. Ihre Entwicklung - preisbereinigt mit Basisjahr 1990 - gibt Abbildung 7-1 wieder. Im Beobachtungszeitraum sind die Zinseinnahmen aus Forderungen an die inländischen Geschäftsbanken demnach um fast zwei Drittel geschrumpft.

\subsubsection{Zinsaufwand für Verbindlichkeiten aus abgegebenen Mobilisierungs- und Liquiditätspapieren}

Die Daten für diese Position lassen sich nur bis 1993 direkt aus der GuV entnehmen, obwohl gerade in diesem Zeitraum (März 1993 bis Herbst 1994) die Bundesbank in größerem Umfang sogenannte Bundesbank-Liquiditäts-U-Schätze (Bulis) anbot (vgl. Deutsche Bundesbank 1995, 112f). Für die Daten von 1994-1997

13 Auch wenn Österreich und Finnland erst 1995 der EU betraten, kann doch davon ausgegangen werden, daß in Folge der Beitrittsverhandlungen auch diese Staaten schon ab 1992 darum bemüht waren, die Konvergenzkriterien zu erfüllen. Deshalb gilt auch für diese Staaten der gleiche Beobachtungszeitraum. 
wird daher eine Schätzung mit Hilfe der Passivposition "Verbindlichkeiten aus abgegebenen Mobilisierungs- und Liquiditätspapieren" und dem Diskontzinssatz vorgenommen. Abb. 7-2 zeigt die gute Übereinstimmung der in den Geschäftsberichten bis 1993 enthaltenen Angabe über den Zinsaufwand und der Schätzung mit Hilfe des Produkts aus der Passivposition "Verbindlichkeiten aus abgegebenen Mobilisierungs- und Liquiditätspapieren" und dem Diskontsatz.

Abbildung 7-1: Zinserträge auf Forderungen an inländische Geschäftsbanken

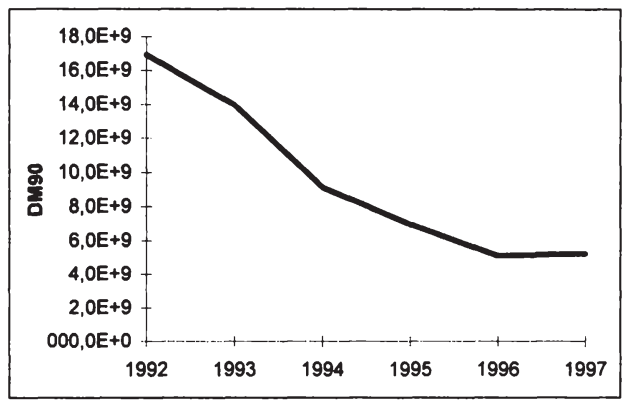

Quelle:

eigene Berechnungen nach Geschäftsberichten der Deutschen Bundesbank und eurostat

Abbildung 7-2: Zinsaufwendungen für abgegebene Mobilisierungs- und Liquiditätspapiere im Vergleich zur Schätzung

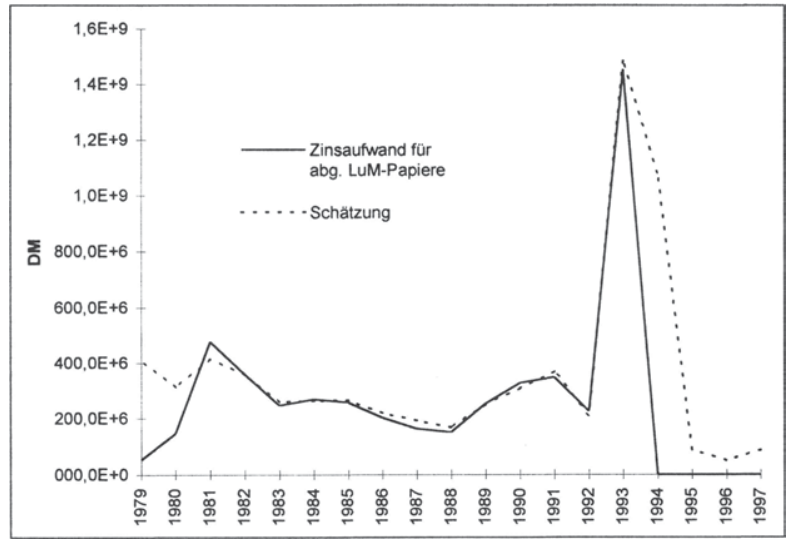

Quelle:

eigene Berechnungen nach Deutsche Bundesbank: Geschäftsbericht, verschiedene Jahrgänge

Legt man diese Schätzung zu Grunde, so ergeben sich von 1992 bis 1997 folgende Zinsaufwendungen (Abbildung 7-3): 
Abbildung 7-3: Zinsaufwendungen für abgegebene Mobilisierungs- und Liquiditătspapiere

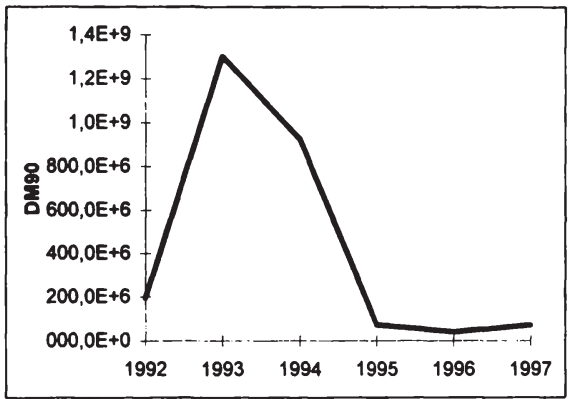

Quelle: $\quad$ eigene Berechnungen nach Geschäftsberichten der Deutschen Bundesbank und eurostat

Auffallend ist auch im Zusammenhang mit Abbildung 7-2 der außergewöhnlich starke Anstieg der Zinsaufwendungen für die Jahre 1993 und 1994.

\subsubsection{Zinsgewinne aus Währungsreserven}

Die Zinseinnahmen aus den Währungsreserven (zur Entstehung der Währungsreserven vgl. 6.1.4.1) reduzierten sich im Betrachtungszeitraum von 8 auf etwa 6 Mrd. DM90 und die Zinsausgaben von 3 auf 0,4 Mrd. DM90, so daß sich der Zinsgewinn aus den Währungsreserven während des Betrachtungszeitraums zwischen 5 Mrd. und 6 Mrd. DM90 belief.

Abbildung 7-4: Zinsgewinn aus Währungsreserven der Deutschen Bundesbank

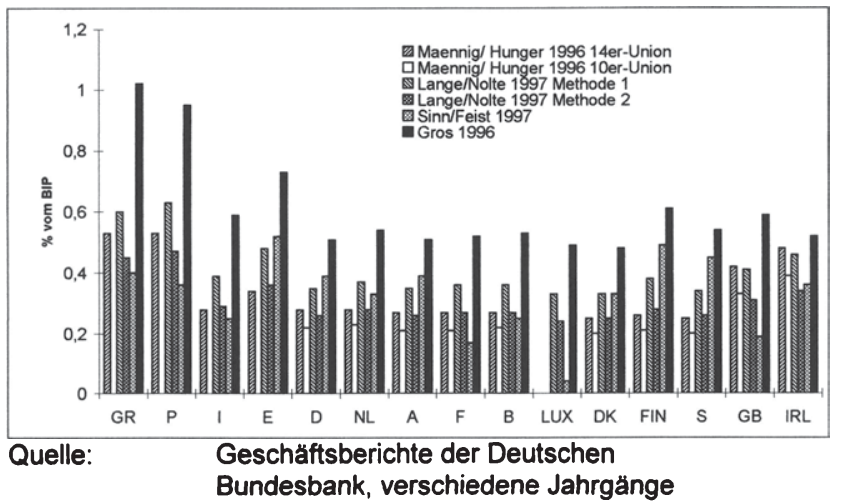

Die Zinseinnahmen aus den Währungsreserven übertrafen somit 1996 und 1997 sogar die Zinseinnahmen aus Forderungen an inländische Geschäftsbanken. 


\subsubsection{Kosten}

Die anteiligen Kosten an der Geldschöpfung (vgl. 6.2.5) lagen zwischen 1,8 und 1,6 Mrd. DM90 und erfuhren somit keine starken Veränderungen.

Abbildung 7-5: Anteilige Kosten der Deutschen Bundesbank

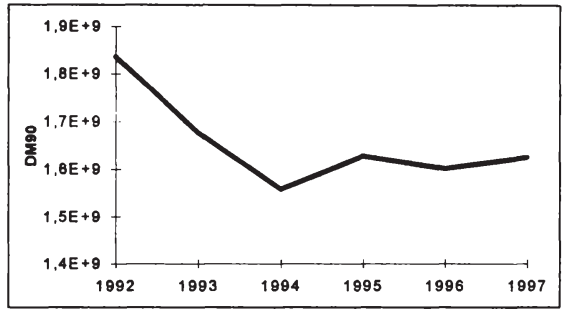

Quelle:

eigene Berechnungen nach Geschäftsberichten der Deutschen Bundesbank und eurostat

\subsubsection{Gesamteffekt}

Berechnet man den fiskalischen Seigniorage nach obiger Formel, so ergibt sich für Deutschland folgendes Bild:

Abbildung 7-6: Fiskalischer Seigniorage und seine Entstehung für Deutschland

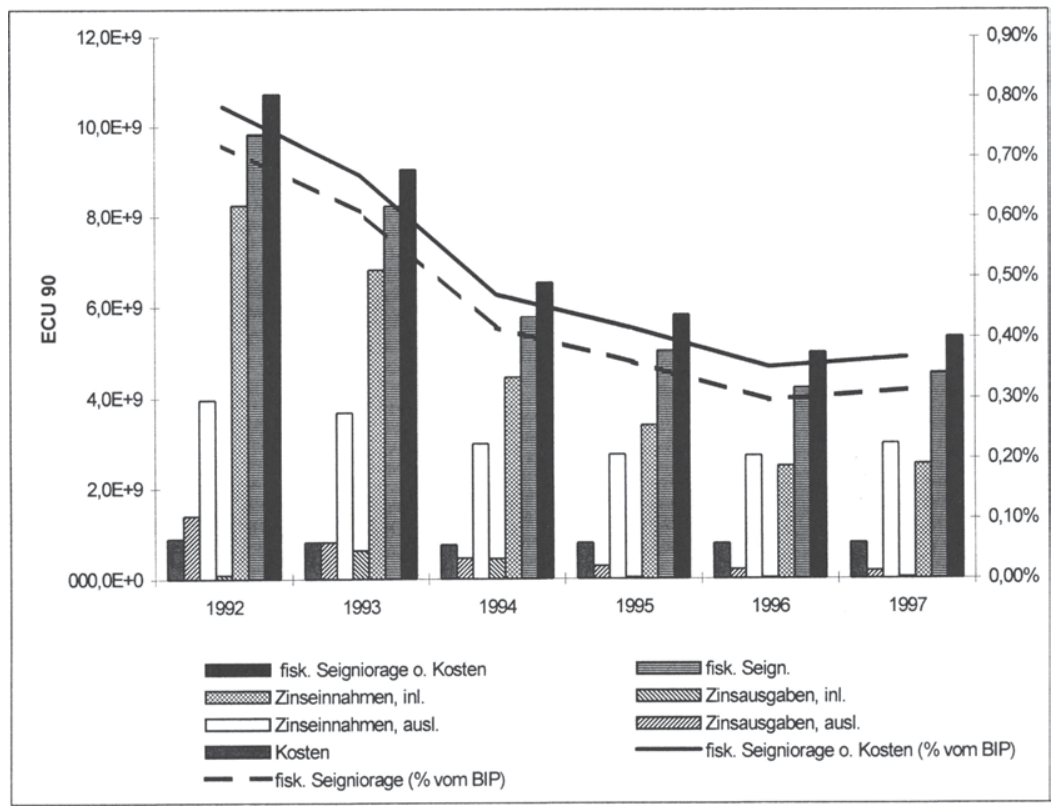

Quelle:

eigene Berechnungen nach Geschäfts- und Monatsberichten der Deutschen Bundesbank und eurostat 
Zunächst wird deutlich, daß sich der fiskalische Seigniorage seit der Verabschiedung des Maastrichter Vertrags 1992 etwa halbiert hat. Maßgeblichen Anteil daran hatte der Rückgang der inländischen Zinseinnahmen.

\subsubsection{Ursachenanalyse}

\subsubsection{Zins aus Diskont-, Lombard- und Offenmarktgeschäften}

Die Zinseinnahmen aus den Diskont-, Lombard- und Offenmarktgeschäften bestimmen sich aus den entsprechenden Beständen an Wertpapieren bei der Bundesbank und dem dazugehörigen Zinssatz, die sich aus den Wochenausweisen der Deutschen Bundesbank ersehen lassen. Inwieweit allerdings diese Daten die ausgewiesenen Zinseinnahmen tatsächlich erklären, soll zunächst mit Hilfe einer Schätzung der Zinseinnahmen, berechnet aus dem Produkt von Beständen an Wertpapieren aus dem Diskont-, Lombard- und Offenmarktgeschäft und den jeweiligen Zinssätzen, analysiert werden. Dazu wurde der Mittelwert aus den wöchentlichen Beständen an Wertpapieren aus dem Lombardgeschäft mit dem jeweils geltenden Lombardsatz und der Mittelwert aus den Beständen aus Wertpapieren aus dem Diskont- und dem Offenmarktgeschäft zur Monatsmitte mit den jeweiligen Diskont- und Offenmarktzinssätzen multipliziert. Das Ergebnis der so ermittelten Schätzung und der Verlauf der Zinseinnahmen für Kredite an inländische Geschäftsbanken werden in Abbildung 7-7 einander gegenübergestellt.

\section{Abbildung 7-7: Vergleich von Zinserträgen und deren Schätzung}

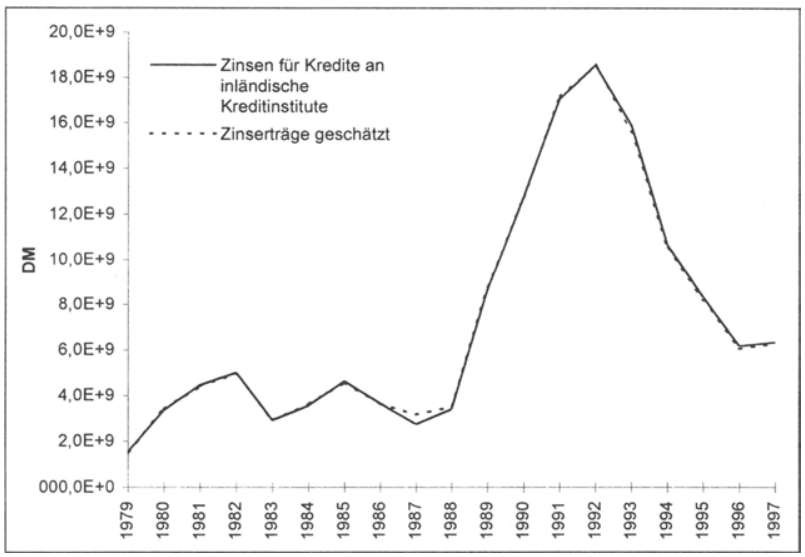

Quelle:

eigene Berechnungen nach Geschäfts- und Monatsberichten der Deutschen Bundesbank, verschiedene Jahrgänge

Aus der Abbildung wird deutlich, daß die Schätzung die ausgewiesenen Gewinne sehr gut abbildet; die einzelnen Komponenten der Schätzung können demnach zur Ursachenanalyse des Zinseinnahmenverlaufs herangezogen werden. 
Bis 1988 pendelt der Verlauf der Zinseinnahmen zwischen 3 und 5 Mrd. DM, um in den nächsten 4 Jahren deutlich bis auf über $18 \mathrm{Mrd}$. DM anzusteigen. In den Jahren 1992 bis 1996 folgte ein fast ebenso deutlicher Rückgang bis auf 6 Mrd., wobei dieses Niveau in 1997 gehalten werden konnte.

Zur Ursachenanalyse soll zunächst die Entwicklung der Zinseinnahmen aus den Lombard-, Diskont- und Offenmarktgeschäften getrennt nach Geschäftsart betrachtet werden.

Abbildung 7-8: Komponenten des Zinsertrags der Deutschen Bundesbank aus Krediten an die Geschäftsbanken

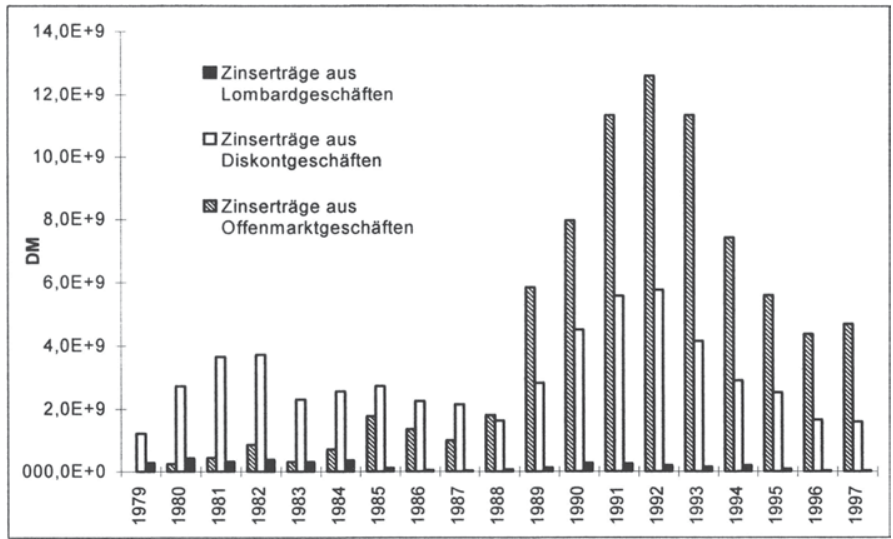

Quelle:

Geschäfts- und Monatsberichte der Deutschen Bundesbank

Zunächst wird deutlich, daß die Spitzenfazilität "Lombardgeschäfte" nur Anfang der achtziger Jahre eine nennenswerte Rolle gespielt hat. Mit dem Einsatz der Offenmarktgeschäfte gingen die Zinseinnahmen aus Lombardgeschäften aber stark zurück und spielten erst Anfang der neunziger Jahre während des allgemeinen Anstiegs der Zinseinnahmen wieder eine - wenn auch bescheidene - Rolle. Auch die dominante Rolle der Zinseinnahmen aus Diskontgeschäften ging mit wachsendem Volumen der Offenmarktgeschäfte spätestens ab 1989 verloren. Seither sind die Zinseinnahmen aus dem Offenmarktgeschäften regelmäßig etwa doppelt so hoch wie die aus den Diskontgeschäften.

Ob diese Entwicklung von den Beständen oder von den Zinssätzen dieser geldpolitischen Instrumente abhängig ist, soll durch eine Betrachtung dieser beiden Komponenten im folgenden analysiert werden.

Abbildung 7-9 zeigt, daß die Wertpapierbestände aus den Diskontgeschäften seit Anfang der achtziger Jahre nahezu unverändert sind, während die Papiere aus Offenmarktgeschäften während der Jahre 1988 bis 1991 stark zunahmen und anschließend zwischen 130 und 150 Mrd. DM schwankten. 
Abbildung 7-9: Bestände aus geldpolitischen Operationen der Deutschen Bundesbank

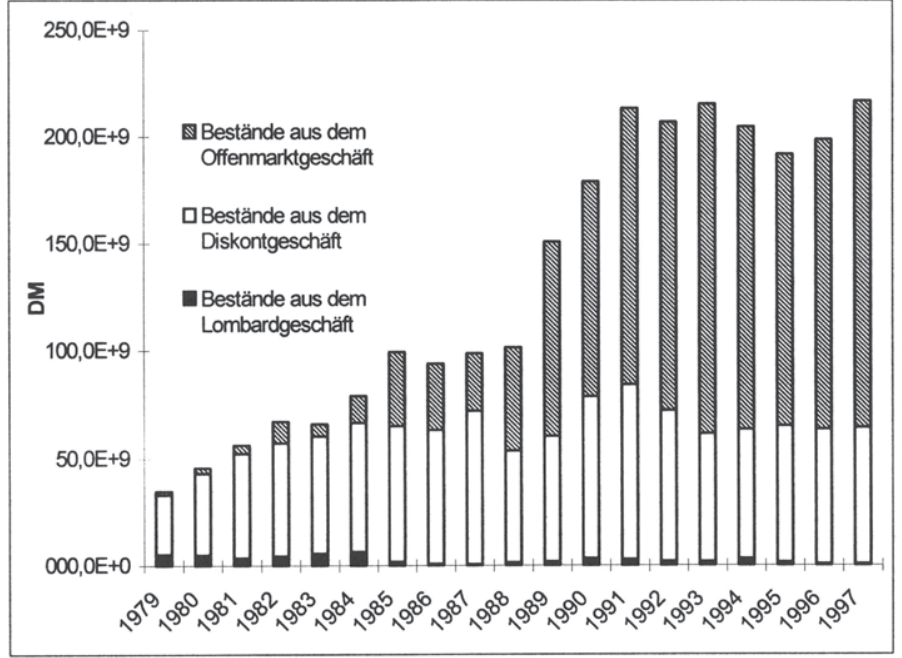

Quelle:

Geschäfts- und Monatsberichte der Deutschen Bundesbank, eurostat

Demnach läßt sich zwar der Anstieg der Zinseinnahmen bis 1991 mit Hilfe des Anstiegs der Wertpapierbestände - maßgeblich der Papiere aus dem Offenmarktgeschäft - erklären, da es anschließend aber keine nennenswerten Bestandsveränderungen mehr gegeben hat, muß für die Einnahmenentwicklung ab 1991 demnach die Entwicklung der Zinsen verantwortlich sein, wie folgende Abbildung bestätigt.

Abbildung 7-10: Entwicklung der Notenbankzinsen für Deutschland

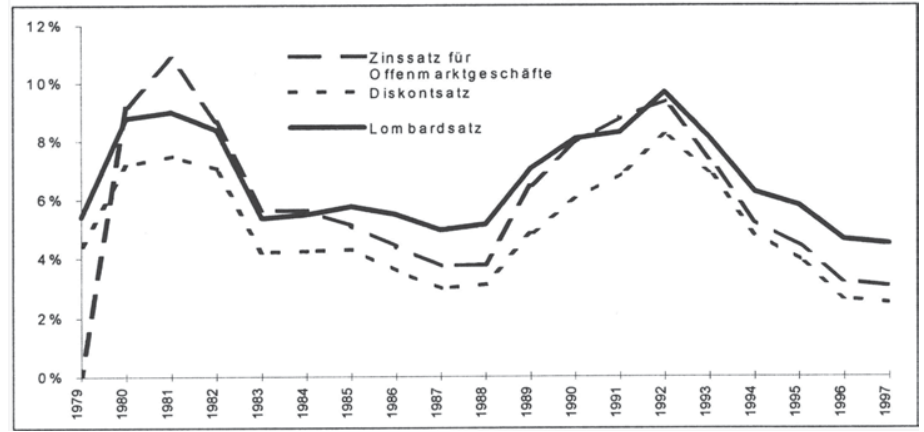

Quelle:

Geschäfts- und Monatsberichte der Deutschen Bundesbank

Der Anstieg der Wertpapierbestände ab Ende der achtziger bis Anfang der neunziger Jahre wurde von einem ebenso starken Anstieg der Zinsen begleitet, so daß 
die Einnahmen aus Krediten an die Geschäftsbanken überproportional steigen konnten. Der ab 1992 einsetzende Rückgang der Zinseinnahmen läßt sich allerdings eindeutig auf einen Rückgang der Zinssätze zurückführen, da die Wertpapierbestände in dieser Zeit zwar eine leichte "Delle" erfuhren, 1997 aber schon wieder das Niveau von 1991 erreichten, während die Zinssätze von 1992 bis 1997 um $54 \%$ (Offenmarkt) bis $67 \%$ (Diskont) sanken.

Berechnet man die möglichen Zinserträge bei gegebenen Beständen aus der Kreditvergabe an inländische Geschäftsbanken mit den 1992 geltenden Notenbankzinssätzen, so errechnet sich für Deutschland - komparativ-statisch - ein potentieller Zinsertrag von 19,6 Mrd. DM statt 6,4 Mrd. DM, d.h. ohne eine Konvergenz der Zinssätze hätten die Zinseinnahmen 1997 um 13,2 Mrd. DM höher gelegen.

\subsubsection{Zins zur Liquiditätsabschöpfung}

Auch wenn der Zinsaufwand für abgegebene Mobilisierungs- und Liquiditätspapiere bei der Bestimmung des fiskalischen Seigniorage in Deutschland nur eine geringe Rolle spielt (siehe 7.1.1.6), sollen hier die Ursachen für seine Veränderungen analysiert werden. Die Verbindlichkeiten aus diesen Geschäften betrugen in den Jahren 1981 bis 1991 zwischen 5,1 Mrd. und 6,2 Mrd. DM. 1992 gingen sie auf 2,6 Mrd. DM zurück, um in den beiden folgenden Jahren - bedingt durch die EWS-Krise und den daraus erwachsenden Interventionsverpflichtungen - auf über 20 Mrd. DM anzusteigen. Schon 1995 gingen die Verbindlichkeiten aber auf unter 3 Mrd. DM zurück. Demnach fielen auch nur in den Jahren 1993 und 1994 nennenswerte Zinsaufwendungen zur Liquiditätsabschöpfung an, da in diesem Zeitraum ein starker Anstieg die Verbindlichkeiten zu verzeichnen war. Der Zinssatz - hier angenähert durch den Diskontsatz - hat dagegen kaum einen Einfluß auf die Höhe der Aufwendungen.

Abbildung 7-11: Verbindlichkeiten aus abgegebenen Mobilisierungs- und Liquiditätspapieren und deren Zinssatz

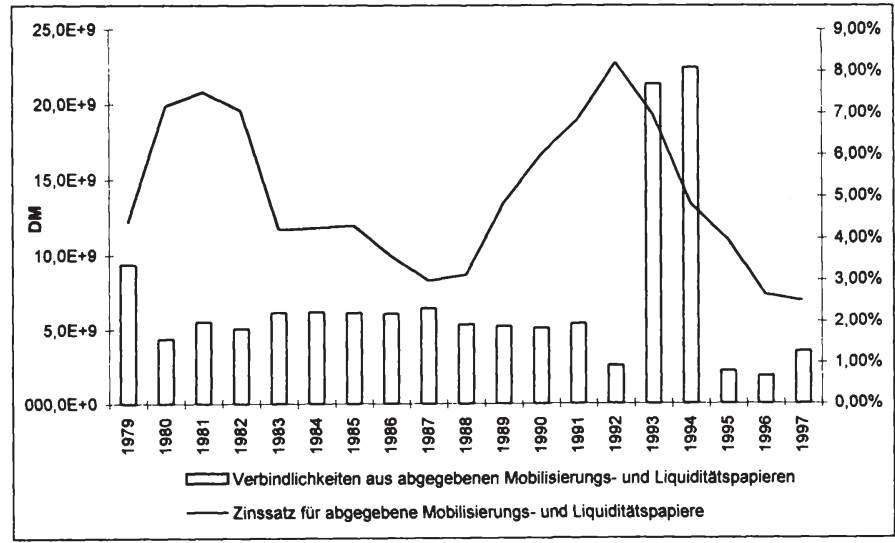

Quelle:

Geschäftsberichte der Deutschen Bundesbank 
Im Gegensatz zu den Zinseinnahmen haben bei den Zinsausgaben also die Bestände aus den jeweiligen Geschäften den maßgeblichen Einfluß auf den Verlauf der Einnahmen bzw. Ausgaben. Der Konvergenzeffekt auf die Zinsausgaben ist dementsprechend gering: Ohne eine Konvergenz der Zinsen hätten die Ausgaben um 0,2 Mrd. DM höher gelegen.

\subsubsection{Nachfrage nach Zentralbankgeld}

\section{Mindestreserven}

Den Rückgang der Reserven und den durchschnittlichen Mindestreservesatz zeigt die folgende Abbildung:

Abbildung 7-12: Mindestreservehaltung der Geschäftsbanken in Deutschland

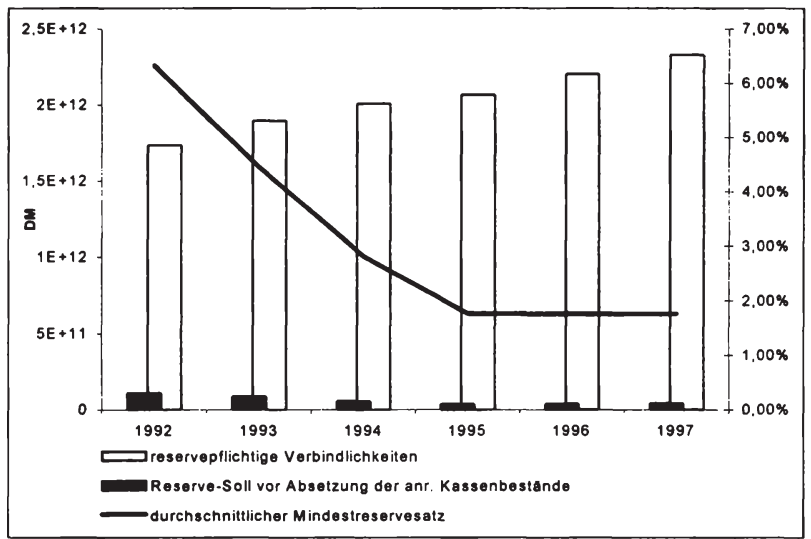

Quelle: $\quad$ Monatsbericht der Deutschen Bundesbank

Die reservepflichtigen Verbindlichkeiten (Sichtverbindlichkeiten, befristete Verbindlichkeiten und Spareinlagen) stiegen innerhalb des Betrachtungszeitraums von 1,7 auf 2,3 Billionen DM an. Demnach ist der Rückgang der Mindestreservebestände von 110 auf 41 Mrd. DM bis 1995 auf die Reduzierung der Mindestreservesätze auf unter $2 \%$ zurückzuführen. Ein Teil des Rückgangs der Bestände aus dem Offenmarktgeschäft ab 1992 (s.o.) kann man demnach mit einem Rückgang der Verpflichtung, Mindestreserven zu halten, erklären. Dementsprechend führte auch die Verminderung der Mindestreservesätze zu einer Verminderung des Seigniorage.

\section{Inflation}

Die Veränderung der Preissteigerungsrate im Betrachtungszeitraum zeigt die folgende Abbildung: 
Abbildung 7-13: Jährliche Preissteigerungsrate des BIP (Deutschland)

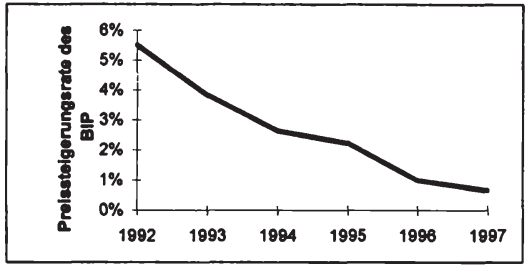

Quelle:

eurostat

Unterstellt man ein konstantes Verhältnis von mindestreservepflichtigen Verbindlichkeiten zu nominalem BIP sowie von Banknotenumlauf zu nominalem BIP, so läßt sich der Einfluß der zunehmenden Preisstabilität auf die Zentralbankgeldmenge bestimmen, da ein Rückgang der Preissteigerungsrate einen langsameren Anstieg des nominalen BIP zur Folge hat, was sich wiederum in einem langsameren Ansteigen der Zentralbankgeldmenge als bei einer hohen Preissteigerungsrate niederschlägt ${ }^{14}$.

Tabelle 7-1: Berechnung des Seigniorageverlusts aufgrund steigender Preisstabilităt und Reduzierung der Mindestreserve für Deutschland

\begin{tabular}{|l|l|}
\hline ZBG97 & $529,8 \mathrm{E}+9$ \\
\hline C97 & $363,5 \mathrm{E}+9$ \\
\hline MR97 & $166,3 \mathrm{E}+9$ \\
\hline BIPn97 & $4,3 \mathrm{E}+12$ \\
\hline DMR97 & $2,6 \mathrm{E}+12$ \\
\hline BIPr90(97) & $3,0 \mathrm{E}+12$ \\
\hline PI92 & $5,50 \%$ \\
\hline mrs92 & $6,32 \%$ \\
\hline ZBG(97) & $301,7 \mathrm{E}+9$ \\
\hline d ZBG & $228,1 \mathrm{E}+9$ \\
\hline d Seigniorage (DM) & $21,4 \mathrm{E}+9$ \\
\hline Deflator97 & 143,24282 \\
\hline DM90 & $14,9 \mathrm{E}+9$ \\
\hline ECU90 & $7,3 \mathrm{E}+9$ \\
\hline$\%$ vom BIP & $0,50 \%$ \\
\hline
\end{tabular}

Quelle:

eigene Berechnungen

Unterstellt man für 1997 die Preissteigerungsrate von 1992 (5,05 \%) und einen Mindestreservesatz von 6,32 \%, der dem Durchschnittssatz von 1992 entspricht, so hätte die Menge an Zentralbankgeld um $228 \mathrm{Mrd}$. DM höher liegen können bei gleicher nominaler Geldmenge und sich somit ca. $21 \mathrm{Mrd}$. DM mehr Zinsein-

14 Etwas abgefedert wurde dieser Effekt allerdings durch einen leichten Anstieg des Bargeldhaltungskoeffizienten und des Verhältnisses zwischen reservepflichtigen Verbindlichkeiten und nominalem BIP (vgl. Anhang). 
nahmen erzielen lassen. Die zusätzlichen Zinseinnahmen bei einem Offenmarktzinssatz von 9,36 \% (durchschnittlicher Offenmarktzinssatz von 1992) hätten dann 21 Mrd. DM betragen. Bezogen auf 1990 - mit Hilfe des modifizierten Deflators - ist dies ein realer Seigniorageverlust von 14,9 Mrd. DM90 jährlich, bzw. 0,50\% des BIP.

\subsubsection{Kosten}

Abbildung 7-14 zeigt die Entwicklung der Kosten für den Notendruck und der anteiligen Verwaltungskosten. Es lassen sich hier keine starken Veränderungen erkennen, bis auf die 1992 und 1993 außergewöhnlich hohen Kosten für den Notendruck (290 und $236 \mathrm{Mrd}$. DM gegenüber 160 bis $170 \mathrm{Mrd}$. DM in den darauffolgenden Jahren), die sich im Zusammenhang mit der Ausgabe der neuen Banknotenserie in den Jahren 1991 und 1992 erklären (vgl. Deutsche Bundesbank Geschäftsbericht 1993, 149).

Abbildung 7-14: Kosten des Notendrucks und anteilige Verwaltungskosten

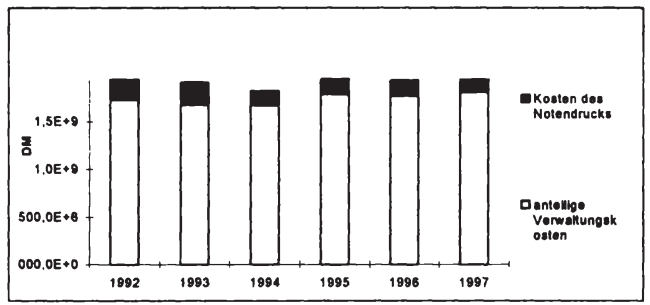

Quelle: $\quad$ Geschäftsberichte der Deutschen Bundesbank

Der Kostenverlauf ist demnach unabhängig von der aus der Einhaltung der Konvergenzkriterien geprägten Geldpolitik, so daß diese Komponente keinen Beitrag zur Ursachenanalyse stellen kann.

\subsubsection{Währungsreserven}

Die Währungsreservenbestände der Deutschen Bundesbank zeigt folgende Abbildung.

Abbildung 7-15: Bestände der Deutschen Bundesbank an Währungsreserven

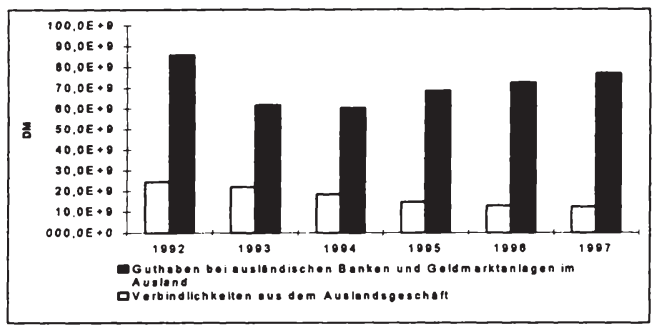

Quelle:

Geschäftsberichte der Deutschen Bundesbank 
Der Rückgang der Währungsreserven von 1992 bis 1994 bietet eine Erklärung für den Rückgang der Zinseinkünfte, ebenso der anschließende Anstieg für den Zuwachs an ausländischen Zinseinkünften nach 1994. Ohne allerdings das genaue Portefeuille zu kennen und die Zinsentwicklungen im Ausland lassen hier keine weiteren Analysen durchführen.

\subsubsection{Gesamteffekt}

Der gesamte Konvergenzeffekt errechnet sich als Summe aus den Konvergenzeffekten für Zinseinnahmen und -ausgaben, die sich aus einer Veränderung der Notenbankzinsen ergeben, sowie dem Konvergenzeffekt durch die Verminderung der Mindestreservesätze und der Inflationsreduzierung.

Abbildung 7-16: Quantifizierter Konvergenzeffekt für Deutschland

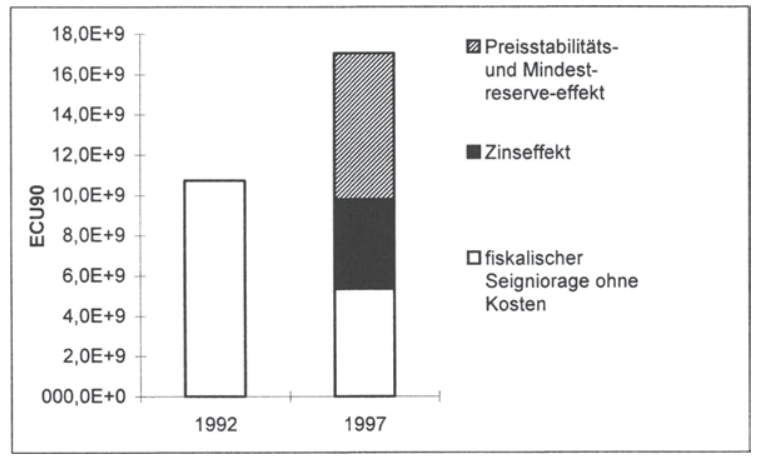

Quelle: $\quad$ eigene Berechnungen

Für Deutschland errechnet sich ein Seigniorageverlust von 11,7 Mrd. ECU90; das entspricht $0,81 \%$ des BIP. D. $h$, w4ären Preissteigerungsrate, Mindestreservesätze und Zinssätze 1997 die gleichen gewesen wie 1992, so hätte in Deutschland - komparativ-statisch, d.h. ohne die Berücksichtigung der dadurch implizierten Mengeneffekte - ein fiskalischer Seigniorage von 17 Mrd. ECU90 erreicht werden können.

Tabelle 7-2: Konvergenzeffekt für Deutschland

\begin{tabular}{|c|c|c|c|c|c|}
\hline \multirow{2}{*}{\begin{tabular}{|l|} 
aus Zinsănderungen \\
\end{tabular}} & \multicolumn{2}{|r|}{ DM } & DM90 & ECU90 & $\%$ vom BIP \\
\hline & d Zinseinnahmen & $-13,2 E+9$ & $-9,2 E+9$ & $-4,5 E+9$ & $-0,31 \%$ \\
\hline & $d$ Zinsausgaben & $-200,5 E+6$ & $-139,9 E+6$ & $-68,2 E+6$ & $0,00 \%$ \\
\hline aus $\mathrm{d} \mathrm{mrs}$ und $\mathrm{d} \mathrm{PI}$ & d potentielle Zinseinnahmen & $-21,4 E+9$ & $-14,9 E+9$ & $-7,3 E+9$ & $-0,50 \%$ \\
\hline Konvergenzeffekt & & $-34,4 E+9$ & $-24,0 E+9$ & $-11,7 \mathrm{E}+9$ & $-0,80 \%$ \\
\hline
\end{tabular}

Quelle:

eigene Berechnungen

Der Zinseffekt, d.h. wieviel mehr Gewinne bei einem Zinsniveau von 1992 hätten erreicht werden können, beträgt 4,4 Mrd. ECU90 und etwa 7,3 Mrd. ECU90 der 
Preisstabilitäts- und Mindestreserveeffekt, d.h. der zusätzlich mögliche Gewinn bei einer Inflationsrate und einer Mindestreserve, die denen von 1992 entspricht.

\subsection{Quantifizierung für Belgien}

\subsubsection{Quantifizierung des Konvergenzeffekts}

7.2.1.1 Zinsertrag, Zinsaufwand im inländischen Kreditgeschäft und anteilige Kosten

Zinsertrag und Zinsaufwand im inländischen Kreditgeschäft sowie die anteiligen Verwaltungskosten zeigt folgende Abbildung. Für 1997 unterscheidet der Geschäftsbericht der belgischen Zentralbank nicht zwischen Erträgen und Aufwendungen aus dem inländischen und ausländischen Geschäft, so daß diese Daten fehlen. Laut Geschäftsbericht soll es allerdings bei den Zinseinnahmen aus dem inländischen Geschäft keine Veränderungen gegenüber dem Vorjahr gegeben haben. Ein deutlicher Anstieg des Zinsaufwands ist im Jahr 1997 von 627 Mio. BF90 auf 7 Mrd. BF90 zu verzeichnen.

Abbildung 7-17: Zinsertrag, Zinsaufwand und anteilige Kosten (Belgien)

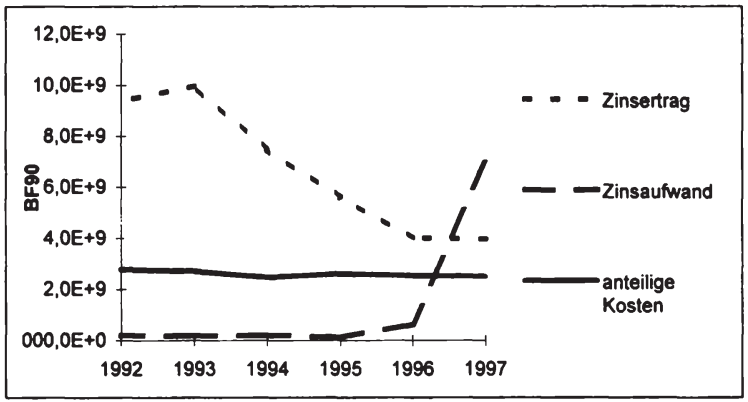

Quelle:

Geschäftsberichte der Banque Nationale de Belgique, verschiedene Jahrgänge

Bis 1995 belief sich der Zinsaufwand dagegen auf etwa 200 Mio. BF90 und stieg erst 1996 leicht an, während die Zinseinnahmen 1993 zunächst einen kleinen Anstieg von 9,4 Mrd. BF90 auf 10 Mrd. BF90 aufweisen und danach kontinuierlich bis auf 4 Mrd. BF90 im Jahr 1996 absanken. Die Kosten blieben relativ konstant mit Werten zwischen 2,5 und 2,8 Mrd. BF90.

\subsubsection{Zinseinnahmen aus Währungsreserven}

Die Zinseinnahmen aus Währungsreserven beliefen sich im Beobachtungszeitraum auf etwa das doppelte der Zinseinnahmen aus dem inländischen Geschäft. Zunächst erlitten sie aber von 1992 bis 1994 einen deutlichen Einbruch von 22 Mrd. BF90 auf 12 Mrd. BF90. Anschließend stiegen sie wieder bis auf 23,4 Mrd. BF90 im Jahre 1997. 
Abbildung 7-18: Zinseinnahmen aus Währungsreserven der Banque Nationale de Belgique

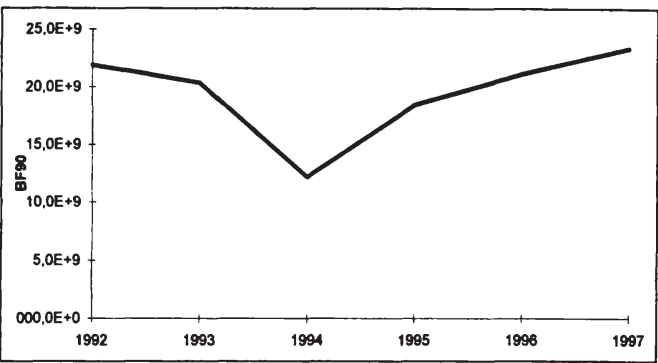

Quelle: $\quad$ Geschäftsberichte der Banque Nationale de Belgique, verschiedene Jahrgänge

\subsubsection{Gesamteffekt}

In Belgien wird der fiskalische Seigniorage zunächst deutlich vom Verlauf der Zinseinnahmen aus den Währungsreserven geprägt. Ohne Berücksichtigung der Kosten fällt der fiskalische Seigniorage von 727 Mio. ECU90 (1992) auf 454 Mio. ECU90 (1994). Der anschließend einsetzende Anstieg bis auf über 563 Mio. ECU90 - im wesentlichen von den Zinseinnahmen aus Währungsreserven bestimmt - wird allerdings im Jahre 1997 deutlich vom Anstieg des inländischen Zinsaufwands gedämpft, so daß der fiskalische Seigniorage 1997 nur noch 472 Mio. ECU90 (0,28 \% des BIP) betrug.

Abbildung 7-19: Fiskalischer Seigniorage und seine Entstehung für Belgien

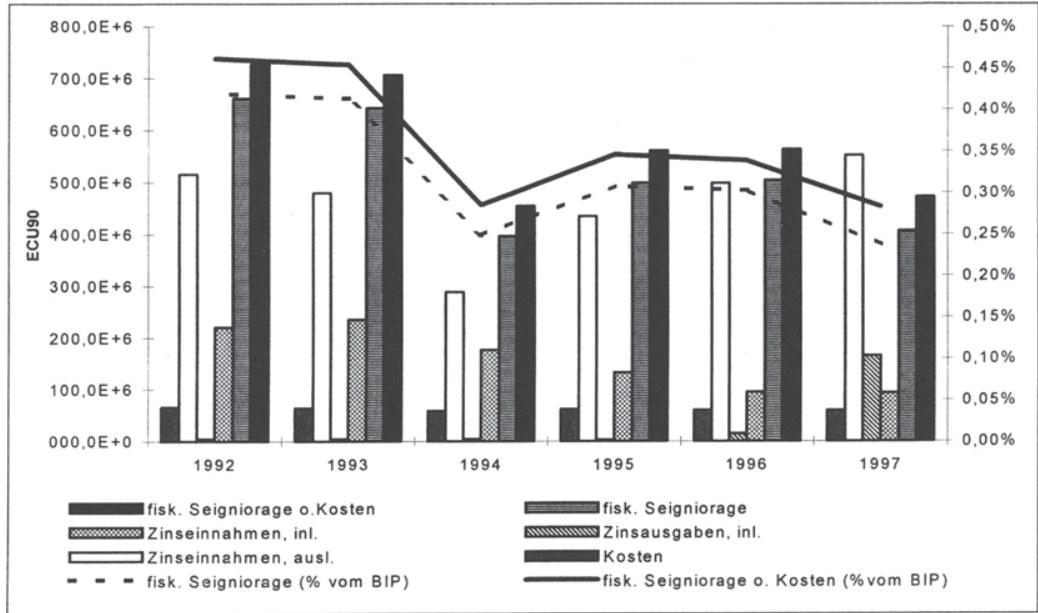

Quelle:

eigene Berechnungen, Geschäftsberichte der Banque Nationale de Belgique, verschiedene Jahrgänge 


\subsubsection{Ursachenanalyse}

7.2.2.1 Bestände aus Diskont-, Lombard- und Offenmarktgeschäften sowie Zinssätze

Die Bestände aus den Refinanzierungsgeschäften der belgischen Zentralbank spiegelt folgende Abbildung wieder:

Abbildung 7-20: Bestănde aus Diskont-, Lombard- und

Offenmarktgeschäften (Belgien)

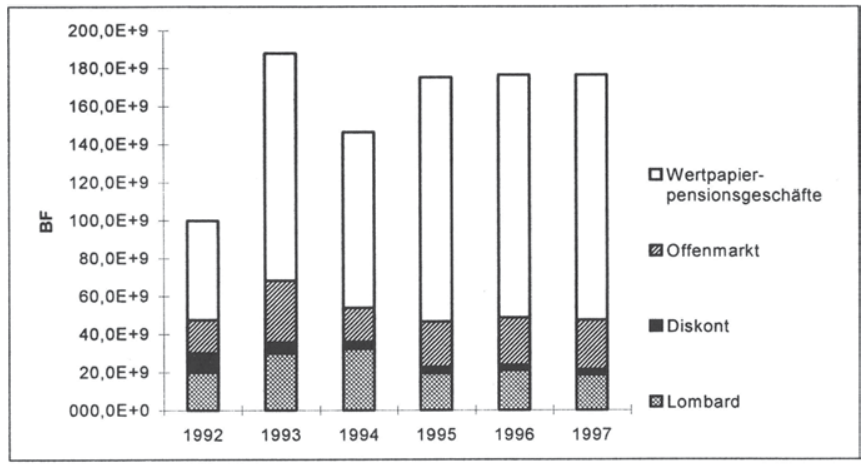

Quelle: $\quad$ eigene Berechnungen nach Geschäftsberichten der Banque Nationale de Belgique, verschiedene Jahrgänge

Abbildung 7-21: Zinssätze für Diskont, Lombard- und Offenmarktgeschäfte, Periodendurchschnitt (Belgien)

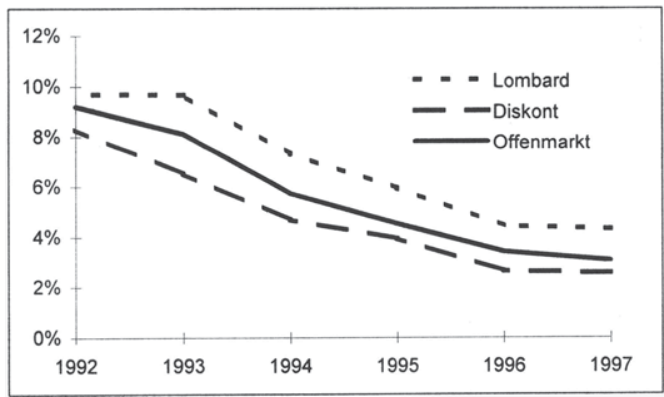

Quelle:

eigene Berechnungen nach Geschäftsberichten der Banque Nationale de Belgique, verschiedene Jahrgänge

Starke Veränderungen ergaben sich im Jahr 1993 vor allem durch den Anstieg der Bestände aus Wertpapierpensionsgeschäften von 52 auf $120 \mathrm{Mrd}$. BF. Der im darauffolgenden Jahr zu verzeichnende Rückgang wurde aber 1995 wieder fast vollständig aufgeholt, und seit 1995 verbleiben die gesamten Bestände auf knapp 180 Mrd. BF. Der Anstieg der Einnahmen 1993 läßt sich demnach mit der verstär- 
ken Refinanzierung der Geschäftsbanken bei der Zentralbank erklären. Der kontinuierliche Rückgang der Einnahmen erklärt sich allerdings nur aus den Verläufen der Zinsen, die Abbildung 7-21 zeigt.

Die Zinsen fielen im Beobachtungszeitraum von 9,21\% auf 3,06\% (Offenmarktzins), womit sich die ständig sinkenden Zinseinnahmen nach 1993 begründen lassen. Erst 1997 verlangsamte sich die Geschwindigkeit des Zinsrückgangs, was die nahezu unveränderte Höhe der inländischen Zinseinnahmen in diesem Jahr erklären kann.

Der Konvergenzeffekt läßt sich hier, da Schätzungen von Zinseinnahmen mit den in den Geschäftsberichten veröffentlichten Werten wenig übereinstimmen, nur über das Verhältnis der Offenmarktzinsen von 1992 und 1997 und die Zinseinnahmen von 1997 ( $\mathrm{vgl}$. 6.2.1) bestimmen. Danach beträgt der Konvergenzeffekt aus den Zinsänderungen für die Einnahmenseite rd. 9,4 Mrd. BF.

\subsubsection{Zins für liquiditätsabschöpfende Maßnahmen}

Die belgische Zentralbank bietet den Geschäftsbanken eine Einlagefazilität zur Verzinsung ihrer überschüssigen Zentralbankguthaben. Zudem wurden 1996 Wertpapiere der Zentralbank zu variablen Zinssätzen ausgegeben. Die daraus entstehenden Verbindlichkeiten und den Einlagezinssatz zeigt folgende Abbildung:

Abbildung 7-22: Verbindlichkeiten aus der Einlagenfazilität und Wertpapieren der Zentralbank (Belgien)

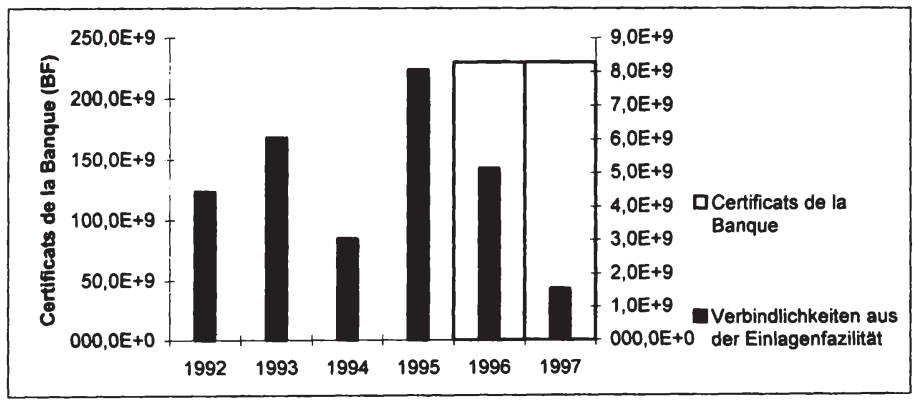

Quelle:

Geschäftsberichte der Banque Nationale de Belgique, verschiedene Jahrgänge

Der kontinuierliche Rückgang der Zinsausgaben läßt mit der Entwicklung der Bestände und dem Einlagenzinssatz nicht erklären. Zudem stimmen Schätzung und tatsächliche Angaben im Geschäftsbericht so wenig überein, daß davon ausgegangen werden muß, daß die dort angegeben Ausgaben keine reinen Zinsausgaben darstellen.

Ein Konvergenzeffekt läßt sich für die Zinsausgaben daher nur über die schon bei den Zinseinnahmen verwendete Methode berechnen. Aufgrund der sehr hohen Zinsausgaben in 1997 beträgt er 16,7 Mrd. BF. 


\subsubsection{Nachfrage nach Zentralbankgeld}

\section{Mindestreserven}

Da eine Mindestreserve in Belgien nicht existiert, kann die Nachfrage nach Zentralbankgeld von dieser Seite nicht beeinflußt werden.

Inflation

Die Preissteigerungsrate für Belgien reduzierte sich im Betrachtungszeitraum von $3,5 \%$ auf $1,36 \%$.

Abbildung 7-23: Preissteigerungsrate des BIP für Belgien

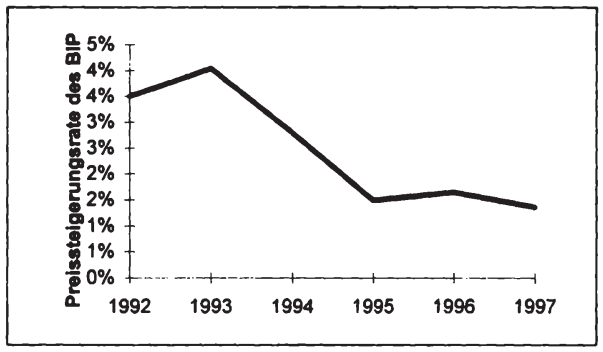

Quelle:

eurostat

Tabelle 7-3: Berechnung des Seigniorageverlusts aufgrund steigender Preisstabilität für Belgien

\begin{tabular}{|l|l|}
\hline ZBG97 & $527,3 \mathrm{E}+9$ \\
\hline C97 & $527,3 \mathrm{E}+9$ \\
\hline MR97 & $000,0 \mathrm{E}+0$ \\
\hline BIPn97 & $9,2 \mathrm{E}+12$ \\
\hline DMR97 & $000,0 \mathrm{E}+0$ \\
\hline BIPr90(97) & $7,3 \mathrm{E}+12$ \\
\hline PI92 & $3,50 \%$ \\
\hline mrs92 & $0,00 \%$ \\
\hline ZBG(97) & $478,6 \mathrm{E}+9$ \\
\hline d ZBG & $48,7 \mathrm{E}+9$ \\
\hline d Seigniorage (BF) & $4,5 \mathrm{E}+9$ \\
\hline Deflator97 & 126,25 \\
\hline d Seigniorage (BF90) & $3,6 \mathrm{E}+9$ \\
\hline d Seigniorage (ECU90) & $83,7 \mathrm{E}+6$ \\
\hline bzgl. BIP & $0,05 \%$ \\
\hline
\end{tabular}

Quelle:

eigene Berechnungen

Bei Konstanz der Preissteigerungsrate von 1992 (3,50\%) hätte die Nachfrage nach Zentralbankgeld 1997 nominal etwa 49 Mrd. BF mehr betragen als tatsächlich erreicht, so daß die Zinseinnahmen bei einem Offenmarktzinssatz von 9,21\% (1992) um 4,5 Mrd. BF höher ausgefallen wären. Bezogen auf 1990 ist dies - bei 
Anwendung des modifizierten Deflators 97 - ein realer Seigniorageverlust von 3,6 Mrd. BF90 jährlich (83,7 Mio. ECU90), bzw. 0,05\% des BIP.

\subsubsection{Kosten}

Da sich die Kosten im Zeitablauf nur wenig veränderten und zudem eine detaillierte Aufteilung in allgemeine Verwaltungskosten und Kosten für den Banknotendruck nicht möglich ist, wird eine genauere Kostenanalyse hier nicht vorgenommen.

\subsubsection{Währungsreserven}

Die Währungsreserven der belgischen Nationalbank stiegen im Beobachtungszeitraum etwa um das zweieinhalbfache. Betrugen die Bestände 1992 noch weniger als $200 \mathrm{Mrd}$. BF, so waren es 1997 mehr als $450 \mathrm{Mrd}$. BF.

Abbildung 7-24: Bestände an Währungsreserven der Banque National de Belgique

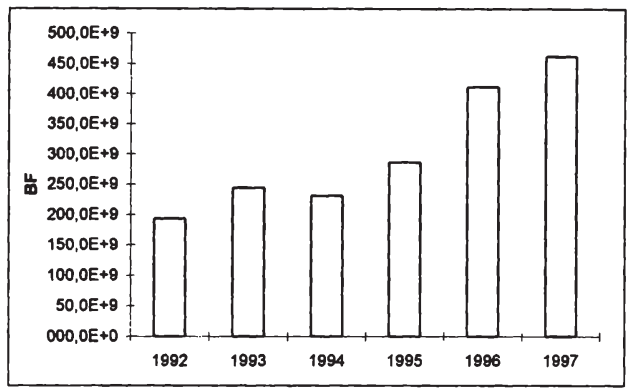

Quelle:

Geschäftsberichte der Banque Nationale de Belgique, verschiedene Jahrgänge

Allerdings läßt sich anhand der Bestände keine Erklärung für den Rückgang der Zinseinnahmen aus den Währungsreserven während der Jahre 1992 bis 1994 finden, da weitere Informationen über Portefeuille und Zinssätze den Geschäftsberichten nicht zu entnehmen sind.

\subsubsection{Gesamteffekt}

Tabelle 7-4: Konvergenzeffekt für Belgien

\begin{tabular}{|c|c|c|c|c|}
\hline & BF & BF90 & ECU90 & $\%$ vom BIP \\
\hline Differenz aus Zinsänderung Zinseinnahmen & $-9,4 E+9$ & $-7,5 E+9$ & $-176,4 E+6$ & $-0,1030 \%$ \\
\hline Zinsausgaben & $-16,7 E+9$ & $-13,2 E+9$ & $-311,1 E+6$ & $-0,1817 \%$ \\
\hline d potentielle Zinseinnahmen & $-4,5 E+9$ & $-3,6 E+9$ & $-83,7 E+6$ & $-0,0489 \%$ \\
\hline Konvergenzeffekt & $2,7 E+9$ & $2,2 \mathrm{E}+9$ & $51,0 E+6$ & $0,03 \%$ \\
\hline
\end{tabular}

Quelle: $\quad$ eigene Berechnungen

Der gesamte Konvergenzeffekt errechnet sich als Summe aus den Konvergenzeffekten für Zinseinnahmen und -ausgaben, die sich aus einer Veränderung der No- 
tenbankzinsen ergeben, sowie dem Konvergenzeffekt durch Verminderung der Mindestreservesätze und der Inflationsreduzierung.

Abbildung 7-25: Quantifizierter Konvergenzeffekt für Belgien

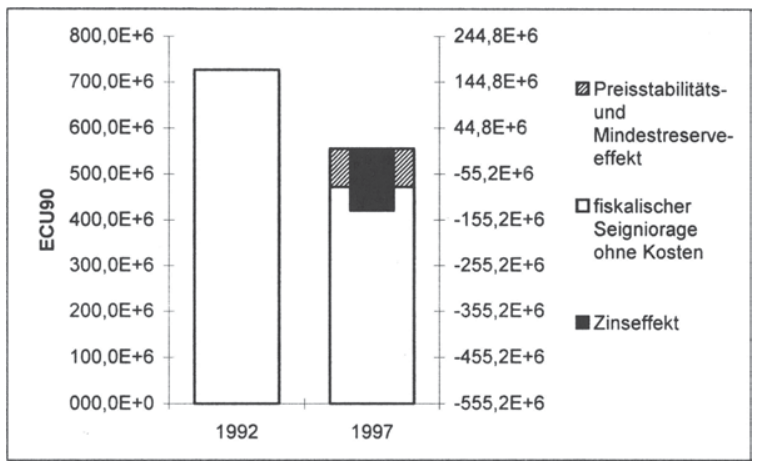

Quelle:

eigene Berechnungen

Der fiskalische Seigniorage würde demnach ohne Konvergenz geringer ausfallen als mit Konvergenz. Zwar hatte der Preisstabilitäts- und Mindestreserveeffekt einen negativen Einfluß auf den Seigniorage aber die Zinszahlungen auf die 1996 ausgegebenen Zentralbankpapiere waren so hoch, daß sie die höheren Zinseinnahmen und den Preisstabilitäts- und Mindestreserveeffekt mehr als kompensieren. Statt 471,5 Mio. ECU90 betrüge der Seigniorage ohne Konvergenzeffekte nur 420,5 Mio. ECU.

\subsection{Quantifizierung für Finnland}

\subsubsection{Quantifizierung des Konvergenzeffekts}

\subsubsection{Zinsertrag aus Forderungen gegen inländische Geschäftsbanken}

Die Zinserträge aus den Forderungen gegenüber den inländischen Geschäftsbanken haben sich von 2,8 Mrd. (1992) auf etwa 600 Mio. FIM (1997) reduziert. Ihre Entwicklung gibt Abbildung 7-26 wieder. Die Abbildung läßt erkennen, daß die Zinserträge aus der Refinanzierung über die Spitzenfazilität (Lombard) auch in Finnland quantitativ nur einen sehr geringen Anteil am gesamten Zinseinkommen ausmachten. Den größten Zinsanteil erzielen die Offenmarktgeschäfte (Outright-, Devisenswap- und Wertpapierpensionsgeschäfte). Die Einnahmen haben sich von 1992 bis 1996 auf weniger als ein fünftel reduziert. Erst 1997 stiegen sie erstmals wieder von 456 Mio. FIM auf 616 Mio. FIM. 
Abbildung 7-26: Zinserträge auf Forderungen an inländische Geschäftsbanken (Finnland)

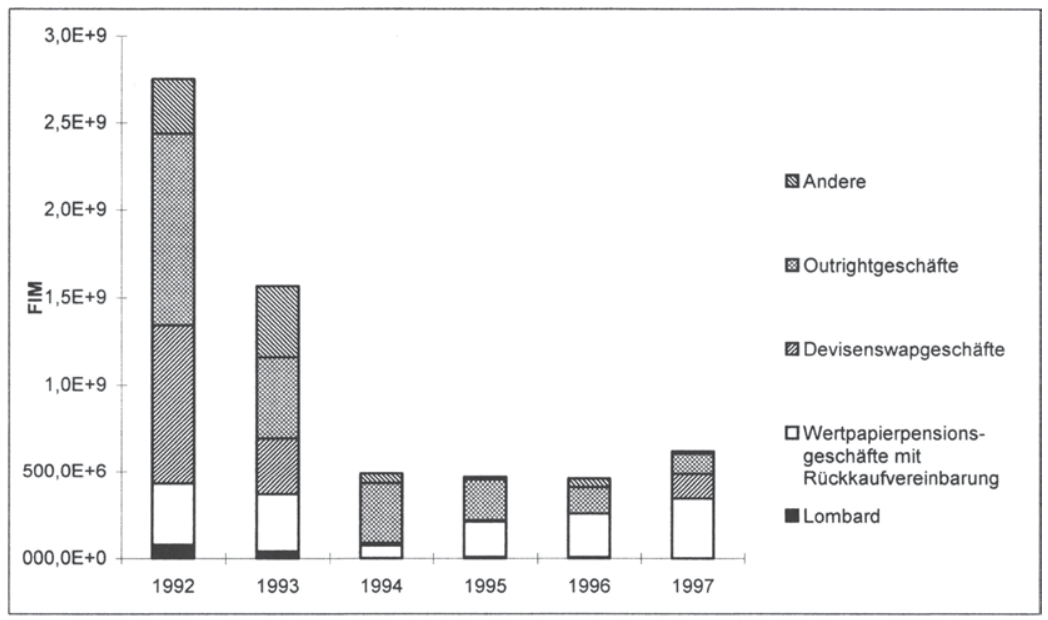

Quelle:

eigene Berechnungen nach Geschäftsberichten der Suomi Pannki

7.3.1.2 Zinsaufwand aus liquiditätsabschöpfenden Maßnahmen und der verzinsten Mindestreserve

Abbildung 7-27: Zinsaufwendungen liquiditätsabschöpfender Maßnahmen und verzinste Mindestreserve

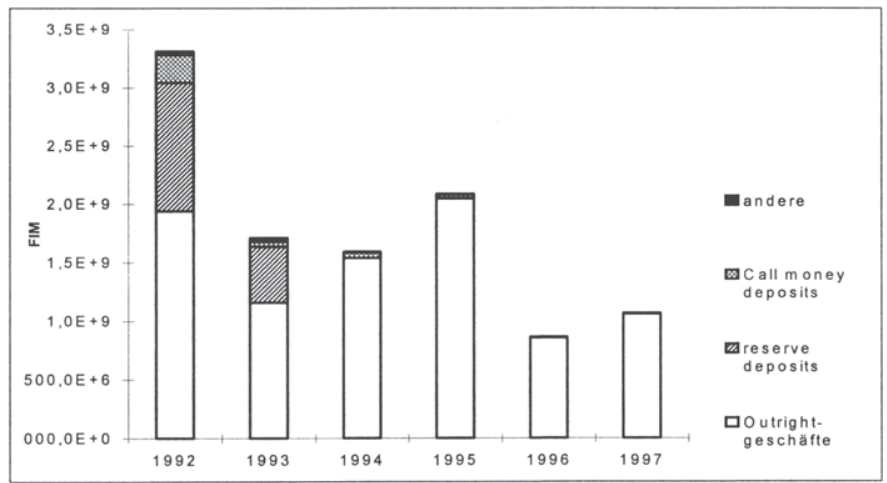

Quelle:

eigene Berechnungen nach Geschäftsberichten der Suomi Pankki, verschiedene Jahrgänge

Zur Liquiditätsabschöpfung bedient sich die finnische Zentralbank der Outrightgeschäfte, d.h. verkauft eigene Papiere (certificates of deposit). Zudem konnten fin- 
nische Geschäftsbanken bis 1995 überschüssiges Zentralbankgeld verzinslich bei der Zentralbank hinterlegen (Einlagefazilität, call money deposit).

Neben den Zinsen für diese Liquiditätspapiere und der Einlagefazilität entstanden der Zentralbank bis 1993 noch Zinsaufwendungen in Form einer verzinsten Mindestreserve (reserve deposit).

Insgesamt reduzierten sich die Zinsaufwendungen von 3,3 Mrd. FIM (1992) auf 1,1 Mrd. FIM (1997).

\subsubsection{Zinsertrag aus Währungsreserven}

Die Zinseinnahmen aus Währungsreserven schwankten im Beobachtungszeitraum zwischen 1,3 und 2,2 Mrd. FIM.

Abbildung 7-28: Zinseinnahmen aus Währungsreserven der Suomi Pannki

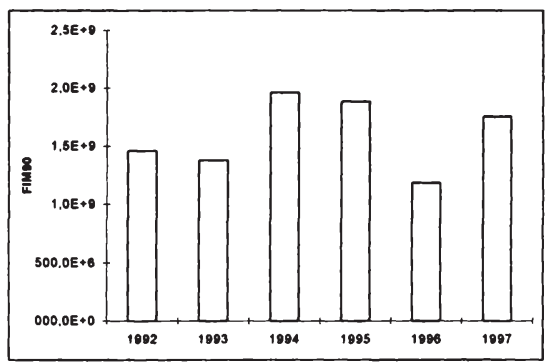

Quelle:

eigene Berechnungen nach

Geschäftsberichten der Suomi Pannki

\subsubsection{Kosten}

Die Kosten bewegten sich um 200 Mio. FIM, wobei die Anteile der allgemeinen Verwaltungskosten und die Kosten für den Notendruck stark schwankten.

Abbildung 7-29: Kosten für Notendruck und anteilige Verwaltungskosten der Suomi Pankki

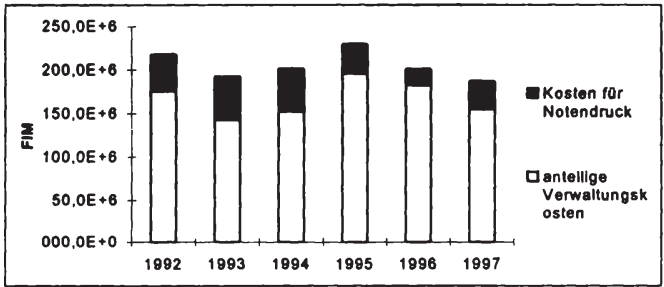

Quelle:

eigene Berechnungen nach

Geschäftsberichten der Suomi Pannki 


\subsubsection{Gesamteffekt}

Da die Zinsausgaben regelmäßig - und ab 1994 sehr deutlich - die Zinseinnahmen übertrafen, wurde der Seigniorage in Finnland insbesondere durch die Zinseinnahmen aus den Währungsreserven geprägt. Seit 1994 übertrifft diese Einnahmeart die Zinseinnahmen aus dem inländischen Geschäft vor allem aufgrund des deutlichen Einbruchs der inländischen Zinsen in diesem Jahr.

Abbildung 7-30: Fiskalischer Seigniorage und seine Entstehung für Finnland

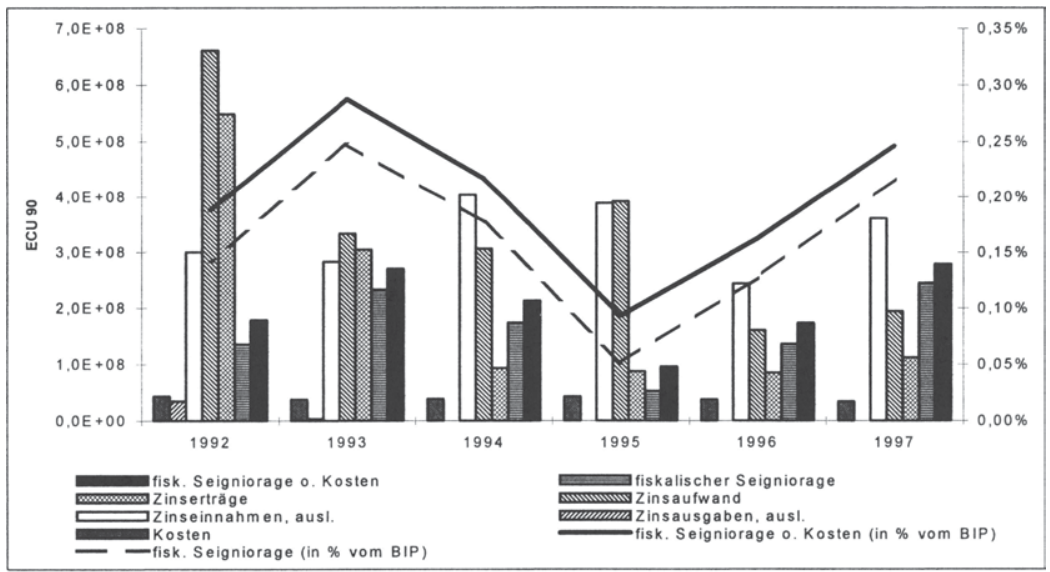

Quelle:

eigene Berechnungen nach Geschäftsberichten der Suomi Pankki und eurostat

\subsubsection{Ursachenanalyse}

\subsubsection{Zins aus Lombard- und Offenmarktgeschäften}

Abbildung 7-31: Bestände aus geldpolitischen Operationen und Zinssätze der Suomi Pankki

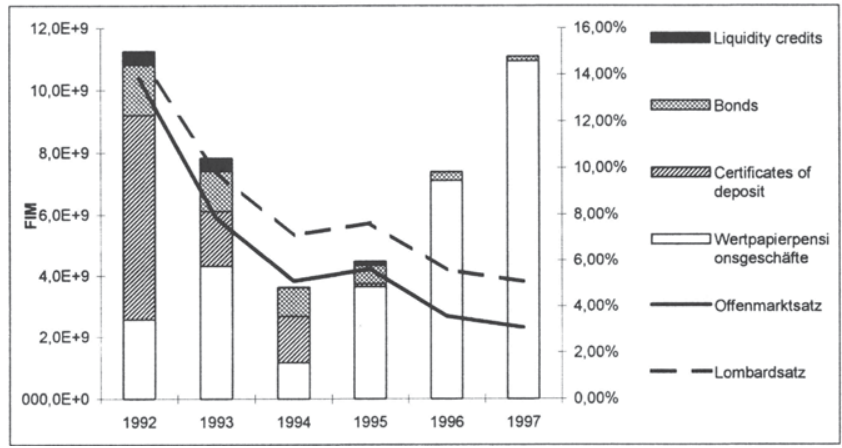

Quelle:

Geschäftsberichte der Suomi Pankki, eurostat 
In der folgenden Abbildung sind die Bestände aus den Refinanzierungsgeschäften der finnischen Zentralbank und die zugehörigen Zinssätze dargestellt. Deutlich wird der zunehmende Anteil der Wertpapierpensionsgeschäfte mit Rückkaufvereinbarung, während die übrigen Refinanzierungsinstrumente kaum mehr zur Anwendung kommen. Der Rückgang der Zinseinnahmen läßt sich im Vergleich zwischen 1992 und 1997 eindeutig auf eine Senkung der Zinssätze zurückführen, da die Summe der Bestände in beiden Jahren gleich sind, während die Zinsen nur noch ein Fünftel des Ausgangsniveaus erreichen.

Da sich der Zinsertrag nicht genügend genau anhand der Bestände schätzen läßt, muß der Zinseffekt auf die Zinseinnahmen anhand der Methode 2 berechnet werden (vgl. 6.2.1). Der Zinseffekt beträgt dann 2,2 Mrd. FIM bei 617 Mio. FIM Zinseinnahmen in 1997.

\subsubsection{Zins zur Liquiditätsabschöpfung und Verzinsung der Mindestreserve}

Abbildung 7-32: Bestände von liquiditätsabschöpfenden Instrumenten und Mindestreserve sowie die entsprechenden Zinssätze

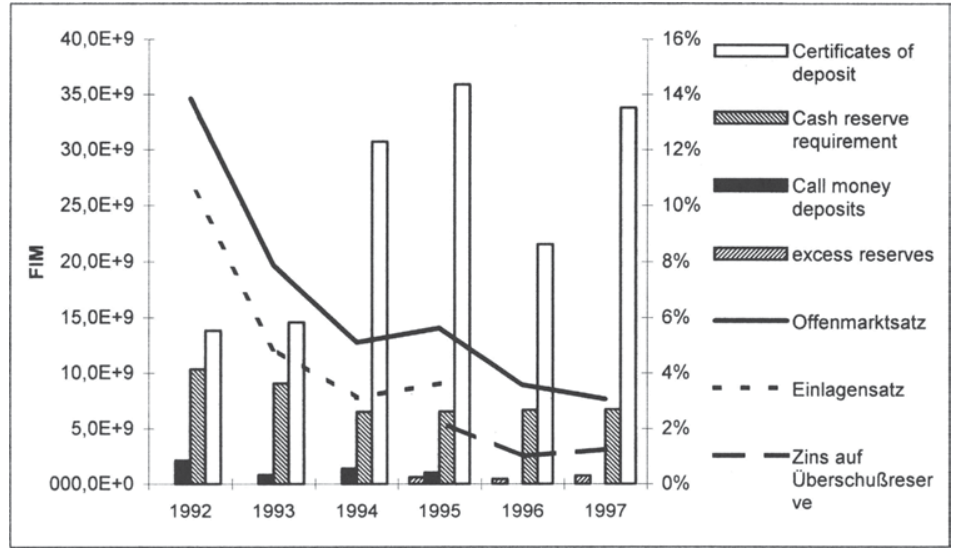

Quelle:

eigene Berechnungen nach Geschäftsberichten der Suomi

Pankki, verschiedene Jahrgänge

Die Abbildung zeigt den deutlichen Anstieg der ausgegebenen Wertpapiere zur Liquiditätsabschöpfung im Jahre 1994, der dazu geführt hat, daß trotz dem Wegfall der Mindestreserveverzinsung und eines sinkenden Zinssatzes die Zinsaufwendungen in diesem Jahr annähernd konstant blieben. Erst 1996 konnte die Liquiditätsabschöpfung soweit zurückgeführt werden, daß zusammen mit dem weiter sinkenden Offenmarktzinssatz eine deutliche Senkung der Zinsaufwendungen verzeichnet werden konnte. Da sich die Zinsaufwendungen genügend genau schätzen lassen (vgl. Abbildung 7-33), läßt sich hier für 1997 eine Schätzung der potentiellen Zinsaufwendungen anstellen, indem die Zinssätze von 1992 auf die Passivbestände von 1997 angewendet werden. Zudem wird unterstellt, die Min- 
destreserve sei weiterhin verzinslich. Dann würden die Zinsausgaben 5,5 Mrd. FIM betragen, bzw. 1 Mrd. ECU90, das entspricht 0,88 \% des BIP. Der Konvergenzeffekt auf die Zinsausgaben beträgt demnach 4,4 Mrd. FIM bzw. 0,7 \% des BIP.

Abbildung 7-33: Schätzung der Zinsaufwendungen

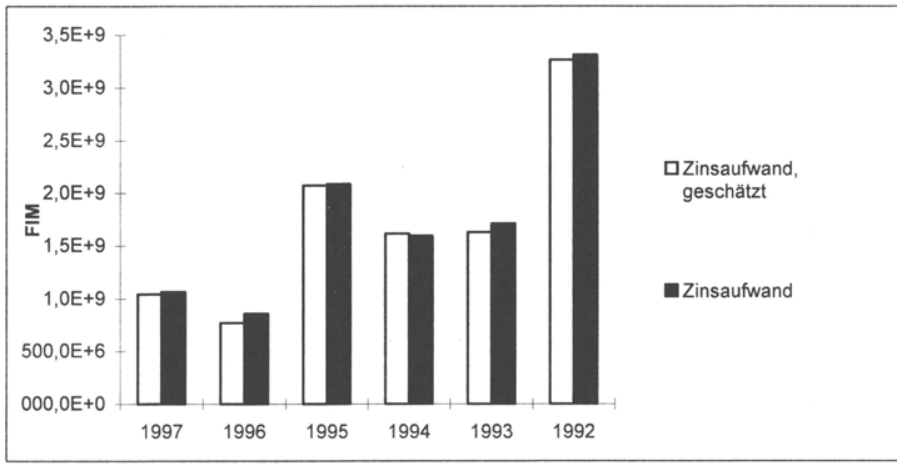

Quelle:

eigene Berechnungen nach Geschäftsberichten der Suomi Pankki, verschiedene Jahrgänge

\subsubsection{Nachfrage nach Zentralbankgeld}

\section{Mindestreserven}

Den Rückgang der Reserven und den durchschnittlichen Mindestreservesatz zeigt die folgende Abbildung:

Abbildung 7-34: Mindestreservehaltung der Geschäftsbanken in Finnland

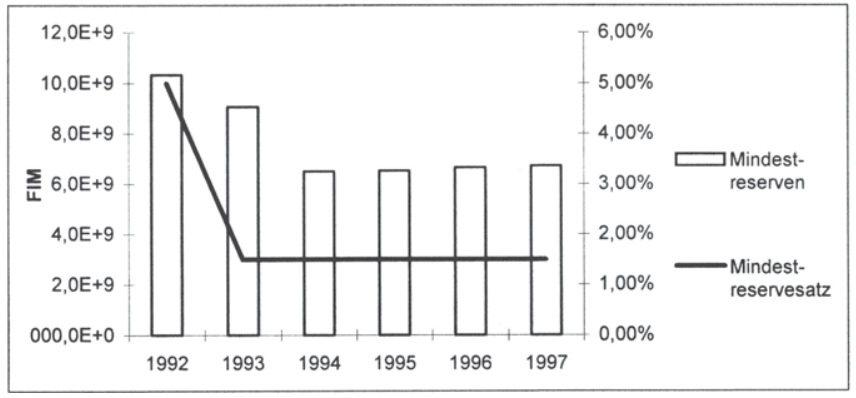

Quelle:

Geschäftsbericht der Suomi Pankki, verschiedene Jahrgänge

Der Mindestreservesatz wurde Mitte des Jahres 1993 von $5 \%$ auf durchschnittlich $1,5 \%$ gesenkt. Gleichzeitig wurden die reservepflichtigen Einlagen neu bestimmt. Dadurch reduzierte sich die Reservehaltung der Geschäftsbanken bis 1994 von 10,3 Mio. FIM (1992) auf 6,5 Mio. FIM. Nach 1994 blieb die Mindestre- 
servehaltung gleich, so daß man davon ausgehen kann, daß sich auch die reservepflichtigen Einlagen nicht verändert haben ${ }^{15}$. Hätten 1997 die gleiche Mindestreservepflicht und die gleichen Zinssätze bestanden wie 1992, so hätte diese einen zusätzlichen Seignioragebeitrag erbringen können, und zwar in Höhe der Differenz zur heutigen Mindestreservehöhe, verzinst um die Differenz zwischen Offenmarktsatz und Einlagensatz von 1992. Dies bedeutete einen Seignioragezugewinn von ca. 108 Mio. FIM, bzw. 20 Mio. ECU90 (0,02 \% vom BIP).

\section{Inflation}

Die Veränderung der Preissteigerungsrate im Betrachtungszeitraum zeigt die folgende Abbildung:

Abbildung 7-35: Jährliche Preissteigerungsrate des BIP (Finnland)

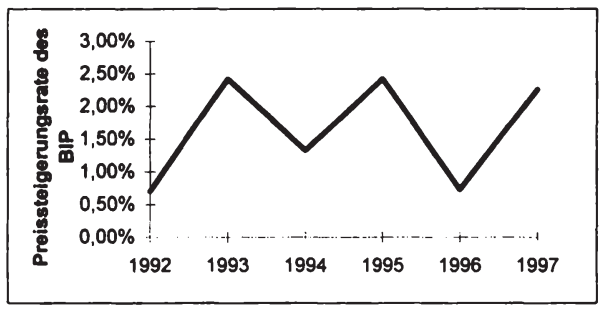

Quelle: $\quad$ eurostat

Da sich hier kein Trend der Entwicklung der Preisstabilität zeigt, wird an dieser Stelle auf die Analyse der Auswirkungen auf die Geldnachfrage verzichtet. Zudem werden auch die übrigen Teileffekte der Konvergenz mit dem Deflator von 1997 auf die Basis 1990 bezogen, ohne einen modifizierten Deflator97 zu verwenden.

\subsubsection{Kosten}

Der Verlauf der Kosten läßt auch in diesem Fall keinen Rückschluß auf eine Veränderung durch geldpolitische Maßnahmen $z u$, weshalb eine Ursachenanalyse nicht weiter verfolgt wird.

\subsubsection{Währungsreserven}

Abbildung 7-36 zeigt die Bestände an Währungsreserven zwischen 1992 und 1997.

Der Verlauf der Währungsreserven spiegelt etwa den Verlauf der Zinseinnahmen aus diesen wieder. Ohne Zinsanalyse lassen sich allerdings auch hier keine weiteren Einflüsse auf den fiskalischen Seigniorage erkennen.

15 Die Geschäftsberichte der finnischen Zentralbank treffen keine Aussagen über die Höhe der mindestreservepflichtigen Einlagen bei Geschäftsbanken. 
Abbildung 7-36: Währungsreserven der finnischen Zentralbank

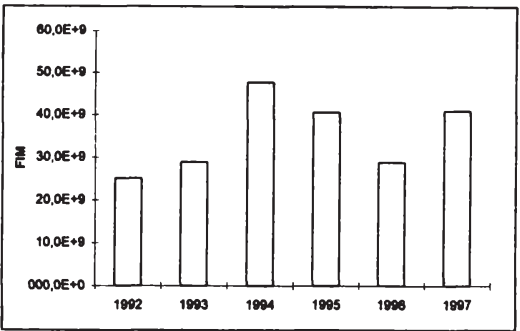

Quelle: $\quad$ Geschäftsbericht der Suomi

Pankki, verschiedene Jahrgänge

\subsubsection{Gesamteffekt}

Der gesamte Konvergenzeffekt errechnet sich als Summe aus den Konvergenzeffekten für Zinseinnahmen und -ausgaben, die sich aus einer Veränderung der Notenbankzinsen ergeben, sowie dem Konvergenzeffekt durch Verminderung der Mindestreservesätze.

Abbildung 7-37: Quantifizierter Konvergenzeffekt für Finnland

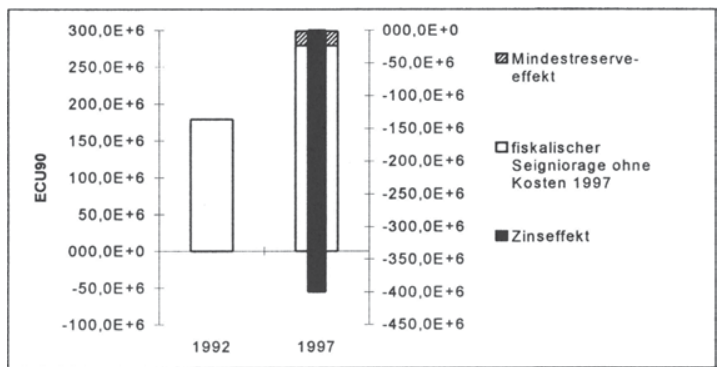

Quelle: $\quad$ eigene Berechnungen nach Geschäftsberichten der Suomi Pankki und eurostat, verschiedene Jahrgänge

Aus der höheren Mindestreserve hätte sich zwar nach Abzug ihrer Verzinsung für 1997 ein Plus von 20 Mio. ECU90 eingestellt, der Zinseffekt hätte allerdings für Mehrausgaben von 400 Mio. gesorgt, so daß der fiskalische Seigniorage ohne Konvergenz sogar negativ ausgefallen wäre (-100 Mio. ECU90).

Tabelle 7-5: Konvergenzeffekt für Finnland

\begin{tabular}{|llrrrr|}
\hline & & FM & \multicolumn{1}{c}{ FIMPO } & ECU90 & \% vom BIP \\
\hline aus Znsänderungen & dZnseimahmen & $-2,2 E+9$ & $-1,9 E+9$ & $-394,7 E+6$ & $-0,35 \%$ \\
& d Znsausgaben & $-4,4 E+9$ & $-3,9 E+9$ & $-794,4 E+6$ & $-0,70 \%$ \\
aus d mis und dPI & d potentielle Znseinnahmen & $-108,3 E+6$ & $-95,8 E+6$ & $-19,7 E+6$ & $-0,02 \%$ \\
\hline Konvergerveffelt & & $2,1 E+9$ & $1,8 E+9$ & $380,0 E+6$ & $0,34 \%$ \\
\hline
\end{tabular}

Quelle.

eigene Berechnungen 


\subsection{Quantifizierung für Frankreich}

\subsubsection{Quantifizierung des Konvergenzeffekts}

7.4.1.1 Zinsertrag, Zinsaufwand im inländischen Kreditgeschäft und anteilige Kosten

Die Zinseinnahmen erhöhten sich zunächst 1993 von 13,4 Mrd. FRF auf knapp 18,6 Mrd. FRF, um anschließend kontinuierlich auf 4,1 Mrd. FRF (1997) zu sinken.

Abbildung 7-38: Zinsertrag, Zinsaufwand und anteilige Kosten (Frankreich)

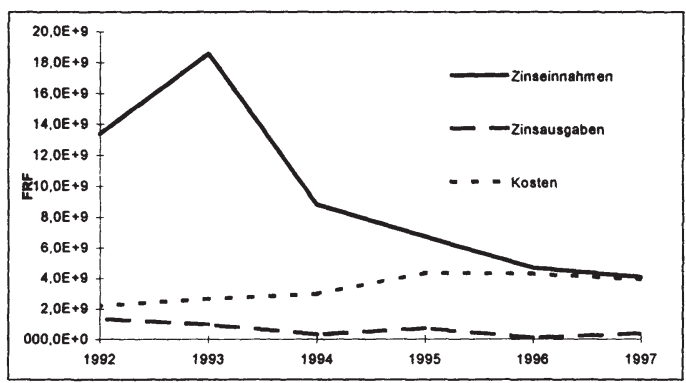

Quelle: Geschäftsberichte der Banque de France, verschiedene Jahrgänge

Dagegen blieben die Zinsausgaben mit Werten, die nur zu Beginn des Betrachtungszeitraumes über $1 \mathrm{Mrd}$. lagen, unbedeutend. Die anteiligen Kosten stiegen dagegen von anfänglich $2 \mathrm{Mrd}$. FRF auf $4 \mathrm{Mrd}$. FRF an, so daß die Zinseinnahmen 1997 gänzlich aufgezehrt wurden.

\subsubsection{Zinsgewinne aus den Währungsreserven}

Die Zinseinnahmen aus den Währungsreserven bewegten sich im Beobachtungszeitraum zwischen 5 und 7,6 Mrd. FRF90. Eine Tendenz ist im Zeitverlauf nicht zu erkennen. Die Zinsausgaben blieben bis auf 1994 (3,8 Mrd. FRF90) deutlich unter den Einnahmen.

Abbildung 7-39: Zinseinnahmen und -ausgaben aus den Währungsreserven

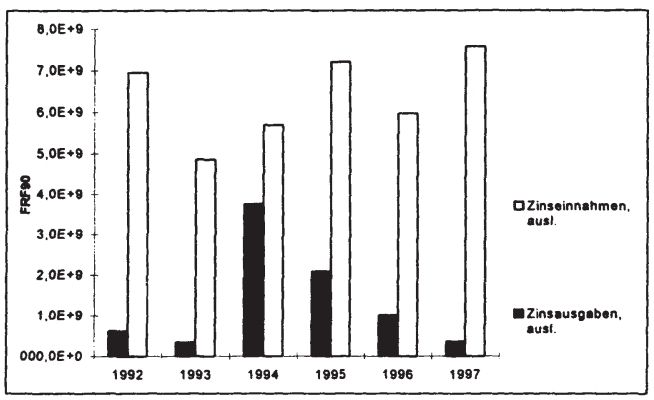

Quelle:

Geschäftsberichte der Banque de France, verschiedene Jahrgänge 


\subsubsection{Gesamteffekt}

Der fiskalische Seigniorage Frankreichs wird im wesentlichen von den inländischen Zinseinnahmen der Notenbank geprägt. So betrug er (ohne Berücksichtigung der Kosten) 1992 und 1993 noch 2,6 bzw. 3 Mrd. ECU90. Nach dem deutlichen Rückgang der inländischen Zinseinnahmen sinkt allerdings auch der Seigniorage 1994 auf 1,4 Mrd. ECU90, um dort bis 1997 zu verharren.

Abbildung 7-40: Fiskalischer Seigniorage und seine Entstehung für Frankreich

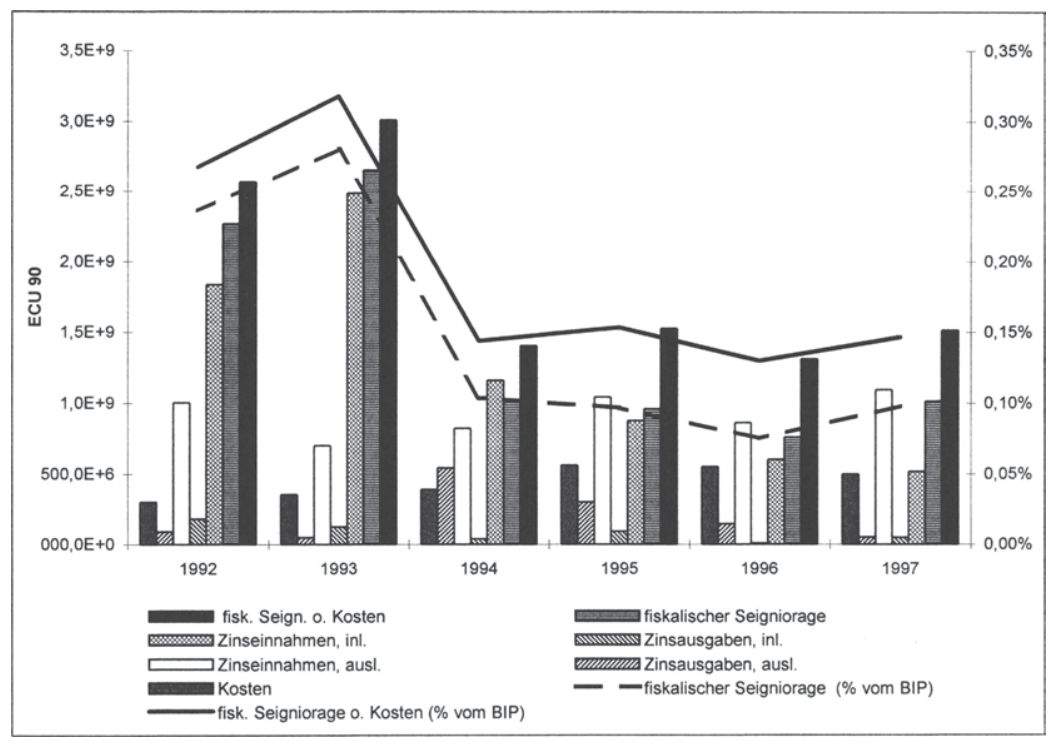

Quelle:

eigene Berechnungen, Geschäftsberichte der Banque de France, verschiedene Jahrgänge

\subsubsection{Ursachenanalyse}

\subsubsection{Bestände aus Diskont-, Lombard- und Offenmarktgeschäften}

Die Betrachtung der Bestände aus den Refinanzierungsgeschäften macht zunächst den Anstieg der Zinserträge im Jahre 1993 erklärlich. Auch das starke Absinken der Erträge 1994 und 1995 läßt sich hier durch den Rückgang der Bestände aus den Refinanzierungsgeschäften erklären. Das weitere Absinken der Zinserträge nach 1995 trotz konstanten Beständen aus den Refinanzierungsgeschäften wird allerdings erst bei einem Blick auf die Notenbankzinsen verständlich, die 1995 noch bei 6,9\% (Zinssatz für Refinanzierungsgeschäfte von 5 bis 10 Tagen) bzw. knapp $5 \%$ (REPO Tender Satz) lagen und bis 1997 auf 4,6 bzw. $3,1 \%$ sanken. 
Abbildung 7-41: Bestände aus Refinanzierungsgeschäften (Frankreich)

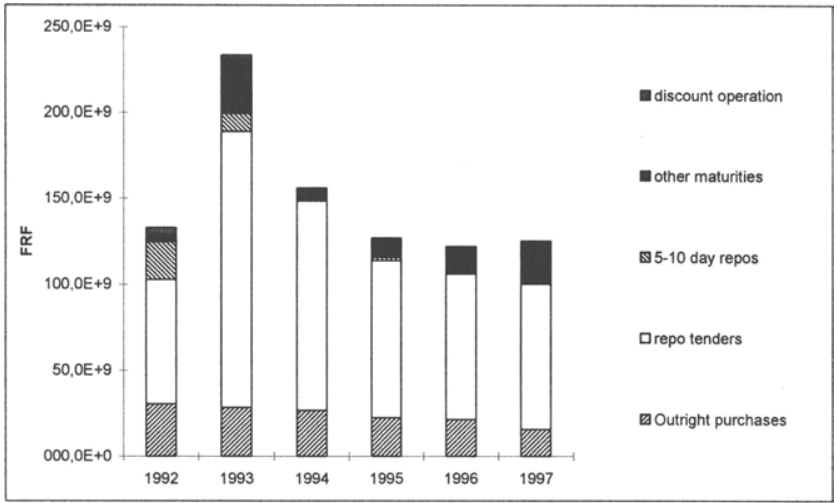

Quelle: $\quad$ eigene Berechnungen nach Geschăftsberichten der Banque de France, verschiedene Jahrgänge

Abbildung 7-42: Zinssätze für Refinanzierungsgeschäfte, Periodendurchschnitt (Frankreich)

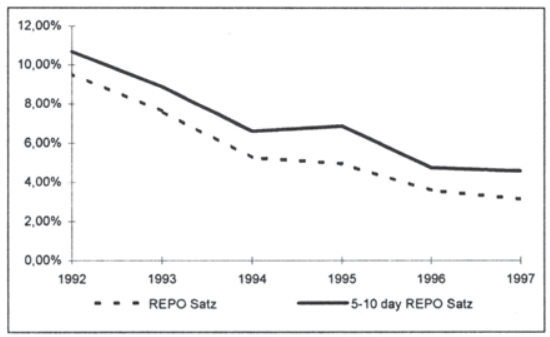

Quelle:

eigene Berechnungen nach Geschäftsberichten der Banque de France, verschiedene Jahrgänge

Die Quantifizierung des Zinseffekts auf die Zinserträge läßt sich mit Hilfe der Bestände aus den Refinanzierungsgeschäften durchführen, da sich die Zinseinnahmen hinreichend gut mit den Beständen und Notenbankzinsen erklären lassen:

Abbildung 7-43: Schätzung der Zinseinnahmen

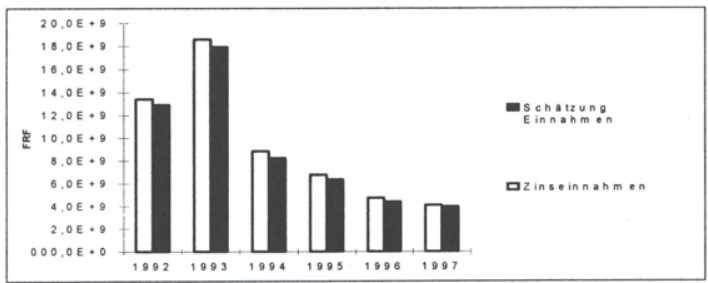

Quelle:

eigene Berechnungen nach Geschäftsberichten der Banque de France, verschiedene Jahrgänge 
Danach hätte die Banque de France ohne eine Konvergenz der Zinsen 8 Mrd. FRF mehr an Einnahmen aus dem inländischen Geschäft ziehen können gegenüber tatsächlichen Einnahmen in 1997 von etwa 4 Mrd. FRF.

\subsubsection{Zins für liquiditätsabschöpfende Maßnahmen}

Die Banque de France bedient sich zur Liquiditätsabschöpfung der Wertpapierpensionsgeschäfte und der Interventionen am Geldmarkt. Die daraus entstehenden Verbindlichkeiten und den darauf zu zahlende Zinssatz zeigt folgende Abbildung:

Abbildung 7-44: Verbindlichkeiten aus liquiditätsabschöpfenden Maßnahmen und dem Zinssatz (Frankreich)

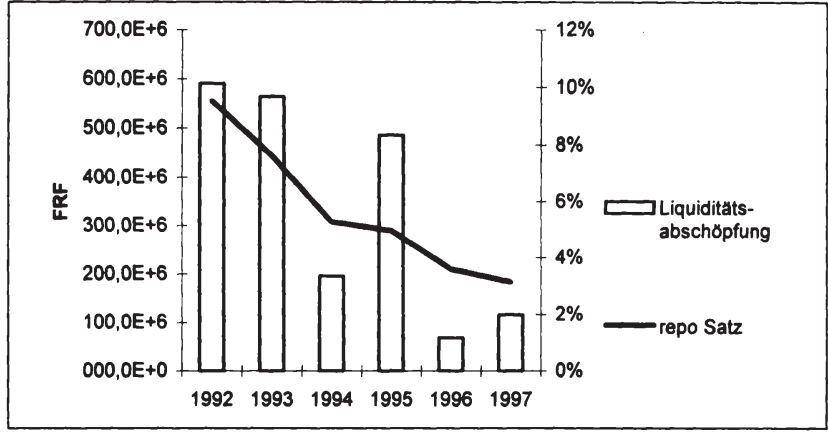

Quelle:

Geschäftsberichte der Banque Nationale de France, verschiedene Jahrgänge

Der Verlauf der Zinsausgaben erklärt sich im wesentlichen aus dem Volumen der liquiditätsabschöpfenden Maßnahmen; der kontinuierlich sinkende Zinssatz führte parallel dazu zu einem Absinken des Ausgabenniveaus.

Abbildung 7-45: Schätzung der Zinsausgaben

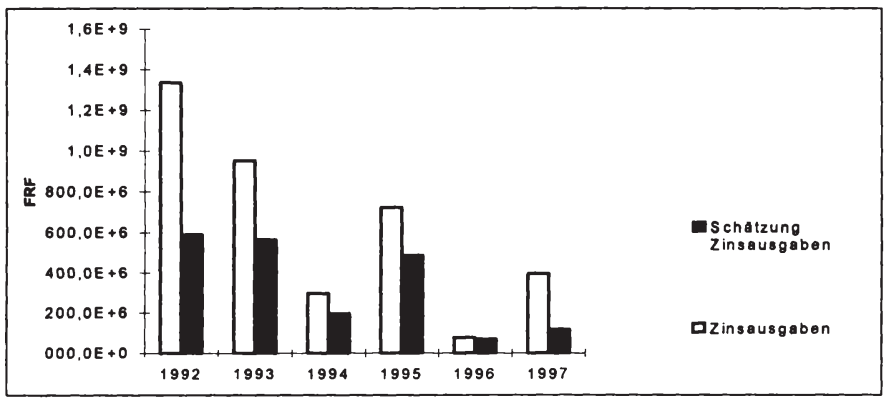

Quelle: eigene Berechnungen nach Geschäftsberichten der Banque de France, verschiedene Jahrgänge 


\subsubsection{Nachfrage nach Zentralbankgeld}

\section{Mindestreserven}

Die Mindestreservesätze für Sicht- und Spareinlagen wurden 1992 reduziert, so daß die durchschnittliche Mindestreserve - hier der Monatsdurchschnitt 15. Januar bis 15. Februar - 1993 von 47 auf 18,6 Mrd. FRF fiel. In den anschließenden Jahren stieg er leicht bis auf 20,2 Mrd. FRF (1997) an. Zur Schätzung des Konvergenzeffekts aus der Mindestreserve fehlen allerdings in den Geschäftsberichten der Banque de France die Angaben über die mindestreservepflichtigen Einlagen bei den Geschäftsbanken. Daher wird dieser Konvergenzeffekt durch die verzinste Differenz der Einlagen aus der Mindestreservepflicht von 1992 und 1993 angenähert. D.h. es wird angenommen, daß bei Konstanz der Mindestreservesätze die Mindestreserve 1997 um die Differenz zwischen 1992 und 1993 höher gelegen hätte.

\section{Abbildung 7-46: Mindestreserven und Mindestreservesätze (Frankreich)}

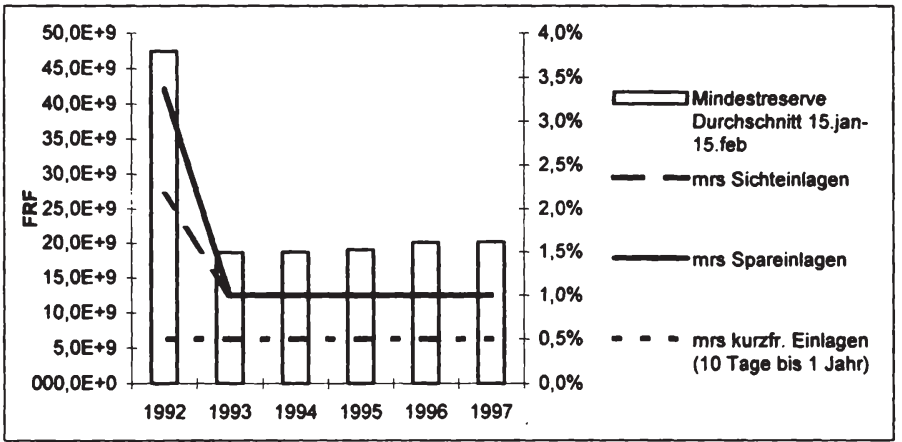

Quelle: $\quad$ eigene Berechnungen nach Geschäftsberichten der Banque de France, verschiedene Jahrgänge

Statt den tatsächlichen 20,2 Mrd. FF wären 1997 demnach 49 Mrd. FF Mindestreserve zu verzeichnen gewesen.

\section{Inflation}

Die Preissteigerungsrate für Frankreich stieg im Betrachtungszeitraum zunächst von $2,1 \%$ auf $2,46 \%$ an, anschließend reduzierte sie sich bis auf $0,89 \%$ in 1997.

Bei Konstanz der Preissteigerungsrate von 1992 (2,10\%) wäre die Nachfrage nach Zentralbankgeld 1997 nominal etwa 56 Mrd. FF höher ausgefallen als sie tatsächlich betragen hat. Die zusätzlichen Zinseinnahmen bei einem Offenmarktzinssatz von 9,53\% (Offenmarktsatz von 1992) hätten dann 5,4 Mrd. FF betragen. Bezogen auf 1990 (mit Hilfe des modifizierten Deflators97) entspricht 
dies einem realen Seigniorageverlust von 4,5 Mrd. FF90 jährlich (647 Mio. ECU90), bzw. 0,06 \% des BIP.

Abbildung 7-47: Preissteigerungsrate des BIP für Frankreich

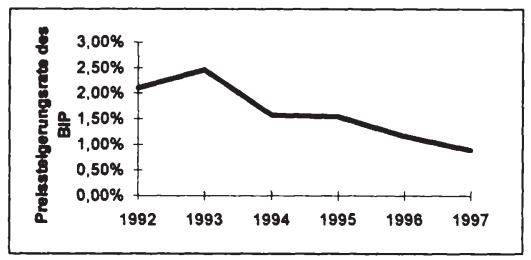

Quelle:

eurostat

Tabelle 7-5: Berechnung des Seigniorageverlusts aufgrund steigender Preisstabilität für Frankreich

\begin{tabular}{|l|l|}
\hline ZBG97 & $344,1 \mathrm{E}+9$ \\
\hline C97 & $295,1 \mathrm{E}+9$ \\
\hline MR97 & $49,0 \mathrm{E}+9$ \\
\hline BIPn97 & $8,3 \mathrm{E}+12$ \\
\hline DMR97 & $000,0 \mathrm{E}+0$ \\
\hline BIPr90(97) & $7,1 \mathrm{E}+12$ \\
\hline PI92 & $2,10 \%$ \\
\hline mrs92 & $?$ \\
\hline ZBG(97) & $287,6 \mathrm{E}+9$ \\
\hline d ZBG & $56,4 \mathrm{E}+9$ \\
\hline d Seigniorage (FF) & $5,4 \mathrm{E}+9$ \\
\hline Deflator97 & 120,16 \\
\hline FF90 & $4,5 \mathrm{E}+9$ \\
\hline ECU90 & $647,0 \mathrm{E}+6$ \\
\hline \%vom BIP & $0,06 \%$ \\
\hline
\end{tabular}

Quelle

eigene Berechnungen

\subsubsection{Kosten}

Da sich die Kosten im Zeitablauf nur wenig veränderten und zudem eine detaillierte Aufteilung in allgemeine Verwaltungskosten und Kosten für den Banknotendruck nicht möglich ist, wird eine genauere Kostenanalyse hier nicht vorgenommen.

\subsubsection{Währungsreserven}

Die Währungsreserven der Banque de France beliefen sich im Beobachtungszeitraum auf 70 bis $106 \mathrm{Mrd}$. FRF, wobei sie einen ähnlichen Verlauf annahmen wie die zugehörigen Zinseinnahmen aus den Währungsreserven. Allerdings fehlen zu einer vollständigen Ursachenanalyse die Informationen über Zusammensetzung und Verzinsung der Währungsreserven. 
Abbildung 7-48: Währungsreserven der Banque de France

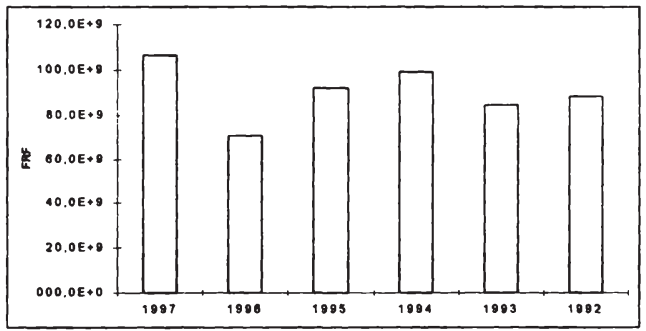

Quelle: $\quad$ Geschäftsbericht der Banque de France, verschiedene Jahrgänge

\subsubsection{Gesamteffekt}

Der gesamte Konvergenzeffekt errechnet sich als Summe aus den Konvergenzeffekten für Zinseinnahmen und -ausgaben, die sich aus einer Veränderung der Notenbankzinsen ergeben, sowie dem Konvergenzeffekt durch Verminderung der Mindestreservesätze und der Inflationsreduzierung.

Tabelle 7-6: Konvergenzeffekt für Frankreich

\begin{tabular}{|llrrrr|}
\hline & & FRF & \multicolumn{1}{c}{ FRF90 } & ECU90 & \% vom BIP \\
\hline aus Zinsănderungen & d Zinseinnahmen & $-8,0 E+9$ & $-6,7 E+9$ & $-962,4 E+6$ & $-0,0932 \%$ \\
& d Zinsausgaben & $-799,2 E+6$ & $-665,1 E+6$ & $-96,2 E+6$ & $-0,0093 \%$ \\
aus d mrs und d PI & d potentielle Zinseinnahmen & $-5,4 E+9$ & $-4,5 E+9$ & $-647,0 E+6$ & $-0,0626 \%$ \\
\hline Konvergenzeffekt & & $-12,6 E+9$ & $-10,5 E+9$ & $-1,5 E+9$ & $-0,15 \%$ \\
\hline
\end{tabular}

Quelle:

eigene Berechnungen

Der gesamte Zinseffekt beträgt demnach 866 Mio. ECU90; hinzu kommt der Effekt aus der Verminderung der Mindestreserve und der Inflationsrate von 647 Mio. ECU90, wodurch der fiskalische Seigniorage ohne Konvergenz $3 \mathrm{Mrd}$. ECU90 (0,3\% des BIP) statt tatsächlichen 1,5 Mrd. ECU90 hätte betragen können.

Abbildung 7-49: Quantifizierter Konvergenzeffekt für Frankreich

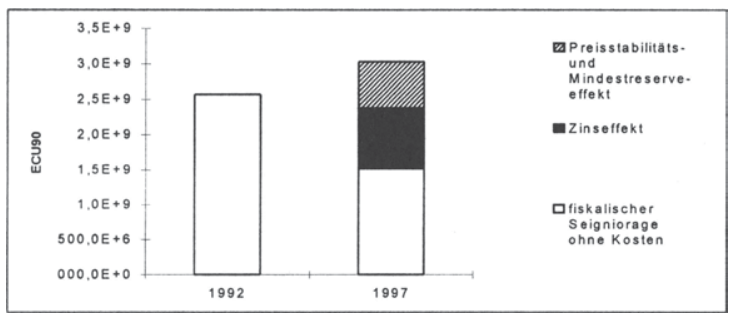

Quelle:

eigene Berechnungen 


\subsection{Quantifizierung für Irland}

\subsubsection{Quantifizierung des Konvergenzeffekts}

\subsubsection{Einnahmen, Ausgaben und Kosten aus dem inländischen Geschäft}

Die Zinsen aus dem inländischen Refinanzierungsgeschäft lassen sich für die Jahre 1992 und 1993 nicht explizit aus den gesamten Einnahmen aus dem inländischen Geschäft herausfiltern, da die Geschäftsberichte für diese Jahre nicht den gewünschten Detailierungsgrad aufweisen. Deshalb werden für den gesamten Beobachtungszeitraum zunächst alle Einnahmen und Ausgaben aus inländischen Anlagen betrachtet.

Bei den gesamten Einnahmen sind neben Zinsen und Coupons auch Aufwertungsgewinne und Abwertungsverluste der inländischen Papiere enthalten, deren Anteil sich aber nur zwischen $0 \%$ und 3,5 \% (1995) bewegt, weshalb die gesamten Einnahmen auch für die weiteren Analysen als Näherung an die Zinseinnahmen aus dem Refinanzierungsgeschäft dienen soll. Bei den Ausgaben ist neben den Zinsen für Einlagen der Kreditinstitute allerdings auch ein beträchtlicher Anteil an Zinsen an den Staat enthalten.

Abbildung 7-50: Einnahmen, Ausgaben und Kosten

des inländischen Zentralbankgeschäfts (Irland)

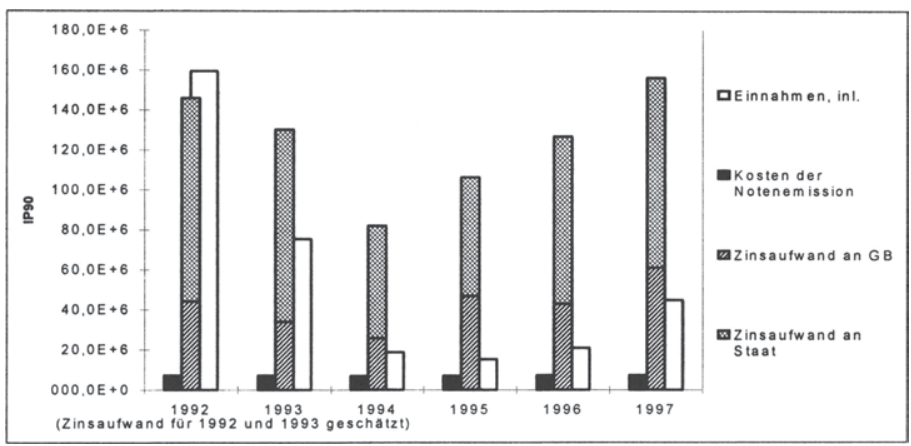

Quelle:

eigene Berechnungen nach Geschäftsberichten der Central Bank of Ireland

Da aber gerade die Zinsausgaben an den Staat keinen Einnahmeverlust im Sinne des fiskalischen Seigniorage darstellt, wurde für die Jahre 1992 und 1993 eine Schätzung der Einnahmen und Ausgaben mit Hilfe der Zinssätze und Einlagen des Staates bei der Zentralbank durchgeführt.

Bis 1993 hat demnach der inländische Zinsaufwand an die Geschäftsbanken unter den Einnahmen aus dem Refinanzierungsgeschäft gelegen, danach lagen die Zinsausgaben regelmäßig über den Einnahmen. Die Kosten der Notenemission blieben mit gut 7 Mio. IP9O recht konstant und deutlich unter den Werten der Zinseinnahmen und Ausgaben. 


\subsubsection{Zinseinnahmen aus den Währungsreserven}

Die Zinseinnahmen aus den Währungsreserven übertreffen die Zinseinnahmen aus dem inländischen Geschäft deutlich und bewegten sich meist zwischen 200 und 220 Mio. IP90 bis auf das Jahr 1995 mit fast 280 Mio. IP90.

Abbildung 7-51: Zinseinnahmen aus den Währungsreserven (Irland)

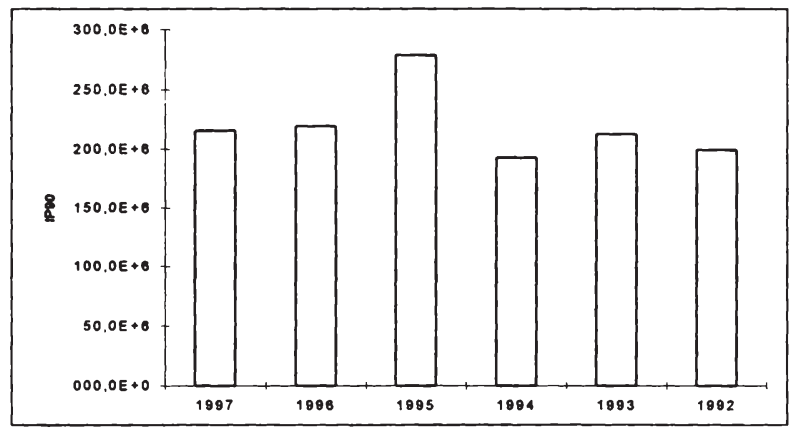

Quelle: Geschäftsberichte der Central Bank of Ireland, verschiedene Jahrgänge

\subsubsection{Gesamteffekt}

Abbildung 7-52: Konvergenzeffekt und seine Entstehung für Irland

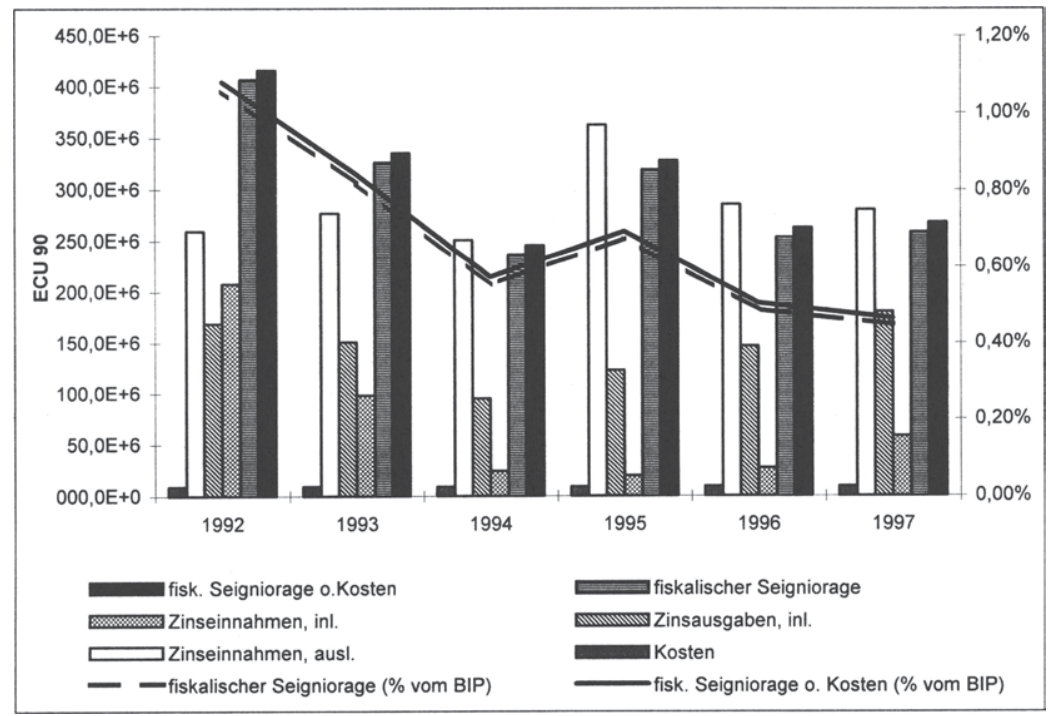

Quelle: 
Der fiskalische Seigniorage (ohne Kostenberücksichtigung) sank im Beobachtungszeitraum von über 400 Mio. ECU90 im Jahr 1992 auf unter 270 Mio. ECU90 (1997). Der Anteil des fiskalischen Seigniorage am BIP sank entsprechend von über $1 \%$ auf unter $0,5 \%$. Obwohl die Zinseinnahmen aus den Währungsreserven einen sehr hohen Anteil am Seigniorage ausmachen, spielten sie beim Rückgang des Seigniorage aufgrund ihrer großen Konstanz keine große Rolle. Vielmehr waren der Rückgang der Zinseinnahmen aus den Refinanzierungsgeschäften und der gleichzeitige Anstieg der Zinsausgaben an die Geschäftsbanken ab 1994 für diese Entwicklung maßgeblich bestimmend.

\subsubsection{Ursachenanalyse}

\subsubsection{Bestände und Zinssätze der Refinanzierungsgeschäfte}

Die Refinanzierung der Geschäftsbanken in Irland erfolgt vorwiegend über kurzfristige Kredite mit einer Laufzeit zwischen einem Tag und einer Woche. Die Jahresendstände dieser Refinanzierung zeigt die folgende Abbildung. Allerdings lassen sich aus den Geschäftsberichten der Central Bank of Ireland keine Schlüsse über die durchschnittliche Bestandshöhe ziehen, so daß insbesondere der hohe Jahresendbestand von 1997 vermutlich nicht für den Jahresdurchschnittsbestand repräsentativ ist.

\section{Abbildung 7-53: Bestănde und Zinssätze der Refinanzierungsgeschäfte}

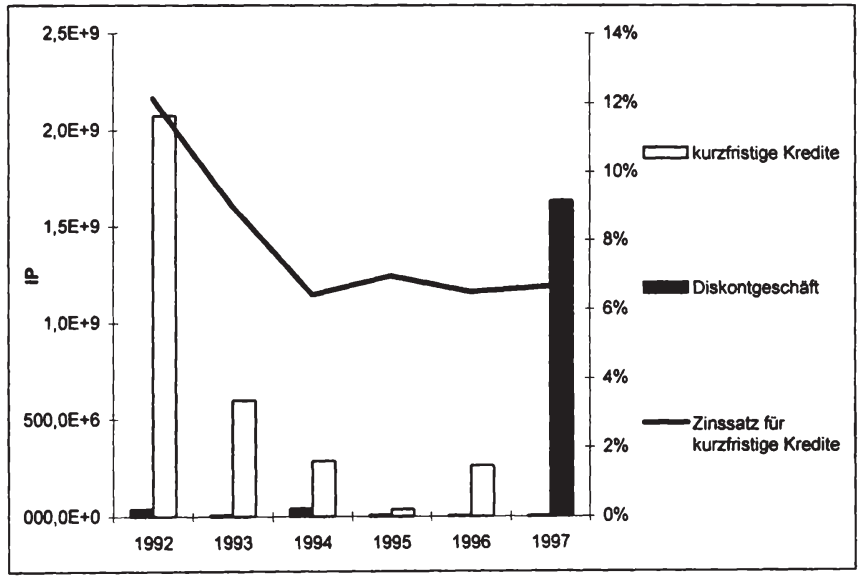

Quelle:

Geschäftsbericht der Central Bank of Ireland, verschiedene Jahrgänge

Allerdings läßt der Verlauf des Zinssatzes für kurzfristige Kredite der Zentralbank eine Erklärung für den Verlauf der Zinseinnahmen aus dem Refinanzierungsgeschäft zu. So lagen dieser Zinssatz 1992 zwischenzeitlich noch bei 10,5 \% (durchschnittlich 8,88\%) und befand sich am Jahresende 1997 nur noch bei 3,5\% (durchschnittlich 3,42\%). Eine Schätzung der Zinseinnahmen ist allerdings nicht 
möglich, so daß hier der Konvergenzeffekt auf die Zinseinnahmen anhand der Zinsentwicklung und der Zinseinnahmen bestimmt werden soll (Methode 2, vgl. 6.2.1). Die zusätzlichen Zinseinnahmen ohne Konvergenzeffekt hätten etwa 42 Mio. IP betragen bei tatsächlichen 51 Mio. IP im Jahr 1997.

\subsubsection{Bestände und Zinssätze der liquiditätsabschöpfenden Maßnahmen}

Zur Liquiditätsabschöpfung bediente sich die irische Zentralbank im wesentlichen der Mindestreserve und in geringerem Umfang einer Einlagefazilität.

Die Einlagen (inklusive Mindestreserven) und den Einlagezinssatz zeigt die folgende Abbildung:

Abbildung 7-54: Einlage der Geschäftsbanken bei der irischen Zentralbank und Einlagezinssatz

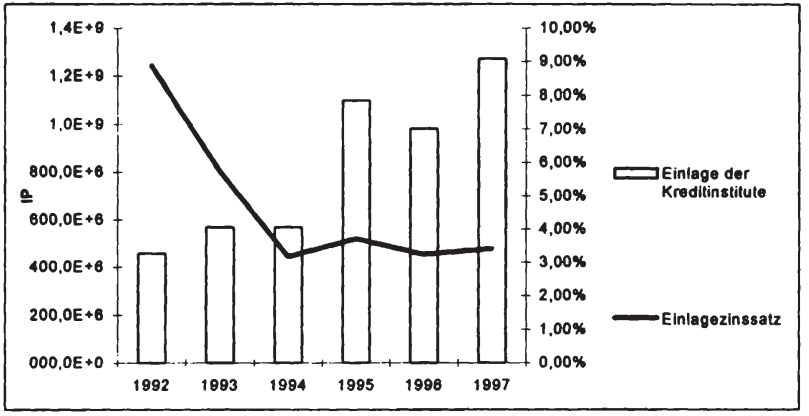

Quelle:

Geschäftsbericht der Central Bank of Ireland, verschiedene Jahrgänge

Die steigenden Einlagen der Geschäftsbanken rühren im wesentlichen aus der Mindestreserve, die sich aufgrund der zunehmenden mindestreservepflichtigen Einlagen bei den Geschäftsbanken ebenfalls vergrößert hat. Eine Schätzung der Zinsausgaben ist dennoch nicht möglich, so daß auch der Konvergenzeffekt auf die Zinsausgaben anhand Methode 2 (vgl. 6.2.1) berechnet wird. Demnach hätten die Zinsausgaben ohne Konvergenz knapp 100 Mio. IP mehr betragen als die tatsächlich verausgabten 62 Mio. IP im Jahr 1997.

\subsubsection{Kosten}

Da sich die Kosten im Zeitablauf konstant zeigten, sollen sie nicht weiter in der Ursachenanalyse berücksichtigt werden.

\subsubsection{Nachfrage nach Zentralbankgeld}

Die Mindestreservesätze - implizit aus Daten des IFS berechnet - erhöhten sich nur 1995 von 3,2 \% auf rund $4 \%$, dementsprechend - aber auch aufgrund steigender Mindestreserveverpflichtungen - stiegen die Mindestreserven der Geschäftsbanken (vgl. Abbildung 7-55). 
Abbildung 7-55: Mindestreserve und Mindestreservesatz für Irland

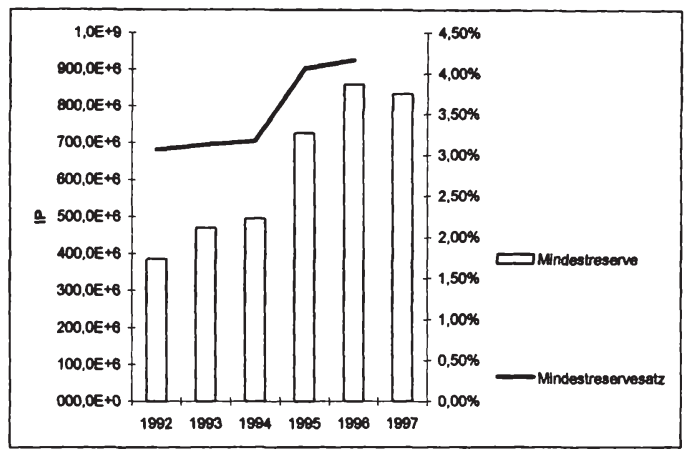

Quelle:

IMF

Da die Veränderung der Mindestreservesätze sich nur in einem geringen Rahmen bewegte und zudem die Mindestreserven in Irland mit einem nahe dem Marktzinssatz liegenden Zinssatz verzinst werden, können diese Veränderungen kaum Einfluß auf den fiskalischen Seigniorage gehabt haben.

Abbildung 7-56: Preissteigerungsrate in Irland

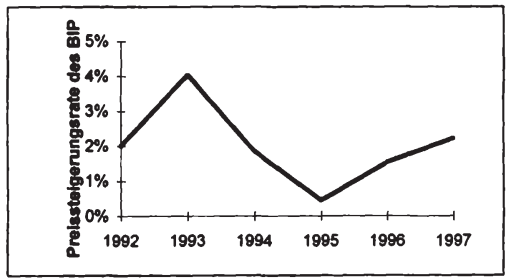

Quelle: $\quad$ eurostat

Tabelle 7-7: $\quad$ Preisstabilisierungs- und Mindestreserveeffekt für Irland

\begin{tabular}{|l|r|}
\hline ZBG97 & $3,1 \mathrm{E}+9$ \\
\hline C97 & $2,4 \mathrm{E}+9$ \\
\hline MR97 & $687,0 \mathrm{E}+6$ \\
\hline BIPn97 & $51,0 \mathrm{E}+9$ \\
\hline MRV97 & $22,4 \mathrm{E}+9$ \\
\hline BIPr90(97) & $44,4 \mathrm{E}+9$ \\
\hline PI92 & $2,00 \%$ \\
\hline mrs92 & $3,06 \%$ \\
\hline ZBG(97) & $3,3 \mathrm{E}+9$ \\
\hline d ZBG & $-122,5 \mathrm{E}+6$ \\
\hline d Seigniorage & $-8,2 \mathrm{E}+6$ \\
\hline Deflator97 & 114,60 \\
\hline IP90 & $-7,1 \mathrm{E}+6$ \\
\hline ECU90 & $-9,3 \mathrm{E}+6$ \\
\hline \%vom BIP & $-0,02 \%$ \\
\hline
\end{tabular}

Quelle: $\quad$ eigene Berechnungen 
Auch die Inflation hat sich von 1992 bis 1997 nur unwesentlich von $2 \%$ auf $2,23 \%$ verändert (vgl. Abbildung 7-56), so daß ein nachhaltiger Einfluß auf den Seigniorage kaum zu beobachten sein wird.

Tatsächlich beträgt der Preisstabilisierungs- und Mindestreserveeffekt auch nur $0,02 \%$ des BIP, etwa 9 Mio. ECU90.

\subsubsection{Währungsreserven}

Der Verlauf der Währungsreserven der irischen Zentralbank läßt keinen Schluß auf den Verlauf der Zinseinnahmen aus dem ausländischen Geschäft zu, ohne das genaue Portefeuille bzw. die zugehörigen Zinssätze zu kennen.

Abbildung 7-57: Währungsreserven der Central Bank of Ireland

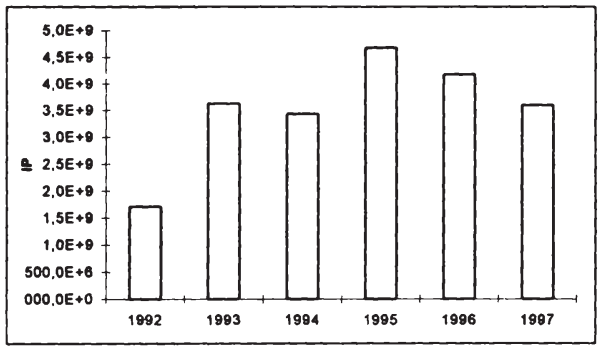

Quelle: $\quad$ Geschäftsberichte der Central Bank of Ireland, verschiedene Jahrgänge

\subsubsection{Gesamter Konvergenzeffekt}

Der Konvergenzeffekt für Irland besteht aufgrund der marktnahen Mindestreserveverzinsung und der Stabilität der Preise im Beobachtungszeitraum nur aus einem negativen Zinseffekt, d.h. ohne Konvergenz hätte der Seigniorage 1997 mit rund 200 Mio. ECU90 noch niedriger gelegen als die tatsächlich erreichten knapp 270 Mio. ECU90.

Abbildung 7-58: Konvergenzeffekt für Irland

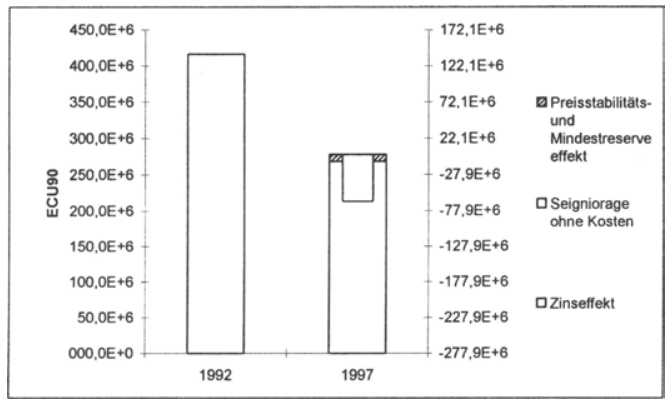

Quelle:

eigene Berechnungen 


\subsection{Quantifizierung für Italien}

\subsubsection{Quantifizierung des Konvergenzeffekts}

\subsubsection{Zinsertrag aus Forderungen gegen inländische Geschäftsbanken}

Hauptrefinanzierungsinstrument der Banca d'Italia sind Offenmarktgeschäfte mit unterschiedlicher Laufzeit. Daneben spielen Diskont- und Lombardgeschäfte eine signalisierende aber quantitativ untergeordnete Rolle (vgl. Escrivá/Fagan 1996, Table 2). Den Verlauf der Erträge aus diesen Geschäften stellt die folgende Abbildung dar.

Abbildung 7-59: Zinserträge aus Offenmarkt, Diskont- und Lombardgeschäften

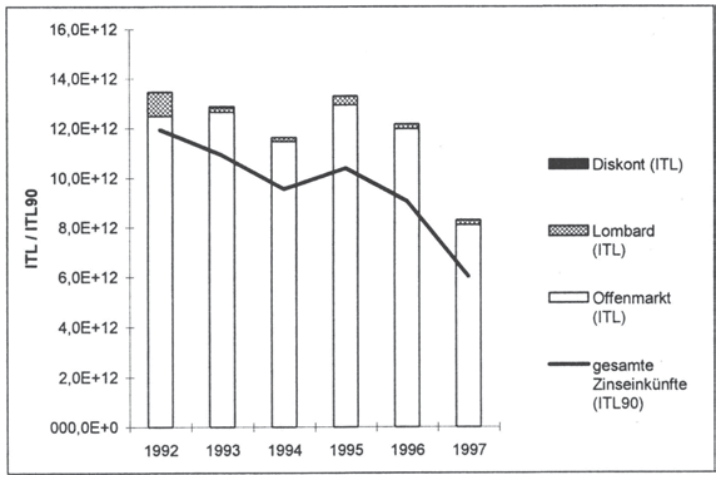

Quelle:

Geschäftsberichte der Banca d'Italia, verschiedene Jahrgänge

Abgesehen von einem kurzzeitigem Anstieg im Jahre 1995 halbierten sich die Zinserträge im Betrachtungszeitraum von 12 Bill. ITL90 in 1992 auf 6 Bill. ITL90 in 1997.

\subsubsection{Zinsaufwand}

Die italienische Zentralbank schöpft Liquidität mit Hilfe von umgekehrten Wertpapierpensionsgeschäften und Outrightgeschäften ab. Zudem ergibt sich ein Zinsaufwand dadurch, daß die Banca d'Italia die Mindestreserven der Geschäftsbanken verzinst. Die unterschiedlichen Aufwandsarten werden in Abbildung 7-60 dargestellt.

Zunächst zeigt sich, daß die Aufwendungen für die verzinste Mindestreserve im Zeitablauf kontinuierlich gesunken sind. Sie halbierten sich von ehemals 8,1 Bill. ITL auf 3,9 Bill. ITL in 1997. Die Aufwendungen für Outrightgeschäfte stiegen dagegen von knapp 1 Bill. ITL in 1992 auf über 6 Bill. im Jahre 1995. Der anschlieBend einsetzende Rückgang der Zinsaufwendungen für dieses liquiditätsabschöpfende Instrument ließ die gesamten Zinsaufwendungen schließlich von zwischenzeitlich 8,2 Bill. ITL90 auf 5,5 Bill. ITL90 im Jahre1997 sinken. Die Aufwendungen 
für die umgekehrten Wertpapierpensionsgeschäfte spielten quantitativ keine große Rolle und stiegen nur 1995 und 1996 über 100 Mrd. ITL.

Abbildung 7-60: Aus geldpolitischen Instrumenten resultierende Zinsaufwendungen (Italien)

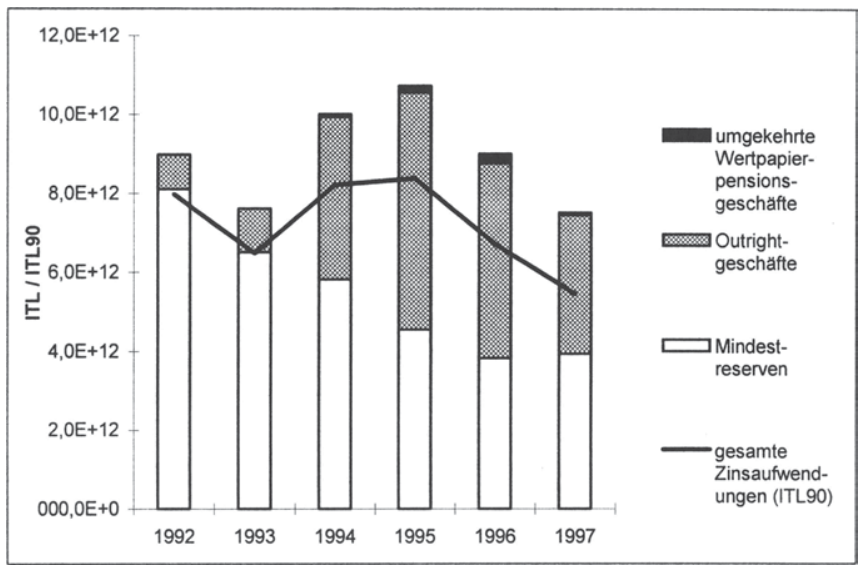

Quelle: $\quad$ eigene Berechnungen nach Geschäftsberichten der Banca d'Italia, verschiedene Jahrgänge

\subsubsection{Zinseinnahmen aus Währungsreserven}

Die Zinseinnahmen aus Währungsreserven erlitten von 1992 bis 1994 einen Einbruch von 3,2 auf 1,5 Bill. ITL. Anschließend erholten sie sich bis 1997 auf 2,9 Bill. ITL.

Abbildung 7-61: Zinseinnahmen aus Währungsreserven

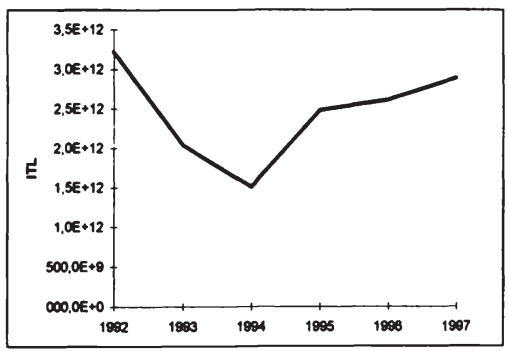

Quelle: $\quad$ Geschäftsberichte der Banca d'Italia, verschiedene Jahrgänge

Im Vergleich zu den Einnahmen aus den inländischen Refinanzierungsgeschäften spielen die Einnahmen aus Währungsreserven demnach eine geringere Rolle innerhalb der Komponenten des fiskalischen Seigniorage. 


\subsubsection{Kosten}

Die anteiligen Kosten bewegten sich im Betrachtungszeitraum zwischen 1 und 1,2 Bill. ITL90; Kosten für den Notendruck werden nicht extra ausgewiesen.

Abbildung 7-62: Anteilige Verwaltungskosten der Banca d'Italia

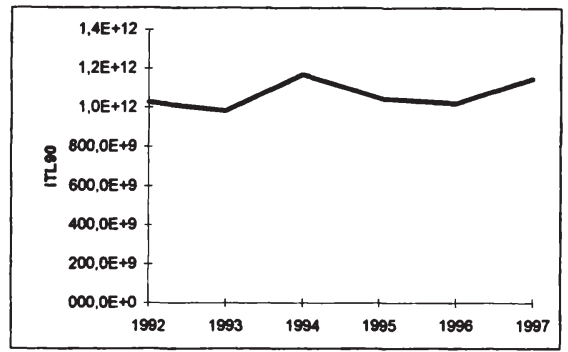

Quelle: $\quad$ eigene Berechnungen nach Geschäftsberichten der Banca d'Italia, verschiedene Jahrgänge

\subsubsection{Gesamteffekt}

Insgesamt läßt sich zweimal ein deutlicher Rückgang des Seigniorage erkennen. 1994 fiel der Seigniorage (ohne Kosten) von 4,1 Mrd. ECU90 auf 1,7 Mrd. ECU90. Nach einem Anstieg bis auf 2,8 Mrd. ECU90 in 1996 fiel er 1997 abermals auf 1,8 Mrd. ECU90.

Abbildung 7-63: Fiskalischer Seigniorage und seine Entstehung für Italien

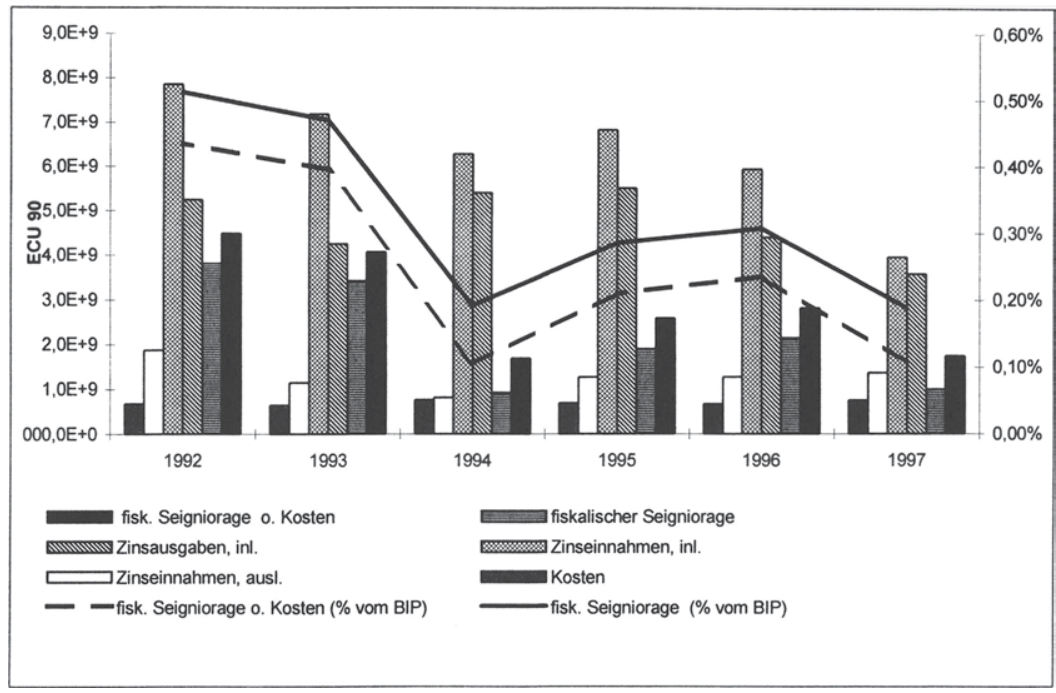

Quelle: eigene Berechnungen, Geschäftsberichte der Banca d'Italia, verschiedene Jahrgänge 
Bei einer Berücksichtigung der relativ hohen Kosten ${ }^{16}$ lag der Seigniorage für 1997 mit knapp 1 Mrd. ECU90 nach anfänglichen 0,43\% des BIP (1992) nur noch bei $0,11 \%$.

\subsubsection{Ursachenanalyse}

\subsubsection{Zins aus Diskont-, Lombard- und Offenmarktgeschäften}

Abbildung 7-64 zeigt die Bestände der Banca d'Italia aus den geldpolitischen Geschäften und die zugehörigen Zinssätze. Allerdings läßt sich aus diesen Werten keine zufriedenstellende Schätzung des Zinsertrags erstellen, da es neben diesen Zinssätzen eine Fülle anderer Zinssätze gibt, die unter bestimmten Bedingungen zur Anwendung kommen. Zudem ist ein Strukturbruch bei der Aufstellung der Zentralbankbilanz zwischen 1993 und 1994 zu verzeichnen, der eine Schätzung der Zeitreihen nicht erlaubt.

Abbildung 7-64: Bestände aus Diskont-, Lombard- und Offenmarktgeschäften (Italien)

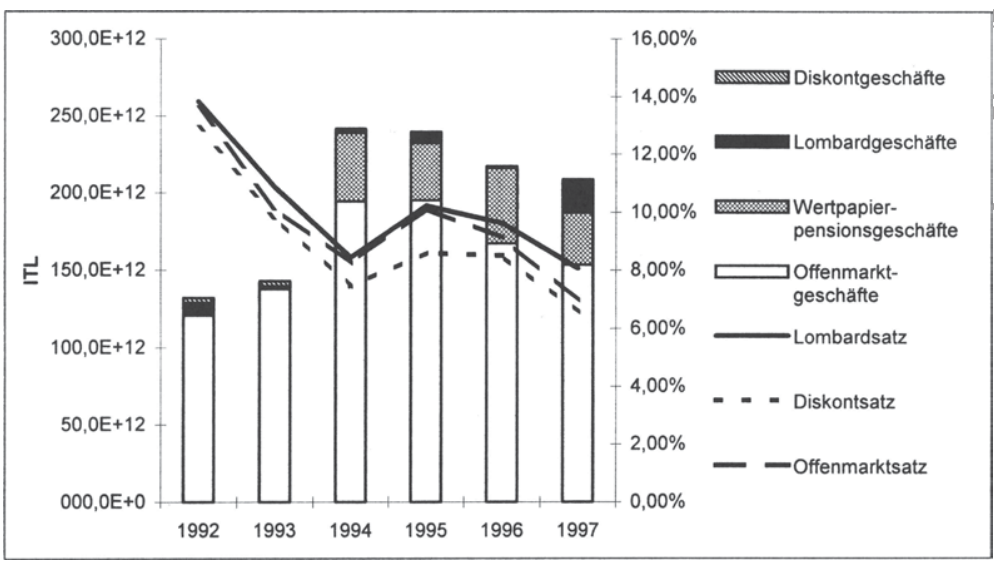

Quelle: $\quad$ eigene Berechnungen nach Geschäftsberichten der Banca d'Italia, verschiedene Jahrgänge

Qualitativ läßt sich das starke Absinken der Zinseinnahmen bis 1994 mit dem Sinken der Zinssätze erklären, ebenso der Anstieg 1995. Nach 1995 waren sowohl der sinkende Zinssatz als auch die sinkenden Bestände - vor allem aus dem Offenmarktgeschäft - verantwortlich für den zweiten Rückgang der Zinseinnahmen im Betrachtungszeitraum. Der Zinseffekt - berechnet nach Methode 2 (vgl. 6.2.1) - beträgt fast 8 Bill. ITL bei tatsächlichen Zinserträgen im Inland in 1997 von 8,3 Mrd. ITL.

161997 erreichten die Kosten mit 756 Mio. ECU90 ein ähnliches Niveau wie in Deutschland mit 793 Mio. ECU. 
7.6.2.2 Zins für Liquiditätsabschöpfung und Verzinsung der Mindestreserve

Abbildung 7-65 zeigt die Bestände aus den Zinsaufwendungen verursachenden Verbindlichkeiten des geldpolitischen Instrumentariums und die zugehörigen Zinssätze. Der Zinssatz für die Verzinsung der Mindestreserve wurde erst Mitte 1997 von $5,5 \%$ auf $4,5 \%$ herabgesetzt, so daß Veränderungen des Zinsaufwands hier nur auf die Reduzierung der Mindestreserveverpflichtungen zurückzuführen ist. Dem steht allerdings ein Anstieg der Verbindlichkeiten durch Outrightgeschäfte von 1992 bis 1995 gegenüber. Der Anstieg der Zinsaufwendungen von 1993 bis 1995 dürfte demnach vor allem hierin begründet sein, bzw. ab 1994 auch in einem Anstieg der Zinsen. Der Rückgang des Zinsniveaus bei gleichbleibenden Verbindlichkeiten reduzierte die Zinsaufwendungen wieder ab 1995.

Insbesondere die hohe Verzinsung der Mindestreserven reduzierte den fiskalischen Seigniorage erheblich.

Abbildung 7-65: Verbindlichkeiten aus liquiditätsabschöpfenden Instrumenten, Mindestreserveeinlagen und entsprechende Zinssätze

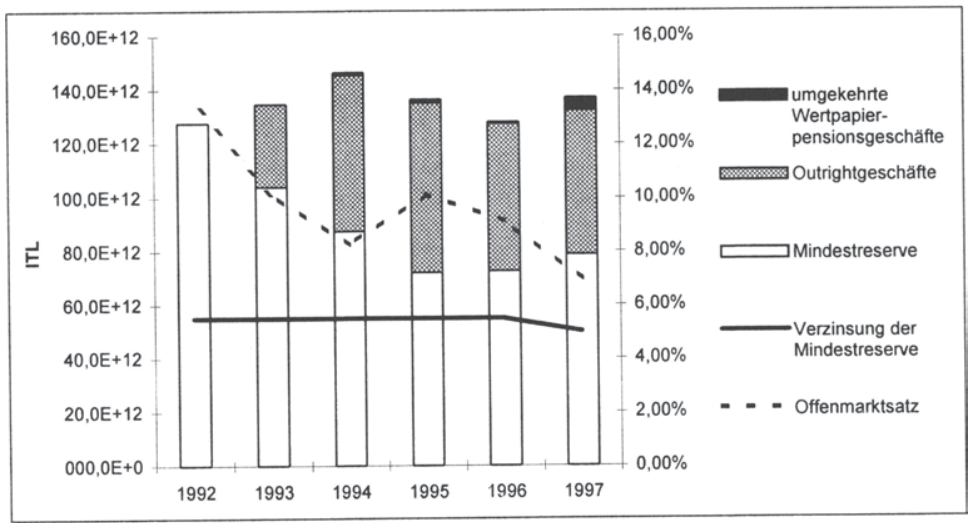

Quelle:

Geschäftsberichte der Banca d'Italia, verschiedene Jahrgănge

Abbildung 7-66: Schätzung der Zinsausgaben für Italien

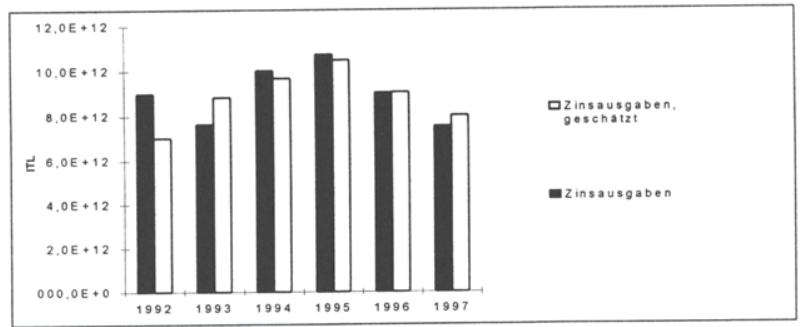

Quelle: eigene Berechnungen nach Geschäftsberichten der Banca d'Italia, verschiedene Jahrgänge 
Da die Schätzung der Zinsausgaben eine genügend gute Annäherung an die tatsächlichen Zinsausgaben darstellt (vgl. Abbildung 7-66), kann der Zinseffekt auf die Zinsausgaben anhand der Zinsdifferenzen von 1992 und 1997 und der Bestände berechnet werden.

Die Zinsmehrausgaben ohne Konvergenz betragen 4,3 Bill. ITL bei tatsächlichen Zinsausgaben von 7,5 Bill. ITL in 1997.

\subsubsection{Währungsreserven}

Die Währungsreserven der Banca d'Italia beliefen sich von 1992 bis 1994 auf etwa 43 Bill. ITL. 1995 begannen sie zu steigen und erreichten im Jahre 1997 ihren vorläufigen Höchststand von 73 Bill. ITL. Durch diesen Anstieg läßt sich auch die Zunahme der Zinseinnahmen aus den Währungsreserven von 1994 bis 1997 erklären. Der Rückgang von 1992 bis 1994 ließe sich allerdings nur anhand einer detaillierten Portefeuille- und Zinsanalyse erklären, da die Währungsreservenbestände in diesem Zeitraum keine Veränderungen aufweisen.

Abbildung 7-67: Währungsreserven der Banca d'Italia

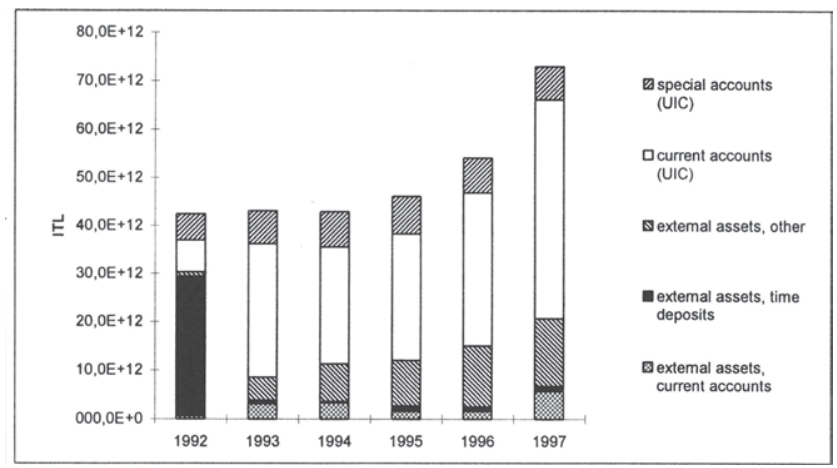

Quelle:

Geschäftsberichte der Banca d'Italia, verschiedene Jahrgänge

\subsubsection{Nachfrage nach Zentralbankgeld}

\section{Mindestreserven}

Die Mindestreservesätze lassen sich in Ermangelung an Informationen in den Geschäftsberichten nur aus den IFS (vgl. IMF 1997) errechnen. Danach sank der Mindestreservesatz in Italien von anfänglich fast $15 \%$ auf $7,5 \%$ in 1996 (vgl. Abbildung 7-68). Entsprechend sank die Mindestreservehaltung von 128 Bill. ITL (1992) auf 73 Bill. ITL (1996). 1997 stieg sie wieder leicht an auf 79 Bill. ITL.

Die Verringerung des Zentralbankgelds in Italien von 217 Bill. (1992) auf 193 Bill. ITL (1997) hat demnach einen wesentlichen Ursprung in der Entwicklung der Mindestreserve. 
Abbildung 7-68: Mindestreservehaltung in Italien

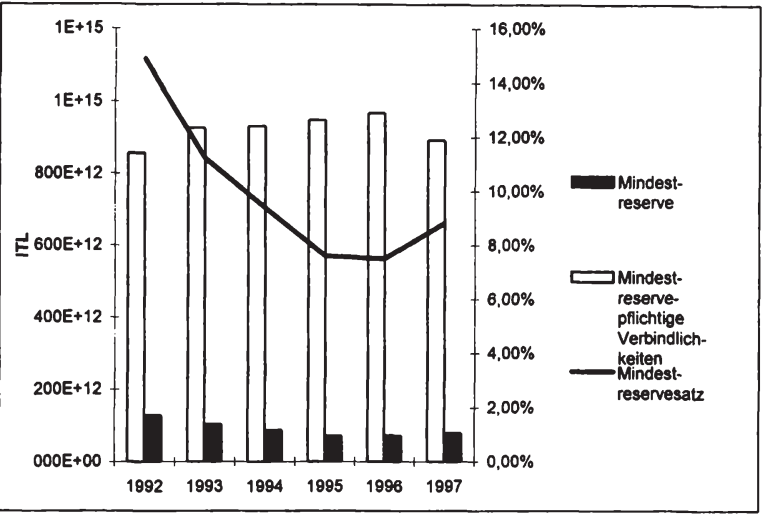

Quelle: $\quad$ eigene Berechnungen nach IMF (1997)

Inflation

Die Preissteigerungsrate für Italien reduzierte sich zunächst von anfänglich 4,7 \% auf 3,4\% im Jahre 1994, um anschließend 1995 noch einmal auf über $5 \%$ anzusteigen. 1997 erreichte sie schließlich weniger als $3 \%$.

Abbildung 7-69: Preissteigerungsrate des BIP für Italien

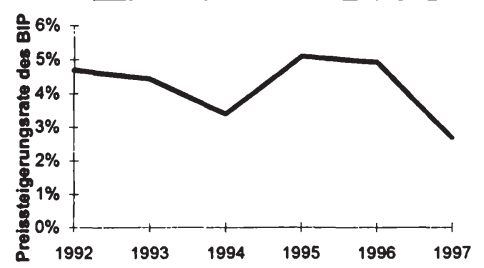

Quelle:

eurostat

Der Inflationseffekt auf die Zentralbankgeldmenge in Verbindung mit dem Mindestreserveeffekt errechnet sich folgendermaßen (vgl. Tabelle 7-8): Bei einer Inflation von 4,7\% von 1992 bis 1997 hätte das nominale BIP 1997 rund 2 Billiarden ITL betragen. Unter der Annahme eines konstanten Bargeldhaltungskoeffizienten und eines konstanten Verhältnisses von mindestreservepflichtigen Einlagen und nominalem BIP sowie einer Mindestreserveverpflichtung von 14,89 \% (1992) hätte das Zentralbankgeld 1997 277,5 Bill. ITL betragen. Verzinst zum Offenmarktzinssatz von 1992 (13,6\%) hätten die Seignioragemehreinnahmen 11,5 Bill. ITL betragen (5,3 Mrd. ECU90); dies entspricht einem Anteil am BIP von 0,57 \%. 
Tabelle 7-8: Berechnung des Seigniorageverlusts aufgrund steigender Preisstabilităt und Reduzierung der Mindestreserve für Italien

\begin{tabular}{|l|l|}
\hline ZBG97 & $277,5 \mathrm{E}+12$ \\
\hline C97 & $115,5 \mathrm{E}+12$ \\
\hline MR97 & $162,0 \mathrm{E}+12$ \\
\hline BIPn97 & $2,0 \mathrm{E}+15$ \\
\hline DMR97 & $1,1 \mathrm{E}+15$ \\
\hline BIPr90(97) & $1,4 \mathrm{E}+15$ \\
\hline PI92 & $4,70 \%$ \\
\hline Mrs92 & $14,89 \%$ \\
\hline ZBG(97) & $192,7 \mathrm{E}+12$ \\
\hline D ZBG & $84,8 \mathrm{E}+12$ \\
\hline d Seigniorage (ITL) & $11,5 \mathrm{E}+12$ \\
\hline Deflator97 & 141,79 \\
\hline ITL90 & $8,1 \mathrm{E}+12$ \\
\hline ECU90 & $5,3 \mathrm{E}+9$ \\
\hline \%vom BIP & $0,57 \%$ \\
\hline
\end{tabular}

Quelle:

eigene Berechnungen

Die unter diesen Annahmen zusätzlich entstandene Mindestreserve von 83,4 Bill. ITL. hätte nach den 1992 angewendeten geldpolitischen Instrumenten aber auch mit einem Zinssatz von 5,5\% verzinst werden müssen, weshalb zusätzliche Zinsausgaben in Höhe von 4,6 Bill. ITL (2,1 Mrd. ECU90) hätten getätigt werden müssen. Diese wären bei der Berechnung des Konvergenzeffekts gleichermaßen zu berücksichtigen gewesen.

\subsubsection{Kosten}

Da sich die Kosten im Zeitablauf kaum verändern und zudem eine detaillierte Aufteilung in allgemeine Verwaltungskosten und Kosten für den Banknotendruck nicht möglich ist, wird eine genauere Kostenanalyse hier nicht vorgenommen.

\subsubsection{Gesamteffekt}

Italien hätte ohne Konvergenz 1997 Seigniorageeinnahmen in Höhe von 6,7 Mrd. ECU90 erzielen können, wobei die zusätzliche Mindestreserveverzinsung von 2,1 Mrd. ECU90 schon berücksichtigt ist. Das entspricht 0,72 \% des BIP. Der Preisstabilitäts- und Mindestreserveeffekt betrug dabei 5,3 Mrd. ECU90 und der Zinseffekt 1,7 Mrd. ECU90, so daß der Seigniorage 1997 nur knapp 1,8 Mrd. ECU90 erreichte.

Tabelle 7-9: Konvergenzeffekt für Italien

\begin{tabular}{|llrrrr|}
\hline & & \multicolumn{1}{c}{ ITL } & ITL90 & ECU90 & \% vom BIP \\
\hline aus Zinsanderungen & potentielle Zinseinnahmen & $-7,9 E+12$ & $-5,6 E+12$ & $-3,7 E+9$ & $-0,39 \%$ \\
& potentielle Zinsausgaben & $-4,3 E+12$ & $-3,0 E+12$ & $-2,0 E+9$ & $-0,21 \%$ \\
aus d mrs und d PI & d potentielle Zinseinnahmen & $-11,5 \mathrm{E}+12$ & $-8,1 \mathrm{E}+12$ & $-5,3 \mathrm{E}+9$ & $-0,57 \%$ \\
aus Verzinsung der Mindestreserve & $4,6 \mathrm{E}+12$ & $3,2 \mathrm{E}+12$ & $2,1 \mathrm{E}+9$ & $0,23 \%$ \\
\hline Konvergenzeffekt & $-10,6 \mathrm{E}+12$ & $-7,5 \mathrm{E}+12$ & $-4,9 \mathrm{E}+9$ & $-0,53 \%$ \\
\hline
\end{tabular}

Quelle:

eigene Berechnungen 
Abbildung 7-70: Quantifizierter Konvergenzeffekt für Italien

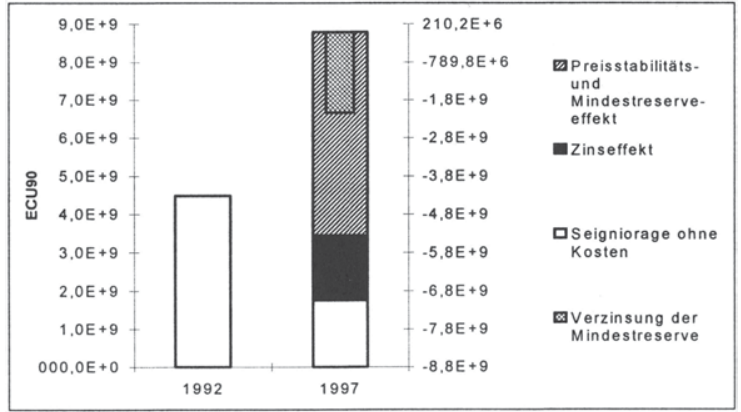

Quelle: $\quad$ eigene Berechnungen

\subsection{Quantifizierung für die Niederlande}

\subsubsection{Quantifizierung des Konvergenzeffekts}

7.7.1.1 Einnahmen, Ausgaben und Kosten aus dem inländischen Geschäft

Die Zinserträge aus dem inländischen Refinanzierungsgeschäft sanken von 1992 bis 1997 kontinuierlich von 1 Mrd. HFL90 auf unter 200 Mio. HFL90, während die Zinsausgaben zunächst von 1992 bis 1993 von weniger als 1 Mrd. HFL90 auf 1,1 Mrd. HFL90 anstiegen. Danach ging die Höhe der Zinsausgaben zwar zurück, konnte aber im gesamten Beobachtungszeitraum nicht mehr unter das Niveau der Zinseinnahmen sinken (vgl. Abbildung 7-71).

Die Kosten bewegten sich im Beobachtungszeitraum zwischen 137 Mio. und 147 Mio. HFL90 (vgl. Abbildung 7-72).

\subsubsection{Zinserträge aus Währungsreserven}

Die Zinserträge aus Währungsreserven überschreiten die Einnahmen aus dem inländischen Geschäft um mehr als das doppelte, wobei Schwankungen sehr hoch sind. Die Einnahmenhöhe schwankt zwischen 1,8 und 3,2 Mrd. HFL90 (vgl. Abbildung 7-71).

Abbildung 7-71: Zinserträge aus Krediten an inländische Geschäftsbanken und Zinsausgaben aus dem inländischen Geschäft (Niederlande)

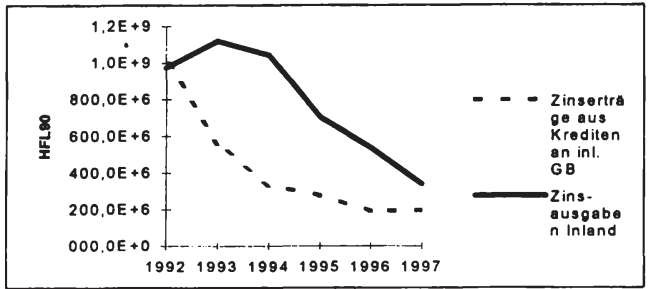

Quelle:

Geschäftsberichte De Nederlandsche Bank, verschiedene Jahrgänge 
Abbildung 7-72: Anteilige Verwaltungskosten und Kosten der Banknotenausgabe De Nederlandsche Bank

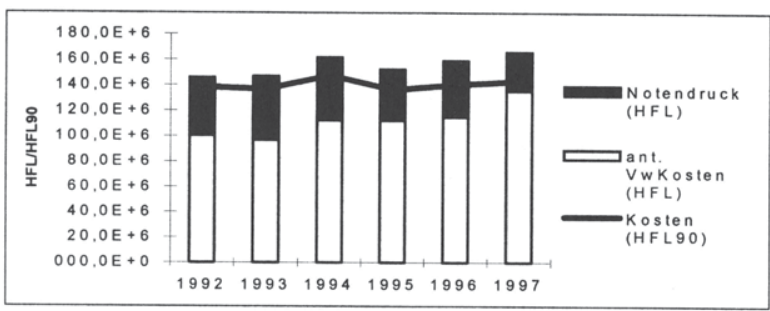

Quelle: Geschäftsberichte De Nederlandsche Bank, verschiedene Jahrgänge

Abbildung 7-73: Zinserträge aus Währungsreserven (Niederlande)

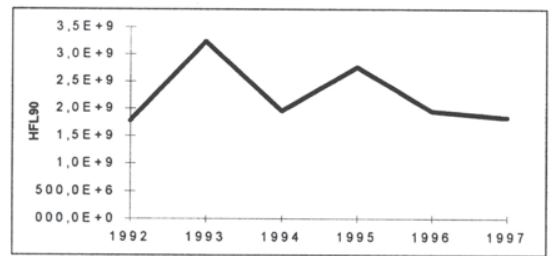

Quelle: $\quad$ Geschäftsberichte De Nederlandsche Bank, verschiedene Jahrgänge

\subsubsection{Gesamteffekt}

Abbildung 7-74: Fiskalischer Seigniorage für die Niederlande

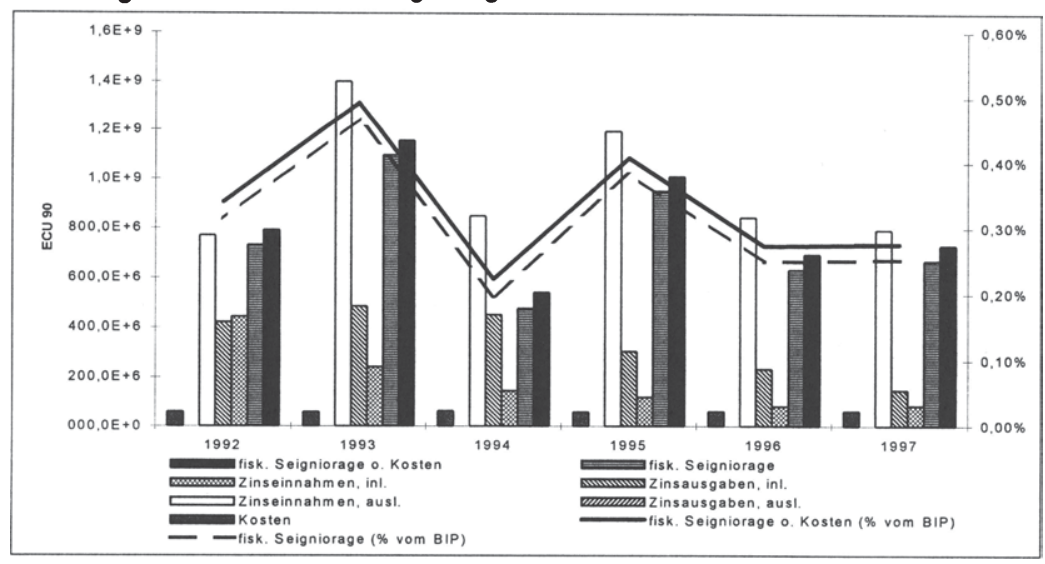

Quelle: 
Der fiskalische Seigniorage unterlag im Beobachtungszeitraum starken Schwankungen von 540 Mio. ECU90 bis 1,2 Mrd. ECU90, die im wesentlichen auf die Schwankungen der Zinseinnahmen aus den Währungsreserven zurückzuführen sind. Eine Tendenz zu sinkendem oder steigendem fiskalischen Seigniorage läßt sich nicht ausmachen.

\subsubsection{Ursachenanalyse}

\subsubsection{Bestände und Zinssätze der Refinanzierungsgeschäfte}

Die Niederländische Notenbank bediente sich im wesentlichen zweier Instrumente zur Refinanzierung der Geschäftsbanken. Zum einen nahm sie bis 1993 als ständige Fazilität Wechsel zum subventionierten Diskontsatz an; diese subventionierte Fazilität wurde durch eine ständige Fazilität (Annahme von Staatspapieren und sehr guten privaten Papieren) nahe am Marktsatz ersetzt (current account) (vgl. Europäisches Währungsinstitut Jahresbericht 1994, 126 und Borio 1997, 44ff). Zum anderen setzte die Notenbank den Lombard als diskretionäres Instrument ein (special loans). Allerdings läßt sich der starke Rückgang der Zinseinnahmen nicht allein aus diesen Verläufen heraus erklären. Vermutlich liegen hier im Zeitablauf sehr stark schwankende Größen vor, so daß die Jahresendstände der Refinanzierungsgeschäfte nicht repräsentativ für die Entwicklung während des Jahres sind. Anhand der Zinssätze läßt sich aber ein deutlicher Trend ablesen, der vermutlich ausschlaggebend für die Verringerung der inländischen Zinseinnahmen sein dürfte.

Abbildung 7-75: Bestände und Zinssätze der Refinanzierungsgeschäfte

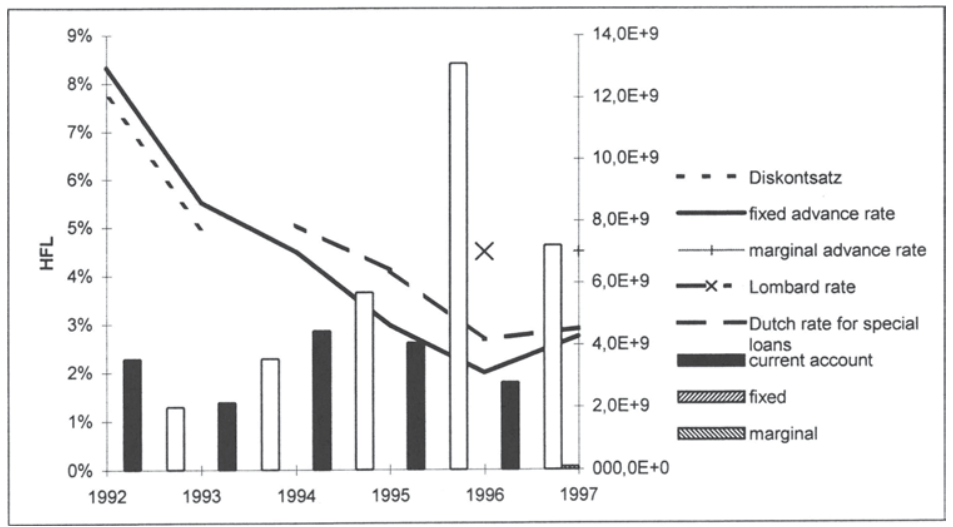

Quelle:

eigene Berechnungen nach Geschäftsberichten De

Nederlandsche Bank, verschiedene Jahrgänge; eurostat; IMF

Der Konvergenzeffekt für die Zinseinnahmen - berechnet mit Hilfe des Verhältnisses der Zinssätze 1997 und 1992 (vgl. 6.2.1) - beträgt 385 Mio. HFL90, bei tatsächlichen Zinseinnahmen von 196 Mio. HFL90. 


\subsubsection{Bestände und Zinssätze der liquiditätsabschöpfenden Maßnahmen}

Der Instrumentenmix zur Abschöpfung von Liquidität änderte sich innerhalb des Beobachtungszeitraumes zweimal: Bis 1994 herrschte eine verzinste Mindestreserve mit variablem Mindestreservesatz vor, die anschließend von der Ausgabe von Notenbankwertpapieren abgelöst wurde. Um den Übergang zur Europäischen Währungsunion zu erleichtern wurde 1997 die Mindestreserve wieder eingeführt und zusätzlich eine ständige Einlagefazilität erschaffen, die es den Geschäftsbanken ermöglicht, überschüssiges Zentralbankgeld über Nacht verzinslich zu hinterlegen (De Nederlandsche Bank 1998, Annual Report 1997, 91).

Die Verzinsung der Mindestreserve bis 1994 erfolgte durch einen variablen Zinssatz, der dem Marktzinssatz nahe war, so daß hierdurch kein fiskalischer Seigniorage erzielt werden konnte (vgl. Borio 1997, 27). Dies bedeutet gleichzeitig, daß die Reduzierung des Mindestreservesatzes 1995 auf Null den fiskalischen Seigniorage in keiner Weise verändert hat.

Die Veränderungen der Verbindlichkeiten aus den liquiditätsabschöpfenden Maßnahmen zeigt folgende Abbildung:

Abbildung 7-76: Verbindlichkeiten aus liquiditätsabschöpfenden Maßnahmen

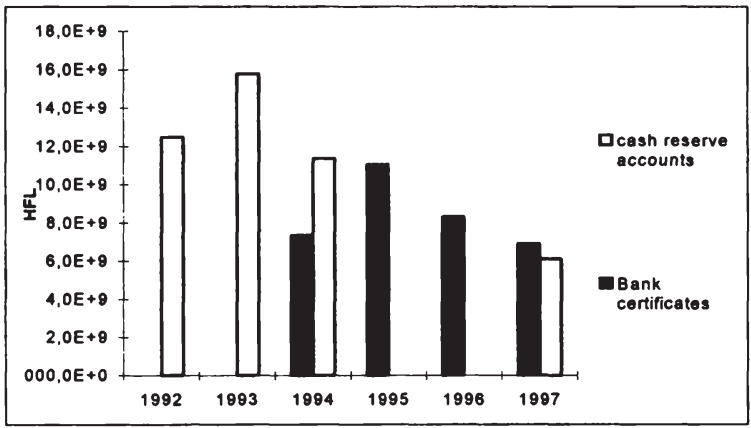

Quelle: $\quad$ Geschäftsberichte De Nederlandsche Bank, verschiedene Jahrgänge

Wenn auch eine genaue Schätzung der Zinsausgaben im inländischen Geschäft nicht möglich ist, so zeigen doch die Verbindlichkeiten zumindest einen ähnlichen Verlauf wie die Ausgaben. Der Konvergenzeffekt auf die Zinsausgaben wird daher anhand des Zinsverhältnisses berechnet (vgl. 6.2.1). Danach hätten die Zinsausgaben 1997 ohne Konvergenz um 670 Mio. HFL90 höher gelegen (1997: 340 Mio. HFL90).

\subsubsection{Kosten}

Da sich die Kosten kaum im Zeitablauf verändern und auch in der Gesamtwirkung auf den fiskalischen Seigniorage nur eine geringe Rolle spielen, sollen sie an dieser Stelle vernachlässigt werden. 


\subsubsection{Nachfrage nach Zentralbankgeld}

Da die Mindestreserven marktnah verzinst werden, spielt die Veränderung der Mindestreserve für den fiskalischen Seigniorage keine Rolle. Demnach kann nur die Preisstabilität einen Einfluß gehabt haben. Folgende Abbildung zeigt den Verlauf der Preissteigerungsrate des BIP für die Niederlande:

Abbildung 7-77: Preissteigerungsrate des BIP für die Niederlande

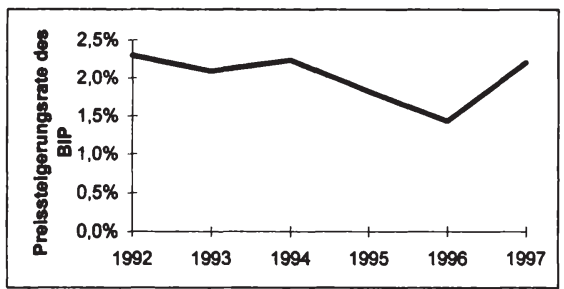

Quelle:

eurostat

Ohne die zwischenzeitlich niedrigeren Preissteigerungsraten von teilweise unter 1,5\% hätte die Nachfrage nach Zentralbankgeld bei gleichbleibenden Kassenhaltungskoeffizienten um 4,9 Mrd. HFL höher gelegen, was bei den Zinssätzen von 1992 einen zusätzlichen fiskalischen Seigniorage von 320,8 Mio. HFL (138,7 Mio. ECU90) bzw. 0,05\% des BIP bedeutet hätte.

Tabelle 7-10: Preisstabilitätseffekt für die Niederlande

\begin{tabular}{|l|l|}
\hline ZBG97 & $43,9 E+9$ \\
\hline C97 & $43,9 E+9$ \\
\hline MR97 & \\
\hline BIPn97 & $717,4 E+9$ \\
\hline DMR97 & - \\
\hline BIPr90(97) & $611,9 E+9$ \\
\hline PI92 & $2,30 \%$ \\
\hline mrs92 & - \\
\hline ZBG(97) & $39,3 E+9$ \\
\hline d ZBG & $4,6 E+9$ \\
\hline d Seigniorage (HFL) & $383,8 E+6$ \\
\hline Deflator97 & 119,66 \\
\hline d Seigniorage (HFL90) & $320,8 E+6$ \\
\hline d Seigniorage (ECU90) & $138,7 E+6$ \\
\hline bzgl. BIP & $0,05 \%$ \\
\hline
\end{tabular}

Quelle: eigene Berechnungen

\subsubsection{Währungsreserven}

Die Währungsreserven wurden 1993 von 18 auf knapp 40 Mrd. HFL mehr als verdoppelt und bewegten sich anschließend zwischen 34 und $41 \mathrm{Mrd}$. HFL. 
Abbildung 7-78: Zinsbringende Währungsreserven

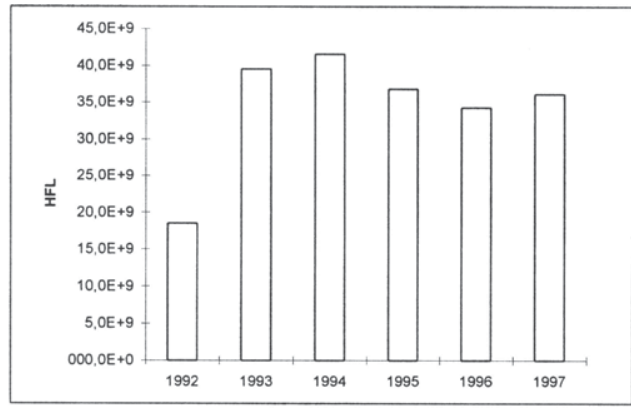

Quelle:

Geschäftsberichte De Nederlandsche

Bank, verschiedene Jahrgänge

Der Verlauf der Währungsreserven spiegelt allerdings den Verlauf der Zinseinnahmen aus den Währungsreserven kaum wieder, weshalb zur genauen Ursachenbestimmung eine Analyse des Portefeuille und der Zinssätze nötig wäre.

\subsubsection{Gesamter Konvergenzeffekt}

Der gesamte Konvergenzeffekt für die Niederlande ist aufgrund des negativen Zinseffekts von 123 Mio. ECU90, der den Preisstabilitätseffekt von 139 Mio. ECU90 fast vollständig kompensiert, nahezu Null.

Abbildung 7-79: Konvergenzeffekt für die Niederlande

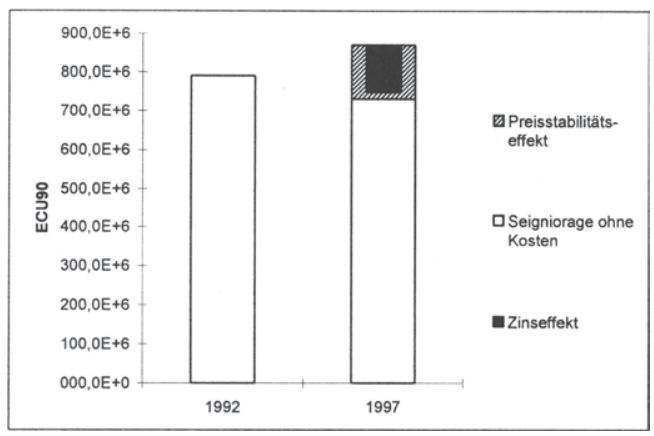

Quelle: $\quad$ eigene Berechnungen

Ohne Konvergenz hätte der fiskalische Seigniorage demnach für die Niederlande nicht wesentlich höher gelegen. 


\subsection{Quantifizierung für Österreich}

\subsubsection{Quantifizierung des Konvergenzeffekts}

\subsubsection{Zinsertrag aus Forderungen gegen inländische Geschäftsbanken}

Hauptrefinanzierungsinstrumente der Österreichischen Nationalbank sind die Offenmarktgeschäfte mit einwöchiger Laufzeit sowie die Eskontgeschäfte zum Eskontsatz, der unter dem Marktzinssatz festgelegt wird (vgl. Borio 1997, 44ff). Zur Spitzenrefinanzierung dienen die Darlehensgeschäfte zum Lombardsatz (vgl. Borio 1997, 42). Den Verlauf der Erträge aus diesen Geschäften stellt die folgende Abbildung dar.

Abbildung 7-80: Zinserträge aus Eskont-, Darlehens- und Offenmarktgeschäften

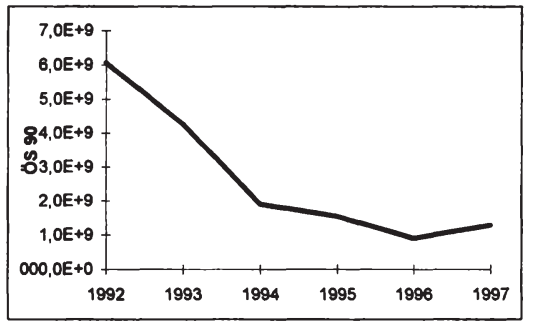

Quelle: $\quad$ Geschäftsberichte der Osterreichischen Nationalbank, verschiedene Jahrgänge

Bis 1996 fiel der jährliche Ertrag auf unter 1 Mrd. ÖS90, erst 1997 konnte wieder ein Ertragszuwachs auf ca. 1,3 Mrd. ÖS90 erreicht werden.

\subsubsection{Zinsaufwand}

Zur Liquiditätsabschöpfung existiert in Österreich eine ständige Einlagefazilität (REGOM), die zum Eskontsatz verzinst wird. Der Zinsaufwand läßt sich bis 1995 direkt aus der GuV der Österreichischen Nationalbank ersehen, Daten für 1996 und 1997 existieren nicht. Dazu wurde eine Schätzung mit Hilfe der Höhe der Einlageverbindlichkeiten und dem jeweiligen Eskontsatz vorgenommen. Das Ergebnis von Schätzung und Analyse der Geschäftsberichte zeigt folgende Abbildung:

Abbildung 7-81: Zinsaufwand (Österreich)

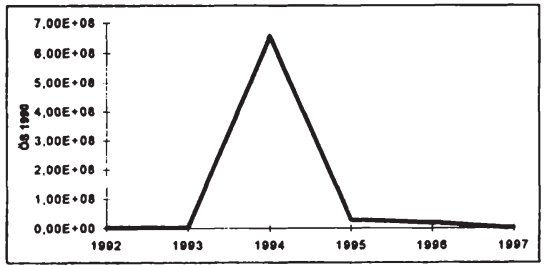

Quelle: $\quad$ eigene Berechnungen nach Geschäftsberichten der Österreichischen Nationalbank, verschiedene Jahrgänge 
Die Abbildung zeigt, daß der Zinsaufwand nur im Jahre 1994 eine bedeutende Größe von etwa 750 Mio. ÖS90 erreichte. In den Jahren davor bewegte er sich um 3 Mio. ÖS90 und nach 1994 sank er auf 34 Mio. (1995) bzw. 23 Mio. (1996) und 2 Mio. ÖS90 im Jahre 1997.

\subsubsection{Zinseinnahmen aus Währungsreserven}

Die Zinseinnahmen aus den Währungsreserven bewegten sich während des gesamten Beobachtungszeitraums zwischen 9 und 12 Mrd. ÖS90, mit steigender Tendenz.

Abbildung 7-82: Zinseinnahmen und -ausgaben aus Währungsreserven

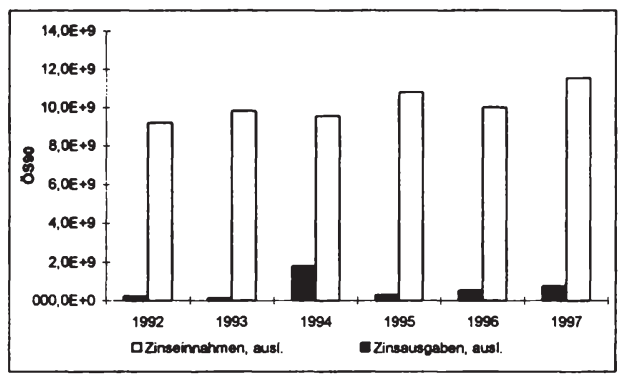

Quelle: $\quad$ Geschäftsberichte der Österreichischen Nationalbank, verschiedene Jahrgänge

\subsubsection{Kosten}

Da in den Geschäftsberichten der Österreichischen Nationalbank die Kosten für den Notendruck nicht direkt ausgewiesen sind, können hier nur alle Kosten nach obigem Schlüssel gewichtet betrachtet werden.

Abbildung 7-83: Anteilige Verwaltungskosten der Osterreichischen Nationalbank

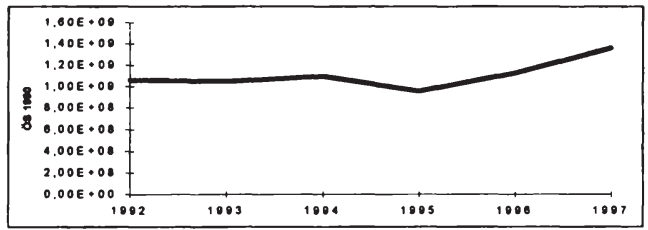

Quelle:

eigene Berechnungen nach Geschäftsberichten der

Osterreichischen Nationalbank, verschiedene Jahrgänge

Die Kosten beliefen sich in den Jahren 1992 bis 1996 auf Werte zwischen 0,95 und 1,2 Mrd. ÖS90. Der Anstieg in 1997 auf knapp 1,4 Mrd. ÖS90 resultiert im wesentlichen aus einem Neubau (Österreichische Nationalbank II in Wien) (vgl. Geschäftsbericht der Österreichischen Nationalbank 1997, 118). 


\subsubsection{Gesamteffekt}

Insgesamt läßt sich ein deutlicher Rückgang des Seigniorage in den Jahren 1992 bis 1994 von $0,8 \%$ auf $0,45 \%$ des BIP (ohne Kostenberücksichtigung erkennen. Anschließend setzte ein leichter Anstieg unterbrochen von den Ergebnissen aus 1996 ein, so daß 1997 wieder ein fiskalischer Seigniorage von etwa 0,6 \% des BIP erzielt wurde.

Abbildung 7-84: Fiskalischer Seigniorage und seine Entstehung für Österreich

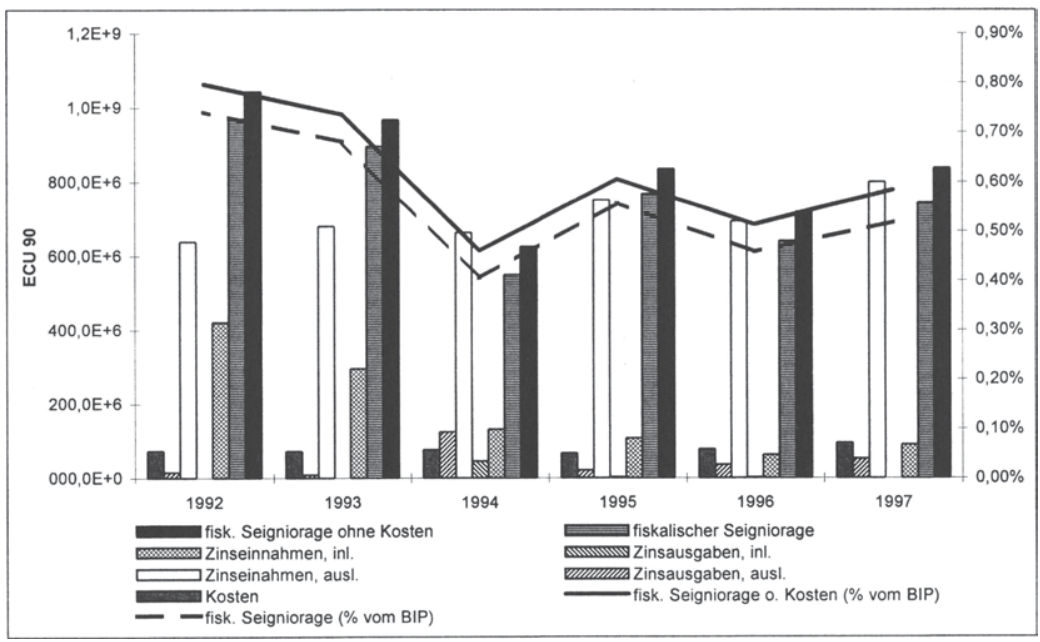

Quelle:

eigene Berechnungen, Geschäftsbericht der Osterreichischen Nationalbank, verschiedene Jahrgänge

Zunehmenden Anteil am Seigniorage hatten die Zinseinnahmen aus ausländischen Anlagen. Während 1992 der ausländische Anteil an den gesamten Zinseinnahmen etwa $60 \%$ betrug, erreichten diese Einnahmen 1997 einen Anteil von $90 \%$. Diese Bedeutungszunahme lag zwar auch an einer absoluten Zunahme der Zinseinnahmen aus den Währungsreserven in erster Linie aber an dem starken Rückgang der inländischen Zinseinnahmen.

\subsubsection{Ursachenanalyse}

\subsubsection{Zins aus Eskont-, Darlehens- und Offenmarktgeschäften}

Abbildung 7-22 zeigt den Verlauf der Bestände aus den der Geldpolitik der Österreichischen Nationalbank dienenden Geschäften. Hier zeigt sich, daß sich die gesamten Bestände von 1992 bis 1996 etwa halbiert haben, wobei die Bestände aus den Eskontgeschäften nahezu unverändert blieben, während die Offenmarktgeschäfte stark an Volumen abnahmen. Erst 1997 gab es wieder eine Zunahme der Bestände aus der Offenmarktpolitik, so daß auch die Gesamtbestände wieder auf über $60 \mathrm{Mrd}$. ÖS stiegen. Die zugehörigen Zinsen zeigt Abbildung 7-23. Die ein- 
nahmerelevanten Sätze für Tender- und Eskontgeschäfte sanken von über $9 \%$ bzw. $8 \%$ auf $3 \%$ bzw. 2,5\%. Der Rückgang des Seigniorage bis 1996 ist also sowohl durch einen Rückgang der Kreditvergabe an die inländischen Geschäftsbanken als auch durch einen Rückgang der Zinssätze für diese Geschäfte erklärbar.

Abbildung 7-85: Bestände aus Eskont-, Darlehens- und Offenmarktgeschäften (Österreich)

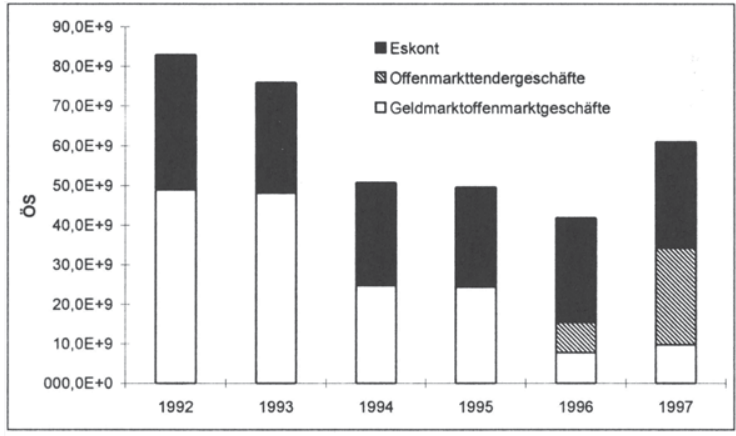

Quelle: $\quad$ eigene Berechnungen nach Geschäftsberichten der Osterreichischen Nationalbank, verschiedene Jahrgänge

Abbildung 7-86: Zinssätze für Eskont-, Darlehens- (Lombardsatz) und Offenmarktgeschäften (GOMEX- und Tendersatz), Periodendurchschnitt (Österreich)

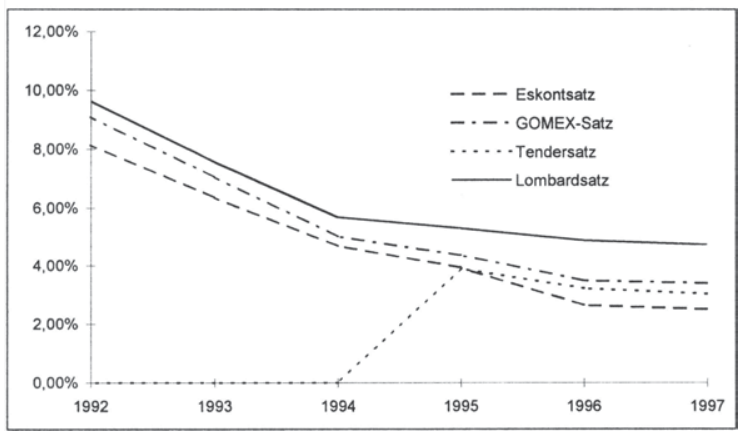

Quelle:

Während der Rückgang der Kreditvergabe später analysiert werden soll, läßt sich an dieser Stelle der Seignioragerückgang aufgrund der sinkenden Zinsen quantifizieren. Dazu kann man sich der ersten Methode (vgl. 6.2.1) der Berechnung des Zinseffekts bedienen, da sich die Zinserträge hinreichend genau mit Hilfe der Bestände und der jeweiligen Zinssätze berechnen lassen (vgl. Abbildung 7-87). 
Abbildung 7-87: Schätzung der Zinseinnahmen für Osterreich

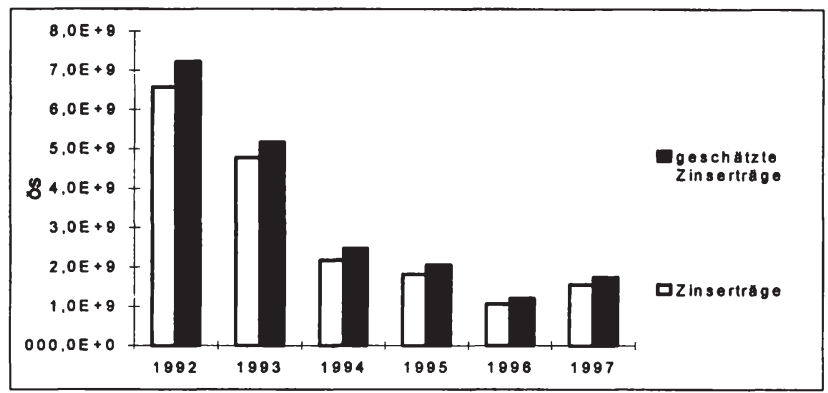

Quelle: $\quad$ eigene Berechnungen nach Geschäftsberichten der Osterreichischen Nationalbank, verschiedene Jahrgänge

Berechnet man die möglichen Zinserträge bei gegebenen Beständen aus der Kreditvergabe an inländische Geschäftsbanken mit den 1992 geltenden Notenbankzinssätzen, so ergibt sich für Österreich ein potentieller Zinsertrag für 1997 von 5,1 Mrd. ÖS. Das sind 3,5 Mrd. ÖS mehr als der tatsächlich 1997 erreichte Zinsertrag.

\subsubsection{Zins für Einlagefazilität}

Der Zinsaufwand für die Einlagefazilität läßt sich nur für die Jahre 1995 bis 1997 analysieren, da vor diesem Zeitraum keine Bestände aus dieser Fazilität in den betreffenden Geschäftsberichten ausgewiesen werden.

Abbildung 7-88: Bestände und Zinssatz der Liquiditätsabschöpfung

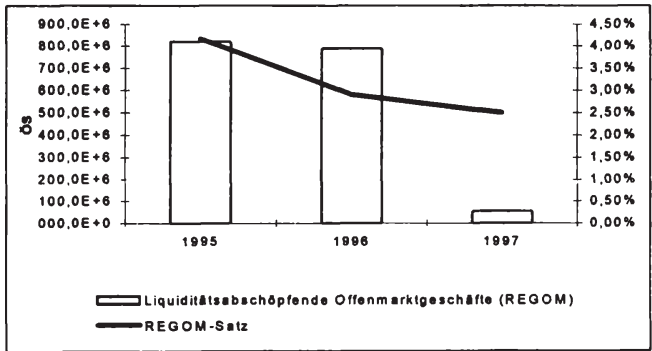

Quelle:

eigene Berechnungen nach Geschäftsberichten der Osterreichischen Nationalbank, verschiedene Jahrgänge

Da sich der REGOM-Satz im wesentlichen am Eskontsatz orientiert (vgl. Borio 1997, 43), der im Betrachtungsraum kontinuierlich gesunken ist, ist der starke Anstieg der Zinsausgaben für die Einlagefazilitäten im Jahre 1994 offenbar auf eine starke Inanspruchnahme dieses Instruments von Seiten der Geschäftsbanken zurückzuführen. 
Hätte der REGOM-Zinssatzes (angenähert durch den Eskontsatz) von 1992 auch in 1997 gegolten, so hätte die Österreichische Nationalbank Zinsausgaben von 3,1 Mio. ÖS statt tatsächlichen 1,4 Mio. ÖS zu verzeichnen gehabt.

\subsubsection{Nachfrage nach Zentralbankgeld}

\section{Mindestreserven}

Den Verlauf der Mindestreservehaltung österreichischer Geschäftsbanken gibt Abbildung 7-25 wieder:

Abbildung 7-89: Mindestreservehaltung der Geschäftsbanken in Österreich

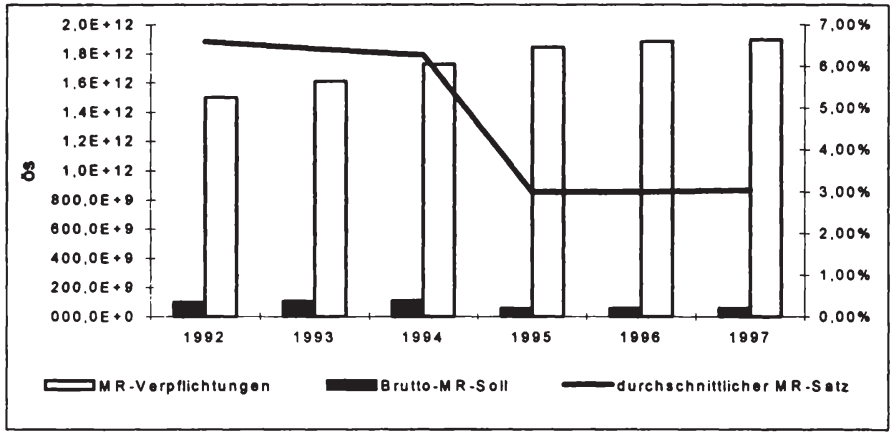

Quelle:

eigene Berechnungen nach Geschäftsbericht der Osterreichischen Nationalbank 1997, 11*

Der Verlauf des Mindestreservesolls läßt zwei Phasen erkennen: Die erste Phase von 1992 bis 1994 ist geprägt von einem leicht sinkenden Mindestreservesatz bei gleichzeitig ansteigenden mindestreservepflichtigen Verbindlichkeiten der Geschäftsbanken. In der Summe resultieren daraus leicht ansteigende Mindestreservesolls von 99 Mrd. ÖS (1992) auf 108 Mrd. ÖS (1994). Die zweite Phase zeichnet sich durch konstante Mindestreservesätze und ebenfalls relativ konstante Mindestreserveverpflichtungen aus, so daß die Mindestreservehaltung in dieser Phase bei 55 bis 57 Mrd. ÖS lag. Die faktische Halbierung dieser Reservehaltung ist auf eine drastische Reduzierung der Mindestreservesätze in zwei Schritten im Jahre 1995 zurückzuführen (vgl. Geschäftsbericht der Österreichischen Nationalbank 1997, 11*). Allerdings wirkte sich diese Verringerung der Mindestreserve keineswegs auf die Kreditnachfrage der Geschäftsbanken aus (siehe Abbildung 7-22). Die gesamten Bestände aus Geldmarktoperationen der Nationalbank veränderten sich im Jahresdurchschnitt nicht. Demgegenüber gab es aber 1994 einen starken Nachfragerückgang nach Zentralbankgeld, der sich vor allem in einem Rückgang der Offenmarktgeschäfte widerspiegelte. Als Ursache hierzu wird im Geschäftsbericht der Österreichischen Nationalbank allerdings nur "die gute Liquiditätssituation der Geschäftsbanken" (Geschäftsbericht der Österreichischen Nationalbank 1994, 76) genannt, die sich teilweise aus einer liquiditätswirksamen Zunahme der 
Devisenbestände und einer hohen Gewinnausschüttung der Nationalbank während des Jahres erklärt.

Inflation

Die Preissteigerungsrate für Österreich reduzierte sich im Betrachtungszeitraum von $4,1 \%$ auf $1,6 \%$.

Abbildung 7-90: Preissteigerungsrate des BIP für Osterreich

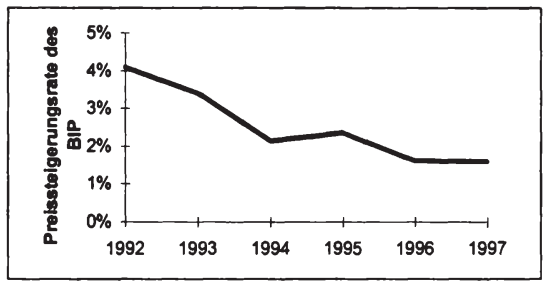

Quelle:

eurostat

Unterstellt man wieder die Konstanz der Verhältnisse von reservepflichtigen Verbindlichkeiten sowie dem Banknotenumlauf zum nominalen BIP und bildet den Mittelwert dieser Verhältnisse über den Betrachtungszeitraum, so wird eine komparativ-statische Analyse der Zentralbankgeldnachfrage mit und ohne Veränderung der Preissteigerungsrate sowie des Mindestreservesatzes möglich.

Tabelle 7-11: Berechnung des Seigniorageverlusts aufgrund steigender Preisstabilität und Reduzierung der Mindestreserve für Osterreich

\begin{tabular}{|l|c|}
\hline ZBG97 & $325,5 \mathrm{E}+9$ \\
\hline C97 & $187,0 \mathrm{E}+9$ \\
\hline MR97 & $138,5 \mathrm{E}+9$ \\
\hline BIPn97 & $2,7 \mathrm{E}+12$ \\
\hline DMR97 & $2,1 \mathrm{E}+12$ \\
\hline BIPr90(97) & $2,1 \mathrm{E}+12$ \\
\hline PI92 & $4,10 \%$ \\
\hline mrs92 & $6,59 \%$ \\
\hline ZBG(97) & $318,4 \mathrm{E}+9$ \\
\hline d ZBG & $7,1 \mathrm{E}+9$ \\
\hline d Seigniorage (OOS) & $646,0 \mathrm{E}+6$ \\
\hline Deflator97 & 132,40 \\
\hline OS90 & $487,9 \mathrm{E}+6$ \\
\hline ECU90 & $237,8 \mathrm{E}+6$ \\
\hline \%vom BIP & $0,02 \%$ \\
\hline
\end{tabular}

Quelle:

eigene Berechnungen

Bei Konstanz der Preissteigerungsrate von 1992 (4,10\%) und einem Mindestreservesatz von durchschnittlich $6,59 \%$, entsprechend des Durchschnittssatzes von 1992, hätte die Nachfrage nach Zentralbankgeld 1997 nominal etwa 7 Mrd. ÖS 
mehr betragen als sie tatsächlich betrug. Die zusätzlichen Zinseinnahmen bei einem Offenmarktzinssatz von 9,1\% (durchschnittlicher GOMEX-Satz von 1992) hätten dann 646 Mio. ÖS betragen. Bezogen auf 1990 (mit Hilfe des Deflators97) ist dies ein realer Seigniorageverlust von $488 \mathrm{Mio}$. ÖS90 jährlich, bzw. 0,02\% des BIP.

\subsubsection{Kosten}

Da sich die Kosten kaum im Zeitablauf veränderten und zudem eine detaillierte Aufteilung in allgemeine Verwaltungskosten und Kosten für den Banknotendruck nicht möglich ist, wird eine genauere Kostenanalyse hier nicht vorgenommen.

\subsubsection{Währungsreserven}

Die Währungsreserven der Österreichischen Nationalbank stiegen im Beobachtungszeitraum von 130 auf $195 \mathrm{Mrd}$. ÖS an, während die Verbindlichkeiten meist unter 200 Mio. ÖS blieben. Erst 1997 stiegen sie auf knapp 1,4 Mrd. ÖS waren aber selbst nach diesem Anstieg im Vergleich zu den Devisen und Valuten weiterhin unbedeutend. Mit dem Anstieg der Währungsreserven läßt sich zwar auch der Anstieg der Zinseinnahmen aus den Währungsreserven nachvollziehen, für eine genauere Analyse wären allerdings Informationen zum Portefeuille und den ausländischen Zinssätzen nötig. Kein Zusammenhang läßt sich zwischen den Verbindlichkeiten gegenüber ausländischen Kreditinstituten und den Zinsausgaben an das Ausland erkennen.

Abbildung 7-91: Devisen und Valuten sowie Verbindlichkeiten gegenüber ausländischen Kreditinstituten der Osterreichischen Nationalbank

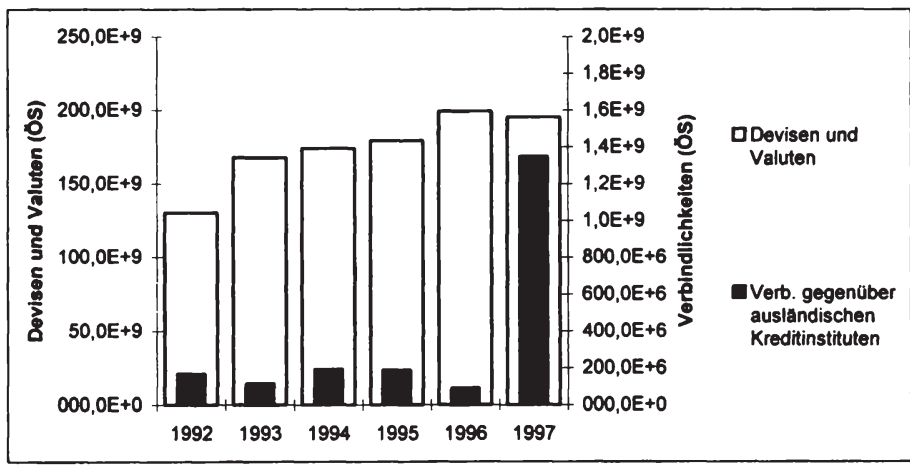

Quelle:

Geschäftsberichte der Österreichischen Nationalbank, verschiedene Jahrgänge

Deutlich wird aber auch, daß die Devisenbestände die Forderungen gegenüber den inländischen Geschäftsbanken deutlich übertreffen, womit sich die Dominanz der Zinserträge aus dem Ausland beim fiskalischen Seigniorage erklärt. 


\subsubsection{Gesamteffekt}

Der gesamte Konvergenzeffekt errechnet sich als Summe aus den Konvergenzeffekten für Zinseinnahmen und -ausgaben, die sich aus einer Veränderung der Notenbankzinsen ergeben (Zinseffekt), sowie dem Konvergenzeffekt durch Verminderung der Mindestreservesätze und der Inflationsreduzierung.

Abbildung 7-92: Quantifizierter Konvergenzeffekt für Österreich

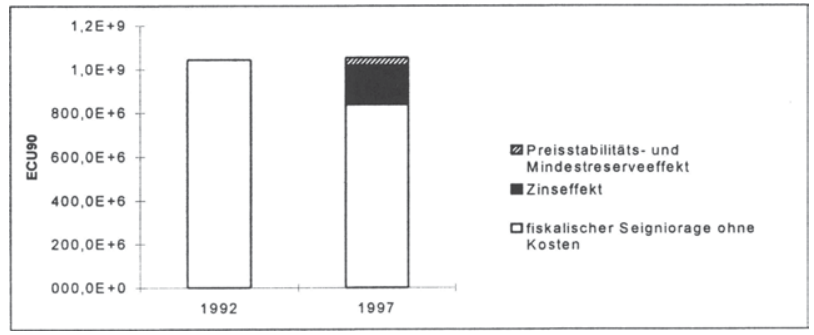

Quelle: eigene Berechnungen

Es zeigt sich, daß Österreich ohne Konvergenz Seigniorageeinnahmen in Höhe von 1,1 Mrd. ECU90 hätte erzielen können; das entspricht 0,73\% des BIP. D.h. ohne Zinseffekt sowie Preisstabilitäts- und Mindestreserveeffekt hätte der fiskalische Seigniorage 1997 etwa die gleiche Höhe erreicht wie 1992.

Tabelle 7-12: Konvergenzeffekt für Osterreich

\begin{tabular}{|c|c|c|c|c|c|}
\hline & & & OS90 & ECU90 & $\%$ vom BIP \\
\hline \multirow{2}{*}{ aus Zinsănderungen } & potentielle Zinseinnahmen & $-3,5 E+9$ & $-2,6 E+9$ & $-180,9 E+6$ & $-0,13 \%$ \\
\hline & potentielle Zinsausgaben & $-3,1 E+6$ & $-2,3 E+6$ & $-162,5 E+3$ & $0,00 \%$ \\
\hline aus $\mathrm{d} \mathrm{mrs}$ und $\mathrm{d} \mathrm{PI}$ & d potentielle Zinseinnahmen & $-646,0 E+6$ & $-487,9 E+6$ & $-33,8 E+6$ & $-0,02 \%$ \\
\hline Konvergenzeffekt & & $-4,1 E+9$ & $-3,1 E+9$ & $-214,5 E+6$ & $-0,15 \%$ \\
\hline
\end{tabular}

Quelle: $\quad$ eigene Berechnungen

Der Zinseffekt hatte am Rückgang des Seigniorage den maßgeblichen Anteil mit 181 Mio. ECU90 gegenüber 34 Mio. ECU90 für den Preisstabilitäts- und Mindestreserveeffekt.

\subsection{Quantifizierung für Portugal}

\subsubsection{Quantifizierung des Konvergenzeffekts}

\subsubsection{Zinsertrag}

Die geldpolitischen Instrumente der portugiesischen Nationalbank veränderten sich im Beobachtungszeitraum derart, daß eine Wirkung auf den fiskalischen Seigniorage nicht ausblieb. Bis 1993 wurde eine expansive Geldpolitik hauptsächlich über den Ankauf von staatlichen Wertpapieren betrieben. Erst 1993 wurden Wertpapierpensionsgeschäfte mit eintägiger Gültigkeitsdauer zu flexiblen Zinssätzen eingeführt (vgl. Banco de Portugal Annual Report 1997, 140) und seit 1997 
werden neben den staatlichen Wertpapieren auch Wertpapiere von privaten Institutionen zur Refinanzierung akzeptiert. Demnach belaufen sich die Zinserträge aus der Kreditvergabe an die Geschäftsbanken erst seit 1994 auf einen höheren Betrag als die Zinsen aus sonstigen inländischen Wertpapieren.

\section{Abbildung 7-93: Zinsertrag aus inländischen Geschäften der Banco de Portugal}

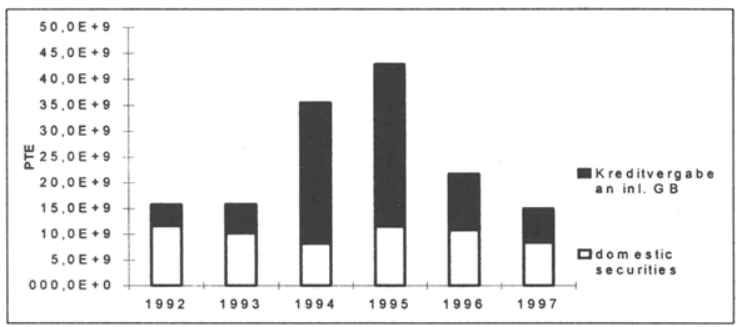

Quelle:

Geschäftsberichte der Banco de Portugal, verschiedene Jahrgänge

\subsubsection{Zinsaufwand}

Auch der Einsatz liquiditätsabschöpfender Instrumente erfuhr in den letzten Jahren eine Wandlung hin zu marktnäheren Maßnahmen. Bis 1994 dominierte hier die Mindestreserve mit einem Zinssatz in Höhe von $17 \%$, der erst im November 1994 auf $2 \%$ gesenkt wurde. Statt dessen konnten die Geschäftsbanken dann überschüssige Zentralbankguthaben über Nacht bei der Zentralbank zu einem fixen Einlagenzinssatz hinterlegen. Zudem begann die Notenbank mit der Liquiditätsabschöpfung mit Hilfe der Ausgabe von Notenbankpapieren.

Die Struktur des Zinsaufwands wandelte sich daher 1994 von mehrheitlich Aufwendungen für die Verzinsung der Mindestreserve $(8,6 \%$ in 1992 und $6,7 \%$ in 1993) zu Zinsaufwendungen aus der Einlagefazilität und aus der Ausgabe von Notenbankpapieren ( $\mathrm{vgl}$. Abbildung). Insgesamt reduzierten sich die Zinsaufwendungen deutlich von 256 Mrd. ECU90 (1992) auf 76 Mrd. ECU90 (1997).

Abbildung 7-94: Zusammensetzung des inländischen Zinsaufwands für die Banco de Portugal

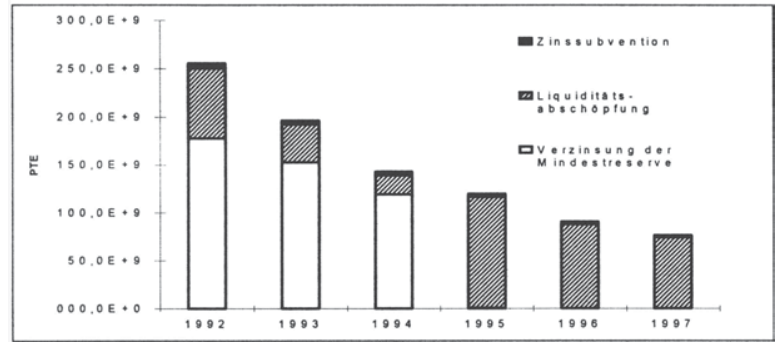

Quelle:

Geschäftsberichte der Banco de Portugal, verschiedene Jahrgänge 


\subsubsection{Kosten}

Die anteiligen Verwaltungskosten beliefen sich zusammen mit den Kosten für die Banknotenausgabe auf Werte zwischen 7 und $10 \mathrm{Mrd}$. PTE, wobei sie im Zeitlauf großen Schwankungen unterlagen. Allerdings ist der Kostenanteil im Verhältnis zu den übrigen Determinanten des Seigniorage so gering, daß eine Analyse hier entfallen soll.

Abbildung 7-95: Anteilige Verwaltungskosten und Kosten der Banknotenausgabe der Banco de Portugal

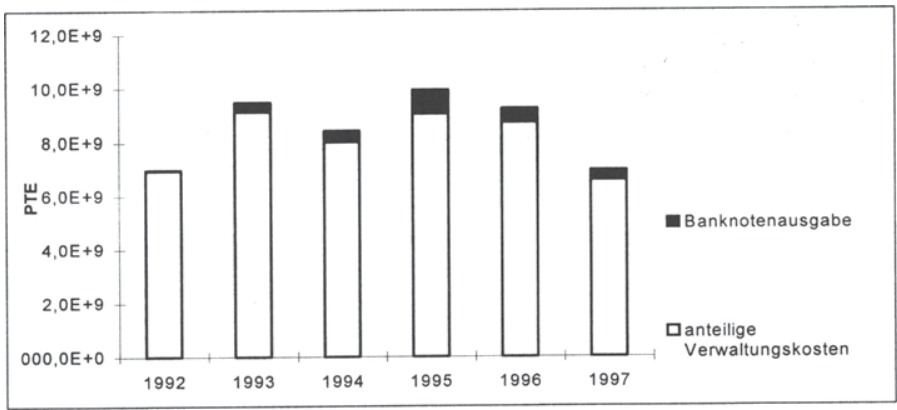

Quelle: eigene Berechnungen nach Geschäftsberichten der Banco de Portugal, verschiedene Jahrgänge

\subsubsection{Gesamteffekt}

Abbildung 7-96: Fiskalischer Seigniorage und seine Entstehung für Portugal

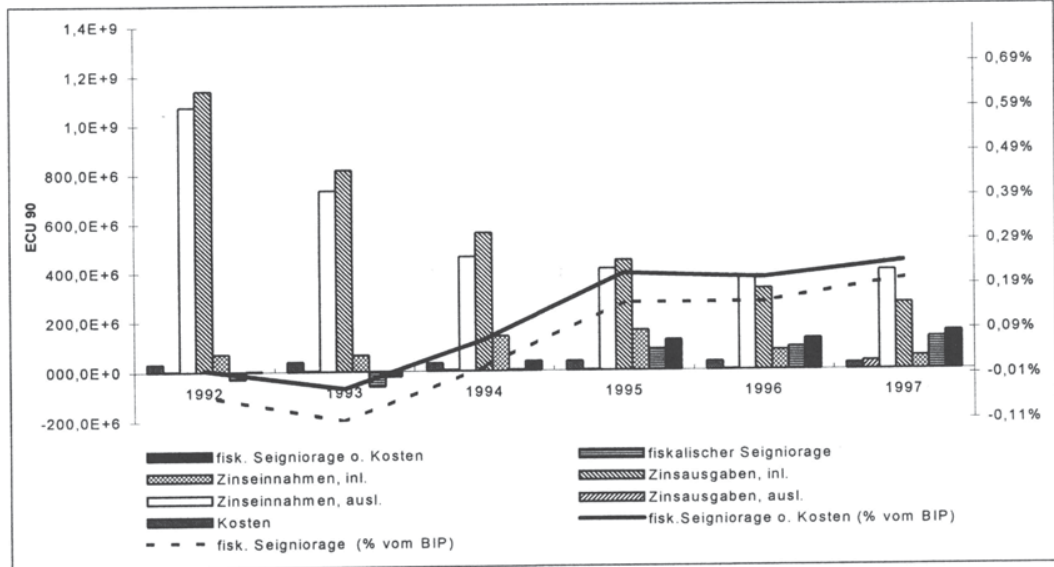

Quelle:

eigene Berechnungen nach Geschäftsberichten der Banco de Portugal, verschiedene Jahrgänge 
Insbesondere aufgrund der hohen Zinskosten im inländischen Geschäft betrug der fiskalische Seigniorage zu Beginn des Beobachtungszeitraumes in Portugal annähernd Null bzw. war bei Berücksichtigung der anteiligen Verwaltungskosten sogar negativ. Erst 1994 bewegte er sich in den positiven Bereich und wuchs bis 1997 (ohne Kostenberücksichtigung) auf 0,24\% des BIP an.

\subsubsection{Ursachenanalyse}

\subsubsection{Bestände aus Diskont-, Lombard- und Offenmarktgeschäften}

Erst 1993 taucht in der Bilanz der Banco de Portugal der Posten der Wertpapierpensionsgeschäfte mit Rückkaufvereinbarung auf, der bis 1995 einen Betrag von 632 Mrd. PTE aufweisen konnte. In den folgenden beiden Jahren sanken die Bestände allerdings bis 113 Mrd. PTE (1997).

Abbildung 7-97: Bestände aus Refinanzierungsgeschäften (Portugal)

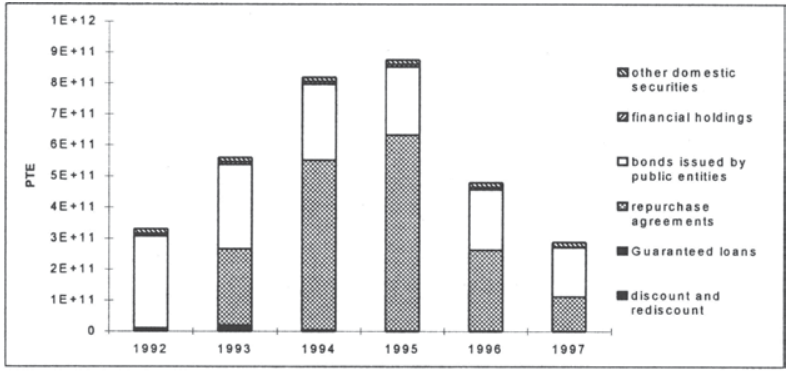

Quelle:

eigene Berechnungen nach Geschäftsberichten der Banco de Portugal, verschiedene Jahrgänge

Allein dieser Verlauf läßt schon die Entwicklung der Zinseinnahmen nachvollziehen. Wenn zudem noch die Entwicklung der Notenbankzinsen mitberücksichtigt wird, kann zumindest der sehr deutliche Rückgang der Zinseinnahmen ab 1995 erklärt werden.

Abbildung 7-98: Zinssătze für Refinanzierungsgeschäfte (Portugal)

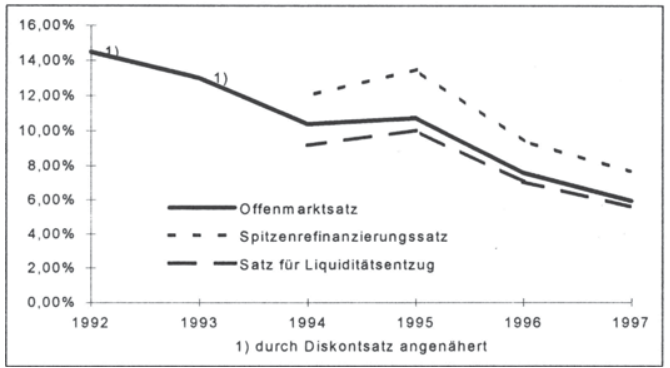

Quelle: $\quad$ eigene Berechnungen nach Geschäftsberichten der Banco de Portugal, verschiedene Jahrgänge 
Dennoch fällt eine Schätzung der Zinseinnahmen mit Hilfe der Bestände und zugehörigen Zinssätze nicht zufriedenstellend aus, so daß der Konvergenzeffekt nur durch das Verhältnis der Zinssätze 1997 und 1992 berechnet werden kann. Allerdings fehlen auch hier die Daten des Offenmarktzinses, weshalb diese für die Jahre 1992 und 1993 durch den Diskontsatz angenähert werden. Ohne Konvergenz hätten die Einnahmen aus dem inländischen Geschäft um $22 \mathrm{Mrd}$. PTE (1997: 15 Mrd. PTE) höher liegen können.

\subsubsection{Liquiditätsabschöpfende Maßnahmen und Verzinsung der Mindestreserve}

1994 wurde in Portugal die Mindestreserve im wesentlichen durch die Ausgabe von Notenbankpapieren ersetzt, was sich deutlich auf der Passivseite der Notenbankbilanz bemerkbar machte. Die Mindestreserve verringerte sich deutlich von 2,2 Mrd. PTE auf knapp 400 Mio. PTE, während die Verbindlichkeiten aus Notenbankpapieren von 24 Mio. PTE auf 1,9 Mrd. PTE anstiegen. Insgesamt läßt sich der kontinuierliche Rückgang der Zinsausgaben allerdings nicht allein aus diesen Daten erklären. Denn danach hätte es 1994 einen Anstieg der Zinsausgaben geben müssen, da die gesamten Verbindlichkeiten gestiegen sind und der Zinssatz der Notenbankpapiere zunächst höher lag als der der Mindestreserveverzinsung. Offenbar wurden auch schon vor 1994 liquiditätsabschöpfende Maßnahmen neben der Mindestreserve eingesetzt, die aber in den Geschäftsberichten nicht explizit aufgeführt wurden, bzw. nach 1994 unterschiedliche Zinssätze auf die Notenbankpapiere zur Anwendung kamen, die ebenfalls nicht explizit aufgeführt wurden.

Abbildung 7-99: Verbindlichkeiten aus der Liquidationsabschöpfung, Mindestreserve und entsprechende Zinssätze (Portugal)

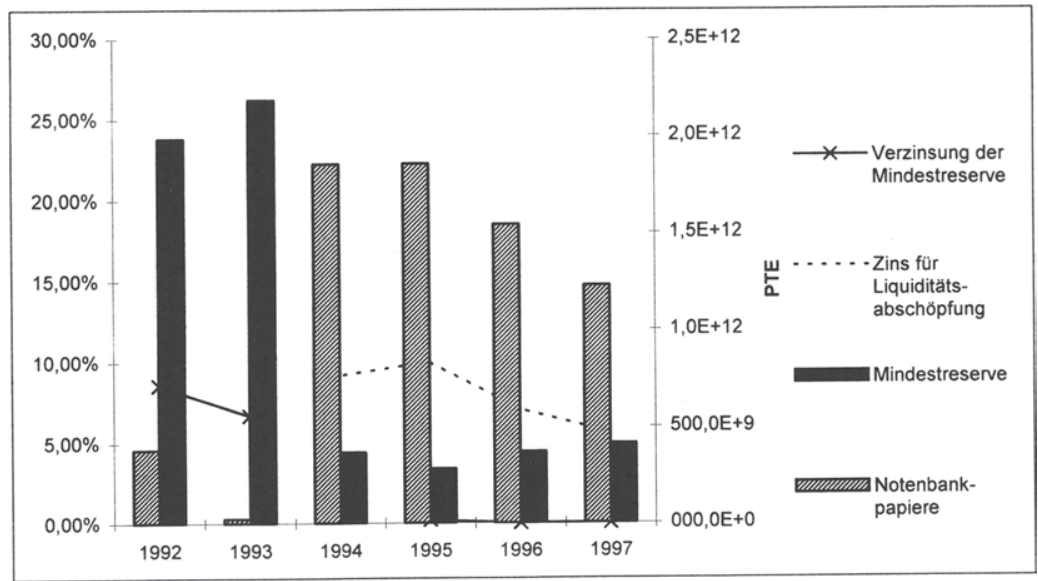

Quelle: $\quad$ Geschäftsberichte der Banco de Portugal, verschiedene Jahrgänge 
Da die Schätzung der Zinsausgaben keine zufriedenstellenden Ergebnisse erbringt, wird auch der Konvergenzeffekt auf die Zinsausgaben nach zweiter Methode (vgl. 6.2.1) berechnet. Als Vergleichszinssatz für 1992 dient in diesem Fall der Satz für die Verzinsung der Mindestreserve, da 1992 keine Notenbankpapiere ausgegeben wurden. Danach ergibt sich ein Konvergenzeffekt auf die Zinsausgaben von 122 Mrd. PTE, d.h. ohne Konvergenz lägen die Zinsausgaben 1997 um diesen Betrag höher.

\subsubsection{Nachfrage nach Zentralbankgeld}

\section{Mindestreserven}

Die drastische Verminderung des Mindestreservesatzes im November 1994 von $17 \%$ auf $2 \%$ (vgl. Banco de Portugal, Annual Report 1997, 140) führte trotz einer hohen Verzinsung der Mindestreserven zu einem Rückgang der Einnahmen. Zunächst sanken die Mindestreserven deutlich von 2,2 Mrd. auf knapp 400 Mio. PTE (vgl. Abbildung). Die Mindestreserve hätte ohne Konvergenz, d.h. Beibehaltung des Mindestreservesatzes und gleicher Inflation wie $1992 \mathrm{im}$ Jahr 1997 rund 5 Bill. PTE betragen statt nur $558 \mathrm{Mrd}$. PTE.

\section{Inflation}

Die Inflation konnte im Beobachtungszeitraum von fast $11 \%$ auf knapp $3 \%$ zurückgeführt werden. Hätte die Preissteigerungsrate von 1992 im gesamten Beobachtungszeitraum weiter gegolten, wäre die Nachfrage nach Zentralbankgeld 1997 nominal um 4,5 Bill. PTE höher ausgefallen.

Abbildung 7-100: Preissteigerungsrate des BIP für Portugal

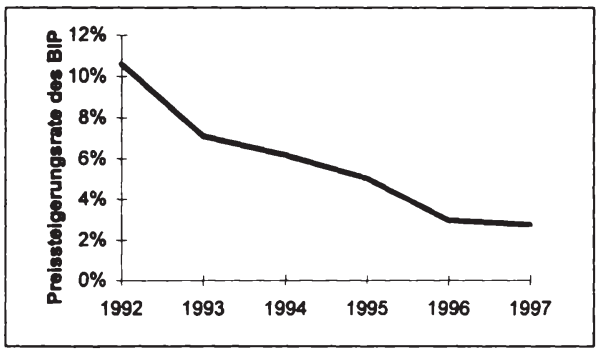

Quelle: $\quad$ eurostat

Die zusätzlichen Zinseinnahmen bei dem 1992 geltenden Offenmarktzinssatz von $14,5 \%$ hätten dann 717 Mrd. PTE betragen. Bezogen auf 1990 - mit dem dann wesentlich höheren Deflator97 - ist dies ein realer Seigniorageverlust von etwa 250 Mrd. PTE90 jährlich (1,9 Mrd. ECU90), bzw. 3,06 \% des BIP.

Dabei muß allerdings noch die zusätzliche Mindestreserveverzinsung berücksichtigt werden, die gut die Hälfte des Effekts - 1 Mrd. ECU90 - wieder kompensiert. 
Tabelle 7-13: Berechnung des Seigniorageverlusts aufgrund steigender Preisstabilität und sinkender Mindestreserve für Portugal

Quelle

\begin{tabular}{|l|l|}
\hline ZBG97 & $6,2 \mathrm{E}+12$ \\
\hline C97 & $1,3 \mathrm{E}+12$ \\
\hline MR97 & $4,9 E+12$ \\
\hline BIPn97 & $23,1 \mathrm{E}+12$ \\
\hline DMR97 & $28,8 \mathrm{E}+12$ \\
\hline BIPr90(97) & $11,4 \mathrm{E}+12$ \\
\hline PI92 & $10,60 \%$ \\
\hline mrs92 & $17,00 \%$ \\
\hline ZBG(97) & $1,3 \mathrm{E}+12$ \\
\hline d ZBG & $4,9 E+12$ \\
\hline d Seigniorage (PTE) & $716,9 \mathrm{E}+9$ \\
\hline Deflator97 & 205,04 \\
\hline d Seigniorage (PTE90) & $349,6 \mathrm{E}+9$ \\
\hline d Seigniorage (ECU90) & $1,9 \mathrm{E}+9$ \\
\hline bzgl. BIP & $3,06 \%$ \\
\hline
\end{tabular}

eigene Berechnungen

\subsubsection{Kosten}

Die Schwankungen der anteiligen Verwaltungskosten im Beobachtungszeitraum ist auf die Schlüsselung der Kosten in Zusammenhang mit der Veränderung der Mindestreserve zurückzuführen. Denn beliefen sich die Mindestreserven 1993 noch auf 2,2 Bill. PTE, so waren es 1994 nur noch 267 Mrd. PTE, während die Verbindlichkeiten aus ausgegebenen Banknotenpapiere in stärkerem Maße stiegen und somit den Schlüssel der anteiligen Verwaltungskosten von $29 \%$ auf $37 \%$ anhoben. Erst 1996 und 1997 ging der Schlüssel aufgrund einer Verringerung dieser beiden Posten auf 34 \% bzw. 35 \% zurück. Der höhere Kostenschlüssel während der Jahre 1993 bis 1995 läßt sich sicherlich rechtfertigen, wenn man bedenkt, welche administrativen Umstellungen der Instrumentenwechsel mit sich gebracht hat.

\subsubsection{Währungsreserven}

Abbildung 7-101: Wăhrungsreserven der Banco de Portugal

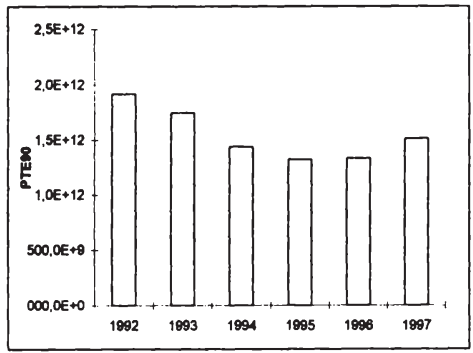

Quelle:

Geschäftsbericht der Banco de Portugal, verschiedene Jahrgänge 
Die Entwicklung der Währungsreserven in Portugal zeigt Abbildung 7-10.

Danach haben sich die Währungsreserven zwischen 1992 und 1997 von 1,9 Bill. auf zwischenzeitlich 1,3 Bill. und 1997 schließlich auf 1,5 Bill. PTE reduziert. Während sich zumindest der Verlauf der Währungsreserven im Verlauf der Zinseinnahmen aus diesen widerspiegelt, lassen sich über die Entwicklung der absoluten Höhe der Zinseinnahmen ohne eine detaillierte Zinsstrukturanalyse des Devisenportefeuille wenig Aussagen treffen.

\subsubsection{Gesamteffekt}

Der gesamte Konvergenzeffekt errechnet sich als Summe aus den Konvergenzeffekten für Zinseinnahmen und -ausgaben, die sich aus einer Veränderung der Notenbankzinsen ergeben, sowie dem Konvergenzeffekt durch Verminderung der Mindestreservesätze und der Inflationsreduzierung unter Berücksichtigung der Mindestreserveverzinsung.

Tabelle 7-14: Konvergenzeffekt für Portugal

\begin{tabular}{|c|c|c|c|c|c|}
\hline \multirow{2}{*}{\begin{tabular}{|l|} 
\\
aus Zinstinderungen
\end{tabular}} & & PIE & PIE9O & EQ90 & \%vom BP \\
\hline & dZnseimahmen & $-21, \bar{E}+9$ & $-10,6 E+9$ & $-58,4 E+6$ & $-0,09 \%$ \\
\hline & dZnsausgaben & $-121, \pi E+9$ & $-59,4 E+9$ & $-327,7 E+6$ & $-0,52 \%$ \\
\hline aus $d$ ms und $d P$ & d potentielle Znseimahmen & $-716,9 E+9$ & $-349,6 E+9$ & $-1,9 E+9$ & $-3,06 \%$ \\
\hline \multicolumn{2}{|c|}{ Verzinsung der Mindestresenve } & $371,4 E+9$ & $181,1 E+9$ & $1,0 E+9$ & $1,58 \%$ \\
\hline \multicolumn{2}{|l|}{ Konvergeresefiliald } & $-245,5 E+9$ & $-119,7 E+9$ & $-61,2 E+6$ & $-1,05 \%$ \\
\hline
\end{tabular}

Quelle:

eigene Berechnungen

1997 betrug der fiskalische Seigniorage ohne Kosten 128.500 ECU90, ohne Konvergenz hätte er um 661.200 ECU90 höher liegen können. Zwar hätten die potentiellen Mehreinnahmen aus einer verstärkten Nachfrage nach Zentralbankgeld aufgrund hoher Inflation und hoher Mindestreservesätze über $3 \%$ des BIP betragen, jedoch reduziert sich dieser Effekt im wesentlichen aufgrund der Verzinsung der Mindestreserve. Auch die übrigen liquiditätsabschöpfenden Maßnahmen lassen den Zinseffekt insgesamt negativ werden, d.h. die zusätzlichen Zinsausgaben ohne Konvergenz hätten die Zinseinnahmen mehr als kompensiert. Insgesamt ergibt sich daraus ein Konvergenzeffekt von 1,05\% des BIP.

Abbildung 7-102: Quantifizierter Konvergenzeffekt für Portugal

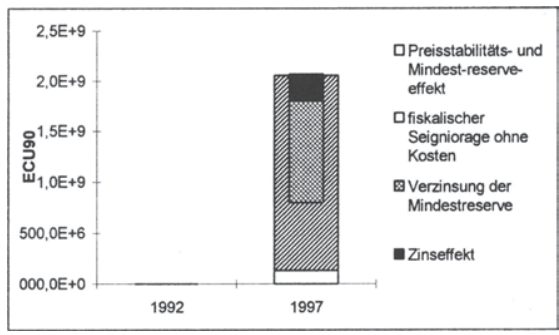

Quelle: eigene Berechnungen 


\subsection{Quantifizierung für Spanien}

\subsubsection{Quantifizierung des Konvergenzeffekts}

\subsubsection{Zinsertrag, Zinsaufwendungen und Kosten}

Die Zinserträge aus den Forderungen gegenüber den inländischen Geschäftsbanken, Zinsaufwendungen aus dem Liquiditätsentzug sowie die anteiligen Verwaltungskosten Kosten entwickelten sich wie folgt:

Abbildung 7-103: Zinserträge, Zinsaufwendungen und Kosten für die Banco de España

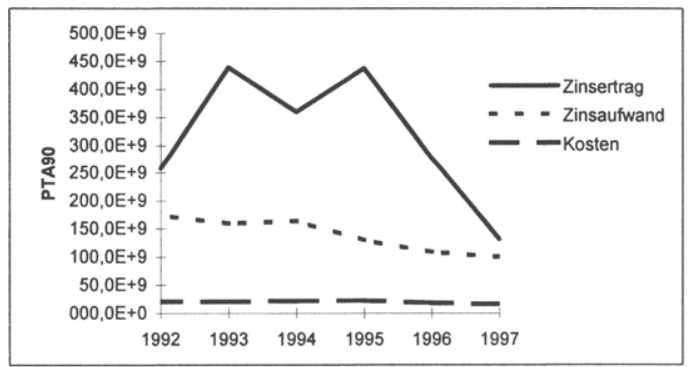

Quelle:

eigene Berechnungen nach Geschäftsberichten der

Banco de España, verschiedene Jahrgänge

Während der Zinsaufwand stetig von knapp $180 \mathrm{Mrd}$. auf $100 \mathrm{Mrd}$. PTA90 fiel, zeigten sich die Zinseinnahmen aus dem inländischen Geschäft vergleichsweise volatil: Nach deutlichen Spitzen 1993 und 1995 von jeweils 440 Mrd. PTA90 fielen die Einnahmen 1997 schließlich auf 130 Mrd. PTA90. Die Kosten blieben dagegen unbedeutend bei knapp $20 \mathrm{Mrd}$. PTA90.

\subsubsection{Zinserträge aus Währungsreserven}

Abbildung 7-104: Zinseinnahmen- und ausgaben aus den Währungsreserven

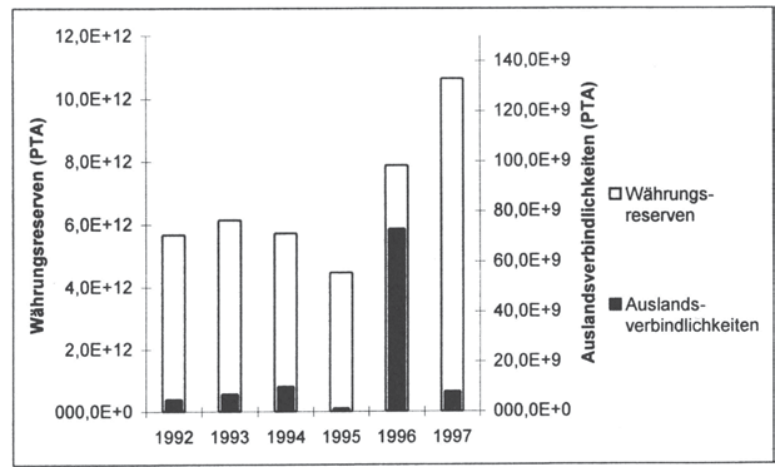

Quelle:

Geschäftsberichte der Banco de España, verschiedene Jahrgänge 
Die Zinseinnahmen aus den Währungsreserven der spanischen Notenbank sanken von rd. 525 Mrd. PTA90 1992 auf zwischenzeitlich (1994) 210 Mrd. PTA90, um anschließend bis 1997 wieder auf knapp 400 Mrd. PTA90 zu steigen. Die Zinsausgaben an das Ausland spielten dagegen keine bedeutende Rolle und bewegten sich zwischen 3,5 und 1,8 Mrd. PTA90.

\subsubsection{Gesamteffekt}

Der Seigniorage in Spanien entwickelte sich sehr volatil: Von 4,7 Mrd. ECU90 $(1,18 \%$ vom BIP) in 1992 startend erreichte der fiskalische Seigniorage ohne Kostenberücksichtigung in den Jahren 1993-95 Werte zwischen 5,4 und 3,8 Mrd. ECU90, um sich anschließend 1996 und 1997 auf einem Niveau von etwa 3,2 Mrd. ECU90 zu stabilisieren. Dies entspricht einem Anteil von 0,75 \% des BIP.

\section{Abbildung 7-105: Fiskalischer Seigniorage und seine Entstehung für Spanien}

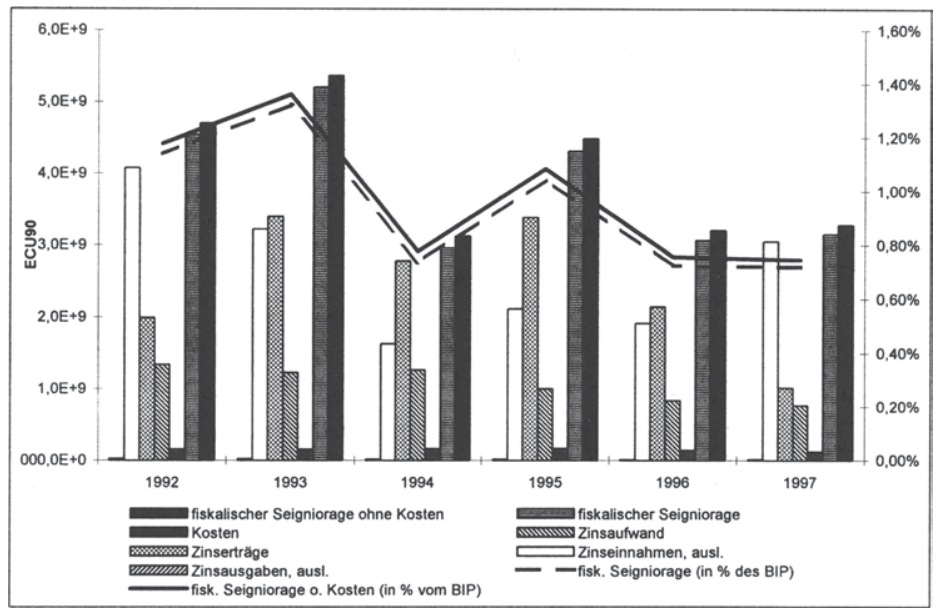

Quelle:

eigene Berechnungen nach Geschäftsberichten der Banco de España und eurostat

\subsubsection{Ursachenanalyse}

\subsubsection{Zins aus Offenmarktgeschäften}

Die Banco de España setzt bei ihrer Geldpolitik keine dauerhaften Fazilitäten ein, sondern konzentriert sich auf Offenmarktgeschäfte. Zur Basisrefinanzierung der Geschäftsbanken dienen 10tägige Offenmarktgeschäfte mit Rückkaufvereinbarungen (vgl. Borio 1997, 47). Die Entwicklung der Jahresendstände der Forderungen der Zentralbank an die inländischen Geschäftsbanken aus diesen Geschäften und den entsprechenden Zinssatz gibt die folgende Abbildung wieder: 
Abbildung 7-106: Bestände aus dem Offenmarktgeschäft und Offenmarktzinssatz (Spanien)

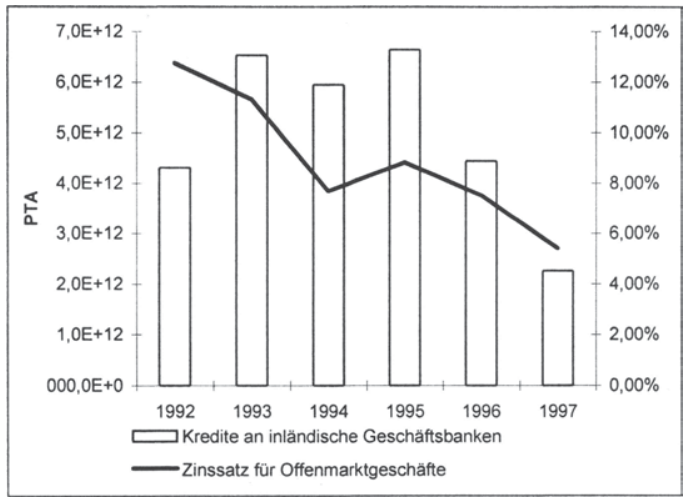

Quelle:

Geschäftsberichte der Banco de España, eurostat, Monatsberichte der Deutschen Bundesbank, verschiedene Jahrgänge

Eine Abschätzung des Seigniorageverlusts aufgrund des Zinsrückgangs läßt sich nur anhand des Verhältnisses der Offenmarktzinssätze von 1992 und 1997 und den tatsächlichen Zinseinnahmen von 1997 durchführen, da die Daten der Geschäftsberichte keine zufriedenstellende Schätzung des Zinsertrags erbringen konnten (vgl. 6.2.1). Danach wären mit den 1992 geltenden Offenmarktzinsen 1997 Zinseinnahmen von 425 Mrd. PTA statt 180 Mrd. PTA erzielbar gewesen.

\subsubsection{Zins zur Liquiditätsabschöpfung}

Zur Liquiditätsabschöpfung verwendet die spanische Zentralbank eigene Wertpapiere, die für einen Tag ausgegeben werden. Allerdings lassen der Zentralbankbilanz der Banco de España keine Angaben über die Höhe dieser Verbindlichkeiten im Zeitablauf entnehmen, so daß hier keine Ursachenanalyse stattfinden kann. Da somit auch keine Zinsaufwandsschätzung mit Hilfe von Beständen durchgeführt werden kann, wird der Zinseffekt der Aufwendungen (d.h. um wieviel höher wären die Zinsaufwendungen, wenn für liquiditätsabschöpfende Maßnahmen die 1992 geltenden Zinssätze anzuwenden wären) abgeschätzt, indem die Aufwendungen von 1997 mit dem Verhältnis der Offenmarktzinssätze von 1992 und 1997 multipliziert wird (vgl. 6.2.1). Die zusätzlich nötigen Aufwendungen würden 186 Mrd. PTA betragen (Zinsaufwendungen 1992: 137 Mrd. PTA).

\subsubsection{Nachfrage nach Zentralbankgeld}

\section{Mindestreserven}

Die Mindestreservesätze wurden, da den Geschäftsberichten der Banco de España keine entsprechenden Daten zu entnehmen sind, den International Financial Statistics (vgl. IMF 1998) entnommen. 
Abbildung 7-107: Mindestreserve und durchschnittlicher Mindestreservesatz in Spanien

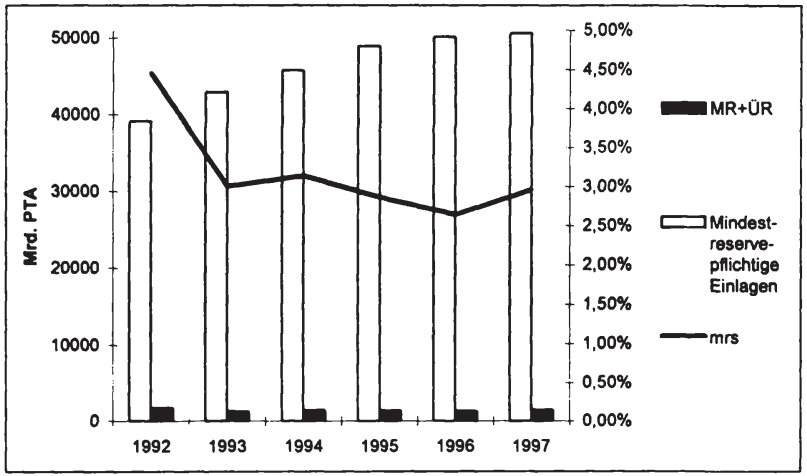

Quelle:

eigene Berechnungen nach IMF (1998)

Der durchschnittliche Mindestreservesatz sank von anfänglich 4,5\% auf knapp $3 \%$ in 1997. Da parallel dazu die mindestreservepflichtigen Einlagen von 40 auf 50 Bill. PTA zunahmen, erlitt die Mindestreserve nur einen deutlichen Einbruch im Jahre 1993 von 1,7 auf 1,3 Bill. PTA. In den darauffolgenden Jahren stieg sie aber wieder leicht an und erreichte 1997 wieder 1,5 Bill. PTA.

Inflation

Die Veränderung der Preissteigerungsrate im Betrachtungszeitraum zeigt die folgende Abbildung:

Abbildung 7-108: Jährliche Preissteigerungsrate des BIP (Spanien)

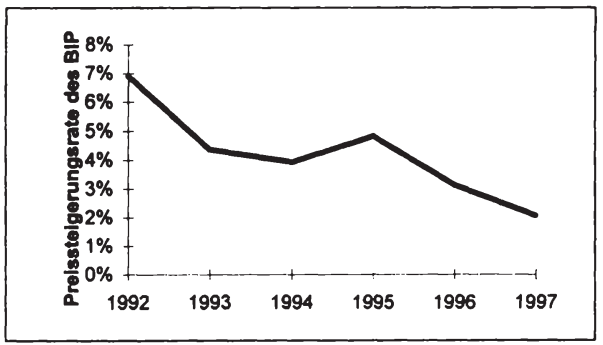

Quelle:

eurostat

Von knapp $7 \%$ sank die Preissteigerungsrate des BIP im Beobachtungszeitraum fast auf $2 \%$. Die Auswirkungen auf die Höhe des Zentralbankgelds waren dementsprechend hoch: Ohne den Rückgang von Mindestreserve und Inflation wäre die Nachfrage nach Zentralbankgeld c. p. um 2,6 Bill. PTA höher ausgefallen, d.h. bei gleichbleibenden Refinanzierungssätzen der Zentralbank von 1992 hätte der Seigniorage 1997 deflationiert mit dem modifizierten Deflator97 um knapp 700 Mio. ECU90, bzw. 0,16 \% vom BIP höher liegen können. 
Tabelle 7-15: Berechnung des Seigniorageverlusts aufgrund steigender Preisstabilität und Reduzierung der Mindestreserve für Spanien

\begin{tabular}{|l|r|}
\hline ZBG97 & $12,5 \mathrm{E}+12$ \\
\hline C97 & $9,7 \mathrm{E}+12$ \\
\hline MR97 & $2,8 \mathrm{E}+12$ \\
\hline BIPn97 & $90,6 \mathrm{E}+12$ \\
\hline DMR97 & $62,7 \mathrm{E}+12$ \\
\hline BIPr90(97) & $56,8 \mathrm{E}+12$ \\
\hline PI92 & $6,90 \%$ \\
\hline mrs92 & $4,45 \%$ \\
\hline ZBG(97) & $9,9 \mathrm{E}+12$ \\
\hline d ZBG & $2,6 \mathrm{E}+12$ \\
\hline d Seigniorage & $141,2 \mathrm{E}+9$ \\
\hline Deflator97 & 159,84 \\
\hline PTA90 & $88,4 \mathrm{E}+9$ \\
\hline ECU90 & $683,3 \mathrm{E}+6$ \\
\hline \%vom BIP & $0,16 \%$ \\
\hline
\end{tabular}

Quelle

eigene Berechnungen

\subsubsection{Kosten}

Der geringe Anteil der Kosten am Seigniorage und die nur geringe Veränderung der anteiligen Verwaltungskosten im Zeitablauf lassen hier keine Ursachenanalyse sinnvoll erscheinen.

Abbildung 7-109: Kosten des Notendrucks und anteilige Verwaltungskosten

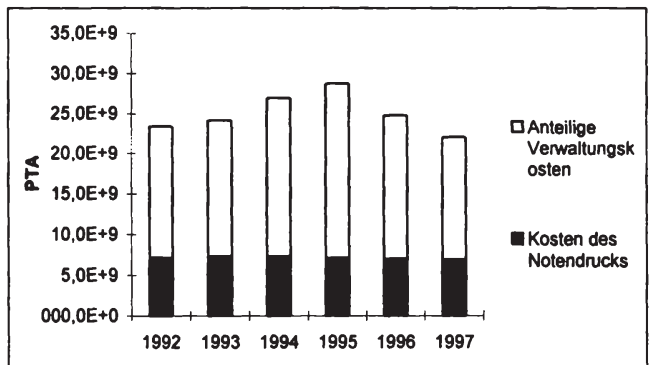

Quelle: $\quad$ Geschäftsberichte Banco de España, verschiedene Jahrgänge

\subsubsection{Währungsreserven}

Die Währungsreserven nahmen im Beobachtungszeitraum von 5,7 auf 10,6 Bill. PTA zu. Die Verbindlichkeiten gegenüber dem Ausland blieben dagegen unter 10 Mrd. PTA und erreichten nur 1996 einen Wert von gut 70 Mrd. PTA. Die Zunahme der Währungsreserven steht in keinem Zusammenhang zur Entwicklung der Zinseinnahmen aus den Währungsreserven. Allerdings kann anhand der Geschäftsberichte der spanischen Nationalbank auch keinerlei Unterscheidung getroffen werden zwischen ertragbringenden Währungsreserven (Devisen) und sol- 
chen, die keinen Ertrag erzielen (Gold, Valuten, Sonderziehungsrechte etc.) ${ }^{17}$. Eine genaue Analyse der Zinsentwicklung aus den Währungsreserven würde aber Informationen darüber und über die entsprechende Verzinsung der Aktivposten erfordern.

Abbildung 7-110: Auslandsaktiva und -passiva der spanischen Notenbank

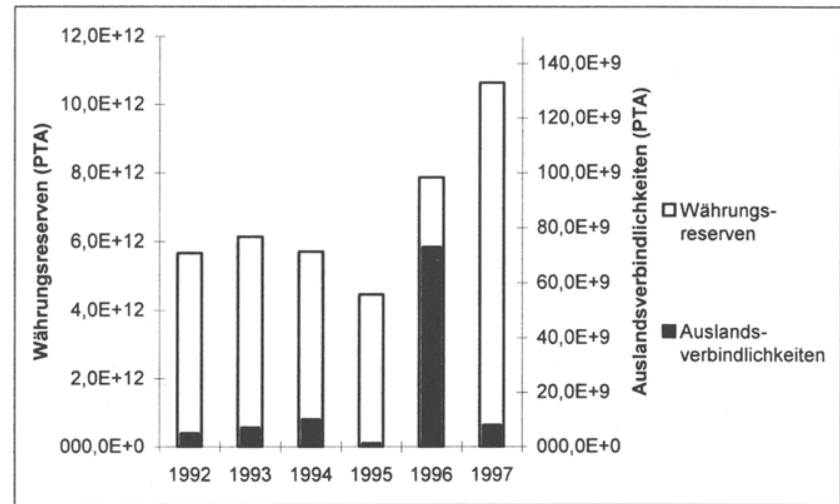

Quelle: $\quad$ Geschätsberichte Banco de España, verschiedene Jahrgänge

\subsubsection{Gesamteffekt}

Der Konvergenzeffekt setzt sich zusammen aus dem Preisstabilitäts- und Mindestreserveeffekt sowie dem Zinseffekt.

Abbildung 7-111: Quantifizierter Konvergenzeffekt für Spanien

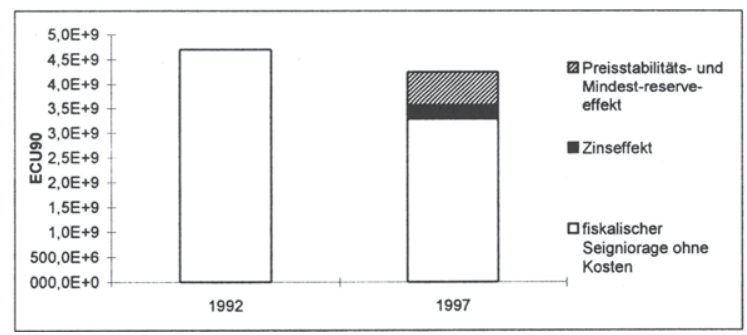

Quelle: $\quad$ eigene Berechnungen

17 Spätestens an dieser Stelle stellt sich die Frage, welche Informationen der Geschäftsbericht der Banco de España überhaupt enthält. Leider muß die Antwort darauf lauten: „sehr wenig"; und auch Versuche, telefonische Auskünfte zu erlangen, waren aufgrund ausschließlich spanisch sprechender Auskunftswilliger nicht von Erfolg gekennzeichnet, so daß die Analyse für Spanien mit sehr viel Vorsicht betrachtet werden muß. 
Tabelle 7-16: Zusammensetzung des Konvergenzeffekts für Spanien

\begin{tabular}{|llrrrr|}
\hline & & PTA & PTASO & ECUSO & \%vomBIP \\
\hline aus Znsänderungen & dZnseimahmen & $-245,0 E+9$ & $-153,3 E+9$ & $-1,2 E+9$ & $-0,27 \%$ \\
& d Znsausgaben & $-186,0 E+9$ & $-116,4 E+9$ & $-900,1 E+6$ & $-0,20 \%$ \\
aus d mrs und d PI & d potentielle Znseimahmen & $-141,2 E+9$ & $-88,4 E+9$ & $-683,3 E+6$ & $-0,16 \%$ \\
\hline Kormergenrzefielt & & $-200,2 E+9$ & $-125,2 E+9$ & $-968,5 E+6$ & $-0,22 \%$ \\
\hline
\end{tabular}

Quelle:

eigene Berechnungen

Der Konvergenzeffekt beträgt demnach bei allen Einschränkungen, die man aufgrund der mangelhaften Datenlage für Spanien konstatieren muß knapp 1 Mrd. ECU90 bzw. 0,22\%.

\subsection{Vergleich der Konvergenzeffekte}

Ein Vergleich des fiskalischen Seigniorage der einzelnen Mitgliedsstaaten der EWU-11 von 1992 und 1997 ergibt folgendes Bild:

Abbildung 7-112: Fiskalischer Seigniorage 1992 und 1997 der EWU-11 im Vergleich

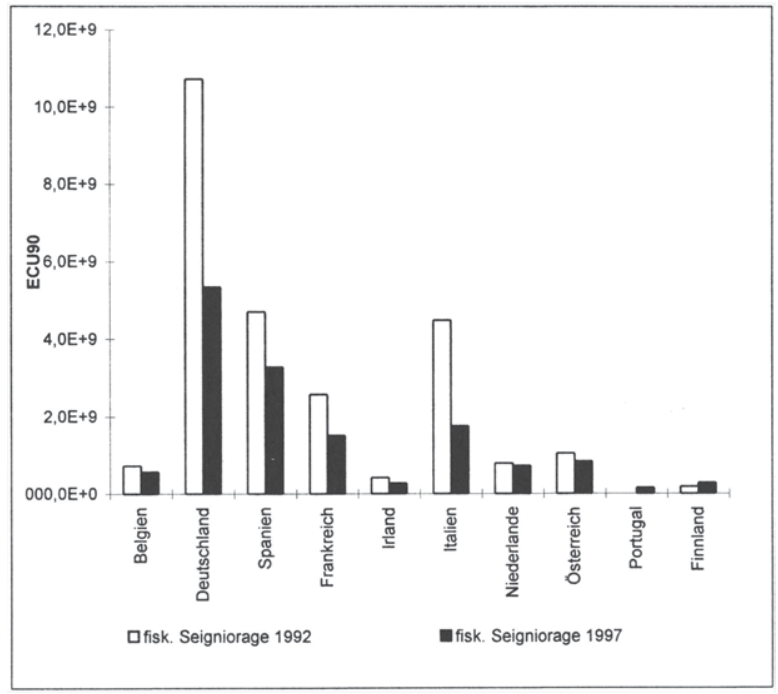

Quelle: $\quad$ eigene Berechnungen

Absolut betrachtet reduzierte sich der Seigniorage in allen EWU-11 Staaten erheblich, bis auf den Geldschöpfungsgewinn der Staaten Finnland und Portugal, bei denen der fiskalische Seigniorage - allerdings von einem sehr geringen Niveau aus - sogar anstieg. Die höchsten absoluten Seigniorage-Werte erzielten 1992 die 
Notenbanken Deutschlands (10,7 Mrd. ECU90), Spaniens (4,7 Mrd. ECU90), Italiens (4,5 Mrd. ECU90), Frankreichs (2,6 Mrd. ECU90) und Österreichs (1,0 Mrd. ECU90). Deutschland erzielte auch 1997 noch den höchsten Seigniorage-Wert, allerdings ist dieser gegenüber 1992 um $50 \%$ gesunken. Die weiteren Staaten mit absolut hohem Seigniorage-Einkommen 1997 sind Spanien (3,3 Mrd. ECU90, - $30 \%$ ), Italien (1,8 Mrd. ECU90, - $61 \%$ ) und Frankreich (1,5 Mrd. ECU90, $41 \%)$.

Tabelle 7-17: Veränderungen des Seigniorage zwischen 1992 und 1997

\begin{tabular}{|l|r|r|r|}
\hline & \multicolumn{3}{|c|}{ fiskalischer Seigniorage ECU90 } \\
\hline & 1992 & 1997 & Verănderung \\
\hline Belgien & $727,0 \mathrm{E}+6$ & $563,3 \mathrm{E}+6$ & $-22,52 \%$ \\
\hline Deutschland & $10,7 \mathrm{E}+9$ & $5,3 \mathrm{E}+9$ & $-50,15 \%$ \\
\hline Spanien & $4,7 \mathrm{E}+9$ & $3,3 \mathrm{E}+9$ & $-30,18 \%$ \\
\hline Frankreich & $2,6 \mathrm{E}+9$ & $1,5 \mathrm{E}+9$ & $-41,08 \%$ \\
\hline Irland & $416,1 \mathrm{E}+6$ & $268,6 \mathrm{E}+6$ & $-35,44 \%$ \\
\hline Italien & $4,5 \mathrm{E}+9$ & $1,8 \mathrm{E}+9$ & $-60,85 \%$ \\
\hline Niederlande & $790,9 \mathrm{E}+6$ & $731,2 \mathrm{E}+6$ & $-7,55 \%$ \\
\hline Osterreich & $1,0 \mathrm{E}+9$ & $837,2 \mathrm{E}+6$ & $-19,72 \%$ \\
\hline Portugal & $1,8 \mathrm{E}+6$ & $153,0 \mathrm{E}+6$ & $8569,09 \%$ \\
\hline Finnland & $179,1 \mathrm{E}+6$ & $279,3 \mathrm{E}+6$ & $55,93 \%$ \\
\hline
\end{tabular}

Quelle:

eigene Berechnungen

Betrachtet man die Anteile des Seigniorage am BIP der jeweiligen Staaten, erzielte Spanien 1997 mit 0,75\% den höchsten Anteil, obwohl es einen Rückgang des Seigniorage gegenüber 1992 um 0,43 \%-Punkte erleiden mußte. Einen noch höheren Anteilsverlust mußte Irland mit - 0,62\%-Punkten hinnehmen, ebenfalls erlitten Spanien (- 0,43\%-Punkte), Italien (- 0,32 \%-Punkte) und Österreich ($0,21 \%$-Punkte am BIP) hohe Anteilsverluste am BIP. Portugal konnte dagegen seinen fiskalischen Seigniorage von 0 auf 0,24 \%-Punkte am BIP erhöhen.

Abbildung 7-113: Veränderung der Seigniorage-Anteile am BIP

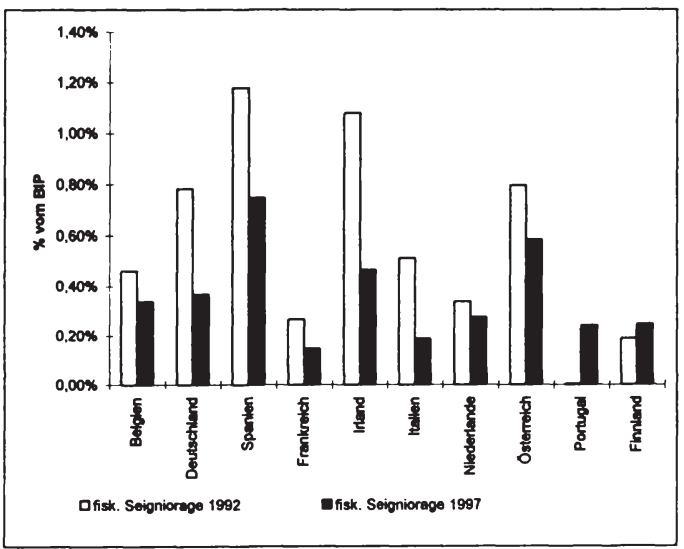

Quelle:

eigene Berechnungen 
Tabelle 7-18: Veränderung des Seigniorage-Anteils am BIP

\begin{tabular}{|l|r|r|r|r|}
\hline & sgn92 & sgn97 & Veränderung & Konv.effekt \\
\hline & $\%$ vom BIP & $\%$ vom BIP & \%Punkte & \%Punkte \\
\hline Belgien & $0,46 \%$ & $0,34 \%$ & $-0,12 \%$ & $0,03 \%$ \\
\hline Deutschland & $0,78 \%$ & $0,37 \%$ & $-0,42 \%$ & $-0,80 \%$ \\
\hline Spanien & $1,18 \%$ & $0,75 \%$ & $-0,43 \%$ & $-0,22 \%$ \\
\hline Frankreich & $0,27 \%$ & $0,15 \%$ & $-0,12 \%$ & $-0,15 \%$ \\
\hline Irland & $1,08 \%$ & $0,46 \%$ & $-0,62 \%$ & $0,10 \%$ \\
\hline Italien & $0,51 \%$ & $0,19 \%$ & $-0,32 \%$ & $-0,53 \%$ \\
\hline Niederlande & $0,34 \%$ & $0,28 \%$ & $-0,06 \%$ & $-0,01 \%$ \\
\hline Osterreich & $0,80 \%$ & $0,58 \%$ & $-0,21 \%$ & $-0,15 \%$ \\
\hline Portugal & $0,00 \%$ & $0,24 \%$ & $0,24 \%$ & $-1,05 \%$ \\
\hline Finnland & $0,19 \%$ & $0,25 \%$ & $0,06 \%$ & $0,34 \%$ \\
\hline
\end{tabular}

Quelle: $\quad$ eigene Berechnungen

Der in fast allen Staaten zu beobachtende Rückgang des fiskalischen Seigniorage kann teilweise durch den Konvergenzeffekt erklärt werden, mit Hilfe dessen versucht wird, den Einfluß der Mindestreservebestimmungen, der Inflationsentwicklung und der Zinsentwicklung auf den fiskalischen Seigniorage abzubilden. Deutlich wird aber, daß der Rückgang des Seigniorage nicht in allen Fällen mit Hilfe des Konvergenzeffekts erklärt werden kann. Eine grobe Übereinstimmung von tatsächlichem Rückgang des fiskalischen Seigniorage und dem Konvergenzeffekt kann man nur für die Staaten Frankreich und Österreich konstatieren. In Spanien und in den Niederlanden ist der Konvergenzeffekt deutlich niedriger als der tatsächliche Rückgang des fiskalischen Seigniorage, und in den Staaten Italien, Deutschland und Portugal hätte aufgrund des Konvergenzeffekts der fiskalische Seigniorage noch stärker sinken müssen als tatsächlich festzustellen ist.

Die Ursachen für ein Abweichen von Konvergenzeffekt und tatsächlichem Seignioragerückgang sind vielfältig. In den meisten Fällen - dies ergibt sich auch aus der Ursachenanalyse - steht die Entwicklung der Zinseinnahmen aus den Währungsreserven in keinem Zusammenhang zu den geldpolitischen Veränderungen im Inland. Da diese Einnahmen aber in vielen Staaten einen sehr hohen Anteil am fiskalischen Seigniorage ausmachen, kann dort der Konvergenzeffekt die tatsächliche Entwicklung nicht nachzeichnen. Weitere Gründe für eine Abweichung zwischen Konvergenzeffekt und dem tatsächlichen Rückgang des fiskalischen Seigniorage sind eine Veränderung der Umlaufgeschwindigkeit des Bargelds oder der mindestreservepflichtigen Guthaben, eine Veränderung der Überschußreserven oder eine Veränderung der Refinanzierungsstruktur der Geschäftsbanken.

Der Konvergenzeffekt kann demnach eine Teilerklärung für die Entwicklung des fiskalischen Seigniorage in den EWU-11 Staaten bieten, diese Entwicklung aber nicht vollständig nachzeichnen. 


\section{Teil III:}

\section{Einnahmeverluste und -gewinne aus der Geldschöpfung als Folge des Übergangs zum Euro}

Das Ziel dieses dritten Teils ist es, eine Näherung für den durch das ESZB (zur Erläuterung des ESZB siehe 11.1) erzielten fiskalischen Seigniorage nach dem Inkrafttreten der dritten Stufe der EWU zu finden und einen Vergleich zu dem 1997 erzielten Seigniorage zu ziehen. Denn nach dem Übergang zum Euro wird sich der Seigniorage insbesondere aufgrund der für viele Nationalbanken neuen, einheitlichen geldpolitischen Instrumente in der dritten Stufe der WWU verändern. Dieser Effekt, im folgenden Übergangseffekt genannt, wird durch Differenzbildung zwischen dem 1997 erzielten Seigniorage und dem voraussichtlich nach dem Übergang am 1.1.99 im Laufe des Jahres 1999 erzielten Seigniorage berechnet.

\section{Ein Prognosemodell zur Berechnung des zukünftigen Geldschöpfungsgewinns des ESZB}

Bevor eine Prognose des zukünftigen Geldschöpfungsgewinns erstellt werden kann, muß zunächst ein Prognosemodell des fiskalischen Seigniorage gefunden werden. Während das Modell des fiskalischen Seigniorage gut dafür geeignet ist, den nationalen Seigniorage einer Notenbank ex post zu berechnen, ist er für die Prognose des fiskalischen Seigniorage nicht geeignet. Zwar lassen sich Prognosen über die Verzinsung der Aktivposten des ESZB treffen, dagegen ist es allerdings kaum möglich, die Höhe der verschiedenen Aktivpositionen des ESZB zu prognostizieren, ohne Annahmen über die makroökonomischen Zusammenhänge und Größen zu treffen, die die Höhe dieser Aktivpositionen bedingen.

Eine Möglichkeit, den fiskalischen Seigniorage zu prognostizieren, bietet - wie oben theoretisch (vgl. 3.4) und empirisch gezeigt (vgl. 3.5) - das Prinzip des Opportunitätskosten-Seigniorage, wenn auch erhebliche Abweichungen zwischen beiden Konzepten zu beobachten sind. Im folgenden soll daher der Verlauf des Opportunitätskosten-Seigniorage der EWU-11 Staaten für die Jahre 1992 bis 1997 mit dem Verlauf des fiskalischen Seigniorage verglichen werden, und dabei unterschiedliche Zinsannahmen getroffen werden, um systematische Abweichungen zu analysieren und darauf aufbauend eine Prognose des fiskalischen Seigniorage durchzuführen.

\subsection{Empirischer Vergleich der Konzepte des fiskalischen Seigniorage und des Opportunitätskosten-Seigniorage für die EWU-Staaten für die Jahre 1992 bis 1997}

Im folgenden soll untersucht werden, ob der Opportunitätskosten-Seigniorage ein geeignetes Konzept zur Prognose des fiskalischen Seigniorage darstellt. Dazu werden die Ergebnisse der Berechnungen des fiskalischen Seigniorage aus Kapitel 
7 den Berechnungen des Opportunitätskosten-Seigniorage für die Jahre 1992 bis 1997 gegenübergestellt. Dabei sollen drei unterschiedliche OpportunitätskostenZinssätze zur Anwendung kommen.

Zum einen soll der Zinssatz für langfristige Staatsanleihen verwendet werden (vgl. Lange/Nolte 1997), weiterhin soll der Zinssatz des Hauptrefinanzierungsgeschäfts der jeweiligen nationalen Zentralbank eingesetzt werden und als drittes soll die in einigen Staaten praktizierte Verzinsung der Mindestreserve Berücksichtigung finden.

Zur Berechnung des Opportunitätskosten-Seigniorage dient allgemein die in 3.2 dargestellte Formel:

$S_{t}^{o p p}=\frac{i M_{t}}{P_{t}}$

Zur Vergleichbarkeit mit dem fiskalischen Seigniorage wird auch der Opportunitätskosten-Seigniorage auf das reale BIP bezogen, so daß gilt:

$$
\frac{S_{t}^{o p p}}{B I P_{\text {real }}}=\frac{i M_{t}}{P_{t}} * \frac{P}{B I P_{n}}=\frac{i M_{t}}{B I P_{n}}
$$

Während für alle drei im folgenden zu untersuchenden Varianten des Opportunitätskosten-Seigniorage das nominale BIP den International Financial Statistics des IWF entnommen wurde ${ }^{18}$, unterscheiden sich die drei Varianten in den verschiedenen Annahmen über den Opportunitätskosten-Zinssatz i und die Zentralbankgeldmenge $M$.

\subsubsection{Opportunitätskosten-Seigniorage - Variante 1}

Variante 1 des Opportunitätskosten-Seigniorage stellt fest, welchen Seigniorage die einzelnen EWU-11 Staaten bei Verzinsung ihrer monetären Basis mit dem Zinssatz für langfristige Staatsanleihen (government bond yield) erzielt hätten bzw. welche Kosten der Staat hätte aufbringen müssen, wenn er die Mittel, die inm durch die Vergabe von Zentralbankgeld zugehen, auf dem Geldmarkt hätte aufnehmen müssen und zu dem Zinssatz für langfristige Staatspapiere hätte verzinsen müssen (vgl. Kapitel 3.2 und Lange/Nolte 1997). Als OpportunitätskostenZinssatz wird in dieser Variante dementsprechend der Zinssatz für langfristige Staatspapiere und als Geldmenge die Zentralbankgeldmenge der nationalen Zentralbanken verwendet. Alle Daten wurden den International Financial Statistics des IWF entnommen ${ }^{19}$.

18

BIPn = Gross Domestic Product (Linie 99b.c). Fehlende Daten der Linie 99b.c wurden durch Daten von eurostat ersetzt.

${ }^{10} \mathrm{M}=$ Reserve Money (Linie 14), $\mathrm{i}=$ Government Bond Yield (Linie 61), BIPn = Gross Domestic Product (Linie 99b.c). Fehlende Daten der Linie 99b.c wurden durch Daten von eurostat ersetzt. 
Folgende Abbildung zeigt die Ergebnisse der Berechnung der ersten Variante des Opportunitätskosten-Seigniorage der EWU-11 Staaten für die Jahre 1992-1997.

Abbildung 8-1: Opportunitätskosten-Seigniorage der EWU-11 Staaten

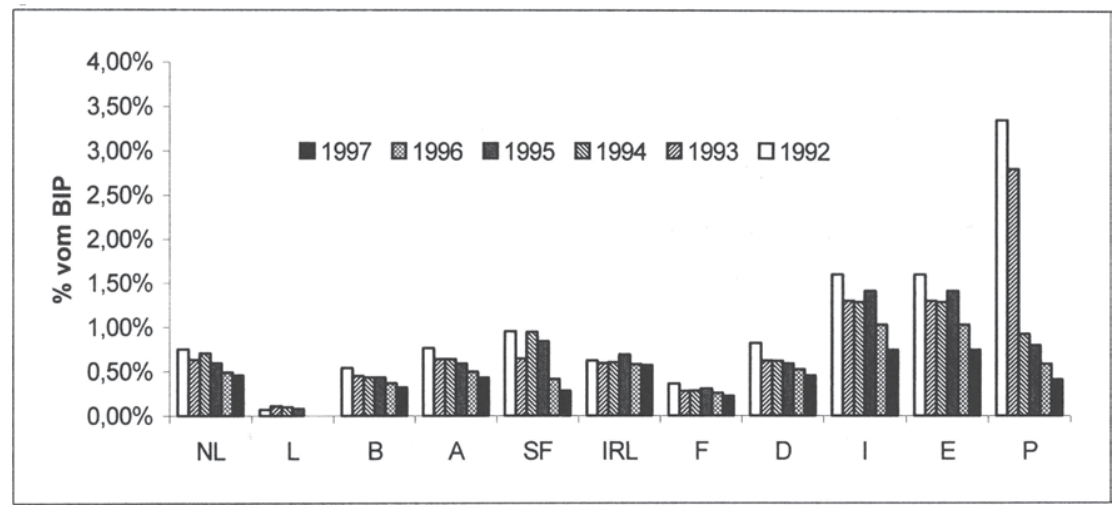

Quelle:

eigene Berechnungen nach International Monetary Fund (1998 und 1999)

Hierbei wird der tendenzielle Einnahmerückgang für alle $11 \mathrm{EWU}$-Staaten deutlich. Besonders auffällig ist die in der Vergangenheit große Bedeutung des Seigniorage für die Staaten Portugal, Italien und Spanien, verbunden allerdings mit einem gerade dort besonders stark zu beobachtenden Rückgang des Seigniorage bis 1997.

Der Vergleich des Opportunitätskosten-Seigniorage mit dem fiskalischen Seigniorage in diesem Zeitraum zeigt aber, daß der fiskalische Seigniorage erstens in der Regel ein niedrigeres Niveau aufweist als der Opportunitätskosten-Seigniorage und zweitens teilweise sogar ein Anstieg des fiskalischen Seigniorage bei gleichzeitigem Sinken des Opportunitätskosten-Seigniorage zu beobachten ist. D.h. der Rückgang des Opportunitätskosten-Seigniorage gerade für die Staaten Portugal, Italien und Finnland spiegelt sich in keiner Weise in der Notenbankbilanz wider. Im Gegenteil: In Portugal ist sogar ein Anstieg des fiskalischen Seigniorage zu beobachten und in Finnland zumindest ein Verharren der Einnahmen. Auch wenn man die Einnahmen aus den Währungsreserven aus der Betrachtung herausläßt ${ }^{20}$, wird der Zusammenhang zwischen OpportunitätskostenSeigniorage und fiskalischem Seigniorage nicht deutlicher.

Da die Zinssätze für die im Ausland angelegten Wertpapiere in keinem Zusammenhang zum Opportunitätskosten-Zinssatz stehen und die Höhe der Devisenbestände auch vom Wechselkurs abhängig ist, der nicht im Konzept des Opportunitätskosten-Seigniorage enthalten ist, wird in Abbildung 8-2 zusätzlich der fiskalische Seigniorage ohne Berücksichtigung der Kosten und ohne die Einnahmen aus Währungsreserven dargestellt. 
Allerdings kann man den Opportunitätskosten-Seigniorage - sieht man einmal von den Jahren 1992 und 1993 ab, in denen das Ansteigen des US-Dollars gegenüber den Währungen der EWS-Staaten die Zinsgewinne aus den Währungsreserven teilweise sehr stark ansteigen ließ - als eine obere Grenze für den fiskalischen Seigniorage betrachten.

Für eine Prognose des fiskalischen Seigniorage kann der OpportunitätskostenSeigniorage demnach zwar nicht herangezogen werden, allerdings kann er als eine obere Grenze der prognostizierten Werte dienen.

\subsubsection{Opportunitätskosten-Seigniorage - Variante 2}

Bei einer zweiten Variante soll der Tatsache Rechnung getragen werden, daß der Mittelzufluß von den Zentralbanken an die nationalen Haushalte nicht der Höhe des Zentralbankgelds entspricht, wie es Gedanke der ersten Variante des Opportunitätskosten-Seigniorage ist ${ }^{21}$, sondern nur den Einnahmen der Zentralbanken aufgrund der Ausgabe von Zentralbankgeld. Dementsprechend wird als Opportunitätskosten-Zinssatz in diesem Fall der jeweilige Zentralbankzinssatz für das Hauptrefinanzierungsgeschäft eingesetzt. Aufgrund der zunehmenden und in den letzten Jahren dominierenden Bedeutung der Offenmarktgeschäfte ist dies für alle EWU-11-Staaten der Offenmarktzinssatz, der den Geschäftsberichten der Zentralbanken entnommen werden kann. Die Zentralbankgeldmenge wird - wie in Variante 1 - den IFS entnommen.

Auch diese Variante verdeutlicht den Rückgang des Seigniorage im Beobachtungszeitraum allerdings auf einem bei den meisten Staaten niedrigerem Niveau als in Variante 1, da die Offenmarktzinsen in der Regel unter denen der Zinsen für langfristige Staatspapiere liegen.

Beim Vergleich der Variante 2 mit dem fiskalischen Seigniorage zeigt sich eine deutliche Annäherung der beiden Seignioragekonzepte für die Staaten Deutschland, Irland, Spanien und Frankreich. Für Belgien, die Niederlande und Österreich hat die Variante 2 des Opportunitätskosten-Seigniorage zumindest ein ähnliches Niveau wie der fiskalische Seigniorage, wenn auch der Verlauf teilweise noch abweichend ist. Allein für die Staaten Portugal, Italien und Finnland liegt das Niveau des fiskalischen Seigniorage noch deutlich unter den Vergleichswerten aus Variante 2. Ursache hierfür könnte die Verzinsung der Mindestreserve in Italien und bis 1994 in Portugal sowie die hohe Einlagefazilität in Finnland sein. In einer dritten Variante werden deshalb für diese Staaten und die Niederlande (Verzinsung der Mindestreserve) die Kosten dieser liquiditätsabschöpfenden Maßnahmen berücksichtigt und ein Vergleich zum fiskalischen Seigniorage gezogen.

21 Variante 1 unterstellt, daß der Staat die Alternative hat, Geld auszugeben oder Staatspapiere (vgl. Gros 1989, 2). Da die Einnahmen aus einer Nettokreditaufnahme dem nationalen Haushalt direkt zugehen, wird bei dieser Vorgehensweise unterstellt, daß auch die Ausgabe von Zentralbankgeld einen sofortigen Mittelzufluß in gleicher Höhe generiert. 


\subsubsection{Opportunitätskosten-Seigniorage - Variante 3}

Zur Berücksichtigung der Mindestreserveverzinsung und der hohen Einlagefazilitäten werden in einer dritten Variante des Opportunitätskosten-Seigniorage die Kosten dieser Instrumente durch folgende Modifikation der Formel 6 berücksichtigt: Von den Einnahmen $i^{\star} M$, die wie in Variante 2 mit Hilfe des Zentralbankgelds und des Offenmarktzinses berechnet werden, werden die Ausgaben für die Mindestreserve- bzw. die Einlageverzinsung - geschätzt durch die Zentralbankgeldmenge abzüglich des Bargeldumlaufs multipliziert mit dem Zinssatz der Mindestreserveverzinsung bzw. dem Einlagezinssatz - abgezogen ${ }^{22}$ :

$$
\begin{aligned}
& \frac{S^{\text {opp } 3, \text { nat }}}{B I P_{\text {real }}^{\text {nat }}}=\frac{i_{\text {offen }}^{\text {nat. }} M^{\text {nat. }}-i_{m r}\left(M^{\text {nat. }}-c^{\text {nat. }}\right)}{P} * \frac{P}{B I P_{n}^{\text {nat. }}}= \\
& =\frac{i_{\text {offen }}^{\text {nat. }} M^{\text {nat. }}-i_{m r}\left(M^{\text {nat. }}-c^{\text {nat. }}\right)}{B I P_{n}^{\text {nat. }}}
\end{aligned}
$$

Auch die Ergebnisse dieser Berechnung zeigen ein deutliches Absinken des Seigniorage für die betreffenden Staaten und - aufgrund der Berücksichtigung der Kosten - ein niedrigeres Niveau als Variante 1 und 2. Der Vergleich mit dem fiskalischen Seigniorage bringt zumindest für Finnland und für Portugal ab dem Jahr 1994 eine gute Annäherung, für Italien eine verbesserte aber nicht befriedigende Annäherung und für die Niederlande keine Verbesserung in der Annäherung beider Konzepte.

22 Die Daten für M (= Reserve Money (Linie 14)) und c (= Currency Outside DMBs (Linie 14a)) sind den IFS, die Daten für $i_{\text {offen }}$ (Offenmarktzins) und $i_{m r}$ (Verzinsung der Mindestreserve bzw. Einlagezinssatz) den Geschäftsberichten der nationalen Zentralbanken entnommen. Auch bei der Darstellung dieser Formel wurde aus Gründen der Übersichtlichkeit der Zeitindex weggelassen. 
Abbildung 8-2a: Vergleich fiskalischer Seigniorage - Opportunitătskosten-Seigniorage für die EWU-11 Staaten 1992 - 1997
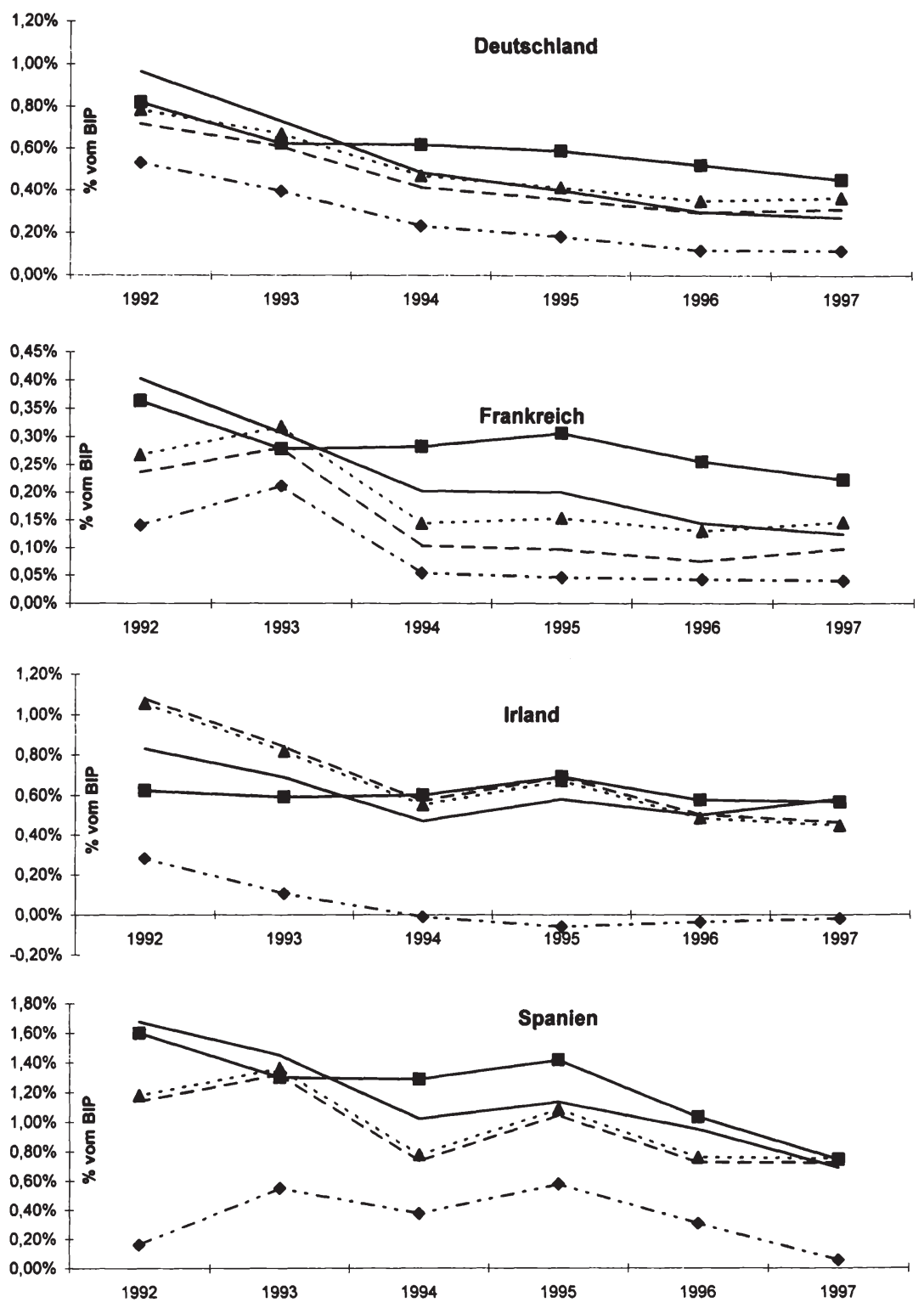

(Legende siehe Abb. 8-2b)

Quelle: $\quad$ eigene Berechnungen 
Abbildung 8-2b: Vergleich fiskalischer Seigniorage - Opportunitătskosten-Seigniorage für die EWU-11 Staaten 1992 - 1997
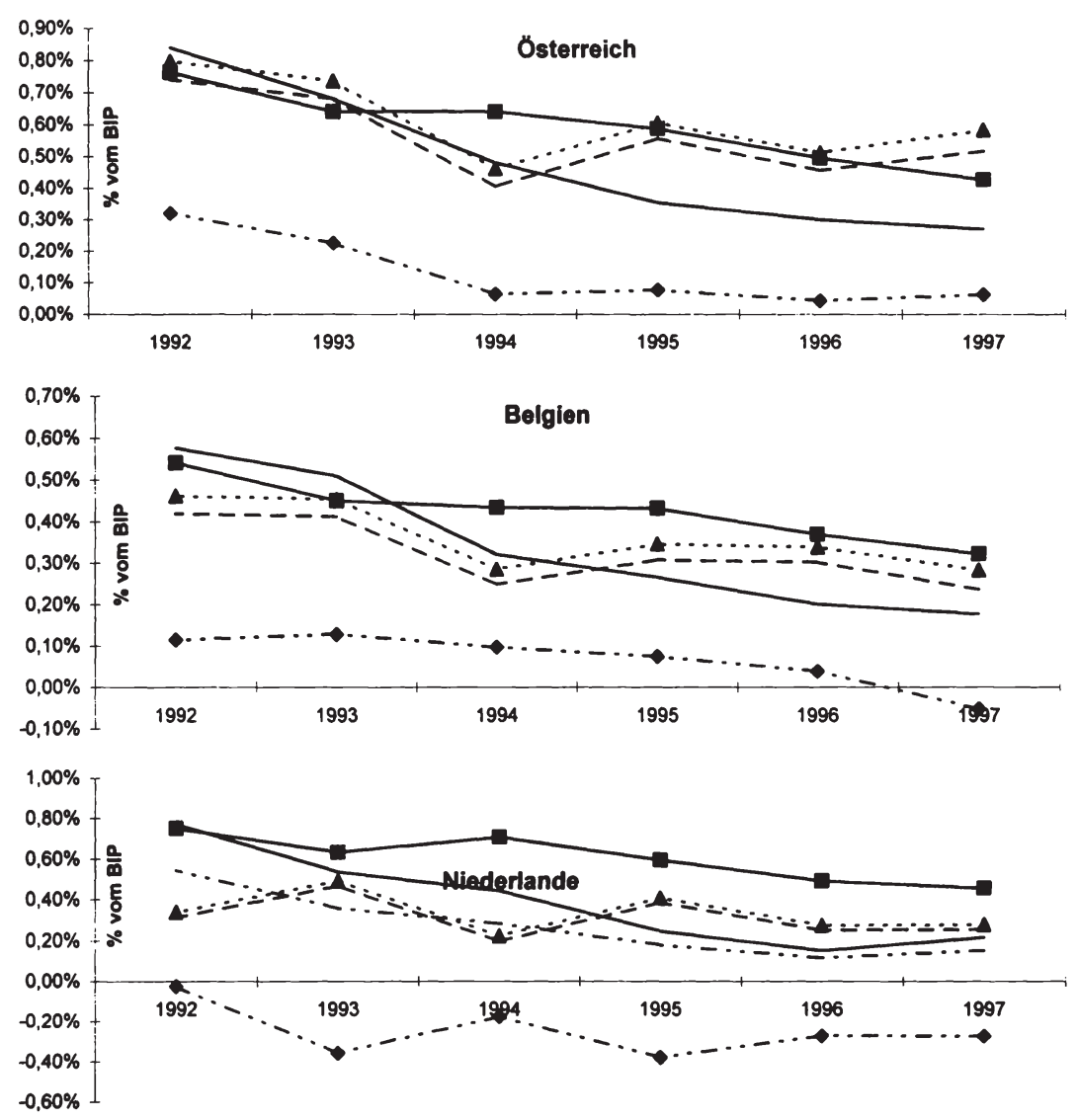

- - fisk. Seigniorage ( $\%$ vom BIP)

- - fisk. Seigniorage o. Kosten (\% vom BIP)

- - - fisk. Seigniorage 0 . Kosten und Gewinne aus Wahrungsreserven

$\longrightarrow$ Opportunitătskosten-Seigniorage (i=Zins fur langfristige Staatspapiere)

- Opportunitătskosten-Seigniorage (i=Offenmarktzinssatz)

- - - Opportunitătskosten-Seigniorage (i=Offenmarktzinssatz) mit Berücksichtigung der Mindestreserveverzinsung

Quelle: $\quad$ eigene Berechnungen 
Abbildung 8-2c: Vergleich fiskalischer Seigniorage - Opportunitätskosten-Seigniorage für die EWU-11 Staaten 1992 - 1997
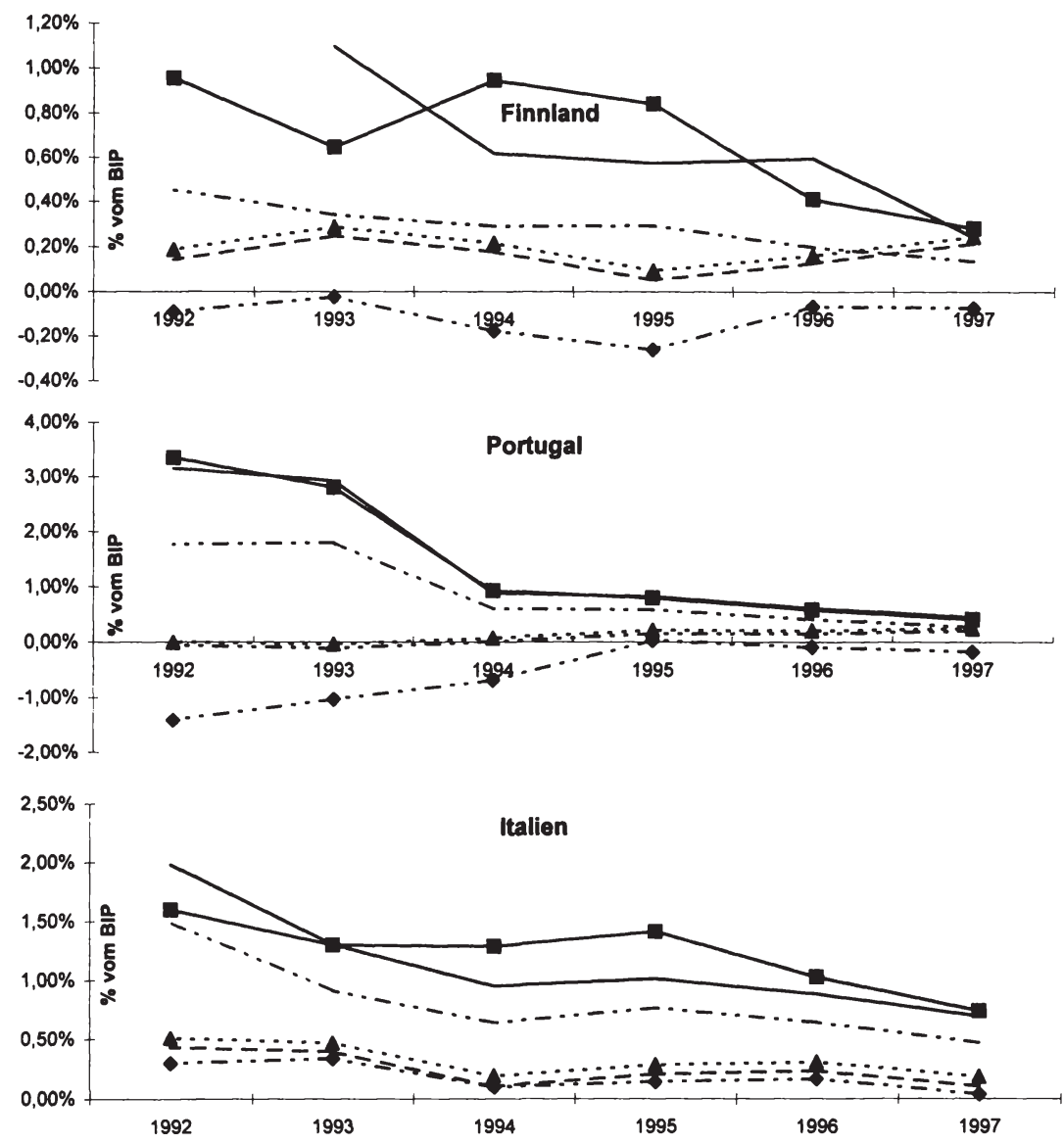

- - - fisk. Seigniorage (\% vom BIP)

-. - fisk. Seigniorage o. Kosten (\% vom BIP)

- - fisk. Seigniorage 0 . Kosten und Gewinne aus Wahrungsreserven

$\longrightarrow$ Opportunitătskosten-Seigniorage (i=Zins fur langfristige Staatspapiere)

- Opportunitătskosten-Seigniorage (i=Offenmarktzinssatz)

-..- Opportunitătskosten-Seigniorage (i=Offenmarktzinssatz) mit Berücksichtigung der Mindestreserveverzinsung

Quelle: $\quad$ eigene Berechnungen 


\subsection{Ergebnisse des empirischen Vergleichs der Opportunitätskosten- Seigniorage-Konzepte und des fiskalischen Seigniorage}

Die Ergebnisse haben gezeigt, daß der Opportunitätskosten-Seigniorage - berechnet mit dem Zinssatz für langfristige Staatsanleihen - allenfalls als obere Grenze des fiskalischen Seigniorage dienen kann. Da die Zentralbankzinsen und damit der Zinssatz, der die Einnahmen der Zentralbank bestimmt, in der Regel deutlich niedriger liegt als der Zinssatz für langfristige Staatspapiere, kann dieses Konzept kaum zu Prognosezwecken genutzt werden. Erst die Verwendung des Offenmarktzinses erbringt eine Annäherung an den fiskalischen Seigniorage in den Staaten, in denen keine Verzinsung der Mindestreserve oder ähnlich kostenträchtige Instrumente der Liquiditätsabschöpfung zur Anwendung kommen. Bei den übrigen Staaten kann die dritte Variante des Opportunitätskosten-Seigniorage zur Abschätzung des fiskalischen Seigniorage herangezogen werden. 


\section{Prognose des Opportunitätskosten-Seigniorage für die EWU-11}

In diesem Abschnitt wird eine Prognose des Opportunitätskosten-Seigniorage für alle drei Varianten für die Gemeinschaft der EWU-11-Staaten vorgenommen, die anschließend - in Abhängigkeit von der Anwendung geldpolitischer Instrumente innerhalb des ESZB - als Schätzgröße für den zukünftigen fiskališchen Seigniorage dient. Aufgrund noch nicht vorliegender Daten für das Jahr 1998 werden die Prognosen auf der Grundlage der IFS-Daten bis 1997 erstellt. Aufgrund der nicht quantifizierbaren Auswirkungen von Strukturbrüchen auf die Geldnachfrage, soll hinsichtlich dieser Frage eine Vergangenheits-Zukunfts-Symmetrie unterstellt werden, d.h. die zukünftige Geldnachfrage wird aus dem Mittel vergangener Werte berechnet (vgl. 9.1) ${ }^{23}$.

\subsection{Prognose des Opportunitätskosten-Seigniorage - Variante 1}

Ausgegangen wird von der in 3.2 vorgestellten Formel des OpportunitätskostenSeigniorage:

$$
S_{t}^{o p p}=\frac{i M_{t}}{P_{t}}
$$

Für eine Prognose dieser Variante müssen zunächst Annahmen über die zukünftige Entwicklung des Zinses und der Zentralbankgeldmenge getroffen werden. Dazu wird die Zentralbankgeldmenge in ihre Bestandteile "Reserve der Geschäftsbanken" und "Bargeld" aufgeteilt, die dazugehörigen Kassenhaltungskoeffizienten der vergangenen Jahre ermittelt und als zukünftige Kassenhaltungskoeffizienten angenommen. Die Reserven der Geschäftsbanken beschränken sich in der Regel auf die Mindestreserven; Überschußreserven spielen kaum eine Rolle mehr und sollen deshalb vernachlässigt werden. Demnach errechnen sich die Reserven als Produkt aus den mindestreservepflichtigen Depositen und dem Mindestreservesatz. Die Depositen wiederum lassen sich aus dem Produkt aus Kassenhaltungskoeffizient für Depositen und dem nominellen BIP ermitteln. Mathematisch lassen sich die Zusammenhänge folgendermaßen darstellen:

$$
\begin{aligned}
M^{E S Z B} & =C^{E S Z B}+M R^{E S Z B}=C^{E S Z B}+m r s^{E S Z B} \cdot D^{E S Z B}= \\
& =k_{1}^{E W U-11} \cdot B I P_{n}{ }^{E W U-11}+m r s^{E S Z B} \cdot k_{2}{ }^{E W U-11} \cdot B I P_{n}{ }^{E W U-11}
\end{aligned}
$$

23 Daß sich die Geldnachfrage respektive die Kassenhaltungskoeffizienten infolge eines Strukturbruchs durch die Europäische Währungsunion verändern könnten (vgl. 4.1.3), ist zwar nicht unwahrscheinlich aber quantitativ kaum prognostizierbar. Zu den Auswirkungen des Strukturbruchs der EWU und den Auswirkungen auf die Geldnachfrage siehe Kap. 14. 


$$
\begin{aligned}
& \Rightarrow \frac{S^{O p p l, E S Z B}}{B I P_{n} E W U-I I}=\frac{i \cdot M^{E S Z B}}{B I P_{n} E W U-11}= \\
& =\frac{i\left(k_{1}{ }^{E W U-11} B I P_{n}^{E W U-11}+m r s^{E S Z B} \cdot k_{2}^{E W U-11} \cdot B I P_{n}^{E W U-11}\right)}{B I P_{n}^{E W U-11}}= \\
& =i\left(k_{1}^{E W U-11}+m r s^{E S Z B} \cdot k_{2}^{E W U-11}\right)
\end{aligned}
$$

Der Vorteil der Berechnung des Opportunitätskosten-Seigniorage als Anteil am realen BIP besteht hierbei auch darin, keine Prognose über das Wachstum des BIP treffen zu müssen. Der Mindestreservesatz ist von der EZB z. Zt. auf $2 \%$ festgesetzt. Die zu erwartenden langfristigen Nominalzinsen lassen sich mit Hilfe der sog. Fischerhypothese aus erwarteter Inflationsrate $\hat{\mathrm{P}}$ und dem Realzins $\rho$ berechnen (vgl. Lange/Nolte 1997, 16 und Jarchow 1998, 245):

$i=\rho+\hat{P}+\rho \cdot \hat{P}$.

Als erwartete Inflation soll das Inflationsziel der EZB (2\%) angenommen werden. Der Realzins soll $4 \%$ betragen. Dies liegt geringfügig unter der Rendite für zehnjährige Staatsanleihen im Euro-Währungsgebiet (vgl. Monatsbericht der EZB Mai 1999; $\left.18^{\star}\right)^{24}$. Der nominelle Zinssatz errechnet sich dann zu

$i=6,08 \%$.

Die Kassenhaltungskoeffizienten werden für die jeweiligen Staaten für die Jahre 1992 bis 1997 mit Hilfe von IFS-Daten ${ }^{25}$ berechnet, gemäß der Anteile der Staaten am gesamten BIP der EWU-11 Gemeinschaft gewichtet und zu einem EWU11 Kassenhaltungskoeffizient aufsummiert (vgl. Anhang und Lange/Nolte 1997, 16) ${ }^{26}$. Danach ergeben sich

$k_{l}{ }^{\text {EWU-H }}=0,062$ und $k_{2}{ }^{\text {EWU-HI }}=0,614$

als Kassenhaltungskoeffizienten der EWU-11 Gemeinschaft.

Mit Hilfe dieser Annahmen errechnet sich für die EWU-11 Staatengemeinschaft ein Opportunitätskosten-Seigniorage von $0,44 \%$ am gesamten BIP. Dies ist ge-

24 Nach Auffassung von Lange/Nolte 1997 wird es zu einer Senkung und Annäherung der Realzinsen im Gebiet der Währungsunion kommen, da die Grenzleistungsfähigkeit der Investitionen auf einem gemeinsamen Markt kaum Unterschiede aufweisen wird und Zinsaufschläge aufgrund von Wechselkursrisiken innerhalb der Gemeinschaft verschwinden. Allerdings wird es weiterhin Differenzen in der Bonität der Mitgliedsstaaten geben, die sich aber nach Lange/Nolte trotz Bestehens der No-Bail-Out-Regel aufgrund des Solidarcharakters der Währungsunion verringern werden (vgl. Lange/Nolte 1997, 17).

$25 \mathrm{C}=$ Currency outside Deposit Money Banks (Linie 14a), $M R=$ Demand Deposits + Time Deposits (Linie $24+$ Linie 25), BIP = Gross Domestic Product (Linie 99b.c).

26 Die hierbei anzubringende Kritik - diese Vorgehensweise impliziert die einfache und vermutlich nicht zulässige Aggregation der Geldnachfragen durch Aufsummierung - soll erst bei der Relativierung der Ergebnisse des Opportunitätskosten-Seigniorage durch eine Prognose des fiskalischen Seigniorage erfolgen (siehe auch Fußnote 15). 
messen am BIP mehr als für die Staaten Frankreich, Belgien und Finnland und deutlich weniger als für die Staaten Spanien, Italien und Irland 1997 an Opportunitätskosten-Seigniorage nach der Variante 1 errechnet wurde, während Deutschland $(0,45 \%)$, Portugal $(0,41 \%)$, Österreich $(0,43 \%)$ und die Niederlande $(0,46 \%) 1997$ fast einen identischen Opportunitätskosten-Seigniorage gemessen am BIP erzielten.

\subsection{Prognose des Opportunitätskosten-Seigniorage - Variante 2}

Für die zweite Variante des Opportunitätskosten-Seigniorage wird der Zinssatz des Hauptrefinanzierungsgeschäfts der EZB verwendet.

$$
\begin{aligned}
\frac{S^{O p p 2, E S Z B}}{B I P_{n}^{E W U-11}} & =\frac{i_{r e f i} \cdot M^{E S Z B}}{B I P_{n}^{E W U-11}}= \\
& =\frac{i_{r e f i}\left(k_{1}^{E W U-11} \cdot B I P_{n}^{E W U-11}+m r s^{E S Z B} \cdot k_{2} \cdot B I P_{n}^{E W U-11}\right)}{B I P_{n}^{E W U-11}}= \\
& =i_{r e f i}\left(k_{1}^{E W U-11}+m r s^{E S Z B} \cdot k_{2}^{E W U-11}\right)
\end{aligned}
$$

Bislang (Stand Juni 1999) fand nur der Mengentender mit einem Festsatz von $3 \%$, seit 8. April 1999 2,5\% Anwendung. Angesichts der "zunehmenden Anzeichen einer deutlichen Konjunkturabkühlung in Euroland und des sehr günstigen stabilitätspolitischen Umfeldes" (Dallmeyer/Preuschl 1999, 10) wird dieser Zinssatz vermutlich bis ins Jahr 2000 hinein Bestand haben und bei einer zu vermutenden „Besserung der Konjunkturlage im Euroraum und aufgrund steigender Rohstoffpreise mit leicht anziehenden Inflationsraten" erst dann (Jahr 2000) nach oben gerichtet sein. Mittelfristig soll daher mit einem Hauptrefinanzierungszinssatz von $3 \%$ gerechnet werden. Alle übrigen Annahmen bleiben mit denen der Variante 1 identisch. Somit ergibt sich ein Opportunitätskosten-Seigniorage für die Gemeinschaft der EWU-11-Staaten von 0,22\% des BIP. Dies ist gegenüber dem nationalen Opportunitätskosten-Seigniorage für 1997 deutlich weniger als in den Staaten Portugal, Spanien, Italien und Irland. Nur gegenüber dem Opportunitätskosten-Seigniorage von Frankreich ist diese Prognose höher, während sie etwa das gleiche Niveau wie der Opportunitätskosten-Seigniorage für die Staaten Deutschland, Finnland, Österreich, Belgien und die Niederlande aufweist. Geht man von einer Konstanz des Refinanzierungssatzes aus, bzw. will den kurzfristig (1999) erzielbaren Opportunitätskosten-Seigniorage prognostizieren, so ergibt sich für diesen beim aktuellen Refinanzierungszinssatz von 2,5\% ein Wert von $0,18 \%$, der dem Opportunitätskosten-Seigniorage (Variante 2) Finnlands und Belgiens näher kommt, sich allerdings deutlich unter das Niveau der Staaten Deutschland und Österreich schiebt. 


\subsection{Prognose des Opportunitätskosten-Seigniorage - Variante 3}

Bei einer Verzinsung der Mindestreserve - wie es die EZB derzeit praktiziert - ist zur Schätzung des fiskalischen Seigniorage die Variante 3 des Opportunitätskosten-Seigniorage, in der die Kosten der Mindestreserveverzinsung von den Einnahmen aus der Geldschöpfung abgezogen werden, am besten geeignet. Die Mindestreserveverzinsung der EZB orientiert sich am Durchschnitt des Zinssatzes für die Hauptrefinanzierungsgeschäfte. Somit berechnet sich der Opportunitätskosten-Seigniorage der EWU-11-Gemeinschaft aus 27

$$
\begin{aligned}
& \frac{S^{o p p 3,} E S Z B}{B I P_{\text {real }}^{E W U-11}}=\frac{i_{\text {offen }} M^{E S Z B}-i_{m r}\left(M^{E S Z B}-c^{E W U-11}\right)}{P^{E W U-11}} * \frac{P^{E W U-11}}{B I P_{n}^{E W U-11}}= \\
& =\frac{i_{\text {offen }} M^{E S Z B}-i_{m r}\left(M^{E S Z B}-c^{E W U-11}\right)}{B I P_{n}^{E W U-11}}
\end{aligned}
$$

mit $i_{\text {offen }}=i_{m r}$ gilt 28

$$
\begin{aligned}
& \frac{S_{\text {opp } 3, E S Z B}}{B I P_{\text {real }}^{E W U-11}}=\frac{i_{\text {offen }} \cdot M^{E S Z B}-i_{\text {offen }}\left(M^{E S Z B}-C^{E S Z B}\right)}{B I P_{n}^{E W U-11}}= \\
& =\frac{\left.i_{\text {offen }} \cdot M^{E S Z B}-i_{\text {offen }} \cdot M^{E S Z B}+i_{\text {offen }} \cdot C^{E S Z B}\right)}{B I P_{n}^{E W U-11}}= \\
& =\frac{i_{\text {offen }} \cdot C^{E S Z B}}{B I P_{n}^{E W U-11}}=\frac{i_{\text {offen }} \cdot k_{l}^{E S Z B} \cdot B I P_{n}^{E W U-11}}{B I P_{n}^{E W U-11}}=i_{\text {offen }} \cdot k_{l}{ }_{l}^{E S Z B}
\end{aligned}
$$

Da die Mindestreserve die gleichen Zinsausgaben verursacht, wie die Refinanzierungsgeschäfte Einnahmen erwirken, spielt die Höhe der Mindestreserveverpflichtung für die Höhe des Opportunitätskosten-Seigniorage in der Variante 3 keine Rolle mehr. Für die Gemeinschaft der EWU-11-Staaten errechnet sich dann folgender Opportunitätskosten-Seigniorage: Bei einem Offenmarktzins von $3 \%$ wird in der EWU-11 Staatengemeinschaft ein Opportunitätskosten-Seigniorage von gut $0,18 \%$ zu erwarten sein; beim derzeitigen Refinanzierungssatz von $2,5 \%$ liegt der Opportunitätskosten-Seigniorage bei $0,15 \%$ des BIP. Dieses Niveau erreichte der Opportunitätskosten-Seigniorage in der Variante $3 \mathrm{im} \mathrm{Jahr}$ 1997 in den Niederlanden und Finnland, während Portugal trotz Mindestreserveverzinsung 1997 noch doppelt so viel und Italien sogar dreimal so viel Opportuni-

27 Der Zeitindex wurde aus Gründen der Übersichtlichkeit weggelassen.

28 Der Zeitindex wurde aus Gründen der Übersichtlichkeit weggelassen. 
tätskosten-Seigniorage erzielte. Ein ähnlich niedriges Niveau erzielten von den restlichen Staaten der EWU-11, die keine Mindestreserveverzinsung vornahmen, nur Frankreich und Belgien.

\subsection{Prognose des fiskalischen Seigniorage des ESZB nach dem Übergang zum Euro}

Anhand der Prognose des Opportunitätskosten-Seigniorage in seinen verschiedenen Varianten läßt sich nun eine Prognose des fiskalischen Seigniorage anstellen bzw. ein Korridor bestimmen, in dem sich der fiskalische Seigniorage bewegen wird.

Zur Übersicht sind in folgender Tabelle noch einmal die Prognosen aller Varianten des Opportunitätskosten-Seigniorage dargestellt.

Tabelle 9-1: $\quad$ Prognosen des Opportunitätskosten-Seigniorage für die EWU-11-Staaten

\begin{tabular}{|l|r|rrrrrr|}
\hline & Variante 1 & Variante 2 a & b & c Variante 3 a & b & c \\
\hline mrs & $2,00 \%$ & $2,00 \%$ & $2,00 \%$ & $2,00 \%$ & $2,00 \%$ & $2,00 \%$ & $2,00 \%$ \\
$i$ & $6,08 \%$ & $3,00 \%$ & $2,75 \%$ & $2,50 \%$ & $3,00 \%$ & $2,75 \%$ & $2,50 \%$ \\
MR-Verzins. & - & - & - & - & $3,00 \%$ & $2,75 \%$ & $2,50 \%$ \\
\hline SopplEs; & $\mathbf{0 , 4 3 \%}$ & $\mathbf{0 , 2 1 \%}$ & $\mathbf{0 , 2 0 \%}$ & $\mathbf{0 , 1 8 \%}$ & $\mathbf{0 , 1 8 \%}$ & $\mathbf{0 , 1 6 \%}$ & $\mathbf{0 , 1 5 \%}$ \\
\hline
\end{tabular}

Quelle: $\quad$ eigene Berechnungen

Variante 1 des Opportunitätskosten-Seigniorage kann, wie in 8.2.1 gezeigt, als obere Grenze des fiskalischen Seigniorage interpretiert werden, d.h. der fiskalische Seigniorage wird im ESZB - selbst bei starken Währungsschwankungen sowie deren Auswirkungen auf die Einnahmen aus den Währungsreserven - kaum über einen Wert von $0,43 \%$ des BIP hinausgehen. Da auf absehbare Zeit die Verzinsung der Mindestreserve im Instrumentenmix der EZB Bestand haben wird, kommt Variante 2 als Prognosevariante nicht in Betracht. Vielmehr wird Variante 3 mit seinen unterschiedlichen Annahmen über den Refinanzierungszinssatz dem fiskalischen Seigniorage am nächsten kommen, d.h. der fiskalische Seigniorage des ESZB wird für das 1999 etwa $0,15 \%$ des BIP betragen, wobei dies als untere Grenze zu interpretieren ist, da mittelfristig mit einem steigenden Refinanzierungszinssatz zu rechnen ist, mit dem der fiskalische Seigniorage auf 0,18\% oder darüber ansteigen kann. 


\section{Quantifizierung des Übergangseffekts}

Prognostiziert man den Opportunitätskosten-Seigniorage der nationalen Zentralbanken in der Anfangsphase der dritten Stufe der EWWU vor einer Verteilung der Gewinne durch die EZB, so läßt sich der Einfluß berechnen, den der Übergang zum Euro auf die Geldschöpfungsgewinne nach Ablauf der Konvergenzphase hat, d.h. der Einfluß, der allein durch die Veränderung der geldpolitischen Instrumente und Zinssätze beim Übergang der geldpolitischen Entscheidungsgewalt von den nationalen Zentralbanken zur EZB zum Tragen kommt (vgl. 6.1.3).

Zur Prognose der Geldschöpfungsgewinne der nationalen Zentralbanken vor einer Verteilung werden die Varianten 1 und 3 des Opportunitätskosten-Seigniorage herangezogen und zur Berechnung der nationalen Größen modifiziert.

Variante 1 des Opportunitätskosten-Seigniorage auf nationaler Ebene errechnet sich dann wie folgt:

$\frac{S^{O p p l, n a t .}}{B I P_{n}^{\text {nat. }}}=i\left(k_{1}^{\text {nat. }}+\mathrm{mrs}^{E Z B} \cdot k_{2}{ }^{\text {nat. }}\right)$

wobei $k_{1}{ }^{\text {nat. }}$ und $k_{2}{ }^{\text {nat. }}$ die nationalen Kassenhaltungskoeffizienten gemittelt über die Jahre 1992 bis 1997 sind.

Variante 3 berechnet sich zu29

$\frac{S^{\text {opp } 3, \text { nat. }}}{\text { BIP }_{\text {real }}^{\text {nat. }}}=i_{\text {offen }}^{E Z B} \cdot k_{I}^{\text {nat }}$.

Die Ergebnisse der Berechnungen zeigt folgende Tabelle:

Tabelle 10-1: Opportunitätskosten-Seigniorage nach dem Übergang zum Euro

\begin{tabular}{|c|c|c|c|c|c|c|c|}
\hline \multirow{2}{*}{ iopp } & \multicolumn{3}{|c|}{ nach Übergang } & \multicolumn{4}{|c|}{ Übergangseffekt (Differenz zu 1997) } \\
\hline & Sopp1 & Sopp3 a & b & c & dSopp1 & dSopp $2 / 3 c$ & 3c-sfisk \\
\hline B & $0,38 \%$ & $0,14 \%$ & $0,13 \%$ & $0,12 \%$ & $0,05 \%$ & $-0.06 \%$ & $-0,22 \%$ \\
\hline D & $0,48 \%$ & $0,20 \%$ & $0,19 \%$ & $0,17 \%$ & $0,03 \%$ & $-0,11 \%$ & $-0,20 \%$ \\
\hline $\mathbf{E}$ & $0,74 \%$ & $0,32 \%$ & $0,29 \%$ & $0,27 \%$ & $-0,01 \%$ & $-0,42 \%$ & $-0,48 \%$ \\
\hline $\bar{F}$ & $0,28 \%$ & $0,10 \%$ & $0,09 \%$ & $0,09 \%$ & $0,06 \%$ & $-0,04 \%$ & $-0,18 \%$ \\
\hline IRL & $0,34 \%$ & $0,14 \%$ & $0,13 \%$ & $0,12 \%$ & $-0,23 \%$ & $-0,46 \%$ & $-0,35 \%$ \\
\hline 1 & $0,41 \%$ & $0,17 \%$ & $0,15 \%$ & $0,14 \%$ & $-0,33 \%$ & $-0,33 \%$ & $-0,05 \%$ \\
\hline NL & $0,47 \%$ & $0,18 \%$ & $0,17 \%$ & $0,15 \%$ & $0,01 \%$ & $-0,06 \%$ & $-0,12 \%$ \\
\hline A & $0,47 \%$ & $0,18 \%$ & $0,16 \%$ & $0,15 \%$ & $0,04 \%$ & $-0,12 \%$ & $-0,43 \%$ \\
\hline $\mathbf{P}$ & $0,41 \%$ & $0,16 \%$ & $0,14 \%$ & $0,13 \%$ & $0,00 \%$ & $-0,14 \%$ & $-0,11 \%$ \\
\hline SF & $0,20 \%$ & $0,07 \%$ & $0,06 \%$ & $0,06 \%$ & $-0,08 \%$ & $-0,08 \%$ & $-0,19 \%$ \\
\hline
\end{tabular}

Quelle: $\quad$ eigene Berechnungen

29 Der Zeitindex wurde aus Gründen der Übersichtlichkeit weggelassen. 
Nach dem Übergang auf den Euro am 1.1.1999 ist demnach unter Zugrundelegen des Opportunitätskosten-Seigniorage (Variante 3c, d.h. mit einem Refinanzierungszinssatz von 2,5\%) in jedem der EWU-11-Staaten maximal ein Gewinn aus der Geldschöpfung von knapp 0,3\% des BIP (Spanien) zu erreichen. Die meisten anderen nationalen Zentralbanken erzielen Geldschöpfungsgewinne von etwa 0,12 bis $0,17 \%$ ihres nationalen BIP. Frankreich und Finnland erreichen nur noch einen Seigniorage von weniger als $0,1 \%$ ihres BIP.

Der Übergangseffekt fällt für Irland (-0,46\%-Punkte), Spanien (-0,42 \%-Punkte) und Italien (-0,33 \%-Punkte) am stärksten aus, in den übrigen Staaten bewegt er sich um $-0,1 \%$. Allerdings ist im Übergangseffekt noch ein Teil des Konvergenzeffekts enthalten, der aufgrund der noch nicht vorliegenden Daten für 1998 nicht herausgerechnet werden konnte. Dies dürfte ein Grund für den starken Fall der Geldschöpfungseinnahmen in den drei erwähnten Staaten sein, da dort insbesondere die Notenbankzinsen 1997 deutlich über denen der anderen Mitgliedsstaaten lagen. Aber auch der hohe Anteil der Mindestreserven an der Zentralbankgeldmenge in Italien und Irland - die Bank von Italien senkte beispielsweise erst im Dezember 1998 ihren Mindestreservesatz von $6 \%$ auf $2 \%$-, die entweder unter dem Marktzinssatz (Italien) oder gar nicht (Irland) verzinst wurden, dürften den Übergangseffekt dort deutlich nach unten beeinflußt haben. 


\section{Teil IV: \\ Einnahmeverluste und -gewinne aus der Geldschöpfung als Folge des Verteilungsschlüssels der EZB}

\section{Wirkung des Verteilungsschlüssels auf die Einnahmen der EWU-Mitgliedsstaaten aus der Geldschöpfung}

Nach der Prognose des Geldschöpfungsgewinns auf der Ebene des ESZB nach dem Übergang auf den Euro wird im folgenden Kapitel der Verteilungsschlüssel des Gewinns der EZB angewendet, um den Mittelzufluß an die nationalen Zentralbanken auf Grundlage der Prognose des fiskalischen Seigniorage zu berechnen.

Zunächst soll die Art der Entstehung und Verteilung der Gewinne innerhalb des föderalen Systems des ESZB erläutert werden, um anschließend den Verteilungseffekt quantifizieren zu können.

\subsection{Die föderale Struktur des ESZB und der Begriff der monetären Einkünfte}

Das ESZB besteht aus der EZB und den nationalen Zentralbanken (vgl. Art. 106 (1) EG-Vertrag). Die grundlegenden Aufgaben des ESZB sind nach Artikel 3 des Protokolls über die Satzung des ESZB und der EZB (im folgenden ESZB Protokoll), die Geldpolitik der Gemeinschaft festzulegen und auszuführen, Devisengeschäfte durchzuführen, die offiziellen Währungsreserven der Mitgliedsstaaten zu halten und $\mathrm{zu}$ verwalten und das reibungslose Funktionieren der Zahlungssysteme zu fördern. Die EZB ist hierbei der Kopf des Systems und die nationalen Zentralbanken handeln gemäß den Leitlinien und Weisungen der EZB (vgl. Art. 14.3 ESZB Protokoll). Ausführende Organe sind die nationalen Zentralbanken (Art. 14.3 ESZB Protokoll). Dementsprechend fließen die Geldschöpfungsgewinne des ESZB zunächst den nationalen Zentralbanken zu. „Die Einkünfte, die den nationalen Zentralbanken aus der Erfüllung der währungspolitischen Aufgaben des ESZB zUfließen (im folgenden als "monetäre Einkünfte" bezeichnet), werden am Ende eines jeden Geschäftsjahres nach diesem Artikel verteilt" (Art. 32.1 ESZB Protokoll). Die „monetären Einkünfte" einer jeden Zentralbank entsprechen gemä $B$ Art. 32.2 ESZB Protokoll "ihren jährlichen Einkünften aus Vermögenswerten, die sie als Gegenposten zum Bargeldumlauf und zu ihren Verbindlichkeiten aus Einlagen der Kreditinstitute hält. Diese Vermögenswerte werden von den nationalen Zentralbanken gemäß den vom EZB-Rat zu erlassenden Richtlinien gesondert erfaßt." Nähere Ausführungen darüber, welche Aktiva hierunter zu verstehen sind, findet man allerdings bislang nicht. Zwar werden die seit dem 1.1.99 getätigten liquiditätszuführenden und -abschöpfenden Geschäfte der nationalen Zentralbanken einheitlich bilanziert, allerdings fehlen bislang Richtlinien, welche der restlichen in den vergangenen Jahren kumulierten Aktiva "monetäre Einkünfte" im Sinne des ESZB Protokolls erzielen. Probleme bereiten hierbei offenbar die unterschiedlichen Bilanzen der nationalen Zentralbanken (vgl. Courtis 1999, 52), die 
sich nicht ohne weiteres harmonisieren lassen, um feststellen zu können, welche Zinseinnahmen zu den monetären Einkünften gehören und dementsprechend der Verteilung durch die EZB zugeführt werden müßten.

Bis zum Jahre 2002 gilt daher eine Übergangslösung für die Berechnung der monetären Einkünfte: Dazu werden nicht die Aktiva der nationalen Zentralbanken betrachtet, sondern deren Passiva gegenüber den Geschäftsbanken, mehrheitlich die Einlagen der Geschäftsbanken zur Erfüllung der Mindestreserve. Banknoten und Münzen werden aus der Berechnung ausgeklammert, da man der Meinung ist, daß die Einnahmen aus dem Bargeldumlauf so lange den nationalen Zentralbanken zustehen, wie es noch nationale Banknoten und Münzen gibt. Erst mit der Einführung der Eurobanknoten und -münzen wären die Einnahmen dem ESZB zuzuschreiben (vgl. Courtis 1999, 52).

Demnach bleiben bis zur Einführung des Euro-Bargelds im Jahr 2002 zur Verteilung nur die Einnahmen aus der Reservehaltung der Geschäftsbanken, angenähert durch die Einlagen der Geschäftsbanken bei der Zentralbank, multipliziert mit einem Referenzzinssatz, in diesem Falle dem Zinssatz der Offenmarktgeschäfte der EZB. Vor dem Transfer dieser monetären Einkünfte an die EZB dürfen die nationalen Zentralbanken allerdings noch den Betrag etwaiger Zinsen, die von dieser Zentralbank auf ihre Verbindlichkeiten aus Einlagen der Kreditinstitute gezahlt werden, von den monetären Einkünften abziehen (vgl. Art. 32.4 ESZB Protokoll). Da die Reservehaltung der Geschäftsbanken bei den nationalen Zentralbanken aber im wesentlichen aus der Mindestreservehaltung besteht und diese mit einem Satz verzinst wird, der dem Durchschnitt des EZB-Satzes für die Hauptrefinanzierungsgeschäfte des Eurosystems entspricht, entfällt das Pooling und die Weiterverteilung von Geldschöpfungseinnahmen durch die EZB bis zum Jahr 2002 völlig.

Erst mit der Einführung der Eurobanknoten und Münzen werden die monetären Einkünfte der nationalen Zentralbanken - auf noch zu bestimmende Weise festgestellt und der Verteilung durch die EZB zugeführt.

Für eine Prognose des zukünftigen Geldschöpfungsgewinns des ESZB, der der Verteilung an die nationalen Zentralbanken unterliegt, also der monetären Einkünfte, müssen daher Annahmen über die Art der einkunftsrelevanten Aktiva bei den nationalen Zentralbanken, über deren Höhe und deren Verzinsung angestellt werden.

Eine Bestimmung der einkunftsrelevanten Aktiva wurde bereits im Rahmen dieser Arbeit bei der Bestimmung des fiskalischen Seigniorage für die Jahre 1992 bis 1997 durchgeführt und mit Hilfe des Opportunitätskosten-Seigniorage (Variante 3) soweit angenähert, daß dieses Konzept zur Bestimmung des Verteilungseffekts beibehalten werden soll. Bei der Wahl des Zinssatzes sollen die beiden Untervarianten 3a und $3 \mathrm{c}$ zur Anwendung kommen, um der Mittelfristigkeit des Verteilungseffekts gerecht zu werden. 


\subsection{Verteilungsmodus zur Bestimmung des nationalen Seigniorage}

Die Ausschüttung des EZB-Gewinns an die nationalen Teilnehmerstaaten erfolgt entsprechend der Kapitalanteile an der EZB (Art. 33.1 ESZB Protokoll). Der Schlüssel für die Kapitalzeichnung wurde in Art. 29 des Vertrags über die Europäische Union festgestellt und berechnet sich aus dem Mittel des Anteils des jeweiligen Staates an der Gesamtbevölkerung im vorletzten Jahr vor der Errichtung des ESZB und des Anteils am BIP der letzten fünf Jahre vor dem vorletzten Jahr der Errichtung des ESZB. Die offiziellen Anteile wurden im Juni 1998 bekanntgegeben und lauten wie folgt:

Tabelle 11-1: Kapitalanteile der Nationalen Zentralbanken an der EZB

\begin{tabular}{|lrr|}
\hline & Kapitalanteil & Ant. EWU-11 \\
\hline Banque Nationale de Belgique & $2,87 \%$ & $3,63 \%$ \\
Danmarks Nationalbank & $1,67 \%$ & - \\
Deutsche Bundesbank & $24,49 \%$ & $31,03 \%$ \\
Bank of Greece & $2,06 \%$ & $-11,27 \%$ \\
Banco de España & $8,89 \%$ & $11 \%$ \\
Banque de France & $16,83 \%$ & $21,33 \%$ \\
Central Bank of Ireland & $0,85 \%$ & $1,08 \%$ \\
Banca d'Italia & $14,90 \%$ & $18,87 \%$ \\
Banque centrale du Luxembourg & $0,15 \%$ & $0,19 \%$ \\
De Nederlandsche Bank & $4,28 \%$ & $5,42 \%$ \\
Osterreichische Nationalbank & $2,36 \%$ & $2,99 \%$ \\
Banco de Portugal & $1,92 \%$ & $2,44 \%$ \\
Suomen Pankki & $1,40 \%$ & $1,77 \%$ \\
Sveriges Riksbank & $2,65 \%$ & - \\
Bank of England & $14,68 \%$ & - \\
\hline Summe EWU11 & $78,94 \%$ & $100,00 \%$ \\
\hline
\end{tabular}

Quelle: $\quad$ EZB Jahresbericht 1998, 128

Abbildung 11-1: Gewinnverteilungsschlüssel der EZB

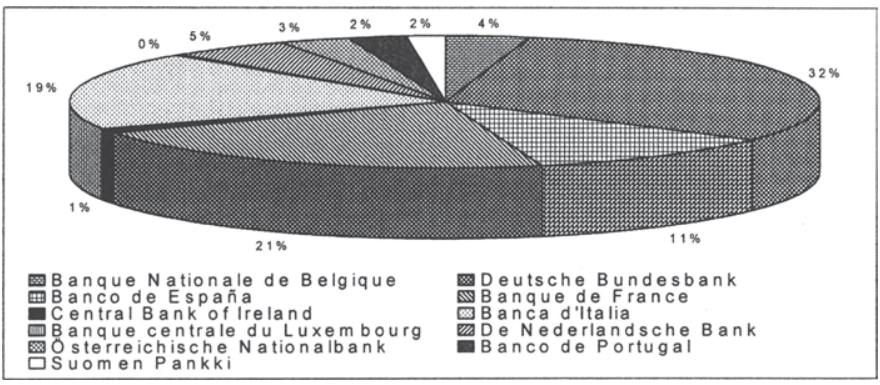

Quelle:

EZB Jahresbericht 1998, 128

Solange Großbritannien, Dänemark, Griechenland und Schweden nicht der EWU beigetreten sind, gilt für die Gewinnverteilung an die nationalen Zentralbanken allerdings, daß der Gewinn entsprechend der Kapitalanteile der EWU-11-Staaten verteilt wird, so daß eine Gewinnverteilung nach dem Kapitalanteilsschlüssel der 
zweiten Spalte in Tabelle 11-1 und wie in Abbildung 11-1 dargestellt erfolgt (vgl. Art. 43.5 ESZB Protokoll).

Als weitere Übergangslösung wurde in Abweichung von Art. 32 beschlossen, daß der EZB-Rat im ersten Jahr nach Beginn der dritten Stufe die zu verteilenden Einkünfte um bis zu $60 \%$ kürzen darf, falls die $100 \%$-ige Verteilung eine "wesentliche Änderung" zu dem relativen Stand der Einkünfte der nationalen Zentralbanken zur Folge hat (vgl. Art. 51 ESZB-Protokoll). Diese Reduktion der zu verteilenden Gewinne muß in den folgenden vier Jahren jährlich um mindestens $12 \%$ Punkte zurückgeführt werden.

Da die über die Anwendung dieses Artikels erst nach Ablauf des ersten Geschäftsjahres entschieden wird, soll er zunächst bei der Berechnung des Verteilungseffekts außer acht gelassen werden.

\subsection{Quantifizierung des Verteilungseffekts}

Der nationale Opportunitätskosten-Seigniorage als Anteil am nationalen BIP berechnet sich aus dem Produkt des Anteils der nationalen Zentralbank am Kapital der EZB und dem Seigniorage in \% des EWU-11-BIP dividiert durch den Anteil des nationalen BIP am EWU-11-BIP30:

$\frac{S^{\text {fisk.,nat. }}}{B I P^{n}}=a^{\text {nat. }} \cdot \frac{S^{\text {fisk., ESZB }}}{B I P^{n}}=a^{\text {nat. }} \cdot \frac{S^{\text {fisk.,ESZB }}}{B I P^{E W U-11}} \cdot \frac{B I P^{E W U-11}}{B I P^{n}}$

Den Geldschöpfungsgewinn der nationalen Zentralbanken nach dieser Verteilung und die Differenz zum Seigniorage nach dem Übergang zum Euro zeigt folgende Tabelle:

Tabelle 11-2: Geldschöpfungsgewinn und Verteilungseffekt in den EWU-11-Staaten nach der Verteilung

\begin{tabular}{|lr|rrrrrr|r|}
\hline & & \multicolumn{3}{c|}{ nach Vertellung (\% vom BIP) } & \multicolumn{3}{c|}{ Differenz zu "nach Ubergang" (\% vom BIP) } & (ECU90) \\
& Ant. EWU-BIP & Sopp1 & Sopp3a & Sopp3c & d Sopp1 & d Sopp3a & d Sopp3c & d Sopp3c \\
\hline B & $3,84 \%$ & $0,41 \%$ & $0,17 \%$ & $0,14 \%$ & $0,03 \%$ & $0,03 \%$ & $0,02 \%$ & $40,1 E+6$ \\
D & $33,25 \%$ & $0,41 \%$ & $0,17 \%$ & $0,14 \%$ & $-0,08 \%$ & $-0,04 \%$ & $-0,03 \%$ & $-456,7 E+6$ \\
E & $8,46 \%$ & $0,58 \%$ & $0,24 \%$ & $0,20 \%$ & $-0,16 \%$ & $-0,09 \%$ & $-0,07 \%$ & $-312,1 E+6$ \\
F & $22,16 \%$ & $0,42 \%$ & $0,17 \%$ & $0,14 \%$ & $0,13 \%$ & $0,07 \%$ & $0,06 \%$ & $583,9 E+6$ \\
IRL & $1,23 \%$ & $0,38 \%$ & $0,16 \%$ & $0,13 \%$ & $0,05 \%$ & $0,01 \%$ & $0,01 \%$ & $6,1 E+6$ \\
I & $18,23 \%$ & $0,45 \%$ & $0,18 \%$ & $0,15 \%$ & $0,04 \%$ & $0,02 \%$ & $0,01 \%$ & $116,5 E+6$ \\
NL & $5,77 \%$ & $0,41 \%$ & $0,17 \%$ & $0,14 \%$ & $-0,06 \%$ & $-0,02 \%$ & $-0,01 \%$ & $-36,0 E+6$ \\
A & $3,26 \%$ & $0,40 \%$ & $0,16 \%$ & $0,14 \%$ & $-0,07 \%$ & $-0,02 \%$ & $-0,01 \%$ & $-19,8 E+6$ \\
P & $1,63 \%$ & $0,65 \%$ & $0,27 \%$ & $0,22 \%$ & $0,24 \%$ & $0,11 \%$ & $0,09 \%$ & $57,1 E+6$ \\
SF & $1,91 \%$ & $0,40 \%$ & $0,16 \%$ & $0,14 \%$ & $0,20 \%$ & $0,10 \%$ & $0,08 \%$ & $93,2 E+6$ \\
\hline
\end{tabular}

Quelle.

eigene Berechnungen

Die Verteilung der "monetären Einkünfte" an die nationalen Zentralbanken egalisiert deren Geldschöpfungsgewinne bei Berechnung durch den Opportunitätskosten-Seigniorage (Variante 3 ) je nach Referenzzinssatz auf 0,13\% bis $0,15 \%\left(i_{\text {opp }}\right.$

30 Der Zeitindex wurde aus Gründen der Übersichtlichkeit weggelassen. 
$=2,5 \%$ ) bzw. $0,16 \%$ bis $0,18 \%\left(i_{o p p}=3 \%\right)$. Nur Spanien und Portugal erzielen noch einen Geldschöpfungsgewinn von über $0,20 \%$, wobei Portugal durch die Verteilung der Gewinne gegenüber dem Zustand nach dem Übergang zum Euro etwa 0,1\%-Punkte vom BIP hinzugewinnt, während Spanien nochmals durch diesen Übergangseffekt knapp 0,1\%-Punkte verliert.

Abbildung 11-2: Der Verteilungseffekt in \%-Punkten der nationalen BIPs

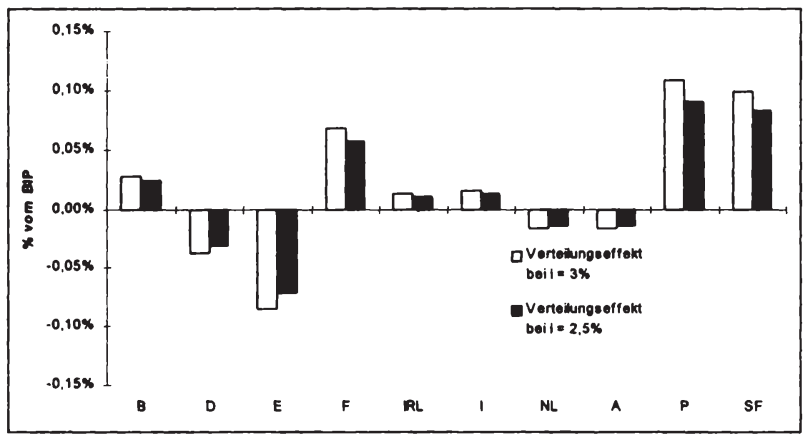

Quelle:

eigene Berechnungen

Ebenfalls Gewinner der Verteilung ist Finnland mit knapp 0,1\%-Punkten vom BIP. Alle übrigen Staaten werden von der Verteilung der Gewinne durch die EZB kaum berührt. Allenfalls Frankreich mit $+0,06 \%$-Punkten könnte man noch zu den Gewinnern der Verteilung zählen. Wenn man allerdings die Größenordnung der verteilten Gewinne betrachtet, gelangt man zu dem Schluß, daß die Verteilung der Geldschöpfungsgewinne nach dem Schlüssel kaum eine Veränderung der Gewinnsituation gegenüber der Situation nach der Umstellung auf den Euro bewirkt. In absoluten Zahlen ist einzig Frankreich mit einem Verteilungseffekt von + 0,6 Mrd. ECU90 und Deutschland mit - 0,5 Mrd. ECU90 pro Jahr erwähnenswert.

Abbildung 11-3: Verteilungseffekt (ECU90)

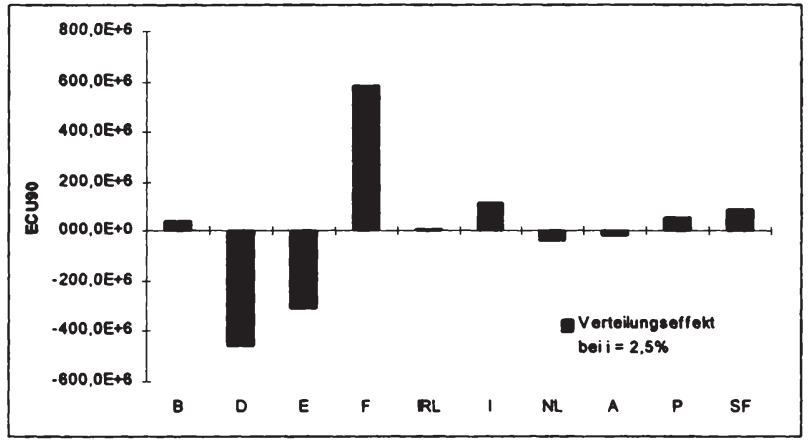

Quelle:

eigene Berechnungen 
Roland Klopfleisch - 978-3-631-75045-2

Downloaded from PubFactory at 01/11/2019 08:55:36AM

via free access 


\section{Teil V:}

\section{Zusammenfassung, Wirtschaftspolitische Optionen und Ausblick}

In diesem Teil werden die drei quantitativ untersuchten Effekte noch einmal zusammengefaßt und verglichen, um daraus qualitative Aussagen bezüglich der langfristigen Wirkung der EWWU auf den Geldschöpfungsgewinn abzuleiten.

\section{Zusammenfassung von Konvergenz-, Übergangs- und Verteilungseffekt}

Folgende Abbildung verdeutlicht die Größenverhältnisse von Konvergenz, Übergangs- und Verteilungseffekt:

Abbildung 12-1: Vergleich von Konvergenz-, Übergangs- und Verteilungseffekt

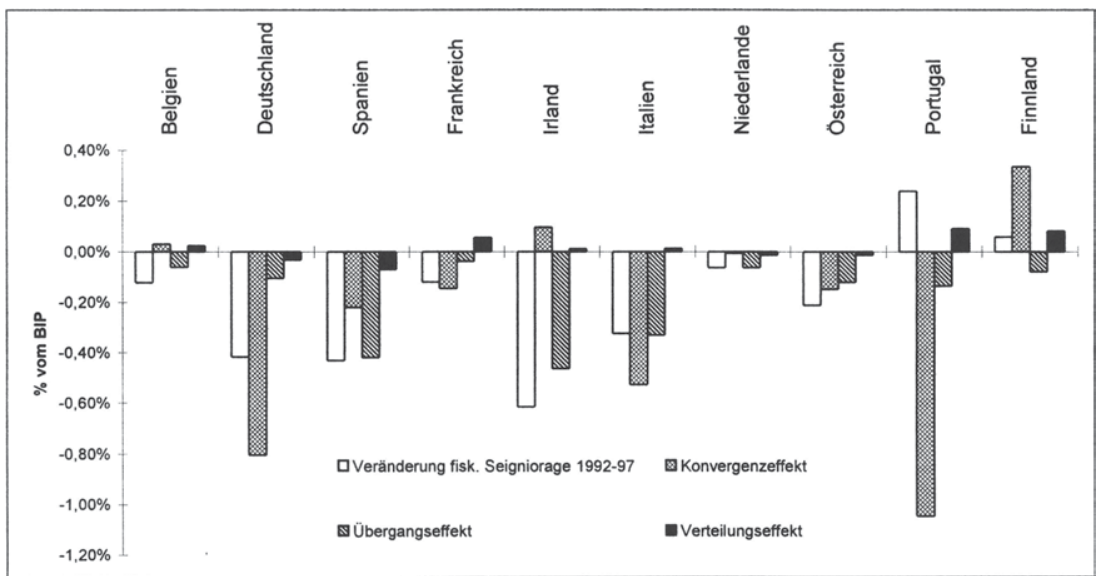

Quelle:

eigene Berechnungen

Hieraus wird ersichtlich, daß die meisten Staaten einen erheblichen Rückgang an fiskalischem Seigniorage in den Jahren 1992 bis 1997 zu verzeichnen hatten. Dieser Rückgang kann in den überwiegenden Fällen durch den Konvergenzeffekt erklärt werden (vgl. 7.11). Mit der Erfüllung der Konvergenzkriterien sind die fiskalischen Effekte für viele EWU-11-Staaten allerdings noch nicht beendet, denn mit dem Übergang auf den Euro und einer einheitlichen durch die EZB bestimmten Geldpolitik werden weitere Einbußen bei den Geldschöpfungsgewinnen auf sie zukommen. Insbesondere für die Staaten Spanien, Irland und Italien bewegen sich die prognostizierten Verluste nochmals in einer Größenordnung von 0,4\% des BIP. Aber auch die übrigen Staaten werden beim Übergang auf den Euro nochmals eine Seignioragereduktion, vor allem aufgrund der sehr niedrigen Refinanzierungszinsen und der Verzinsung der Mindestreserve, erfahren. Diese beiden Effekte - Konvergenz- und Übergangseffekt - lassen den Seigniorage in den 
beteiligten Staaten zum einen in der absoluten Höhe auf ein solch niedriges $\mathrm{Ni}$ veau und zum anderen im zwischenstaatlichen Vergleich gleiches Niveau schmelzen, daß der anschließende Verteilungseffekt fast vernachlässigt werden kann und allenfalls für Spanien $(-0,07 \%$ des BIP), Frankreich $(+0,06 \%$ des BIP), Portugal $(+0,09 \%$ des BIP) und Finnland $(+0,08 \%$ des BIP) eine haushaltspolitische Bedeutung erlangt. Absolut gesehen wird zwar Deutschland den höchsten Anteil am Verteilungsverlust zu tragen haben (-460 Mio. ECU90), mit $0,03 \%$ des BIP wird aber auch dieser Betrag nicht in dem Maße ins Gewicht fallen, wie in einigen zu Beginn untersuchten Studien behauptet wurde. 


\section{Wirtschaftspolitische Optionen}

Um wirtschaftspolitische Schlußfolgerungen aus den fiskalischen Effekten der Europäischen Währungsunion ziehen zu können, müssen die Ursachen der drei in dieser Arbeit analysierten Effekte streng voneinander getrennt werden. Während die Ursachen für den Konvergenz- und den Übergangseffekt in den Integrationsbemühungen der Mitgliedsstaaten zur Verwirklichung der Europäischen Währungsunion zu suchen sind, ist der Verteilungseffekt ein Phänomen eines zunächst vertraglich vereinbarten Schlüssels zur Verteilung der Gewinne aus der Geldschöpfung, der vor dem Hintergrund von Gerechtigkeitsaspekten beleuchtet werden kann.

Zunächst sind die fiskalischen Folgen der im Rahmen des Konvergenzeffekts schon eingetretenen und die im Rahmen des Übergangseffekts noch eintretenden Seigniorageverringerungen nicht zu unterschätzen.

Für einige Staaten betrug der erste fiskalische Effekt - der Konvergenzeffekt zwischen 1992 und 1997 rund ein Sechstel bis ein Drittel der Grenze des im Maastrichter Vertrag festgelegten Defizitkriteriums von 3\% des BIP (Portugal $1,05 \%$, Deutschland $-0,81 \%$, Italien $-0,53 \%$ ). Diese Einbußen konnten im Beobachtungszeitraum zumindest teilweise innerhalb der nationalen Zentralbanken kompensiert werden. So stieg der fiskalische Seigniorage Portugals entgegen seines hohen negativen Konvergenzeffekts sogar um 0,24\% des BIP an. Auch in Deutschland konnte der Konvergenzeffekt deutlich abgemildert werden, so daß der fiskalische Seigniorage nur um $0,42 \%$ des BIP zurückging. Die Gründe hierfür sind vielfältig. Zum einen liegen sie in einer Veränderung der geldpolitischen Instrumente, zum anderen in der Entwicklung der Währungsreserven. In Portugal beispielsweise wurde 1994 die hohe Verzinsung der Mindestreserve aufgehoben und ebenfalls spielten dort die Einnahmen aus den Währungsreserven eine überaus große Rolle. Auch in Deutschland war eindeutig der wachsende Anteil der Zinseinnahmen aus den Währungsreserven dominant bei der Kompensation des Konvergenzeffekts. Dabei war zwar weniger die absolute Höhe der Währungsbestände ausschlaggebend, als vielmehr die Zinsstruktur der ausländischen Anlagen ${ }^{31}$. Aber auch die Zinsstruktur der Refinanzierungsgeschäfte kann den fiskalischen Seigniorage eindeutig beeinflussen. So trug der Wandel in der Anwendung der geldpolitischen Instrumente weg von den niedrig verzinsten Diskontgeschäften hin zu marktnahen Offenmarktgeschäften eindeutig zu einem Anwachsen der - wie es Klein/Neumann $(1990,219)$ nennen - "Zentralbankeffizienz” bei, nicht zuletzt auch deshalb, weil sich aufgrund der befristeten Offenmarktgeschäfte gegenüber den längerfristigen Refinanzierungen über Diskontgeschäfte die Kontrolle der Zentralbankgeldbereitstellung der Notenbank verbesserte

31 Während die Refinanzierungssätze zwischen 1992 und 1997 von knapp 10 \% auf 3 \% gesenkt wurden, hielt sich die Rendite der Guthaben bei ausländischen Banken und Geldmarktanlagen im Ausland bei über $9 \%$ (vgl. Anhang). 
(Steuerungseffizienz), so daß kostspielige Liquidationsgeschäfte überflüssig wurden (vgl. Feldmann 1998, 281). Zudem sparen Offenmarktgeschäfte gegenüber den Instrumenten der Mindestreserve und des Rediskont Abwicklungskosten ein, da dort im allgemeinen große Blöcke an Papieren gehandelt werden, weniger Prüfungen der Papiere vorgenommen werden müssen und die Zentralbanken auf bestehende Infrastrukturen für Geld- und Rentenmärkte zurückgreifen können (vgl. Menkhoff 1996²). Der positive Effekt der Effizienzsteigerung auf den fiskalischen Seigniorage kann den negativen Effekt der Inflationsrückführung auf den Opportunitätskosten-Seigniorage zumindest teilweise kompensieren (vgl. Klein/Neumann 1990, 219).

Die verbleibenden Rückgänge des fiskalischen Seigniorage mußten in den betroffenen Staaten allerdings auf der haushaltspolitischen Ebene kompensiert werden. Die dabei nötigen Anstrengungen relativieren sich jedoch erheblich im Vergleich zu den Auswirkungen, die beispielsweise Lange/Nolte 1998 (-2,5\% des BIP) oder auch Gros 1996 (- 1 \% des BIP) für Portugal errechnen. Der fiskalische Verlust für Deutschland betrug $0,4 \%$ des BIP und lag damit in der von den meisten Autoren prognostizierten Größenordnung.

Der zweite fiskalische Effekt entsteht den EWU-Mitgliedsstaaten beim Übergang ihrer nationalen Währungen auf den Euro infolge der einheitlichen Geldpolitik der EZB. Insbesondere für die Staaten Italien, Spanien und Irland werden die fiskalischen Auswirkungen bei dieser letzten Konvergenzstufe nochmals zwischen $0,3 \%$ und $0,45 \%$ des BIP liegen 32 .

Die Kompensation der Einnahmeverluste aus dem Konvergenz- und dem Übergangseffekt auf der Haushaltsebene dürfte den betroffenen Staaten schwerfallen, da die übrigen Konvergenzkriterien eine zusätzlich Verschuldung ausschlieBen. Auf der Einnahmenseite wird es den Staaten aufgrund des Steuerwettbewerbs der EWWU Mitgliedsstaaten ebenfalls kaum möglich sein, ihre Steuersätze unabhängig von den übrigen Sätzen innerhalb der Währungsunion festzusetzen; ebenfalls sind die Ausgaben als Folge des Standortwettbewerbs nicht beliebig reduzierbar (vgl. Jordan 1994, 300). Allerdings geht eine nicht zu vernachlässigende Verminderung der Ausgabenseite direkt mit dem Konvergenzeffekt einher: Infolge der Verminderung der Refinanzierungszinsen gingen im Beobachtungszeitraum auch die Kapitalmarktzinsen zurück, so daß zumindest der Zinsendienst der hochverschuldeten Staaten der EWU-11 Staaten deutlich gedrückt werden konnte. Allein 1998 sanken die Zinsausgaben der Gesamtheit der EWU-11 Staaten infolge der gesunkenen Zinsen von $5 \%$ auf 4,5\% am BIP (vgl. Künstle 1999, 8).

32 Ein Teil der Anpassungen in diesen Staaten erfolgte vermutlich aber schon 1998 - de facto also vor dem eigentlichen Übergang zum Euro -, da aus Datengründen ein Teil des Konvergenzeffektes von 1998 im Übergangseffekt enthalten ist. Da Ende 1998 alle EWU-11 Staaten die Konvergenzkriterien erfüllt hatten, ist davon auszugehen, daß dieser Teil sogar die Mehrheit stellt. 
Der dritte fiskalische Effekt tritt durch die Verteilung der nach dem Übergang zum Euro national erwirtschafteten Zentralbankgewinne nach dem Kapitalschlüssel ein. Die Analyse dieses Verteilungseffekts hat ergeben, daß im Verhältnis zu ihrem BIP nur Spanien als Verlierer dieses Verteilungsschlüssels betrachtet werden kann, während Frankreich, Portugal und Finnland zu den Gewinnern gezählt werden können, wobei sich die Effekte jeweils unter $0,1 \%$ des BIP bewegen. Der Verteilungseffekt tritt also weit zurück hinter die fiskalischen Effekte, die aus der Integrationsbemühung resultieren, und im Verhältnis zu den Ergebnissen der eingangs untersuchten Studien ist er weit geringer als dort prognostiziert. Hätte die Höhe des Verteilungseffektes wirklich die Ausmaße angenommen, wie in einigen Studien berechnet, so hätte man tatsächlich nach den Ursachen fragen müssen und einen neuen "gerechteren" Schlüssel suchen müssen.

Die in den untersuchten Studien berechneten Effekte bezogen sich aber in quantitativer Hinsicht meist auf den Konvergenz- und den Übergangseffekt, so daß die dort aufgrund der quantitativen Ergebnisse erhobene Forderung, der Verteilungsschlüssel müsse nach einer neuen Methode berechnet werden, an den Ursachen der Einnahmenveränderung vorbeigeht und somit verworfen werden muß.

Ein - wenn auch mit 0,03\% des BIP geringer - negativer Verteilungseffekt für Deutschland bleibt dennoch, und er ist mit einer halben Mrd. ECU90 immerhin der höchste absolute Verteilungsverlust innerhalb der EWU-11.

Aber auch dieser verbleibende Verteilungsverlust begründet noch keine Veränderung des Verteilungsschlüssels:

Der Grund für den Verlust ist die im Verhältnis zu seiner ökonomischen Bedeutung (BIP) und Bevölkerungsgröße große monetäre Basis, weshalb einige Autoren und Politiker für einen neuen Verteilungsschlüssel plädieren, der sich auf die monetäre Basis beziehen soll (vgl. Kap. 2). Dieser Argumentation kann allerdings aus folgendem Grund nicht zugestimmt werden:

Die große monetäre Basis ist im wesentlichen ein Resultat des hohen Bargeldumlaufs im Ausland. Nach einer Analyse von Seitz (1995) betrug dieser Ende 1994 zwischen 65 und 90 Mrd. DM, d.h. 27 - $38 \%$ des gesamten Bargeldumlaufs, und wird im Ausland sowohl als Wertaufbewahrungsmittel als auch zu Transaktionszwecken verwendet. Darauf deutet der hohe Gebrauch sowohl kleiner als auch sehr großer Banknotenwerte im Ausland hin (vgl. Seitz 1997, 73). Der dadurch generierte Opportunitätskosten-Seigniorage (Variante 2, $\mathrm{i}_{\text {opp }}=5,25 \%{ }^{33}$ ) betrug demnach 3,4 bis 4,7 Mrd. DM, bzw. 1,4 bis 2 Mrd. ECU90. Der durch die Geldnachfrage im Ausland generierte Seigniorage übertrifft also den Verteilungseffekt um ein vielfaches. Wenn man nun davon ausgeht, daß sich die vormalige Nachfrage nach DM im Ausland auf den Euro erstrecken wird, ist fraglich, warum dieser Anteil des Seigniorage dem deutschen Staat zukommen soll. Allenfalls

33 Offenmarktzins von 1994 
kann man argumentieren, daß die Nachfrage nach Bargeld im Ausland eine Folge der hohen Reputation der Deutschen Bundesbank sei und diese Reputation ginge nun auf die Europäische Zentralbank über, weshalb die Erträge aus der in der Vergangenheit aufgebauten Reputation auch Deutschland zugute kommen müßten. Dem ist aber entgegenzuhalten, daß der Übergang der Reputation, wenn er denn überhaupt zustande kommt ${ }^{34}$, ebenfalls im Vertrag von Maastricht intendiert war und somit ein Teil der Integrationsbemühungen ist. Ein Teil der Bargeldnachfrage des Auslands wird sich nach dem Übergang zum Euro ohnehin auch auf andere EWU-11 Staaten erstrecken - z.B. die Nachfrage Sloweniens oder Kroatiens nach Euro auf Österreich oder Italien -, so daß allein aufgrund dessen die monetäre Basis Deutschlands sinken wird und damit auch der Verteilungseffekt ${ }^{35}$.

Bei der Frage nach dem Grund der Einwilligung Deutschlands zum Verteilungsschlüssel wird deshalb teilweise auch von einer "pan-europäischen" Sichtweise gesprochen, die der Bundesbank bei den Verhandlungen zum Maastrichter Vertrag zugrunde gelegen haben soll bzw. diese Verluste der Preis dafür seien, daß sich die EZB dem Ziel der Preisstabilität verschreibt und von politischer Kontrolle frei sein wird (vgl. Courtis 1998, 24).

Eine Reduzierung des Verteilungseffektes mit Hilfe eines auf die monetäre Basis der Mitgliedsstaaten bezogenen Verteilungsschlüssels ist deshalb abzulehnen. Die mit Hilfe des geltenden Verteilungsschlüssels den nationalen Zentralbanken zufließenden Mittel entsprechen am ehesten der in den jeweiligen Staaten entstandenen Geldschöpfungsgewinne. Die von deutscher Seite erhobene Forderung nach einer Änderung des Schlüssels scheint eher aus der Tradition des mit der Nettozahlerposition Deutschlands begründeten ständigen Aufschreis bei EU-Finanzfragen geboren zu sein.

Man kann sogar fragen, ob der innerhalb des ESZB entstandene Seigniorage überhaupt den nationalen Haushalten zufließen muß, oder nicht gleich auf europäischer Ebene verbleiben sollte. Es ist nicht einsichtig, warum Gewinne der Bundesbank als deutsche Gewinne anzusehen sind, obwohl das den zinsbringenden Aktiva auf der Passivseite entsprechende Bargeld innerhalb ganz Europas als Zahlungsmittel verwendet wird, was z.B. dann der Fall sein wird, wenn Bargeld infolge von Tourismus ins europäische Ausland transferiert wird (vgl. Gros 1998,

34 Erzielt der Euro keine entsprechende Nachfrage im Ausland, so sinkt die Verteilungswirkung für Deutschland sowieso entsprechend dem Rückgang seiner monetären Basis und einer Angleichung von Kapitalschlüssel und Anteil an der europäischen monetären Basis. Ein Indiz dafür, daß die Geldnachfrage nach DM und somit eventuell auch nach Euro im Ausland sinkt ist, ist der seit Mitte 1997 sinkende Bargeldumlauf, der sich nicht allein mit inländischen Entwicklungen erklären läßt (vgl. Deutsche Bundesbank, Geschäftsbericht 1997, 85).

35 Falls der EZB-Rat dem Reputationseinwand in den ersten fünf Jahren nach dem Übergang zum Euro entsprechen möchte, kann er nach Art. 51 ESZB-Protokoll die zu verteilenden Gewinne kürzen, so daß der Verteilungseffekt reduziert wird (vgl. 11.2). 
15). Eine einfache Lösung bestünde nach Gros (1998) darin, die Notenbankgewinne, die aus dem Geldmengenwachstum nach dem Übergang auf den Euro entstehen, bilanziell auf der europäischen Ebene entstehen zu lassen und diese Gewinne an die Mitgliedsstaaten nach dem Kapitalschlüssel zu verteilen, ohne Überweisungen von der nationalen auf die europäische Ebene und deren Zurückverteilung auf die nationale Ebene tätigen zu müssen. Andere Autoren gehen weiter und fordern einen Verbleib aller Gewinne des ESZB auf der europäischen Ebene, beispielsweise zur Finanzierung des EU-Haushalts, denn auch die Gewinne der Bundesbank werden, obwohl sie in den ausführenden Landeszentralbanken entstehen, nicht nach einem Kapitalschlüssel auf die Länder Deutschlands verteilt, sondern dem Bundeshaushalt überwiesen (vgl. Dickertmann 1999, 81). Zusätzliches Gewicht gewinnt dieses Argument nach dem Prinzip der Finanzautonomie, nach dem jede föderale Ebene - auch höhere - eine eigene gewichtige Einnahmequelle haben sollte, um deren finanzielle Autonomie zu stärken (vgl. Wagner 1999, 35). Dies ist auf EU-Ebene derzeit noch nicht gegeben, sondern der EUHaushalt finanziert sich aus Zuweisungen der nationale Haushalte.

Die Zuweisung der Seigniorageeinnahmen innerhalb einer Ebene (von der EZB direkt an den EU-Haushalt) würde sich deshalb anbieten, „weil die Geldpolitik eine Gemeinschaftsaufgabe darstellt, die spill-over-Effekte generiert, d.h. Effekte hat, die nicht an nationalen Grenzen einzelner Mitgliedsstaaten halt machen, und deshalb nicht von einer untergeordneten Ebene übernommen bzw. bereitgestellt werden können. In einer Währungsunion gilt dies gerade für die Leistungen der supranationalen Geldpolitik und für die zentrale Geldschöpfung, weil die Geldschöpfungsgewinne sich nicht mehr den einzelnen Staaten zurechnen lassen und innerhalb einer Währungsunion quasi flächendeckend anfallen" (Larbig 1997. 27f).

Zusammenfassend ist zu konstatieren, daß es im Zuge der Europäischen Währungsunion Veränderungen der nationalen Seigniorage gegeben hat und geben wird, die haushaltspolitische Anpassungen nötig machten und machen. Allerdings ist der Ruf nach einer Veränderung des Verteilungsschlüssels nicht zu rechtfertigen, da die Seigniorageveränderungen im wesentlichen aus der politisch gewünschten Konvergenz der Mitgliedsstaaten und den Übergangseffekten resultiert. Die dann verbleibenden Verteilungseffekte sind als gering einzustufen. Vielmehr ist zu fragen, ob der innerhalb des ESZB entstehende Geldschöpfungsgewinn nicht vielleicht sogar auf europäischer Ebene verbleiben und zur fiskalen Autonomie des EU-Haushalts beitragen sollte. 


\section{Ausblick}

Bei einer langfristigen Betrachtung des Seigniorage innerhalb des ESZB spielen mehrere Einflußfaktoren eine Rolle, die im folgenden stichwortartig skizziert werden sollen.

\section{- Erweiterung der Europäischen Währungsunion}

Eine Erweiterung der EWU um die Staaten des EWS-II (Dänemark, Griechenland, Großbritannien und Schweden) oder der Staaten Osteuropas wird ebenfalls Auswirkungen auf den Seigniorage aller beteiligten Staaten haben. Sowohl der nationale Seigniorage der "Pre-Ins" wird sich im Vorfeld des Beitritts verändern, als auch jener der derzeitigen EWU-11 Staaten im Rahmen der Verteilung der Gewinne. Insbesondere für Griechenland werden im Rahmen der für einen Beitritt zur EWU noch nötigen Inflationsreduzierung hohe Seigniorageverluste prognostiziert (vgl. Alogoskoufis/Christodoulakis 1991, 266). Dagegen werden sich die durch weitere Beitritte zur EWU induzierten Verteilungseffekte dann in einem kleinen Rahmen halten, wenn im Vorfeld eine ausreichende Konvergenz der "Pre-Ins" erzielt wurde.

\section{- $\quad$ Elektronisches Geld}

In den meisten europäischen Staaten hat sich die Umlaufgeschwindigkeit des Geldes in den letzten Jahren aufgrund der Zunahme des bargeldlosen Zahlungsverkehrs erhöht und somit den Seigniorage vermindert. Das Aufkommen von elektronischem Geld wird diesen Trend verstärken und für weitere Seigniorageverluste des Staates sorgen. Dabei versteht man unter elektronischem Geld karten- oder netzwerkbasierte Geldeinheiten, auf deren Zugriff wie beim Bargeld kein Rückgriff auf ein Konto eines Kreditinstituts erfolgt (vgl. Bibow/Wichmann 1997, 116ff).

Die elektronische Geldbörse - eine Geldkarte oder eine spezielle Software - ist Aufbewahrungsort für die elektronischen Geldeinheiten und befindet sich im unmittelbaren Besitz des Verwenders. Zum Bezahlen wird nur auf die elektronische Geldbörse zurückgegriffen, das Auffüllen besorgt in der Regel ein Kreditinstitut gegen die Belastung eines Girokontos oder gegen Einzahlung von Bargeld. Den Kreditinstituten fließt dadurch Bargeld bzw. Überschußreserve zu, die zinsbringend weiterverliehen werden kann, während die Guthaben in den elektronischen Geldbörsen bislang nicht verzinst werden.

Damit ist den privaten Geschäftsbanken die Möglichkeit gegeben, Geld zu schöpfen, ohne - zumindest solange keine Mindestreserve auf die ausgegebenen elektronischen Geldeinheiten verlangt werden ${ }^{36}$ - dafür Zentralbankgeld nachfragen zu müssen.

36 In Deutschland ist die Ausgabe von elektronischem Geld bislang mindestreservefrei. Die Erhebung einer Mindestreserve aus geldpolitischen Gründen wird jedoch diskutiert. 
Sollte mit der Verwendung des elektronischen Geldes in gleicher Höhe Bargeld substituiert werden, vermindert sich der Seigniorage der Zentralbanken in gleichem Maße wie der Geldschöpfungsgewinn der Geschäftsbanken zunimmt ${ }^{37}$. Für Deutschland prognostizieren Janssen/Lange einen jährlichen Seigniorageverlust der Deutschen Bundesbank, der den Kreditinstituten zukommen wird, von 365 Mio. DM unter Zugrundelegung von Daten aus dem Jahr 1996 (vgl. Janssen/Lange 1998, 58). Dies wären etwa $0,01 \%$ vom BIP. Boeschoten/Hebbink berechnen für Deutschland einen Seigniorage-Verlust in Höhe von $0,03 \%$ des BIP. Für die übrigen europäischen Staaten ergibt sich dort ein bis zu doppelt so hoher Verlust (vgl. Boeschoten/Hebbink 1996, 14).

Sollte sich der nationale Seigniorage in dieser Weise vermindern, wird der Verteilungseffekt zukünftig noch geringer ausfallen, da die zu verteilenden Gewinne ebenfalls abnehmen werden. D.h. mit einer Zunahme des elektronischen Geldes steigt die Möglichkeit der Geschäftsbanken Giralgeld zu schöpfen zu Lasten der Zentralbankgeldmenge. Der Geldschöpfungsgewinn nimmt somit auf der Ebene der Geschäftsbanken zu und verringert sich auf der Ebene des ESZB. Somit verringern sich die an die nationalen Zentralbanken zu verteilenden Summen und somit auch ihr Gewicht bezüglich des BIP. Der Verteilungseffekt verringert sich deshalb in dem Maße wie der Seigniorage auf europäischer Ebene aufgrund des elektronischen Geldes sinkt.

\section{- Nachfrage nach Euro im Ausland}

Die hohen Geldschöpfungseinnahmen der Deutschen Bundesbank in der Vergangenheit beruhten, wie oben gezeigt nicht nur auf den Zahlungsgewohnheiten der Einwohner Deutschlands, sondern ebenso auf der Nachfrage nach DM im Ausland. Diese Nachfrage kann sich in Zukunft auf den Euro erstrecken und wird maßgeblich vom Vertrauen in die neue Währung geprägt sein. Dabei ist zu unterscheiden, ob es sich erstens um Nachfrage nach Bargeld handelt, z.B. in der Untergrundökonomie oder zu Transaktionszwecken in Staaten mit instabilen Währungen, oder zweitens um Buchgeld zu Transaktionszwecken im internationalen Handel bzw. in Wertpapierfonds. Im ersten Fall könnte der Euro - zumindest in Teilen Osteuropas - die bisherige Rolle der DM übernehmen, in anderen Staaten die Rolle des US-Dollars als Bartransaktionswährung. Im zweiten Fall wird er gegen den US-Dollar als Welt-, Anlage- und Reservewährung konkurrieren.

Den ersten Markt dominiert zumindest in weiten Teilen Lateinamerikas, - insbesondere Argentinien - , in den Staaten der ehemaligen Sowjetunion, insbesondere Rußland, und im mittleren Osten der US-Dollar. Der Euro könnte hier eine

37 Bei einem funktionierenden Wettbewerb zwischen den Kreditinstituten wird es langfristig allerdings zu einer Verzinsung der elektronischen Guthaben kommen, so daß die Geldschöpfungsgewinne der Geschäftsbanken zugunsten einer Verringerung der Kosten der elektronischen Geldhaltung sinken werden. Auf das Sinken des Seigniorage des ESZB hat dies allerdings keinen Einfluß. 
attraktive Alternative zum US-Dollar darstellen, denn die EU ist sowohl bezüglich des Bruttoinlandsprodukts als auch bezüglich der Einwohnerzahl etwas größer und außerdem geographisch gesehen näher an den ehemaligen Sowjetstaaten und dem mittleren Osten gelegen als die USA. Insbesondere die Notenstückelung - mit 100, 200 und 500 Noten - kann den Euro vor allem im Untergrundsektor zu einer beliebten Währung zu Transaktions- und Aufbewahrungszwecken machen (vgl. Rogoff 1998, 264)38.

Auch als Transaktionswährung dominiert bislang der US-Dollar die übrigen Währungen. Der Wert des Welthandels, der in US-Dollar abgewickelt wird, ist fast viermal so hoch wie der US-amerikanische Exportwert, während dieser Faktor für die D-Mark nur 1,6 beträgt und andere Währungen in diesem Zusammenhang gar keine Rolle spielen (vgl. Müller/Straubhaar 1998, 286). Mit dem Übergang zum Euro ist zu erwarten, daß viele europäische Unternehmen, die bislang kaum in heimischer Währung fakturieren ${ }^{39}$, Waren zukünftig in Euro berechnen werden.

Als Anlagewährung wird der Euro - nach Beilegung der Unsicherheiten über die Qualität des Euro und die Geldpolitische Strategie der EZB zu Beginn der Stufe drei - mittelfristig mit dem US-Dollar gleich auf liegen, da der Wertpapiermarkt in Euro größer und liquider werden wird und die Transaktionskosten fallen werden (vgl. Portes/Rey 1998).

Devisenreserven werden von Zentralbanken zur Glättung von Wechselkursschwankungen gehalten, wobei hier bislang ebenso dem US-Dollar die dominante Rolle zukommt. Zwar werden die Reserven der nationalen europäischen Zentralbanken nach dem Übergang zum Euro zu groß sein und vermutlich reduziert werden, allerdings ist nicht anzunehmen, daß der Euro in gleicher Weise in anderen Staaten als Reservewährung reüssiert (vgl. Masson/Turtelboom 1997, 29).

Sollte die Substitution des US-Dollars durch die europäische Währung in den dargestellten Gebieten greifen, hat dies natürlich positive Auswirkungen auf die monetäre Basis des ESZB und damit auf die Höhe des Seigniorage, so daß letztendlich alle EWU Teilnehmerstaaten zu Gewinnern werden (vgl. Gros/Thygesen 19982, 298f). Die Gewinne der USA allein aus der Geldhaltung ihrer Währung im Ausland wird - berechnet nach dem Konzept des Opportunitätskosten-Seigniorage - auf etwa 0,1\% des BIP geschätzt und beträgt damit seit Ende der 80er Jahre mehr als der Seigniorage aus der heimischen Geldhaltung (vgl. Jefferson 1998, 228). Insgesamt wird die teilweise sicherlich mögliche Substitution des US-

Den Einnahmen aus der zusätzlichen Geldschöpfung durch das Ausland stehen allerdings die Mindereinnahmen durch Untergrundökonomie und Steuerhinterziehung im Inland entgegen (vgl. Rogoff 1998, 288ff).

39 Während drei Viertel der deutschen Exporte in DM abgewickelt werden, sind diese Anteile in anderen EU-Staaten - z.B. Frankreich mit 55 \% - deutlich niedriger (vgl. Hartmann 1996, 12). 
Dollar von der Stabilität des Euro und damit vom Vertrauen in die Politik der EZB und der europäischen Staaten abhängen. Dazu ist zum einen eine transparente Geldpolitik mit dem Ziel der Geldwertstabilität und zum anderen eine solide Finanzpolitik der Mitgliedsstaaten nötig. Geschwächt werden kann dieses Vertrauen natürlich dann, wenn einzelne Staaten eine unsolide Verschuldungspolitik betreiben, so daß auch im Zusammenhang mit dem Seigniorage der Stabilitätspakt eine wichtige Rolle spielen kann, um Free-Rider-Verhalten einzelner Staaten auf Kosten von Seigniorageeinnahmen zu verhindern. 
Roland Klopfleisch - 978-3-631-75045-2

Downloaded from PubFactory at 01/11/2019 08:55:36AM

via free access 


\section{Literatur}

Alogoskoufis, G.S./Christodoulakis, N. (1991): Fiscal Deficits, Seigniorage, and External Dept: The Case of Greece, in Alogoskoufis, G./Papademos, L./Portes, R. (Hrsg.): External Constraints on Macroeconomic Policy: The European Experience. Cambridge u.a., 264301.

Baltensperger, E./Jordan, T.J. (1997): Principles of Seigniorage. In: Swiss Journal of Economics and Statistics, 133, 133-152.

Baltensperger, E./Jordan, T.J. (1998): Seigniorage and the Transfer of Central Bank Profits to the Government. In: Kyklos, 51, 73-88.

Barro, RJ. (1982): Measuring the Fed's Revenue from Money Creation. In: Economic Letters, 10(1982), 327-332.

Barro, RJ. (1995): Inflation and economic growth. In: Bank of England Quarterly Bulletin, May, 166-175.

Beetsma, R.M.WJ./Bovenberg, A.L. (1996): Does Monetary Unification Lead to Excessive dept Accumulation? WP-96-41 Limburg Institute of Financial Economics, Maastricht.

Bibow, J.Michmann, T. (1997): Elektronisches Geld: Funktionsweise und wirtschaftspolitische Konsequenzen. In RWI-Mitteilungen, 47, 115-139.

Bofinger, P./Reischle, J./Schächter, A. (1996): Geldpolitik - Ziele, Institutionen, Strategien und Instrumente. München.

Borio, C.E.V. (1997): Monetary Policy Operating Procedures in Industrial Countries. In: BIS Working Paper, No. 40. Basel.

Bundesrechnungshof (1989): Bemerkungen des Bundesrechnungshofes 1989 zur Haushaltsund Wirtschaftsführung. In: Deutscher Bundestag (Hrsg.): Drucksache 11/5383, 121, Bonn.

Courtis, N. (1999): Commission eyes juicy ESCB profits. In: Central Banking IX(1999)3, 52-54.

Dallmeyer, J. und Preuschl, M. (1999): Wirtschaftlicher Ausblick für Euroland. In: Deutsche Bank Research (Hrsg.): Wirtschaftstrends, Nr. 4/ 1999, 7-10.

Deutsche Bundesbank (1995): Die Geldpolitik der Bundesbank. Frankfurt/M.

Dickertmann, D. (1999): EU: Die Nettozahler- und Empfängerpositionen auf dem Prüfstand. In: Wirtschaftsdienst 2/99, 77-83.

Drazen, A. (1985): A general measure of inflation tax revenues. In: Economic Letters 17(1985), 327-330.

Emerson, Michael u. a. (1992): One Market, One Money, Oxford New York.

Escrivá, J.L./Fagan, G.P. (1996): Empirical Assessment of Monetary Policy Instruments and Procedures (MPIP) in EU Countries. EMI Staff Paper No. 2. Frankfurt/M. 
Europäische Union, Europäische Gemeinschaft (19954): Die Vertragstexte von Maastricht mit den deutschen Begleitgesetzen. Bonn.

Feldmann, H. (1998): Das geldpolitische Intrumentarium des Europäischen Systems der Zentralbanken - Eine Analyse des EWI-Vorschlages. In: Kredit und Kapital 2/98, 273-301.

Feldsieper, M. (1998): Die Zukunft des Goldes im Internationalen Währungssystem. In: Hamburger Jahrbuch für Wirtschafts- und Gesellschaftspolitik, 43, 311-325.

Friedman, M. (1971): Government Revenue from Inflation. In: The Journal of Political Economy, 79, 846-856.

Frenkel, M./Nickel, C. (1999): EWS II: Der neue europäische Wechselkursmechanismus. In: WiSt 3/99, 141-144.

Gebauer, W. (1996): Geld: Angebot versus Nachfrage. In: Bofinger, P./Ketterer, K.-H. (Hrsg.): Neuere Entwicklungen in der Geldtheorie und Geldpolitik. Tübingen.

Gros, D. (1989): Seigniorage in the EC: The Implications of the EMS and Financial Market Integration. IMF Working Paper, Nr. 7, January 23.

Gros, D. (1996): Seigniorage and EMU: The Fiscal Implications of Price Stability and Financial Market Integration. In: Bofinger, P./Kletterer, K.-H. (Hrsg.): Neuere Entwicklungen in der Geldtheorie und Geldpolitik. Tübingen. 431-454.

Gros, D. (1998): Mehr Gewicht für die Europäische Zentralbank. In: FAZ vom 2.5.98, Nr. 101, 15.

Gros, D. und Thygesen, N. (19982): European Monetary Integration. New York.

Hayo, B. (1998): Empirische und theorethische Studien zur Europäischen Währungsunion. Frankfurt/M.

Hasse, R. (1997): Die Saga vom Transfer des Rheingolds an Europa. In: Handelsblatt vom 13.8.97, Nr. 154. 8.

Hartmann, P. (1996): The Future of the Euro as an International Curency: A Transactions Perspective. In: Centre for European Policy Studies (Hrsg.): Research Report, 20, Brüssel.

International Monetary Fund (1997): International Financial Statistics, Yearbook 1997.

International Monetary Fund (1998): International Financial Statistics, January 1998.

Issing, O. (19939a): Einführung in die Geldtheorie. München.

Issing, O. (19936b): Einführung in die Geldpolitik. München.

Janssen, O./Lange, C. (1998): Umverteilung des Geldschöpfungsgewinnes durch elektronische Geldbörsen. In: Jahrbuch für Wirtschaftswissenschaften, 49, 51-60.

Jarchow, H.-J. (1998'10): Theorie und Politik des Geldes 1. Göttingen.

Jefferson, P. N. (1998): Seigniorage payments for use of the dollar: 1977 - 1995. In: Economic Letters, 58, 225-230. 
Jordan, T. (1994): Seigniorage, Defizite, Verschuldung und Europäische Währungsunion. Bern u. a..

Klein, M./Neumann, M.J.M. (1990): Seigniorage: What is it and Who Gets it? In: Weltwirtschaftliches Archiv, 126, 205-221.

Künstle, M. (1999): Fiskalpolitik im Euroland - Konsolidierungsschwung gebremst. In: Helaba (Hrsg.): Märkte und Trends Euro 1/99.

Kurm-Engels, M. (1997): Bundesbank verhandelt über neue Verteilung der Notenbankgewinne. In: Handelsblatt vom 4.8.97, Nr. 147, S. 8.

Lange, C. (1995): Seigniorage. Eine theoretische und empirische Analyse des Geldschöpfungsgewinnes. Berlin.

Lange, C. und Nolte, F. (1997): Geldschöpfungsgewinne in einer Europäischen Währungsunion, Diskussionspapier Nr. 205, Fachbereich Wirtschaftswissenschaften, Universität Hannover, Juli 1997.

Lange, C. und Nolte, F. (1998): Konsequenzen der Europäischen Währungsunion für den Geldschöpfungsgewinn der Mitgliedsländer. In: Kredit und Kapital 4/98, 494-519.

Larbig, G.A. (1997): Zur aktuellen Diskussion des Just-Retour in der EWU: SeigniorageWettbewerb und Verteilungsspielräume aus fiskalischer Sicht. Friedrich-SchillerUniversität Jena Wirtschaftswissenschaftliche Fakultät, Diskussionspapier Serie B, Nr. 97/07.

Läufer, N.K.A. (1997): Die Seigniorage-Kosten des Euro für Deutschland - Eine Kritik an Sinn und Feist, Universität Konstanz, Fakultät für Wirtschaftswissenschaften und Statistik, Diskussionsbeiträge Serie II - Nr. 349, Juli 1997.

Lübbersmann, R. (1995): Geldemissionsgewinne der Deutschen Bundesbank. Frankfurt am Main.

Maennig, W./Hunger, A. (1996): Seigniorageverluste - Hemmnis für die Europäische Währungsunion? In: WiSt 5/96, 227-232.

Masson, P.R./Turtelboom, B.G. (1997): Characteristics of the Euro, the Demand for Reserves, and Policy Coordination Under EMU. IMF Working Paper, WP/97/58.

Menkhoff, L. (19962): Geldpolitische Intrumente der Europäischen Zentralbank. Eine Analyse unter den Aspekten Effizienz, Wettbewerbsneutralität und Dezentralität. Stuttgart.

Monticelli, C./Papi, L. (1996): European Integration, Monetary Co-ordination, and the Demand for Money

Müller, H./Straubhaar, T. (1998): Die Stellung des Euro im Weltwährungssystem. In: Wirtschaftsdienst 5/98, 284-292.

Olivera, J.H.G. (1967): Money, Prices and Fiscal Lags: A Note on the Dynamics of Inflation. In: Banca Nazionale Del Lavoro Quarterly Review, 82, 258-267.

o. V. (1997a): The winners and losers from EMU. In: Central Banking, VII(1997)2, 6-10. 
o. V. (1997b): Dispute over ESCB profits. In: Central Banking, VII(1997)4, 7-10.

o. V. (1997c): Euro kostet Deutschland bis zu 25 Milliarden DM. In: FAZ vom 31. Juli 1997, Nr. 175, S. 9.

o. V. (1997d): SPD: Korrektur unerläßlich. In: Handelsblatt vom 4.8.97, Nr. 147, S. 8.

Portes, R./Rey, H. (1998): The emergence of the euro as an international currency. In: Begg, D. u.a. (Hrsg.): EMU: Prospects and Challanges for the Euro. Oxford, Malden, 305-343.

Radl, S. (1997): Bundesbank verliert durch Euro 28 Milliarden Schilling. In: Wirtschaftsblatt vom 5. 8. 97 , S. A5.

Rogoff, K. (1998): Blessing or curse? Foreign and underground demand for euro notes. In: Begg, D. u.a. (Hrsg.): EMU: Prospects and Challanges for the Euro. Oxford, Malden, 261. 303.

Schenk, J. (1997): Die Gewinnverwendung der Zentralbanken im internationalen Vergleich. Eine liquiditätsanalytische Untersuchung der Zentralbanken der G7-Staaten und der Schweiz. Pfaffenweiler.

Seitz, F. (1995): Der DM-Umlauf im Ausland. Diskussionspapier Nr. 1, Volkswirtschaftliche Forschungsgruppe der Deutschen Bundesbank, Frankfurt/M.

Seitz, F. (1997): How Many Deutschmarks are Held Abroad? In: Intereconomics 3-4/97, 67-73.

Sinn, H.-W./Feist, H. (1997): Eurowinners and Eurolosers: The Distribution of Seigniorage Wealth in EMU, Working Paper No. 134, Center for Economic Studies, München.

Tanzi, V. (1977): Inflation, Lags in Collection, and the Real Value of Tax Revenue. In: IMF Staff Papers 24(1977)1, 154-167.

Wagner, H. (1992): Seigniorage und Inflationsdynamik - Einige grundlegende Zusammenhänge. In: Kredit und Kapital 3/92, 335-358.

Wagner, W. (1999): Die Finanzverfassung der Europäischen Union. In: Aus Politik und Zeitgeschichte. Beilage zur Wochenzeitung Das Parlament, B 1-2/99, 32-38.

Wenger, E./Kaserer, C. (1997): 0. T. (ungekürzte Fassung eines Leserbriefes an die FAZ vom 21.6.97). In: http://uww.wifak.uni-wuerzburg.de/wilan/wifak/bw//bw/4/faz_fett.html.

\section{Geschäfts- und Monatsberichte der nationalen Zentralbanken, des EWI und der EZB}

Banca d'Italia: Ordinary general meeting of shareholders. Abridged Report. 1992-1997.

Banco de España: Annual Report. 1992-1997.

Banco de Portugal: Annual Report. 1992-1997.

Banque de France: Annual Report. 1992-1997.

Banque Nationale de Belgique: Rapport de la Banque Nationale de Belgique. 1992-1997.

Central Bank of Ireland: Annual Report. 1995-1997. 
De Nederlandsche Bank: Annual Report, Jahrgänge 1992-1997.

Deutsche Bundesbank: Geschäftsbericht der Deutschen Bundesbank, Jahrgänge 1980-1998.

Deutsche Bundesbank: Monatsbericht, 1/1979-6/1999.

Europäisches Währungsinstitut: Jahresbericht 1994.

Europäische Zentralbank: Jahresbericht 1998.

Europäische Zentralbank: Monatsbericht, 1/99-6/99.

Osterreichische Nationalbank: Geschäftsbericht. 1992-1997.

Suomen Pankki: Yearbook. 1992-1997. 
Roland Klopfleisch - 978-3-631-75045-2

Downloaded from PubFactory at 01/11/2019 08:55:36AM

via free access 


\section{Abbildungen}

ABBILDUNG 2-1: ENTWICKLUNG DER GELDSCHÖPFUNGSGEWINNE NACH GROS 1989, METHODE 1

ABBILDUNG 2-2: ENTWICKLUNG DER GELDSCHÖPFUNGSGEWINNE NACH GROS 1989, METHODE 2

ABBILDUNG 2-3: ENTWICKLUNG DER GELDSCHÖPFUNGSGEWINNE NACH GROS 1996. VOLLE KONVERGENZ, METHODE 1

ABBILDUNG 2-4: ENTWICKLUNG DER GELDSCHÖPFUNGSGEWINNE NACH GROS 1996, UNVOLLSTÄNDIGE KONVERGENZ, METHODE 1

ABBILDUNG 2-5: ENTWICKLUNG DER GELDSCHÖPFUNGSGEWINNE NACH GROS 1996, VOLLE KONVERGENZ, METHODE 2

ABBILDUNG 2-6: GEWINNE UND VERLUSTE DURCH DIE VERTEILUNG DES GELDSCHÖPFUNGSGEWINNS

ABBILDUNG 2-7: VERÄNDERUNG DER GELDSCHÖPFUNGSGEWINNE VOR EINFÜHRUNG DER EWU NACH LANGE/NOLTE 1996, METHODE 1

ABBILDUNG 2-8: VERÄNDERUNG DER GELDSCHÖPFUNGSGEWINNE VOR EINFÜHRUNG DER EWU NACH LANGE/NOLTE 1996, METHODE 2

ABBILDUNG 2-9: ÄNDERUNG DES GELDSCHÖPFUNGSGEWINNS NACH EINFÜHRUNG DER EWU GEGENÜBER 1991-95, DURCHSCHNITT VON 12 SZENARIEN

ABBILDUNG 2-10: GEWINNE UND VERLUSTE AN GELDSCHÖPFUNGSVERMÖGEN BEI EINFÜHRUNG DER EWU

ABBILDUNG 2-11: VERÄNDERUNG DER GELDSCHÖPFUNGSGEWINNE BEI EINFÜHRUNG DER EWU

ABBILDUNG 2-12: BISHERIGE UND ZU ERWARTENDE FINANZIERUNGSBEITRÄGE DER AUSGESCHÜTTETEN NOTENBANKBEITRÄGE

ABBILDUNG 2-13: ERGEBNISSE BISHERIGER STUDIEN ÜBER DIE VERÄNDERUNG DER GELDSCHÖPFUNGSGEWINNE

ABBILDUNG 2-14: ERGEBNISSE BISHERIGER STUDIEN ZUR ÄNDERUNG DER GELDSCHÖPFUNGSGEWINNE FÜR DEUTSCHLAND

ABBILDUNG 2-15: ERGEBNISSE BISHERIGER STUDIEN ÜBER DIE HÖHE DER GELDSCHÖPFUNGSGEWINNE INNERHALB EINER EUROPÄISCHEN WÄHRUNGSUNION

ABBILDUNG 3-1: ZENTRALBANKGELD UND MONETÄRE BASIS

ABBILDUNG 3-2: EMPIRISCHE GEGENÜBERSTELLUNG DER VERSCHIEDENEN SEIGNIORAGEKONZEPTE FÜR DEUTSCHLAND 1979 - 1996

ABBILDUNG 7-1: ZINSERTRÄGE AUF FORDERUNGEN AN INLÄNDISCHE GESCHÄFTSBANKEN 
ABBILDUNG 7-2: ZINSAUFWENDUNGEN FÜR ABGEGEBENE MOBILISIERUNGS- UND LIQUIDITÄTSPAPIERE IM VERGLEICH ZUR SCHÄTZUNG

ABBILDUNG 7-3: ZINSAUFWENDUNGEN FÜR ABGEGEBENE MOBILISIERUNGS- UND LIQUIDITÄTSPAPIERE

ABBILDUNG 7-4: ZINSGEWINN AUS WÄHRUNGSRESERVEN

DER DEUTSCHEN BUNDESBANK

ABBILDUNG 7-5: ANTEILIGE KOSTEN DER DEUTSCHEN BUNDESBANK

ABBILDUNG 7-6: FISKALISCHER SEIGNIORAGE UND SEINE ENTSTEHUNG FÜR DEUTSCHLAND

ABBILDUNG 7-7: VERGLEICH VON ZINSERTRÄGEN UND DEREN SCHÄTZUNG

ABBILDUNG 7-8: KOMPONENTEN DES ZINSERTRAGS DER DEUTSCHEN BUNDESBANK AUS KREDITEN AN DIE GESCHÄFTSBANKEN

ABBILDUNG 7-9: BESTÄNDE AUS GELDPOLITISCHEN OPERATIONEN DER DEUTSCHEN BUNDESBANK

ABBILDUNG 7-10: ENTWICKLUNG DER NOTENBANKZINSEN FÜR DEUTSCHLAND

ABBILDUNG 7-11: VERBINDLICHKEITEN AUS ABGEGEBENEN MOBILISIERUNGS- UND LIQUIDITÄTSPAPIEREN UND DEREN ZINSSATZ

ABBILDUNG 7-12: MINDESTRESERVEHALTUNG DER GESCHÄFTSBANKEN IN DEUTSCHLAND

ABBILDUNG 7-13: JÄHRLICHE PREISSTEIGERUNGSRATE DES BIP (DEUTSCHLAND)

ABBILDUNG 7-14: KOSTEN DES NOTENDRUCKS UND ANTEILIGE VERWALTUNGSKOSTEN

ABBILDUNG 7-15: BESTÄNDE DER DEUTSCHEN BUNDESBANK AN WÄHRUNGSRESERVEN 73

ABBILDUNG 7-16: QUANTIFIZIERTER KONVERGENZEFFEKT FÜR DEUTSCHLAND 74

ABBILDUNG 7-17: ZINSERTRAG, ZINSAUFWAND UND ANTEILIGE KOSTEN (BELGIEN) 75

ABBILDUNG 7-18: ZINSEINNAHMEN AUS WÄHRUNGSRESERVEN

DER BANQUE NATIONALE DE BELGIQUE

ABBILDUNG 7-19: FISKALISCHER SEIGNIORAGE UND SEINE ENTSTEHUNG FÜR BELGIEN 76

ABBILDUNG 7-20: BESTÄNDE AUS DISKONT-, LOMBARD- UND OFFENMARKTGESCHÄFTEN (BELGIEN)

ABBILDUNG 7-21: ZINSSÄTZE FÜR DISKONT, LOMBARD- UND OFFENMARKTGESCHÄFTE, PERIODENDURCHSCHNITT (BELGIEN)

ABBILDUNG 7-22: VERBINDLICHKEITEN AUS DER EINLAGENFAZILITÄT UND WERTPAPIEREN DER ZENTRALBANK (BELGIEN)

ABBILDUNG 7-23: PREISSTEIGERUNGSRATE DES BIP FÜR BELGIEN

ABBILDUNG 7-24: BESTÄNDE AN WÄHRUNGSRESERVEN DER BANQUE NATIONAL DE BELGIQUE 
ABBILDUNG 7-25: QUANTIFIZIERTER KONVERGENZEFFEKT FÜR BELGIEN

ABBILDUNG 7-26: ZINSERTRÄGE AUF FORDERUNGEN AN INLÄNDISCHE GESCHÄFTSBANKEN (FINNLAND)

ABBILDUNG 7-27: ZINSAUFWENDUNGEN LIQUIDITÄTSABSCHÖPFENDER MABNAHMEN UND VERZINSTE MINDESTRESERVE

ABBILDUNG 7-28: ZINSEINNAHMEN AUS WÄHRUNGSRESERVEN DER SUOMI PANNKI

ABBILDUNG 7-29: KOSTEN FÜR NOTENDRUCK UND ANTEILIGE VERWALTUNGSKOSTEN DER SUOMI PANKKI

ABBILDUNG 7-30: FISKALISCHER SEIGNIORAGE UND SEINE ENTSTEHUNG FÜR FINNLAND

ABBILDUNG 7-31: BESTÄNDE AUS GELDPOLITISCHEN OPERATIONEN UND ZINSSÄTZE DER SUOMI PANKKI

ABBILDUNG 7-32: BESTÄNDE VON LIQUIDITÄTSABSCHÖPFENDEN INSTRUMENTEN UND MINDESTRESERVE SOWIE DIE ENTSPRECHENDEN ZINSSÄTZE

ABBILDUNG 7-33: SCHÄTZUNG DER ZINSAUFWENDUNGEN

ABBILDUNG 7-34: MINDESTRESERVEHALTUNG DER GESCHÄFTSBANKEN IN FINNLAND

ABBILDUNG 7-35: JÄHRLICHE PREISSTEIGERUNGSRATE DES BIP (FINNLAND)

ABBILDUNG 7-36: WÄHRUNGSRESERVEN DER FINNISCHEN ZENTRALBANK

ABBILDUNG 7-37: QUANTIFIZIERTER KONVERGENZEFFEKT FÜR FINNLAND

ABBILDUNG 7-38: ZINSERTRAG, ZINSAUFWAND UND ANTEILIGE KOSTEN (FRANKREICH)

ABBILDUNG 7-39: ZINSEINNAHMEN UND -AUSGABEN AUS DEN WÄHRUNGSRESERVEN

ABBILDUNG 7-40: FISKALISCHER SEIGNIORAGE UND SEINE ENTSTEHUNG FÜR FRANKREICH

ABBILDUNG 7-41: BESTÄNDE AUS REFINANZIERUNGSGESCHÄFTEN (FRANKREICH)

ABBILDUNG 7-42: ZINSSÄTZE FÜR REFINANZIERUNGSGESCHÄFTE, PERIODENDURCHSCHNITT (FRANKREICH)

ABBILDUNG 7-43: SCHÄTZUNG DER ZINSEINNAHMEN

ABBILDUNG 7-44: VERBINDLICHKEITEN AUS LIQUIDITÄTSABSCHÖPFENDEN MABNAHMEN UND DEM ZINSSATZ (FRANKREICH)

ABBILDUNG 7-45: SCHÄTZUNG DER ZINSAUSGABEN

ABBILDUNG 7-46: MINDESTRESERVEN UND MINDESTRESERVESÄTZE (FRANKREICH)

ABBILDUNG 7-47: PREISSTEIGERUNGSRATE DES BIP FÜR FRANKREICH

ABBILDUNG 7-48: WÄHRUNGSRESERVEN DER BANQUE DE FRANCE 
ABBILDUNG 7-50: EINNAHMEN, AUSGABEN UND KOSTEN DES INLÄNDISCHEN ZENTRALBANKGESCHÄFTS (IRLAND)

ABBILDUNG 7-51: ZINSEINNAHMEN AUS DEN WÄHRUNGSRESERVEN (IRLAND) 97

ABBILDUNG 7-52: KONVERGENZEFFEKT UND SEINE ENTSTEHUNG FÜR IRLAND 97

ABBILDUNG 7-53: BESTÄNDE UND ZINSSÄTZE DER REFINANZIERUNGSGESCHÄFTE 98

ABBILDUNG 7-54: EINLAGE DER GESCHÄFTSBANKEN BEI DER IRISCHEN ZENTRALBANK UND EINLAGEZINSSATZ $\quad 99$

ABBILDUNG 7-55: MINDESTRESERVE UND MINDESTRESERVESATZ FÜR IRLAND 100

ABBILDUNG 7-56: PREISSTEIGERUNGSRATE IN IRLAND 100

ABBILDUNG 7-57: WÄHRUNGSRESERVEN DER CENTRAL BANK OF IRELAND 101

ABBILDUNG 7-58: KONVERGENZEFFEKT FÜR IRLAND 101

ABBILDUNG 7-59: ZINSERTRÄGE AUS OFFENMARKT, DISKONT- UND LOMBARDGESCHÄFTEN

ABBILDUNG 7-60: AUS GELDPOLITISCHEN INSTRUMENTEN RESULTIERENDE ZINSAUFWENDUNGEN (ITALIEN)

ABBILDUNG 7-61: ZINSEINNAHMEN AUS WÄHRUNGSRESERVEN 103

ABBILDUNG 7-62: ANTEILIGE VERWALTUNGSKOSTEN DER BANCA D'ITALIA 104

ABBILDUNG 7-63: FISKALISCHER SEIGNIORAGE UND SEINE ENTSTEHUNG FÜR ITALIEN 104

ABBILDUNG 7-64: BESTÄNDE AUS DISKONT-, LOMBARD- UND OFFENMARKTGESCHÄFTEN (ITALIEN) 105

ABBILDUNG 7-65: VERBINDLICHKEITEN AUS LIQUIDITÄTSABSCHÖPFENDEN INSTRUMENTEN, MINDESTRESERVEEINLAGEN UND ENTSPRECHENDE ZINSSÄTZE 106

ABBILDUNG 7-66: SCHÄTZUNG DER ZINSAUSGABEN FÜR ITALIEN 106

ABBILDUNG 7-67: WÄHRUNGSRESERVEN DER BANCA D'ITALIA 107

ABBILDUNG 7-68: MINDESTRESERVEHALTUNG IN ITALIEN 108

ABBILDUNG 7-69: PREISSTEIGERUNGSRATE DES BIP FÜR ITALIEN 108

ABBILDUNG 7-70: QUANTIFIZIERTER KONVERGENZEFFEKT FÜR ITALIEN 110

ABBILDUNG 7-71: ZINSERTRÄGE AUS KREDITEN AN INLÄNDISCHE GESCHÄFTSBANKEN UND ZINSAUSGABEN AUS DEM INLÄNDISCHEN GESCHÄFT (NIEDERLANDE) 110

ABBILDUNG 7-72: ANTEILIGE VERWALTUNGSKOSTEN UND KOSTEN DER BANKNOTENAUSGABE DE NEDERLANDSCHE BANK

ABBILDUNG 7-73: ZINSERTRÄGE AUS WÄHRUNGSRESERVEN (NIEDERLANDE) 111

ABBILDUNG 7-74: FISKALISCHER SEIGNIORAGE FÜR DIE NIEDERLANDE 111 
ABBILDUNG 7-75: BESTÄNDE UND ZINSSÄTZE DER REFINANZIERUNGSGESCHÄFTE

ABBILDUNG 7-76: VERBINDLICHKEITEN AUS LIQUIDITÄTSABSCHÖPFENDEN MABNAHMEN 113

ABBILDUNG 7-77: PREISSTEIGERUNGSRATE DES BIP FÜR DIE NIEDERLANDE

114

ABBILDUNG 7-78: ZINSBRINGENDE WÄHRUNGSRESERVEN

115

ABBILDUNG 7-79: KONVERGENZEFFEKT FÜR DIE NIEDERLANDE

115

ABBILDUNG 7-80: ZINSERTRÄGE AUS ESKONT-, DARLEHENS- UND

OFFENMARKTGESCHÄFTEN

116

ABBILDUNG 7-81: ZINSAUFWAND (ÖSTERREICH)

ABBILDUNG 7-82: ZINSEINNAHMEN UND -AUSGABEN AUS WÄHRUNGSRESERVEN

ABBILDUNG 7-83: ANTEILIGE VERWALTUNGSKOSTEN DER ÖSTERREICHISCHEN

NATIONALBANK

ABBILDUNG 7-84: FISKALISCHER SEIGNIORAGE UND SEINE ENTSTEHUNG FÜR ÖSTERREICH 118 ABBILDUNG 7-85: BESTÄNDE AUS ESKONT-, DARLEHENS- UND

OFFENMARKTGESCHÄFTEN (ÖSTERREICH)

ABBILDUNG 7-86: ZINSSÄTZE FÜR ESKONT-, DARLEHENS- (LOMBARDSATZ) UND

OFFENMARKTGESCHÄFTEN (GOMEX- UND TENDERSATZ),

PERIODENDURCHSCHNITT (ÖSTERREICH)

ABBILDUNG 7-87: SCHÄTZUNG DER ZINSEINNAHMEN FÜR ÖSTERREICH

ABBILDUNG 7-88: BESTÄNDE UND ZINSSATZ DER LIQUIDITÄTSABSCHÖPFUNG

ABBILDUNG 7-89: MINDESTRESERVEHALTUNG DER GESCHÄFTSBANKEN

IN ÖSTERREICH

ABBILDUNG 7-90: PREISSTEIGERUNGSRATE DES BIP FÜR ÖSTERREICH

ABBILDUNG 7-91: DEVISEN UND VALUTEN SOWIE VERBINDLICHKEITEN GEGENÜBER AUSLÄNDISCHEN KREDITINSTITUTEN DER ÖSTERREICHISCHEN NATIONALBANK

ABBILDUNG 7-92: QUANTIFIZIERTER KONVERGENZEFFEKT FÜR ÖSTERREICH

ABBILDUNG 7-93: ZINSERTRAG AUS INLÄNDISCHEN GESCHÄFTEN

DER BANCO DE PORTUGAL

ABBILDUNG 7-94: ZUSAMMENSETZUNG DES INLÄNDISCHEN ZINSAUFWANDS FÜR DIE BANCO DE PORTUGAL

ABBILDUNG 7-95: ANTEILIGE VERWALTUNGSKOSTEN UND KOSTEN DER

BANKNOTENAUSGABE DER BANCO DE PORTUGAL

ABBILDUNG 7-96: FISKALISCHER SEIGNIORAGE UND SEINE ENTSTEHUNG FÜR PORTUGAL

ABBILDUNG 7-97: BESTÄNDE AUS REFINANZIERUNGSGESCHÄFTEN (PORTUGAL) 
ABBILDUNG 7-98: ZINSSÄTZE FÜR REFINANZIERUNGSGESCHÄFTE (PORTUGAL)

ABBILDUNG 7-99: VERBINDLICHKEITEN AUS DER LIQUIDATIONSABSCHÖPFUNG, MINDESTRESERVE UND ENTSPRECHENDE ZINSSÄTZE (PORTUGAL) 128

ABBILDUNG 7-100:PREISSTEIGERUNGSRATE DES BIP FÜR PORTUGAL

ABBILDUNG 7-101:WÄHRUNGSRESERVEN DER BANCO DE PORTUGAL

ABBILDUNG 7-102: QUANTIFIZIERTER KONVERGENZEFFEKT FÜR PORTUGAL

ABBILDUNG 7-103:ZINSERTRÄGE, ZINSAUFWENDUNGEN UND KOSTEN FÜR DIE BANCO DE ESPAÑA

ABBILDUNG 7-104:ZINSEINNAHMEN- UND AUSGABEN AUS DEN WÄHRUNGSRESERVEN

ABBILDUNG 7-105:FISKALISCHER SEIGNIORAGE UND SEINE ENTSTEHUNG FÜR SPANIEN

ABBILDUNG 7-106:BESTÄNDE AUS DEM OFFENMARKTGESCHÄFT UND OFFENMARKTZINSSATZ (SPANIEN)

ABBILDUNG 7-107:MINDESTRESERVE UND DURCHSCHNITTLICHER MINDESTRESERVESATZ IN SPANIEN

ABBILDUNG 7-108: JÄHRLICHE PREISSTEIGERUNGSRATE DES BIP (SPANIEN)

ABBILDUNG 7-109:KOSTEN DES NOTENDRUCKS UND ANTEILIGE VERWALTUNGSKOSTEN

ABBILDUNG 7-111: QUANTIFIZIERTER KONVERGENZEFFEKT FÜR SPANIEN

ABBILDUNG 7-112:FISKALISCHER SEIGNIORAGE 1992 UND 1997

DER EWU-11 IM VERGLEICH

ABBILDUNG 7-113:VERÄNDERUNG DER SEIGNIORAGE-ANTEILE AM BIP

ABBILDUNG 8-1: OPPORTUNITÄTSKOSTEN-SEIGNIORAGE DER EWU-11 STAATEN

ABBILDUNG 8-2A: VERGLEICH FISKALISCHER SEIGNIORAGE - OPPORTUNITÄTSKOSTENSEIGNIORAGE FÜR DIE EWU-11 STAATEN 1992 - 1997

ABBILDUNG 8-2B: VERGLEICH FISKALISCHER SEIGNIORAGE - OPPORTUNITÄTSKOSTENSEIGNIORAGE FÜR DIE EWU-11 STAATEN 1992 - 1997

ABBILDUNG 8-2C: ERGLEICH FISKALISCHER SEIGNIORAGE - OPPORTUNITÄTSKOSTENSEIGNIORAGE FÜR DIE EWU-11 STAATEN 1992 - 1997

ABBILDUNG 11-1: GEWINNVERTEILUNGSSCHLÜSSEL DER EZB

ABBILDUNG 11-2: DER VERTEILUNGSEFFEKT IN \%-PUNKTEN DER NATIONALEN BIPS

ABBILDUNG 11-3: VERTEILUNGSEFFEKT (ECU90)

ABBILDUNG 12-1: VERGLEICH VON KONVERGENZ-, ÜBERGANGS- UND VERTEILUNGSEFFEKT 


\section{Tabellen}

TABELLE 2.1: SYNOPTISCHE ZUSAMMENFASSUNG DER ERGEBNISSE BISHERIGER STUDIEN ZUR VERTEILUNG DER GELDSCHÖPFUNGSGEWINNE INNERHALB EINER EUROPÄISCHEN WÄHRUNGSUNION

- ÄNDERUNG DER GELDSCHÖPFUNGSGEWINNE

TABELLE 2-2: SYNOPTISCHE ZUSAMMENFASSUNG DER ERGEBNISSE BISHERIGER STUDIEN ZUR VERTEILUNG DER GELDSCHÖPFUNGSGEWINNE INNERHALB EINER EUROPÄISCHEN WÄHRUNGSUNION - HÖHE DER GELDSCHÖPFUNGSGEWINNE

TABELLE 3-1: VEREINFACHTE NOTENBANKBILANZ AM BEISPIEL DER DEUTSCHEN BUNDESBANK 1997

TABELLE 3-2: VEREINFACHTE SALDIERTE NOTENBANKBILANZ

TABELLE 6-1: $\quad$ NOTENBANKBILANZ AM BEISPIEL DER DEUTSCHEN BUNDESBANK (STAND AM JAHRESENDE 1997)

TABELLE 7-1: BERECHNUNG DES SEIGNIORAGEVERLUSTS AUFGRUND STEIGENDER PREISSTABILITÄT UND REDUZIERUNG DER MINDESTRESERVE FÜR DEUTSCHLAND

TABELLE 7-2: KONVERGENZEFFEKT FÜR DEUTSCHLAND

TABELLE 7-3: BERECHNUNG DES SEIGNIORAGEVERLUSTS AUFGRUND STEIGENDER PREISSTABILITÄT FÜR BELGIEN

TABELLE 7-4: KONVERGENZEFFEKT FÜR BELGIEN

TABELLE 7-5: KONVERGENZEFFEKT FÜR FINNLAND

TABELLE 7-5: BERECHNUNG DES SEIGNIORAGEVERLUSTS AUFGRUND STEIGENDER PREISSTABILITÄT FÜR FRANKREICH

TABELLE 7-6: KONVERGENZEFFEKT FÜR FRANKREICH 95

TABELLE 7-7: PREISSTABILISIERUNGS- UND MINDESTRESERVEEFFEKT FÜR IRLAND

TABELLE 7-8: BERECHNUNG DES SEIGNIORAGEVERLUSTS AUFGRUND STEIGENDER PREISSTABILITÄT UND REDUZIERUNG DER MINDESTRESERVE FÜR ITALIEN

TABELLE 7-9: KONVERGENZEFFEKT FÜR ITALIEN 109

TABELLE 7-10: PREISSTABILITÄTSEFFEKT FÜR DIE NIEDERLANDE

TABELLE 7-11: BERECHNUNG DES SEIGNIORAGEVERLUSTS AUFGRUND STEIGENDER PREISSTABILITÄT UND REDUZIERUNG DER MINDESTRESERVE FÜR OSTERREICH

TABELLE 7-12: KONVERGENZEFFEKT FÜR ÖSTERREICH 
188

TABELLE 7-13: BERECHNUNG DES SEIGNIORAGEVERLUSTS AUFGRUND STEIGENDER PREISSTABILITÄT UND SINKENDER MINDESTRESERVE FÜR PORTUGAL 130

TABELLE 7-14: KONVERGENZEFFEKT FÜR PORTUGAL

TABELLE 7-15: BERECHNUNG DES SEIGNIORAGEVERLUSTS AUFGRUND STEIGENDER PREISSTABILITÄT UND REDUZIERUNG DER MINDESTRESERVE

FÜR SPANIEN

TABELLE 7-16: ZUSAMMENSETZUNG DES KONVERGENZEFFEKTS FÜR SPANIEN 138

TABELLE 7-17: VERÄNDERUNGEN DES SEIGNIORAGE ZWISCHEN 1992 UND 1997139

TABELLE 7-18: VERÄNDERUNG DES SEIGNIORAGE-ANTEILS AM BIP 140

TABELLE 9-1: PROGNOSEN DES OPPORTUNITÄTSKOSTEN-SEIGNIORAGE

FÜR DIE EWU-11-STAATEN 154

TABELLE 10-1: OPPORTUNITÄTSKOSTEN-SEIGNIORAGE NACH DEM ÜBERGANG ZUM EURO

TABELLE 11-1: KAPITALANTEILE DER NATIONALEN ZENTRALBANKEN AN DER EZB 159

TABELLE 11-2: GELDSCHÖPFUNGSGEWINN UND VERTEILUNGSEFFEKT

IN DEN EWU-11-STAATEN NACH DER VERTEILUNG 160 


\section{Abkürzungen}
A
Zinsausgaben
B
monetäre Basis
BIP
Bruttoinlandsprodukt
C
Bargeldhaltungskoeffizient
C
Bargeldumlauf
D
Depositen
E
Zinseinnahmen
EFWZ Europäischer Fonds für währungspolitische Zusammenarbeit
ESZB Europäisches System der Zentralbanken
EWI Europäisches Währungsinstitut
EWU Europäische Währungsunion
EWWU Europäische Wirtschafts- und Währungsunion
EZB Europäische Zentralbank
FAus! Forderungen der Zentralbank gegen das Ausland
FGB Forderungen der Zentralbank gegen die Geschäftsbanken
Foffen Forderungen aus dem Offenmarktgeschäft
Fspize Forderungen aus Spitzenrefinanzierungsgeschäften
Fstaat Forderungen der Zentralbank gegen den Staat
$\Delta \mathrm{F}^{\text {staat }}$ Nettokreditgewährung der Zentralbank an den Staat
Fsubv Forderungen aus Kreditfazilitäten unter Marktzinssatz
Gausg an den Staat ausgeschütteter Gewinn der Zentralbank
Gthes thesaurierter Gewinn
GuV
Gewinn und Verlustrechnung
i Zins
Zinssatz auf die Mindestreserve
Offenmarktzinssatz
Zinssatz der Spitzenrefinanzierung
Zinssatz der Refinanzierungsgeschäfte unter Marktzinssatz Internationaler Währungsfonds
IWF Kassenhaltungskoeffizient Geldschöpfungskosten 
m

$\mathrm{mrs}$

M

MR

p

$P$

r

RV

Sisk

Smon

Smon, enw

Sopp

ÜR

Um

$\mathrm{V}$

Vliq

$V_{m}$

Y

ZBG

nominale Wachstumsrate der Zentralbankgeldmenge

Mindestreservesatz

Zentralbankgeldmenge

Mindestreserven

Inflationsrate

Preisniveau

reale Wachstumsrate der Zentralbankgeldmenge

Reinvermögen der Zentralbank (Summe der thesaurierten Gewinne)

fiskalischer Seigniorage

monetärer Seigniorage

erweiteter monetärer Seigniorage

Opportunitätskosten-Seigniorage

Überschußreserven

Umbewertungen

Verbindlichkeiten

Verbindlichkeiten der Zentralbank infolge von Liquiditätsentzug

Umlaufgeschwindigkeit der Zentralbankgeldmenge

Volkseinkommen

Zentralbankgeldmenge

\section{Staaten}
A
Österreich
B
Belgien
D
Deutschland
DK
Dänemark
E
Spanien
$\mathrm{F}$
Frankreich
FIN
Finland
GB
Großbritannien
GR
Griechenland
Italien 


$\begin{array}{ll}\text { IRL } & \text { Irland } \\ \text { L } & \text { Luxemburg } \\ \text { NL } & \text { Niederlande } \\ \text { P } & \text { Portugal } \\ \text { S } & \text { Schweden }\end{array}$

\section{Währungen}

BF

Belgischer Franc

DM

Deutsche Mark

FIM

Finnische Mark

FRF

Französischer Franc

HFL Holländischer Gulden

IP

Irisches Pfund

ITL

Italienische Lira

ÖS

Österreichischer Schilling

PTA

Spanische Peseta

PTE

Portugiesischer Escudo 
Roland Klopfleisch - 978-3-631-75045-2

Downloaded from PubFactory at 01/11/2019 08:55:36AM

via free access 
Anhang

Roland Klopfleisch - 978-3-631-75045-2

Downloaded from PubFactory at 01/11/2019 08:55:36AM

via free access 
Deutschland

Zinsaufwand für MuL-Papiere
Zinserträge aus Krediten an inl. GB

DM

$\begin{array}{lrrr}1997 & 6,4 E+9 & 5,2 E+9 & 2,6 E+9 \\ 1996 & 6,2 E+9 & 5,1 E+9 & 2,5 E+9 \\ 1995 & 8,3 E+9 & 7,0 E+9 & 3,4 E+9 \\ 1994 & 10,7 E+9 & 9,1 E+9 & 4,5 E+9 \\ 1993 & 15,9 E+9 & 14,0 E+9 & 6,8 E+9 \\ 1992 & 18,6 E+9 & 16,9 E+9 & 8,3 E+9 \\ 1991 & 17,1 E+9 & & \end{array}$

\begin{tabular}{rrr} 
DM & \multicolumn{2}{c}{ DM90 } \\
$87,9 E+6$ & $72,4 \mathrm{E}+6$ & $35,3 \mathrm{E}+6$ \\
$49,5 \mathrm{E}+6$ & $41,0 \mathrm{E}+6$ & $20,0 \mathrm{E}+6$ \\
$87,1 \mathrm{E}+6$ & $73,0 \mathrm{E}+6$ & $35,6 \mathrm{E}+6$ \\
$1,1 \mathrm{E}+9$ & $925,8 \mathrm{E}+6$ & $451,1 \mathrm{E}+6$ \\
$1,5 \mathrm{E}+9$ & $1,3 \mathrm{E}+9$ & $635,2 \mathrm{E}+6$ \\
$211,3 \mathrm{E}+6$ & $192,8 \mathrm{E}+6$ & $94,0 \mathrm{E}+6$ \\
$368,8 \mathrm{E}+6$ & & \\
$307,8 \mathrm{E}+6$ & &
\end{tabular}

Kosten Notendruck+ant. VwKosten

Kosten

Notendruck sonst. VwKos Schlüssel

$1997 \quad 172,2 \mathrm{E}+6 \quad 2,6 \mathrm{E}+9 \quad 69,60 \%$

$\begin{array}{llll}1996 & 169,8 \mathrm{E}+6 & 2,5 \mathrm{E}+9 & 69,99 \%\end{array}$

$1995 \quad 163,0 \mathrm{E}+6 \quad 2,6 \mathrm{E}+9 \quad 69,41 \%$

$1994 \quad 156,7 E+6 \quad 2,3 E+9 \quad 72,86 \%$

$1993 \quad 236,4 E+6 \quad 2,5 E+9 \quad 65,87 \%$

$1992 \quad 289,6 E+6 \quad 2,5 E+9 \quad 69,46 \%$

$1991 \quad 331,0 E+6 \quad 2,5 E+9 \quad 65,63 \%$

1990

$2,2 E+9 \quad 61,19 \%$

DM90

ECU90

$2,0 E+9$
$1,9 E+9$
$1,9 E+9$
$1,8 E+9$
$1,9 E+9$
$2,0 E+9$
$1,9 E+9$
$1,5 E+9$

$1,6 E+9$

$1,6 E+9$

$792,5 E+6$

$781,0 \mathrm{E}+6$

ant. W-Kosten

$1,8 E+9$

$1,6 E+9$

$793,5 E+6$

$759,5 E+6$

$1,8 E+9$

$1,8 E+9$

$1,7 E+9$

$817,3 E+6$

$1,7 E+9$

$1,7 E+9$

$1,8 E+9$

$895,0 E+6$

$1,7 E+9$

$1,6 E+9$

$1,3 E+9$

Währungsreserven

\begin{tabular}{crrr}
\multicolumn{4}{c}{ Zinseinnahmen } \\
DM & \multicolumn{2}{c}{ DM90 } & \multicolumn{2}{c}{ ECU90 } \\
1997 & $7,5 E+9$ & $6,2 E+9$ & $3,0 E+9$ \\
1996 & $6,8 E+9$ & $5,6 E+9$ & $2,7 E+9$ \\
1995 & $6,7 E+9$ & $5,6 E+9$ & $2,8 E+9$ \\
1994 & $7,2 E+9$ & $6,1 E+9$ & $3,0 E+9$ \\
1993 & $8,6 E+9$ & $7,6 E+9$ & $3,7 E+9$ \\
1992 & $8,9 E+9$ & $8,1 E+9$ & $4,0 E+9$
\end{tabular}

Zinsausgaben

DM

DM90

ECU90

Gewinn
DM

$432,3 E+6 \quad 356,1 E+6 \quad 173,5 E+6$

$508,7 E+6 \quad 421,8 E+6 \quad 205,5 E+6$

$709,2 E+6 \quad 594,0 E+6 \quad 289,5 E+6$

$1,1 \mathrm{E}+9 \quad 955,9 \mathrm{E}+6 \quad 465,8 \mathrm{E}+6$

$1,9 E+9$

$1,7 E+9$

$816,8 E+6$

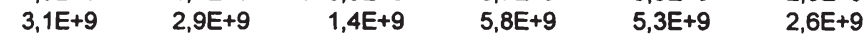

DM90

ECU90

$7,0 E+9 \quad 5,8 E+9 \quad 2,8 E+9$

$6,2 E+9 \quad 5,2 E+9 \quad 2,5 E+9$

$6,0 \mathrm{E}+9 \quad 5,1 \mathrm{E}+9 \quad 2,5 \mathrm{E}+9$

$6,1 \mathrm{E}+9 \quad 5,2 \mathrm{E}+9 \quad 2,5 \mathrm{E}+9$

$6,7 \mathrm{E}+9 \quad 5,9 \mathrm{E}+9 \quad 2,9 \mathrm{E}+9$ 
fiskalischer Seigniorage

\begin{tabular}{|c|c|c|c|}
\hline DM & DM90 & ECU90 & in $\%$ vom BIP \\
\hline $11,3 E+9$ & $9,3 E+9$ & $4,6 E+9$ & $0,31 \%$ \\
\hline $10,4 E+9$ & $8,7 E+9$ & $4,2 E+9$ & $0,30 \%$ \\
\hline $12,3 E+9$ & $10,3 E+9$ & $5,0 E+9$ & $0,36 \%$ \\
\hline $13,8 E+9$ & $11,9 E+9$ & $5,8 E+9$ & $0,42 \%$ \\
\hline $19,2 E+9$ & $16,9 E+9$ & $8,2 E+9$ & $0,61 \%$ \\
\hline 22,1E+9 & $20,2 E+9$ & $9,8 E+9$ & $0,72 \%$ \\
\hline
\end{tabular}

fiskalischer Seigniorage ohne Kosten und Währungsreserven

\begin{tabular}{|c|c|c|c|c|}
\hline \multicolumn{2}{|c|}{ DM } & DM90 & ECU90 & in \% vom BIP \\
\hline 1997 & $4,3 E+9$ & $3,5 E+9$ & $1,7 E+9$ & $0,12 \%$ \\
\hline 996 & $4,2 E+9$ & $3,5 E+9$ & $1,7 E+9$ & $0,12 \%$ \\
\hline 995 & $6,3 E+9$ & $5,3 E+9$ & $2,6 E+9$ & $0,18 \%$ \\
\hline 994 & $7,8 E+9$ & $6,7 E+9$ & $3,2 E+9$ & $0,23 \%$ \\
\hline 93 & $12,5 E+9$ & $11,0 E+9$ & $5,4 E+9$ & $0,40 \%$ \\
\hline 992 & $16,3 E+9$ & $14,9 E+9$ & $7,3 E+9$ & $0,53 \%$ \\
\hline
\end{tabular}

fiskalischer Seigniorage ohne Kosten Zinserträge-Zinsaufwand

$$
\text { DM }
$$
DM90 ECU90

in \% vom BIP

$12,4 E+9 \quad 10,3 E+9$

$5,3 E+9$

$0,37 \%$

$14,3 E+9 \quad 12,0 E+9$

$5,0 E+9$

$0,35 \%$

$13,4 \mathrm{E}+9$

$5,8 \mathrm{E}+9$

$0,41 \%$

$21,1 E+9$

$18,6 E+9$

$6,5 \mathrm{E}+9$

$0,47 \%$

$24,1 \mathrm{E}+9$

$22,0 E+9$

$10,7 E+9$

Bilanzgewinn

\begin{tabular}{rrrr} 
DM & \multicolumn{2}{c}{ DM90 } & \multicolumn{2}{c}{ ECU90 in \% vom BIP } \\
$24,2 E+9$ & $20,0 E+9$ & $9,7 E+9$ & $0,67 \%$ \\
$9,4 E+9$ & $7,8 E+9$ & $3,8 E+9$ & $0,27 \%$ \\
$10,9 E+9$ & $9,2 E+9$ & $4,5 E+9$ & $0,32 \%$ \\
$10,9 E+9$ & $9,3 E+9$ & $4,5 E+9$ & $0,33 \%$ \\
$18,8 E+9$ & $16,6 E+9$ & $8,1 E+9$ & $0,60 \%$ \\
$14,7 E+9$ & $13,4 E+9$ & $6,5 E+9$ & $0,48 \%$
\end{tabular}

Guthaben bei ausländischen Banken und (Verbindlichkeiten aus dem Auslandsgeschäft

\begin{tabular}{lrrr}
$\begin{array}{l}\text { Aktiva } \\
\text { DM }\end{array}$ & \multicolumn{2}{c}{ Rendite } & \multicolumn{2}{l}{$\begin{array}{l}\text { Passiva } \\
\text { DM }\end{array}$} \\
\hline & $76,6 E+9$ & $9,76 \%$ & $12,4 E+9$ \\
6 & $72,3 E+9$ & $9,34 \%$ & $13,0 E+9$ \\
5 & $68,5 E+9$ & $9,85 \%$ & $14,8 E+9$ \\
4 & $60,2 E+9$ & $11,93 \%$ & $18,6 E+9$ \\
3 & $61,8 E+9$ & $13,93 \%$ & $22,1 E+9$ \\
2 & $85,8 E+9$ & $10,38 \%$ & $24,7 E+9$
\end{tabular}

Mindestreserve (Monatsbericht 1/99, 41*)

Reservepflich Reserve-Soll ' durchschnittlicher Mindestre

\begin{tabular}{rcc}
\multicolumn{2}{c}{$\begin{array}{c}\text { R3 } \\
\text { Reservepflichtige Vert. I nom. BIP }\end{array}$} & \multicolumn{1}{c}{ C/ nom. BIP } \\
1997 & 0,6425653 & 0,08735624 \\
1996 & 0,62480753 & 0,08912654 \\
1995 & 0,60035349 & 0,08614895 \\
1994 & 0,60333013 & 0,08289207 \\
1993 & 0,60016826 & 0,08087042 \\
1992 & 0,56401796 & 0,07603146 \\
\cline { 2 - 3 } Durchschnitt & 0,60587378 & 0,08373761
\end{tabular}


Zentralbankgeld

Reservepflich Banknotenum Reserve-Ist reales BIP Preisniveau

$\begin{array}{lrlrrr}1997 & 2,3 \mathrm{E}+12 & 260,7 \mathrm{E}+9 & 41,7 \mathrm{E}+9 & 2,2532 \mathrm{E}+12 & 121,4 \\ 1996 & 2,2 \mathrm{E}+12 & 260,4 \mathrm{E}+9 & 39,5 \mathrm{E}+9 & 2,0978 \mathrm{E}+12 & 120,6 \\ 1995 & 2,1 \mathrm{E}+12 & 248,4 \mathrm{E}+9 & 37,3 \mathrm{E}+9 & 2,0151 \mathrm{E}+12 & 119,4 \\ 1994 & 2,0 \mathrm{E}+12 & 236,2 \mathrm{E}+9 & 44,4 \mathrm{E}+9 & 2,1469 \mathrm{E}+12 & 116,8 \\ 1993 & 1,9 \mathrm{E}+12 & 224,3 \mathrm{E}+9 & 60,4 \mathrm{E}+9 & 2,1705 \mathrm{E}+12 & 113,8 \\ 1992 & 1,7 \mathrm{E}+12 & 213,4 \mathrm{E}+9 & 86,4 \mathrm{E}+9 & 2,4827 \mathrm{1}+12 & 109,6 \\ & & & & & 103,886256\end{array}$

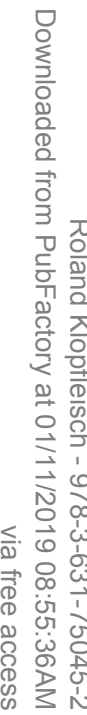

Vergleich Refinanzierungsbestände und Mindestreserve+Cash

\begin{tabular}{llr}
\multicolumn{2}{c}{ ZBG } & Bestände \\
1997 & $302,4 E+9$ & $213,2 E+9$ \\
1996 & $299,9 E+9$ & $196,8 E+9$ \\
1995 & $285,7 E+9$ & $189,6 E+9$ \\
1994 & $280,5 E+9$ & $182,2 E+9$ \\
1993 & $284,7 E+9$ & $193,9 E+9$ \\
1992 & $299,7 E+9$ & $204,3 E+9$
\end{tabular}

\begin{tabular}{|c|c|c|c|c|c|}
\hline & & DM & DM90 & ECU90 & $\%$ vom BIP \\
\hline \multirow[t]{2}{*}{ aus Zinsänderungen } & d Zinseinnahmen & $-13,2 E+9$ & $-9,2 E+9$ & $-4,5 E+9$ & $-0,31 \%$ \\
\hline & d Zinsausgaben & $-200,5 E+6$ & $-139,9 E+6$ & $-68,2 E+6$ & $0,00 \%$ \\
\hline aus d & d potentielle Zinseinnahmen & $-21,4 E+9$ & $-14,9 E+9$ & $-7,3 E+9$ & $-0,50 \%$ \\
\hline Konv & & $-34,4 \mathrm{E}+9$ & $-24,0 \mathrm{E}+9$ & $-11,7 \mathrm{E}+9$ & $-0,80 \%$ \\
\hline
\end{tabular}


Vergleich Opportunitätskosten-Seigniorage und fisk. Seigniorage

Bestände monetäre Bas Porte-feuille-Z Govern-ment Bond Yield

$\begin{array}{llrrr}1997 & 293,4 E+9 & 52,4 E+9 & 4,70 \% & 7,20 \% \\ 1996 & 271,0 E+9 & 59,7 E+9 & 4,73 \% & 7,20 \% \\ 1995 & 260,3 E+9 & 56,4 E+9 & 5,74 \% & 6,51 \% \\ 1994 & 264,9 E+9 & 52,5 E+9 & 6,68 \% & 8,10 \% \\ 1993 & 277,0 E+9 & 000,0 E+0 & 8,75 \% & 0,00 \% \\ 1992 & 292,7 E+9 & 000,0 E+0 & 9,38 \% & 0,00 \%\end{array}$

Schätzung der Zinsen für MuL-Papiere

Zinsen für Kre Zinserträge geschätzt

Zinsen für

$\begin{array}{lrr}1979 & 1,5 \mathrm{E}+9 & 1,5 \mathrm{E}+9 \\ 1980 & 3,4 \mathrm{E}+9 & 3,4 \mathrm{E}+9 \\ 1981 & 4,5 \mathrm{E}+9 & 4,4 \mathrm{4}+9 \\ 1982 & 5,0 \mathrm{E}+9 & 5,0 \mathrm{E}+9 \\ 1983 & 2,9 \mathrm{E}+9 & 2,9 \mathrm{E}+9 \\ 1984 & 3,6 \mathrm{E}+9 & 3,6 \mathrm{E}+9 \\ 1985 & 4,6 \mathrm{E}+9 & 4,6 \mathrm{E}+9 \\ 1986 & 3,7 \mathrm{E}+9 & 3,6 \mathrm{E}+9 \\ 1987 & 2,7 \mathrm{E}+9 & 3,2 \mathrm{E}+9 \\ 1988 & 3,4 \mathrm{E}+9 & 3,5 \mathrm{E}+9 \\ 1989 & 8,7 \mathrm{E}+9 & 8,8 \mathrm{~B}+9 \\ 1990 & 12,8 \mathrm{E}+9 & 12,7 \mathrm{E}+9 \\ 1991 & 17,1 \mathrm{E}+9 & 17,2 \mathrm{E}+9 \\ 1992 & 18,6 \mathrm{E}+9 & 18,6 \mathrm{E}+9 \\ 1993 & 15,9 \mathrm{E}+9 & 15,6 \mathrm{E}+9 \\ 1994 & 10,7 \mathrm{E}+9 & 10,5 \mathrm{E}+9 \\ 1995 & 8,3 \mathrm{E}+9 & 8,2 \mathrm{E}+9 \\ 1996 & 6,2 \mathrm{E}+9 & 6,1 \mathrm{E}+9 \\ 1997 & 6,4 \mathrm{E}+9 & 6,3 \mathrm{E}+9\end{array}$

Mobilitäts- unı Verbindlichkei i subv

$\begin{array}{lr}1997 \text { k.A. } & \\ 1996 \text { k.A. } & \\ 1995 \text { k.A. } & \\ 1994 \text { k.A. } & \\ 1993 & 1,5 E+9 \\ 1992 & 226,0 \mathrm{E}+6 \\ 1991 & 348,6 \mathrm{E}+6 \\ 1990 & 327,6 \mathrm{E}+6 \\ 1989 & 254,0 \mathrm{E}+6 \\ 1988 & 151,6 \mathrm{E}+6 \\ 1987 & 164,2 \mathrm{E}+6 \\ 1986 & 203,3 \mathrm{E}+6 \\ 1985 & 258,4 \mathrm{E}+6 \\ 1984 & 270,4 \mathrm{E}+6 \\ 1983 & 248,1 \mathrm{E}+6 \\ 1982 & 360,1 \mathrm{E}+6 \\ 1981 & 477,4 \mathrm{E}+6 \\ 1980 & 146,5 \mathrm{E}+6 \\ 1979 & 53,0 \mathrm{E}+6\end{array}$

$3,5 E+9$

$2,50 \%$

Schätzung i offen (ungew Schätzung2

$\begin{array}{llll}2,65 \% & 87,9 E+6 & 3,07 \% & 108,0 E+6 \\ 3,5 E+6 & 3,23 \% & 60,3 E+6\end{array}$

$3,96 \%-87,1 \mathrm{E}+6 \quad 4,42 \%-97,2 \mathrm{E}+6$

$\begin{array}{rrrrr}22,4 E+9 & 4,82 \% & 1,1 E+9 & 5,25 \% & 1,2 E+9\end{array}$

$\begin{array}{lllll}21,3 E+9 & 6,95 \% & 1,5 E+9 & 7,38 \% & 1,6 E+9\end{array}$

$\begin{array}{lllll}2,6 \mathrm{E}+9 & 8,20 \% & 211,3 \mathrm{E}+6 & 9,36 \% & 241,2 \mathrm{E}+6\end{array}$

$\begin{array}{lllll}5,4 E+9 & 6,85 \% & 368,8 E+6 & 8,79 \% & 473,3 E+6\end{array}$

$\begin{array}{lllll}5,1 \mathrm{E}+9 & 6,00 \% & 307,8 \mathrm{E}+6 & 7,92 \% & 406,3 \mathrm{E}+6\end{array}$

$5,2 \mathrm{E}+9 \quad 4,83 \% \quad 252,9 \mathrm{E}+6 \quad 6,47 \% \quad 338,7 \mathrm{E}+6$

$\begin{array}{lllll}5,4 E+9 & 3,13 \% & 167,7 E+6 & 3,78 \% & 202,5 E+6\end{array}$

$\begin{array}{lllll}6,5 \mathrm{E}+9 & 2,99 \% & 192,9 \mathrm{E}+6 & 3,74 \% & 241,3 \mathrm{E}+6\end{array}$

$6,1 E+9 \quad 3,59 \% \quad 219,0 E+6 \quad 4,41 \% \quad 268,8 E+6$

$6,2 \mathrm{E}+9 \quad 4,31 \% \quad 265,1 \mathrm{E}+6 \quad 5,12 \% \quad 314,9 \mathrm{E}+6$

$6,2 \mathrm{E}+9 \quad 4,25 \% \quad 263,4 \mathrm{E}+6 \quad 5,62 \% \quad 348,3 \mathrm{E}+6$

$\begin{array}{lllll}6,2 E+9 & 4,21 \% & 259,7 E+6 & 5,65 \% & 348,5 E+6\end{array}$

$\begin{array}{lllll}5,1 E+9 & 7,06 \% & 358,6 E+6 & 8,68 \% & 440,8 E+6\end{array}$

$\begin{array}{lllll}5,5 E+9 & 7,50 \% & 415,9 E+6 & 10,86 \% & 602,3 E+6\end{array}$

$\begin{array}{lllll}4,4 E+9 & 7,17 \% & 313,5 E+6 & 9,17 \% & 401,0 E+6\end{array}$

$9,4 E+9 \quad 4,39 \% \quad 412,2 E+6 \quad 0,00 \% \quad 000,0 E+0$ 
Offenmarkt i offen (ungeu Diskont i subv

Lombard i refi $735,4 \mathrm{E}+6$ $2,50 \%$ $63,6 \mathrm{E}+9$ $62,7 E+9$ $2,65 \%$ $752,1 E+6$ refi $4,50 \%$

$\begin{array}{ll}135,2 E+9 & 3,23 \%\end{array}$

$63,6 \mathrm{E}+9$

$3,96 \%$

$1994 \quad 141,3 \mathrm{E}+9 \quad 5,25 \%$

$60,2 E+9$ $1,5 \mathrm{E}+9$

$5,81 \%$

$153,7 E+9-7,38 \%$

$59,6 \mathrm{E}+9$

$4,82 \%$

$3,2 \mathrm{E}+9$

$6,26 \%$

$134,6 E+9$

$70,2 \mathrm{E}+9$

, $\mathrm{E}+9$

$8,10 \%$

$129,0 \mathrm{E}+9 \quad 8,79 \%$

$81,3 E+9$

$8,20 \%$

$1990 \quad 100,5 \mathrm{E}+9$

$7,92 \%$

$75,2 E+9$

$6,85 \%$

$2,1 \mathrm{E}+9$

$9,68 \%$

$3,0 E+9$

$8,30 \%$

$90,3 \mathrm{E}+9 \quad 6,47 \%$

$58,6 E+9$

$6,00 \%$

$47,9 \mathrm{E}+9 \quad 3,78 \%$

$52,1 \mathrm{E}+9$

$3,5 \mathrm{E}+9$

$8,08 \%$

$3,13 \%$

$1,8 E+9$

$7,06 \%$

$1,4 E+9 \quad 5,15 \%$

1987

1986

$3,74 \%$

$71,4 \mathrm{E}+9$

$2,99 \%$

$30,7 \mathrm{E}+9 \quad 4,41 \%$

$62,4 E+9$

$3,59 \%$

1985
1984

$34,4 \mathrm{E}+9$

$5,12 \%$

$63,2 \mathrm{E}+9$

$12,5 E+9 \quad 5,62 \%$

$60,2 E+9$

$4,31 \%$

$5,5 \mathrm{E}+9 \quad 5,65 \%$

$1982 \quad 9,9 \mathrm{E}+9 \quad 8,68 \%$

$1981 \quad 4,0 E+9 \quad 10,86 \%$

1980

$54,6 \mathrm{E}+9$

$4,25 \%$

$4,21 \%$

$52,6 \mathrm{E}+9$

$48,7 E+9$

$7,06 \%$

$7,50 \%$

$38,0 \mathrm{E}+9$

$7,17 \%$

$626,3 \mathrm{E}+6$

$4,96 \%$

932, $3 E+6$

$5,50 \%$

$1,9 \mathrm{E}+9$

$5,77 \%$

$6,5 \mathrm{E}+9$

$5,50 \%$

$8 \mathrm{E}+9$

$4,6 \mathrm{E}+9$

$8,39 \%$

$9,00 \%$

$4,9 \mathrm{E}+9$

$8,78 \%$

$1,7 \mathrm{E}+9 \quad 0,00 \%$

$27,7 E+9$

$4,39 \%$

$5,3 E+9$

$5,42 \%$

Sgesch $6,3 E+9$

$6,1 E+9$

insertrag von inl. tatsächlic sonstiger Zins

$\quad 6,4 \mathrm{E}+9$

$6,2 \mathrm{E}+9$

$7,5 E+9$

$6,8 \mathrm{E}+9$

$10,7 E+9$

$18,6 E+9 \quad 18,6 E+9 \quad 8,9 E+9$

$17,2 \mathrm{E}+9 \quad 17,1 \mathrm{E}+9$

$12,7 E+9 \quad 12,8 E+9 \quad 8,1 E+9$

$8,8 E+9 \quad 8,7 E+9 \quad 8,7 E+9$

$3,5 \mathrm{E}+9 \quad 3,4 \mathrm{E}+9 \quad 8,3 \mathrm{E}+9$

$3,2 \mathrm{E}+9 \quad 2,7 \mathrm{E}+9 \quad 7,9 \mathrm{E}+9$

$3,6 \mathrm{E}+9 \quad 3,7 \mathrm{E}+9 \quad 7,4 \mathrm{E}+9$

$4,6 E+9 \quad 4,6 E+9 \quad 9,5 E+9$

$3,6 \mathrm{E}+9 \quad 3,6 \mathrm{E}+9$

$2,9 E+9 \quad 2,9 E+9 \quad 10,2 E+9$

$5,0 E+9 \quad 5,0 E+9$

$10,2 E+9$
$8,9 E+9$

$3,4 E+9 \quad 3,4 E+9$

$6,4 \mathrm{E}+9$

$6,7 E+9$ 
Belgien

Wahrungsreserven

Zinseinnahmen

BF BF90

$23,4 E+9$ ECU9

Zinsausgaben

\begin{tabular}{llll}
\multicolumn{1}{c}{ BF } & \multicolumn{2}{c}{ BF90 } & ECU90 \\
1997 & $27,8 E+9$ & $23,4 E+9$ & $551,0 E+6$ \\
1996 & $24,8 E+9$ & $21,1 E+9$ & $498,3 E+6$ \\
1995 & $21,3 E+9$ & $18,4 E+9$ & $434,5 E+6$ \\
1994 & $13,9 E+9$ & $12,2 E+9$ & $287,7 E+6$ \\
1993 & $22,5 E+9$ & $20,4 E+9$ & $479,7 E+6$ \\
1992 & $23,3 E+9$ & $21,9 E+9$ & $515,6 E+6$
\end{tabular}

BF

BF90 ECU90

$000,0 E+0 \quad 000,0 E+0 \quad 000,0 E+0$

$000,0 E+0 \quad 000,0 E+0 \quad 000,0 E+0$

$000,0 E+0 \quad 000,0 E+0 \quad 000,0 E+0$

$000,0 E+0 \quad 000,0 E+0 \quad 000,0 E+0$

$000,0 \mathrm{E}+0 \quad 000,0 \mathrm{E}+0 \quad 000,0 \mathrm{E}+0$

$000,0 E+0 \quad 000,0 E+0 \quad 000,0 E+0$

Zinsertrăge aus Krediten an inl. GB

Produit des opérations de ciBrutto

Netto Kosten für St: BF

\begin{tabular}{rrc} 
& \multicolumn{2}{c}{ Kosten für St: BF } \\
1997 & $4,0 E+9$ & $735,0 E+6$ \\
1996 & $4,0 E+9$ & $735,0 E+6$ \\
1995 & $6,3 E+9$ & $145,0 E+6$ \\
1994 & $8,3 E+9$ & $235,8 E+6$ \\
1993 & $10,8 E+9$ & $208,9 E+6$ \\
1992 & $9,8 E+9$ & $216,0 E+6$
\end{tabular}

$4,7 E+9$ BF90

ECU9O

$4,7 E+9$

$6,5 \mathrm{E}+9$

$8,5 E+9$

$11,0 E+9$

$9,8 E+9 \quad 216,0 E+6$

$10,0 E+9$

Kosten

sonst. VwKos Schlussel BF

\begin{tabular}{lcc}
\multicolumn{4}{c}{ sonst. VwKos Schlussel BF } \\
1997 & $9,5 E+9$ & $31,50 \%$ \\
1996 & $9,1 E+9$ & $32,61 \%$ \\
1995 & $9,0 E+9$ & $33,59 \%$ \\
1994 & $9,4 E+9$ & $29,78 \%$ \\
1993 & $9,7 E+9$ & $31,09 \%$ \\
1992 & $9,8 E+9$ & $30,20 \%$
\end{tabular}

\begin{tabular}{lrc} 
& \multicolumn{2}{c}{ BF90 } \\
$3,0 E+9$ & $2,5 E+9$ & $59,0 E+6$ \\
$3,0 E+9$ & $2,5 E+9$ & $59,8 E+6$ \\
$3,0 E+9$ & $2,6 E+9$ & $61,6 E+6$ \\
$2,8 E+9$ & $2,5 E+9$ & $58,1 E+6$ \\
$3,0 E+9$ & $2,7 E+9$ & $64,0 E+6$ \\
$3,0 E+9$ & $2,8 E+9$ & $65,6 E+6$
\end{tabular}

Gewinne aus Geldschopfung

Zinsaufwand

Parts del'Etat

Opérations de crédit

BF BFoO

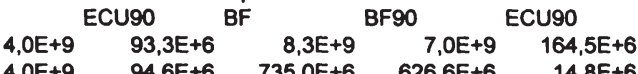

$\begin{array}{ll}94,6 E+6 & 735,0 E+6\end{array}$

$5,6 \mathrm{E}+9 \quad 132,1 \mathrm{E}+6 \quad 145,0 \mathrm{E}+6 \quad 125,6 \mathrm{E}+6 \quad 3,0 \mathrm{E}+6$

$7,5 \mathrm{E}+9 \quad 176,3 \mathrm{E}+6 \quad 235,8 \mathrm{E}+6 \quad 207,4 \mathrm{E}+6 \quad 4,9 \mathrm{E}+6$

$10,0 E+9 \quad 235,0 E+6 \quad 208,9 E+6 \quad 188,9 E+6 \quad 4,5 E+6$

$9,4 E+9 \quad 221,0 E+6 \quad 216,0 E+6 \quad 203,2 E+6 \quad 4,8 E+6$

fiskalischer Seigniorage ohne Kosten BF BF90 ECU90

ECU90

in \% vom BIP BF

fiskalischer Seigniorage ohne Kosten und Währungsreserven

\begin{tabular}{lrrrrrrrr} 
BF & \multicolumn{2}{c}{ BF90 } & \multicolumn{2}{c}{ ECU90 } & in \% vom BIP BF & \multicolumn{3}{c}{ BF90 } \\
1997 & $23,5 E+9$ & $20,0 E+9$ & $471,5 E+6$ & $0,28 \%$ & $-4,3 E+9$ & $-3,7 E+9$ & $-87,0 E+6$ & $-0,05 \%$ \\
1996 & $28,0 E+9$ & $23,9 E+9$ & $563,3 E+6$ & $0,34 \%$ & $3,2 E+9$ & $2,8 E+9$ & $65,0 E+6$ & $0,04 \%$ \\
1995 & $27,5 E+9$ & $23,8 E+9$ & $560,7 E+6$ & $0,35 \%$ & $6,2 E+9$ & $5,3 E+9$ & $124,1 E+6$ & $0,07 \%$ \\
1994 & $21,9 E+9$ & $19,3 E+9$ & $454,2 E+6$ & $0,29 \%$ & $8,0 E+9$ & $6,8 E+9$ & $161,4 E+6$ & $0,10 \%$ \\
1993 & $33,1 E+9$ & $29,9 E+9$ & $705,8 E+6$ & $0,45 \%$ & $10,6 E+9$ & $9,0 E+9$ & $213,2 E+6$ & $0,13 \%$ \\
1992 & $32,8 E+9$ & $30,8 E+9$ & $727,0 E+6$ & $0,46 \%$ & $9,5 E+9$ & $8,1 E+9$ & $191,6 E+6$ & $0,12 \%$
\end{tabular}


Aktivseite

Passiv

Advances age commercial bisecurities pur claims due to other interventions in the mc Liabilities due to interventions in the money market

Avances sur r Effects de cor Effects acheti Créances suit Foreign currencies Engagements suite à des interventions sur le marché m

Lombard Diskont Offenmarkt Wertpapier-pi Währungs-reserven

Wertpapierpe The Bank's certificates

$\begin{array}{llrlrlll}1997 & 18,6 \mathrm{E}+9 & 2,8 \mathrm{E}+9 & 25,9 \mathrm{E}+9 & 129,0 \mathrm{E}+9 & 462,0 \mathrm{E}+9 & 1,5 \mathrm{E}+9 & 230,0 \mathrm{E}+9 \\ 1996 & 20,9 \mathrm{E}+9 & 2,9 \mathrm{E}+9 & 24,9 \mathrm{E}+9 & 127,7 \mathrm{E}+9 & 411,4 \mathrm{E}+9 & 5,1 \mathrm{E}+9 & 230,0 \mathrm{E}+9 \\ 1995 & 19,4 \mathrm{E}+9 & 3,3 \mathrm{E}+9 & 23,9 \mathrm{E}+9 & 128,5 \mathrm{E}+9 & 285,9 \mathrm{E}+9 & 8,1 \mathrm{E}+9 & 000,0 \mathrm{E}+0 \\ 1994 & 32,3 \mathrm{E}+9 & 3,7 \mathrm{E}+9 & 17,9 \mathrm{E}+9 & 92,3 \mathrm{E}+9 & 231,2 \mathrm{E}+9 & 3,0 \mathrm{E}+9 & 000,0 \mathrm{E}+0 \\ 1993 & 30,1 \mathrm{E}+9 & 5,6 \mathrm{E}+9 & 32,4 \mathrm{E}+9 & 119,7 \mathrm{E}+9 & 244,2 \mathrm{E}+9 & 6,0 \mathrm{E}+9 & 000,0 \mathrm{E}+0 \\ 1992 & 20,0 \mathrm{E}+9 & 10,1 \mathrm{E}+9 & 17,4 \mathrm{E}+9 & 52,4 \mathrm{E}+9 & 193,4 \mathrm{E}+9 & 4,4 \mathrm{E}+9 & 000,0 \mathrm{E}+0\end{array}$

Zinsen

Taux des ava Taux d'escom Taux des octrois de crédits par adjudication Lombard Diskont Offenmarkt Einlagenzins

$\begin{array}{llll}1997 & 4,31 \% & 2,55 \% & 3,06 \% \\ 1996 & 4,44 \% & 2,65 \% & 3,41 \% \\ 1995 & 5,94 \% & 3,94 \% & 4,53 \% \\ 1994 & 7,32 \% & 4,70 \% & 5,74 \% \\ 1993 & 9,67 \% & 6,53 \% & 8,12 \% \\ 1992 & 9,71 \% & 8,30 \% & 9,21 \%\end{array}$

Einnahmenschătzung

Lombard Diskont

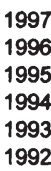
$802,9 \mathrm{E}+6$ $926,9 E+6$

$1,2 \mathrm{E}+9$

$2,4 \mathrm{E}+9$

$2,9 E+9$

$1,9 E+9$

6

Offenmarkt Wertpapierpe Summe +

$75,5 E+6$

$849,1 E+6$

$1,1 \mathrm{E}+9$
$1,0 \mathrm{E}+9$

$4,4 E+9$

$6,2 \mathrm{E}+9$

$174,9 E+6$

$1,0 \mathrm{E}+9$

$5,8 E+9$

$8,2 E+9$

$364,0 \mathrm{E}+6$

$2,6 \mathrm{E}+9$

$5,3 E+9$

$8,9 E+9$

$1,6 E+9$

$9,7 E+9$

$15,6 \mathrm{E}+9$

$9,2 \mathrm{E}+9$

Ausgabenschătzung

$7,1 E+9$
$8,0 E+9$
$365,0 E+6$
$174,9 E+6$
$490,7 E+6$
$409,8 E+6$

Banknotenumlauf/nat. nom. BIP

\begin{tabular}{|c|c|}
\hline \multicolumn{2}{|c|}{ C } \\
\hline 1997 & $5,54 \%$ \\
\hline 1996 & $5,62 \%$ \\
\hline 1995 & $5,61 \%$ \\
\hline 1994 & $5,37 \%$ \\
\hline 1993 & $6,04 \%$ \\
\hline 1992 & $6,05 \%$ \\
\hline
\end{tabular}

\begin{tabular}{ll} 
Durchschnitt $\quad 6,05 \%$ \\
\hline
\end{tabular} 


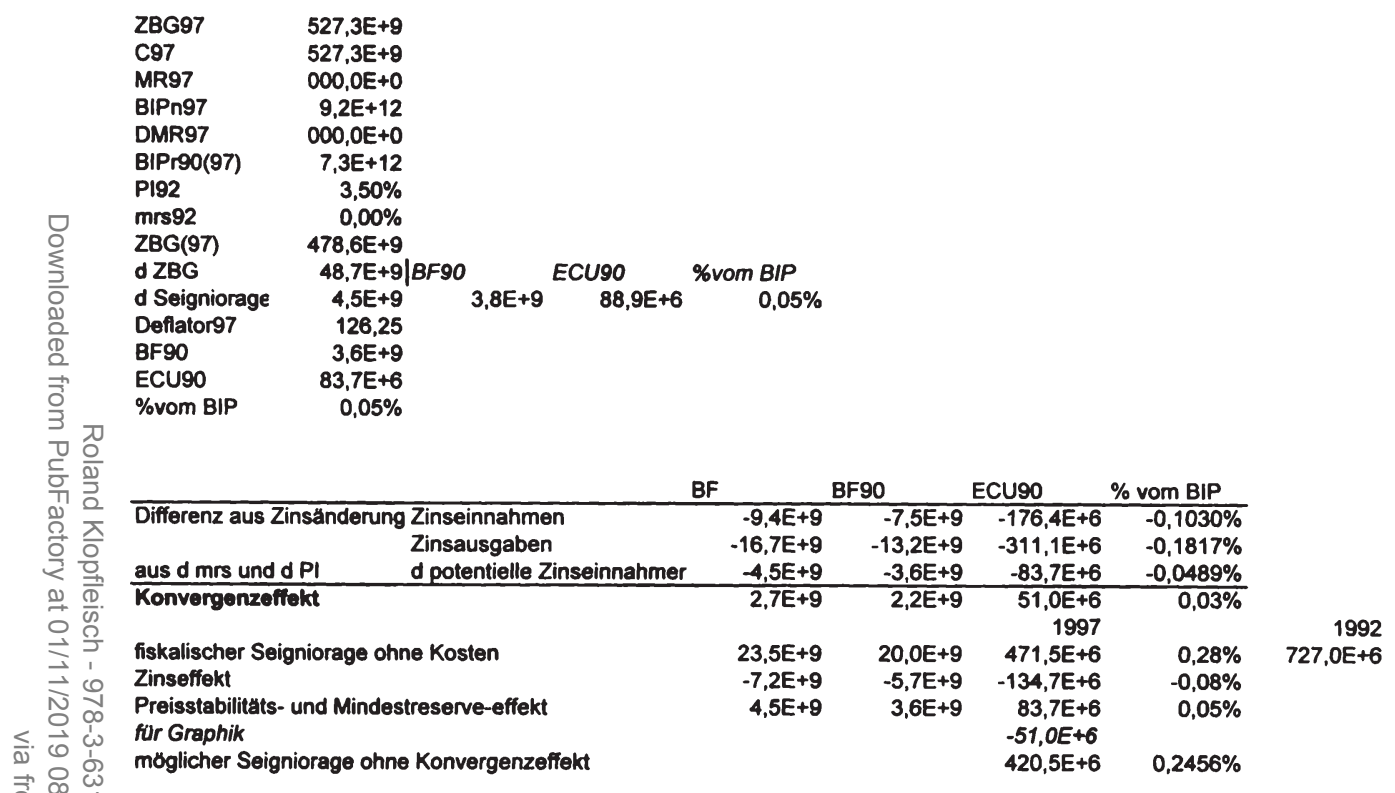


foreign securities

Währungsreserven

Zinseinnahmen

$\begin{array}{ll}\text { FIM } & \text { FIMSO } \\ 1997 & 2,0 E+9 \\ 1996 & 1,3 E+9 \\ 1995 & 2,1 E+9 \\ 1994 & 2,2 E+9 \\ 1993 & 1,6 E+9 \\ 1992 & 1,6 E+9\end{array}$

FIM90 $1,8 \mathrm{E}+9$ ECU

$2 E+9$

$1,9 \mathrm{E}+9$

$2,0 \mathrm{E}+9$

$1,4 \mathrm{E}+9$

$1,5 \mathrm{E}+9$

$244,1 \mathrm{E}+6$

$388,2 E+6$

$403,9 E+6$

$283,1 \mathrm{E}+6$

$300,5 E+6$ loans under swap arrangements

Zinsausgaben

FIM

$000,0 E+0$

$000,0 \mathrm{E}+0$

$000,0 \mathrm{E}+0$

$000,0 \mathrm{E}+0$

$18,4 \mathrm{E}+6$

$190,5 E+6$

1990

OOO,OE+0

$000,0 \mathrm{E}+0$

$000,0 E+0$

$16,3 \mathrm{E}+6$

$168,6 \mathrm{E}+6$

Kosten

Interest costs

interest expense, domestic

FIM FIM90

ECU90

$V w-K$

-Kosten, a pur
$154,7 E+6$
$182,3 E+6$
$195,7 E+6$
$152,2 E+6$
$142,3 E+6$
$175,6 E+6$





vom BIP
$0,22 \%$
$0,13 \%$
$0,05 \%$
$0,18 \%$
$0,25 \%$
$0,14 \%$

32

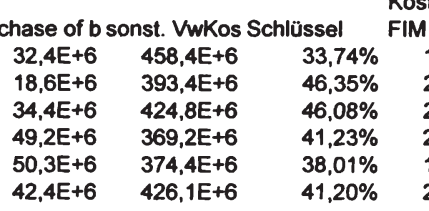

fiskalischer Seigniorage ohne Kosten

fiskalischer Seigniorage ohne Kosten
FIM
$\begin{array}{rrrr}\text { FIM90 } & \text { ECU90 } & \text { in \% vom BIP } \\ 1,5 E+9 & 1,4 E+9 & 279,3 E+6 & 0,25 \% \\ 931,2 E+6 & 842,7 E+6 & 173,6 E+6 & 0,16 \% \\ 510,9 E+6 & 465,7 E+6 & 95,9 E+6 & 0,09 \% \\ 1,1 E+9 & 1,0 E+9 & 213,2 E+6 & 0,22 \% \\ 1,4 E+9 & 1,3 E+9 & 270,4 E+6 & 0,29 \% \\ 897,5 E+6 & 869,7 E+6 & 179,1 E+6 & 0,19 \%\end{array}$

Zinsertrăge aus Krediten an inl. GB

Interest Income, domestic+interest margin

FIM

FIM90 ECU90

$\begin{array}{rr}545,7 E+6 & 112,4 E+6 \\ 412,8 E+6 & 85,0 E+6 \\ 425,3 E+6 & 87,6 E+6 \\ 455,9 E+6 & 93,9 E+6 \\ 1,5 E+9 & 305,0 E+6 \\ 2,7 E+9 & 549,1 E+6\end{array}$

fiskalischer Seigniorage ohne Kosten und Wăhrungsreserven

\begin{tabular}{|c|c|c|c|c|}
\hline \multicolumn{2}{|c|}{ FIM } & FIM90 & ECU9O & in $\%$ vom BIP \\
\hline 1997 & $-450,9 \mathrm{E}+6$ & $-399,0 \mathrm{E}+6$ & $-82,2 \mathrm{E}+6$ & $-0,07 \%$ \\
\hline 99 & $-407,7 E+6$ & $-360,8 E+6$ & $-74,3 E+6$ & $-0,07 \%$ \\
\hline 19 & $-1,6 E+9$ & $-1,4 E+9$ & $-295,1 E+6$ & $-0,26 \%$ \\
\hline 1994 & $-1,1 E+9$ & $-979,7 E+6$ & $-201,8 E+6$ & $-0,18 \%$ \\
\hline 1993 & $-147,0 E+6$ & $-130,1 E+6$ & $-26,8 E+6$ & $-0,02 \%$ \\
\hline 1992 & $-560,4 E+6$ & $-496,0 E+6$ & $-102,2 E+6$ & $-0,09 \%$ \\
\hline
\end{tabular}


other

Zinsertrăge

certificates of Loans for stabilizing the money market

Liquidity credi securities witt Net interest o, Bonds Financing of domestic deliveries

$\begin{array}{rrrrrrr}1997 & 000,0 \mathrm{E}+0 & 342,5 \mathrm{E}+6 & 141,8 \mathrm{E}+6 & 118,8 \mathrm{E}+6 & 13,5 \mathrm{E}+6 & 616,6 \mathrm{E}+6 \\ 1996 & 6,7 \mathrm{E}+6 & 249,8 \mathrm{E}+6 & 000,0 \mathrm{E}+0 & 151,2 \mathrm{E}+6 & 48,4 \mathrm{E}+6 & 456,1 \mathrm{E}+6 \\ 1995 & 8,0 \mathrm{E}+6 & 201,9 \mathrm{E}+6 & 8,1 \mathrm{E}+6 & 233,2 \mathrm{E}+6 & 15,4 \mathrm{E}+6 & 466,6 \mathrm{E}+6 \\ 1994 & 1,0 \mathrm{E}+6 & 72,6 \mathrm{E}+6 & 15,2 \mathrm{E}+6 & 342,2 \mathrm{E}+6 & 57,3 \mathrm{E}+6 & 488,3 \mathrm{E}+6 \\ 1993 & 40,0 \mathrm{E}+6 & 329,2 \mathrm{E}+6 & 324,0 \mathrm{E}+6 & 464,5 \mathrm{E}+6 & 407,4 \mathrm{E}+6 & 1,6 \mathrm{E}+9 \\ 1992 & 77,6 \mathrm{E}+6 & 351,3 \mathrm{E}+6 & 911,8 \mathrm{E}+6 & 1,1 \mathrm{E}+9 & 311,1 \mathrm{E}+6 & 2,8 \mathrm{E}+9\end{array}$

\section{Zinsaufwendungen}

Cash reserve deposits

certificates of Call money de reserve depo: other

Outright-gesc Einlagefazility Einlagefazility andere

$1997 \quad 1,1 E+9-000,0 E+0 \quad$ Summe

$\begin{array}{rrrrr}1997 & 1,1 E+9 & 000,0 E+0 & 8,0 E+6 & 000,0 E+0 \\ 1996 & 857,3 E+6 & 000,0 E+0 & 5,9 E+6 & 600,0 E+3 \\ 1995 & 2,0 E+9 & 29,7 E+6 & 4,1 E+6 & 5,2 E+6 \\ 1994 & 1,5 E+9 & 43,9 E+6 & 000,0 E+0 & 11,9 E+6\end{array}$

1993

1992

$43,9 E+6$

,

$32,6 E+6$

$1,2 \mathrm{E}+9$
$1,9 \mathrm{E}+9$

$239,1 E+6$

$1,1 E+9$

$30,2 \mathrm{E}+6$

Bestănde (soweit moglich Durchschnitt)

Aktiv

Liquidity credi securities witr Certificates of Bonds

Passiv

$\begin{array}{lr}1997 & 0 \\ 1996 & 6,7 E+6 \\ 1995 & 129,0 E+6 \\ 1994 & 10,0 E+6 \\ 1993 & 425,0 E+6 \\ 1992 & 437,0 E+6 \\ & \\ & \text { Gowinnschatzung } \\ \text { Entrag }\end{array}$

$\begin{array}{rrr}10,9 E+9 & 000,0 E+0 & 149,8 E+6 \\ 7,1 E+9 & 000,0 E+0 & 276,5 E+6 \\ 3,6 E+9 & 110,1 E+6 & 600,0 E+6 \\ 1,2 E+9 & 1,5 E+9 & 930,3 E+6 \\ 4,3 E+9 & 1,8 E+9 & 1,3 E+9 \\ 2,6 E+9 & 6,6 E+9 & 1,6 E+9\end{array}$

Wahrungsres Call

Zinsen

standing facilities

ender rate liquidity credit call money de excess reserve rate

Offenmarktsa Lombardsatz Einlagensatz Zins auf Über Rendite der $V$

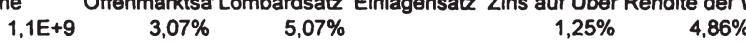

$863,8 E+6$

$3,57 \% \quad 5,57 \%$

$5,63 \% \quad 7,63 \%$

$5,11 \% \quad 7,11 \%$

$7.87 \% \quad 9.87 \%$

$3,63 \%$

$4,65 \%$

$9,87 \%$
$14,85 \%$

$3,11 \%$

$2.25 \%$

$5,26 \%$

$4.65 \%$

$5,38 \%$

$6,58 \%$

$\begin{array}{rrrrr}\text { Wahrungsres } & \text { Call money de Cash reserve excess reserv Certificates of deposit } \\ 40,8 E+9 & 000,0 E+0 & 6,7 E+9 & 747,0 E+6 & 33,8 E+9 \\ 28,8 E+9 & 000,0 E+0 & 6,7 E+9 & 440,0 E+6 & 21,5 E+9 \\ 40,5 E+9 & 1,0 E+9 & 6,5 E+9 & 616,0 E+6 & 35,9 E+9 \\ 47,7 E+9 & 1,4 E+9 & 6,5 E+9 & & 30,7 E+9 \\ 28,9 E+9 & 831,0 E+6 & 9,1 E+9 & & 14,6 E+9 \\ 25,0 E+9 & 2,1 E+9 & 10,3 E+9 & & 13,8 E+9\end{array}$

Aufwendungen

$\begin{array}{rrrrrrrrr}1997 & 000,0 E+0 & 335,8 E+6 & 000,0 E+0 & 4,6 E+6 & 000,0 E+0 & 000,0 E+0 & 9,3 E+6 & 1,0 E+9 \\ 1996 & 373,2 E+3 & 253,2 E+6 & 000,0 E+0 & 9,9 E+6 & 000,0 E+0 & 000,0 E+0 & 4,4 E+6 & 769,3 E+6 \\ 1995 & 9,8 E+6 & 204,2 E+6 & 6,2 E+6 & 33,8 E+6 & 37,1 E+6 & 000,0 E+0 & 13,9 E+6 & 2,0 E+9 \\ 1994 & 711,0 E+3 & 59,8 E+6 & 77,1 E+6 & 47,5 E+6 & 43,3 E+6 & 000,0 E+0 & 000,0 E+0 & 1,6 E+9 \\ 1993 & 41,9 E+6 & 339,3 E+6 & 141,9 E+6 & 101,2 E+6 & 40,5 E+6 & 441,3 E+6 & 000,0 E+0 & 1,1 E+9 \\ 1992 & 64,9 E+6 & 356,0 E+6 & 919,5 E+6 & 221,8 E+6 & 228,2 E+6 & 1,1 E+9 & 000,0 E+0 & 1,9 E+9\end{array}$


Summe Summe tatsáchlich

Ertrag Aufwand Ertrag Aufwand

$1997 \quad 340,4 \mathrm{E}+6 \quad 1,0 \mathrm{E}+9 \quad 616,6 \mathrm{E}+6 \quad 1,1 \mathrm{E}+9$

$1996 \quad 263,4 E+6 \quad 773,7 E+6 \quad 456,1 E+6 \quad 863,8 E+6$

$1995 \quad 254,0 E+6 \quad 2,1 E+9 \quad 466,6 E+6 \quad 2,1 E+9$

$1994 \quad 185,2 E+6 \quad 1,6 E+9 \quad 488,3 E+6 \quad 1,6 E+9$

$1993 \quad 624,4 E+6 \quad 1,6 E+9 \quad 1,6 E+9 \quad 1,7 E+9$

$1992 \quad 1,6 \mathrm{E}+9 \quad 3,3 \mathrm{E}+9 \quad 2,8 \mathrm{E}+9 \quad 3,3 \mathrm{E}+9$

Mindestreserven

deposit requir deposits at the end of perioc Mindestreservepflichtige Einlagen

$\begin{array}{lrrrr}1997 & 1,50 \% & 6,7 E+9 & 747,0 E+6 & 447,8 E+9 \\ 1996 & 1,50 \% & 6,7 E+9 & 440,0 E+6 & 443,5 E+9 \\ 1995 & 1,50 \% & 6,5 E+9 & 616,0 E+6 & 435,3 E+9 \\ 1994 & 1,50 \% & 6,5 E+9 & & 433,8 E+9 \\ 1993 & 1,50 \% & 9,1 E+9 & & 604,1 E+9 \\ 1992 & 5,00 \% & 10,3 E+9 & & 206,5 E+9\end{array}$

$206,5 E+9$

\begin{tabular}{|c|c|c|c|c|c|c|}
\hline & & FIM & FIM90 & ECU90 & $\%$ vom BIP & \\
\hline \multirow[t]{2}{*}{ aus Zinsänderungen } & d Zinseinnahmen & $-2,2 E+9$ & $-1,9 E+9$ & $-394,7 \mathrm{E}+6$ & $-0,35 \%$ & \\
\hline & d Zinsausgaben & $-4,4 E+9$ & $-3,9 E+9$ & $-794,4 E+6$ & $-0,70 \%$ & \\
\hline aus $d \mathrm{mrs}$ und $\mathrm{d} P \mathrm{PI}$ & d potentielle Zinseinnahmer & $-108,3 E+6$ & $-95,8 E+6$ & $-19,7 E+6$ & $-0,02 \%$ & \\
\hline \multirow[t]{2}{*}{ Konvergenzefiekt } & & $2,1 E+9$ & $1,8 \mathrm{E}+9$ & $\begin{array}{r}380,0 \mathrm{E}+6 \\
1997\end{array}$ & $0,34 \%$ & \\
\hline & fiskalischer Seigniorage ohne Kosten 1997 & $1,5 E+9$ & $1,4 E+9$ & $\begin{array}{r}1997 \\
279,3 E+6\end{array}$ & $0,25 \%$ & $\begin{array}{r}1992 \\
179,1 E+6\end{array}$ \\
\hline \multicolumn{2}{|c|}{ Zinseffekt } & $-2,2 E+9$ & $-1,9 E+9$ & $-399,8 E+6$ & $-0,35 \%$ & \\
\hline \multicolumn{2}{|l|}{ Mindestreserve-effekt } & $108,3 E+6$ & $95,8 E+6$ & $19,7 E+6$ & $0,02 \%$ & \\
\hline \multicolumn{2}{|l|}{ für graphik } & $-108,3 E+6$ & $-95,8 E+6$ & $-100,7 E+6$ & $-174,0 E-6$ & \\
\hline
\end{tabular}

Deflator97 106,862923

Inflation zu volatil, um zu berücksichtigen 


\section{Frankreich}

Income from foreign currency investments Expenses on foreign exchange transactior Zinsertrage aus Krediten an inl. GB

Wahrungsreserven

Zinseinnahmen Zinsausgaben

come arising on bank refinancing transactions

\begin{tabular}{|c|c|c|c|c|c|c|c|c|c|}
\hline \multicolumn{3}{|c|}{ Zinseinnahmen } & \multicolumn{3}{|c|}{ Zinsausgaben } & & \multicolumn{3}{|c|}{-1994: income fom money marke } \\
\hline & FRF & FRF9O & ECU9O & FRF & FRF90 & ECU9O & FRF & FRF90 & ECU9O \\
\hline 1997 & $8,6 E+9$ & $7,6 E+9$ & $1,1 E+9$ & $413,7 E+6$ & $363,5 E+6$ & $52,6 E+6$ & $4,1 E+9$ & $3,6 E+9$ & $520,7 E+6$ \\
\hline 1996 & $6,7 E+9$ & $6,0 E+9$ & $864,1 E+6$ & $1,1 E+9$ & $1,0 E+9$ & $146,2 E+6$ & $4,7 E+9$ & $4,2 E+9$ & $604,0 E+6$ \\
\hline 1995 & $8,0 E+9$ & $7,2 E+9$ & $1,0 E+9$ & $2,3 E+9$ & $2,1 E+9$ & $301,7 E+6$ & $6,8 E+9$ & $6,1 E+9$ & $878,0 E+6$ \\
\hline 1994 & $6,3 E+9$ & $5,7 E+9$ & $824,2 E+6$ & $4,1 E+9$ & $3,8 E+9$ & $543,5 E+6$ & $8,8 E+9$ & $8,0 E+9$ & $1,2 E+9$ \\
\hline 1993 & $5,3 E+9$ & $4,9 E+9$ & $703,2 E+6$ & $376,0 E+6$ & $347,8 E+6$ & $50,3 E+6$ & $18,6 E+9$ & $17,2 E+9$ & $2,5 E+9$ \\
\hline 1992 & $7,3 E+9$ & $7,0 E+9$ & $1,0 E+9$ & $657,0 E+6$ & $622,7 E+6$ & $90,1 E+6$ & $13,4 E+9$ & $12,7 E+9$ & $1,8 E+9$ \\
\hline
\end{tabular}

Zinsaufwand

Expenses arising on bank refinancing transactions -1994 :money market intervention expenses

FRF

$$
\text { FRF90 ECU9O }
$$

$394,0 E+6 \quad 346,2 E+6 \quad 50,1 E+6$

$77,0 \mathrm{E}+6 \quad 68,3 \mathrm{E}+6 \quad 9,9 \mathrm{E}+6$
$722,5 \mathrm{E}+6$

$722,5 \mathrm{E}+6 \quad 648,0 \mathrm{E}+6 \quad 93,7 \mathrm{E}+6$

$297,0 \mathrm{E}+6 \quad 270,5 \mathrm{E}+6 \quad 39,1 \mathrm{E}+6$

$951,0 E+6 \quad 879,7 E+6 \quad 127,2 E+6$

$$
\begin{array}{rrr}
1,3 E+9 & 1,3 E+9 \quad 183,4 E+6
\end{array}
$$

Kosten

sonst. VwKos Schlüssel FRF FRF90 ECU90

$\begin{array}{rllll}10,9 E+9 & 36,01 \% & 3,9 E+9 & 3,5 E+9 & 499,5 E+6 \\ 10,6 E+9 & 40,58 \% & 4,3 E+9 & 3,8 E+9 & 552,1 E+6 \\ 11,0 E+9 & 39,60 \% & 4,3 E+9 & 3,9 E+9 & 563,1 E+6 \\ 9,3 E+9 & 32,04 \% & 3,0 E+9 & 2,7 E+9 & 391,9 E+6 \\ 8,9 E+9 & 29,66 \% & 2,7 E+9 & 2,5 E+9 & 354,6 E+6 \\ 8,6 E+9 & 25,64 \% & 2,2 E+9 & 2,1 E+9 & 302,9 E+6 \\ 8,2 E+9 & 32,25 \% & 2,6 E+9 & 2,6 E+9 & 369,9 E+6\end{array}$

Gewinne aus Geldschopfung

\begin{tabular}{|c|c|c|c|}
\hline FRF & & ECU9O & in $\%$ vom BIP \\
\hline $8,0 E+9$ & $7,0 \mathrm{E}+9$ & $1,0 E+9$ & $0,0983 \%$ \\
\hline $5,9 E+9$ & $5,3 E+9$ & $760,0 E+6$ & $0,0753 \%$ \\
\hline $7,4 E+9$ & $6,7 E+9$ & $962,8 E+6$ & $0,0968^{\circ}$ \\
\hline $7,7 E+9$ & $7,0 E+9$ & $1,0 E+9$ & $0,1039^{\circ}$ \\
\hline 19,9 & $18,4 E+9$ & $2,7 E+9$ & $0,2804 \%$ \\
\hline $16,5 E+9$ & $15,7 E+9$ & $2,3 E+9$ & 0,236 \\
\hline
\end{tabular}

fiskalischer Seigniorage

fiskalischer Seigniorage ohne Kosten

$$
\text { FRF }
$$
FRF90

$$
\text { ECU90 }
$$

$11,9 E+9$

$10,2 E+9$

$10,5 \mathrm{E}+9$

$9,1 \mathrm{E}+9$

$10,6 E+9$

$9,7 E+9$

$10,7 E+9$

$22,5 E+9$

$20,8 E+9$

$17,8 E+9$ in $\%$ vom BIP

$0,1466 \%$

$1,3 E+9 \quad 0,1300 \%$

$1,5 E+9 \quad 0,1535 \%$

$1,4 E+9-0,1441 \%$

\begin{tabular}{|c|c|c|c|}
\hline FRF & FRF90 & ECU9O & in $\%$ vom BIP \\
\hline $3,3 E+9$ & $2,9 E+9$ & $418,0 E+6$ & $0,0405 \%$ \\
\hline $3,5 E+9$ & $3,1 E+9$ & $444,0 E+6$ & $0,0430 \%$ \\
\hline $3,7 E+9$ & $3,3 E+9$ & $472,8 E+6$ & $0,0458 \%$ \\
\hline $4,4 E+9$ & $3,9 E+9$ & $558,8 E+6$ & $0,0541 \%$ \\
\hline $17,2 E+9$ & $15,2 E+9$ & $2,2 E+9$ & $0,2122 \%$ \\
\hline $11,4 E+9$ & $10,0 E+9$ & $1,5 E+9$ & $0,1404 \%$ \\
\hline
\end{tabular}

$3,0 E+9 \quad 0,3179 \%$

$2,6 E+9 \quad 0,2678 \%$

fiskalischer Seigniorage ohne Kosten und Wahrungsreserven 
Operationen

Outright purct Repurchase agreements

discount oper. Withdrawels from the marke Lending to Credit Institutions

repo tenders $5-10$ day repo other maturities

\begin{tabular}{rrrr}
1997 & $15,8 E+9$ & $84,7 E+9$ & 000,0 \\
1996 & $21,7 E+9$ & $84,4 E+9$ & $000,0 E$ \\
1995 & $22,6 E+9$ & $91,2 E+9$ & 1,9 \\
1994 & $26,9 E+9$ & $121,4 E+9$ & $000,0 E$ \\
1993 & $28,6 E+9$ & $160,3 E+9$ & 10,61 \\
1992 & $30,6 E+9$ & $72,2 E+9$ & $21,8 E$ \\
\multicolumn{4}{c}{ Zinsen } \\
\multicolumn{4}{c}{ REPO Satz $5-10$ day REPO Satz } \\
1997 & $3,15 \%$ & $4,60 \%$ \\
1996 & $3,60 \%$ & $4,78 \%$ \\
1995 & $4,96 \%$ & $6,89 \%$ \\
1994 & $5,28 \%$ & $6,62 \%$ \\
1993 & $7,63 \%$ & $8,88 \%$ \\
1992 & $9,53 \%$ & $10,69 \%$
\end{tabular}

Schätzung

Einnahmen

$\begin{array}{rrrr}000,0 E+0 & 24,8 E+9 & 0 & 3,7 E+9 \\ 000,0 E+0 & 15,9 E+9 & 0 & 1,9 E+9 \\ 1,9 E+9 & 11,0 E+9 & 400,0 E+6 & 9,8 E+9 \\ 000,0 E+0 & 6,9 E+9 & 800,0 E+6 & 3,7 E+9 \\ 10,6 E+9 & 32,2 E+9 & 1,8 E+9 & 7,4 E+9 \\ 21,8 E+9 & 4,7 E+9 & 3,5 E+9 & 6,2 E+9\end{array}$

Lending to $\mathrm{Cr}$, securities puri Liquidity withdrawals

$\begin{array}{rrr}125,5 E+9 & 17,4 E+9 & 12,7 E+9 \\ 142,5 E+9 & 21,1 E+9 & 24,0 E+9 \\ 147,2 E+9 & 19,5 E+9 & 19,4 E+9 \\ 230,2 E+9 & & 805,0 E+6 \\ 394,8 E+9 & & 2,4 E+9\end{array}$

Ausgaben summe Einna Schătzung Bestände

Outright purct repo tenders 5-10 day repo other maturitic discount oper. Withdrawels from the marke Einnahmen Ausgaben

\begin{tabular}{|c|c|c|c|c|c|c|c|c|c|}
\hline 1997 & $497,0 \mathrm{E}+6$ & $2,7 E+9$ & $000,0 E+0$ & $780,2 E+6$ & $000,0 E+0$ & $116,4 E+6$ & $3,9 E+9$ & $4,5 E+9$ & $399,6 \mathrm{E}+6$ \\
\hline 199 & $781,2 E+6$ & $3,0 E+9$ & $000,0 E+0$ & $572,4 E+6$ & $000,0 E+0$ & $68,4 E+6$ & $4,4 E+9$ & $5,9 E+9$ & $864,1 E+6$ \\
\hline ( & $1,1 E+9$ & $4,5 E+9$ & $130,9 E+6$ & $546,0 E+6$ & $19,9 E+6$ & $486,4 E+6$ & $6,3 E+9$ & $8,3 E+9$ & $964,3 E+6$ \\
\hline & $1,4 E+9$ & $6,4 E+9$ & $000,0 E+0$ & $364,0 E+6$ & $42,2 E+6$ & $195,2 E+6$ & $8,2 E+9$ & $12,1 E+9$ & $42,5 E+6$ \\
\hline & $2,2 E+9$ & $12,2 E+9$ & $941,3 E+6$ & $2,5 E+9$ & $137,3 E+6$ & $564,3 E+6$ & $17,9 E+9$ & $30,1 E+9$ & $179,3 E+6$ \\
\hline & $2,9 E+9$ & $6.9 E+9$ & $2,3 E+9$ & $447,8 E+6$ & $333,4 E+6$ & $590,7 E+6$ & $12,9 E+9$ & $31.0 E+9$ & $4423 E+6$ \\
\hline
\end{tabular}

Mindestreser Mindestreservesătze

Mindestresen mrs Sichteinle mrs Spareinla mrs kurzfr. Eir mittelfr. Einlagen (1 - 2 Jahre)

$\begin{array}{llllll}1997 & 20,2 \mathrm{E}+9 & 1,00 \% & 1,00 \% & 0,50 \% & 0,00 \% \\ 1996 & 20,1 \mathrm{E}+9 & 1,00 \% & 1,00 \% & 0,50 \% & 0,00 \% \\ 1995 & 19,1 \mathrm{E}+9 & 1,00 \% & 1,00 \% & 0,50 \% & 0,00 \% \\ 1994 & 18,7 \mathrm{E}+9 & 1,00 \% & 1,00 \% & 0,50 \% & 0,00 \% \\ 1993 & 18,6 \mathrm{E}+9 & 1,00 \% & 1,00 \% & 0,50 \% & 0,00 \% \\ 1992 & 47,4 \mathrm{E}+9 & 2,16 \% & 3,38 \% & 0,50 \% & 0,00 \%\end{array}$




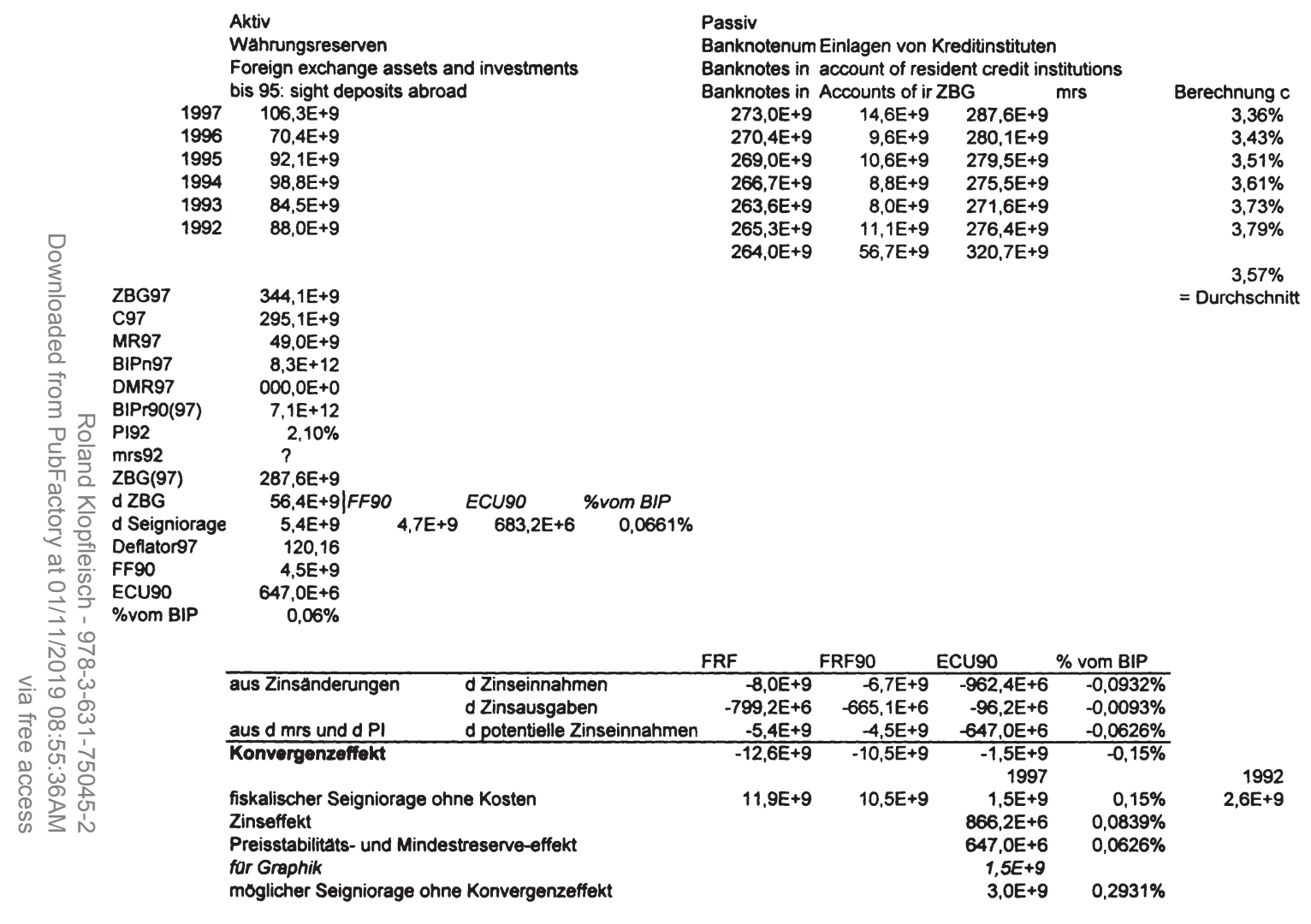


Wahrungsreserven

Zinseinnahmen

90

$246,3 E+6$

$307,8 \mathrm{E}+6$

$215,6 E+6$

$219,5 E+6$

$278,6 \mathrm{E}+6$

$192,8 \mathrm{E}+6$

$1993229,7 \mathrm{E}+6 \quad 212,7 \mathrm{E}+6$

1992

$212,7 E+6$
$199,3 E+6$

CU9O

$280,8 E+6$

$285,9 \mathrm{E}+6$

$362,9 E+6$

$251,1 E+6$

$277,0 \mathrm{E}+6$

$259,6 \mathrm{E}+6$

Zinsertrage aus Krediten an ini. GB und Staat

Zinsaufwand nicht for Seigniorage

an Staat, GB und andere

Interest on deposits

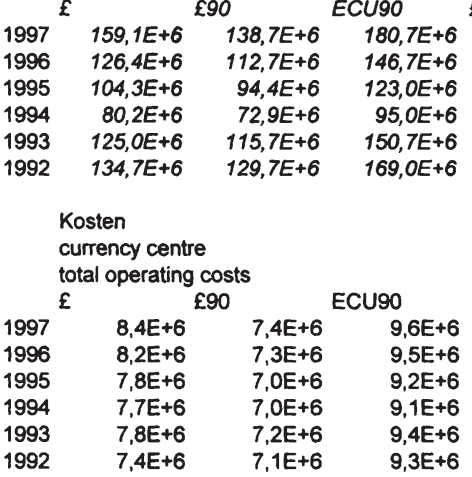

fiskalischer Seigniorage ohne Kosten

\begin{tabular}{|c|c|c|c|c|}
\hline \& & \multicolumn{2}{|c|}{$£ 90$} & ECU9O & in $\%$ vom BIP \\
\hline 397 & $236,6 E+6$ & $206,3 E+6$ & $268,6 E+6$ & $0,46 \%$ \\
\hline 96 & $227,0 E+6$ & $202,3 E+6$ & $263,5 E+6$ & $0,50 \%$ \\
\hline & $278,8 E+6$ & $252,3 E+6$ & $328,6 E+6$ & $0,69 \%$ \\
\hline & $207,6 E+6$ & $188,7 E+6$ & $245,8 E+6$ & $0,57 \%$ \\
\hline & $278,4 E+6$ & $257,8 E+6$ & $335,8 E+6$ & $0,84 \%$ \\
\hline 92 & $331,6 E+6$ & $319,5 E+6$ & $416,1 \mathrm{E}+6$ & $1,08 \%$ \\
\hline
\end{tabular}

Gewinne aus Geldschopfung

fiskalischer Seigniorage

ECU9O

$51,4 E+6 \quad 44,8 E+6 \quad 58,3 E+6$

$23,5 E+6 \quad 20,9 E+6 \quad 27,3 E+6$

$15,2 \mathrm{E}+6 \quad 19,9 \mathrm{E}+6$

$81,4 E+6$

$165,4 E+6 \quad 159,3 E+6 \quad 207,5 E+6$

Zinsaufwand Staat

Zinsaufwand

ohne Staat

$\begin{array}{rrrrrr}97,0 E+6 & 84,6 E+6 & 110,1 E+6 & 62,1 E+6 & 54,2 E+6 & 70,5 E+6 \\ 83,6 E+6 & 74,5 E+6 & 97,0 E+6 & 42,8 E+6 & 38,1 E+6 & 49,7 E+6 \\ 58,4 E+6 & 52,9 E+6 & 68,8 E+6 & 45,9 E+6 & 41,6 E+6 & 54,1 E+6 \\ 55,0 E+6 & 50,0 E+6 & 65,1 E+6 & 25,2 E+6 & 22,9 E+6 & 29,8 E+6 \\ 92,3 E+6 & 85,5 E+6 & 111,3 E+6 & 32,6 E+6 & 30,2 E+6 & 39,4 E+6 \\ 94,1 E+6 & 90,6 E+6 & 118,0 E+6 & 40,6 E+6 & 39,1 E+6 & 50,9 E+6\end{array}$

\begin{tabular}{|c|c|c|c|}
\hline \multicolumn{2}{|c|}{$£ 90$} & ECU9O & in \% vom BIP \\
\hline $228,1 E+6$ & $198,9 E+6$ & $259,1 \mathrm{E}+6$ & $0,45 \%$ \\
\hline $218,8 E+6$ & $195,0 E+6$ & $253,9 E+6$ & $0,49 \%$ \\
\hline $271,0 \mathrm{E}+6$ & $245,2 E+6$ & $319,4 E+6$ & 0,67 \\
\hline $199,9 E+6$ & $181,7 E+6$ & $236,7 E+6$ & 0,55 \\
\hline $270,6 E+6$ & $250,6 E+6$ & $326,4 E+6$ & 0,82 \\
\hline $324,2 E+6$ & $312,4 E+6$ & $406,8 E+6$ & 1,06 \\
\hline
\end{tabular}

fiskalischer Seigniorage ohne Kosten und Wăhrungsresreevn

$£ \quad £ 90 \quad$ ECU 90 in \% vom BIP

$-10,7 E+6 \quad-9,4 E+6 \quad-12,2 E+6 \quad-0,02 \%$

$-19,3 E+6 \quad-17,2 E+6 \quad-22,4 E+6 \quad-0,04 \%$

$-29,1 E+6 \quad-26,3 E+6 \quad-34,3 E+6 \quad-0,06 \%$

$-4,5 E+6 \quad-4,1 E+6 \quad-5,3 E+6 \quad-0,01 \%$

$48,7 \mathrm{E}+6 \quad 45,1 \mathrm{E}+6 \quad 58,8 \mathrm{E}+6 \quad 0,11 \%$

$124,8 E+6 \quad 120,2 E+6 \quad 156,6 E+6 \quad 0,28 \%$ 
Bilanz

Aktiv

Domestic sec Advances Cheques in th Deposits and Securities

Passiv

credit institutic davon

Government [ Legal Tender

$\begin{array}{rrrrr}1997 & 131,7 E+6 & 1,6 E+9 & 3,9 E+6 & 3,6 E+9 \\ 1996 & 131,7 E+6 & 261,1 E+6 & 4,8 E+6 & 4,2 E+9 \\ 1995 & 182,6 E+6 & 37,2 E+6 & 7,1 E+6 & 4,7 E+9 \\ 1994 & 252,9 E+6 & 285,8 E+6 & 41,9 E+6 & 3,4 E+9 \\ 1993 & 315,1 E+6 & 597,7 E+6 & 7,5 E+6 & 3,6 E+9 \\ 1992 & 361,3 E+6 & 2,1 E+9 & 38,6 E+6 & 1,7 E+9\end{array}$

\begin{tabular}{rr}
\multicolumn{2}{c}{ Primary Liquic } \\
$1,3 E+9$ & $748,0 E+6$ \\
$981,5 E+6$ & $786,8 E+6$ \\
$1,1 E+9$ & $663,5 E+6$ \\
$567,5 E+6$ & $452,4 E+6$ \\
$567,7 E+6$ & $433,5 E+6$ \\
$457,3 E+6$ & $355,0 E+6$ \\
\multicolumn{2}{c}{} \\
\multicolumn{3}{c}{ tats.o.Staat } \\
sgaben & $62,1 E+6$ \\
$43,4 E+6$ & $42,8 E+6$ \\
$31,9 E+6$ & $45,9 E+6$ \\
$40,7 E+6$ & \\
$18,0 E+6$ & $25,2 E+6$ \\
$32,6 E+6$ & \\
$40,6 E+6$ &
\end{tabular}

Mindestreserve

DMB

MR (GB) Demand Depr Time Deposit: MRV

mrs

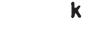

$45,88 \%$

$4,75 \%$

(

$1996859,3 E+6$

$3,6 \mathrm{E}+9$

$17,1 E+9$

20,7E+9

$726,3 E+6$

(

$15,0 E+9$

$4,16 \%$

$45,88 \%$

$4,68 \%$

$1994 \quad 494,9 E+6$

$2,5 E+9 \quad 13,1 E+9$

$4,06 \%$

$44,46 \%$

$4,79 \%$

$1993470,5 E+6$

$2,2 E+9$

$12,9 E+9$

$15,0 E+9$

$3,17 \%$

$43,14 \%$

$4.85 \%$

$1992385,8 E+6$

$1,7 E+9$

$10,9 E+9$

$12,6 E+9$

$3,06 \%$

$41,03 \%$

$43,98 \%-\quad 4,75 \%$

$\begin{array}{lrl}\text { Deposit Protection Account } & \\ 85,7 \mathrm{E}+6 & 1,2 \mathrm{E}+9 & 2,4 \mathrm{E}+9 \\ 72,4 \mathrm{E}+6 & 1,2 \mathrm{E}+9 & 2,1 \mathrm{E}+9 \\ 62,8 \mathrm{E}+6 & 1,1 \mathrm{E}+9 & 1,9 \mathrm{E}+9 \\ 42,5 \mathrm{E}+6 & 835,2 \mathrm{E}+6 & 1,8 \mathrm{E}+9 \\ 37,0 \mathrm{E}+6 & 1,4 \mathrm{E}+9 & 1,6 \mathrm{E}+9 \\ 30,8 \mathrm{E}+6 & 635,3 \mathrm{E}+6 & 1,5 \mathrm{E}+9\end{array}$




\begin{tabular}{l|r} 
ZBG97 & $3,1 E+9$ \\
\hline C97 & $2,4 E+9$ \\
\hline MR97 & $687,0 E+6$ \\
\hline BIPn97 & $51,0 E+9$ \\
\hline MRV97 & $22,4 E+9$ \\
\hline BIPr90(97) & $44,4 E+9$ \\
\hline PI92 & $2,00 \%$ \\
\hline mrs92 & $3,06 \%$ \\
\hline ZBG(97) & $3,3 E+9$ \\
\hline dZBG & $-122,5 E+6$ \\
\hline d Seigniorag & $-8,2 E+6$ \\
\hline Deflator97 & 114,60 \\
\hline IP90 & $-7,1 E+6$ \\
\hline ECU90 & $-9,3 E+6$ \\
\hline \%vom BIP & $-0,02 \%$
\end{tabular}

\begin{tabular}{llrrrrr} 
& & \multicolumn{2}{c}{ IP9 } & \multicolumn{2}{c}{ ECU90 } & \multicolumn{1}{c}{$\%$ vom BIP } \\
\hline aus Zinsănderungen & potentielle Zinseinnahmen & $-42,1 \mathrm{E}+6$ & $-36,7 \mathrm{E}+6$ & $-47,8 \mathrm{E}+6$ & $-0,08 \%$ \\
& potentielle Zinsausgaben & $-99,2 \mathrm{E}+6$ & $-86,6 \mathrm{E}+6$ & $-112,8 \mathrm{E}+6$ & $-0,20 \%$ & \\
aus d mrs und d PI & d potentielle Zinseinnahmen & $-8,2 \mathrm{E}+6$ & $-7,1 \mathrm{E}+6$ & $-9,3 \mathrm{E}+6$ & $-0,02 \%$ & \\
\hline Konvergenzeffiekt & & $49,0 \mathrm{E}+6$ & $42,8 \mathrm{E}+6$ & $55,7 \mathrm{E}+6$ & $0,10 \%$ & \\
& & & 1997 & & 1992 \\
Seigniorage ohne Kosten & $236,6 \mathrm{E}+6$ & $206,3 \mathrm{E}+6$ & $268,6 \mathrm{E}+6$ & $4,6 \mathrm{E}-3$ & $416,1 \mathrm{E}+6$ \\
Zinseffekt & $-57,2 \mathrm{E}+6$ & $-49,9 \mathrm{E}+6$ & $-65,0 \mathrm{E}+6$ & $-0,11 \%$ & \\
Preisstabilităts- und Mindestreserve-effekt & $8,2 \mathrm{E}+6$ & $7,1 \mathrm{E}+6$ & $9,3 \mathrm{E}+6$ & $0,02 \%$ &
\end{tabular}




\section{Italien}

Zinsertrăge aus Krediten an inl. GB

interest received on discounts and advanci Interest received+interest, premiums and dividents on securities

Diskont Lombard Offenmarkt

bill portfolio advances Interest freely ITL

\begin{tabular}{|c|c|c|c|c|c|c|}
\hline \multicolumn{2}{|r|}{ } & 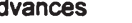 & \multicolumn{2}{|l|}{ Int } & -90 & EC \\
\hline 1997 & $11,4 E+9$ & $192,8 E+9$ & $8,1 E+12$ & $8,3 E+12$ & $6,0 E+12$ & $4,0 E+9$ \\
\hline & $14,9 E+9$ & $170,7 E+9$ & $12,0 E+12$ & $12,2 E+12$ & $9,1 E+12$ & $6,0 E+9$ \\
\hline & $16,1 E+9$ & $348,8 E+9$ & $12,9 E+12$ & $13,3 E+12$ & $10,4 E+12$ & $6,8 E+9$ \\
\hline & $14,2 E+9$ & $155,6 E+9$ & $11,5 E+12$ & $11,6 E+12$ & +12 & $6,3 E+9$ \\
\hline & $45,6 E+9$ & $175,0 E+9$ & $12,6 E+12$ & $12,9 E+12$ & $10,9 E+12$ & $7,2 E+9$ \\
\hline & $28,5 E+9$ & $950,1 E+9$ & $12,5 E+12$ & $13,5 E+12$ & $11,9 E+12$ & $7,8 E+9$ \\
\hline
\end{tabular}

\section{Zinsaufwand}

Interest paid

on bank's con on treasury ac financial costs Summe

$\begin{array}{lrrrrrr}1997 & 3,9 E+12 & 3,5 E+12 & 66,8 E+9 & 7,5 E+12 & 5,5 E+12 & 3,6 E+9 \\ 1996 & 3,8 E+12 & 4,9 E+12 & 247,1 E+9 & 9,0 E+12 & 6,7 E+12 & 4,4 E+9 \\ 1995 & 4,6 E+12 & 6,0 E+12 & 169,6 E+9 & 10,7 E+12 & 8,4 E+12 & 5,5 E+9 \\ 1994 & 5,8 E+12 & 4,1 E+12 & 67,1 E+9 & 10,0 E+12 & 8,2 E+12 & 5,4 E+9 \\ 1993 & 6,5 E+12 & 1,1 E+12 & & 7,6 E+12 & 6,5 E+12 & 4,3 E+9 \\ 1992 & 8,1 E+12 & 883,6 E+9 & & 9,0 E+12 & 8,0 E+12 & 5,2 E+9\end{array}$

Kosten

sonst. VwKos Schlussel ITL ITL90 ECU90

$\begin{array}{rrrrrr}1997 & 2,7 \mathrm{E}+12 & 58,24 \% & 1,6 \mathrm{E}+12 & 1,2 \mathrm{E}+12 & 755,8 \mathrm{E}+6 \\ 1996 & 2,5 \mathrm{E}+12 & 55,28 \% & 1,4 \mathrm{E}+12 & 1,0 \mathrm{E}+12 & 670,7 \mathrm{E}+6 \\ 1995 & 2,3 \mathrm{E}+12 & 58,37 \% & 1,3 \mathrm{E}+12 & 1,0 \mathrm{E}+12 & 689,1 \mathrm{E}+6 \\ 1994 & 2,4 \mathrm{E}+12 & 60,31 \% & 1,4 \mathrm{E}+12 & 1,2 \mathrm{E}+12 & 767,7 \mathrm{E}+6 \\ 1993 & 2,2 \mathrm{E}+12 & 51,74 \% & 1,2 \mathrm{E}+12 & 984,1 \mathrm{E}+9 & 646,6 \mathrm{E}+6 \\ 1992 & 2,0 \mathrm{E}+12 & 57,19 \% & 1,2 \mathrm{E}+12 & 1,0 \mathrm{E}+12 & 675,9 \mathrm{E}+6\end{array}$


Währungsreserven

\section{Zinsein-nahmen}

\begin{tabular}{|c|c|c|}
\hline ITL & & SU90 \\
\hline $2,9 E+12$ & $2,1 E+12$ & $1,4 E+9$ \\
\hline $2,6 E+12$ & $2,0 E+12$ & $1,3 E+9$ \\
\hline $2,5 E+12$ & $1,9 E+12$ & $1,3 E+9$ \\
\hline $1,5 E+12$ & $1,2 E+12$ & $815,3 E+6$ \\
\hline $2,0 E+12$ & $1,7 E+12$ & $1,1 E+9$ \\
\hline $3,2 E+12$ & $2,9 E+12$ & $1,9 \mathrm{E}+9$ \\
\hline
\end{tabular}

Gewinne aus Geldschöpfung

vereinfachter fiskalischer Seigniorage

ITL

$2,1 E+12$
$4,4 E+12$
$3,7 E+12$
$1,7 E+12$
$6,1 E+12$
$6,5 E+12$

ITL90

$1,5 \mathrm{E}+12$
$3,3 \mathrm{E}+12$
$2,9 \mathrm{E}+12$
$1,4 \mathrm{E}+12$
$5,2 \mathrm{E}+12$
$5,8 \mathrm{E}+12$

CU90

$999,3 E+6$

$2,2 \mathrm{E}+9$

$1,9 \mathrm{E}+9$

$928,3 E+6$

$3,4 \mathrm{E}+9$

1993

1992

$5,8 E+12$

$3,8 E+9$ in \% vom BIP

$0,11 \%$

$0,24 \%$

$0,21 \%$

$0,10 \%$

$0,40 \%$

$0,43 \%$
Gewinne aus Geldschopfung

fiskalischer Seigniorage ohne Kosten

ITL

$3,7 \mathrm{E}+12$
$5,8 \mathrm{E}+12$
$5,1 \mathrm{E}+12$
$3,1 \mathrm{E}+12$
$7,3 \mathrm{E}+12$
$7,7 \mathrm{E}+12$

$2,7 E+12$

$4,3 E+12$

ECU90

$2,8 \mathrm{E}+9$

in \% vom BIP

$2,6 \mathrm{E}+12$

$2,6 E+9$

$0,29 \%$

$7,7 E+12$

$6,2 \mathrm{E}+12$

$4,1 E+9$

$0,47 \%$

Zinsen

\section{Offenmarkt}

securities repos

purchases sales

Diskont

Lombard ordinary bills aricultuntin! advan average average

1997
1996
1995
1994
1993
1992

average

$\begin{array}{rr}6,96 \% & 6,24 \% \\ 9,12 \% & 8,60 \% \\ 10,12 \%- & \\ 8,25 \%- & \\ 10,14 \%- & \\ 13,60 \% \text { - } & \end{array}$

$8,50 \% \quad 5,50 \%$

$8,59 \% \quad 5,50 \%$

$7,44 \% \quad 5,50 \%$

$9,83 \% \quad 5,75 \%$

$12,93 \% \quad 6,00 \%$
$6,56 \% \quad 5,13 \%$
$4,5 E+9$

$0,51 \%$
$10,22 \%$

$\mathbf{7 , 4 4 \%} \quad \mathbf{8 , 4 4 \%}$

$10,88 \%$

$13,84 \%$ 
Mindestreserve DMB

Resreve depo Demand Depc Time, Savings DMR

\begin{tabular}{|c|c|c|c|c|c|c|c|}
\hline 1997 & $78,6 E+12$ & $531,7 E+12$ & $359,5 E+12$ & $891,2 E+12$ & $8,82 \%$ & $45,68 \%$ & $5,85 \%$ \\
\hline 1996 & $72,6 E+12$ & $499,0 E+12$ & $468,8 E+12$ & $967,8 \mathrm{E}+12$ & $7,50 \%$ & $51,68 \%$ & $5,67 \%$ \\
\hline 1995 & $72,1 E+12$ & $471,1 E+12$ & $476,5 E+12$ & $947,6 E+12$ & $7,61 \%$ & $53,45 \%$ & $5,82 \%$ \\
\hline 1994 & $87,4 E+12$ & $471,4 E+12$ & $458,9 E+12$ & $930,3 E+12$ & $9,40 \%$ & $56,79 \%$ & $6,11 \%$ \\
\hline 1993 & $103,9 \mathrm{E}+12$ & $454,9 E+12$ & $469,9 E+12$ & $924,8 E+12$ & $11,24 \%$ & $59,63 \%$ & $6,03 \%$ \\
\hline 1992 & $127,6 E+12$ & $426,2 E+12$ & $430,9 E+12$ & $857,1 E+12$ & $14,89 \%$ & $\frac{57,05 \%}{55,72 \%}$ & $\frac{5,94 \%}{5,91 \%}$ \\
\hline
\end{tabular}

\begin{tabular}{|c|c|c|c|}
\hline \multicolumn{4}{|c|}{ tatsächlich97 tatsăchlich92 } \\
\hline $115,5 E+12$ & $114,1 E+12$ & & \\
\hline $162,0 E+12$ & $78,6 E+12$ & $83,4 E+12$ & \\
\hline $2,0 E+15$ & $1,9512 \mathrm{E}+15$ & & \\
\hline $1,1 E+15$ & & & \\
\hline $1,4 E+15$ & & & \\
\hline $\begin{array}{r}4,70 \% \\
14,89 \%\end{array}$ & $2,68 \%$ & & \\
\hline $192,7 E+12$ & & $216,8 E+12$ & \\
\hline $84,8 E+12$ & ITL9O & ECU9O & \%vom BIP \\
\hline $11,5 E+12$ & $8,4 E+12$ & $5,5 E+9$ & $0,59 \%$ \\
\hline 141,79 & & & \\
\hline $8,1 E+12$ & & & \\
\hline $5,3 E+9$ & & & \\
\hline $0,57 \%$ & & & \\
\hline
\end{tabular}


Liquiditătsabsc Mindestreserve (verzinst)

liabilities arisin Resreve depo Treasury payr Verzinsung MR

$4,78933 E+12$

$598,1 E+9$

$78,6 \mathrm{E}+12$

$72,6 \mathrm{E}+12$

$1,2 \mathrm{E}+12$

$875,3 E+9$

$\begin{array}{ll}53,5 E+12 & 5,00 \% \\ 54,8 E+12 & 5,50 \% \\ 63,1 E+12 & 5,50 \% \\ 58,0 E+12 & 5,50 \% \\ 30,7 E+12 & 5,50 \% \\ & 5,50 \%\end{array}$

Zinseinnahmen

GuV

$14,8 E+12 \quad 8,3 E+12$

$19,8 E+12 \quad 12,2 E+12$

$24,2 E+12 \quad 13,3 E+12$

$19,9 E+12 \quad 11,6 E+12$

$14,5 E+12 \quad 12,9 E+12$
Zinsausgaben

\begin{tabular}{rr}
\multicolumn{2}{c}{ GuV } \\
$8,0 E+12$ & $7,5 E+12$ \\
$9,0 E+12$ & $9,0 E+12$ \\
$10,5 E+12$ & $10,7 E+12$ \\
$9,7 E+12$ & $10,0 E+12$ \\
$8,8 E+12$ & $7,6 E+12$ \\
$7,0 E+12$ & $9,0 E+12$
\end{tabular}

Aktivseite

Kredite an inl. GB

claims arising from securities repurchase a! offenmarkt

discounts and discounts advances securities

$\begin{array}{rrrr}208 E+12 & 259,2 E+9 & 21,3 E+12 & 153,4 E+12 \\ 217 E+12 & 234,2 E+9 & 943,9 E+9 & 167,1 E+12 \\ 240 E+12 & 213,4 E+9 & 7,3 E+12 & 195,0 E+12 \\ 242 E+12 & 182,4 E+9 & 2,5 E+12 & 194,2 E+12 \\ & 3,2 E+12 & 2,1 E+12 & 137,7 E+12 \\ 132 E+12 & 3,0 E+12 & 8,4 E+12 & 120,7 E+12\end{array}$

Währungsreserven

external assets in foreign currencies

claims arising current accou time deposits other
$33,7 \mathrm{E}+12$
$5,7 \mathrm{E}+12$
$1,0 E+12$
$13,9 \mathrm{E}+12$
$48,8 E+12$
$1,6 E+12$
$12,5 E+12$
$1,6 \mathrm{E}+12$
$1,2 \mathrm{~F}+12$
$9,3 E+12$
$44,6 E+12$
$3,4 E+12$
$297,7 \mathrm{E}+9$
$7,6 \mathrm{E}+12$
$3,1 \mathrm{E}+12$
$725,3 E+9$
$4,7 E+12$
$612,2 E+9$
$28,8 \mathrm{E}+12$
$917,4 \mathrm{E}+9$
$45,4 \mathrm{E}+12$
$6,9 \mathrm{E}+12$
$31,8 E+12 \quad 7,3 E+12$
$26,2 E+12 \quad 7,8 E+12$
$24,3 E+12 \quad 7,4 E+12$
$27,6 \mathrm{E}+12 \quad 6,9 \mathrm{E}+12$
$6,7 E+12 \quad 5,4 E+12$

Italien foreign exchange office (UIC) current accou special accounts

\begin{tabular}{ll} 
& \\
\hline aus Zinsänderungen & $\begin{array}{l}\text { potentielle Zinseinnahmen } \\
\text { potentielle Zinsausgaben }\end{array}$ \\
aus d mrs und d PI & $\begin{array}{l}\text { d potentielle Zinseinnahmen } \\
\text { aus Verzinsung der Mindestreserve }\end{array}$ \\
\hline Konvergenzeffekt &
\end{tabular}

Seigniorage ohne Kosten

Zinseffekt

Preisstabilităts- und Mindestreserve-effekt

Verzinsung der zusătzlichen Mindestreserve

ITL

ITL90

$-7,9 E+12$

$$
90
$$

$-11,5 E+12$

$-5,6 \mathrm{E}+12$

$-3,0 E+12$

$-8,1 \mathrm{E}+12$

$\frac{4,6 E+12}{10,6 E+12}$

$\frac{3,2 E+12}{-7,5 E+12}$

$-3,7 \mathrm{E}+$

$\%$ vom BIP

$-2,0 E+9 \quad-0,21 \%$

$-5,3 E+9 \quad-0,57 \%$

TE+12

$-4,9 E+9$

$0.23 \%$

$3,7 E+12$

2,7E+12

1997

$3,7 E+12$

$2,6 \mathrm{E}+12$

$1,8 E+9$

$1,7 \mathrm{E}+9$

$8,1 \mathrm{E}+12$

$5,3 E+9$

$-4,6 \mathrm{E}+12$

$-3,2 E+12$

$-2,1 E+9$
$0,19 \%$

$0,18 \%$

$0,57 \%$

$-0,23 \%$
1992

$4,5 E+9$ 


\section{Niederlande}

Zins-erträge aus Währungs-reserven Zinsertrăge aus Krediten an inl. GB Zinsaufwand

\begin{tabular}{rrrrrrrrrr} 
& HFL & \multicolumn{2}{c}{ HFL90 } & \multicolumn{2}{c}{ ECU90 } & \multicolumn{2}{c}{ HFL } & \multicolumn{1}{c}{ HFL90 } & \multicolumn{2}{c}{ ECU90 } & \multicolumn{1}{c}{ HFL } & HFL90 \\
1997 & $2,1 E+9$ & $1,8 E+9$ & $793,6 E+6$ & $227,0 E+6$ & $196,2 E+6$ & $84,9 E+6$ & $394,0 E+6$ & $340,5 E+6$ & $147,3 E+6$ \\
1996 & $2,2 E+9$ & $2,0 E+9$ & $845,1 E+6$ & $215,0 E+6$ & $189,9 E+6$ & $82,1 E+6$ & $608,0 E+6$ & $537,1 E+6$ & $232,3 E+6$ \\
1995 & $3,1 E+9$ & $2,8 E+9$ & $1,2 E+9$ & $309,0 E+6$ & $276,9 E+6$ & $119,8 E+6$ & $784,0 E+6$ & $702,5 E+6$ & $303,8 E+6$ \\
1994 & $2,2 E+9$ & $2,0 E+9$ & $848,8 E+6$ & $366,0 E+6$ & $333,9 E+6$ & $144,4 E+6$ & $1,1 E+9$ & $1,0 E+9$ & $451,4 E+6$ \\
1993 & $3,5 E+9$ & $3,2 E+9$ & $1,4 E+9$ & $598,0 E+6$ & $557,8 E+6$ & $241,3 E+6$ & $1,2 E+9$ & $1,1 E+9$ & $485,0 E+6$ \\
1992 & $1,9 E+9$ & $1,8 E+9$ & $769,4 E+6$ & $1,1 E+9$ & $1,0 E+9$ & $442,4 E+6$ & $1,0 E+9$ & $973,3 E+6$ & $421,0 E+6$
\end{tabular}

Kosten

Notendruck (t sonst. VwKos Schlüssel ant. VwKoster HFL

\begin{tabular}{crrrrrr}
\multicolumn{2}{c}{ tendruck (t sonst. VwKos Schlüssel } & ant. VwKoster HFL & \multicolumn{3}{c}{ HFL90 } & ECU90 \\
$30,0 \mathrm{E}+6$ & $340,0 \mathrm{E}+6$ & $39,90 \%$ & $135,7 \mathrm{E}+6$ & $165,7 \mathrm{E}+6$ & $143,2 \mathrm{E}+6$ & $61,9 \mathrm{E}+6$ \\
$44,0 \mathrm{E}+6$ & $312,0 \mathrm{E}+6$ & $36,86 \%$ & $115,0 \mathrm{E}+6$ & $159,0 \mathrm{E}+6$ & $140,5 \mathrm{E}+6$ & $60,7 \mathrm{E}+6$ \\
$40,0 \mathrm{E}+6$ & $320,0 \mathrm{E}+6$ & $35,12 \%$ & $112,4 \mathrm{E}+6$ & $152,4 \mathrm{E}+6$ & $136,5 \mathrm{E}+6$ & $59,1 \mathrm{E}+6$ \\
$49,0 \mathrm{E}+6$ & $307,0 \mathrm{E}+6$ & $36,65 \%$ & $112,5 \mathrm{E}+6$ & $161,5 \mathrm{E}+6$ & $147,4 \mathrm{E}+6$ & $63,7 \mathrm{E}+6$ \\
$50,0 \mathrm{E}+6$ & $289,0 \mathrm{E}+6$ & $33,50 \%$ & $96,8 \mathrm{E}+6$ & $146,8 \mathrm{E}+6$ & $137,0 \mathrm{E}+6$ & $59,2 \mathrm{E}+6$ \\
$45,0 \mathrm{E}+6$ & $270,0 \mathrm{E}+6$ & $37,24 \%$ & $100,5 \mathrm{E}+6$ & $145,5 \mathrm{E}+6$ & $138,6 \mathrm{E}+6$ & $60,0 \mathrm{E}+6$
\end{tabular}

fiskalischer Seigniorage

HFL HFL90

ECU90

fiskalischer Seigniorage ohne Kosten

\begin{tabular}{lrrrrrrrr} 
& \multicolumn{3}{c}{ HFL90 } & \multicolumn{2}{c}{ ECU90 } & \multicolumn{3}{c}{ in $\%$ vom BIP HFL } \\
1997 & $1,8 E+9$ & $1,5 E+9$ & $669,3 E+6$ & $0,25 \%$ & $2,0 E+9$ & $1,7 E+9$ & $731,2 E+6$ & $0,28 \%$ \\
1996 & $1,7 E+9$ & $1,5 E+9$ & $634,2 E+6$ & $0,25 \%$ & $1,8 E+9$ & $1,6 E+9$ & $695,0 E+6$ & $0,27 \%$ \\
1995 & $2,5 E+9$ & $2,2 E+9$ & $951,3 E+6$ & $0,38 \%$ & $2,6 E+9$ & $2,3 E+9$ & $1,0 E+9$ & $0,41 \%$ \\
1994 & $1,2 E+9$ & $1,1 E+9$ & $478,1 E+6$ & $0,20 \%$ & $1,4 E+9$ & $1,3 E+9$ & $541,8 E+6$ & $0,22 \%$ \\
1993 & $2,7 E+9$ & $2,5 E+9$ & $1,1 E+9$ & $0,47 \%$ & $2,9 E+9$ & $2,7 E+9$ & $1,2 E+9$ & $0,49 \%$ \\
1992 & $1,8 E+9$ & $1,7 E+9$ & $730,9 E+6$ & $0,31 \%$ & $1,9 E+9$ & $1,8 E+9$ & $790,9 E+6$ & $0,34 \%$
\end{tabular}

fiskalischer Seigniorage ohne Kosten und Wăhrungsreserven

HFL

$$
\text { HFL90 ECU9O }
$$

in \% vom BIP

$\begin{array}{lrrrr}1997 & -1,9 E+9 & -1,7 E+9 & -720,1 E+6 & -0,27 \% \\ 1996 & -1,8 E+9 & -1,6 E+9 & -686,6 E+6 & -0,27 \% \\ 1995 & -2,4 E+9 & -2,2 E+9 & -938,9 E+6 & -0,38 \% \\ 1994 & -1,1 E+9 & -985,6 E+6 & -426,3 E+6 & -0,18 \% \\ 1993 & -2,1 E+9 & -1,9 E+9 & -838,3 E+6 & -0,36 \% \\ 1992 & -141,8 E+6 & -135,1 E+6 & -58,4 E+6 & -0,03 \%\end{array}$


Zinssătze

AR

SPR

Diskontsatz fixed advance marginal adve Lombard rate Dutch rate for special loans

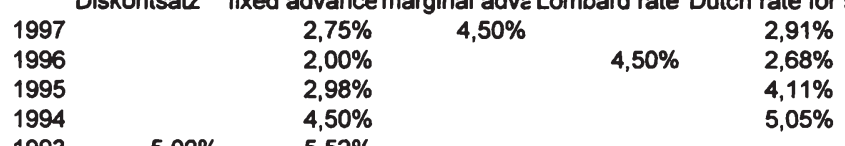

Quelle $\quad 1992$ IMF $\quad \begin{array}{lll}7,75 \% \text { IMF } & \mathbf{8 , 3 3 \%}\end{array}$

Aktiv GB

eurostat

\begin{tabular}{|c|c|c|c|c|c|c|c|c|c|}
\hline \multirow{2}{*}{\multicolumn{3}{|c|}{$\begin{array}{l}\text { Aktiv } \\
\text { VOORSCHOI vast } \\
\text { advances } \\
\text { current accou fixed }\end{array}$}} & \multirow{2}{*}{$\begin{array}{l}\text { marginaal } \\
\text { marginal }\end{array}$} & beleningen & Währungsres & $\begin{array}{l}\text { assiv } \\
\text { en } \\
\text { sreserver }\end{array}$ & tk & Bankcertific & iljetten in omloop \\
\hline & & & & loans & receivables a! & sh reserve & asury & Bank certifical & knotes in circulation \\
\hline 1997 & $000,0 \mathrm{E}+0$ & $4,0 E+9$ & $99,0 E+6$ & $7,2 E+9$ & $36,1 E+9$ & $6,1 E+9$ & $50,0 E+6$ & $6,9 E+9$ & $39,3 E+9$ \\
\hline 1996 & $2,8 E+9$ & $000,0 E+0$ & $000,0 E+0$ & $13,1 E+9$ & $34,3 E+9$ & $000,0 E+0$ & $14,4 E+9$ & $8,3 E+9$ & $39,0 E+9$ \\
\hline 1995 & $4,1 E+9$ & $000,0 E+0$ & $000,0 E+0$ & $5,7 E+9$ & $36,8 E+9$ & $000,0 \mathrm{E}+0$ & $14,8 E+9$ & $11,0 E+9$ & $38,6 E+9$ \\
\hline 1994 & $4,5 E+9$ & $000,0 \mathrm{E}+0$ & $000,0 \mathrm{E}+0$ & $3,6 E+9$ & $41,5 E+9$ & $11,4 E+9$ & $9,6 E+9$ & $7,3 E+9$ & $38,3 E+9$ \\
\hline 1993 & $2,2 E+9$ & $000,0 E+0$ & $000,0 E+0$ & $2,0 E+9$ & $39,6 E+9$ & $15,8 E+9$ & $8,0 E+9$ & $000,0 E+0$ & $37,8 E+9$ \\
\hline 1992 & $3,5 E+9$ & $000,0 E+0$ & $000,0 \mathrm{E}+0$ & $1,6 E+9$ & $18,5 E+9$ & $12,5 E+9$ & $3,1 E+9$ & $000,0 E+0$ & $37,3 E+9$ \\
\hline
\end{tabular}

Schătzung Zinseinnahmen

$\begin{array}{rr}1997 & \\ 1996 & 56,1 \mathrm{E}+6 \\ 1995 & 121,1 \mathrm{E}+6 \\ 1994 & 200,8 \mathrm{E}+6 \\ 1993 & 118,8 \mathrm{E}+6 \\ 1992 & 295,5 \mathrm{E}+6\end{array}$

$109,1 \mathrm{E}+6$

$\begin{array}{cl}4,5 E+6 \quad & 198,0 E+6 \\ 261,7 E+6 \\ 169,4 E+6 \\ 160,2 E+6 \\ 110,8 E+6 \\ 134,4 E+6\end{array}$

Summe

tats.

Schătzung Zinsausgaben

$311,6 \mathrm{E}+6$ tats.

$358,6 E+6 \quad 394,0 E+6$

$215,0 E+6 \quad 166,5 E+6 \quad 608,0 E+6$

$290,5 E+6 \quad 309,0 E+6 \quad 329,3 E+6 \quad 784,0 E+6$

$361,0 E+6 \quad 366,0 E+6 \quad 841,9 E+6 \quad 1,1 E+9$

$110,8 \mathrm{E}+6 \quad 229,6 \mathrm{E}+6 \quad 598,0 \mathrm{E}+6 \quad 871,2 \mathrm{E}+6 \quad 1,2 \mathrm{E}+9$

$1992 \quad 295,5 E+6$

$\begin{array}{rrrr}229,6 \mathrm{E}+6 & 598,0 \mathrm{E}+6 & 871,2 \mathrm{E}+6 & 1,2 \mathrm{E}+9 \\ 429,9 \mathrm{E}+6 & 1,1 \mathrm{E}+9 & 1,0 \mathrm{E}+9 & 1,0 \mathrm{E}+9\end{array}$ 


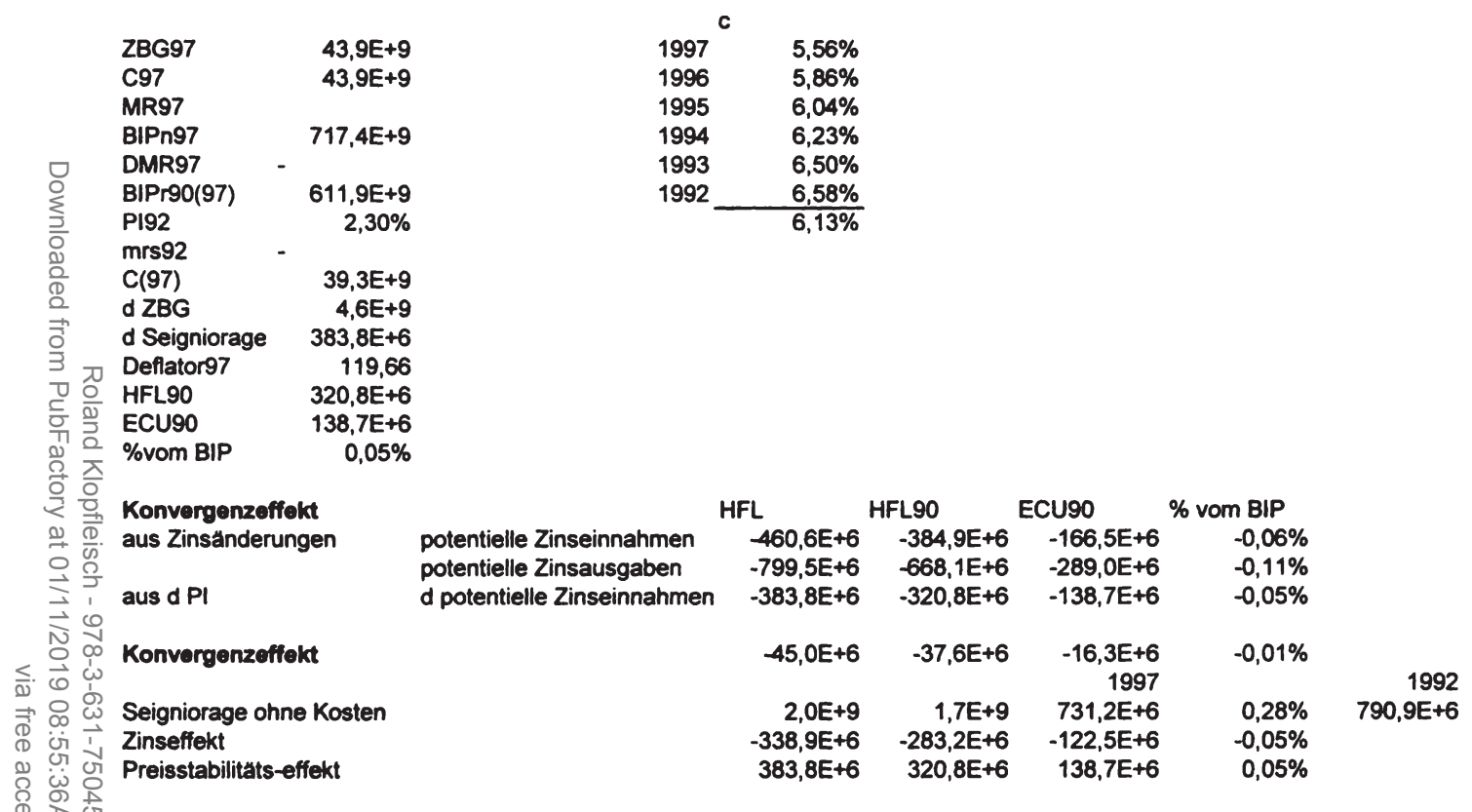


Wăhrungsreserven

\begin{tabular}{rrrr}
\multicolumn{2}{c}{ OS } & \multicolumn{2}{c}{ OS90 } \\
1997 & $14,0 E+9$ & $11,6 E+9$ & $800,3 E+6$ \\
1996 & $11,9 E+9$ & $10,0 E+9$ & $693,7 E+6$ \\
1995 & $12,7 E+9$ & $10,8 E+9$ & $749,9 E+6$ \\
1994 & $11,0 E+9$ & $9,6 E+9$ & $662,9 E+6$ \\
1993 & $11,0 E+9$ & $9,8 E+9$ & $680,6 E+6$ \\
1992 & $10,0 E+9$ & $9,2 E+9$ & $638,6 E+6$
\end{tabular}

insausgaben

OS OS90

757

$916,0 \mathrm{E}+6$

$629,0 \mathrm{E}+6$

$357,0 E+6$

$2,1 \mathrm{E}+9$

$145,0 E+6$

$249,0 \mathrm{E}+6$

$528,6 E+6$

$304,9 E+6$

$1,8 E+9$

$129,5 E+6$

$229,9 E+6$

Kosten

Zinsaufwand, inl.

$\begin{array}{lr}1997 & \text { OS } \\ 1996 & 1,4 E+6 \\ 1995 & 32,9 E+6 \\ 1994 & 751,2 E+6 \\ 1993 & 3,0 E+6 \\ 1992 & 2,7 E+6\end{array}$

S90

$1,14 E+06$

$1,93 E+07$

$2,92 \mathrm{E}+07$

$6,57 \mathrm{E}+08$

$2,70 \mathrm{E}+06$

$2,53 E+06$

ECU90

4,34E+09

$3,60 \mathrm{E}+09$

$3,18 E+09$

$2,0 E+6$

$45,5 \mathrm{E}+6$

$187,2 E+3$

$175,4 E+3$

$2,99 \mathrm{E}+09$

$2,83 E+09$

$2,60 E+09$

fiskalischer Seigniorage

\begin{tabular}{|c|c|c|c|c|}
\hline \multicolumn{2}{|c|}{ OS } & Os90 & ECU90 & in $\%$ vom BIP \\
\hline 1997 & $13,0 E+9$ & $10,7 E+9$ & $743,1 E+6$ & $0,5183 \%$ \\
\hline 1996 & $11,0 E+9$ & $9,2 E+9$ & $640,0 \mathrm{E}+6$ & $0,4575 \%$ \\
\hline 995 & $13,0 E+9$ & $11,1 E+9$ & $767,8 E+6$ & $0,5569 \%$ \\
\hline 1994 & $9,1 E+9$ & $7,9 E+9$ & $548,6 E+6$ & $0,4052 \%$ \\
\hline 1993 & $14,5 E+9$ & $12,9 E+9$ & $894,7 E+6$ & $0,6810 \%$ \\
\hline 1992 & $15,2 E+9$ & $14,0 E+9$ & $969,3 E+6$ & $0,7405 \%$ \\
\hline
\end{tabular}

fiskalischer Seigniorage ohne Kosten und Wăhrungsreserven

1997

OS

OS90

S90 ECU90

in \% vom BIP

$1,0 E+9$

$89,4 E+6$

$0,0623 \%$

$1,8 \mathrm{E}+9$

$1,4 E+9$

$878,3 E+6$

$60,8 \mathrm{E}+6$

$0435 \%$

$1,5 E+9$

$105,4 E+6$

$0,0764 \%$

$4,8 \mathrm{E}+9$

$4,3 E+9$

$0,0636 \%$

$0,2249 \%$

1992

$6,1 E+9$

$295,4 E+6$

$0,3210 \%$

Zinserträge aus Krediten an inl. GB

Zinsertrăge aus dem Escont-, Darlehens- und Offenmark

\begin{tabular}{rrrr} 
ECU 90 & \multicolumn{2}{c}{ OS 0} & \multicolumn{1}{c}{ ECU90 } \\
$52,5 E+6$ & $1,6 E+9$ & $1,3 E+9$ & $89,4 E+6$ \\
$36,6 E+6$ & $1,1 E+9$ & $897,6 E+6$ & $62,2 E+6$ \\
$21,1 E+6$ & $1,8 E+9$ & $1,6 E+9$ & $107,4 E+6$ \\
$124,4 E+6$ & $2,2 E+9$ & $1,9 E+9$ & $131,6 E+6$ \\
$9,0 E+6$ & $4,8 E+9$ & $4,3 E+9$ & $295,6 E+6$ \\
$15,9 E+6$ & $6,6 E+9$ & $6,1 E+9$ & $420,4 E+6$
\end{tabular}

Kosten Notendruck+ant. WwKosten

OS OS90 ECU90

\begin{tabular}{lrrr}
\multicolumn{2}{c}{ OS } & \multicolumn{2}{c}{ OS90 } \\
$37,84 \%$ & $1,64 E+09$ & $1,36 E+09$ & $94,1 E+6$ \\
$37,15 \%$ & $1,34 E+09$ & $1,13 E+09$ & $77,9 E+6$ \\
$35,33 \%$ & $1,12 E+09$ & $9,59 E+08$ & $66,4 E+6$ \\
$42,04 \%$ & $1,26 E+09$ & $1,10 E+09$ & $76,0 E+6$ \\
$41,48 \%$ & $1,17 E+09$ & $1,05 E+09$ & $72,4 E+6$ \\
$44,19 \%$ & $1,15 E+09$ & $1,06 E+09$ & $73,5 E+6$
\end{tabular}

fiskalischer Seigniorage ohne Kosten

OS \begin{tabular}{rrrr}
2 & \multicolumn{2}{c}{ ECU90 } & in \% vom BIP \\
$14,6 E+9$ & $12,1 E+9$ & $837,2 E+6$ & $0,5839 \%$ \\
$12,3 E+9$ & $10,4 E+9$ & $717,9 E+6$ & $0,5132 \%$ \\
$14,1 E+9$ & $12,0 E+9$ & $834,2 E+6$ & $0,6051 \%$ \\
$10,3 E+9$ & $9,0 E+9$ & $624,6 E+6$ & $0,4613 \%$ \\
$15,6 E+9$ & $14,0 E+9$ & $967,1 E+6$ & $0,7361 \%$ \\
$16,3 E+9$ & $15,1 E+9$ & $1,0 E+9$ & $0,7967 \%$
\end{tabular}

Zinserträge aus Krediten an inl. GB

Zinsertrăge aus dem Escont d Zinseinnahmen

OS

$1,6 E+9$

Os

$1 \mathrm{E}+9$

$1,8 E+9$

$2,2 E+9$

$4,8 E+9$

$6,6 \mathrm{E}+9$ 
Mindestreserveergebnisse (Geschaftsbericht 1997, 11")

MR-Verpflicht Brutto-MR-So durchschnittlicher MR-Satz

$\begin{array}{llrl}1997 & 1,9 E+12 & 57,7 E+9 & 3,04 \% \\ 1996 & 1,9 E+12 & 56,5 E+9 & 3,00 \% \\ 1995 & 1,8 E+12 & 55,1 E+9 & 2,99 \% \\ 1994 & 1,7 E+12 & 108,2 E+9 & 6,27 \% \\ 1993 & 1,6 E+12 & 103,3 E+9 & 6,42 \% \\ 1992 & 1,5 E+12 & 98,9 E+9 & 6,59 \%\end{array}$

Geldnachfrag'k3

c

Wahrungsreserven

Reservepflich Banknotenumlauf / BIP nom

$1997 \quad 75,83 \% \quad 6,84 \%$

$1996 \quad 78,37 \% \quad 7,04 \%$

$1995 \quad 79,14 \% \quad 6,92 \%$

$1994 \quad 77,25 \% \quad 6,77 \%$

$1993 \quad 75,73 \% \quad 6,74 \%$

$1992 \quad 73,26 \% \quad 6,59 \%$

Durchschnitt $\quad 76,60 \% \quad 6,82 \%$

$\begin{array}{lr}\text { ZBG97 } & 325,5 E+9 \\ \text { C97 } & 187,0 E+9 \\ \text { MR97 } & 138,5 E+9 \\ \text { BIPn97 } & 2,7 E+12 \\ \text { DMR97 } & 2,1 E+12 \\ \text { BIPr90(97) } & 2,1 E+12 \\ \text { PI92 } & 4,10 \% \\ \text { mrs92 } & 6,59 \% \\ \text { ZBG(97) } & 318,4 E+9 \\ \text { d ZBG } & 7,1 E+9 \\ \text { d Seigniorage } & 646,0 E+6 \\ \text { Deflator97 } & 132,40 \\ \text { OS90 } & 487,9 E+6 \\ \text { ECU90 } & 237,8 E+6 \\ \text { \%vom BIP } & 0,02 \%\end{array}$

Schatzung Zinsaurwand, inl.

\begin{tabular}{|c|c|c|c|c|}
\hline Durchschittsb & EGOM & ub & & \\
\hline 1997 & $55,0 E+6$ & 0,025 & & $1,4 E+6$ \\
\hline 1996 & $350,0 E+6$ & & & \\
\hline & $1,2 E+9$ & & & \\
\hline & $413,0 E+6$ & & & \\
\hline & $1,8 E+9$ & 0,025 & $7,9 E+6$ & \\
\hline & $1,8 E+9$ & & & \\
\hline & $516,0 E+6$ & & & \\
\hline & $2,2 E+9$ & & & \\
\hline & $1,5 E+9$ & 0,03 & $15,0 E+6$ & $22,9 E+6$ \\
\hline 1995 & $820,0 E+6$ & 0,039375 & $32,3 E+6$ Zinsen und sc & $34,2 \mathrm{E}+6$ \\
\hline 1994 & & & & $751,3 E+6$ \\
\hline 1993 & & & & $3,0 E+6$ \\
\hline 1992 & & & & $2,7 E+6$ \\
\hline 1991 & & & & $3,1 \mathrm{E}+$ \\
\hline
\end{tabular}

Devisen und IVerb. gegenüber ausländischen Kreditinstituten

$1997 \quad 195,3 E+9 \quad 1,3 E+9$

$1996 \quad 199,3 E+9 \quad 91,0 E+6$

$1995 \quad 179,3 E+9 \quad 187,0 E+6$

$1994 \quad 174,1 \mathrm{E}+9 \quad 192,0 \mathrm{E}+6$

$1993 \quad 167,7 E+9 \quad 115,0 E+6$

$1992130,2 E+9 \quad 169,0 E+6$

$3,1 E+6$ 
Periodendurchschnitt

Wechselesko: Eskontsatz Geldmarktoffe GOMEX-Satz Offenmarktter Tendersatz Wertpapierlon Lombardsatz

\begin{tabular}{|c|c|c|c|c|c|c|c|c|c|}
\hline 1997 & $19,0 \mathrm{E}+9$ & $2,50 \%$ & $9,7 E+9$ & $3,40 \%$ & $24,4 E+9$ & $3,03 \%$ & $000,0 E+0$ & $4,75 \%$ & \\
\hline 1996 & $18,0 \mathrm{E}+9$ & $2,65 \%$ & $7,8 E+9$ & $3,49 \%$ & $7,6 E+9$ & $3,22 \%$ & $000,0 \mathrm{E}+0$ & $4,90 \%$ & \\
\hline 1995 & $16,5 E+9$ & $3,94 \%$ & $24,3 E+9$ & $4,37 \%$ & $115,0 E+6$ & $3,90 \%$ & $000,0 E+0$ & $5,31 \%$ & \\
\hline 1994 & $17,8 E+9$ & $4,71 \%$ & $24,7 E+9$ & $5,03 \%$ & $000,0 \mathrm{E}+0$ & $0,00 \%$ & $000,0 \mathrm{E}+0$ & $5,70 \%$ & \\
\hline 1993 & $19,6 \mathrm{E}+9$ & $6,36 \%$ & $48,1 E+9$ & $7,06 \%$ & $000,0 E+0$ & $0,00 \%$ & $2,0 E+6$ & $7,57 \%$ & \\
\hline 992 & $25,6 \mathrm{E}+9$ & $8,15 \%$ & $48,9 E+9$ & $9,10 \%$ & $000,0 \mathrm{E}+0$ & $0,00 \%$ & $3,0 E+6$ & $9,63 \%$ & \\
\hline \multicolumn{9}{|c|}{ nachrichtlich: } & chătzte Ertrăge \\
\hline 1997 & $55,0 \mathrm{E}+6$ & $2,50 \%$ & $7,8 E+9$ & $2,50 \%$ & & $2,68 E+10$ & $2,50 \%$ & $1,4 E+6$ & $1,7 E+9$ \\
\hline 1996 & $788,0 \mathrm{E}+6$ & $2,91 \%$ & $8,4 E+9$ & $2,65 \%$ & & $2,64 E+10$ & $2,65 \%$ & $22,9 E+6$ & $1,2 E+9$ \\
\hline 1995 & $820,0 E+6$ & $4,17 \%$ & $8,6 E+9$ & $3,94 \%$ & & $2,51 E+10$ & $3,94 \%$ & $34,2 E+6$ & $2,1 E+9$ \\
\hline 1994 - & & & $8,2 E+9$ & $4,71 \%$ & & $2,60 E+10$ & $4,71 \%$ & & $2,5 E+9$ \\
\hline $3-$ & & & $8,1 E+9$ & $6,36 \%$ & & $2,78 E+10$ & $6,36 \%$ & & $5,2 E+9$ \\
\hline 992 - & & & $8,3 E+9$ & $8,15 \%$ & & $3,39 E+10$ & $8,15 \%$ & & $7,2 E+9$ \\
\hline
\end{tabular}

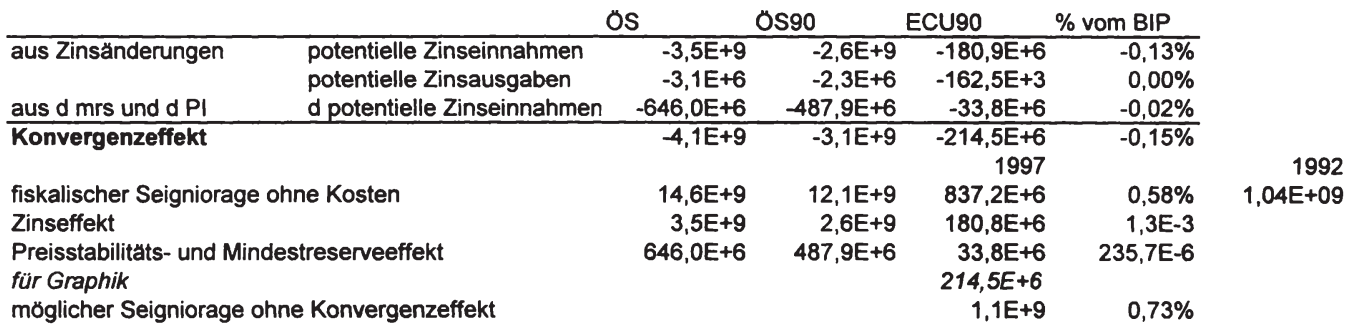




\section{Portugal}

\begin{tabular}{|c|c|c|c|c|c|c|c|c|c|}
\hline & \multicolumn{3}{|c|}{$\begin{array}{l}\text { Wahrungsreserven } \\
\text { external operations } \\
\text { Zinseinnahmen }\end{array}$} & \multicolumn{3}{|c|}{$\begin{array}{l}\text { external liabilities } \\
\text { Zinsausgaben }\end{array}$} & \multicolumn{3}{|c|}{$\begin{array}{l}\text { Zinserträge aus Krediten an inl. GB } \\
\text { Interest Income }\end{array}$} \\
\hline & PTE & PTE90 & ECU90 & PTE & PTE90 & ECU90 & PTE & PTE9O & ECU9O \\
\hline 1997 & $114,1 E+9$ & $72,9 E+9$ & $402,5 E+6$ & $9,4 E+9$ & $6,0 E+9$ & $33,1 E+6$ & $15,0 E+9$ & $9,6 E+9$ & $52,9 E+6$ \\
\hline 1996 & $104,0 E+9$ & $68,3 E+9$ & $376,9 E+6$ & $600,4 E+6$ & $394,0 E+6$ & $2,2 E+6$ & $21,7 E+9$ & $14,2 E+9$ & $78,7 E+6$ \\
\hline 1995 & $110,2 E+9$ & $74,5 E+9$ & $411,3 E+6$ & $889,4 E+6$ & $601,0 E+6$ & $3,3 E+6$ & $42,9 E+9$ & $29,0 E+9$ & $160,0 E+6$ \\
\hline 1994 & $118,2 E+9$ & $83,9 E+9$ & $463,3 E+6$ & $1,1 \mathrm{E}+9$ & $790,2 E+6$ & $4,4 E+6$ & $35,5 E+9$ & $25,2 E+9$ & $139,1 E+6$ \\
\hline 1993 & $176,6 \mathrm{E}+9$ & $133,1 E+9$ & $734,7 E+6$ & $850,7 E+6$ & $641,0 E+6$ & $3,5 E+6$ & $15,8 E+9$ & $11,9 E+9$ & $65,9 E+6$ \\
\hline 1992 & $241,1 E+9$ & $194,6 E+9$ & $1,1 E+9$ & $741,3 E+6$ & $598,3 E+6$ & $3,3 E+6$ & $15,8 E+9$ & $12,7 E+9$ & $70,3 E+6$ \\
\hline
\end{tabular}

\section{Zinsaufwand}

Interest costs

deposits of Pc Liquidity appli interest rate subsidies$$
\text { PTE }
$$
PTE PTE

Summe PTE PTE90 ECU90

$\begin{array}{rrrrrrr}1997 & 000,0 \mathrm{E}+0 & 74,2 \mathrm{E}+9 & 2,2 \mathrm{E}+9 & 76,3 \mathrm{E}+9 & 48,8 \mathrm{E}+9 & 269,2 \mathrm{E}+6 \\ 1996 & 000,0 \mathrm{E}+0 & 87,9 \mathrm{E}+9 & 2,6 \mathrm{E}+9 & 90,6 \mathrm{E}+9 & 59,4 \mathrm{E}+9 & 328,1 \mathrm{E}+6 \\ 1995 & 672,1 \mathrm{E}+6 & 115,9 \mathrm{E}+9 & 3,1 \mathrm{E}+9 & 119,7 \mathrm{E}+9 & 80,9 \mathrm{E}+9 & 446,5 \mathrm{E}+6 \\ 1994 & 119,1 \mathrm{E}+9 & 20,0 \mathrm{E}+9 & 3,8 \mathrm{E}+9 & 142,9 \mathrm{E}+9 & 101,4 \mathrm{E}+9 & 560,0 \mathrm{E}+6 \\ 1993 & 152,5 \mathrm{E}+9 & 39,9 \mathrm{E}+9 & 4,0 \mathrm{E}+9 & 196,5 \mathrm{E}+9 & 148,1 \mathrm{E}+9 & 817,6 \mathrm{E}+6 \\ 1992 & 177,6 \mathrm{E}+9 & 72,7 \mathrm{E}+9 & 5,5 \mathrm{E}+9 & 255,8 \mathrm{E}+9 & 206,4 \mathrm{E}+9 & 1,1 \mathrm{E}+9\end{array}$

\begin{tabular}{|c|c|c|c|c|}
\hline \multirow[b]{2}{*}{1997} & \multicolumn{4}{|c|}{$\begin{array}{l}\text { Kosten } \\
\text { cost of issuinc sonst. VwKos Schlüssel }\end{array}$} \\
\hline & $6,6 E+9$ & $374,6 E+6$ & $23,0 E+9$ & 0,29 \\
\hline 1996 & $8,7 E+9$ & $521,8 E+6$ & $23,2 E+9$ & 0,37 \\
\hline 1995 & $9,0 E+9$ & $895,2 E+6$ & $21,9 E+9$ & 0,41 \\
\hline 1994 & $8,0 E+9$ & $415,0 E+6$ & $20,1 E+9$ & 0,40 \\
\hline 1993 & $9,1 E+9$ & $356,2 E+6$ & $26,6 E+9$ & 0,34 \\
\hline \multirow[t]{3}{*}{1992} & $6,9 E+9$ & $25,7 E+6$ & $19,6 E+9$ & 0,35 \\
\hline & - & INorage & & \\
\hline & & TE90 & U90 & in \% vom BIP \\
\hline 1997 & $36,5 E+9$ & $23,3 E+9$ & $128,5 E+6$ & $0,20 \%$ \\
\hline 1996 & $25,3 E+9$ & $16,6 E+9$ & $91,7 E+6$ & $0,15 \%$ \\
\hline 1995 & $22,6 E+9$ & $15,3 E+9$ & $84,5 E+6$ & $0,15 \%$ \\
\hline 1994 & $1,3 E+9$ & $904,9 E+6$ & $5,0 E+6$ & $0,01 \%$ \\
\hline 1993 & $-14,4 E+9$ & $-10,9 E+9$ & $-59,9 E+6$ & $-0,11 \%$ \\
\hline 1992 & $-6,6 E+9$ & $-5,3 E+9$ & $-29,3 E+6$ & $-0,05 \%$ \\
\hline
\end{tabular}

\section{Kosten Notendrucktant. VwKosten}

PTE PTE90 ECU9O

$\begin{array}{lll}6,9 E+9 & 4,4 E+9 & 24,5 E+6\end{array}$

$9,9 E+9 \quad 6,7 \mathrm{E}+9 \quad 37,0 \mathrm{E}+6$

$8,4 \mathrm{E}+9 \quad 6,0 \mathrm{E}+9 \quad 33,0 \mathrm{E}+6$

$9,5 E+9 \quad 7,1 E+9 \quad 39,4 E+6$

$7,0 \mathrm{E}+9 \quad 5,6 \mathrm{E}+9 \quad 31,0 \mathrm{E}+6$

\begin{tabular}{|c|c|c|c|}
\hline PTE & PTE90 & ECU9O & in $\%$ vom BIP \\
\hline $43,4 E+9$ & $27,7 E+9$ & $153,0 E+6$ & $0,24 \%$ \\
\hline $34,6 E+9$ & $22,7 E+9$ & $125,2 E+6$ & $0,21 \%$ \\
\hline $32,6 E+9$ & $22,0 E+9$ & $121,5 E+6$ & $0,22 \%$ \\
\hline $9,7 E+9$ & $6,9 E+9$ & $38,0 E+6$ & $0,07 \%$ \\
\hline$-4,9 E+9$ & $-3,7 E+9$ & $-20,5 E+6$ & $-0,04 \%$ \\
\hline $396,0 \mathrm{E}+6$ & $319,6 E+6$ & $1,8 E+6$ & $0,00 \%$ \\
\hline
\end{tabular}


fiskalischer Seigniorage ohne Kosten und Währungsreserven

\begin{tabular}{|c|c|c|c|c|}
\hline \multicolumn{2}{|c|}{ PTE } & PTE90 & ECU90 & in \% vom BIP \\
\hline 997 & $-31,2 E+9$ & $-20,0 E+9$ & $-110,2 E+6$ & $-0,17 \%$ \\
\hline 9 & $-15,4 E+9$ & $-10,1 E+9$ & $-55,7 E+6$ & $-0,09 \%$ \\
\hline 1995 & $4,8 E+9$ & $3,2 E+9$ & $17,8 E+6$ & $0,03 \%$ \\
\hline 1994 & $-97,4 E+9$ & $-69,1 E+9$ & $-381,8 E+6$ & $-0,69 \%$ \\
\hline 1993 & $-135,9 E+9$ & $-102,4 E+9$ & $-565,5 E+6$ & $-1,03 \%$ \\
\hline 1992 & $-174,7 E+9$ & $-141,0 E+9$ & $-778,5 E+6$ & $-1,41 \%$ \\
\hline
\end{tabular}

Zinsen

Offenmarkt Spitzenfinanz Liquiditătsabschöpfung

PR R SFR DR R DRO PRO auf Mindestre $5,92 \%$ $7,58 \%$ $10,72 \%$

$10,38 \%$ $7,63 \%$ $5,59 \%$

$7,06 \% \quad 7,06 \%$

$13,00 \%$ $\begin{array}{rr}9,43 \% & 7,06 \% \\ 13,50 \% & 10,03 \%\end{array}$ $8,41 \%$ $12,00 \%$

$9,17 \%$

$9,72 \%$

$14,50 \%$

Aktivseite

credit to financial institutions

Domestic securities

nachrichtlich (IMF): 999

iscount and I Guaranteed k repurchase ạ bonds issued finan

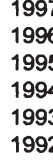

$500,0 E+6$
$530,0 E+6$
$4,1 E+9$
$17,8 E+9$
$8,8 E+9$

$1,6 \mathrm{E}+9$
$1,6 \mathrm{E}+9$

$\begin{array}{ll}112,6 E+9 & 160,3 E+9 \\ 261,9 E+9 & 195,0 E+9 \\ 631,9 E+9 & 220,2 E+9 \\ 547,1 E+9 & 245,3 E+9 \\ 247,3 E+9 & 270,5 E+9 \\ 000,0 E+0 & 296,7 E+9\end{array}$

ncial holdi othe domesti ReserveMone Currer Currency outs ÜR+MR

assiv

Banknotenum Einlagen von Kreditinstituten

notes in circul deposits of criapplications of credit institutions and financial companies

$\begin{array}{rrrr}1997 & 873,5 \mathrm{E}+9 & 412,8 \mathrm{E}+9 & 1,2 \mathrm{E}+12 \\ 1996 & 937,0 \mathrm{E}+9 & 370,9 \mathrm{E}+9 & 1,5 \mathrm{E}+12 \\ 1995 & 894,8 \mathrm{E}+9 & 282,5 \mathrm{E}+9 & 1,9 \mathrm{E}+12 \\ 1994 & 841,2 \mathrm{E}+9 & 368,6 \mathrm{E}+9 & 1,9 \mathrm{E}+12 \\ 1993 & 808,3 \mathrm{E}+9 & 2,2 \mathrm{E}+12 & 23,8 \mathrm{E}+9 \\ 1992 & 761,9 \mathrm{E}+9 & 2,0 \mathrm{E}+12 & 381,4 \mathrm{E}+9\end{array}$

DMR MR

\begin{tabular}{rrrrr}
\multicolumn{2}{c}{ DMR } & \multicolumn{2}{c}{ MR } & \multicolumn{2}{c}{$c$} \\
1997 & $27,9 E+12$ & $558,6 E+9$ & $156,01 \%$ & $4,88 \%$ \\
1996 & $23,7 E+12$ & $473,7 E+9$ & $140,92 \%$ & $5,58 \%$ \\
1995 & $18,9 E+12$ & $377,3 E+9$ & $125,21 \%$ & $5,94 \%$ \\
1994 & $22,7 E+12$ & $453,9 E+9$ & $161,18 \%$ & $5,97 \%$ \\
1993 & $13,4 E+12$ & $2,3 E+12$ & $101,76 \%$ & $6,14 \%$ \\
1992 & $12,2 E+12$ & $2,1 E+12$ & $98,12 \%$ & $6,13 \%$ \\
\cline { 3 - 5 } & & & $124,41 \%$ & $5,77 \%$
\end{tabular}


Wăhrungsres deposits and , Foreign secur Summe PTE90

$\begin{array}{lllll}1997 & 689,9 E+9 & 1,7 \mathrm{E}+12 & 2,4 \mathrm{E}+12 & 1,5 \mathrm{E}+12 \\ 1996 & 547,2 \mathrm{E}+9 & 1,5 \mathrm{E}+12 & 2,0 \mathrm{E}+12 & 1,3 \mathrm{E}+12 \\ 1995 & 600,1 \mathrm{E}+9 & 1,4 \mathrm{E}+12 & 2,0 \mathrm{E}+12 & 1,3 \mathrm{E}+12 \\ 1994 & 304,6 \mathrm{E}+9 & 1,7 \mathrm{E}+12 & 2,0 \mathrm{E}+12 & 1,4 \mathrm{E}+12 \\ 1993 & 381,7 \mathrm{E}+9 & 1,9 \mathrm{E}+12 & 2,3 \mathrm{E}+12 & 1,7 \mathrm{E}+12 \\ 1992 & 360,3 \mathrm{E}+9 & 2,0 \mathrm{E}+12 & 2,4 \mathrm{E}+12 & 1,9 \mathrm{E}+12\end{array}$

Schătzung Zinseinnahmen Zinsausgaben

$\begin{array}{lrr}1997 & 17,1 E+9 & 68,6 E+9 \\ 1996 & 36,3 E+9 & 109,0 E+9 \\ 1995 & 93,7 E+9 & 186,5 E+9 \\ 1994 & 85,0 E+9 & 266,7 E+9 \\ 1993 & 72,8 E+9 & 146,3 E+9 \\ 1992 & 47,8 E+9 & 169,9 E+9\end{array}$

$\begin{array}{lr}\text { ZBG97 } & 6,2 E+12 \\ \text { C97 } & 1,3 E+12 \\ \text { MR97 } & 4,9 E+12 \\ \text { BIPn97 } & 23,1 E+12 \\ \text { DMR97 } & 28,8 E+12 \\ \text { BIPr90(97) } & 11,4 E+12 \\ \text { PI92 } & 10,60 \% \\ \text { mrs92 } & 17,00 \% \\ \text { ZBG(97) } & 1,3 E+12 \\ \text { d ZBG } & 4,9 E+12 \\ \text { d Seigniorage } & 716,9 E+9 \\ \text { Deflator97 } & 205,04 \\ \text { PTE90 } & 349,6 E+9 \\ \text { ECU90 } & 1,9 E+9 \\ \text { \%vom BIP } & 3,06 \%\end{array}$

\begin{tabular}{llrrrr} 
& & PTE & PTE90 & ECU90 & $\%$ vom BIP \\
\hline aus Zinsänderungen & d Zinseinnahmen & $-21,7 E+9$ & $-10,6 E+9$ & $-58,4 E+6$ & $-0,09 \%$ \\
& d Zinsausgaben & $-121,7 E+9$ & $-59,4 E+9$ & $-327,7 E+6$ & $-0,52 \%$ \\
aus d mrs und d PI & d potentielle Zinseinnahmer & $-716,9 E+9$ & $-349,6 E+9$ & $-1,9 E+9$ & $-3,06 \%$ \\
Verzinsung der Mindestreserve & $371,4 E+9$ & $181,1 E+9$ & $1,0 E+9$ & $1,58 \%$ \\
\hline Konvergenzeffekt & $-245,5 E+9$ & $-119,7 E+9$ & $-661,2 E+6$ & $-1,05 \%$ \\
& & & 1997 & \\
fiskalischer Seigniorage ohne Kosten & $396,0 E+6$ & $23,3 E+9$ & $128,5 E+6$ & $0,20 \%$ \\
Zinseffekt & $-100,0 E+9$ & $-48,8 E+9$ & $-269,3 E+6$ & $-0,43 \%$ \\
Preisstabilitats- und Mindest-reserve-effekt & $716,9 E+9$ & $349,6 E+9$ & $1,9 E+9$ & $3,06 \%$ \\
Verzinsung der Mindestreserve & $-371,4 E+9$ & $-181,1 E+9$ & $-1,0 E+9$ & $-1,58 \%$
\end{tabular}

1992

$1,8 E+6$ 
Zinserträge aus Krediten an inl. GB

Interest paid

Interest received+interest, premiums and c Intereses cuentas del Tesoro PTA90 ECU90

PTA

PTA90

ECU90

$\begin{array}{rrrrrrr}1997 & 180,4 \mathrm{E}+9 & 131,6 \mathrm{E}+9 & 1,0 \mathrm{E}+9 & 137,0 \mathrm{E}+9 & 99,9 \mathrm{E}+9 & 772,7 \mathrm{E}+6 \\ 1996 & 373,1 \mathrm{E}+9 & 277,8 \mathrm{E}+9 & 2,1 \mathrm{E}+9 & 145,9 \mathrm{E}+9 & 108,6 \mathrm{E}+9 & 840,1 \mathrm{E}+6 \\ 1995 & 570,4 \mathrm{E}+9 & 438,1 \mathrm{E}+9 & 3,4 \mathrm{E}+9 & 169,0 \mathrm{E}+9 & 129,8 \mathrm{E}+9 & 1,0 \mathrm{E}+9 \\ 1994 & 447,0 \mathrm{E}+9 & 359,9 \mathrm{E}+9 & 2,8 \mathrm{E}+9 & 203,5 \mathrm{E}+9 & 163,8 \mathrm{E}+9 & 1,3 \mathrm{E}+9 \\ 1993 & 525,0 \mathrm{E}+9 & 439,3 \mathrm{E}+9 & 3,4 \mathrm{E}+9 & 190,0 \mathrm{E}+9 & 159,0 \mathrm{E}+9 & 1,2 \mathrm{E}+9 \\ 1992 & 295,0 \mathrm{E}+9 & 257,6 \mathrm{E}+9 & 2,0 \mathrm{E}+9 & 199,0 \mathrm{E}+9 & 173,8 \mathrm{E}+9 & 1,3 \mathrm{E}+9\end{array}$

Kosten

Notendruck sonst. VwKos Schlüssel ant. WWKostePTA

1997

$6.9 \mathrm{E}+9$

$42,36 \% \quad 1,5165 E+10$

$22,1 E+9$

PTA90

ECU90

1996

1995

$7,0 E+9$

$35,5 E+9$

$50,15 \% \quad 1,7803 E+10$

$24,8 E+9$

$16,1 \mathrm{E}+9$

$124,5 E+6$

1994

$7,1 E+9$

$34,6 \mathrm{E}+9$

$2,1683 E+10$

$28,8 E+9$

$18,5 E+9$

$142,8 E+6$

1993

$7,3 E+9$

$33,4 E+9$

$58,97 \% \quad 1,9695 E+10$

$27,0 E+9$

$1 E+9$

(1)+6

1992

$7,1 \mathrm{E}+9$

$29,9 E+9$

$54,60 \% \quad 1,6326 E+10$

$23,4 E+9$

$21,7 \mathrm{E}+9$

$168,1 E+6$

$20,3 \mathrm{E}+9 \quad 156,7 \mathrm{E}+6$

$20,5 E+9 \quad 158,2 E+6$

Währungsreserven

Zinseinnahmen

$1997 \begin{array}{ccc}\text { PTA } & \text { PTA90 } & \text { ECU9 }\end{array}$

$1997 \begin{array}{ccc}\text { PTA } & \text { PTA90 } & \text { ECU9 }\end{array}$

1996

$333,2 E+9$

$248,1 \mathrm{E}+9$

$3,1 E+9$ PTA

Zinsausgaben

1995

1994

$356,8 E+9$

$274,0 E+9$

$1,9 \mathrm{E}+9$

A

PTA90

ECU90

$261,8 E+9$

$210,8 \mathrm{E}+9$

$2,1 \mathrm{E}+9$

$2,9 E+9$

$2,1 E+9$

$16,4 E+6$

1993

$497,7 \mathrm{E}+9$

$416,5 E+9$

$1,6 E+9$

$2,8 E+9$

$1,8 \mathrm{E}+9$

$13,8 E+6$

1992

$604,0 E+9$

$527,5 E+9$

$3,2 E+9$

$2,7 E+9$

$2,2 E+9$

$16,6 E+6$

$2,2 E+9 \quad 16,8 E+6$

$3,1 \mathrm{E}+9$

$23,9 E+6$

fiskalischer Seigniorage

PTA

PTA90

ECU90

fiskalischer Seigniorage ohne Kosten

1997

1996

$408,3 E+9$

$397,0 \mathrm{E}+9$

$3,2 \mathrm{E}+9$

in \% vom BIP PTA

PTA90

ECU90

in \% vom BIP

$726,6 \mathrm{E}+9 \quad 558,1 \mathrm{E}+9$

$3,1 \mathrm{E}+9$

$0,72 \% \quad 581,9 E+9$

$424,4 E+9$

$3,3 E+9$

$0,75 \%$

1994

$475,6 E+9$

$382,9 E+9$

$4,3 E+9$

$1,04 \%$

$558,0 \mathrm{E}+9$

$415,5 E+9$

$3,2 E+9$

$0,76 \%$

1993

$804,8 E+9$

$673,5 \mathrm{E}+9$

$3,0 \mathrm{E}+9$

$0,74 \%$

$502,6 \mathrm{E}+9$

$4,5 \mathrm{E}+9$

$1,08 \%$

1992

$672,6 E+9$

$587,4 E+9$

$4,5 E+9$

$1,14 \% \quad 696,0 E+9$

$1,14 \% \quad 696,0 E+9$

$693,7 \mathrm{E}+9$

$3,1 E+9$

$0,78 \%$

607 , $\mathrm{E}+9$

$5,4 E+9$

$1,36 \%$

$1,18 \%$ 
fiskalischer Seigniorage ohne Kosten und Wahrungsreserven

$$
\text { PTA PTA90 ECU90 }
$$

$244,8 E+6$

in \% vom BIP

1997

$43,4 E+9$

$31,7 E+9$

$1,3 E+9$

$0,06 \%$

$227,2 E+9$

$2,4 E+9$

1995

1993

$243,5 E+9$

$1,5 E+9$

$0,58 \%$

$335,0 E+9$

$2,2 \mathrm{E}+9$

$0,38 \%$

1992

$96,0 E+9$

$83,8 E+9$

$648,4 E+6$

$0,16 \%$

Schatzung

Zinsertrag

\section{Zinsaufwand}

Verbindlichke IZinsaufwand I Zinsaufwand

$\begin{array}{lllll}1997 & 122,5 E+9 & 2,5 E+12 & 323,0 E+9 & 138,1 E+9 \\ 1996 & 333,8 E+9 & 1,9 E+12 & & 207,2 E+9 \\ 1995 & 586,6 E+9 & 1,9 E+12 & & 289,1 E+9 \\ 1994 & 457,3 E+9 & 2,6 E+12 & & 298,0 E+9 \\ 1993 & 739,0 E+9 & 1,7 E+12 & & 447,0 E+9 \\ 1992 & 548,7 E+9 & 1,6 E+12 & & 593,0 E+9\end{array}$

0

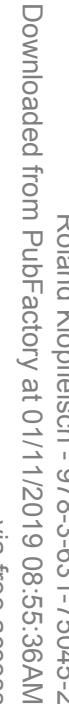

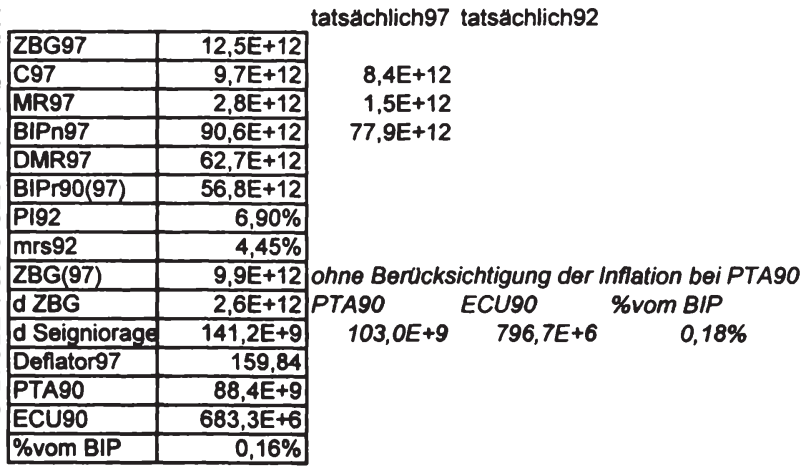

Wăhrungsreserve, Bestände

Activos exterii Pasivos exteriores

$\begin{array}{rrr}1997 & 10,6 \mathrm{E}+12 & 8,0 \mathrm{E}+9 \\ 1996 & 7,9 \mathrm{E}+12 & 73,0 \mathrm{E}+9 \\ 1995 & 4,5 \mathrm{E}+12 & 1,3 \mathrm{E}+9 \\ 1994 & 5,7 \mathrm{E}+12 & 10,0 \mathrm{E}+9 \\ 1993 & 6,1 \mathrm{E}+12 & 7,0 \mathrm{E}+9 \\ 1992 & 5,7 \mathrm{E}+12 & 5,0 \mathrm{E}+9\end{array}$


Schătzung Mindestresreve

Monetary Authorities

DMBs

Reserve Mon of which: Curr MR+ÜR

Demand Depc Time and Sav Mindest-reser mrs

$\begin{array}{llll}1997 & 9877 & 8378 & 149 \\ 1996 & 9268 & 7942 & 132 \\ 1995 & 8937 & 7535 & 140 \\ 1994 & 8603 & 7165 & 143 \\ 1993 & 7800 & 6509 & 129 \\ 1992 & 7767 & 6025 & 174\end{array}$

14967

12637

35652

50619

11629

37536

37315

11411

34395

50173

48944

10878

32053

45806

10944

28208

42931

39152

nom. BIP

k3

aus Zinsänderungen d Zinseinnahmen PTA

PTA PTA90 $\%$ vom BIP aus $\mathrm{d}$ mrs und $\mathrm{dPI}$ d pinsausgaben $-186,0 E+9$

$-116,4 \mathrm{E}+9$ $-1,2 \mathrm{E}+9$ $-0,20 \%$ Konvergenzeffekt

$-200,2 E+9$
$-88,4 \mathrm{E}+9$

Diskalischer Seigniorage ohne Kosten

$-200,2 \mathrm{E}+9$

$-125,2 E+9$

$-683,3 \mathrm{E}+6$ $-0,16 \%$

Zinseffekt

$581,9 \mathrm{E}+9$

$424,4 \mathrm{E}+9$

$-968,5 \mathrm{E}+6$

$-0,22 \%$

$3,3 E+9 \quad 0,75 \%$

$\begin{array}{llll}141,2 E+9 & 88,4 E+9 & 683,3 E+6 & 1,6 E-3\end{array}$

$1,6 \mathrm{E}-3$ 
Berechnungen zu Teil III und IV

Berechnung Übergangseffekt

\begin{tabular}{|c|c|c|c|c|c|c|c|}
\hline \multicolumn{4}{|c|}{ nach Übergang } & \multicolumn{4}{|c|}{ Übergangseffekt (Differenz zu 1997) } \\
\hline \multirow[b]{2}{*}{ iopp } & Sopp1 & Sopp3 a & b & c & dSopp1 & dSopp $2 / 3 c$ & 3c-Sfisk \\
\hline & $6,08 \%$ & $3,00 \%$ & $2,75 \%$ & $2,50 \%$ & & & \\
\hline $\mathbf{B}$ & $0,38 \%$ & $0,14 \%$ & $0,13 \%$ & $0,12 \%$ & $0,05 \%$ & $-0,06 \%$ & $-0,22 \%$ \\
\hline D & $0,48 \%$ & $0,20 \%$ & $0,19 \%$ & $0,17 \%$ & $0,03 \%$ & $-0,11 \%$ & $-0,20 \%$ \\
\hline E & $0,74 \%$ & $0,32 \%$ & $0,29 \%$ & $0,27 \%$ & $-0,01 \%$ & $-0,42 \%$ & $-0,48 \%$ \\
\hline $\mathrm{F}$ & $0,28 \%$ & $0,10 \%$ & $0,09 \%$ & $0,09 \%$ & $0,06 \%$ & $-0,04 \%$ & $-0,18 \%$ \\
\hline IRL & $0,34 \%$ & $0,14 \%$ & $0,13 \%$ & $0,12 \%$ & $-0,23 \%$ & $-0,46 \%$ & $-0,35 \%$ \\
\hline 1 & $0,41 \%$ & $0,17 \%$ & $0,15 \%$ & $0,14 \%$ & $-0,33 \%$ & $-0,33 \%$ & $-0,05 \%$ \\
\hline NL & $0,47 \%$ & $0,18 \%$ & $0,17 \%$ & $0,15 \%$ & $0,01 \%$ & $-0,06 \%$ & $-0,12 \%$ \\
\hline A & $0,47 \%$ & $0,18 \%$ & $0,16 \%$ & $0,15 \%$ & $0,04 \%$ & $-0,12 \%$ & $-0,43 \%$ \\
\hline $\mathbf{P}$ & $0,41 \%$ & $0,16 \%$ & $0,14 \%$ & $0,13 \%$ & $0,00 \%$ & $-0,14 \%$ & $-0,11 \%$ \\
\hline SF & $0,20 \%$ & $0,07 \%$ & $0,06 \%$ & $0,06 \%$ & $-0,08 \%$ & $-0,08 \%$ & $-0,19 \%$ \\
\hline
\end{tabular}

Berechnung Verteilungseffekt

nach Verteilung (\% vom BIP)Ｄifferenz zu "nach Übergang" (\% vom BIP)（ECU90) Kontrolle ECU90

\begin{tabular}{|c|c|c|c|c|c|c|c|c|c|c|}
\hline & & & & & & & & & & \\
\hline $\bar{R}$ & Ant. EWU-BIP & Sopp1 & Sopp3a & Sopp3c & d Sopp1 & d Sopp3a & d Sopp3c & d Sopp3c & d Sopp3c & to \\
\hline & $3,84 \%$ & $0,41 \%$ & $0,17 \%$ & $0,14 \%$ & $0,03 \%$ & $0,03 \%$ & $0,02 \%$ & $40,1 E+6$ & $0,06 \%$ & $94,9 E+6$ \\
\hline D & $33,25 \%$ & $0,41 \%$ & $0,17 \%$ & $0,14 \%$ & $-0,08 \%$ & $-0,04 \%$ & $-0,03 \%$ & $-456,7 E+6$ & $-0,04 \%$ & $-542,3 E+6$ \\
\hline$E$ & $8,46 \%$ & $0,58 \%$ & $0,24 \%$ & $0,20 \%$ & $-0,16 \%$ & $-0,09 \%$ & $-0,07 \%$ & $-312,1 E+6$ & $-0,08 \%$ & $-349,1 E+6$ \\
\hline $\mathrm{F}$ & $22,16 \%$ & $0,42 \%$ & $0,17 \%$ & $0,14 \%$ & $0,13 \%$ & $0,07 \%$ & $0,06 \%$ & $583,9 E+6$ & $0,06 \%$ & $579,3 E+6$ \\
\hline IRL & $1,23 \%$ & $0,38 \%$ & $0,16 \%$ & $0,13 \%$ & $0,05 \%$ & $0,01 \%$ & $0,01 \%$ & $6,1 E+6$ & $0,01 \%$ & $7,1 E+6$ \\
\hline 1 & $18,23 \%$ & $0,45 \%$ & $0,18 \%$ & $0,15 \%$ & $0,04 \%$ & $0,02 \%$ & $0,01 \%$ & $116,5 E+6$ & $0,01 \%$ & $90,9 E+6$ \\
\hline NL & $5,77 \%$ & $0,41 \%$ & $0,17 \%$ & $0,14 \%$ & $-0,06 \%$ & $-0,02 \%$ & $-0,01 \%$ & $-36,0 E+6$ & $0,00 \%$ & $-7,9 \mathrm{E}+6$ \\
\hline A & $3,26 \%$ & $0,40 \%$ & $0,16 \%$ & $0,14 \%$ & $-0,07 \%$ & $-0,02 \%$ & $-0,01 \%$ & $-19,8 E+6$ & $-0,02 \%$ & $-22,4 E+6$ \\
\hline $\mathbf{P}$ & $1,63 \%$ & $0,65 \%$ & $0,27 \%$ & $0,22 \%$ & $0,24 \%$ & $0,11 \%$ & $0,09 \%$ & $57,1 E+6$ & $0,10 \%$ & $66,1 \mathrm{E}+6$ \\
\hline SF & $1,91 \%$ & $0,40 \%$ & $0,16 \%$ & $0,14 \%$ & $0,20 \%$ & $0,10 \%$ & $0,08 \%$ & $93,2 E+6$ & $0,07 \%$ & $83,7 E+6$ \\
\hline & & & & & & & hler & $72,3 E+6$ & & $278,9 E+3$ \\
\hline & & & & & & & BIPEV & $0,00 \%$ & & $0,00 \%$ \\
\hline
\end{tabular}


Sopp1

Opportunitătskosten-Seigniorage i=langfristiger Zins für Staatsanleihen

Opportunităts| Opportunităts| Opportunităts| Opportunităts| Opportunităts| Opportunităts| Opportunităts $\mid$ Opportunităts $\mid$ Opportunităts $\mid$ Opportunităts $\mid$ Opportunităts $\mid$ Opportunităts $\mid$

Anteil am rea Anteil am rea Anteil am real Anteil am rea Anteil am realAnteil am realAnteil am realAnteil am realAnteil am real Anteil am realAnteil am real Anteil am real

$$
P
$$

$\begin{array}{ccc}\text { E } & \text { I } & \text { D } \\ 0,41 \% & 0,74 \% & 0,74 \% \\ 0,58 \% & 1,03 \% & 1,03 \%\end{array}$

$0,80 \%$

$0,93 \%$

$2,80 \%$

$1,03 \%$

$1,41 \%$

$1,29 \%$

$1,03 \%$

$1,41 \%$

$1,29 \%$

$1,60 \%$

$1,60 \%$

$0,45 \%$
$0,52 \%$

$0,52 \%$

$0,59 \%$

$0,62 \%$

$0,82 \%$

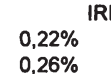

$0,26 \%$

$0,31 \%$

$0,28 \%$

$0,28 \%$

$0,36 \%$

IRL

$0,57 \%$
$0,58 \%$

$0,58 \%$

$0,69 \%$

$0,60 \%$

$0,59 \%$

$0,62 \%$

\begin{abstract}
A
\end{abstract}
$0,41 \%$

$0,84 \%$

$0,95 \%$

$0,95 \%$

$0,95 \%$

$0,43 \%$
$0,50 \%$

$0,50 \%$

$0,59 \%$

$0,64 \%$
$0,64 \%$

$0,76 \%$ Anteil

am real

L

$0,37 \%$

$0,43 \%$

$0,43 \%$

$0,43 \%$

$0,54 \%$

$0,10 \%$

$0,11 \%$

$0,07 \%$

NL

$0,46 \%$

$0,59 \%$

$0.71 \%$

Sopp2

Opportunitătskosten-Seigniorage $\mathrm{i}=$ Offenmarktzins

1997
1996
1995
1994
1993
1992

$$
\text { P }
$$

$0,44 \%$

E

$0,61 \%$

$0,83 \%$

$0,89 \%$
$2,93 \%$

$0,69 \%$

$0,70 \%$

$0,27 \%$
$0,30 \%$

$0,12 \%$
$0,14 \%$
$0,20 \%$
$0,20 \%$
$0,31 \%$
$0,40 \%$

IRL

$0,58 \%{ }^{\text {SF }}$

$0,89 \% \quad 0,30 \%$

$1,13 \%$

$1,01 \%$

$0,40 \%$

$1,02 \%$
$1,45 \%$

$0,95 \%$

$0,49 \%$

$0,73 \%$

$1,98 \%$

$0,96 \%$

$0,50 \%$

$0,58 \%$

$0,47 \%$

$0,69 \%$

$0,83 \%$

$0,18 \%$
$0,24 \%$
$0,60 \%$
$0,58 \%$
$0,62 \%$
$1,10 \%$

${ }^{A}$

$0,27 \%$
$0,30 \%$
$0,35 \%$
$0,48 \%$
$0,68 \%$
$0,84 \%$

B

$0,18 \%$

$0,20 \%$

$0,27 \%$
$0,32 \%$

$0,51 \%$

$0,58 \%$

Sopp3

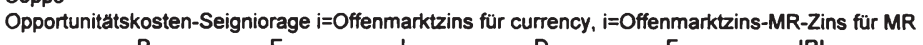

1997
1996
1995
1994
1993
1992

P

$\begin{array}{lll}\text { E } & \text { I } \\ 0,27 \% & & 0,47 \% \\ 0,41 \% & & 0,65 \% \\ 0,59 \% & & 0,77 \% \\ 0,60 \% & 0,64 \% \\ 1,79 \% & & 0,92 \% \\ 1,77 \% & & 1,49 \%\end{array}$

\begin{abstract}
D
\end{abstract}
$F$

\begin{abstract}
IRL
\end{abstract}

SF
$0,14 \%$
$0,20 \%$
$0,29 \%$
$0,29 \%$
$0,34 \%$
$0,45 \%$

A

, $45 \%$

L

NL

$0,15 \%$
$0,12 \%$
$0,18 \%$
$0,28 \%$
$0,36 \%$
$0,54 \%$


Datengrundlage zur Berechnung des Opportunitătskosten-Seigniorage (Quelle: IFS und eurostat)

Portugal of wich:

Reserve Monı Currency outs Government EGDP (99b.c) Offenmarktzin Verzinsung M Demand Dep Time and Savings Deposit (25)

\begin{tabular}{|c|c|c|c|c|c|c|c|c|}
\hline & & & & & & & & \\
\hline 1997 & 1336,8 & 778,2 & $5,48 \%$ & 17905,2 & $5,92 \%$ & $5,59 \%$ & 4637,9 & 8781 \\
\hline 1996 & 1354,6 & 880,9 & $7,25 \%$ & 16803,6 & $7,58 \%$ & $7,06 \%$ & 3914,6 & 8396,7 \\
\hline 1995 & 1218,3 & 841 & $10,34 \%$ & 15817,7 & $10,72 \%$ & $10,03 \%$ & 3435 & 8137 \\
\hline 1994 & 1249,7 & 795,8 & $10,83 \%$ & 14628,9 & $10,38 \%$ & $9,17 \%$ & 3038,7 & 7468,7 \\
\hline 1993 & 3031,1 & 752,9 & $12,45 \%$ & 13463,1 & $13,00 \%$ & $6,69 \%$ & 2861,6 & 6724,2 \\
\hline 1992 & 2781,7 & 708,2 & $15,38 \%$ & 12759 & $14,50 \%$ & $8,56 \%$ & 2556,7 & 6037,8 \\
\hline \multicolumn{9}{|c|}{ Spanien } \\
\hline 1997 & 9877 & 8378 & $5,84 \%$ & 77786 & $5,41 \%$ & & 14967 & 35652 \\
\hline 1996 & 9268 & 7942 & $8,18 \%$ & 73572 & $7,52 \%$ & & 12637 & 37536 \\
\hline 1995 & 8937 & 7535 & $11,04 \%$ & 69761 & $8,83 \%$ & & 12629 & 37315 \\
\hline 1994 & 8603 & 7165 & $9,69 \%$ & 64789 & $7,69 \%$ & & 11411 & 34395 \\
\hline 1993 & 7800 & 6509 & $10,16 \%$ & 60953 & $11,32 \%$ & & 10878 & 32053 \\
\hline 1992 & 7767 & 6025 & $12,17 \%$ & 59105 & $12,75 \%$ & & 10944 & 28208 \\
\hline \multicolumn{9}{|c|}{ Italien } \\
\hline 1997 & 195,35 & 107,39 & $6,86 \%$ & 1950,7 & $6,96 \%$ & $5,00 \%$ & 531,72 & 359,51 \\
\hline 1996 & 181,85 & 100,11 & $9,40 \%$ & 1872,6 & $9,12 \%$ & $5,50 \%$ & 498,87 & 469,39 \\
\hline 1995 & 177,51 & 98,18 & $12,21 \%$ & 1772,3 & $10,12 \%$ & $5,50 \%$ & 471,06 & 476,5 \\
\hline 1994 & 189,4 & 96,05 & $10,56 \%$ & 1638,7 & $8,25 \%$ & $5,50 \%$ & 471,38 & 458,91 \\
\hline 1993 & 199,41 & 89,68 & $11,31 \%$ & 1550,3 & $10,14 \%$ & $5,50 \%$ & 454,92 & 469,88 \\
\hline 1992 & 218,83 & 85,49 & $13,27 \%$ & 1502,5 & $13,60 \%$ & $5,50 \%$ & 426,2 & 430,86 \\
\hline \multicolumn{9}{|c|}{ Deutschland } \\
\hline 1997 & 326.1 & 246,9 & $5,08 \%$ & 3646,3 & $3,07 \%$ & & 650 & 1511,8 \\
\hline 1996 & 329 & 246,8 & $5,63 \%$ & 3540 & $3,23 \%$ & & 631,8 & 1479 \\
\hline 1995 & 314 & 237,5 & $6,50 \%$ & 3459,6 & $4,42 \%$ & & 545,5 & 1411,6 \\
\hline 1994 & 307,8 & 225,9 & $6,67 \%$ & 3320,3 & $5,25 \%$ & & 505,3 & 1366,7 \\
\hline 1993 & 312,9 & 212 & $6,28 \%$ & 3154,9 & $7,38 \%$ & & 484,8 & 1350,6 \\
\hline 1992 & 317 & 200,5 & $7,96 \%$ & 3075,6 & $9,36 \%$ & & 439,6 & 1194,7 \\
\hline \multicolumn{9}{|c|}{ Frankreich } \\
\hline 1997 & 323 & 263 & $5,63 \%$ & 8137,1 & $3,15 \%$ & & 1670 & 3855 \\
\hline 1996 & 315 & 260 & $6,39 \%$ & 7871,7 & $3,60 \%$ & & 1554 & 3582 \\
\hline 1995 & 309 & 258 & $7,59 \%$ & 7662,4 & $4,96 \%$ & & 1557 & 3374 \\
\hline 1994 & 284 & 255 & $7,35 \%$ & 7389,7 & $5,28 \%$ & & 1415 & 3012 \\
\hline 1993 & 285 & 253 & $6,91 \%$ & 7077,1 & $7,63 \%$ & & 1364 & 2776 \\
\hline & & 256 & & 6999,6 & & & 1910 & \\
\hline
\end{tabular}

$1349-2619$ 
Reserve Monı Currency outs Government E GDP (99b.c) Offenmarktzin Verzinsung M Demand Depc Time and Savings Deposit (25)

\begin{tabular}{|c|c|c|c|c|c|c|c|c|}
\hline \\
\hline 1997 & 55,17 & 38,69 & $5,81 \%$ & 703,4 & $2,75 \%$ & $2,75 \%$ & 170,49 & 395,16 \\
\hline 1996 & 50,09 & 38,26 & $6,49 \%$ & 661,8 & $2,00 \%$ & $2,00 \%$ & 155,58 & 372,14 \\
\hline 1995 & 52,39 & 38,19 & $7,20 \%$ & 634,7 & $2,98 \%$ & $2,98 \%$ & 134,71 & 363,23 \\
\hline 1994 & 59,74 & 38,11 & $7,20 \%$ & 608,4 & $4,50 \%$ & $4,50 \%$ & 114,04 & 353,92 \\
\hline 1993 & 56,35 & 37,59 & $6,51 \%$ & 579 & $5,52 \%$ & $5,52 \%$ & 111,92 & 355,15 \\
\hline 1992 & 52,46 & 36,99 & $8,10 \%$ & 566,1 & $8,33 \%$ & $8,33 \%$ & 98 & 342,32 \\
\hline & & & & & & & & \\
\hline 1997 & 4219 & 2305 & $6,49 \%$ & 48241 & $6,67 \%$ & & & \\
\hline 1996 & 3317 & 2009 & $7,48 \%$ & 42942 & $6,50 \%$ & & 3562 & 17089 \\
\hline 1995 & 3280 & 1881 & $8,30 \%$ & 39315 & $6,96 \%$ & & 2894 & 15005 \\
\hline 1994 & 2591 & 1690 & $8,19 \%$ & 35231 & $6,42 \%$ & & 2476 & 13140 \\
\hline 1993 & 2485 & 1572 & $7,72 \%$ & 32442 & $9,00 \%$ & & 2166 & 12880 \\
\hline 1992 & 2062 & 1411 & $9,11 \%$ & 30125 & $12,13 \%$ & & 1681 & 10911 \\
\hline & and & & Seschauftst & & & & & \\
\hline 1997 & 36,228 & 14,517 & $4,86 \%$ & 622,11 & $3,07 \%$ & $1,25 \%$ & 201,246 & 102,105 \\
\hline 1996 & 39,25 & 13,645 & $6,03 \%$ & 574,03 & $3,57 \%$ & $1,00 \%$ & 191,188 & 104,963 \\
\hline 1995 & 58,377 & 12,401 & $7,93 \%$ & 549,86 & $5,63 \%$ & $3,63 \%$ & 163,521 & 142,71 \\
\hline 1994 & 57,463 & 10,81 & $8,40 \%$ & 509,99 & $5,11 \%$ & $3,11 \%$ & 143,547 & 145,67 \\
\hline 1993 & 38,031 & 10,394 & $8,19 \%$ & 482,4 & $7,87 \%$ & $4,87 \%$ & 131,365 & 153,618 \\
\hline 1992 & 37,803 & 9,404 & $12,04 \%$ & 476,78 & $13,85 \%$ & $10,85 \%$ & 125,425 & 154,861 \\
\hline & rreich & & & & & & & \\
\hline 1997 & 225,1 & 146,2 & $4,79 \%$ & 2516,9 & $3,03 \%$ & & 273,5 & 1840,7 \\
\hline 1996 & 226,8 & 146,7 & $5,30 \%$ & 2421,6 & $3,22 \%$ & & 255,2 & 1812,1 \\
\hline 1995 & 212,1 & 142,7 & $6,47 \%$ & 2334,3 & $3,90 \%$ & & 244 & 1770,9 \\
\hline 1994 & 214,2 & 133,6 & $6,69 \%$ & 2239,6 & $5,03 \%$ & & 201,1 & 1721 \\
\hline 1993 & 205 & 127,4 & $6,64 \%$ & 2125,3 & $7,06 \%$ & & 181,2 & 1643,1 \\
\hline 1992 & 189,7 & 120,9 & $8,27 \%$ & 2057,3 & $9,10 \%$ & & 162 & 1567,3 \\
\hline & & & & & & & & \\
\hline 1997 & 502,3 & 272,5 & $5,57 \%$ & 8673 & $3,06 \%$ & & 1237 & 5915,4 \\
\hline 1996 & 490,9 & 240,4 & $6,26 \%$ & 8305 & $3,41 \%$ & & 1200 & 5490,4 \\
\hline 1995 & 473,5 & 428 & $7,34 \%$ & 8056 & $4,53 \%$ & & 1152,7 & 4936,3 \\
\hline 1994 & 433,7 & 396,3 & $7,76 \%$ & 7762 & $5,74 \%$ & & 1111,3 & 4706 \\
\hline 1993 & 464,8 & 425 & $7,18 \%$ & 7410 & $8,12 \%$ & & 1060,6 & 4560,7 \\
\hline 1992 & 451,8 & 412,6 & $8,64 \%$ & 7222 & $9,21 \%$ & & 966,4 & 4148,9 \\
\hline
\end{tabular}


Berechnung der Kassenhaltungskoeffizienten

\begin{tabular}{|c|c|c|c|c|c|c|c|c|c|}
\hline \multirow{3}{*}{2} & \multicolumn{3}{|c|}{ Kassenhaltungskoeffizientei Wechselkurs } & \multirow{2}{*}{$\begin{array}{l}\text { GDP } \\
\text { ECU }\end{array}$} & \multicolumn{4}{|c|}{ Anteil am EWU-11-BIP 1997} & \multirow{2}{*}{$\begin{array}{l}\text { Cnat } \\
\text { ECU }\end{array}$} \\
\hline & k2 & k1 & Q: eurostat & & Q: IFS & Q: eurostat & k2-gew & k1-gew & \\
\hline & 0,7494415 & 0,04346223 & 198,59 & $90,2 E+9$ & 0,0162695 & 0,01625164 & & & 9 \\
\hline 1996 & 0,73265848 & 0,05242329 & & & & & & & \\
\hline 1995 & 0,7315855 & 0,05316829 & & & & & & & \\
\hline
\end{tabular}

$0,7120054110,05592323$

Durchschnitt $0,71969283 \quad 0,06248035$

$0,011694560,00085289$

$\begin{array}{lrr}1997 & 0,65074692 & 0,10770576 \\ 1996 & 0,68195781 & 0,10794868 \\ 1995 & 0,7159301 & 0,10801164 \\ 1994 & 0,70700273 & 0,11058976 \\ 1993 & 0,70432957 & 0,1067872 \\ 1992 & 0,66241435 & 0,10193723\end{array}$

$165,89 \quad 468,9 E+9 \quad 0,08461232 \quad 0,08463759$

$50,5 E+9$

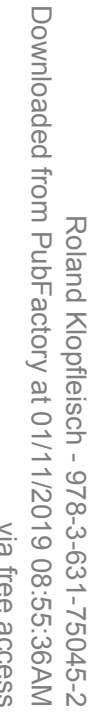

$0,058161410,00907005$

$\begin{array}{lrr}1997 & 0,45687702 & 0,05505203 \\ 1996 & 0,51706718 & 0,05346043 \\ 1995 & 0,53464989 & 0,05539694 \\ 1994 & 0,56770001 & 0,05861354 \\ 1993 & 0,5965297 & 0,05784687 \\ 1992 & 0,57042263 & 0,0568985 \\ & & \end{array}$

$\begin{array}{lrr}1997 & 0,59287497 & 0,06771248 \\ 1996 & 0,59627119 & 0,06971751 \\ 1995 & 0,56570124 & 0,06864955 \\ 1994 & 0,56380448 & 0,06803602 \\ 1993 & 0,5817617 & 0,06719706 \\ 1992 & 0,53137599 & 0,06519053 \\ \text { Durchsechnitt } & 0,67196493 & 0,06775053\end{array}$

$1929,3 \quad 1,0 E+12 \quad 0,18244967 \quad 0,18231919$

$55,7 E+9$

$0,098551010,01024841$

$1,964 \quad 1,9 E+12 \quad 0,33501424 \quad 0,33253303$

$125,7 E+9$

$0,190197230,02252929$

\begin{tabular}{|c|c|c|}
\hline 1997 & 0,67898883 & 0,0323211 \\
\hline 1996 & 0,65246389 & 0,03302971 \\
\hline 1995 & 0,64353205 & 0,03367091 \\
\hline 1994 & 0,59907709 & 0,03450749 \\
\hline 1993 & 0,58498538 & 0.03574911 \\
\hline 1992 & 0,566888954 & 0,03657352 \\
\hline Durchschnitt & 0,62098946 & 0,03430864 \\
\hline
\end{tabular}

$6,613 \quad 1,2 E+12 \quad 0,22203604 \quad 0,22160759$

$39,8 E+9$ 


\begin{tabular}{|c|c|c|}
\hline \multicolumn{2}{|l|}{ Niederlande } & \\
\hline 1997 & 0,80416548 & 0,05500426 \\
\hline 1996 & 0,79740103 & 0,05781203 \\
\hline 1995 & 0,78452812 & 0,06017016 \\
\hline 1994 & 0,76916502 & 0,06263971 \\
\hline 1993 & 0,80668394 & 0,06492228 \\
\hline 1992 & 0,77781311 & 0,06534181 \\
\hline $\begin{array}{l}\text { Durchschnitt } \\
\text { Irland }\end{array}$ & 0,78995945 & 0,06098171 \\
\hline 1997 & & 0,04778093 \\
\hline 1996 & 0,48090448 & 0,04678403 \\
\hline 1995 & 0,45527152 & 0,04784433 \\
\hline 1994 & 0,443246 & 0,04796912 \\
\hline 1993 & 0,46378152 & 0,04845571 \\
\hline 1992 & 0,4179917 & 0,04683817 \\
\hline $\begin{array}{l}\text { Durchschnitt } \\
\text { Finnland }\end{array}$ & 0,37686587 & 0,04761205 \\
\hline 1997 & 0,48761634 & 0,0233351 \\
\hline 1996 & 0,51591554 & 0,02377053 \\
\hline 1995 & 0,5569254 & 0,02255301 \\
\hline 1994 & 0,56710328 & 0,02119649 \\
\hline 1993 & 0,59076078 & 0,02154643 \\
\hline 1992 & 0,58787281 & 0,01972398 \\
\hline $\begin{array}{l}\text { Durchschnitt } \\
\text { Osterreich }\end{array}$ & 0,55103236 & 0,02202093 \\
\hline 1997 & 0,84000159 & 0,05808733 \\
\hline 1996 & 0,85369177 & 0,06057978 \\
\hline 1995 & 0,86317097 & 0,06113182 \\
\hline 1994 & 0,85823361 & 0,05965351 \\
\hline 1993 & 0,85837294 & 0,05994448 \\
\hline 1992 & 0,84056773 & 0,05876634 \\
\hline $\begin{array}{l}\text { Durchschnitt } \\
\text { Belgien }\end{array}$ & 0,85233977 & 0,05969388 \\
\hline 1997 & 0,82467428 & 0,03141935 \\
\hline 1996 & 0,805587 & 0,02894642 \\
\hline 1995 & 0,75583416 & 0,0531281 \\
\hline 1994 & 0,7494589 & 0,05105643 \\
\hline 1993 & 0,75860999 & 0,05735493 \\
\hline 1992 & 0,7082941 & 0,05713099 \\
\hline Durchschnitt & 0,7670764 & 0,04650604 \\
\hline
\end{tabular}

$\begin{array}{llll}2,211 & 318,1 E+9 & 0,05740715 & 0,05771979\end{array}$

$17,5 E+9$

$0,0455963 \quad 0,00351985$

$\begin{array}{llll}0,7475 & 64,5 E+9 & 0,01164548 & 0,01227457\end{array}$

0,00058649

$3,1 E+9$

$0,004625870,00058442$

$5,881 \quad 105,8 E+9 \quad 0,01908835 \quad 0,01907339$

$2,5 E+9$

$0,010510050,00042001$

$13,82 \quad 182,1 E+9 \quad 0,03286323 \quad 0,03264563$

$10,6 \mathrm{E}+9$

$0,027825170,00194874$

$40,53 \quad 214,0 E+9 \quad 0,03861403 \quad 0,03842657$
$6,7 E+9$ 


\title{
SOZIALÖKONOMISCHE SCHRIFTEN
}

\author{
Herausgegeben von Professor Dr. Dr. h.c. Bert Rürup
}

Band 1 Marietta Jass: Erfolgskontrolle des Abwasserabgabengesetzes. Ein Konzept zur Erfassung der Gesetzeswirkungen verbunden mit einer empirischen Untersuchung in der Papierindustrie. 1990.

Band 2 Frank Schulz-Nieswandt: Stationäre Altenpflege und "Pflegenotstand" in der Bundesrepublik Deutschland. 1990.

Band 3 Helmut Böhme, Alois Peressin (Hrsg.): Sozialraum Europa. Die soziale Dimension des Europäischen Binnenmarktes. 1990.

Band 4 Stephan Ruß: Telekommunikation als Standortfaktor für Klein- und Mittelbetriebe. Telekommunikative Entwicklungstendenzen und regionale Wirtschaftspolitik am Beispiel Hessen. 1991.

Band 5 Reinhard Grünewald: Tertiärisierungsdefizite im Industrieland Bundesrepublik Deutschland. Nachweis und politische Konsequenzen. 1992.

Band 6 Bert Rürup, Uwe H. Schneider (Hrsg.): Umwelt und Technik in den Europäischen Gemeinschaften. Teil I: Die grenzüberschreitende Entsorgung von Abfällen. Bearbeitet von: Thomas Kemmler, Thomas Steinbacher. 1993.

Band 7 Mihai Nedelea: Erfordernisse und Möglichkeiten einer wachstumsorientienten Steuerpolitik in Rumänien. Dargestellt am Beispiel der Textil- und Bekleidungsindustrie. 1995.

Band 8 Andreas Schade: Ganzjährige Beschäftigung in der Bauwirtschaft - Eine Wirkungsanalyse. Analyse und Ansätze für eine Reform der Winterbauförderung. 1995.

Band 9 Frank Schulz-Nieswandt: Ökonomik der Transformation als wirtschafts- und gesellschaftspolitisches Problem. Eine Einführung aus wirtschaftsanthropologischer Sicht. 1996.

Band 10 Wemer Sesselmeier / Roland Klopfleisch / Martin Setzer: Mehr Beschäftigung durch eine Negative Einkommensteuer. Zur beschäftigungspolitischen Effektivität und Effizienz eines integrierten Steuer- und Transfersystems. 1996.

Band 11 Sylvia Liebler: Der Einfluß der Unabhängigkeit von Notenbanken auf die Stabilität des Geldwertes. 1996.

Band 12 Werner Sesselmeier: Einkommenstransfers als Instrumente der Beschäftigungspolitik. Negative Einkommensteuer und Lohnsubventionen im Lichte moderner Arbeitsmarkttheorien und der Neuen Institutionenökonomik. 1997.

Band 13 Stefan Lorenz: Der Zusammenhang von Arbeitsgestaltung und Erwerbsleben unter besonderer Berücksichtigung der Erwerbstätigkeiten von Frauen und Älteren. 1997.

Band 14 Volker Ehrlich: Arbeitslosigkeit und zweiter Arbeitsmarkt. Theoretische Grundlagen, Probleme und Erfahrungen. 1997.

Band 15 Philipp Hartmann: Grenzen der Versicherbarkeit. Private Arbeitslosenversicherung. 1998.

Band 16 Martin Setzer / Roland Klopfleisch / Werner Sesselmeier: Langzeitarbeitslose und Erster Arbeitsmarkt. Eine kombinierte Strategie zur Erhöhung der Wiederbeschäftigungschancen. 1999.

Band 17 Dorothea Wenzel: Finanzierung des Gesundheitswesens und Interpersonelle Umverteilung. Mikrosimulationsuntersuchung der Einkommenswirkung von Reformvorschlägen zur GKV-Finanzierung. 1999.

Band 18 Ingo Schroeter: Analyse und Bewertung der intergenerativen Verteilungswirkungen einer Substitution des Umlage- durch das Kapitalstocksverfahren zur Rentenfinanzierung. 1999. 
Band 19 Roland Klopfleisch: Fiskalische Konsequenzen der Europäischen Währungsunion. Die Veränderung des Seigniorage und dessen Bedeutung für die nationalen EWU-11 Haushalte. 2000. 